部ibrarng of the thluscum

$0 \mathrm{H}^{\circ}$

\section{COMPARATIVE ZOÖLOGY,}

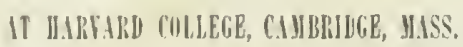

founoco by pribate subscription, in 1 \$6 1.

Deposited by ALEX. AGASSIZ.

$N o .7022$
May 22.1878. 

EXTINCT MAMMALS OF AUSTRALIA. 



\section{RESEARCHES}

ON THE

FOSSIL REMAINS

OF THE

\section{EXTINCT MAMIIALS OF AUSTRALIA;}

WITH A NOTICE OF THE

EXTINCT MARSUPIALS OF ENGLAND.

BY

RICHARD OWEN, C.B., F.R.S.,

FOREIGN ASSOCIATE OF THE INSTITUTE OF FRANCE, ETC.

VOL. I. TEXT.

L O N D O :

J. ERXLEBEN, 2 HENRIETT'A STREET, BRUNSWICK SQUARE.

1877. 


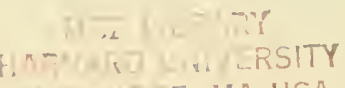

CRIBBR.DUE, MA USA

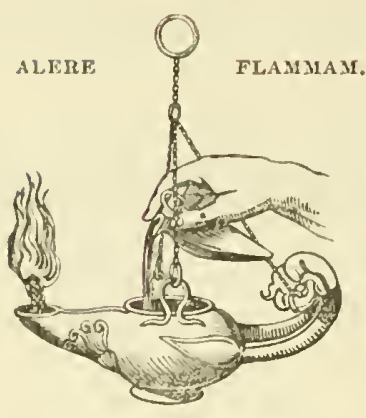

PRINTED BY TAYLOR AND PRANG, RED LION COURT, FLEET STREET. 


\section{P R E F A C E.}

A FEELING of good will to the Colony, such as influences all, from the highest administrator to the humblest labourer, who are able and desirous to cooperate with our distant countrymen, has animated me throughout my endearours to obtain and interpret the evidences of ancient mammalian life in Australia.

A 'Natural History' of that noble continent must result from its occupancy by a high and intellectual race of men. The more needful works, the rough conquests of primitive wilds, necessarily absorb the time and energies of the first generation of settlers. Their successors and their children, inheritors of the wealth created by their forefathers and forerunners, will improve and embellish the first peaceful conquests. After the body the needs of the intellect stimulate the acquisition of the essential conditions of a scientific knowledge of the new territory.

The generations issuing from colonial schools, colleges, universities, look abroad upon an environing nature, so new and strange to their forefathers, with an irresistible impulse to interpret it. Some of its aspects need more aids to their right comprehension than others; and it is to the strange and difficult task of restoring past phases of the mammalian life that I am encouraged to think the present work may be found helpful.

The great Master whose methods of restoration have been my guide, thought, and in his day not unnaturally, that few species of large quadrupeds remained to be discovered in the fossil state. "Il y a peu d'espérance de découvrir de nouvelles espèces de grands quadrupèdes "*.

Rich and unlooked for, however, as were the additions to the mammalian class made known in his immortal Work, they were but the beginnings or samples of that harvest which he has taught his successors to garner in.

Nerertheless, in bringing to a close the researches on the Fossil Mammals of Australia, which have occupied part of my annual labours since 1836 t, and taking a retrospect of their results, I sometimes indulged in the flattering thought that the chances were small of future discoreries of new species of large extinct marsupial quadrupeds in the Australian continent.

Warned, however, by the rate of progress of the science of palæontology since the

* Currer, Reeherehes sur les Ossemens Fossiles, 4to, 1821, rol. i. p. xxx.

+ Appendix to 'Mrtchell's Three Expeditions into the Interior of Australia,' Sro. 
demise of its lomeler, in 1832 , I deem it more probable that a like lapse of time after the issue of the present volume will have been attended by such rich results to the young and indent naturalists of Australia as to show that their predecessor at home had but "skimmed the cream," and given them the broad outlines of a picture of ancient animated nature, which their labours will fill in and finish.

Civier, at the close of his brilliant demonstration of the fossil Opossum in the Focene quarries at Nontınartre, remarks:- "Le 'Tapir est jusqu'ici le seul genre américain que nous ayons trouvé fossile en Europe: le Sarigue seroit le second. Quant aux genres propres ì l'Australasic, on n'en avoit jamais découvert parmi les fossiles d'Europe"*. It needed, in fact, to go far below the tertiary beds to find the mammalian fossils most allied to those of Australia.

'I'he teeth representing the Rhatic Mierolestes find their nearest resemblance in the disproportionately small hind molars of Thylacoleo. The Plagiaulax of the Purbeck berls pushes the correspondence to the shape and disproportionately large size of the incisors and sectorials; and the foremost large laniariform tecth are reduced to a pair in both the pleistocene paucidentate Carnivore of Australia and its smaller British predecessor from the Upper Oolite.

The multidentate marsupial Ferines from near the Lower Oolitet (Amphitherium, Amphilestes, e. g.) are represented by the rare and singular, still existing, Australian grenus Myrmecolius\$. The mandible and mandibular dentition of the typodentate carnivore Phascolotherium, a British extinct genus of like antiquity, find their characters more nearly repeated in Thylacinus and Sarcophitus than in any ex-Australian genera. The existing and extinct pleistocene Mammals manifesting affinity to British mesozoic forms have not been met with elsewhere than in Anstralasia.

'The existing Didelphids of North and Sonth America have their nearest of kin, among extinct Marsupials, in the Didelphys gypsom, Cuvier, from the eocene tertiary deposits of Montmartre. No Marsupial so closely allied to a true Didelphys has been met with in mesozoic strata-whence it would seem that the deeper we delve in quest of remains of extinct mammals the further afield must we go to find their analogues. If we bring a buried Marsupial to light from British or European Tertiaries, we may find its representative in Maryland. When we reach the Purbeck shales, the Stonesficld slates, and Rhetic deposits of the British Island. we have to travel to the antipodes to obtain their existing analogues.

More than thirty years ago I summed up the evidences of actual Australian forms of life which recall the characters of the extinct forms revealed by fossils from our mesozoic strata.

"Not only Trigonice but Terebratulce exist, and the latter abundantly, in the Australian seas, yielling food to the 'Port-Jackson Shark' (Cestracion), as their extinct molluscous analogues did to the -similarly extinct allicd cartilaginous fishes called

\footnotetext{
* Op. cil. vol. iii. p. 292.

+ See the Tabular View of Strata, p. 4.
}

‡ British Fossil Mammals, 8ro, 18t6, p. 5:3, figs. 18, 19. 
Acrodi, Psammodi, \&c. Araucarice and Cycadeous plants flourish on the Australian continent, where Marsupial quadrupeds abound, and thus appear to complete a picture of an ancient condition of the earth's surface which has been superseded in our hemisphere by other strata and higher types of regetable and animal organizations"*. The most common butterflies in Australia are species of the genus Cynthia; recognizable remains of a butterfly of that genus have been detected in the Jura limestone of Europe. The fossil Polypodium of the mesozoic slates of Saxony has its nearest living representative in a species common upon the Dandenong ranges of Australia. But the most remarkable and unexpected additional illustration of the general view enunciated in $\mathbf{1 8 4 6}$ has been the discovery of a representative and near ally of a palæozoic fossil fish of Europe in the Ceratodus Forsteri, KREFFт, from rivers in Queensland $\uparrow$.

Well-sinkers have made known the great vertical extent of the Australian pleistocene freshwater flood-drifts, in which the fossil remains of the Marsupial analogues of the British mesozoic mammals hare mostly been discovered.

Tracts of land now covered by such drifts may never have been subjected to the alternate submersions and emersions to which the changing successive scenes of life are due since creatures akin to 'Ihylacines, Thylacoleons, and Myrmecobians pursued their predatory work in mesozoic Europe.

It remains, however, for the able geologists of Australia to demonstrate the conditions under which the actual and pleistocene surfaces of their continent, prior to the introduction of European plants and animals, seem exclusively to have exhibited au oolitic phase or scene of life.

LrELL, in 1833, thus summarizes the discoveries of mammalian fossils made there at that date:-

"In several parts of Australia ossiferous breccias have lately been discovered in limestone caverns; and the remains of the fossil mammalia are found to be referable to species now living in that country, mingled with some relics of extinct animals. Many of these have been examined by Major Mitcielu in the Wellington valley, about 210 miles west from Sydney, on the river Bell, one of the principal sources of the Macquarie, and on the Macquarie itself.

"The remains found most abundantly are those of the Kangaroo. Amongst others, those of the Wombat, Dasyurus, Koala, Phalangista have been recognized. The greater part of them belong to existing, but several to extinct, species. One of the bones is of much greater size than the rest, and is supposed by Mr. CLIFT to belong to a Hippopotamus .

"In the collection of these bones sent to Paris, Mr. Pextland thought he could

* British Fossil Mammals, p. 69, 8ro, 1846.

† See the exeellent Memoir by Dr. A. Gürther, F.R.S., in the Philosophieal Transactions of the Royal Society, 1871, p. 511.

¥ "Mr. Chift, Ed. New Phil. Journ. No. xx. p. 394 ; Mrajor Mrrcmelt, Procecdings of Geol. Soe. 1831. p. 321." 
recognize a species of Halmaturus of larger size than the largest living Kangaroo*. The bone of an Eilephant mentioned by Mr. Pentuand was the same large bone alluded to by $\mathrm{Mr}$. Clalrt.

"These facts are full of interest; for they prove that the peculiar type of organization which now characterizes the marsupial tribes has prevailed from a remote period in Australia, and that in that continent, as in Europe, Nortl and South America, and India, many species of mammalia have become extinct. It also appears, although the eridence is less complete than we could have wished, that land quadrupeds far exceeding in magnitude the wild species now inhabiting New Holland, have at some former period existed in that country" $\uparrow$.

While, however, such large land quadrupeds were supposed to be of IIippopotamus or of lilephant, the extinct mammalian fauna of Australia could not be pronounced to be distinct from the existing one of Asia and of Africa.

Even after the determination in 1836 , under the generic name Diprotodon, of parts of a large Mammal with the single pair of lower procumbent incisors so common in Australian Marsupials, the remains of larger and older individuals subsequently transmitted, which I erroneously referred to a Dinotherinm \$, still opposed a barrier to the absolute enunciation of mexceptional correspondence between the extinct and existing mammalian fauna of Australia. 'True it is, I was speedily enabled to correct my error $\S$, and to show that the supposed Dinotherian remains were really those of an adult individual of the same Marsupial genus and species as the immature fragment of lower jaw on which the Diprotodon australis was founded.

'Thus was fulfilled the wish of our eminent geologist; and it was shown that not only were the smaller "wild species now inhabiting New Holland represented by remains of those existing at some former period in that country," but that "the land quadrupeds, far exceeding them in magnitude," were likewise marsupial, and quite distinct from the Elephants, Hippopotamuses, and other large beasts, recent or fossil, of Europe, Asia, Africa, and America.

To what cause, it may be asked, is due the extinction in Australia of the genera Diprotodon, Lototherium, Thylacoleo, Phascolonus, Thylacinus, Sarcophilus, Palorchestes, Procoptodon, P'achysiagon, Protemnodon, Sthenurus, with the larger species of existing genera of Kangaroos and Wombats? No other adequate cause suggests itself to $\mathrm{ny}$ mind save the hostile agency of man. Thylacinus and Sarcophilus are still represented by smaller species in Tasmania; but they will there soon be things of the past.

The common characteristic of all the species of the extinct genera, as compared with those that represent existing genera, is superiority of size, and this in degrees ranging from Protemnodon Anak to Diprotodon australis. 'The same may be said of several of the extinct species of existing genera.

" "Journ. de Géologie, tom. iii. p. 291."

† Principles of Geology, rol. iii. 8vo, 1833, p. 143.

$¥$ Annuls and Magazine of Natural History, Liay 1843.

§ Op. cil. October 1844. 
As yet no evidence of geological catastrophe or climatal change has been adduced to account for the disappearance of Macropus Titan and the survival of Macropus major. The latter is not a degenerate descendant of the larger extinct Kangaroo*. In the section "on the extinct species of Wombat resembling the existing ones in size" (p. 315), the number of such extinct forms is greater than that of "the extinct species exceeding the existing ones in size" (p. 339). Indeed the most diminutive of known Wombats is, geologically, as old in time as the most gigantic. But all the kinds that did exceed the biggest known living Wombats have, somehow, disappeared; so also with the Kangaroos, and with their carnivorous marsupial enemies.

To a race of man depending for subsistence on the chase, the largest and most conspicuous kinds of wild beasts first fall a prey. The smaller kinds, with swifter powers of locomotion, more frequently escape and more easily conceal themselves. The limbs of Diprotodon and Nototherium suggest a slower, heavier mode of progression than those of the Procoptodonts. The proportions, especially of the hind limbs, of the latter extinct Macropodidce show an inferior power of saltatory course than is possessed by the existing forms. The gigantic Kangaroos more nearly akin in limb-structures to the smaller living kinds would be more formidable in defensive struggles, but less favoured for retreat.

As the elephant succumbs to the spears and pitfalls of the negro hunters, the minor bulk of the Diprotodon is not likely to have availed it against the combined assaults of a tribe of Australioid wielders of clubs and throwing-sticks.

True it is that, as yet, no evidence of ancestry of the existing aborigines has been detected in the caves and breccias yielding fossil remains of their hypothetic prey, unless we assume the Dingo to have followed the Papuans in their immigration. But the exploration of ossiferous caves has hitherto been limited to those originally discorered by Sir Thomas Mitcinell. And whilst I write, an announcement has reached me of the discovery of others, sixty miles from Bathurst, in the limestone district midway between Cowra and Canowindra, also in limestone ranges near the stanniferous granites of Northern Queensland, which caves, if explored with due care, patience, and skill, may bring to light some indications of the prehistoric men of Australia, as well as largely supplement the partial restoration of extinct Marsupials in the following pages.

At present the evidence is negative; and its value must be estimated by the known imperishable parts of the tools or weapons of the existing aborigines, which may bear testimony to them in the absence of their fossil bones and teeth.

If the hypothesis of the agency of man be unacceptable on its present slender foundation, geological evidence is equally wanting to apply to the condition of extinction propounded in the following paragraphs:- "In proportion to the bulk of a species is

* For a discussion of the common notion from the bulk of extinct animals, especially mammals, "that the races of animals have deteriorated in respect of size," see Transactions of the Zooiogical Society, 4to, vol. iv. (1850) p. 27. 
the difliculty of the contest which, as a living organized whole, the individual of such specics lias to maintain against the surrounding agencies that are ever tending to dissolve the vital bond, and subjugate the living matter to the ordinary chemical and pliysical forces. Any changes, therefore, in such external conditions as a species may have be'u originally adapted to exist in, will militate against that existence in a degree proportionite, perhaps in a geometrical ratio, to the bulk of the species. If a dry suason be graduilly prolonged, the large Mammal will suffer from the drought sooner than the small one; if any alteration of climate affect the quantity of vegetable food, the bulky Herbivore will first feel the effects of stinted nourishment.

"The actual presence, therefore, of small species of animals in countries where larger species of the same natural families formerly existed, is not the consequence of any gradual diminution of the size of such species, but is the result of circumstances which may he illustrated by the fable of the 'oak and the reed;' the smaller and feebler animals have bent, as it were, and accommodated themselves to changes which have destroyed the larrer species" *.

To the surmise that, through geological and climatal changes, a gradual reduction of the sources of nutriment had been associated, as the cause, with the diminished size of existing regetarian Marsupials, it might be remarked that it is hard to believe that Diprotodonts, Nototheres, Procoptodonts, and Phascolones could not find subsistence where the herds of cattle and horses now "increase and multiply." And if, in Australia, the course of extirpation dated from the incoming of man with his canine satellite, the smaller linds of aboriginal Marsupials may have added to the advantage in escape and conccalment due to such character the gradually acquired habit of browsing by moonlight and at dawn and dusk rather than in the glare of day.

'The sources to which I have been indebted for the fossils described and figured in the present work are duly acknowledged in each instance; the name of my early fellowlabourer and friend GEorge BExNeTT, M.D., F.L.S., will be found in almost every Section; and it only remains for me to express grateful thanks for the liberal votes of the Legislatures of New South Wales and South Australia, and the generous aid of Sir George MAClEAY, K.C.M.G., through which, mainly, I have been enabled to issue the rolume in its present form and with its numerous plates and woodcuts.

" Sce 'Transactions of the Zoological Society of London,' tom. cit. p. 14, and the further derelopment of the principle of the "contest for existence," or "battle of life," in DARwis 'On the Origin of Species,' 12mo, 1859. Eridence, howcrer, of the influence of this dynamic, beyond the extinction of specics, has not yct reached me. 


\section{CONTENTS.}

Page

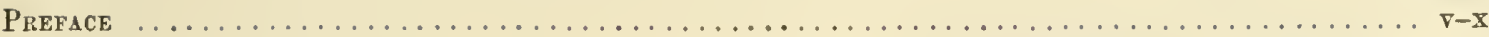

\section{BRITISH MESOZOIC MARSUPIAIS.}

Introductory Remarks and "Table of Strata" $\ldots \ldots \ldots \ldots \ldots \ldots \ldots \ldots \ldots \ldots \ldots \ldots \ldots \ldots \ldots \ldots \ldots$

Rhætrc Spectes.

Genus Microlestes . . . . . . . . . . . . . . . . . . . . . . . . . . . . .

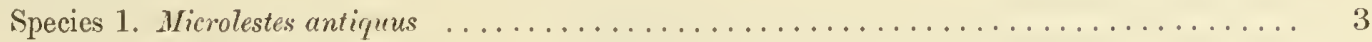

2. H. Moorei .................................. . 6

3. M. rhaticus...................................... 8

Oolitic Species.

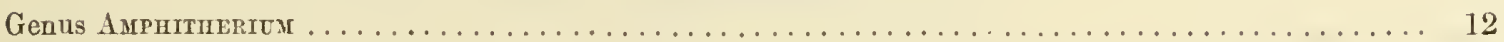

Species 1. Amphitherium Pievostii ............................ 12

2. A. Broderipii ................................ 15

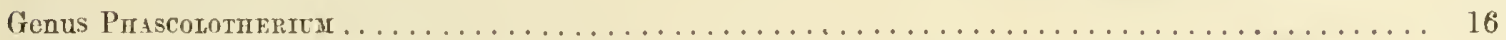

Species 1. Phascolotherium Buchlandi ........................... 16

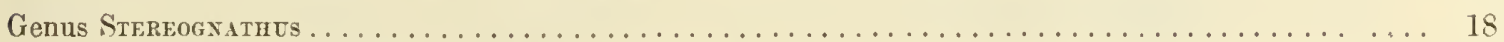

Species 1. Stereognathus ooliticus ............................ 18

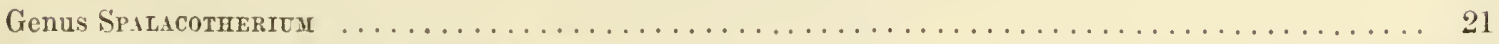

Spccies 1. Spalacotherium tricuspidens ............................ 21

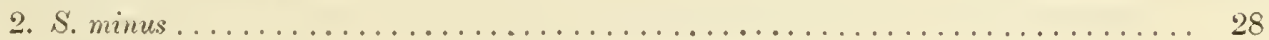

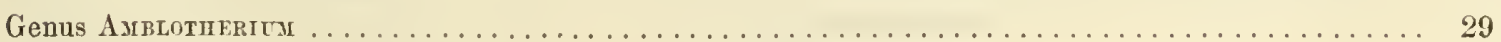

Spccies 1. Amblotherium soricinum .............................. 29

2. A. mustelula ................................. 31

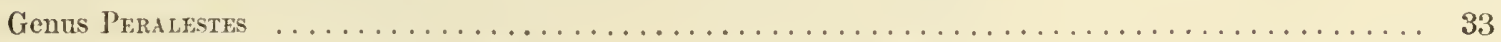

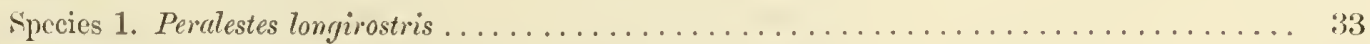

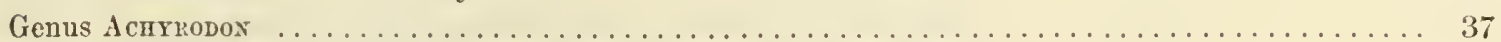

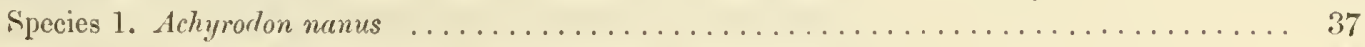

2. A. pusillus ................................... 39

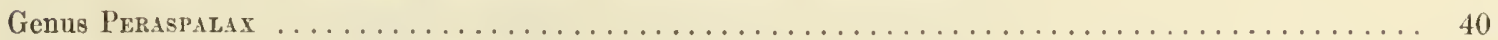

Species 1. Peraspalax talpoüles ............................. 40

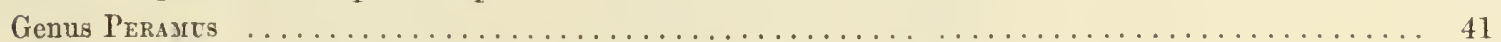

Species 1. Peramus tenuirostris ........................... 41 


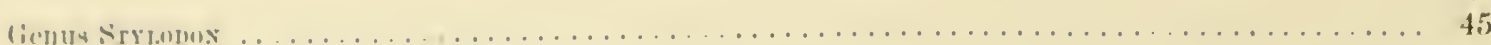

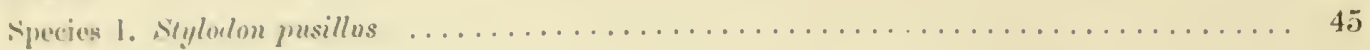

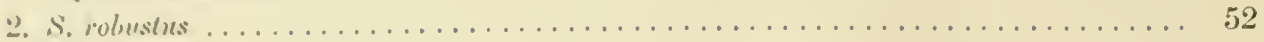

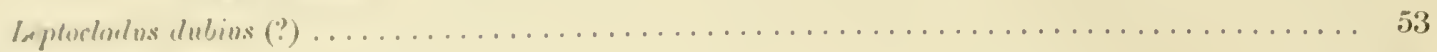

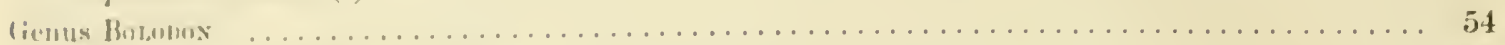

Sinecies 1. Bolodon crassidens ............................... 54

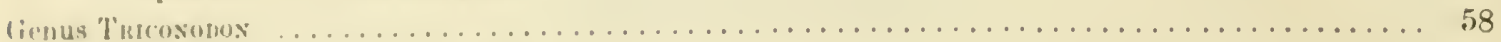

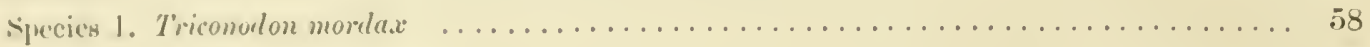

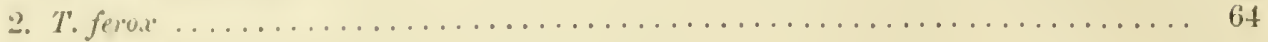

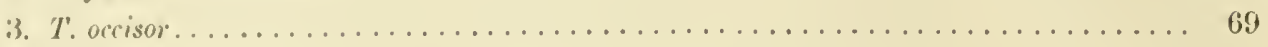

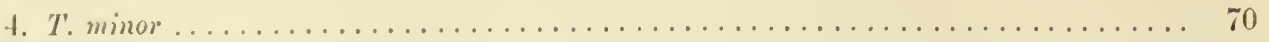

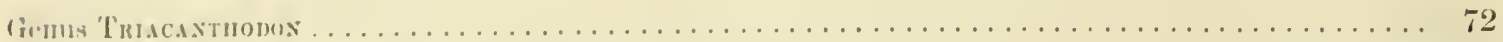

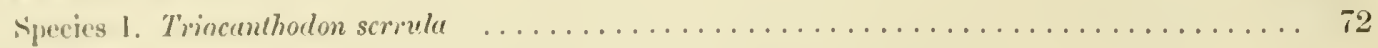

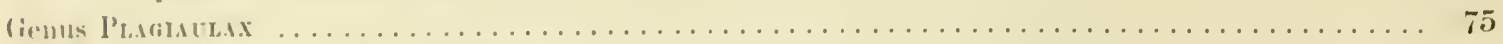

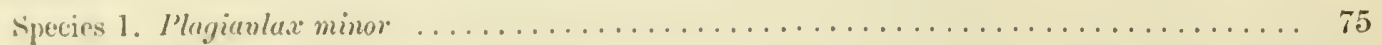

2. I. Beclitesii................................. 77

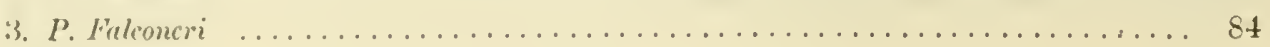

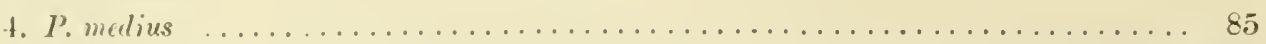

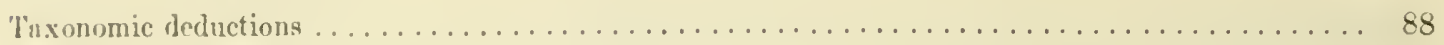

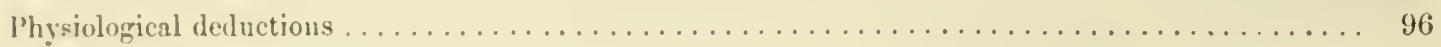

() lijections to the carnirority of Plagiaulax considered $\ldots \ldots \ldots \ldots \ldots \ldots$

\section{AUS'TRALIAN PLEISTOCENE MARSUPIAIS.}

Suborder POLYPROTODONTIA.

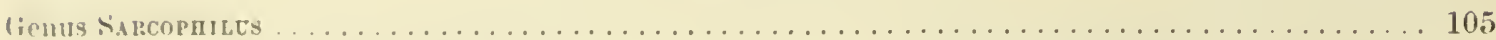

Species 1. Sarcophilus ursinus ............................. 105

2. S. laniarius. ............................... 105

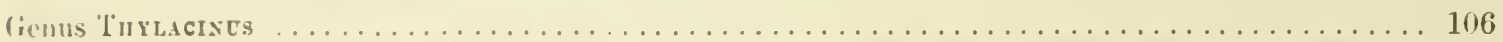

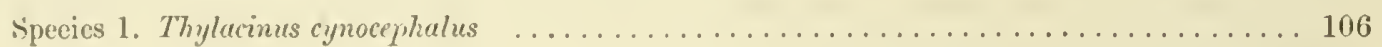

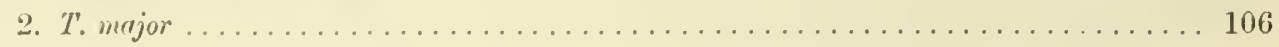

Suborder DIPRO'TODON'TIA.

\section{Section SARCOPHAGA.}

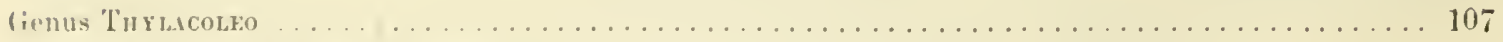

Spccics Thylacoleo carrifex (fragmentary indications) $\ldots \ldots \ldots \ldots \ldots \ldots \ldots \ldots \ldots \ldots$

(mutilated skull) ........................ 110

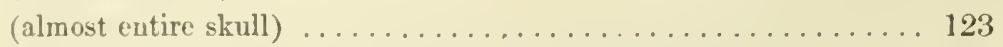

Affinities, living habits, and food ................ 133

Ioeation of laniaries ....................... 148

Comparison of its teeth with those of the Koala $\ldots \ldots \ldots \ldots \ldots \ldots 1$

Mandibular characters of earnivorous and herbivorous Marsupials . 153

Testimony as to the natire food of the Aye-ayc . . . . . . . . . 158

Comparison of the mandibular condyle in Thylacoleo and Rodentia . 160

Interrupted and continuous applications of teeth . . . . . . . . . 162

Work of molars in Herbivora .................... 164

Relation of size to carnirority ................. 177

Localities of fossil cridences of $T$ hylacolco . . . . . . . . . . . 184 


\section{Section POEPHAGA.}

Tribe GRA I G RAD. $\quad$ Page

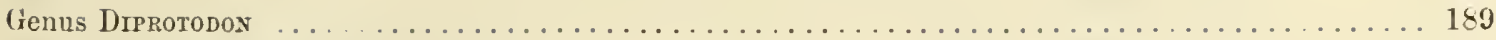

Species Diprotodon australis $\ldots \ldots \ldots \ldots \ldots \ldots \ldots \ldots \ldots \ldots \ldots \ldots \ldots \ldots \ldots \ldots \ldots \ldots$

Introduction $\quad \ldots \ldots \ldots \ldots \ldots \ldots \ldots \ldots \ldots \ldots \ldots \ldots \ldots \ldots \ldots \ldots \ldots \ldots$

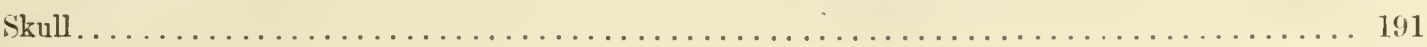

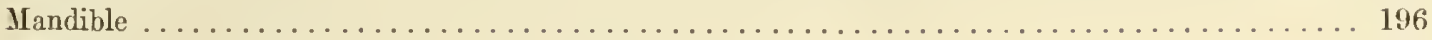

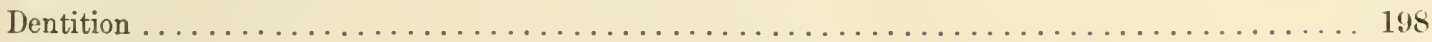

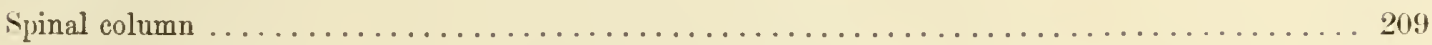

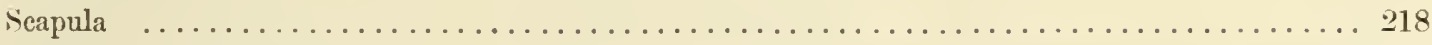

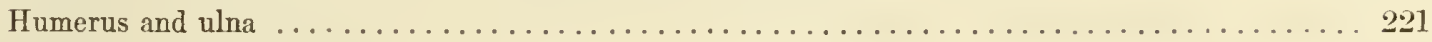

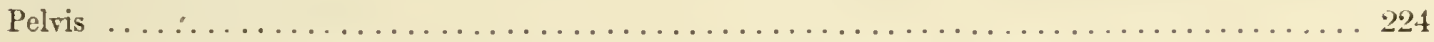

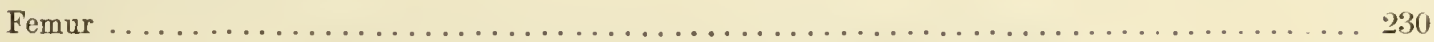

Tibia $\quad \ldots \ldots \ldots \ldots \ldots \ldots \ldots \ldots \ldots \ldots \ldots \ldots \ldots \ldots \ldots \ldots \ldots \ldots \ldots \ldots \ldots$

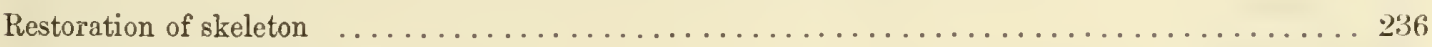

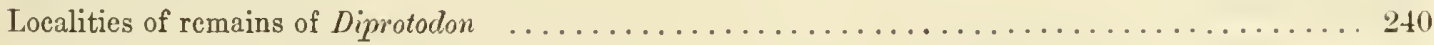

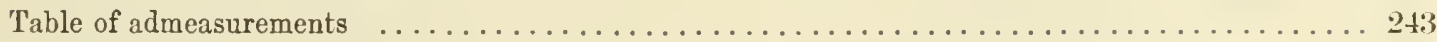

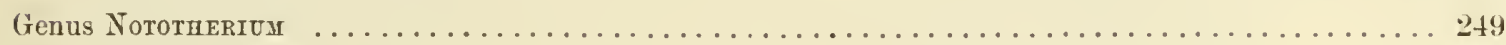

Introduction $\ldots \ldots \ldots \ldots \ldots \ldots \ldots \ldots \ldots \ldots \ldots \ldots \ldots \ldots \ldots \ldots \ldots \ldots \ldots \ldots$

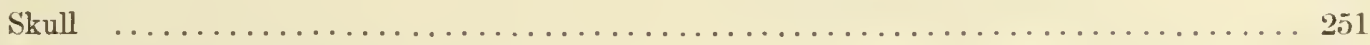

Mandible: A. Nototherium Mitchelii ............................... 259

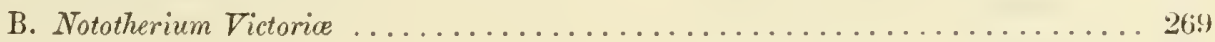

C. Nototherium inerme ............................. 2 .1

D. Comparison of the mandible in those species $\ldots \ldots \ldots \ldots \ldots \ldots \ldots \ldots \ldots$

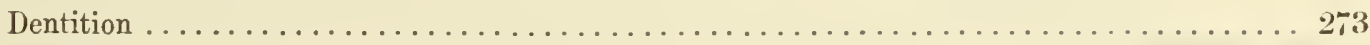

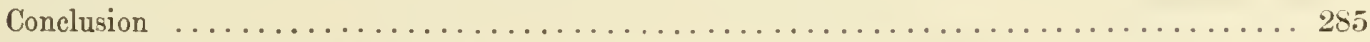

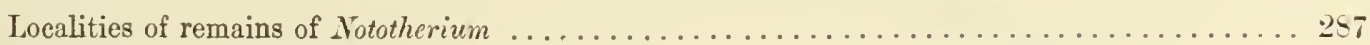

\section{GENERAL OSTEOLOGICAL CHARACTERS OF JARSUPIALIA.}

Skull ..........................................291

Carity of the cranium $\ldots \ldots \ldots \ldots \ldots \ldots \ldots \ldots \ldots \ldots \ldots \ldots \ldots \ldots \ldots \ldots \ldots \ldots$

Vertebral column.................................... 297

Pectoral extremitics. ..................................... 300

Pelvic extremities $\ldots \ldots \ldots \ldots \ldots \ldots \ldots \ldots \ldots \ldots \ldots \ldots \ldots \ldots \ldots \ldots \ldots \ldots \ldots \ldots$

Tribe Fossonid.

Genus Phiscolours. ...........................................

Osteology and dentition of the existing spccies . . . . . . . . . . . . . . . . . . . . . .

Species 1. Phascolomys vombatus .......................... 317, 323

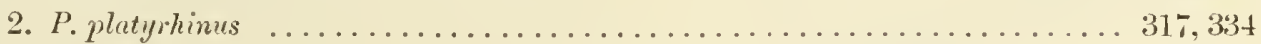

3. P. latifirons............................... 317,323

Extinct Species resembling existing onts in size.

Species 1. Phascolomys Hitchelli ............................. 318

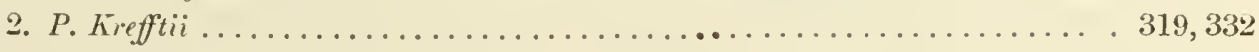

3. P. Thomsoni .................................. 333

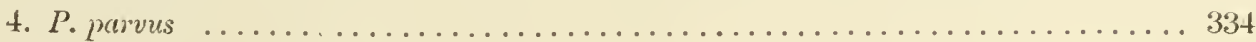


Species of Plinscolomys exceeling axisting ones in size.

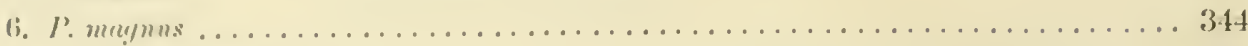

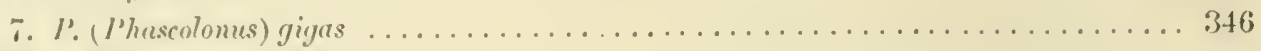

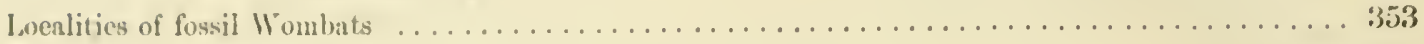

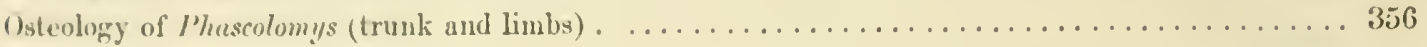

Tribe SAI,TIG RADA.

Family MACROPODID.E:

() st cology of existing speeies, Macropus rufus

\section{Eximet Genera and Species (Cranial and Dental Characters).}

Introduction

Genus IIAcroles

Species 1. Mairopms Titan .................................4400

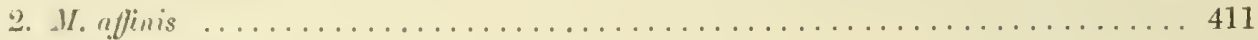

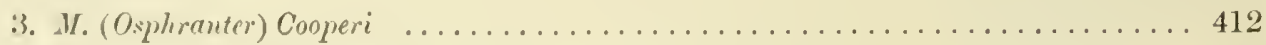

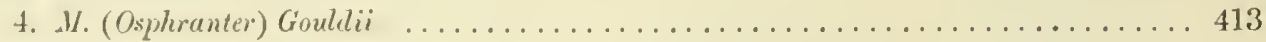

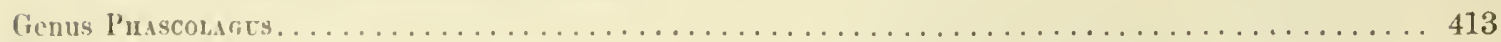

Species 1. Phascolagus altus ...............................413

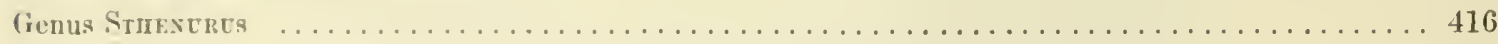

Species 1. Sthenurus Atlas ...............................416

2. S. Brehus ................................ 424

Genus Protraronos $\ldots \ldots \ldots \ldots \ldots \ldots \ldots \ldots \ldots \ldots \ldots \ldots \ldots \ldots \ldots \ldots$

Species 1. Protemnodon Anak ............................ 428

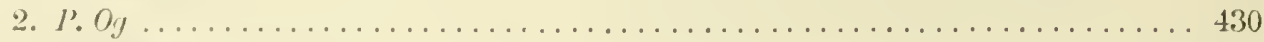

3. I. Vimas $\ldots \ldots \ldots \ldots \ldots \ldots \ldots \ldots \ldots \ldots \ldots \ldots \ldots \ldots \ldots \ldots \ldots \ldots \ldots \ldots$

4. P. Rhnechus ...................................4 434

Macropus Titan $($ skull) $\ldots \ldots \ldots \ldots \ldots \ldots \ldots \ldots \ldots \ldots \ldots \ldots \ldots \ldots \ldots \ldots \ldots$

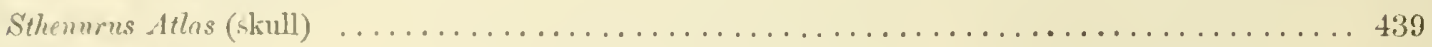

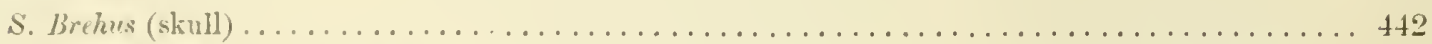

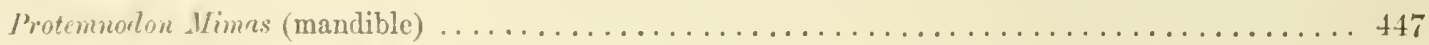

Sirecies 5. Jrotemnodon Anteus .................................448

lienus Pichxiggox . . . . . . . . . . . . . . . . . . . . . . . . . . . 449

Species 1. Prechegsiagon Ferragus ..............................449

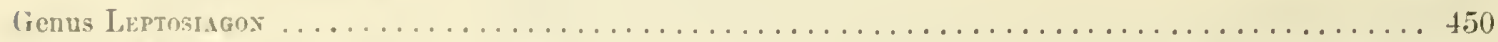

Species 1. Leptosiagn gracilis ................................450

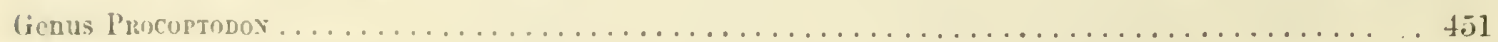

Species 1. Procoptorton Pusio .................................. 454

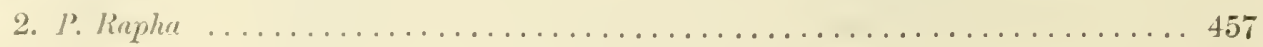

3. P. Golinh .................................... 460

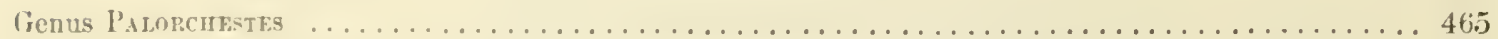

species 1. Palurchestes $1 z a e l \ldots \ldots \ldots \ldots \ldots \ldots \ldots \ldots \ldots \ldots \ldots \ldots \ldots \ldots \ldots$

Procoptodon Rrpha (mandibular characters) $\ldots \ldots \ldots \ldots \ldots \ldots \ldots \ldots \ldots \ldots \ldots \ldots$ 


\section{Family MACROPODIDE.}

Extinct Genera and Species (bones of Trunk and Limbs). Page

Palorchestes (? sacrum) $\ldots \ldots \ldots \ldots \ldots \ldots \ldots \ldots \ldots \ldots \ldots \ldots \ldots \ldots \ldots \ldots \ldots$

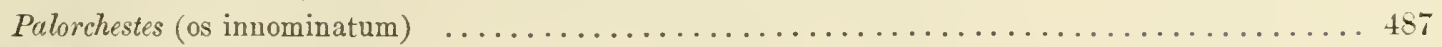

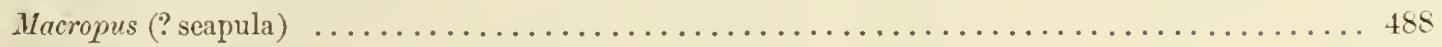

Phascolagus (? humerus) $\ldots \ldots \ldots \ldots \ldots \ldots \ldots \ldots \ldots \ldots \ldots \ldots \ldots \ldots \ldots \ldots \ldots$

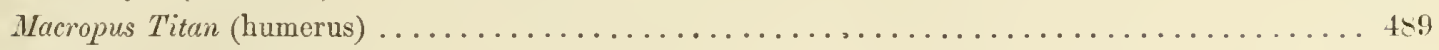

Macropodide (humerus) . . . . . . . . . . . . . . . . . . . . . . . . . 490

Macropus Titan (femur) ...................................... 491

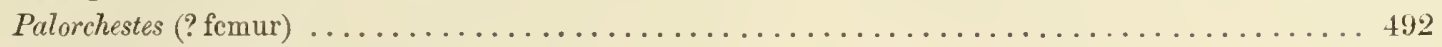

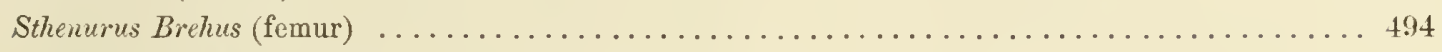

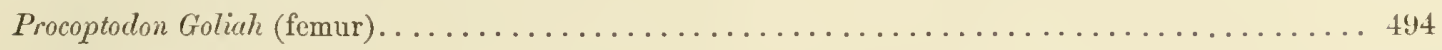

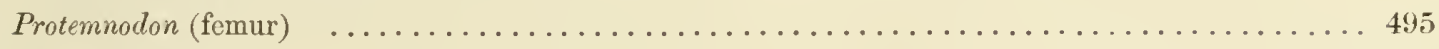

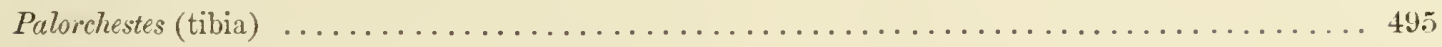

Palorchestes (ealeaneum) . . . . . . . . . . . . . . . . . . . . . . . 496

Macropodida (metatarsals) . . . . . . . . . . . . . . . . . . . . . . . . . 496

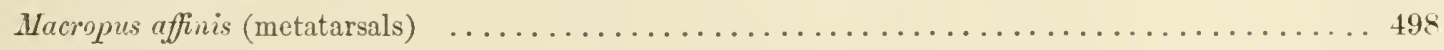

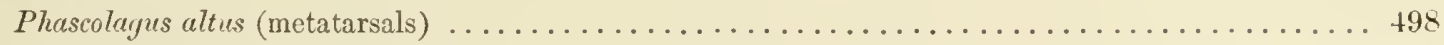

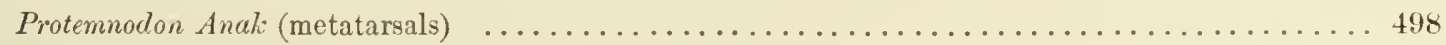

Macropus Titan (metatarsals) . . . . . . . . . . . . . . . . . . . . . . . . . . 499

Pulorchestes Azcel (metatarsals) . . . . . . . . . . . . . . . . . . . . . . . . . 499

Procoptodon Pusio (metatarsals) . . . . . . . . . . . . . . . . . . . . . . . . . 501

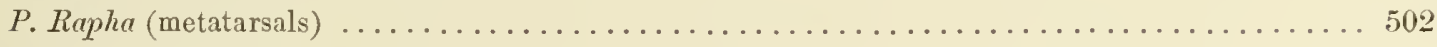

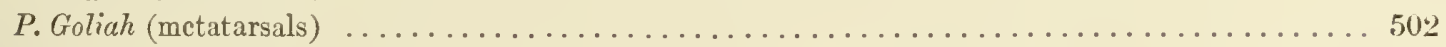

\section{DiPROTODONTIA GRATIGRADA.}

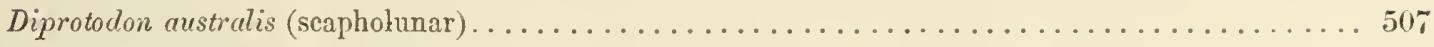

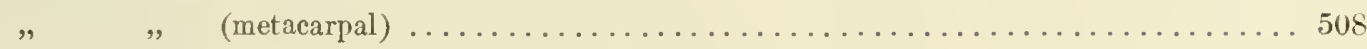

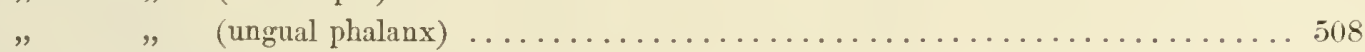

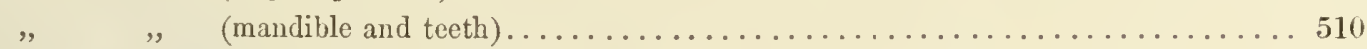

D. Bennettii (mandible and teeth) ................................... 510

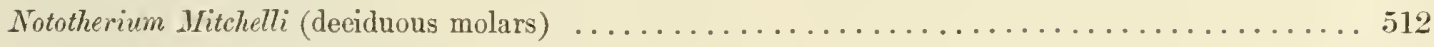

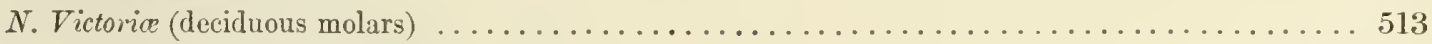

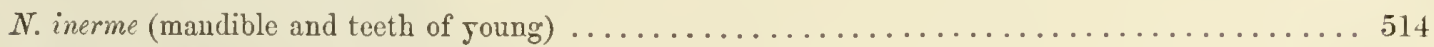

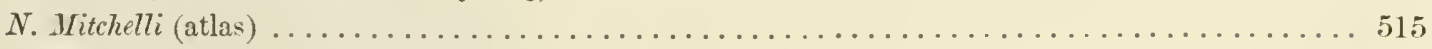

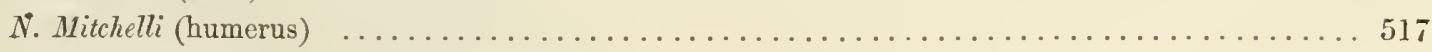

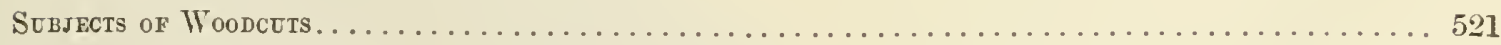





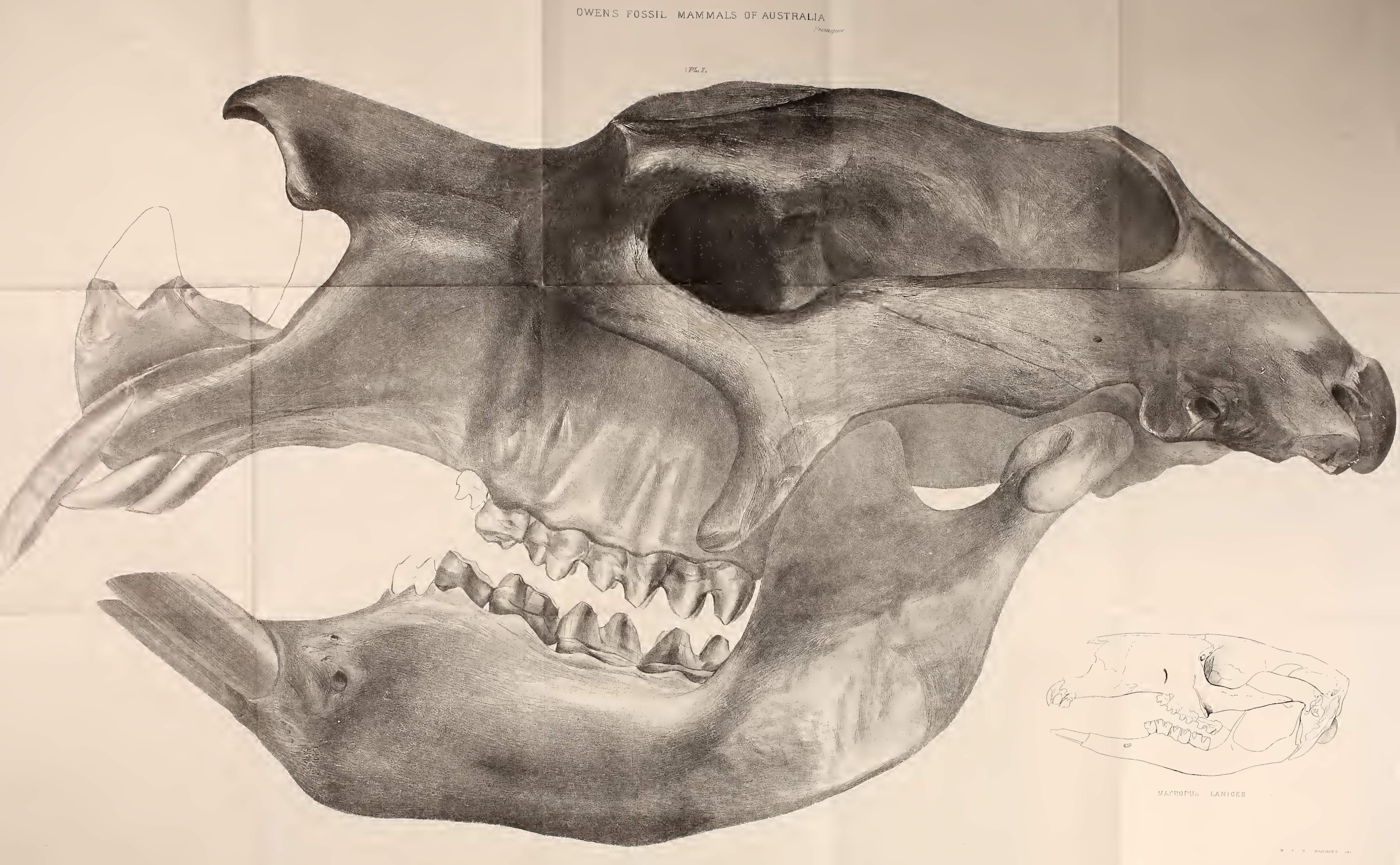





\title{
PREFATORY NOTICE
}

\author{
OF
}

\section{BRITISH MESOZOIC MARSUPIALS.}

\section{§ I. IN'TRODUC'IION.}

SINCE $1839^{1}$ there has not been further question of the occurrence of fossils of the Mammalian Class in Mesozoic deposits.

The number of cunfirmatory facts and the rapidity with which they have accumulated are significant and encouraging.

T'o two members of the University of Oxford Palæontology owes the acquisition of the first evidences from an Oolitic deposit of animals so high in the scale as the Nammalia. In 1812 Prof. Buckland, D.D., F.R.S., and William John Broderif, then an undergraduate, were in friendly relations as professor and pupil. Mr. Broderip had early been initiated by his father, who had formed a fine collection of Natural History, in the elements of that science, and to him, thcrefore, the lectures of BuckLANd had a peculiar charm; whilst the professor found in his pupil one to whose judgment he frequently deferred in the determination of Invertebrate Fossils. Mr. Broderip's fine and choice collection of shells was, in after times, purchased by the British Museum. The history of the acquisition of the original Mesozoic Mammalian Fossils was recorded by Mr. Broderip in 1828, as follows :- "Some years havc elapsed since an ancient stone-mason, living at Heddington, who used to collect for me, made his appearance in my rooms at Oxford with two specimens of the lower jaws of mammiferous animals, imbedded in Stonesfield slate, fresh from the quarry. One of the jaws was purchased by

1 GraNt (Prof. R. E.), "General View of the Characters and Distribution of Extinct Animals," in 'Thomson's British Annual' for 1839.

OGIlby (Wm., F.G.S.), 'Proceedings of the Geological Society,' vol. iii, p. 21, December, 1838. 
my friend Prof. Buckland, who exclained against my retaining both, and thic other I lent to him sone time ago. Dr. Buckland's specinen, which wants incisor and canine teetl, las becu exanined by M. Cuvier, and is figured by M. Prévost as an illustration to his "Obscrvations sur les sclistes calcaires oolitiques de Stonesfield en Angleterre.' "'

'I'le other and more perfect specimen is described by Brodenu' in the "Zoological Jonrual,' Sro, vol. iii ( $18 ; 5)$, p. 405, pl. xi, from which the above quotation is taken.

Botlı professor und pupil believed in the mammalian nature of the fossil jaws thus acquired. But the exceptional character of remains of that high grade of orginization in strata so ancient as Buckland had satisfied himself was the tilestone of Stonesfield, inducer them to loold back the announcement of the discovery until they lad the sanction of the great Palacontologist of the period.

'This they had the gratification to receive on the occasion of the visit which Baron Cuvien paid to the University of Oxford in the year 1S18, when he prononnced Dr. Buckland's specimen to be mammalian, resembling the jaw of a Didelphys.

So encouraged and confirmed in his belief, Dr. Buckland announced the fact in lis "Nemoir on the Megalosaurus," published in 1823, and referred the jaw, on the autlority of Cuvier, to the genus Didelphys, although there is little doubt that Cuvier used the term in a wider sense than it signifies in modern systems of Mamnalogy.

In 1525 M. Prévost, in a paper on the geology of Stonesfield, in the 'Anuales des Sciences,' vol, iv, p. 396, refers to the specimen in the following words:- "Cette pièce unique était conservée dans la collection de l'unversité d'Oxford, lorsque .H. Cuvier la vit en 1818. Une inspection rapide fit dire à ce savant anatomiste qu'clle avait des rapports avec la mâchoire de quelque Didelphe.' Barou Cuvier himself, in the concluding volune of lis great work on 'Fossil Remains,' published in 1825, appended the following note "M. Prérost, who is at present travelling in England, has just sent me a drawing of one of these jaws; it confirms me in the idea which my first inspection gave me of it. It is that of a small Carnassial, the jaws of which bear much rescmblance to those of the: Opossums; but it has ten tecth in a row, a number which no known Carnassial displays. At all events, if this animal be rcally from the schist of Stonesfield, it is a most remarkable exception to an otherwise very gencral rule, that the strata of that high antiquity do not contain the remains of Mammals."3

The above statements did excite close inquiry, first in regard to the geological rclations of the bed of the fossil, and next as to the zoological characters of the fossil itself.

The arguments by which M. Prévost endeavoured to invalidate the conclusions of Buckland as to the relative position of the oolitic tilestone were satisfactorily rebutted by Dr. Fitton." 'The antiquity of this bed (No. 8, fig. 2, p. 11), could not be reduced to

1 'Aunales des Sciences Nat.' Avril, 1825.

2 'Transactions of the Geological Society of London,' 4 to, vol. i (2nd series), p. 399.

3 'Recherches sur les Ossemens Fossiles,' 4to, rol. r, pt. ii, p. 319.

4 'Zoological Juurual,' vol. iil, p. 402, 1828. 
correspond with the then presumed exclusively Mammalian epoch, and the attempts to do away with the supposed anomalous exception were afterwards confined to arguments in favour of the jaw in question having belonged to a cold-blooded oviparous animal, eitber fish or reptile.

The grounds of such conclusion will be found in the papers by Prof. Agassiz, in 'Leonhard und Bronn's Neue Jahrbuch für Mineralogie und Geologie,' 8vo. 1835, vol. iii, p. 185 ; by De Blainville, in his " Doutes sur le prétendu Didelphe de Stonesfield," in 'Comptes Rendus de l'Académie des Sciences,' Paris, August 20th and October 6th, 1५35; in Prof. R. E. Grant's "General View of the Characters and Distribution of Extinct Animals," in 'Thomson's British Annual' for 1839; and in Mr. OGilbr's communication to the London Geological Society in December, 1838.

The facts and arguments for the mammalian character of the fossil in question are given in a paper by Prof. Valexciennes, in the 'Comptes Rendus de l'Académie des Sciences,' Septembre, 1838, p. 572, and in my Memoir containing a description and figures of Dr. Buckland's, Mr. Broderip's, and subsequently discovered specimens from Stonesfield, published in the 'Transactions of the Geological Society of London; 2nd series, vol. vi, pp. 47-65, pls. 5 and 6 .

Subsequent discoveries have not only confirmed Cuvier's conclusion, but have extended our knowledge of small Mammals in Secondary strata both older and newer than the Lower Oolitic one in which they were first discovered.

The suljoined table of the earth's strata containing evidences of life shows the relations to time of the first-known appearances of the warm-blooded viviparous Vertebrates (p. 4).

I'n the description of these fossils, for the most part British, I now proceed.

\section{a. Rhætic Mammals.}

\section{$\S$ II. Genus-Microlestes, Plieninger, $1847 .^{1}$}

Species 1-Microlestes antiquus, Plieninger. Plate I, figs. 14, 15̆, 15 A.

In 1847 Prof. Phieninger, of Stuttgart, discovered, in sifting the sand of a 'bonebed' in the 'Keuper' of Diegerloch and Steinenbronn, two minute teeth, each showing a well-defined enamelled tuberculate crown, supported by two distinct roots or fangs. ${ }^{1}$

The professor, referring to my paper on the Stonesfield jaws, in which the supposed occurrence of that mammalian dental characteristic in the teeth of sharks and of the

1 "Jahreshefte des Vereins für Vaterländische Naturkunde in Würtemberg," 8vo, Bd. ii (1847), p. 164, taf. i, figs. 3, 4; and "Nora Acta Cæs. Acad. Nat. Cur.," \&c., vol. xxii (1850), p. 902, pl, 71, figs. 14, 15. 


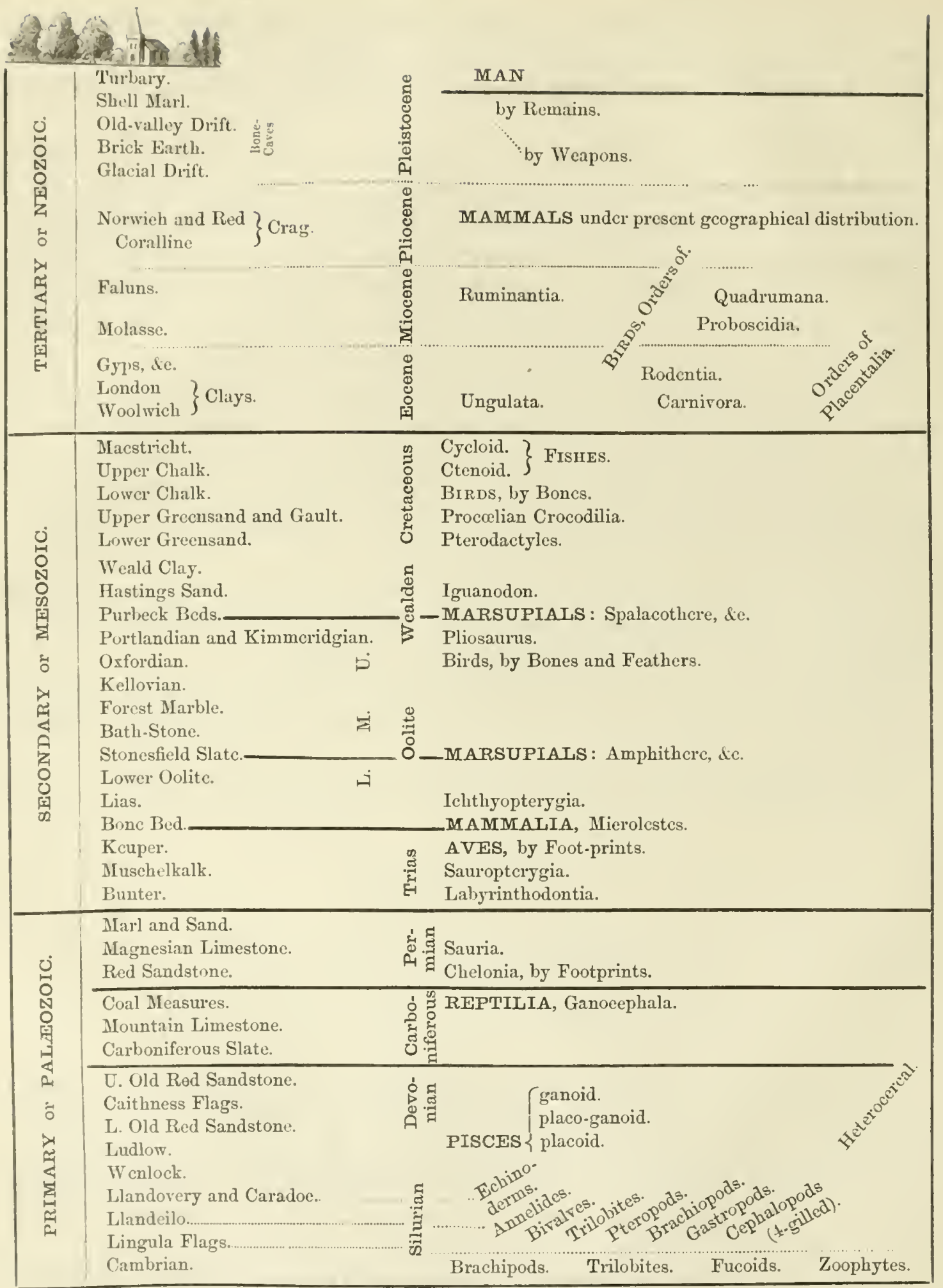

Order of appearance of Vertebrates in Fossiliferous Strata. 
Basilosaurus of Harlan is shown not to affect the rule of two roots, being exclusively mammalian, ${ }^{1}$ concluded that he had evidence of a Mammal from that Mesozoic group of strata now termed 'Rhrtic,' which is older than the Oolitic or Jurassic group, and he proposed for the small species represented by the two teeth the namc Microlestes antiquus, ${ }^{2}$ rightly referring it, notwithstanding the diminutive size indicated by the fossils, to have been a predaceous or zoophagons Mammal.

The long diameter of the crown of the larger of the two teeth (op. cit., taf. I, fig. 4) is one eiglith of an inch; it is divided into two low subobtuse lobes or cones, each of which shows tuberculate subdivisions; the lobes are united at the exposed side by a basal ridge or 'cingulum.' Each root contracts to a subobtuse closed end. This tooth is preserved imbedded in the matrix.

The second tooth (ib., fig. $3, a-d$ ) is of smaller dimensions ; the fore-and-aft diameter does not exceed one line $\left(=\frac{1}{12}\right.$ th inch); the transverse diameter is little more than a third of a line, the tooth being of compressed form, from side to side. The outer side of the crown (Pl. I, fig. 15, of this Monograph) presents one chief cone at the anterior half, succeeded by a low tubercle, and then a smaller one; the inner side of the crown (ib., fig. 14) shows three or more smaller tubercles, decreasing in size as they approach the hind end of the tonth, but the foremost is lower than the one on the outer side of the crown. They are joined anteriorly by a small basal talon. Thus, the grinding surfacc of this tootlı (Pl. I, fig. $15 \mathrm{~A})$ shows an irregular longitudinal mid depression between an nuter and an inner tuberculate ridge or rising of the crown. It is a type of molar which prevails in a still existing member of the multidentate division of the Marsupial order (Myrmecobius fasciatus, Wth., PI. I, fig. 19, from upper jaw, magn. 4 diam. ; fig. 20, from lower jaw, magn. 4 diam.), and which we shall find repeatcd in the ultimate molar of the lower jaw of a small predaceous paucidentate Marsupial from an Upper Mesozoic deposit (comp. Pl. I, figs. 14 and 15, with Pl. IV, fig. 9 B, Plagiaulax minor, and ib., fig. 12 в, Plagiaulax Becklesii).

The tooth (Pl. I, figs. 14, 15, 15 A) from Degerloch is, most probably, a mandibular molar, and, like those in Nyrmecobius, is supported by an anterior longer and narrower root and a posterior shorter and rather broader root, both tapering, with progressire widening of their interval, to their implanted end.

The crown is slort or low in proportion to its forc-and-aft breadth, constituting about one third the length of the entire tooth, which is about two lines. The teeth of the microlestian type still manifestcd by the Australian Insectivore (Pl. I, fig. 24) are quite as minute, with as short crowns, as in Microlestes antiquus; they are carried by an animal with a

1 "Nachdem auch das unter dem Namen 'Basilosaurus' bekannte, mit 2-wurzlichen Zühnen versehene Fossil, mit welchem man die Stonesfielder Kiefer zu Reptilien-resten stempeln wollte, unter die Cetaceen rersetzt war."-Loc. cit.

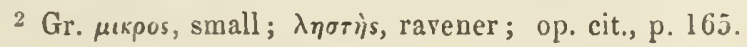


skull two and a quarter inches long, and having a total length of body of eight inches, with at tail of six inches. ${ }^{1}$

The kecmess of observation and patient rescarch with which were scrutinised, lens in hand, bushcls of a formation rife with organic and mostly fragmentary remains, ${ }^{2}$ cannot bc sufficiently praised ; and PhIENINGer was worthily rewarded with this capital discovery of the oldest known Mammal.

Species 2.-Microunstes Moorei, Owen. Plate I, figs. 1-13.

'T'o like perseverance and qualities of discovery applied by Chardes Moore, Esq., l'. R.S., to the fossils of breccia of Rhætic bone-bed and Limcstonc, filling a fissure in the Mountain Limestone at Holwell, Frome, in Somersetshire, is due the discovery of teeth corresponding in size and gencral charncter with those of the Microlestes antiques of Plieninger. ${ }^{3}$

These teeth, with other fossils, were submittcd to my inspection in 1858 , referred to the genus Microlestes, and the following notes were taken of their characters.

Pl. I, figs. I-4, represent (the natural size in outline, and magnified four times in tint) an upper molar tooth, of which the grinding surface (fig. 1) consists of a central smooth depressed area enclosed by a low thick tubercular wall. The inner side of the tooth is indicated by the more prominent part of the wall, which is divided into three tubercles; the outer side by the lower wall with indications of subdivision into smaller and more numerous tubercles, the largest forming the hind part of the wall and a great part of that end of the tooth. 'The working surface of the crown is oblong, narrowest transversely, with the inner and hinder end most produced.

'The length (vertical diameter or depth) of the crown is very short compared with its breadth (fore-and-aft diancter) and thickness (transverse diameter). It is divided by a wcll-defined constriction or 'neck' from the roots, which are four in number. Of these the post-internal root is the best preserved, the other three being broken off near their base.

A second upper molar is represented in Pl. I, fig. 5, from the outer side. In this tooth the enamelled crown has been worn almost to the cement-covered base. One of the larger tubercles at, probably, the fore part of the crown remains. At this part there are the beginnings of two fangs, or of the division of a broad anterior root; the base of a third smaller root supports the opposite end of the crown. The indenta-

1 Wateriouse, "Description of a new Genus of Mammiferous Animals from Australia, Sc.," "Trans. Zool. Soc.'’ vol. ii, p. 149 pls. 27 and 28.

2 "Eine ungeheure Masse rou Zähnen, Schuppen, Coprolithen und unkenutlichen Skelettheilen von Fischen und Sauriern."-Op. cit., p. 165.

3 For a description of the Rhatic Beds of Somersetshire and an excellent account of the geology of the district in which these Microlestian remains were found, see Mr. Moore's paper "On the Abnormal Condition of Secondary Deposits," Sic., in the "Quarterly Journal of the Geological Society of Londun,' December, 1567. 
tion of the coronal basis continuing to the fang from between two of the coronal tubercles may be noted, in elucidation of the like character described and figured (in Letter) by Prof. Phillips, F.R.S., in the tooth of Microlestes rhaticus, which is decisive against the alleged resemblance and affinity signified by the generic name Hypsiprymnopsis imposed upon that tooth by Mr. Boyd Dawkins, F.R.S. ('Quart. Journ. Geol. Soc.,' vol. xx, p. 411.)

Pl. I, fig. 6, represents the crown of a lower molar, showing a well-defincd neck and the beginnings or bases of two equal fangs. The circumference of the crown describes an irregular ellipse, the compression being from without inward.

The Microlestian generic character of a smooth subdepressed central area, enclosed by a thick tubercular wall, is well shown in this tooth. The outer part of the wall developes three tubercles, the divisions between which extend from their outer side upon that surface of the base of the crown toward the fangs. The imner part of the wall $(a)$ developes four small tubercles, the anterior one, forming the antero-internal angle of the crown, being the largest and most prominent.

Were this tubercle to he broken off and the outer part of the tooth worn down as far as the line $b$, the portion left of the working surfacc of the crown would offer an instructive subject of comparison with the portion of the crown of the Microlestes (Hypsiprymnopsis) rhaticns represented in Pl. I, fig. 16, from a drawing of the original kindly made for the author by Prof. Phillips, F.R.S.

The subject of figs. 7 and $7 \mathrm{~A}, \mathrm{Pl}$. I, is the crown, with the base of the two fangs, of a lower molar; the working surface is morc worn than in fig. 6 . Consequently the three outer tubercles of the coronal wall are represented by a plicate outline such as would be presented by the premolar of Hypsiprymnus murinus, (ib., fig. 17) if it were worn down to near the base of its enamel-foldings; only the contrasted extreme shortness of the crown in Microlestes brings the intervals of the tubercles ncarer to the origins of the roots of the tooth. The smaller tubercles of the inner sidc of the wall are almost obliterated in this tooth, and the smooth central area is proportionally enlarged. A fourth lower molar in an old Myrmecobius closely repeats this character.

Pl. I, figs. 8, $8 \mathrm{~A}$, show the crown and beginning of the roots of a lower molar with the trituberculate outer wall, and the summit of the anterior angular larger tubercle of the inner wall. Fig. 8 a gives a view of the crown from the fore end or side, showing the degree of compression from without inwards; it also shows the hindmost of the three outer tubercles, and the summits and intervals of the smaller tubercles of the inner wall extending to the hind end of the crowll.

Pl. I, fig. 9, represents the crown of a lower two-fanged molar with the working surface but little worn, showing the three outer tubercles and the five smaller inner ones, with the characteristic anterior large and prominent corner tubercle (broken off in fig. $16 \mathrm{~A}$ ).

Pl. I, fig. 10, represents the crown of a small molar viewed obliquely from the inner side, showing the anterior larger tubercle followed by three smaller ones; the three larger tubercles of the outer wall are also brouglit into vicw 
I'I. I, fig. II, represents a smaller, probably antcrior, tootl, with one fang supporting a crown or portion of crown, showing its extrcme shortness, increased sccmingly by attrition, which has redued the intervals of the coronal tubereles to low notehes of the ('nand, with intervening exposed dentine.

Pl. I, fig. 12, shows a minnte tooth with a crown of more simple character than the larger molars; it, nevertheless, repeats the charactcristic shortness or lowness of the crown, but slows a more simple tubcrenlar accentuation of the grinding surface, and an indication of two fangs of uncqual size; this indication may, however, be due to a basal flacture of a large single fang, as in fig. 11 .

Species 3.-Microlestes rhaticus, Plate I, figs. 16, 16 А.

Hypsiprymopsis rhexices, Boyd Dawkins, 1864.'

In 1864 Mr. Boyd Dawkins, T.R.S., F.G.S., discovered a small two-fanged, laterally worn molar in Rhectic marlstone at Watchet, Somersetshirc, and, assuming a common or persistent level of the detached patches or 'pockets' of bone-bed in that county, claims for the marlstone a ligher antiquity than the matrix of "the Microlestian teeth of Frome and Diegerloch.,"2

'This tooth is figured of the natural size and magnified four diancters, in Pl.I, figs. 16, $16 \mathrm{~A}$.

'The crown, as in Nicrolestes, is very short in proportion to its forc-and-aft width, being 1 line (1-12th in.) in height at the bifureation of the two fangs, and 2 lines (1-6th in.) from the frout to the hind border. 'The total length of the tooth, including the entire fang, rery slightly exceeds the fore-and-aft diameter of the crown. The breadth or transverse diameter of the tooth, cannot be accurately determined, for the side imbedded is "entirely concenled,"3 and the side exposed to vicw has becn subject to attrition, presenting "a smootlı polished surface, which extends without interruption from the crown into the fangs,"3 and cxposing " a dark band, from $b$ to $l$, crossing what would be called the base of the crown." 'This part of the base shows "four grooves passing downwards from the crown towards the fangs." Whether these grooves (fig. 16, c) are due to the wearing force or indicate original structure is uncertain; if the latter, they are repeated in the lower molars of Wicrolestes and in one of the molars of Plagiaulax, but not in the trenchant premolars of cither this genus or of IIypsiprymmus.

The ligher side of the tooth ( $a b$, fig. $16 \mathrm{~A}$ ) is the one imbedded in the matrix; so much of it as is exposed shows the upper and inner, not the outer, side; it is the thick cramelled border of a low crown bounding the inner side of a pounding surface which

1 " On the Rhrtic Beds and White Lias of Western and Central Somersetshire," \&c., 'Quarterly Journal of the London Geological Society,' vol. xx, 1864. p. 396, \&c.

2 Op. cit., p. 410.

3 Letter to the Author from Prof. Phillips, F.R.S., dated Oxford, 29th August, 1870. 
was depressed, flat and smooth in the centre. This coronal border (fig. 16, a) was disposed in four, probably five, tubercles; on the latter alternative the fifth is broken away, most likely as being the largest and most prominent. The attrition of the masticatory tubercles of the preserved border of the crown of this little molar has exposed the dentine. "The crown of the tooth," writes Prof. Phillips, "is obliquely worn, and on the worn surface are little cusps, as in my figure, also worn, but a little projecting at the edges, as at fig. $16 \mathrm{~A}$, as if they were formed of enamel and dentine within the general border of enamel." 1

Now, this is precisely the appearance which the similarly worn multituberculate border of certain molars of Microlestes present. The lofty compressed trenchant premolars of Hypsiprymnus (fig. 17) lose all trace of the grooves and ridges at the basal part of the crown in proximity with the fangs. The bulging basal part of the premolar is covered by a smooth polished coat of enamel in both Plagiaulax (Pl. IV, figs. 9, 10), Hypsiprymmus (Pl. I, fig. 17), and Bettongia, (ib., fig. 18).

In Hypsiprymmus it is very true that the 'length' or vertical diameter of the crown of the tooth is great compared with the breadth or transverse diameter; but in this ' main characteristic' the Rhætic tooth, like those of Microlestes and the true molars of Plagiaulax, differs widely from the premolar of IIypsiprymnus. The oldest Rat-Kangaroo shows no such wearing down of the crown as must have happened to the rhætic tooth (fig. 16), if it ever possessed one as lofty as that of the hypsiprymnal premolar (figs. 17, 1 5). "The implantation by two fangs [is] seen alike in both" the Rhætic tooth and the premolar of Hypsiprymmus": add, also, in Microlestes (lower molars). Only there is a vagueness of meaning in Mr. Boyd Dawkins' phrase "seen alike;" for though, doubtless, the Rhætic molar and the hypsiprymnal premolar, with divers other teeth, are each inplanted "by two fangs," those fangs are not "alike" in the teeth compared; and where the field of comparison is so restricted-where so few characters can be securely got ont of the worn and broken fossil denticle in the slab of hard marlstone-it is satisfactory to hare anything so plain and conspicuous to reason from as the two fangs so unlike in form and proportions as are those in Hypsiprymmus (fig. 17) and in the so-called Hypsiprymnopsis (fig. $16 \mathrm{~A}$ ). The proportions of the fangs in the Rhætic tooth, supposing them to be the only two it possessed, are much more alike in it and in the lower molar of Microlestes (Pl. 1, figs. 7 A, 14, 15).

The hind fang in Hypsiprymnus is more than twice the breadth, antero-posteriorly, of the front fang; it is subcompressed like the crown it helps to support, and in IIypsiprymnus minor (Pl.I, fig. 17) its proportion of the crown is such as to include all the four vertical ridges and grooves that impress the upper half of the crown.

Mr. Boyd Dawkins figures the anterior (broken) root of the Rhætic denticle as stouter, i.e. antero-posteriorly broader, than the posterior root, and describes the 
"stout" fing which supports "all the plice" of the "fonr-plieated premolars" of Ilypsimrymuns murinus, sc., as the anterior onc. ${ }^{1}$ Prof. Plillips's figure gives a more equal share of the erown to the two supporting fangs. 'The stouter fang of the premolar of Hypsiprymnus (Pl. I, fig. 17), always posterior in position, is impressed by a longitudinal gronve. In the mandible of Mypsiprymus minor the front fang is much smaller than the lind one, and the interval relatively mueh less than in the Rhxtie tooth.

In sum, the Watchet denticle lins two fangs and a erown, and a "well defined cervix" between them; and so has the premolar of IIypsiprymnus: their composition in regard to enamel and dentine is the sane. Further than this no point of resemblance ean be truly predicated as between the Rhaxtic tooth and the premolar of any living form of saltatory herbivorous Marsupial.

The microlestian denticles are comparable with the molars of Myrmecobius and Plagianlax, and with these alone in the Marsupial order. The molars of Myrmecobius form a larger proportion of the entire dental series than do those of Plagiaulax. If these genera were represented by detaehed fossil teeth, it is, numerieally, probable that Plagiaulax would be represented by some of its sixtcen ${ }^{2}$ obliquely ridged carnassials, and Myrmecobius. by some of its tubcreulate molars.

Now, the numbers of sueh minute tubercular nolars as have brought to light the former existence of a small-toothed predaceous, probably insectivorous, Marsupial, in times so far back as the 'I'riassic, lead me to surmise that the extinet species more resembled the multidentate Byrmecolius and Amplitherium than the paucidentate Plagiaulax.

The small tooth figured in $\mathrm{Pl}$ I, fig. 13, nat. sizc in outline, elosely resembles a mammalian canine, and bcars the same proportion to the molars of Microlestes as does the canine to the molars in Myrmecobius.

\section{B. Oolitic Mamals.}

The geologieal relations of the bed from which the fossils next to be described have been obtained will be understood by reference to the diagram, fig. 2, of the seetion at Stonesfield from Fitton's Memoir. ${ }^{3}$

On the side opposite the right hand is marked the depth of the shaft to the horizontal gallcry where the "slate" is worked which contains the manmalian fossils; on the opposite side the strata are numbered in sucecssion as follow's :

Op. cit., p 410

2 On the assumption that there were as many premolars in the upper as in the lower jaw of Playiaulax minor.

3 'Zoological Journal,' loc. cit. 
FIG. 2.

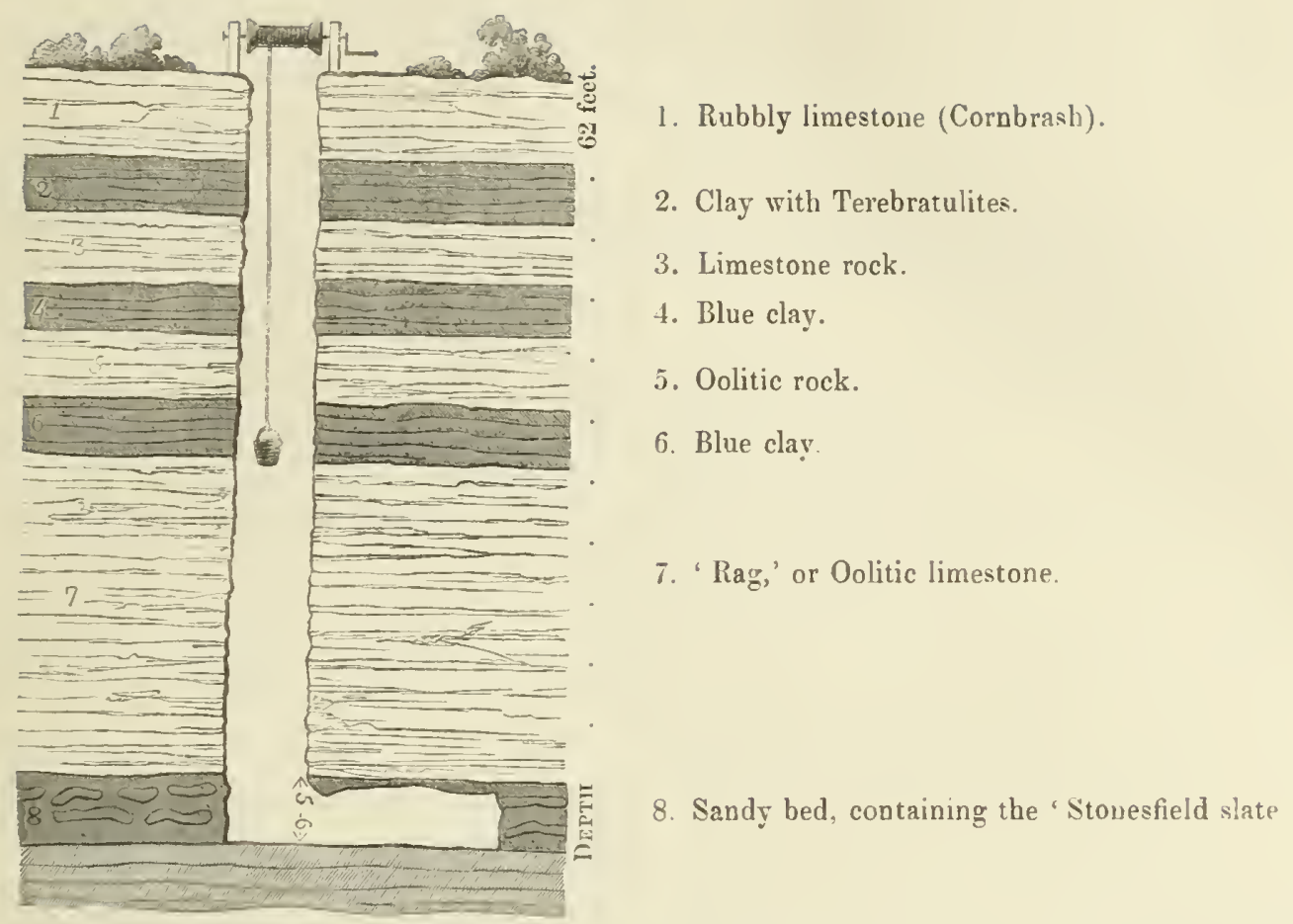

To this succeed other Lower Oolites, leading to the Lias. Prof Sedgwick ${ }^{1}$ was the first to point out the removal of the upper members of the Oolitic or Jurnssic series from the locality, near Oxford, where the above shaft is sunk.

It may be acceptable to some readers to have a brief statement of the generalisations from the exhaustive survey of mandibular and dental characters of Vertebrata required for an effectual grappling with the question discussed, in 1838, before the Academy of Sciences in Paris and the Geological Society of London.

'The mandible in Mammalia consists of two symmetrical halves or 'rami,' which in some coalesce at the symphysis. Each ramus is a single or continuous bone, and offers a convex or flattened surface for the joint with the cranium; not a concavity, as in lower Vertebrates. In most placentals the lower and hind part of the ramus projects backward and is called the 'angle.' In some Carnivora (Hycena crocuta, e.g.) the angle is excavated on its upper and inner surface with a semblance of inflection, but the sharp inner margin is not produced beyond the vertical plane of the coronoid. In the Hare the lower border of the angle expands, so as to project a little beyond both the outer and inner surfaces of the 'ascending ramus:' viewed from the inner side, it appears to be slightly inflected. But the inward bending of the part answering to the 'angle of the jaw' in higher Mammals is peculiar to the Marsupialia, and in some species (Phascolomys, e.g.) to a remarkable extent.

I 'T'rans. of the Geol. Suc.,' 2nd series, vol. iv (1835), p. 26, note. 
'I'le implantation of eertain teeth by two or more roots in correspondingly eomplex sockets, to which the roots do not coalesce, is a mammalian peeuliarity, though not common to the entire class.

\$ III. Genus-Annitnerium, De Blainville, 1S3S. "Doutes sur le prétendu Didelplie fossile de Stonesfield; " Comptes rendus de l'Aead. des Seiences,' Aligust 20tlı, 1S3S.

AMpurgoves, Agassiz, 1835. Neues Jahrbuch für Mineral. und Geolog. von Leonhard und Bronn, Bd. iii, p. 185. (This name was proposed to express the, then, ambiguous nature of the fossil.)

Thy lacothemus, Valenciennes, 1838. Comptes rendus de l'Acad. des Sciences, Septembre, 1838, p. 572 .

Species 1.-Anphitherium Prevosti, Owen. Plate I, figs. 21, 21A, 22, 22A, 23, 23a.

Brit. Foss. Nlammals, 8vo, 1846, p. 29.

Thylacotheriun Prevostit, Val. Comptes rendus de l'Acad. des Sciences, September, 1838.

Pl. I, fig. 21, gives the natural size in outline, and fig. $21 \mathrm{~A}$, part of the same four times that size, in tint, of the original specimen examined by Cuvien in 1818, and notieed by him in 1924.' 'The fossil partly exhibits, partly represents by impression in the matrix, the left half of the lower jaw, with the fore extremity broken off. A thin layer of the original bone adlıeres to that part of the impression which was formed by the joint or 'condyle' $(b)$; the impression above gives the size and shape of the eoronoid proeess $(c)$; a portion of the angle (a), remains, which is eontinued backward nearly as far as the condyle. 'The part of the jaw eontaining the three hindmost grinders is almost entire ; the outer wall of the rest of the bone is left imbedded in the Oolitic slate, but this part retains seven of the molar scries, with their roots, undisturbed in their sockets.

From what has been premised of the mammalian charaeters of the lower jaw and teeth, those which led Cuvier to conclude that the present fossil belonged to that class will be readily appreciated. The courexity of the eondyle and the implantation of the teeth, each by two fangs, are deeisive on this point.

'Ten molars are shown in the present fossil, and the two long inplanted fangs are exposed in seven of these teeth, lodged in deep soekets.

A subsequently acquired half-jaw of the same species (Pl. I, fig. 23, 23 A), with the whole dentition of that mandibular ramus, shows that the first four teeth of the original fossil, counting backward (fig. 21, A), eorrespond with the third, fourth, fifth, and sixth premolars,

' “Carnassier de Stonesfield, voisin des Sarigues," Cuvier, 'Ossem. fossiles,' tom. v, pt. ii, 4to, 1824, p. 349. Id., 8ro ed., 1836, tom. x, p. 484. 
and the remaining six to the true molars. The crowns of the fourth, fifth, and sixth premolars are entire, and consist of a single compressed conical cusp, with a minute tubercle at the hind part of its base, and a more minute one in front; the base of the crown is slightly tumid, and from it are continued, without the intervention of a cervix, the two slender and slightly diverging roots. The fractured crown of the first true molar shows more distinct anterior and posterior basal cusps; those of the second and third show an increased thickness. The fourth gives a view of the anterior cusp, of the large middle cone, and of part of the posterior cusp; the thicker and more complex crowns, as compared with those of the premolars, are unequivocally shown in the last three molars. The roots of the teeth are seen in the specimen, fig. 21, to descend half way or more toward the lower border of the ramus; their substance is contrasted by its denser texture and deeper colour with the surrounding bone, from which the tooth-roots are separated by a thin layer of a distinct substance, infiltrated apparently from the matrix into the sockets. In most Reptiles the base of the fully developed tooth is confluent with the bony substance of the jaw; in the few in which the implanted base remains distinct it is simple; in both cases, with a series of seven contiguous teeth exposed as in the jaw in question, the germ of a successional tooth would be found beneath some of the teeth.

The broad, elevated, slightly recurved coronoid proccss resembles that in Didelphys, Dasyurus, Perameles, Erinaceus, and the like small predatory mammals; the position of the condyle, on a level with the teetl, is also a character of a feeder on animal substances.

The position and form of the entry of the canal $(d)$ transmitting the nerve and vessel of the teeth accord with the mammalian type of the jaw. The (mylohyoid) groove is present in the jaw of Myrmecobius (fig. 24, g); its depth and length are greater in the fossil. Comparative anatomy supports the inference that the Stollesfield fossil examined by Cuvier belonged to a small ferine ${ }^{1}$ mammal with a jaw much resembling that of an Opossum, but differing in the great number of the molar teeth, in this respect exceeding the Myrmecobius, Pl. I, fig. 24), in which they are nine in number.

Four names liave been proposed for the Mammalian genus represented by this jaw; of these Amphitherium is the one adopted in my 'History of British Fossil Mammals,' and which I here retain.

The second fossil of this species (Pl. I, figs. 22, $22 \mathrm{~A}$ )-also a ramus or lialf of the mandible-discovered in the Stonesfield slate, supplied additional evidence of the osseons structure. It is preserved in the Geological Museum at Oxford, and is described and figured in my Mcmoir of $1838 .^{2}$ With the exception of parts of the coronoid, condyloid and articular processes, the exposed inner surface of the ramus is entire; the symphysis $(s)$

'I use the word 'ferine' as equivalent to the French 'carnassier,' the term by which Cuvier signified collectively the Cheiroptera, Insectivora, Carninora, and Marsupialia.

2 'Geol. Trans.,' ser. 2, vol. vi (1839), p. 49, pl. v, fig. 1. 
Is very eharacternstre of the mammalinn uature of the bone; it is long, narrow, and contimted forward in the same line with the gently convex inferior margin of the jaw, precisely ans in Didelplygs, as well as in some other Ferines of both the marsupial and plarental series; its lower margin presents a small notch corresponding with that un the symplyssis of the jaw in Nyrmecobius. $\Lambda$ greater proportion of the eonvex articular condyle (b) is preserved in this than in the preecding specimen; suffieient of the coronoid remains to show that it had the same size and shape as that process in the type specimen. 1 groove $(g)$ is continued from below the dental ennal $(d)$, gradually contracting to a point at the middle of the rmmus. 'There is a broader and shorter groove in the corresponding part of the jaw in the Myrmecobius, and a narrower groove in that of the Sarcoplitus wisimus. 'The posterior molar shows a small middle internal and part of a larger exterual cusp; the premolars (4 and 5) are entire, and show the principal and posterior hasal cusp, as in fig. 21. The sockets of the missing teeth give not less than sixteen teeth in ench rimnus of the jaw, viz. three incisors and one eanine, each with a simple socket; six premolars and six true molnrs, each with a double socket.

'Thus, Amphitherium was seen to differ from Didelphys even more than was inferred from the evidenee possessed by Cuvier. The only known existing Nammal with a dentition approaching to the above is the Marsupial Myrmecobius (fig. 24), peculiar to Anstralia. It has $i 3-3, c 1-1, p 4-4, m 5-5=13$ teeth, in each ramus. The incisors are conical, separated at their base, the first the largest; the premolars have compressed eonical crowns with a hinder talon; the molars are relatively smaller than in Amplitherium, and of the type of those of Microlestes.

The additional evidence, from the second jaw, strengthens the inference from the first, viz. that the Amphitherium was a truc warm-blooded Mammiferous species, unguiculate and inscetivorous, with a probability of its being marsupial.

The third jaw in the order of discovery of Amphitherian fossils (Pl. I, fig. 23, $23 \mathrm{~A}$ ) is the miost complete one, containing the whole scries of molar tecth, the last six being quinquecuspidate; the first six unicuspidate, with basal eusps either on one or both sides; it also displays the socket of one small eanine $(c)$ and three longish slender incisors (i) in situ, altogether amounting to sixtcen tecth on each side of the mandible, as was indieated by the soekets of the sceond specimen above described.

This specimen is the right mandibular ramus presenting the outer side to view. The convex condyle, the broad and high coronoid process, the backwardly projecting angle, the lower margin of which bends slightly inward, the varied kinds and double-rooted implantation of the tecth-all unequivocally displayed in this unique fossil-establish beyond question the conclusions deduced from the foregoing specimens of the existence of a suall insectivorous Mammal during the Lower Oolitic epoch.

Dr. BuckLasd kindly transmitted to me this specimen, soon after it came into his possession, and aceeded to my request to make some further explorations with a view to 
determine the shape of the angular process. The result showed that the lower margin of this process $(a)$ was inflected, so as to render the outer surface convex, yet not in so great and traceable a degree as in Didelphys, Phascogale, and Dasyurus. The onter surface of the ramus presents no trace of the fissures or sutures which, in Lizards and other cold-blooded Vertebrates, separate the angular, dentary, and other, in them, distinct elements of the lower jaw. 'The broad and simple coronoid process $(c)$ of the fossil shows the wide concavity and the anterior marginal ridge, such as were deduced from the impressed matrix in the second specimen of Amplitherium; the entire and prominent condyle $(b)$ rises somewhat higher above the level of the molar teeth than was indicated by its incomplete remains in the former specimens, and the outer surface of the fore part of the present jaw shows four or five small outlets of the dental canal, as in Myrmecobius.

Species 2.-Amphitherium Broderipil, Owen. Plate I, figs. 25, 25a, 25 в.

History of British Fossil Mammals and Birds, 8vo, 1846, p. 58, fig. 19.

The fourth specimen of Amplitherium, discovered in the Oolitic slate at Stonesfield, was obtained there by the Rev. H. Syкes, M.A., and was presented by him to the Museum of the Philosophical Institution at York, where it is now preserved. It contributes as mucl additional information in respect to the shape of the crowns of the teeth as the third specimen had done in respect to that of the jaw-bone. It consists of the left ramus of the jaw, and offers its inner surface to the observer. It presents at its anterior part the sockets of three incisors and one canine, of small and nearly equal size; then follow the empty sockets of three small premolars, each with two fangs; to these succeed three larger premolars, in place, each having two fangs protruded to a certain extent from their sockets. Each of these teetlı shows a small anterior as well as posterior tubercle at the base of the large middle cusp, and there is a slight ridge, or 'cingulum,' along the inner side of the base of the hindmost of these premolars. The first true molar is wanting, the next four have their crowns entire, the last is a little mutilated. The crowns of these molars present a different form from that which might be inferred from the fractured molars of the foregoing specimens, they are more compressed, and have not two cusps on the same transverse line. Each presents a large middle cusp, with a sinaller but welldeveloped and pointed one, at the fore and back part of its base; the 'cingulum,' a part peculiar to mammalian teeth, plainly traverses the inner side of the crown, where it developes three small cusps, one at the base of the large external cusp, and the other two forming the anterior and posterior extremities of the crown of the tooth. This form of tooth is unknown in existing Mammalia, but is as well adapted for crushing the cases of

1 'Owen, Anatomy of Vertebrates,' 8vo, vol. i, figures-88 Arapaima, 91 Chelone, 92 Emys, 93 Crocodilus, 97 Python, 272 Cyclodus, \&c. 
colcopterous Inseets as nre any of the insectivorous multieuspid molars of the Bats and Shrews. The existenee of the wing-eovers of Insects in the Oolitic slate of Stonesfield has heen long known; many of then approach most nearly to those of a Buprestis, a genus now best represented in warm climates.

In the present jaw the eondyloid and coronoid processes are wanting, but have left their impressions on the matrix; there is the same wide and shallow groove near the lower marrin of the hind part of the ramus, and the same noteh at the symphysis, as in Amplitherium Prevostii and in Myrmecobius.

The chicf value of the present speeimen arises out of the very perfect state of the crowns of the molar tecth (fig. $25, \mathrm{~B}$ ). If the strueture they exhibit be really the same with that of the tectls of the Amphitherium Prevostii, yet they differ in number, there being but five instead of six premolars. 'The York jaw also differs in size to a greater degree than has been observed in mature individuals of the same species of Insectivorous Mammal in a state of nature.

I referred this jaw, therefore, to a distinet species, dedicated to my lamented friend the aceomplished naturalist and scholar, WiLLian Join Broderip, F.R.S. It probably, indeed, indieates a distimet genus, for which, if eonfirmed, the name Amplitestes might be appropriated.

\section{§ IV. Genus-Phascolotherium, Owen, $1839 .{ }^{3}$}

Species 1.-Phascolotherium Buckland, Oven. ${ }^{2}$ Plate I, figs. $26,26 \mathrm{~A}$.

Didelpitys Buckland, Broderip, 1828. Zoological Journal, vol. iii, p. 408, pl. xl.

This genus and species are founded on the right half or ramus of a lower jaw imbedded in a slab of Stonesfield slate, and presenting the inner side to view. The natural size is shown, in outline, in Pl. I, fig. 26; and a carefully finished view of the specimen, twice the natural size, is given in fig. $26_{\mathrm{A}}$.

The teeth, in sitû, include three incisors, a canine, and seven molars; it is open to conjecture that a fourth ineisor may have projected near the symphysis.

The incisors in place have long slender erowns, divided by interspaces rather exceeding the breadth of the tooth. A similar interval divides the hind incisor from the canine $(c)$. 'This tooth $(c)$ is longer, larger, and rises almost vertically with a slight backward curve of the crown. The incisors incline more forward as they recede in position from the canine.

An interval of twice the breadth of the eanine divides that tooth from the first of the molary scrics. The first molar (1) is divided by a space of about half the breadth of the crown from the sccond (2), which, with the rest of the seven molars, are nearly or quite in contact with each other.

$$
1 \text { 'Geological Transactions,' 2nd series, vol. vi, p. 58, pl. vi. } \quad{ }^{2} \text { Ibid. }
$$


Of the three incisors present in the fossil, only the inner and hinder parts of the somewhat mutilated crown are seen, not the entire breadtl of the crown, so that these teeth appear to be narrower and farther apart than they really were. Nevertheless, they could not have been so closely in contact as in Sarcoplitus or Thylacimus, nor have occupied so short a relative extent of the alveolar tract, nor a situation turned inward at such an angle from the line of the rest of the teeth. In all these characters the incisors of Phascolotherium more resemble those of Mryrmecobius. The canine, also, in its proportion to the incisors and molars much more resembles that tooth in the above existing insectirorous Marsupial (fig. 24,c) than the canine in the carnivorous genera of recent Marsupials.

In the proportions of the molars, Phascolotherium resembles Myrmecobius more than it does Didelphys, Sarcoplitus, or Thylacimus; but the hinder grinders decrease more gradually, and the last two in a greater degrce, than in Myrmecobius. In the form of the crown the molars of Phascolotherium resemble those of Thylacinus more than those in Myrmecobius or other existing Marsupials. There is, however, a well-marked distinction in the molar type of the present Mesozoic fossil. A principal cone rises from the middle of the crown, but there is no small cusp on the inner side of this, as in the true molars of Didelphiys and Phascogale.

Herein Phascolotherium resembles Sarcoplitus and Thylacinus; but it differs in the presence of a basal ridge or 'cingulum,' shown along the inner side of the tootl in the specimen described, which ridge projects as a 'talon' beyond both the anterior and the posterior subordinate cones, giving the quinquecuspid character of the crown of the tooth in the second to the sixtl of the serics inclusive (fig. $26 \mathrm{~A}$ ). The molars increase in size from the first to the third, and decrease from the fifth to the serenth, but in slight and gradual way.

In this scrics there is no distinction, by way of form, betwcen false and true molars. 'The charactcr given by the successional premolar in existing Marsupials would be arbitrarily applicd to mark off the first three from the last four of the molary series of Phascolotherium. The distinction, by way of specialisation of form, between the (three) false and (four) true molars is much more strongly established in the modern Opossums and Dasyures, as it is in a minor degree in Sarcophilus and Thylacimus.

Phascolotherium shows a closer affinity in the molar type, and in the gradual assumption of that type as the tecth gain in size, to its contemporary Amphitheria; from which, however, it differs in the reduction of the number of the molary series to the prevailing formula in existing Marsupials.

Phascolotherium differs from the extinct and recent 'multidentate' Marsupials, and resembles the Sarcophilus and Thylacinus, in the direct and broad inbending of the mandible below the mandibular condyle, and in the low position of the latter. It is entire in the present specimen (b), and stands out in bold rclief from the matrix. It presents the same convexity from before backward as in Sarcoplitus and Thylacinus, but is relatively less extended transversely, and is rather more convex in that direction. The inflected 
part or 'angle' is continued more direetly from the imner end of the condyle, and, being broken away, its base constitntes the ridge which runs forward, bounding below the large shallow depression on the inner side of the aseending ramus. Viewing the muder surface of that ramus in Sarrophilus and Thylacinus, the flattened plane formed by the imbent angle inclines from withont inward and rather downward (see Cut, fig. 5, p. 73); in Phascolotherium the slope of the same part is rather upward and inward; so that it needs the mylohyoid groore $(y)$ and symphysis $(s)$ to convince one that it is the immer and not the outer surface of the ramus which is exposed. The entry to the dental eanal $(d)$ is more advanced in position than in the existing Australian genera above cited. The coronoid process in direction and proportion and in the depth of the notch between it and the condyle resembles that in Thylacimus more than that of Sarcoplitus; but the anterior border is more convex, the fore-and-aft breadth is relatively greater, and the posterior apex a little more procluced. In the gentle curve by which the lower margin of the mandible is continued to the incisive alveoli, Phascolotherium more resembles Phascogale than it docs Thylacinus or Sarcoplitilis.

'The mylohyoid groove is narrow and sharply defined; it runs from below the entry of the dental canal almost straight forward and downward, terminating at the under border below the third molar tooth; it has been mistaken for a suture, and looks very like one, but the bottom of the groove is entire. In size this fossil mandibular ramns equals that of the existing marsupial P'hascogule penicillatu.

The specimen of Phascolollerium Bucklandi above deseribed is in the British Musenm.

\$.-Genus-Stereognatuls, Charlesworth. ${ }^{1}$ IS54.

Species-Streregrathus ooliticus, Ch. PI. I, figs. 27 -30.

T'he fact of a genus and species distinct from any mammalian fossil at that time got from deposits of Mcsozoic age was made known by Edwand Charleswortir, Esq., F.G.S., to the Geological Scetion of the British Association at the meeting at Liverpool in 1854 . But there appears to be no record of generic or specific characters.

'The fossil itsclf wns submitted to me for description, ${ }^{2}$ at Mr. Charlesworth's instance, by its posscssor, the Rev. J. P. B. Dexxis, M.L., F.G.S. It consists of a portion of jaw with teeth imbedded in a slab of the Oolitic slate of Stonesfield, Oxfordshire.

The portion of bone cxposed to view is about nine lines in extent, and is part of a ramus of the lower jaw, containing three molar teeth (PI. I, figs. 27 and $27 \mathrm{~A}$ ). It is nearly straight ; the side exposed is convex vcrtically, which indieates it to be the outer side; a slight increase of vertical diancter towards the end $(A)$ indicates it to be part of a

1 'Report Brit. Assoc.' (Liverpool), 1851, Rep. Sect., p. 80.

${ }^{2}$ See 'Quarterly Journal of the Geological Sociely of London,' vol. xiii (18.57), pp. 1, \&c., pl. i. 
left ramus: the inclination of the cusps of the teeth (figs. 27, 28) towards the opposite end might, indeed, be deemed evidence of its belonging to the right ramus; but neither this degree of inclination nor the position of the accessory cusp (fig. 29, a) is decisive of the way in which that end of the fragment points. Not more of the matrix could be safely meddled with, on the small chance of further evidence to this comparatively unimportant particular being had; and the description of the fossil assumes that the shallower end is the front one, the decper one $(A)$ the hind end of the fragment, and that it is part of the left ramus of the maudible.

'Tlis ramus is unusually shallow, and broad or thick below, the side passing by a strong convex curve into the lower part; a very narrow longitudinal ridge, continued after its subsidence by a few fine lines, forms a tract which divides the lateral from the under surface; elsewhere the bone is smooth, without conspicuous vascular perforations. The depth or vertical diameter of the ramus is not more than two lines.

This portion of jaw contains three tecth, the middle one of which is the least mutilated; and, by carcfully removing the matrix which partly covered its crown, I exposed the whole of its singularly modified grinding surface. 'The first of the three teeth (fig. 27, a) appears to have been smaller than the others, but its crown has been too much broken to show its original characters. The third tooth $(c)$ is less mutilated: it is of the same size and had the same structure as the middle one (b). Of this tootll, fig. 30 shows the grinding surface magnified about five diameters. It is of a quadrate form, three millimeters by three and a half millimeters, of very little height, and supports six subequal cusps, in three pairs, each pair being more closely connected in the antcroposterior direction of the tooth than transverscly. In the Plate its position is at right augles to that in the jaw, fig. 27.

The outer side of the crown (fig. 29), supported by a narrow fang which contracts as it sinks into the socket, shows two principal cusps or cones $\left(o, o^{\prime}\right)$ and a small (anterior) accessory basal cusp $(a)$. A small portion of the outer side of the anterior cone $(o)$ has been chipped off; that of the sccond conc $\left(o^{\prime}\right)$ shows a well-marked convexity. The hard and shining enamel which covers these parts of the crown contrasts with the lighter ccment that coats the root. 'The two outer lobes or cones are subcompressed, and placed obliquely on the crown, so that the hinder one is a little overlapped externally by the front one, the fore part of the base of the linder one being prolonged inward on the inner side of the base of the front cone. 'The two niddle cones are subcompressed laterally, with the fore part of their base a little broader than the back part. The two inner cones have their inner surfacc (fig. 2S) convex, with their summits slightly inclined forward; a small portion of enamel has been chipped off the hinder lobe. The fore part of the base of the hinder conc is prolonged obliquely towards the centre of the crown, beyond the contiguous end of the base of the front cone, so as to cause an arrangement like that of the two outer cones; the obliquity of the posterior cone of botlı the outer and the inner pairs being such that they shightly converge as they extend forward. 
In the hindmost tootl (fig. 27, c) the two outer cones are broken off, showing that their common base is divirled from the two middle cones by a decper groove than that which separated the two onter cones fiom cach other.

'Thins, the crown of these molars might he described as supporting three parallel antero-posterior ridges; the onter (fig. 29, o, o') and the imuer (fig. 29) ridges being each divided by an oblique eleft converging forward towards the middle of the tooth; whilst the middle ridge is divided by a curved cleft laving its concavity turned forward (fig. 30).

The more mntilated state of the front tooth (fig. 27, a), of which only the base of the middlle ridge of the crown remains, throws no additional light on the modifications of the very remarkable type of the grinding surface of the mandibutar molars of Stereognathus.

'This type of tooth differs from that of all other known recent or extinct Mammals. 'The nearest approach to it is made lyy the trime molars of some of the latter from the most ancient of the Tertiary strata, as, e.g. Pliolophlus, from a septarian nodule of the London Clay (Pl. I, fig. 31, lower molar), and Ilyracotherieme.

'The proportional size and regularity of forn of the cones of the grinding teeth of the Stereognathus give a different charactcr of the crown from that of the multicuspid nolars of the Insectivora, and canse it to resemble more the pentecuspid or sexcuspid molars of the extinct hoofed genera above cited. No Mesozoic Mammal save Slercognathus ooliticus shows better grounds for heing regarded as a diminutive form of the Ungulate order of Mammatia; but, assmming its position in that order, it is probable that its food, if we may jullge from the existing Hogs and Peccaries, was of a mixed nature. There is certainly no other known Mesozoic Mammal which has so good a claim to be considered in any degree herbivorous.

Dr. Emmoss has described and figured the mandibular ramus, 9-10ths of an inch in length, of a Manmal (fig. 3) from the 'Chatham Coal-field' in Nortl Carolina. It contains three incisors, one canine and ten molars; of the latter scries, the first three have simple

Fira. 3.

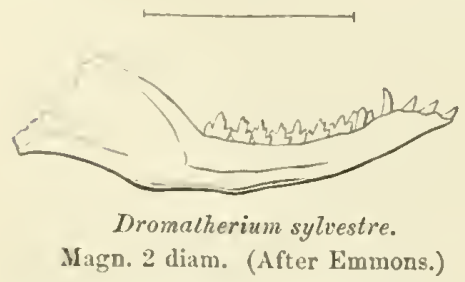
subcompressed conical crowns, the next four are multicuspid, and the last three are tricuspid (according to the figure); the incisors are separated by intervals, as in Myrmecobius and Pliascolotherium.

I opine that Dromathcrium was Marsupial. The extinct species indicated by this mandible Emmons calls 'Dromatherium sylvestrc.' 'The carbonized remains of ancient vegetation in which the foregoing, with two other similar mandibular fossils, have been found, is probably, like the coal of Brora, Sutlierlandshire,

\footnotetext{
1 'Quart. Journ. Geol. Soc.,' rol. xiv, p. 54, pls. ii-iv. '2 'Geol. Trans.,' 2nd ser., vol. vi, p. 203, pl. 24.
} 
not later than the Lower Oolite; or, like the Lettenkohle of Germany, of Triassic age. The Mammalian renains are associated in the Carolina-Virginia Coal-fields with those of thecodont Reptiles. ${ }^{1}$

\section{c. Mammals from Purbeck Beds.}

The strata of the Isle of Purbeck, on the Dorset coast, intervene between the 'Upper' (Portland) Oolites' and the 'Wealden' (see Table I,p.4). They have been successfully studied and accurately described by Mr. Webster, ${ }^{2}$ Dr. Buckland, ${ }^{3}$ and Dr. Fitton, ${ }^{4}$ whose conclusions have been verified with additional details, both palæontological and geological, by subsequent observer's, especially by the able and accomplished officers of the Geological Survey of Great Britain, to one of whom, Robert Etheridge, Esq., F.G.S., Palæontologist to the Survey, I am indebted for the subjoined diagram of the deposits at Durdlestone Bay (Fig. 4), including those from which the Mammalian Fossils of the 'Purbeck' described in the present Monograph have been obtained.

\section{§ VI. Genus-Spalacotherium, Owen, $1854 .{ }^{5}$}

species 1-Spajacotherium tricuspidens, Ow. Pl. I, figs. $32,32 \mathrm{~A}, 3: \mathrm{B}, 32 \mathrm{c}, 33$, $33 \mathrm{~A}, 33 \mathrm{~B}, 33 \mathrm{c}$.

Quart. Journ. Geol. Soc., vol. x, p. 426, 1854.

After Emmons' discovery the next evidence of a Mesozoic Mammal was obtained from a deposit of later date, onc of those which are known as the 'Purbeck Series,' richly developed in the peninsula of that name, at Durdlestone Bay, near Swanage, Dorsetshire.

In the year 1854 a scries of small fossils from that locality were sent to me for determination by Mcssrs. WiLcox and Brodie, of Swanagc. The majority of the specimens were Saurian, and afforded characters of the lacertian gencra Nuthetes, Macellodus, Saurillus, \&c. ; ${ }^{6}$ but some appearances of the teeth in small jaws among Mr. Brodie's specimens, suggesting evidence of a higher grade of life, attructed and excited close and continued scrutiny.

At first sight the specimens appeared, as their discoverer had supposed, to differ only in species from the similarly sized jaws of the Saurians with which thcy were associated, and it was only after a careful removal of the matrix concealing their most characteristic

1 'American Geology,' part vi, 1857,p. 93. A copy of Emmons' figure, and of the reference thereto, in my 'Palæontology,' 8vo, 1860, p. 302, is given in Dana's excellent 'Manual of Geology,' 8vo, 1864, pp. 426. 429 , and fig. 6.50 .

2 'Geol. Trans.,' 2nd series, vol. ii, p. $36 . \quad{ }^{3}$ Ib., vol. iv, p. $11 . \quad{ }^{4}$ Ib., ib., p. 208.

5 'Quarterly Journal of the Geological Society of London,' vol. x, p. 426.

6 Ib., p. 420. 
FIg. 4.

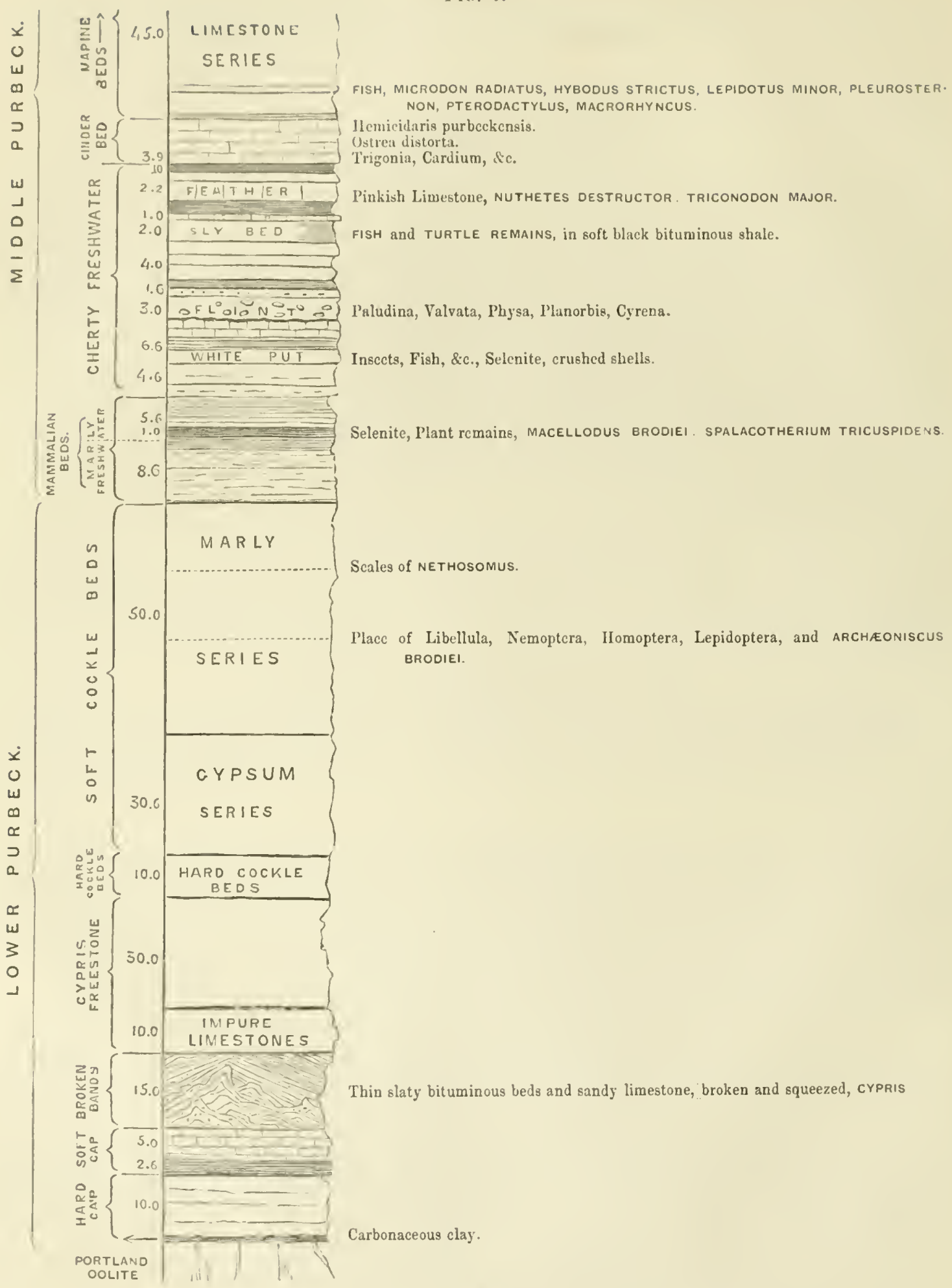

Section of Middle and Lower Purbeck Beds. 
features that I became satisfied of their relationship to the Mammalian class. I proceed to give results of re-examination of these specimens.

In a slab of Purbeck shale, showing part, and the impression of more, of a mandible, with teeth, nearly the whole of the hinder half of the ramus is exposed (Pl. I, fig. 32, natural size, in outline; $32 \mathrm{~A}$, twice natural size). This contains four teeth, not quite in contact, having a long and rather slender crown, terminated by a sharp-pointed sub. triedral cone (fig. $32 \mathrm{c}, 0$ ), the inner side of the base of which is produced before and behind the main cone into a short small cusp $(e, s)$. This tricuspid crown is implanted by two roots (fig. 32 в) in a distinct bifurcate socket of the jaw-bone.

The four teeth in fig. $32 \mathrm{a}$ gradually diminish in size to the hindmost; the jaw becomes slightly contracted vertically behind the teeth, and then expands to include a smooth depression, recognisable as the fore part of that for the insertion of the crotaphyte muscle; the upper swollen boundary $(b)$ indicates the fore part of the base of the coronoid process; the lower boundary ridge $(a)$ is that which would have been continued to the condyle and the angle of the jaw. We have here a left mandibular ramus with the outer side of the preserved bone and teeth exposed. The outer surface is vertically convex; the inner one, as indicated by the impression, is flatter, and faintly shows the termination of a longitudinal channel.

Fig. 3:2 $\mathrm{B}$ is an oblique view of the anterior side of the crown of the first of the four teeth in fig. $3: 2 \mathrm{~A}$; it shows the basal ridge of the outer side of the crown, ascending to be lost on the anterior accessory cusp; fig. $32 \mathrm{c}$ gives the form of the summit of the crown of the tooth riewed vertically.

In the number, proportion, and relative position of the cusps, this modification of the insectivorous molar resembles that in the Cape Mole (Chrysochloris); but in the proportion of the mid-cone $(o)$ and the definition of the side ones it accords more closely with the type of the Amplitherian molar (Pl. I, fig. 25 в).

'I'he inner antero-posterior extent of the crown is considerable as compared with the proportion of that diameter with the height of the crown in the true molars of any of the modern Moles and Shrews, except the Chrysochloris. The impressions of the inner side of some teeth anterior to those in place show plainly the tricuspid character of the crown, and indicate also a greater number of such molars in the fossil than in any of the recent Nammalia, with the exception of the marsupial Myrmecobius. Of this further and more important affinity of the Spalacotherium to the Amplitherium the following specimens yield more decisive evidence.

A portion of the marly fresh-water shales from the Purbeck series at Durdlestone Bay, marked 'manmalian beds' in fig. 4, had imbedded in it part of the lower jaw of the Spalacotherium, wanting the ascending branch ; the alveolar tract includes one incisor, a canine or canine-shaped premolar, and ten succeeding teetlı. It is represented of the natural size in outline Pl. I, fig. 33, and magnified in tint twice the natural size at fig. $33 \mathrm{~A}$. The incisor (i) seemcd to be the smallest of these teetl, but is represented only by a portion of the 
crown, of a subquadrate or obtusely conieal shape, convex externally. 'T'he eanine or canineshaped premolar (r) is more than twice as long and broad as the ineisor, with a subcompressed, sharp-pointed conical crown, a little inelned backward; it appears to have been inserted by a divided root, like the similarly shaped and proportioned first premolar in the Mole. 'I'ho two sncceding teetls (1 and 2) are one third sualler than the eanine, witl subcompressed, conienl crowns, at the fore and back part of which the base is slightly prodnced; cach is implinted by two distinet fangs. 'The third and fonth teeth have a similar form and eomplex inplantation, but are somewhat larger, and the basal cusps are more developed; in the fourth tooth this development gives a distinetly trienspid character to the erown, the unddle ensp, representing the crown of the preeeding teeth, being the largest and highest. The six following teeth (5 to 10) repeat the same nnequal trienspid form, with inercased but varying size, the middle teeth $(6,7,8)$ being the largest, and the last tooth (10) diminishing in size in a greater ratio than the penultimate one (9). 'I'hese six last molar teeth are seen to be elose together when the base with the ridge or 'cingulnm' is exposed. 'I'he lateral cusps incline inward, and projeet from a plane more internal than the longer middle cusp. 'The inner side of the erown presents a wide longitndinal groove at the base of the middle eusp), between the inwardly inflected lateral cusps ; the base of the crown presents externally a well-defined narrow cingulum, beneath whieh the two fings, or the two extermal fangs, descend into the substanee of the jaw. 'The list fonr teetl $(7-10)$ show an inferiority of size, as eompared with those of fig. $32 \mathrm{~A}$, whieh inay be scxul.

In the state in which this instructive portion of the Spalacothere reaehed me, the matrix coneealed all save the large niddle eusp) of the molar teeth, which teeth seemed to be wider apart, and presented a more lacertine aspect. By the careful applieation of a fine needle and graving tool I succeeded in displaying the lateral cusps and griuding surfaee of the erown, and the other teeth, as shown in the enlarged view given in fig. 33 ^. Fig. 33 в gives a magnified view of the antepenultinate molar (8), viewed obliquely from behind; and fig. $33 \mathrm{c}$ is an outline of the erown viewed vertically. We have here a right mandibular ramus, with the outer side exposed.

So much of the jaw-bone as is preserved in this speeinen (fig. 33) nearly eorresponds in size and slape with the portion and impression of the opposite (left) ramus (fig. 3:2), and shows the vertical eontraetion or deerease of that diameter behind the molar series, prior to the expansion of the jaw into the aseending ramus. The horizontai ramus lias suffered an oblique fracture since its fossilization across the alveolar series, with a very slight clepression of the fore part eontaining the four anterior teetl ; a second fraeture erosses the contracted part of the jaw behind the last molar in place. There is not any clear evidence of a smaller molar tooth behind the last in place, marked 10. Between the large laniariform tooth $(c)$ and the fore end of the ramus of the jaw there is a space for three ineisors like the portion of the small one preserved $(i)$, and also for a small eanine-shaped tooth, which is demonstrated in one of the speeimens next to be notieed. 
The specimen, fig. 34, nat. size, and magnified twice nat. size at $\mathrm{A}$, is the anterior half and an impression of most of the remaining part of the left ramus of the lower jaw, its inner surface exposed, showing the canine or canine-shaped premolar, $c$, and five following teeth in place, a fragment of a sixth molar, and impressions of four succeeding molars. 'The crown of the canine-shaped tooth is long, subcompressed, slightly recurved, pointed, with a small post-basal tubercle. The adjoining tooth (1) has a compressed, pointed crown, scarcely half the height of the canine and two thirds as broad at the base, with a ridge along the inner side of the base, and a more developed posterior basal tubercle: it is divided by a small interval from the canine. The second molar (2), with a slight increase in size and a similar shape, has the fore part of the basal ridge developed into a low point, and the hinder tubercle is relatively larger and more pointed. The third tooth (3) is larger than either of the two preceding, but resembles them in fornı. 'The fourth (4), with the same antero-posterior extent, has a lower crown, the middle cusp being relatively shorter, but both the antcrior and posterior ones are larger, and now begin to assume the character of independent cusps ; their bases almost meeting upon the inner side of the base of the middle cusp. 'The fifth molar, with a slight increase of size, shows a still further development of the accessory cusps, which are slightitly inclined backward, or project from a more internal plane than the middle cusp. The impressions of the succeeding teetli show that their middle cusp was longer in proportion to its basal breadth; and thus agrce, like the foregoing teeth, with the teeth similarly marked in fig. 33 . The canine-like tootl seems to lave a bifid fang; the three succeeding premolars, implanted each by two fangs, in this respect as in the general form and proportion resemble those of Amplitheriem.

The proportion of mandibular ramus here preserved and indicated is 1 incl 1 line, or 27 millimeters, in lengtl, that of the Mole being 1 inch, or 25 millimeters. The crown of the laniariform tooth is relatively longer, and the fourtl tooth counting therefrom is of a different form, being of much smaller size and of a more simple structure than is the corresponding tooth, which forms the first true molar of the Mole. The greater number of molar teeth indicated in the present and displayed in other specimens of the Spalacotherium demonstrate its generic distinction from any known existing insectivore, placental or marsupial, the Myrmecobius having nine and the Chrysochlore liaving not more than eight lower molars. 'I'he multident marsupial Myrmecobius is the sole existing Mammal, with incisors and canines, that approaches the Spalacothere in the excessive number of the molar teeth. Fig. $34 \mathrm{~B}$ is a magnified view of the teeth marked 4 and 5 in fig. $34 \mathrm{~A}$, showing the meeting of the accessory cusps on the imner side of the crown.

The last two specimens afford grounds for determining the teeth in place in fig. 3:?: they are accordingly denoted by corresponding numerals.

'The evidence of the Mammalian nature of the above-described specimens, briefly submitted to the Geological Society in 1854, excited an interest in further explorations of their place of deposit. 'I'his was undertaken with characteristic ardour by SAMUeL H. 
BeCKLes, lisq., F.R.S., and the suecess of his explorations, earried on at much eost and personal risk, mily be estimated by what follows of the present Monograph, the suljects of which were cxclusively brought to light by Mr. Beekles.

I commence with those which tend to eomplete our knowledgc of the mandible and mandibular dentition of Spalacolherium.

Pl. I, fig. 35, represents, of the nitural size, in outline, and magnified three times, in tint, at $\Lambda$, the fore part of the left mandibular ramus, showing its outer sidc, and an inpression of the linder part to near the begimning of the rising branch of the same jaw. 'The horizontal ramus is vertically narrow, but is thick, being convex outwardly; it is flatter on the inner side, the impression of which shows a trace of the longitudinal groove $(g)$. 'The ramus gradually contraets, with a gentle inferior convex curve, to the fore end, which is not abruptly raiscd, or bevclled up. There are four rather close-set simple alveoli, anterior to the three prenolars, with more or less mutilated crowns, in place. 'The fourth alvcolus is that of the canine $(c)$. The second premolar (2) shows, as in fig. 3 t, the main cone less raised in proportion to its breadth than in the succeeding teeth. 'The tip of the higher conc of the third premolar (3) is preserved, with the impression of the two inner basal cusps. 'The fourth and fifth of the molar series are not preserved. 'The sixth and seventh are slown by impressions of the two inner cusps (see fig. 34. B, $c, s$ ). Inipressions of the two or threc following teeth are less reeognisably prescrved. There is a small outlet of the dental eanal beneath the first premolar, and a second bencath the alvcolus of the third or last ineisor (i3).

Figures 36 and 37 show the portions and impressions of a mandibular ramus with tceth of Spalacotherium tricuspidens prescrved in counterpart slabs of a split block of Purbeck shale.

In fig. 36, a portion of the middle of the horizontal ranus exposes its inner surfacc, and ineludes thrce tceth $(3,4,5)$ more or less mutilated, with part of a fourth (6). In fig. 37 the continuous hinder part of the ramus is prescrred, showing the outer surface, and includes the basal half of the crown of the sixth and seventh molars, with indications of the soekcts of the eiglith and uinth molars. The tenth molar (10) is in part preserved, together with the hind part of the ramus, broken off, and somewhat displaced, showing the characteristic eontraetion preceding the expansc into the aseending branch with the crotaphytc fossa.

'The impression anterior to the portion of jaw preserved in this block answers to the part of the ramus prescrved in the counterpart block : in advance of which impression a small portion of the forc part of the ramus remains, showing the posterior outlet beneath the socket of the first premolar.

'The tcetlı retained in the block (fig. 36) are the third, fourth and fifth of the molary series. Anterior to them is the impression of the second, showing the same proportions of the main-cone as in 2, fig. 34. That of the third premolar (3) in fig. 36 wants the apex. 
The fourth tooth (4) preserves the summit of the main cone; but the base of the crown is mutilated. The main cone is broken away from the fifth tooth, but the two inner cusps, characteristic of Spalacotherium, are instructively shown. The accentuation of the inner, less bulging, surface of the ramus is well shown in the present slab. The thin inner alveolar wall descending sheer from the outlets of the sockets is at first slightly concave vertically; then swells out into a convexity toward the lower border; near which, at the hind part of the fragment, may be discerned, when the specimen is held in a strong light, the termination of the longitudinal (mylo-hyoid) groove $(g)$.

In the hind portion of jaw (fig. $37 \mathrm{~A}$ ) the equally characteristic base of the external main cone, with its basal cingulum, is seen in the teeth answering to the sixth and seventh molars. The impression of these beforc and behind are less intelligibly preserved in the matrix.

As far as I can safely work away the matrix from the inner side of these teeth, the base (horizontal section) thereto turned seems to be indented; the working surface terminating on that sidc in two low cusps, as shown in fig. $36 \mathrm{~B}$, answering to those shown in the tooth (5) of fig. 34.

All the evidence concurs in giving a tricuspid crown to the molar teeth in the present Purbeck fossil, of the character of that of the type-specimens of Spalacotherium (figs. 32-34), with which the mandibular ramus, so far as it is preserved, corresponds.

The last specimen referable to Spalacotherium tricuspidens supplies very satisfactorily the characters of the hind end and rising part of the lower jaw.

It consists of the left mandibular ramus, wanting the symphysial end, with five more or less mutilated molars in place, the inner side bcing exposcd. It is figured of the natural size in fig. 38, and of twice the natural size at $\mathrm{A}$. This specimen includes the condyle $(b)$ and great part of the coronoid process $(c)$.

From the inner end of the condyle (b) a ridge curves forward, bounding below the depression, terminating anteriorly in the entry of the dental canal $(d)$. The hinder two thirds of the ridge has becn broken away in exposing the specimen, indicative that it has extended inward or transversely to the plane of the rising ramus above, to a greater degree than is hcre shown. The lower border of the ramus is entire and convex, showing that the angle of the jaw was represented by the inflected ridge, plate or proccss.

This marsupial character is well shown in Sarcophilus and Thylacinus (fig. 5, p. 74); but the entry to the dental canal is morc advanced in the present extinct marsupial than in those existing species. The condyle is transversely extended, and holds the same relation of level to the alveolar tract as in Thylacinus. A decp emargination divides it from the hind border of the coronoid. The shape of this process resembles that in Sarcophilus. A linear groove is continued from the inner border of the dental foramen to beneath the third molar here in place.

The most perfect molar-the first in place—shows a fine but well marked 'cingulum 
along the immer side of the base of the crown expanding into an anterior and a posterior basal cusp) between which the crown rises in two inner and lower cones, and one outer and highter conc.

Indications of the same structure are more or less clear in the four succeeding molars, which retain nearly the same forc-and-aft basal breadth. There is an empty socket of a smaller molar between the last in place and the base of the coronoid, and the empty twochambercel socket in front of the first molar in place may have held an anterior one of the sanc complexity, making seven molars. There is sufficient demonstration of the multidentate character to warrant the reference, suggested by the type of molar tecth, to the genus Spalacotherium.

I'lie contour of the lower border of the ramus is not an even curve, but is slightly wavy, the convexity changing to a slight concavity beneath the entry of the dental canal. There is an indication of a slight vertical constriction bchind the molar series, as in the previously described specimens of the present genus.

Species 2.-Spalacothlerium minus, Owen. Plate I, figs. 39, $399_{\text {A. }}$

'The best preserved molar tooth in the specimen (Pl. I, fig. 39, nat. size, and $39 \mathrm{~A}$ magnified three times, in tint) slows the generic type of Spalacotherium, the ant-internal and post-internal cusps mecting at the immer side of the base of the main cone. But the specimen is not only inferior in size to the type species, but liffers in the absence of the constriction of the horizontal ramus anterior to the expansion into the ascending branch. The horizontal ramis preserves, however, the degree of vertical extent forward as far as the sockct of the canine, which tooth is shown in fig. 34. The base of the ascending ramus indicates a curve upward toward the condyle, as in fig. 3S. The dentition is not sufficiently prescrved to afford any ground for gencric scparation; and I therefore retain it as a smaller species of Spalacotherium.

'I'lis specics is represented by a left mandibular ramus with the inner surface exposed, retaining four juxtaposed tceth belonging to the middle of the dental scries with indications of sockets before and behind then. 'Two of the retained teeth are molars, the hindmost yielding the Spalacotherian type of crown as above described. The next in advance gives a main cusp and indications of an accessory one in front, and a lower and more remote one behind; but the crown of this tooth is too much mutilated for precise definition. The tecth are compressed. There are indications of sockets of two molars between the last in situ and the ascending ramus. The premolars show a reduction of forc-and-aft breadth more immediately than in Spalacotherium tricuspidens: their crown consists chiefly of a subcompressed sharp-pointed cone. In advance of the two hinder mutilated tecth in place are sockets of four others, decreasing in size, and then a large and more outwardly projecting alveolns of a canine, the crown of which has left its impression. In advance of this, the symplyysis with the incisive alvcoli has been broken off. 
The inner side of the ramus is marked by the linear groove continued further forward than is indicated in the specimen (PI. I, fig. 38, g) of Spalacotheriun tricuspidens. The vertical extent of the horizontal ramus is preserved as far forward as the socket of the canine, both upper and lower borders being nearly straight and parallel.

\section{§ VII. Genus-Aмblotherium, ${ }^{1}$ Owen.}

In the type of the present genus (Pl. II, fig. 1 , nat. size and $1 \mathrm{~A}$, magn. 3 diam.) the true molars do not exceed in number those of the lower jaw in Amplitherizm (Pl. I, fig. 25), and of the upper jaw in Peralestes (Pl. II, fig. 3); but the incisors are four in each mandibular ramus, equalling in number those in Pliascolestes (Pl. II, fig. 4). The two hind premolars have crowns exceeding in size those of the succeeding molars.

The present species, with the full or adult complement of teeth, is markedly smaller than any of the foregoing Mesozoic mandibles save Spalacotherium minus.

Species 1-Amblotherium soricinum, Owen. Plate II, figs. 1, 1a, lв.

This species is founded on a right mandibular ramus, the inner side exposed ( $\mathrm{Pl}$. II, fig. 1 , nat. size; $1 \mathrm{~A}$, magn. 3 diam.) showing four incisors $(i 1-1)$, the canine $(c)$, four premolars $(p 1-4)$, and six molars $(m 1-6)$, with a trace of what may have been the alveoius of a seventh molar.

The condyle (b) projects midway between the summit of the coronoid $(c)$ and the angle of the jaw (a), its lower end being on the level of the alveolar outlets. A thin ridge $\left(a^{\prime}\right)$, or rather the base of one showing fracture, projects inward from the lower border of the ascending branch, bounding below the groove leading to the entry of the dental canal $(d)$. From the fore part of this entry the groove $(g)$ begins, which extends as a linear fissure, simulating a suture, from a little above the rounded lower border of the ramus to the hind part of the symphysis $(r, s) .^{2}$

The hind border of the coronoid process descends from the fine recurved point $(c)$ in a bold or deep regular concave curve to the condyle, as in Amplitherium and Phascolotherium, but its apex does not reach so far back. 'The state of prescrvation of the articular process shows clcarly ellough its convexity, but not its precise size; it is somewhat crushed, and appears larger in the specimen than it was in the recent bone.

1 ' a $\mu \beta \lambda$ íw, to abort; $\theta \eta p i o v$, beast.

2 It is remarkable that a groove corresponding in position with that lodging the mylohyoid nerve and vessels in the human mandible, but of which no trace exists in most lower placentals and existing marsupials, should reappear, as it were, so distinctly, in these small Mesozoic mammals. It may be questioned whether it was due to the same mechanical cause and relations as in man; whether it may not rather indicate a more definite "splenial" harmonia, remaining longer open than in later mammals; but which is, nevertheless, entirely closed in all the subjects of the present Monograph. 
Below the eondyle the hind border of the aseending ramus deseribes a deep curve to the baekwardly produeed end of the infleeted angle of the jaw. The lower border of this infleeted part is straight, and is not eontinued into that of the horizontal ramus with the undulated eontour shown in Spalacolherium, Phascolotherium, and Amphitherium. 'The depth of the ramus gradually lessens to the horizontal sloping symphysis, as in Amphitherium.

The first ineisor ( $i 1$ ) of Amblotherium soricinum is proeumbent, and eontinues forward, as it were, the gentle eurve of the lower border of the symphysis; it has a long, slightly expanded, obtusely terminated erown, but this is the worn configuration of the fossil tooth and may not have been exaetly its eondition in the recent subjeet. The erown of the sceond ineisor ( $i_{2}$ ) is less than half the length of that of the first, but is almost as broad; it rises at a distanee equal to its own basal breadth from the first. The third ineisor $(i 3)$ is similar to the second, and rises eloser thereto. The erown in each of these ineisors is hollowed on the hinder and inner surfaee, so that the apex is subreeurved, as in Myrmecobius (Pl. 1, fig. 24). After a longer interval comes the erown of a fourth small ineisor $(i, 4)$. Near this rises vertieally, with a slight backward curve, the crown of a tooth which, by its length, represents the canine $(c)$; it terminates more aeutely than do the incisors, and the erown is narrower in proportion to the height than in them.

Behind the eanine, with an interval like that before the canine, is the simple low conical crown of a minute premolar $(p 1)$. In eloser proximity rises that of the seeond premolar $(p 2)$. From the apex of the eone, whieh is near the fore part of this tooth, the hind horder slopes or curves baekward, swelling inwardly, and representing a hind basal prolongation or talon. The third premolar $(p 3)$ presents a like type of crown, with marked gain of size. The fourth premolar $\left(p_{4}\right)$ inereases in height, but not in basal breadtl. Eaeh premolar is implanted by two fangs.

The series of true molars begins by teeth muelı inferior in size to $p 4$ and $p 3$ : they have acquired, abruptly as it were, their eharaeteristie shape and eomplexity of erown (fig. 1, B, magn. 6 diam.). This consists of a long and slender main cone, with an anterior $(c)$ and a posterior $(\delta)$ well-marked eusp, the anterior being the larger, and on a higher level. The intervening tract of the inner part of the crown represents there a low cingulum, rising to, without being well defined from, the base of the prineipal eone (o) which rises in great proportion from the outer part of the crown. In one of the molars, the third (fig.l, B), the intervening part of the inner side of the crown forms a small low prominenee before inelining to blend with the main external conc. The molars inerease in size to the third; then gain, perhaps, a little in basal breadth to the sixtlı; whieh, therefore, by the analogy of hinder decrease of size in the molars of Myrmecobius Spalacotherium, I do not regard as the last. The traees in the fossil at the interval between $m 6$ and the eoronoid proeess would be, I think, rightly interpreted as those of a soeket.

The molars and the last premolar form a series uninterrupted by any 'diastema.' 
The projecting front teeth are made to catch, the canine and premolars to kill, the nolars to pierce and crush chitinous integument; and, by the analogy of Moles, Shrews, and Opossums of like size (Didelphys dorsigera, e.g., p. 105, fig. 22B), we may guess the prey to have been Insects and other Annulosa.

The mandibular dentition of this little marsupial ferine may be formularised as :-

$$
i \cdot \overline{4-4}, c \cdot \overline{1-1}, p \cdot \overline{4-4}, m \cdot \overline{7-7}:=32 \text {. }
$$

The analogy of Myrmecobius checks any hasty conclusion as to there being precisely as many teeth in the upper jaw as in the lower one of Amblotherium.

The dental formula of Myrmecobius is:-

$$
i . \frac{4-4}{3-3}, c \cdot \frac{1-1}{1-1}, p \cdot \frac{3-3}{3-3}, m \cdot \frac{5-5}{6-6}:=52 .{ }^{1}
$$

The mandibular dentition of Amplitherium is :-

$$
i \cdot \overline{3-3}, c \cdot \overline{1-1}, p \cdot \overline{6-6}, m \cdot \overline{6-6}:=32 .
$$

The multicuspid character of the molars of Myrmecobius, and the almost uniform small size of the cusps, are associated with a smaller relative size and a looser or more open arrangement of the teeth than in Amblotherium. The affinity of Amblotherium to Amplitherium is closer than to Myrmecobius. The present species, Amb. soricinum, as represented by the mandible with the full adult complement of teeth, above described, is smaller than any of the previously characterised species so represented.

Species 2-Amblotherium mustelula, Owen. Plate II, fig. $2,2 \mathrm{~A}$.

The present specimen (Pl. II, fig. 2, nat. size, and 2 A, magn. 3 diam.) agrees generically in the character of the crown of the true molars (as exemplified by the tooth marked $m$ 3, in fig. $2 \mathrm{~A}$ ) with the type of Amblotherium, and it presents the same general configuration of the ascending branch and symphysial end of the jaw. The difference of size is such as to lead me to regard it as specific, and this conclusion is strengthened, if not confirmed, by modifications of shape and proportion of the hinder or ascending portion of the ramus.

The species Ambl. mustelula is represented by a right mandibular ramus, the inner side exposed, showing five or six of the molary series in sitû, but with crowns more or less mutilated; there are also some feeble indications of incisors.

The jaw has a larger ascending branch and coronoid process than in Amb. soricinum or in Amplitherium; remarkably larger than in Myrmecobius. 'The condyle (b) projects

1 Waterhouse, "Description of a new Genus of Mammiferous Animals from Australia," \&c., "Trans. Zool. Soc.,' vol. ii (1836), p. 149, pl. xxviii. 
from above the level of the molars, apparently with a longer relative interval between it and the angle than in $A m b$. soricinum, but the outline is not so well preserved.

'The anterior border of the coronoid, so far as preserved, is more vertical and less curverl than in Amblolherinm soricimum or in Amplitherium. The lower margin of the horizontal ramus is continued by a gentle convex line to the end of the symphysis, which is long, narrow, and very little raised from the horizontal level. The breadth of the rising ramuns between the fore part of the base of the coronoid and the back part of the condyle almost equilis the extent between the fore part of the base of the coronoid and the hind cul of the symphysis (r). In Amb. soricinum the same dimension of the rising ramus is equal to three fourths of the extent from the fore part of the base of the coronoid to the hind part of the symphysis (fig. $1, r$ ). In the prescnt jaw, as in that of $A m b$. soricinum, the myloliyoid groove (fig. $2 \Lambda, g$ ) is represented by a finc linear one, extending from near the entry of the dental canal $(d)$ to the symphysis. 'The ridge $(a$ ') retrogrades from that entry, and angments in depth, or inward inflection, as it appronehes the angle $(a)$. The angle which the line of the ridge $\left(a^{\prime}\right)$ forms with the fore margin of the coronoid is more open than in $A m b$. soricimum.

The best preserved of the molar teeth ( $m$ 3) shows the inner side of the erown divided into two tubcrcles answering to $e$ and $s$ in fig. I в : the anterior one, in likc manner, being longer and inclined forward, from a higher level. The main cone rises vertically from the outer side and middle or borly of the tooth. The hindnost molar in place scems to answer to $m 5$ in fig. 1, and, from its relation to the coronoid, should be the antepenultimate molar. 'I'herc possibly may have been threc tecth behind it, if they decreased in sizc, as in Spalacotherivm, but this I think unlikely. An interval for one molar divides the tooth in place $\left(\begin{array}{ll}m & 5\end{array}\right)$ from the next in advance $\left(\begin{array}{ll}m & 3\end{array}\right)$. The molar $\left(\begin{array}{ll}m & 2\end{array}\right)$ in front of that is obliquely tilted up. The one marked $m 1$ is obviously smaller : its two roots have slipped from the socket, and the crown is broken off. This would give seven molars, reckoning the last in sitû as the antepenultimate onc. In advance of the first molar are three premolars, losing size as they advanee in position. They are too much mutilated for any conclusion as to the relative length or height of the main cone. Each is implanted by two roots, and the base of the main cone gives indications of fore and hind cusps. The socket of one ante* cedent premolar is definable. Then comes the base of a small eanine in its socket, and next, one of a small incisor, in adranec of which there is space for two or three sockets of other incisors before the symphysis terminates anteriorly, where the extreme cnd seems to be wanting.

The lower border of the horizontal ramus describes a more marked convex curve than in Amb. soricinum.

The conclusions arrived at from close serutinising of the indications of tecth in this wellmarked form of mandible (fig. 2) are more favorable to generic conformity with the dental formula shown in Amb. soricinum than otherwise. I, therefore, limit mysclf to regarding the species it represents as being generically allied to the smaller type (fig. 1). 


\section{§ VIII. Genus-Peralestes, ${ }^{1}$ Owen.}

The present genus, like Amblotherium, differs from Spalacotherium by a more marked distinction between the premolars and molars; the former being necessarily characterised, through the want of developmental evidence of these long-since extinct Mammals, by shape and relative size of crown.

In Spalacotherium, as in Amplitherium and Phascototherium, it is difficult to draw the line between the members of the numerous molar series, as may be appreciated by reference to the subjects of figs. $23,25,26,33, \mathrm{Pl}$. I. Here, however, the superior length of crown serves to determine the last and penultimate premolars by contrast with the smallness of the tooth by which the molar division of the 'cheek-series' begins.

Species 1.-Peralestes longirostris, Owen. Plate II, figs. 3, 3 a, B, c.

Of the molary series of teeth evidence is given in the present species by instructive portions of the dentition of both upper and lower jaws.

Pl. II, fig. 3, represents of the natural size, in outlinc, a portion of the right upper jaw, which at $\mathrm{A}$ is figured, in tint, magnified 3 diam.; whilst at $\mathrm{B}$, the grinding surface of the preserved upper molars is represented on the same scale.

This specimen includes the external alveolar wall of the maxillary with the last premolar and six following true molars in sitú. As much of the upper jaw as equals in length the series of preserved teeth extends in advance of them : it is a fragmentary tract, but shows part of the bony palate and a few alveoli. A vacuity near the fore end of the palate, and a corresponding fissure on the outer wall of the jaw, may indicate the hind limits of a premaxillary; but this portion of bone is not entire anteriorly.

The interest and instruction afforded by this specimen lie in the demonstration given of the character of the crowns of the upper molar teetl, and especially of the configuration of their outer side.

In a direct side view of the exposed part of the specimen the outer wall or division of the crown shows but little vertical extent compared with the fore-and-aft, or with the transverse, diameter; but the inner half is developed into a longer cone. The front half of the outer wall presents the form of a smooth subhemispheric protuberance $(a)$, from which the hind lalf extends backward at a lower level; its outline being broken by a few slight notches dividing it into two or three minute tubercles $(b)$. The larger anteroexternal tubercle $(a)$ contracts to a low cusp (sharper in $m 4$ and 5 than in $m 3$ ), from which the grinding surface curves outward to the loftier or longer and more acutely terminated cone of the antero-internal lobe $(c)$. The post-external lobe or tract $(b)$ contracts as it extends inward, and ends there in a low cusp (ib, fig. $3 \mathrm{~B}, d, d$ ) at the hind and inncr part of the base of the long antero-internal lobe $(c)$. The horizontal section of

\footnotetext{
1 זípa, pouch; $\lambda_{\eta \sigma \tau} \eta^{\prime} s$, robber.
} 
the crown is triangular, with the base turned outwarks, and the apex formed by the anterointernal lobe: the anterior half of the base projects more outward than the posterior half.

Of the six molars $i n$ situi showing the type above defined, the crowns increase in size from the first ( $m 1$ ) to the third $(m, 3)$ and decrease from the fourth to the sixth ( $m$ 6), which seems to be the least of all. Of this tooth the onter side is turned obliquely backward, the low posterior portion of that side being much eurtailed: thus the foreand-aft dimension of $m g$ is less than that of the antecedent molars. Moreover, the outer surface of the maxillary runs inward behind the sixth molar without appearance of fracture, and confirms the ascription of six molars, and not more, to the series on each side of the upper jaw.

'I'he Mammal indicated by the present specimen is nearly allied to Amblotherium. It belongs, however, to a distinct genus, here represented by a species as large as Amb. mustelinla. In extending the comparison to other genera known by the upper as well as the lower teeth, Stylodon alone arrests attention. But, besides the differences in the number of molars behind the long-crowned premolar, there are differences of eonfiguration of the grinding-surface of the molar teeth, as compared with the fossil upper jaw (PI. II, fig. 14, c.y.). 'I'rue it is that this unique example presents the inner side of the maxillary teeth to view : but, though there be sonic increase of fore-and-aft breadth as the crown extends ontward, there is no accessory cusp in the molars of that speciuren, answering to the one nurked $d$, which is plainly shown at the middle of the hinder border of the crown in the molars of fig. 3 : the fore-and-aft cxtent of the outer part of the crown in fig. 3 is relatively greater than in fig. 14 .

The last premolar in Peralestes, with a fore-and-aft breadth not excecding that of $m$, , has a crown of twice the length. It is a long, sharp cone, and answers serially to the inner one in the truc molars. A 'cingulum' is indicated along the onter side of the base of the cone $(p$, fig. $3 \mathrm{~A}$ ) and derelops a minnte cusp both before and hehind that base, or at least behind it. The front talon may be described as a mere thickening there of the cingulum. 'The outer tubercular wall of the crown in the succeding tceth scems to be a development of the cingulum. This premolar, like the succeding molars, shows two extcrnal roots, the front one being the largest. 'The seven tecth are elose-set.

An mpper strip of the maxillary, in advance of these tecth, inclicates a long and slendersnouted form of head, recalling that in Myrmecobius and Perameles.

Sarcoplitus ursinus comes nearest in the character of its upper molars to the present specics of Peralestes. The outer part of the crown (ib., fig. $3 \mathrm{c}$ ) is low in proportion to its forc-and-aft extent. It develops anteriorly a cusp, $a$, similar in its proportions and position to $a$ in $m 3$ and $m 4$, A. The hinder tract of the outer part in the second true molar of Sarcoplitics develops two cusps, the larger of which answers to $d$ in fig. 3 в. 'The inner cusp (c) is the longest and sharpest cusp) in both Sarcoplitus and Peralestes. The groundwork pattern is the same, with a generic distinction indicated by the accessory low inner basal tubercle, and also by the minor number of molars in the large existing typodcntate zoopliagous Marsupial. 
Species 2.-Peralestes (Phascolestes?) Longurostris, Owen. Plate II, figs. 4, 4 A, B, C.

From the size and shape of the last two premolars and the contrast they present to the small succeeding molars, together with the shape of so much as is preserved of the crowns of these, which show a corresponding similarity with the lower molars of Sarcophilus, with that indicated in the upper molars of fig. 3, I am disposed to refer the specimen to be described (Pl. II, fig. 4, nat. size, fig. 4 A, magnified 3 diam.) to the same genus; although, it is true, that there are indications of a greater number of true molars than in the upper jaw of Peralestes longirostris.

Since, however, in Myrmecobius, the only known existing form of multidentate Marsupial, there is one more true molar on each side the lower jaw than in the upper jaw, I am minwilling, especially as the actual teeth are not preserved in the mandible under consideration, to separate it from the genus showing so marked a resemblance in the proportions of the contiguous premolars and molars, and so close correspondence in the characters of upper and lower molars with those in Sarcoplitus. If an upper jaw should eventually be found showing seven or eight true molars of Peralestian type, following the large cuspidate premolar, the generic name Phascolestes might be accepted for the species represented by the present mandible.

The specimen is the anterior half of a left mandibular ramus, showing the symphysis and inner surface with an impression of the posterior part as far as the beginning of the coronoid process.

The teeth in place are the four incisors $(i, 1,2,3,4)$, the canine $(c)$, four premolars $(p 1,2,3,4)$, the basal part of the erown of five succecding tceth $(m 1,2,3,4,5)$, and the impressions of three successive long and slender cones, which, if belonging each to a distinct tooth, would make the premolar-molar serics twelve in number on each side of the lower jaw, which is that in Amphitherium (Pl. I, fig. 23).

The present specimen is fully one fifth longer and is proportionably deeper at the corresponding part than the jaw of the type of Amplittherium there figured (and in the work cited below ${ }^{1}$ ); it has a longer and larger canine, and also unequivocally shows four incisors in sitú, making eight in front of the lower jaw. These incisor's, instead of being arranged transversely at right angles with the canine and molar series, as in Thylacinus and Dangarus, form a scries of sockets curving gradually forward to that of the foremost, due to the syuphysis, as in Amblotherium, Amplitherium, Plascolotherium, and Myrmecobius. As in the latter Marsupial, also, the foremost incisor is the largest, and is subprocumbent in position. The last three incline rather forward, but less so than docs the first. The second incisor is the smallest; the third and fourth increase without gaining the dimensions of the first. Each stands apart from the other by a short interval, as in Myrmecobius. They are

1 'History of British Fossil Mammals and Birds,' 8vo, 1846, fig. 15. 
set closer together than in Amblotherium, and the foremost is relatively larger. The crown of the canine $(c)$ rises vertically, with a slight backward curve to its sharp summit. It is relatively narrower, antero-posteriorly, at its base than in Myrmecobius. It shows a wellmarked longitudinal groove at the imner side of its basal lialf near the hind border. It is relatively longer and larger than in Amblotherium.

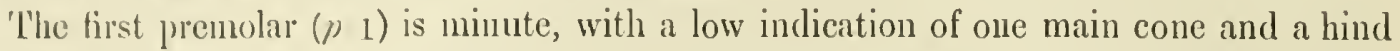
hasal production: it stands distant by more than twice its own fore-and-aft breadth from the canine. 'l'he sccond premolar $\left(\begin{array}{l}p_{2} \\ 2\end{array}\right)$ is one third larger than the first, with its main conc and hind talon better marked: it stands half its breadtl distant from the first. 'The third premolar ( $\left.\begin{array}{l}p_{3} \\ 3\end{array}\right)$ is twice the size of the second ; its nuain cusp is large and lofty; the hasal talon relatively low and small: it rises a little further from the second than docs that behind the first. 'I'le fourth premolar $(p 4)$ inereases chiefly in vertical extent; its main cone is a long subcompressed piercer; the hind talon is fecbly marked: it stands at the same distance from the third as that tooth does from the second premolar.

'The bases of the five succeeding tectl indicate a more complex type of crown. An anterior as wcll as a posterior basal cusp is marked off from the main cone, and the anterior cusp) is larger and higher than the posterior one. One may infer the main cone from the preserved impressions of the last three molars to have been long and slender ; it rises chicfly from the outer side of the crown. Supposing each tooth preserved or indicated in this portion of mandiblc to have worked upon a maxillary fellow, its generic distinction from Peralestes would be established, and the dental formula of Phascolestes would be, $i \frac{1+4}{4-4} c \frac{1-1}{1-1} p_{4-4}^{+4} m \frac{8-8}{5-8}=6 ; 8$, being four more than in Amplitllerium, and fourteen more than Myrmecolius. 13ut, by the analogy of the latter genus, as above remarked, the number of the molar' series may have been less in the upper jaw. 'The lower contour of so much of the ramus as is preserved in the subject of fig. 4, Pl. II, is gently convex, curving gradually up to the incisive arcolar border. The symphysial articulation is long and narrow. There is a fecble indication of the notch which is present at the anterior border of the symphysis in Myrmecolius (Pl. I, fig. 24), and is conspicuous in Amphitherium Broderipii (ib,, fig. 25). The anterior terminations of the linear groove near the lower margin of the ramus, slown in the inner side of most of these small mesozoic mammalian jaws, is here also visible. A fine line is continued from it to the lower end of the symplyysis.

\section{Incerta sedis. Peralestes, sp.?}

In the proportion of depth to length of jaw the fragment of the riglit ramus (Pl. I, fig. 40 and 40 A), figured in my original memoir on Spalacotherinm, ${ }^{1}$ and referred to that genus, more resembles the present. Seeing, also, that the fore part of the ramus has been broken off behind the long symphysial articular surface, one might hazard a supposition that the tecth, there referred to a canine and anterior premolar, miglit be the

\footnotetext{
' 'Quart. Journ. Geol. Soc.,' vol. x, p. 431, fig. 12.
} 
homologues of the last two premolars in Phascolestes. The molar series in Mr. Brodie's specimen are, however, in too mutilated a state to support more than the conjecture that it may belong to a Peralestian species.

\section{§ IX. Gemus-AChYrodon, ${ }^{1}$ Owen. Plate II, figs. ว-S.}

The present genus is represented by four more or less mutilated mandibular rami of small size (Pl. II, figs. 5-8), retaining molar teeth (fig. 7 в) of the general tricuspid type exemplified in Spalacotherium and Amblotherium, but with the externo-median or main cusp (ib., o) sharp and slender, longer in proportion to its basal breadth, and with the antero-internal cusp (ib., $e$ ) of similar shape and proportions, and of nearly equal hcight. The resemblance of these cusps to needle-points suggested the generic name. The postero-internal cnsp (ib., s) retains the small proportions shown in fig. $1 \mathrm{в}, \mathrm{Pl}$. II). The main cusp (fig. 6 B, o), inclines slightly forward, and the front one $(e)$ in a greater degree, overlapping the hind cusp of the antecedent molar.

The specimens exemplifying this curious needle-toothed type of Marsupial are less perfect than some of those exemplifying the preceding genera; but enough of the dentition and alveoli may be recognised to show that the genus enters into the polyprotodont and multimolar group of Entomophaga.

Species 1.-Achyrodon nanus, Owen. Plate II, figs. 5, $5_{\mathrm{A}}, 6,6 \mathrm{~A}, 7,7_{\mathrm{A}}$, and B.

The first exemplar of this species is a right mandibular ramus mutilated at both cnds, but including eight molars of the generic type and two contiguous premolars (Pl. II, fig. 5, nat. size; $5 \mathrm{~A}$, magn. 3 diam.). The inncr surface is exposed. In advance of a rertical line dropped in front of the foremost of these premolars begins the symphysis $(r)$, and as much of the symphysial end of the ramus continues forward as forms the alveoli of two teeth, probably, also, premolars. The last two premolars, in place $(p 3, p 4$, fig. $5 \mathrm{~A})$, have crowns higher than those of the succeeding molars : that of $p 4$ is twice the heiglit of that of $m 1$, and is rather higher than that of $p_{3}$. Both are conical, subcompressed, with apices polished and a little blunted by use. A low cingulum crosses the base obliquely from before downward and backward. Both are implanted by two fangs. The coronal pattern of the molars is at oncc assumed. The long, slender, anterior cusp rises obliquely forward from the fore end of the cingulum. The longer main cone contrasts by its slenderness with that of the antecedent premolar. The low hind cusp is as well marked as in the succeeding tceth. 'These very gradually increase in size to the third $(m 3)$, the seventh and eightl decreasing again.

As inuch of the fore part of the coronoid process as is preserved rises straight and slopes but little from the vertical: it resembles the corresponding part of the coronoid of Amblotherium mustelula (Pl. II, fig. 2), not the more sloping convcxity of that in Ambl.

\footnotetext{
' úxupov, acus ; ódovs, dens.",
} 
soricimum (ih., fig. 1). The pterygoid fossa is hounded by a well-marked inwardly produced ridge, which has declined to the lower border of the ramus at the hind fracture. The dental canal (ib), fig. $5 \mathrm{~A}, d$ ) begins at the fore part of the fossa, below that border of the coronoid. 'The mylolyoid groove $(g)$ begins in advance of the lower hounding ridge of the inner fossa, and, if it lodged a nerve of that name, this nuust have perforated the ridge anterior to the entry of the mandibular nerve-trunk, in order to (merge upon the groove. The groove is well-defined, linear, and extends at first straight forward, then very slightly bends up to the back part of the symphysis $(r)$. 'This is narrow, long, and continues the feeble convexity of the under border of the ramus. without any al)rupt upbending from that contour. Below the last three molars the inner alveolar plate is subconvex vertically to the groove. Beneath the anterior five molars the bone is flatter: in advance of the premolars the inner surface bends inward as it sinks to the sympliysis.

Achyrodon differs from Amblotherium in the greater relative length of the anterior cone of the molars, which projects over the hind cusp of the antecedent tooth, exemplifying the closer, and as it appears interlocked, array of the molars in the present genus. Admitting that one molar may be wanting in the type of Amblotherium (Pl. II, fig. 1), the seven molars then would occupy the same relative extent as do the eight molars in Aclyyrodon. 'They are, nevertheless, in other respects so closely alike as to have led me long to hesitate, and repeatedly pass under comparative review all the Purbeck specimens showing this general slender-coned type of molar, before concluding to indicate the differences above defined by a generic name.

The specinien (Pl. II, fig. 6, nat. size, fig. 6 A, magn. three diam., in tint) might seem to be the left ramus of the same mandible as the right one last described, but that it appears more slender. Like that, it is mutilated at both ends, but in a less degree, retaining the two anterior premolars, and rather more of the reflected lower border of the 'ascending ramus.' There are five molara $\left(\begin{array}{ll}m & 1-5\end{array}\right)$ and sockets for three, if not four, behind the teeth in place. The crown of the best preserved teeth show the base of the long anterior cone and the smaller and lower posterior basal cusp, united by a low oblique smooth rising; external to which, or from which, ascends the principal cone, chiefly supported by the outer side of the coronal base. The molars are close-set; and, indeed, their bases seem, as in the right ramus (fig. 5), obliquely to overlap each other.

The apex of the main cone is broken in all, or more worn than in fig. 5. The last premolar $(p 4)$ shows the usual simple type of one chief subcompressed pointed cone; which, though broken, evidently had the characteristic superiority of height over the succeeding true molar $(m 1)$. It is implanted, as in fig. 5 , by two roots.

'I'he ramus is slender, almost straight. The slight curve of the lower border, and the indications of the ascending ramus ( $a^{\prime}$ and $c$ ) repeat the characters in the mandible (fig. 5). 'The deep pterygoid fossa leads to the entry of the dental canal $(d)$ which is below the 
anterior margin of the coronoid process, as in the right ramus (fig. 5 ). A well-marked linear groove (g) traverses the whole length of the inner surface of the portion of the horizontal ramus preserved, about one third of the depth from the lower margin, ending at the hind part of the symphysis. Its curve and commencement in advance of the anterior boundary of the pterygoid fossa repeat the characters noted in the subject of fig. 5, Pl. II.

The left mandibular ramus (Pl. II, fig. 7, nat. size, 7 A, magn. three diam. in tint), wanting the ascending branch, has four well-preserved molars in place, the inner side exposed. The mylohyoid groove $(g)$ has the same commencement and course. The better preserved, long, narrow, almost horizontal symphysis $(r, s)$ shows that the slender ramus gradually tapers to the obtusely pointed anterior end.

The molars are closely arranged, and well display the anterior slender sharp-pointed cusp (fig. 7, s, e) rather inclined forward; next, a similar, but rather larger, longer, and more nearly vertical, main cone $(o)$, behind which is the basal cusp $(s)$ : a very ninute accessory cusp could be detected at the imner and hinder part, near the base of the main cone.

There is space for one or two such molars, especially if the last one lost size, as in the type jaw (fig. $5 \mathrm{~A}, m$ ), behind those in place; the extent of the empty alveolar tract in advance of the molars indicates teeth in number according to those shorn in fig. 6 .

The four molars in place answer to those marked $m 3-6$, in Pl. II, fig. 5 A. If the proportion which those four teeth there occupy of the extent of alveolar tract from the fore part of the coronoid to the fore end of the symphysis be compared with the corresponding proportion in Amblotherium soricinum (ib., fig. 1), their superiority, both absolutely and in relative size to the jaw, in the present fossil, will be appreciated. But the difference of structure, according to the taxonomic value assigned by Mammalogists to the characters of true molars, is more than specific. The mylohoid groove $(g)$ describes a somewhat different curve from that in Amblotherium.

Species 2.-Achrodon pusiluus, Owen. Plate II, figs. 8, 8 A.

The mandibular character last referred to has not more than specific value, if so much. The curve, convex upward, of the hinder half of the mylohyoid groove (Pl. II, fig. S A, g) in the portion of jaw showing in the few molars prescrved the generic coronal characters of Achyrodon is, howcrer, associated with other differences.

The specimen (ib., fig. 8 , nat. size; 8 A, magn. 3 diam.) is the hinder lalf of the horizontal portion of a left mandibular ramus with the inner side exposed, showing four molars in sitú, which I determine to be the third to the sixth inclusive, as in fig. 7 ; there are sockets of teeth, before and behind those in place, indicative of the same excess of number as characterises the dentition of the preceding specics of Achyrodon. I quote the 
note originally made of the ehisacters of these teeth, before the relations of this specimen to any other in the series liad been determined by comparison.

"The last two molars, scen from the inside, have a crown of two cusps and a hind talon. The cusps are remarkable for their hight, slenderness, and sharpness, rescinbling needle-points. 'They do not rise straight up; the anterior one curves gently forward before it ascends, retaining a slight forward obliquity; the second ensp is more nearly vertical, but little longer, and slightly inelines forward. 'T'he first and second of these tecth in sitû seem to consist each of one main eusp, which is long, slender, and pointed, with a fore and a hind basal cusp; they resemble the two hind molars, with the reduetion of the anterior cusp to a talon; but the second of these tecth has suffered fracture, and the difference in both may be duc to mutilation (as I subsequently satisficd myself was the case). 'The iripression of the fore part of the jaw indicates space for five or six molars or' premolars, besides a canine and threc or, perhaps, four incisors. 'There is room for two molars behind the teeth in place, of equal size with them."

The best preserved teeth in the present mandible are rather less, botl absolutely and in proportion to the depth of the supporting part of the jaw, than in Acliyrodon nanus; and, coupling this with the course of the mylohyoid groove, I venture to indicate the species represented by the present mandibular fragment as an Aclyyrodon pusillus.

\section{Gemus-Peraspalax, Ouen.}

Species 1.-Peraspalax talpoides, Owen. Plate II, figs. 9, 9 a, в.

The molar tecth of this genus, agrecing in general character with those of Amblotherium, are more complex, inasumch as they show a distinct cusp-like rising or prominence (PI. II, fig. $9 \mathrm{~B}, n$ ), from the inner side of the base of the main or external cone $(o)$. In this respect they make a nearer approach to the type of the lower molar in Didelphys (ib., c) than does any of the preceding Purbeck Marsupials. 'The antero-internal cusp (ib., fig. 9 B, e) projects obliqucly forward, and from a higher level than the shorter and smaller hind basal cusp (s), above which the anterior cusp of the following molar projects, giving an interlocked kind of disposition of the close-set series of molars, recalling that in Aclyyrodon.

The main cone $(0)$ is shorter and basally broader relatively than in Amblotherium, much more so, therefore, than in Acliyrodon. 'I'he molar teeth are also larger, and of a more robust character in proportion to the jaw. This charncter is well seen in comparison with Amblotherium mustelula (fig. 2, Pl. II), a species of about the same size as that represented by fig. 9 .

'The present species is represcnted by a portion of the left mandibular ramus, with the inner side exposed, retaining six molars $(m 2-7)$ and one premolar $(p 4)$ in sitú. It shows the socket and impression of the first small molar $\left(\begin{array}{ll}m & 1\end{array}\right)$, and the impressions of the three

I $\pi \dot{\eta} p a$, pouch ; $\dot{\alpha} \sigma \pi \dot{\alpha} \lambda \alpha_{\xi}^{\zeta}$, mole. 
anterior premolars and of a canine. The molars exemplify the generic didelphid modification of the multicuspid mechanism for insect-crushing above defined. They slightly increase in size from the first to the sixth; the third $\left(\begin{array}{ll}m & 3\end{array}\right)$ is a little displaced, exposing the two roots. The molars are close-set, and the anterior oblique lobe of one overlies the posterior talon of the tooth in advance ; but it is much shorter, and more obtuse and procumbent than in Achyrodon (fig. 7).

The last premolar $(p 4)$, with the well-preserved crown, shows distinctly the front and hind basal talon, the main cone rises higher, and the whole tooth is larger than the three succeeding molars. It is divided by the socket of the small first molar from the second one. Impressions of the crowns of two or three anterior premolars, and of that of a longer, sharp, recurved canine, are preserved in the slab of the matrix.

\section{\$ XI. Genus-Peramus, ${ }^{1}$ Owen. Plate II, figs. 10-13.}

In this genus the teeth, implanted in a jaw characteristically long and slender, are large in proportion, and that in fore-and-aft extent rather than in height. The main outer cone in the true molars has a base almost equal to its height, and offers a marked contrast with the proportions of that of Achyrodon. There is an indication of an accessory internal cusp ( $n$, fig. 10, c, Pl. II), from the main cone (ib., o), distinct from the antero-internal basal cusp (ib., e), which, with the general proportions of the main cone, approximate Peramus to Peraspalax. But the five molars retained in the mandible (fig. 10) decrease in size in a greater degree than do those, $m_{4-7}$ (Pl. II, fig. 9 A), in thc type of Peraspalax. Such indications have the greater value in the endeavour to interpret muaterials so minute and fragmentary and often obscure. It is certain that there is not sufficient evidence for the determination of generic collformity of the specimens above cited and compared in their dental system ; and the marked difference in the form and proportions of the mandible, as exemplified in Pl. II, fig. 9 (Peraspalax) and fig. 10 (Peramus), sways with me in offering the present evidence for comparison with future possible acquisitions under the above generic name.

Species 1.-Peramus tenuirostris, Ow. Plate II, figs. $10,10 \wedge, 10$ в, 10 c.

This species is represented by three fossils. The first to be described is a left mandibular ramus ( $\mathrm{Pl}$. II, fig. 10, nat. size, and $10 \mathrm{~A}$ and $\mathrm{B}$, magn. 3 diam.), wanting the symphysial extremity (probably supplied by fig. 11), with the last four molars in situ, and sockets of five antecedent teeth. In the last three molars the main cone is high and boldly convex across, as in Stylodon, but is broader at the base, and lower than in that grenus. The front border is shorter and more nearly vcrtical than the hind one, at the base of which is a short thick talon (fig. $10 \mathrm{c}$ ): the anterior basal talon (ib.,e) is much smaller : the sharp apex of a small cusp (n) rising from the fore and inner part

$1 \pi \eta \mu a$, pouch; $\mu v s$, mouse. 
of the base of the main cone indientes an accessory part, which represents the anterointernal cusp in Peraspalax and Didelphys. 'The three molars showing the above structure progressively, but slightly, decrease in size as they recede in position.

The main cone in the foremost of the four teeth in place $(m$ 4) has its outer surface less bulging or eonvex across, and its acute apex is on a lower level than that of the next molar ( $m$.5). 'The anterior cusp is better marked; but the posterior basal cusp is still the largest, though less than in the succeeding molars. The antecedent alveoli sufficiently show the multidentate character of the fossil ; but it would seem that the premolar shape and degree of coronal simplicity prevailed over a greater proportion of the molar series than in Peraspalux.

'T'he condyle (b) projects hackward on the level of the dental series. The angle of the jaw (a) bends downward and backward, as a short triangular process, in advance of the condyle and from a lower level. Working out the matrix with careful avoidance of disturbance or breakage of so rare a feature in the present series of small jaws, I got the evidence that the angular process was slightly inflected, as shown in the vicw from below, in fig. $10 \mathrm{~B}, a$. 'The fractured surface at the fore part of this process was probably due to the original exposure of the fossil. 'The dotted line in fig. $10 \mathrm{~A}$ inclicates the proportion of the process which I suppose may then lave been broken off. The crotaphyte depression is deep and extensive from behind forward; its fore and under boundary ridges are well marked. The ridge, continued from its anterior margin, curves forward nidway between the molar alveoli and the lower border of the ramus, and, blending with the lower ridge, subsides in advance of the four teeth in place.

Peramus temuirostris differs from Spalacotherium tricuspidens in the non-constriction of the mandible behind the molar serics; in the sharper angle at which the cxternal crotaphyte boundary-ridges meet anteriorly; in the lower position of the condyle $(b)$; as well as in the deflected angle (compare fig. 10 with fig. 38 in Pl. I). Peramus also differs in the two last-defined characters from Amblotherium, and notably from Amblotherium mustelula, in the greater slope of the fore margin of the coronoid process.

Sufficient of the jaw of Achyrodon is preserved, in figs. 6 and 6 A, Pl. II, to show a difference of contour of the lower border of the ramus, but the generic distinction is more decidedly manifested in the forms and proportions of the molar teeth. The contrast which the mandible of Peramus presents with that of Amplitherium and Pliascolotherium will be seen by a glance at figs. 23 and $26 \mathrm{in} \mathrm{Pl.} \mathrm{I.}$

The next example of Percmustenuirostris is the fore end of the left mandibular ramus wanting in the preceding specimen. It is outlined of the natural size, Pl. II, fig. 11, and given in tint at $11 \mathrm{~A}$, magn. 3 diam. It includes the bases of three incisors, a canine, and five prenolars.

The jaw tapers in a singular dcgree to its fore extremity, the line of the incisive alveoli coming down to meet that of the symphysis, while this is nearly horizontal or slightly 
concare. It plainly indicates a produced and slender fore-part of the head, recalling the physiognomy of the insectivorous marsupial Bandicoots (Perameles) and Myrmecobians. This mandibular character suggested the 'nomen triviale' proposed for the present species.

Of the incisors (Pl. II, fig. $11 \mathrm{~A}, i 1,2,3$ ) it call only be said that their crowns have been slender, and were probably long; the first or foremost procumbent, the second and third progressively, though slightly, rising from the horizontal position. The canine $(c)$ is rather more raised, and shows its characteristic curvature to a sharp summit. A slight interval separates each of these front teeth from the other. At a similar interval from the canine rises the compressed sliarply conical crown of a small premolar $\left(\begin{array}{ll}p 1 & 1\end{array}\right)$. The next $\left(\begin{array}{l}p \\ p_{2}\end{array}\right)$ has been forced forward and turned round, the curved hind slope of the cone being pushed behind the base of $p 1$ : the divided socket of this two-rooted tooth is exposed. The third premolar is in place, and well shows the shape of the crown, with the convex front border and concave hind one, produced at the base without any cusp-like elevation of this part. The socket of the fourth premolar is vacant.

The fifth tooth $(p$ 5) shows a change of shape, approaching that of the first of the retained molars in figs. 10 and $10 \mathrm{~A}$. The fore and hind borders of the compressed cone slope or diverge from the sharp apex at almost the same angle, and each end of the base developes a minute cusp or talon. The body of the conc is markedly convex antero-posteriorly, as in the hinder molars. 'There is no indication, impressional or alveolar, of any premolars between the last ( $p 6$, if it be a premolar?) in place and the molars in sitü (in fig. $10 \mathrm{~A}$ ), suggesting the character shown in both upper and lower jaws of Peralestes. Otherwise it might be questioned whether the type of upper molars in Peralestes (Pl. II, figs. 3 and 3 A) might not probably be that of Peramus. But, even if Peramus had shown the marked superiority of height and size of the last two premolars over the sncceeding true molars, the present must have been a different and smaller spccies from the Peralestes longirostris represented by figs. 3 and $4 \mathrm{in} \mathrm{Pl.} \mathrm{II.}$

Peramus tenuirostris (?). Plate II, figs. 12, 12 A.

This is represented by the anterior portion of a left mandibular ramus, with the outer surface exposed, and the symphysial end with its alveoli and teeth broken away: it also shows the premolars, which have suffered some displacement in the foregoing specimen. 'I'hey accord in proportions and shape too closely with the dental characters of Peramus to justify generic separation.

The first tooth in place is a premolar, two-rooted, with a simple subcompressed conical crown. The next tooth seems to show a lower conical crown, with the same fore-and-aft basal extent; but there is evident trace of mutilation by fracture. The third tooth gains in height and fore-and-aft extent. The fourth is similar in size to the third. The fifth 
scents to be smaller, but one cannot be sure that size may not be masked by matrix, which I have thought it too hazardons to endeavour to elear away. 'T'he basal eusps are best marked in the fonrth and sixth teeth.

At the fractured fore part of this jaw is the crown of a small tooth, which slopes obliquely forward (as in $i$, fig. $11 \mathrm{\Lambda}$ ); it is probably an ineisor. 'The soeket of a larger simple tootl follows, answering to the canine in fig. $11 \mathrm{\Lambda}$.

Perames thuunostris (minor?). Plate II, figs. 13, 13 ^.

'l'he left ramus, wanting the aseending portion, of a long and slender mandible with the inner side exposed (Pl. II, figs. 13 and $13 \mathrm{~A}$ ), I refer, from its shape and the eharacter of the few teeth it retains, to the same genus, if not species, as the two foregoing specinens.

The angle at which the pterygoid depression terminates anteriorly suggestively resembles that of the outer depression in fig. $10 \Lambda$, and offers the same distinetion compared with the inner surface of the mandible of Amblotherium, show'n in Pl. II, fig. I A, as has been pointed out in regard to that speeimen. The mylohyoid groove is wide at its hinder half and straighter in its eourse than in Amblotherium or Achyrodon.

The preserved fore part of the base of the eoronoid, and a neatly defined impression of the renainder, slow a shallow emargination of the summit which may be due to fracture, as is donbtless the deeper noteh there in the mandible (fig. $10 \mathrm{~A}, c$ ). But the comcidenee is noteworthy. If one conld trust the part of the impression nurked $b$, in fig. $13 \mathrm{~A}$, as showing the position of the condyle, it wonld scem to be relatively ligher, and divided by a shorter and more angular noteh from the eoronoid than in the type of Peramus tenuirostris (fig. $10_{A}, b$ ). The anterior part of the inward produetion of the lower border of the depression on the immer side of the aseencling rantus indieates the marsupial elaracter, but is not preserved backwardly far enougl to show any downward extension of an angular process, as at $\alpha^{\prime}$ in figurc $10 \mathrm{~A}$.

The erowns of two molars are partially preserved, and the roots of two in advanee are visible. A ehief eone, and indications of smaller basal eusps, as in $m 4$, fig. $10 \mathrm{\Lambda}$, are plainly slrown.

'The end of the symplyysis has heen broken and displaced slightly upward, so that one camnot satisfactorily or with certainty conclude as to a differenee, or the degree of difference, from the shape of that part in fig. $11 \mathrm{~A}$. If the mandibular ramus (fig. 13, I'l. II) should exemplify more than a sexual inferiority of size of Peramus tenuirostris, it ninght bear the specifie name minor. I do not recognise grounds for generie distinetion. 
§ XII. Genus-Strlodon, Owen, 1866. ${ }^{1} \quad$ Plate II, figs. 14-19; Plate III, figs. 1—4.

The present genus of Mesozoic Mammal was founded on a portion of lower jaw with teeth (Pl. II, fig. 15, nat. sizc, $15 \mathrm{~A}$, magn. five diam.) submitted to the Author hy his friend the Rev. Peter B. Brodie, M.A., F.G.S., by whom it had been obtained from the same locality and marly member of the Purbeck beds as that which became subsequently the scene of Mr. Beckles's explorations.

The results of the latter abundantly confirm the title of this, at one time, unique specimen, to the generic distinction, assigned to it, and the later acquisitions instructively add to our knowledge of the dental and mandibular characters of Stylodon.

Species-Struodon pusillus, Owen.2 Plate II, figs. 15, 15 A, to 19, 19 A.

I may be permitted to quote part of my original account of the type-specimen of the present species before procceding to the description of those discovered by Mr. Bcckles.

"The part of the lower jaw is imbedded in a small block of the matrix, with the outer surface exposed: it includes the portion of the ascending ramus supporting the coronoid process (a film of which only remains in the depression of the matrix, mainly indicating its size and shape), and so much of the horizontal ramus as includes the alveoli of the nine posterior teeth, cight of which are in sitú. The articular and angular processes, and the fore part of the ramus, have been broken away, and there is no indication, in the matrix, of the entire ramus having been imbedded therein; it may be inferred, therefore, that the mutilation took place prior to imbedding. Enough, however, has been preserved to demoustrate the class-characters of the animal to which the fossil belouged, and to enable us to add another genus and species to the small category of Mammatia of the Mesozoic period.

"The continuous unity of bone at the part of the mandible which would show most of the sutures in a lacertian jaw - the leight, breadth and contour of the 'processus coronoideus' - and the implantation of one at least of the teeth by two fangs in a double socket, concur in testifying to the warm-blooded, air-breathing, viviparous, and lactiferous class of the aninal. The basc of the coronoid process shows the raised boundary of the lower part of the depression for the insertion of a temporal muscle of mammalian proportions. The lower margin of the ascending ramus has a degrce of thickncss and flatness suggestive of Marsupial affinities; but the angle itself is broken off. As, however, the alternative is the almost cqually low 'lissencephalous' sub-class, to which the present little Inscctivore must be referred, if it be not 'lyenceplalous,' it adds another to the prevalent testimony of the low condition of the Mesozoic mammalian life.

' orúdus, pillar; odous, tooth. The 'Geological Magazine, or Monthly Journal of Geology', \&c. No. xxiii, May, 1866, vol. iii, p. 199, pl. x. figs. 1 and 2.

2 Ib.

ib. 
"'The crowns of the teeth, eneased in lustrous cnamcl, are loug or high in proportion to their breadth and thiekness. They manifest this proportion, indced, in a higher degree tham do the teeth of Spalacotherium; and, being ronnded or cylindroid at the aspect cxposed, have sugrested to me the generic name Stylodon, signifying 'pillar-tooth.' 'The hindmost in place, supported apparcntly on a single columnar fang, which is partly protrnded from the socket, and covered with a darkcr and duller cement, has a longish conical crown, with the fore part of the base rather more produced than the hind part: the crown of the next tooth is somewhat longer: that of the antepenultimate has a broader base, produced anteriorly into a minute angle, and slightly thickencd bchind, but not developed into a continuous cingulum. The apieal half of the crown is broken off in the three tecth next in advance. Each has a small antcrior basal 'talon,' and a single columnar root, so far as it is cxposed; thcy arc, likewise, severally smaller than the antepenultimatc tooth. 'The scventh tooth, counting forward, is more abruptly smaller than the rest, with a simple conical crown, indicating only a fccble promincnce of the fore part of the basc. 'Then rises the crown of the largest tooth of the scrics, laniariform, subrecurved, or seeming to be so, from the convexity of the front border, and the minor concavity of the hind onc, where the base is a little thickened and produced; this crown is supported on two divergent fangs. The convex surface of the jaw bencath these teeth is entire-shows no ncurorascular outlets-the main anterior one has gone with the missing fore part of the ramus.

"Any attempt to determine the nature of the above-described eight teeth must be madc on unsatisfactory and unccrtain grounds. Guided by their shape and proportions, we might view the foremost as a 'canine,' the next four as 'premolars,' the last three as 'true molars,' and thus infer an example of placental diphyodont dentition. The oljection to the two-fanged character of the canine would be met by the same mode of implantation of the canine of the common mole ( $T a l p a$ ), the proportion of which tooth to the succceding premolar is very similar to that presented by Stylodon.

"But the proportion of the prescrved dentigerous part of the present fossil to the part bchind indicates a greater number. and size of teeth in advance of the laniariform tooth than the three small incisors of Talpa. The closer similarity of the narrow columnar hinder molars to those in the Cape Mole (Chrysochloris, Cuv.), and the very probable addition of an eighth such molar to the seven in place behind the laniariform tooth of the fossil, warn us of the deceptive character of the analogy of the dentition of the eommon Mole. It is more likely that Stylodon like Spalacotherium and Chrysochloris (unique in this respect among existing Insectivora), exemplified that exeess of number of tceth which, in Marsupialia, as in Insectivora, is seen in a single known existing genus (11yrmecobius), but was common in the similar small insectivorous pouched Mammals of the older Oolitic deposits. Spalacotherium had ten molar teeth on eneh side of the lower jaw, of which the last six had tricuspid crowns, with proportions and spacing similar to 
those in the Cape Mole." 1 The corresponding teeth of the present genus and species are in closer contact with each other, and are of more simple shape, and apparently more simple implantation.

The first example which I have selected from Mr. Beckles's series (Pl. II, fig. 17) shows the gencric character of the molar teeth of Stylodon; and, if they appear to be a little further apart than in fig. 15, it is because more of the intervening matrix remains. Those who have experienced by how slight a tonch of the finest needle-point the crown or part of the crown of a tooth flies off, in the attempt to develope these delicate fossils from their subpetrified marl-bed, will appreciate the reticence which practice begets of being content when enough has been exposed for comparison and determination, and of "letting well alone."

The alternative of the Cape Mole suggested in my original Memoir as preferable to that of the common Mole for homologizing the teeth in place in the type-jaw, and the probable nearer affinity of Stylodon to Spalacotherium, is confirmed by the fossil now under description. The two-rooted tooth with a canine-shaped and canine-proportioned crown proves to be the last of the premolar series (as definable by shape).

The instructive specimen, figured of the natural size in outline, and magnified three diam. in tint, is a left mandibular ramus, wanting the rising branch, but including the dental series, which may be formulised as-

$$
i \overline{4-4}, c \overline{1-1}, p \overline{4-4}, m \overline{7-7}=32 .
$$

The front or first incisor $(i 1)$, is procumbent, with a long and narrow spatulate crown. The second $\left(i_{2} 2\right)$, with a narrower crown, lies parallel with the first. The third $(i 3)$ is smaller, and more erect: the fourth $\left(i_{4} 4\right)$ is also very small, and is nearer to the canine than to the third incisor. The canine $(c)$, with a longish slender obtuse crown (perhaps not entire at the apex), slopes forward, but less so than do the incisors. The outer side of the root shows a longitudinal fissure, indicative of division.

The first premolar $\left(\begin{array}{ll}p & 1\end{array}\right)$ is small, and near to but not touching the canine: the second $(p$ 2) rises, at an interval equal to its own breadth, from the first, and is also small.

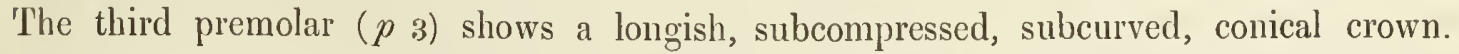
The fourth $(p 4)$ is a similar but a larger tooth. Each premolar has two roots, one before the other.

The truc molar series begins, as in Amblotherium, by tecth of inferior size, as if they had continued backward a series of deciduous tceth which the larger premolars had displaced. 'The first molar $(m 1)$ has a straight, vertical, smaller and more slender cone than $p 4$; it is also more convex antero-posteriorly, and with a cingulum extending into an anterior and a posterior basal cusp. The root, or outer root, supporting the girted crown, rises some way above the alveolus. These characters are repeated in the four

$$
1 \text { 'Quart. Jouru. Geological Society of London,' 1854, vol. x, p. } 425 .
$$


sncceding molars, with slight but progressive inerease of height, not of breadth, of crown. 'The length of the exposerl part of the third molar $(m 3)$ is equal to the cntire (kepth of the ramus below the socket: the same may be said of the fourth $(m$ 4) and fiftl $(m$ 5) molars; but the lower border of the jaw may not be fully cxposed.

'The crowns of the last two molars $(m 6, m 7$ ) arc partly broken away; and those of the last two incisors and first two prenolars liave sufferced mutilation; otherwise, the whole mandibular scrics of teeth of S/ylodon pusillus is instruetivcly displayed in the present specimen. In comparison with the mandible of Amblolherium soricinum (Pl. II, fig. l) it well exemplifies the valuc of the dental characters showing gencrie distinction in these mimute multidentate Marsupials of the Mesozoic period.

'Ihe ncxt cxample supplies almost as much of the dental series of the upper jaw, as does the foregoing specincu of that of the lower jaw. 'The grounds for referring the specimen (Pl. II, figs. 14 and 14. A) to Stylodon pusillus will be given, as might be looked for, in some detail.

In the cxisting Inseetivores which show tecth, or at least the molar series of tecth, rescmbling those of certain speeics of small Mammals represented by fossil jaws and tceth from the Purbeck marl-berls, the longest and largest lobc or cusp projects from the inner part of the crown in the upper molars, from the outer part in the lower ones. This is well shown in Chrysochloris, ${ }^{1}$ in which the inside vicw of the upper teeth and the outside view of the lower tecth present the form or eliaraeter of crown closely resembling the type of that which suggested the grencric name Slylodon. Somewhat of the same character is secu in the 'Tenrecs (Centetes), ${ }^{2}$ which morc nearly rescmble Stylodon in the proportions of the incisors and caninc. In Perameles, ${ }^{3}$ and Didelpliys ${ }^{4}$ also, the longest eusps of the true molars project from the iuncr half or side of the crown in the upper jaw, and the reverse in the lower jaw. The tendeney to adherc to this reversing of position, as it seems, of upper and lower molars in respeet to onter and inner side-configuration of crown is discernible in the teeth of Sarcophilus ursime, Pl. II, fig. $3 c$, and fig. $4 c$.

Upon these considerations, and after close and repeated serutiny of the teeth, which a suecessful application of the needlc-point has exposed in onc of Mr. Becklcs' slabs, affording, at first sight, small promise of suel result, I conclude them to belong to the upper jaw.

The apparent continuation of the jaw-bone $(a, b$, fig. $14 \mathrm{~A})$ direetly down, or vertically, from the alvcolar margin of this specimen, at first suggested a mandibular charactcr. But the cracks and fissures (ib. $a, a$ ) close to that margin, and the thinness of the osseous plate

1 Fr. Cuvier, genre Chrysoclore, 'Annales du Muséum d'Histoire Naturelle,' tom. xii (1808), p. 49, pl. iii, figs. 1-5. I'b., 'Dents de Mammifères,' 8vo, 1825, p. 63, pl., no. 18. (The line-engraving in the original memoir is better than the lithograph in the subsequent work.)

2 Ib., p. 46 ; and ib., p. 69, pl. no. 19.

3 Ib., p. 71 , pl. no. 23, A.

4 Ib., p. 73, pl. no. 23, c. 
itself, show it to be part of a bony palate, broken and bent up into its present position by posthumous pressure. The part $(b)$, moreover, continued from the sockets of the three last molars, retains an inward curve or bend therefrom, suitable to its palatal character, and not in accordance with the disposition of either the inner or outer plate of the ramus of any mandible in the present series of small mammalian fossils.

With this determination the general curve of the molar series also accords : it inclines outward from the canine, and, after a straight course, bends inward at the end of the series, the hinder half of which is thus convex outwards or horizontally. Vertically the series presents, as in the upper molars of Marsupials and Insectivores, a slight sigmoid disposition.

Assuming then that we have-or rather are detecting-in the present specimen, the dentigerous part of the left upper jaw, it exposes the inner side of the teeth, and also the working surface of the last three molars $(m 5,6,7)$. The tecth, in situ, are the canine $(c)$, and eleven of the premolar-molar series.

Of the incisors nothing can be said, satisfactorily or confidently, beyond the fact that there are, in the portion of crushed bone, $d$, anterior to the canine, feeble indications of their alveoli.

The canine $(c)$ is a formidable tooth; its crown is more than twice the lengtly of that of the longest inolar; it is gently bent, as it descends, backward and a little inward, is strongly indented at the middle of the imner side of the base, the indent widening to the socket, as if indicative of a division, or disposition to divide, into two roots. A like indication was noted in the lower canine of Stylodon pusillus.

Close behind the canine projects the crown of a minute premolar $(p 1)$, of a simple, subcylindrical, obtusely pointed form. After an interval there is an indication of a similar minute premolar $\left(\begin{array}{ll}p & 2\end{array}\right)$. Then follows a premolar $(p$ 3), having for its crown a broader based conical cusp with a minute tubercle before and behind: this tooth is not longer than the first, but is much broader from before backward; it is implanted by two roots. Immediately follows a much larger and longer premolar $(p 4)$, the conical crown of which does not show the basal tubercles. The next tooth $\left(\begin{array}{ll}m & 1\end{array}\right)$ presents the form of the exposed inner surface common to the rest of the molars; riz., that of a cylindrical column truncate atop: this terminates internally a crown which expands slightly as it extends outward; the inner cusp does not reach the level of the apex of the antecedent premolar, and the sudden loss of size in $m 1$ significantly recalls that character in the type mandible (Pl. II fig. 15). The second molar ( $m$ 2) in the upper jaw (fig. 14) is merely augmented in size: it shows more of the dark-coloured cement-covered base before the bright amber-coloured enamel begins. The following molar $(m 3)$ is similar. The fourth of these molars $(m 4)$ slows a slight outswelling of the enamelled base of the crown and the summit of the inner column is less worn, rising to an obtuse point. The fifth, sixth, and seventh molars $(m 5,6,7)$ decrease progressively in length ; they slightly expand to the outer side, which is divided by a mid-longitudinal cleft (fig. 14, B, $c$ c) into two low cusps. The grinding 
surface sinks as it slightitly expands from the prodneed sharp summit of the inner cusp, and is eoneave from within ontwards: it is very smooth and polished. 'The series of grimding surfaees of these antero-posteriorly eompressed tri-enspiclate molars deseribes longthwise a moderate eonvexity downward or towarl the mandible, whieh enrve, with the horizontal ontward bend of this part of the dental series, eonfirms the determination of these teeth, as belonging to the npper jaw.

'The: maxillary molars of Stylodon show most resemblance to those of Chrysochloris, but they are elose together, and, indeed, obliquely overlap each other. Being broadest transversely, and extending from within slighthly hackward as well as ontward, a small part of the hinder surfaee, as well as the narrow colmmmar side, of one tooth stands elear of the crown of the following tootl.

If, as is most probable, one of the minute premolars has dropped from the interspaee hetween the first $(p 1)$ and the next $\left(\begin{array}{ll}p_{2} & 2\end{array}\right)$ in place, we may reekon five premolars arcording to shape, and seven molars by the same charaeter, twelve in all, on eneh side the npper jaw, besides the eanines and an unknown quantity of small itreisors. The indication of premaxillaries (a) testifies to a greater extent of dentigerous jaw anterior to the canine than exists in the Cape Mole.

In the outline of the natural size, Pl. II, fig. 14 (and in fig. It A, magn. nearly four (liann. in tint), I eonelnde, therefore, on the foregoing grounds, is represented a great part of the left upper jaw and dentition of Slylodon pusillus.

'T'o the same genns and speeies I refer the left unandibular ramus, with five molars in silu, opposed by portions of the erowns of the eorresponding upper teeth (Pl. II, figs. 16 nat. size; $16 \Lambda$, magn. 3 (liam.). A few of the premolars are more or less perfeetly preserved in the part of the mandible in advance of the lower molars.

The aseending ramus and the symphysial end of this mandible are broken off; the inner surfaee of the preserved part with teeth is exposed. 'The longitudinal groove on the inner side of the ramus is relatively wider than in most other genera of small Mesozoie Marsupials, showing that groove.

Fragmentary portions of the maxilla to which the portions of upper molars belonged are disecrnible in the matrix below the mandibular ramus, but too mueh erushed for working out to any purpose.

In the subjeet of fig. 19, Pl. II, we have aceeptable eonfirmation of the dental characters of the lower jaw shown in figs. 15 and 17 . It eonsists of the two rami of the manclible separated in such a way that the left presents an outside view, and the right turns its lower border to the surfaee of the slab; part of its outer surfaee has been exposed hy removal of matrix.

It is evident that the skull was erushed, together with the jaw, prior to being imbedded in the laenstrine or fluviatile marl. Parts of the basioecipital and basisphenoid, showing 
their 'harmoniæ,' are recognisable, but I am unable to determine any other cranial element in the remaining mass of crushed fragments.

The lower border of the mandible, as shown in the left ramus, magn. 3 diam. in fig. $18 \mathrm{~A}$, slopes from below forward and very gradually upward to the socket of the first or front incisor, as in the specimen, fig. 17, and in Peramus, fig. 11. The foremost tooth is preserved in both rami: it is the largest of the incisors; the crown is shaped like the bowl of a narrow spoon; it expands beyond the root, slightly bends upward and terminates in a rounded edge; it is moderately convex across, externally. Three teeth of smaller size and more slender crown, follow; they are implanted each by a single root, at intervals rather more than their own breadth, save the second, which is closer to the first incisor.

The fifth tooth by resumption of size of crown, though it be less broad than the first incisor, suggests a canine; but it seems to be implanted by two fangs. After an interval of rather more than the coronal breadth of the canine, there is a small simple-crowned premolar; after a shorter interval there is a second still smaller premolar. Then follows an alveolar tract, which may have accommodated four or five teeth of larger size. The molar series is resumed by six successive teeth, which terminate it. The exposed outer side of the crown in the three teeth where it is entire shows the character of the true lower molars of Stylodon, with the type-specimen of which (fig. 15) the present one agrees in size. It yields valuable accession to the evidence of the characters of the fore part of the mandibular dentition of the genus. The cement-covered outer or main fang of the largest molars rises a short distance above the alveolar, and swells into a low quasi-cingulum forming the base of the enamelled crown. The ultimate and last molars seem progressively to decrease in length in a degree not shown in the last two molars in place in the type specimen. Does this indicate an additional or eighth molar? There are two anterior outlets of the dental canal, the foremost of which opens beneath the interval between the canine and the anterior premolar.

In Pl. II, figure 19 gires the nat. size, and 19 a a view magn. 3 diam.., of a portion of a left mandibular ramus, with the base of the ascending ramus, the last two inolars, and the sockets with roots of the six antecedent teeth. This specimen is chiefly valuable as showing the outer part of the crown in the last two molars in place. The tooth rises some way above the socket, and then swells out to form the base of a long and narrow-pointed cusp or cone, which terminates, outwardly, the crown of the tooth; but this, as it extends inwards, expands in fore-and-aft diameter, and develops a minute inner basal cusp. Something of this kind is shown in the ante-penultimate molar of fig. $15 \mathrm{~A}$, which tooth may have been rotated slightly from its natural position. The sockets of the six antecedent molars indicate teeth of the same relative size as those which are in place in the type specimen of Stylodon pusillus.

The proportion of the mandibular ramus preserved in the present fragment corresponds pretty closely with that of the type specimen; only the crowns of the molars anterior to 
the pemitimate one are more or less broken away. The basal half of the crown of the long and large teminal premolar ( $p 4$ ) shows its two roots one before the other. If the sneceeding teeth have their root divided, the fangs must stand on the same transverse line, one on the inner side of the other. 'The fore part of the base of the coronoid projects, ridge-like, eurving forward to subside upon the onter surface of the ramus, as in the typejaw (fig. $15 \mathrm{~A}$ ). The base of the ascending branch extends stright backward to a like degrec, and there is a similar slight indent at or above the angle $(a)$, dividing this from the ridge (b), which would end in the eondyle.

'I'le size is the same in hoth specinicns.

'The apparent slenderness and separation of the crowns of the molars (in the figure) is due so much to the degree of exposure of the specimen that I do not feel the ground safe for proposing specific distinction.

In Pl. III, fig. 2, nat. size ( $2 \Lambda$, magn. 3 diam.), are shown the outer side of a portion of the left mandibular ramus of Stylodon pusillus, with the seven molars and part of the last premolar. 'This spccimen gives another cxample of the mandibular molar characters of the present genus and species. I figure it because it shows better than in any of the forcgoing specimens the angle at which the fore part of the coronoid process arises in this species. 'The last two molars progressively diminish in size; the crowns of the fourth and fifth are the highest.

'The Becklesian collection, containing the counterpart slab with the impression of the above fossil, indicates its fragmentary state when imbelded in the fresh-water marl, and confirms the idea which was derived from inspection of the type-fossil. ${ }^{1}$

Another variety of Stylodon pusillus is exemplified in the portion of the left mandibular ramus, showing the outer side, with the last premolar and six following inolar tceth in situ, forming the subject of Pl. III, fig. 3, and fig. 3 A.

'The second and sixth molars have longer crowns, for example, than in fig. 2. The gencric and specific characters of the type-jaw (Pl. II, fig. 15) are, however, instructively repeated in the extent of the dentition here displayed.

'There is a small outlet of the dental canal below the interval between the penultinute and last premolars and another foramen in advance.

Species 2.-Stylodon robustus, Owen. Plate III, figs. 1, 1 А.

'The present example (Pl. III, fig. 1, nat. size; 1 A, magn. 3 diam.) slows a Stylodon with a deeper and more robust character of jaw than the preceding specimens. It consists of a left mandibular ramus, mutilated at both ends, with ten of the molary series in situ, one only wanting the crown; the outer side is cxposed. The foremost 
tooth of this series is a minute premolar $\left(\begin{array}{l}p 1 \\ p_{1}\end{array}\right)$; the next $\left(\begin{array}{l}p_{2} \\ 2)\end{array}\right)$ is a larger tooth, showing part of the two fangs above the socket, and the conical subcompressed crown rising rapidly or vertically to the apex of the fore part, and sloping more gradually backward. The third premolar ( $\left.\begin{array}{l}p 3 \\ 3\end{array}\right)$ shows more equal fore and hind borders of the cone, with an indication of an anterior basal cusp. The crown of the fourth premolar is, as above noted, wanting; its base was larger than the third, and it probably showed the characteristic height of crown indicated by the dotted line in fig. $1 \mathrm{~A}$ of the last (fourth) premolar, as compared with the first true molar. The succeeding seven teeth exemplify the Stylodont type of true molars; but the hindmost is here preserved, showing a greater inferiority of beight to the penultimate tooth than appears in the type specimen. We have here the signs of individual variation which may have been repeated in generations, as a zoological species.

Incerta sedis [? Leptocladus dulius]. Plate III, figs. 4, 4 A.

After repeated scrutiny and comparison I decided to make the specimen about to be described the subject of a lithograph, the ultimate result impressing me with a belief in its having nıost claim to affinity with Stylodon. It is, however, witl diffidence that I offer this remark; and the fossil is made known rather, or chiefly, as a guide for comparison with future discoveries of better specimens, which may prove the present to be indicative of a distinct genus and species.

Pl. III, figs. 4, and 4 A, magn. 3 diam., represents a left mandibular raınus, with the outer side exposed, wanting the ascending branch, witl nine teeth in place, the socket of a canine, and two sockets of incisors. 'l'he lower contour is almost straight; the alveolar one slightly rises along the niddlc third, and sinks or is concave, but in a very feeble degree, both before and behind. 'The vertical extent of the ramus is the same behind and before the premolar-molar series. The symphysis curves rather abruptly from below the canine to the incisor-alveoli. The teeth, however, are too much mutilated to yield satisfactory gencric characters of the present multidentate Marsupial.

The crown of the best preserved molar consists of one chief cone, which is high and sharp; a basal ridge or 'cingulum' swells into a minute prominence anteriorly, and extends with the base of the crown further back, to form a low hind cusp. 'The cingulum subsides at the middle of the outer convex part of the base of the main cone, and rises as it receles therefrom, forward and backward, to form the accessory cusps. 'The above structure is more or less traceable in the last threc teeth in siti in the present specimens. There is space for one or two such inolars between the hindmost and the rising base of the coronoid process.

The tooth anterior to the foremost of the three molars, by the inferior height of the chief cone in proportion to its breadth, suggests that it may be the last of the premolar series. The minute anterior cusp and the low backward production of the base of the 
main cone are well marked. Four tecth of like type precede the above premolar; they decrease in size, especially in basal fore-and-aft extent as they advanee in position; but this decrease is most marked in the foremost. Each is implanted by two roots.

from the size of the socket the antero-posterior diameter of the eanine must have exceeded that of the largest molar; its crown was probably of the usual proportional length. ithe incisors, which appear not to lave exceeded three in number, were ninute; they were close-set, and not divided by ain interspace from the canine. All the other teeth stand a little apart, as in Spalacotherium and Chrysochloris. 'The intervals are certainly wider thin in Stylodon pusillus.

The outer side of this mimute slender jaw is unusually convex vertically. There are two anterior dental foramina, one $\left(f^{\prime}\right)$ bencath the fourth, another $(f)$ beneath the first, premolar.

If other discoveries should better demonstrate a generic type of teeth in a mandible with horizontal rami of the form and proportions here exhibited, perhaps the name Leptorlachus might be accepter for the genus here indicated. For the convenience of registration I have marked the fossil as Leptocladus dubius.

\section{$\S$ XIII. Gemus-BoLodon, ${ }^{2}$ Oven.}

'I'his genus is founded on elraracters of the maxillary teeth, as shown in two specimens (Pl. III, figs. 5 and 6 ).

Seeing the rarity of an upper jaw as compared with a lower jaw in the manmalian fossils from Mesozoic beds, one is disposed strongly to surmise that some of the many mandibles in the present series must belong to the same species or genus which has left the specimens about to be described.

But there are, anongst the few examples of upper jaw, maxillary tecth with patterns of crown which do permit their association with previonsly recognised mandibular teeth, as, for example, those of Peralestes, Stylodon, Triconodon.

I find, however, no mandibular ramus with teeth which exemplify the same kind or legree of conformity with the three remarkable ones, which have suggested the generic name signifying 'lump-tooth ; and I have, therefore, no alternative but to describe them as indicative of the genus and species, described in the present section.

Species 1.-Bolodon crassidens, Ow. Plate IIl, figs. 5, 5 а, 5 в.

In Pl. III, fig. 5 represents, of the natural size, and figs. 5, $\mathrm{A}$ and B, magnified 3 diam., the right maxillary, with the outer side exposed, showing the beginning of the zygoma $(z)$, and part of the lower rim of the orbit $(0)$. A fossa anterior to the maxillary process or

${ }^{1} \lambda \epsilon \pi \tau \dot{o}$ s, slender; $\ltimes \lambda \dot{\alpha} \delta$ os, ramus.

$2 \beta$ ï̀os, lump ; iduvis, tooth. 
root of the zygoma may include the antorbital foramen $(f)$. The outer wall of the upper jaw in advance of this is remarkable for its height and verticality, and for the arched convexity which deñnes it above, the thick or broad hind part of which arch may be due in part to a nasal bone combined with the maxillary. A crack, fissure, or sutural 'harmonia' runs from the interspace between the second and third teeth in place some way upward where all trace of it is lost. The determination of the teeth depends on the demonstration of the character of this fissure which the present material does not afford. If it be a suture the two anterior teeth are in the premaxillary; if it be an accidental crack, the premaxillary may be wanting at the fore part of the specimen and the foremost tooth would be a canine. Under this doubt I shall merely indicate the six teeth in place, as they follow from before backward, by consecutive numcrals, although the last four with complex crowis are 'molars,' by the character of shape.

The laniariform tooth $(1)$, if a canine, is unusually large among the small Purbeck Mammals : the crown is robust, and terminates somewhat obtusely, retaining its thickness nearer to the apex than usual; in section it is a very full oval, much less compressed than in the canines of any other Hcsozoic Mammal. The inner side is less convex across than the outer. The cnamel there shows two or three low linear longitudinal risings. There is an indication of a rugous talon behind the base of the crown. This tooth is implanted by a single thick root.

The succeeding tooth (2) is of much less size; it is also implanted by one large root, which expands into a low stumpy bulging crown, consisting of one chief thick cone, with a small anterior and posterior ridge-shaped cusp. The cnamel is rugous; it swclls out beyond the snooth fang to form the base of the crown, without, howcver, defining a distinct cingulum. This tooth is contiguous to No. 1.

An interval of the breadth of the tooth (2) divides it from the ncxt (3); the alveolar part of the jaw is there broken, or secms so, if the fissure be not sutural. The outer side of the crown of the tooth (2) developes a low thick stumpy cone $(a)$ : the inner side divides into two similar cones. The outer conc ( $a$ ) is the largest, the antero-internal one $(b)$ the smallest, but the difference is slight. Of the two inner concs or tubercles, onc is rather in alvance of the outer cone, the other is on the same transverse line therewitl. The enamel forming the low apex of each cusp or cone is rugous; it is smooth and polished where it covers the outer bulging convex base of the crown. 'The rugosity is due to ridges converging toward the apex.

The next tooth (4) in close contiguity with the last is of similar size and shape; but the antero-internal cusp (b) is rather larger. In both teeth a low ridge passes from the back part of the base of the extcrnal cusp $(a)$ to that of the post-internal cusp $(c)$ connecting them. The succeeding tooth $(s)$ seems not quite to have ' come into place.' 'The external cusp is below the level of that of the antecedent tooth, and so are the just visible apices of the two internal cusps; it evidcntly has a crown of like size and character with that of the foregoing teeth; but fracture interferes with a satisfactory appreciation of the modifications 
of this molar. 'The longitndinal rugosity of the enamelled summits and the shining smoothness of the onter convex bise of the crown are repeated.

The last tooth in place (6) is a larger one with some modification of the crown. This is not longer, vertieally, but is nore extended from before backward, than in the preceling teeth. This extension is che to a ridge or talon continued from the hind basal half of the main outer cone; the smmmit of which, as well as those of the two immer eones, have suffered fracture. 'The basal part projects outwardly with a polished coat of enamel; but the bulge is less thin that in the antecedent tecth; and, instead of being continued into one cusp, it divides, after inclining inward, into two smaller eusps, with the rugous enamel. The hind lobe of the tooth is less prominent externally than the front one, and terminates in a notcher enamel horder.

'There scems to be a soeket of a smaller molar behind the above-described tooth, and the zygomatic process of the maxillary indicates that socket to terminate the molar series.

A portion of the delicate bony pralate extending from the inner side of the alveolar tract of the maxillary is exposcd in the marly matrix.

On the lyypothesis that the erack is a suture defining the premaxillary, the tooth (1) would be an incisor of a proportion reaching that in Diprotodonts, and the next singlerooted tooth (2) would be a smaller incisor.

It is remarkable that the only other specimen with teeth of the Bolodont type should also be maxillary. It is represented in Pl. III, fig. 6, nat. size; $6 \AA$, $\mathrm{B}$, magn. 4. dian. The specimen is a crushed portion of upper jaw with three teeth of the right and two of the left molar series. The latter inelndes the tooth corresponding to the foremost of the right side and one in advance; the right series, accordingly, has two tecth posterior in position to those shown on the left side. By the obliquity with which the posthumous crushing force las pressed upon the fossil, the left teeth show their outer side, the right teeth their inner side. The bony palate is cntire between these right and left teeth, and shows its median suture.

In the obliqne view of the two molars of the left maxillary (fig. $(6 \mathrm{~A})$, the outer side, which is ehiefly scen, shows one chief cone, the summits of the two inner cones also coming into view; the three molars of the right maxillary (fig. 6 в) show more directly the two main cones of the inner side; the summit of the main outer cone also coming into riew in the sccond of these teeth.

The main outer cone answers to that marked $a$ in the molars numbered 3,4 in fig. 5 , $\mathrm{A}$ and $\mathrm{B}$; the two main inner cones in fig. $6 \mathrm{~B}$, answer to those marked $b$ and $c$ in figs. J., $A$ and $B$.

But the teeth in the present specimen show some minor featurcs, not so recognisable in the preceding one.

The onter main cone $(a)$ in the second left tooth developes from the hind part of its base a talon or thiek ridge (e) which inelines obliquely inward, and joins the hind part of 
the base of the hinder inner cone $(c)$. A less thick ridge extends from the fore part of the outer lobe (a) from its base half way or more to its summit, and bounds the fore part of the crown, being continued to the base of the front inner lobe $(b)$; this anterior talon or ridge $(d)$ is less developed in the anterior than in the posterior of the two molars of the left side; the hiud ridge or talon is also less developed, and it is to the diminution of the accessory parts $(d$ and $e$ ) that the smaller size of the anterior of the two left molars is chiefly due. The two best preserved molars of the right maxillary are more equal in size and similar in character; they show the convex bulge of the inner surface of the two main inner cones. The third molar, which may be the hindmost, is not sufficiently entire for useful description, but the indication of the division of the inner wall of the crown into the two main cones is unmistakable.

The same characteristic sculpturing of the enamel which was noted in the preceding specimen is conspicuous in the best preserved teeth of the present, viz. the vertically ridged summits of the chief cones, the ridges being comparatively thick, few, and converging toward the apex. The sides of the main cones turned toward each other are shorter and less vertical than those forming the outer and inner surfaces of the crown. The inner side of the outer cone extends a short way between the outer sides of the two inner cones.

Again and again lave I gone over all the mandibular specimens and fragments of lower jaws in quest of teeth approximating sufficiently in character with the well-marked upper molars above described, but in vain. Had there occurred any Purbeck mandibular specimen allied to the Oolitic Stereognathus, it might have suggested a relationship to the maxillary evidences of Bolodon crassidens.

Incerta sedis. Plate III, figs. 14, 14 A, 14 B, $16 \mathrm{~A}, 16 \mathrm{~B}, 20$.

The subject of fig. 14, Pl. III, is a portion of a right mandibular ramus, with parts of two molars $(a)$; with the intervening sockets of, seemingly, the last premolar and the first and second molars, and with a mutilated premolar in advance of that $(b)$ in place.

The chief value of this specimen is its demonstration of a broad triturating surface, such as might be produced by attrition against upper molars of the breadth of those in the preceding specimen. But the antero-posterior length of the best preserved molar $(a)$ in the present mandible forbids a reference to Bolodon. The last molar, or what seems to be such $(c)$, is about one third the size of the antecedent tooth $(a)$, with a low one-lobed crown, the enamel of which is feebly wrinkled on its outside near the grinding surface. It may answer to the small tubercular in Thylacoleo and Plagiaulax. The premolar ( $b$ ) has a low but sharp-pointed chief cone, thick, convex externally in proportion to its height; the lind cusp is well developed. The state of this specimen forbids ne to 
luand a generic or specific name, and $I$ eamnot eertainly refer it to any of the well(hancterised species.

'The sulject of fig. 16, nat. sizc, $16 \mathrm{~s}$, magn. 3 diam., Pl. III, is a considerable portion of a left mandibular ramus, apparently showing the contour of the lower half of the aseculing branch, with a few fractured molars in sitú. 'The symphysial end is broken away.

Fig. 20, Pl. I1I, slows the impression, with two small portions, of the left mandibular ramus. 'T'he anterior (ib., a) part of the bone contains the canine, the crown of which is long, strong, snbrecurved, and rather obtuse at the apex; it is supported on a root of twice the lengtlı of the crown, which seems to bifureate at its implanted end. 'The impression on the matrix sliows the fine ridge which was moulded on the nsual longitudinal linear groove of the inner side of the ramus. 'The impressions of the same side of the molar teeth indicate a middle principal pointed conical lobe, and anterior and posterior smaller, but similar lobes. Of these impressions six may be counted, leaving space for premolars between them and the eanine. 'I'he lind portion of preserved bone is from the lower part of the ascending ramus.

\section{§ XIV, Genus-'T'riconodon, Owen, 1860.'}

In the typo-dentate section of polyprotodont Marsupials a generie form is as well marked in the Purbeck series as is that typified by Phascololherium in the Lower Oolitic stage.

But at the Purbeck period the prineiple of differentiation manifests itself in the present genus by the abrupt assumption of the definite and well-marked triconodont eharacter of the molars (Pl. III, fig. 7, $m$ 1, 2,3) as contrasted with the premolars; and the molars, as defined by shape, are three in number, a reduction rare in the Marsupial order, and unique in association with the four antecedent premolars as, similarly, defined by shape of crown.

Species 1.-T'Riconodon mordax, Owen. Plate III, figs. 7, 7 ^.

Pl. III, fig. 7 , represents of the nat. size, and fig. $7 \mathrm{~A}$, magn. 2 diam., the original specimen on which was founded the present genus and species.

'The generie name relates to the form of the crown in the three last teeth $(m 1,2,3)$, which is subcompressed, antero-posteriorly extended, and divided into three nearly equal cones in the same longitudinal line, the mid cone being very little larger or longer than the frout and hind cones; there is no cingulum on the outer side of the crown, but I may add

I tpeis, three; aīros, cone; odwis, tooth.

2 'Enc. Brit.,' rol. xvii, 1859, Art. "Palæontology," p. 161, fig. 86; 'Palæontology,' 8vo, 1860, p. 318, fiuc. 91. 
to the original description that at the posterior margin of the posterior cone a rudimental talon is feebly marked off by a short vertical indent from the rest of the outer surface of that cone.

The first of these teeth (fig. $7 \mathrm{~A}, m_{1}$ ) is very little less than the others; the fore ridge of the base of the coronoid $(c)$ screens part of the last cone of the third molar ( $m_{3} 3$ ) from view.

The last premolar $(p 4)$ seems to have slipped some way from its socket, exposing its two roots, and bringing the base of its crown on a level with the apices of the cones of the succeeding molars. The crown of $p 4$ has a principal subcompressed cone, with a small and low anterior basal cusp, and a larger and higher posterior one. The two divisions of the socket of the premolar in advance $\left(\begin{array}{l}p \\ 3\end{array}\right)$ indicate a tooth of ratler inferior size. The next premolar $\left(\begin{array}{ll}p_{2} & 2\end{array}\right)$ is much less, but of like character; the main cone, however, is much reduced in proportion to the basal cusps. The indications of teeth anterior to $p 2$ are obscure; they show, however, the socket of a minute two-rooted anterior premolar $\left(\begin{array}{l}p 1 \\ 1\end{array}\right)$, the apex of an emerging crown of a canine $(c)$, and one, or perhaps two, of the sockets of the small incisors.

An outlet of the dental canal opens beneath the socket of $p$ 1, midway between the upper and lower borders of that part of the jaw.

The symphysis rises rather abruptly from the lower border, sloping at an open angle therewith, more resembling that part in Sarcoplitus than in Thylacinus, where it tapers forward more gradually.

The lower border of the ramus is nearly straight, very feebly wavy, from the convexity below the molars, which is repeated rather less feebly below the crotaphyte depression : it is obtuse, rounded, losing thickness as it recedes to beneath the rising branch. The crotaphyte depression is there bounded by a low ridge $\left(a^{\prime}\right)$, extending backward to the outer and under side of the condyle (b), as in Thylacinus, only more depressed, so as to cause the slight convexity of that part of the lower contour of the jaw. In advance of the crotaphyte depression a more shallow longitudinal one extends some way forward, just above the rounded lower border of the ramus.

The condyle $(b)$ is large, convex both transversely and vertically, most extended in the latter direction; it projects from a level a little below the outlets of the alveoli. The notch between it and the coronoid process gives the condyle a subpedunculate character (this is better marked in the larger species of Triconodon). So much of the coronoid process as remains does not extend back so far as the hind part of the condyle, but the process might have done so when the apex was entire.

From the relation of the last molar $\left(\begin{array}{ll}m & 3)\end{array}\right)$ to the fore margin of the coronoid, and the degree of protrusion of the crown of the canine, this specimen may be concluded to have come from an individual not quite fully grown.

I am led to the same inference by the appearance of the less complete specimen 
figured, of the natural size, in Pl. III, fig. 8. 'This also consists of a left mandibular ranums with the onter side exposed, but wanting the hind half of the ascending branch and the fore part, if not the whole, of the symphysis. It shows well the three triconodont molars and the sockets of the anterior teeth as far as that of the first premolar. Beneath it is a 'foramen mentale,' and behind, under the second premolar, is another ontlet of the dental canal; the inlet of this may be seen at the hind fractured part of the jaw. 'I'he anterior boundary of the outer crotaphyte depression is well marked; it is angular anteriorly, the corner just rounded off; the lowcr horizontal boundary projects as it receles, recalling a character of the mandible of Thylacimus. 'The outer plate of the ramus falls shecr from the alveoli, not swelling ont first, as the imner plate does. 'Two thirds down, the outer plate begins to swell out and curve to form the thick convex lower border of the ramus.

'The bone is marked by fine longitudinal strix. There is no trace of the longitudinal depression shown in fig. 7. 'The three molars occupy an alveolar tract slightly exceeding that in the type-specimen. Like it, I suspect the present jaw may have come from an animal not fully adult.

In the magnified view ( 3 diam.) of the crown of $m 2$ (fig. $8 \mathrm{~A}$ ) the vertical indent is shown at the hind border of the hind cone, and a minute notch and prominence appears at the fore part of the base of the front cone, which the specimen (fig. $9 \mathrm{~A}$ ) shows to be due to the begiming of the imner 'cingulum.'

'T'riconodon mordax (?). Plate III, figs. 9, 9 A, 10, $10 \mathrm{~A}$.

The specimen, Pl. IIl, fig. 9, nat. size, $9 \mathrm{~A}$, second molar, magn. 4 diam., is a part of a right mandibular ramus, with the three molars and the sockets of the four premolars, showing the inner surface. In exposing the triconodont molars the fore part of the first $\left(\begin{array}{ll}m & 1\end{array}\right)$ flew off, leaving, however, a distinct impression of its two anterior cones.

The cingulum traversing the base of the inner side of the crown of $m 2$, and turning up to the fore margin of the first cone and the hind margin of the last, is lere instructively displayed (fig. $9 \mathrm{~A}$ ), as is also the continuation of the cingulum into a small hind basal cusp of the last molar ( $m 3$ ). 'The cingulum thus limited to the inner side of the lower molars is here minutely tuberculate. 'The crown of the second premolar $\left(\begin{array}{l}p_{2} \\ 2\end{array}\right)$ shows a main median cone with the apex slightly recurved, and a fore and hind basal cusp, the latter being the larger.

The symphysis begins belind at the rertical line dropped from the interspace between the first and sccond premolars. The inner part of the lower border of the ramus is produced to form the lower boundary of the longitudinal groove extending forward from near the entry of the dental canal.

In size, especially in the extent of the three molars, this specimen shows a slight 
inferiority as compared with the type-jaw (Pl. III, fig. 7) and the subject of fig. 8 . But both this difference of size and some slight modification of the shape of the cones, as viewed from the inner side (fig. $9 \mathrm{~A}$ ) and outer side (fig. $9 \mathrm{~A}$ ), may well come within the sexual and other variations of a species. 'The limitation of the cingulum to the inner surface of the base of the molars is generic. In subsequent specimens I shall show the reverse position of it in the upper molars of Triconodon.

The next specimen (Pl. III, fig. 10, nat. size, and $10 \mathrm{~A}$, teeth, magn. 3 diam.) yields confirmatory evidence of the characters of $p 4$ and $m \mathrm{l}$, as shown in the type-specimen (fig. 7). It consists of a right mandibular ramus, with the outer side exposed, wanting part of the ascending branch, of which the form is indicated by a smooth impression on the matrix.

The alveolar tract includes the last premolar $\left(\begin{array}{ll}p & 4)\end{array}\right)$ and first true molar $(m 1)$, in situi; it shows the empty sockets of the second and third molars, and of a third and second premolar, each of which is two-rooted. The socket of the first prcmolar retains the base of the crown of that tooth $\left(p_{1} 1\right)$; it is preceded by a larger socket of a single-rooted canine, and by the sockets of three small incisors.

The fore part of the depression for the insertion of the crotaphyte muscle is shown on the part of the ascending ramus preserved. The impression on the matrix shows that the angle of the jaw was inflected, in a way and degree from which may be inferred the marsupial nature of the species.

The true molar (fig. $10 \mathrm{~A}, m$ ) consists of three principal lobes and a small posterior talon. Each lobe is a subcompressed sharp-pointed cusp; the mid one rather the largest and highest, but the apices of the three rise nearly to the same level. 'The 'talon' is also pointed, and ends about half way up the third lobe. The fore-and-aft extent of this tooth much exceeds either its height or breadth, the latter being the least dimension. No cingulum appears on the side of the tooth exposed. 'The crown is implanted by two roots.

'The crown of the last premolar has one conical, subcompressed, pointed lobe, with a minute basal cusp in front and a larger one behind; the fore-and-aft extent of this premolar is nearly equal that of the succeeding three-coned molar. It is implanted by two

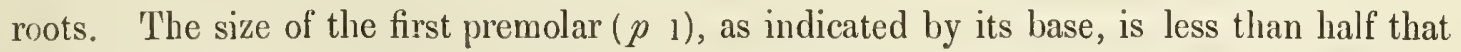
of the last $(p 4)$. 'The canine must have had an antero-posterior breadth of base nearly equal to that of the last premolar. The incisors were the least of all the teeth. There was no break, or 'diastcma,' in the dental series.

Along the outer side of the ramus near its lower border runs a linear fissure, but this may be accidental; above the back part of this fissure appears a shallow longitudinal depression, as in the type-jaw (fig. 7).

As compared with Phascolotherium ${ }^{1}$ from Stonesfield Oolite, with the same dental

1 'History of British Fossil Mammals,' 8vo, 1846, p. 61, fig. 20. 
formula, Triconodon differs in the close and unbroken array of the several teeth in the same ramus. 'The nandible is shorter in proportion to its deptlı; it maintains this depth more equably from the ascending ramus to the symphysis: the anterior eontour bends up abruptly from the lower one, instead of the gradual rise and continuation forward to the end of the syuphysis, as in all the known Stoncsfield Mammals, ${ }^{1}$ and as in the cxisting Myrmecobius (Pl. 1, fig. 24). ${ }^{2}$

The ehief value of the spceimcn (Pl. III, fig. 10, nat. sizc) lies in the repetition of the characters of the symphysial anglc, and the almost straight coursc, or feeble undulation, of the lower border of the mandibular ramus, as in that of the typc-jaw (fig. 7) of Triconodon mordax.

'T'riconodon (?). Plate III, figs. 15, 16, 20.

The subject of fig. 15, Pl. III, is part of a right mandibular ramus of a young Mammal allicel to and perhaps of the genus last described. The main cone of a premolar $(p)$ is rising into plaec. The tooth marked $m 1$, but which might be the last of the premolar serics, has a low main cone, boldly convex externally, with a low anterior basal eusp, and a large postcriorly produced hind eusp, making the fore-and-aft length of the crown cxcecd its height. The foremost empressed eone of the succeeding molar and part of the suceeeding cone of the same tooth are preserved. Near the fractured fore end of the ramus two or three outlets of the dental eanal are disccrnible.

The inferiority of size, as compared with fig. 9 or with the type of Triconodon mordax (fig. 7 ), seems to be more than individual immaturity would aecount for, and I hesitate either to affirm or deny its spccific identity.

The more mutilated ramus (Pl. III, fig. 16), of the same size as the preceding, and with a like straight eontour of the lower border of the jaw, is figured and here noted with the view ehiefly of calling attention to similar better preserved specimens, in the event of such being obtained, capable of throwing light upon the true nature of the subjects of figs. 15 and 16.

Fig. 20 is ehiefly an impression of a similar sized ramus, with a wcll-prescrved canine and impressions, which at the hind part of the molar series recall a 'T'riconodont charaeter.

Tricosodon (?). Plate IV, figs. 5, 5 A.

The subject of Pl. IV, fig. $5, a$ and $b$, nat. size, and 5 A, magn. 3 diam., is a portion of a right maxillary bone, with the antepennltimate and penultimate molars, and

\footnotetext{
1 Ib., figs. 15, 17, 19.

2 Ib., fig. 18.
} 
the socket of the last molar. A portion of the bony palate and the beginning of the zygomatic or malar process of the maxillary are preserved; the outer side is exposed.

The molars in place are worn down nearly to the cingulum, which extends along the outer side of the base of the crown; its division into the three compressed lobes is just traceable; the grooves on the inner side of the crown indicate the action of the lobes of the lower molars. In size the molars in the present specimen are rather less than those of the smaller sized example of Triconodon mordax (Pl. III, fig. 9).

'Triconodox, sp. ind. Plate IV, figs. 6, 6 A.

The subject of Pl. IV, fig. 6, nat. size, with the three molars magnified 3 diam. at A, is part of a right mandibular ramus, with the three molars and sockets of the premolars. The lower portion of the ramus, as well as the fore and hind ends, are mutilated, and the specimen is chiefly valuable as showing the characters of the imner side of the true molars.

There is a progressive increase in antero-posterior extent from the first $(m 1)$ to the third $(m 3)$ molars; the cones show an inclination backward, not observable in Pl. III, figs. 7, 8, and 9. Moreover, the cingulum is not tuberculate or crenate, as in Pl. III, figs. 9 and 11, and it extends into and developes a larger posterior basal prominence or talon in each molar.

The correspondence in general size or extent of the series of three molars is very close between the present specimens (Pl. IV, fig. 6) and the subject of Pl. III, fig. 9. But the above-defined differences in form and proportions lead me strongly to incline to see in the specimen here described the indication of a distinct species of Triconodon.

Triconodon, sp. ind. Plate III, fig. 21 .

The subject of Pl. III, fig. 21, is the fore part of a right mandibular ramus, with the first and fourth premolars, part of the first true molar, and the crushed socket of a canine, nat. size. The molar $\left(\begin{array}{ll}m & 1\end{array}\right)$ has a compressed antero-posteriorly extended crown of the triconodont type, but with the mid cone only entire; the front one, as in fig. 12, was obviously lower, the hind one more nearly equal to the mid one. The last premolar consists of a main cone with a fore and hind basal talon, the apex of the cone rising higher than that of the mid cone of the contiguous molar. The small anterior premolar $(p \quad 1)$ is too mutilated for characterising. All the premolars and the molar were inserted, each by two fangs.

'The teeth agree in size with those in Triconodon ferox (figs. 12 and 13). The ramus of the jaw beneath the first and second premolar is less deep and more convex externally 
than in that species. There are two antcrior ontlets of the dental canal, one beneath $p 1$, the other bencatli the socket of $p 2$. 'The outer alveolar wall desecnds at once from the sockets to the outward swelling of the ramus, two thirds down toward the thick rounded lower border of this part of the mandible. 'The angle at which the symphysial end seems to rise from the lower border rescmbles that in Triconodon mordax.

'The subject of Pl. IV, fig. 4, nat. size, is a portion of a left mandibular ramus, with the imer surface exposed, showing the symphysis and the broken bases of the third or fourth premolars. 'I'he faint lincar groove along the inner part of the thick under border of the ramus does not answer to that called 'mylohyoid' in fig. 11, Pl. III ; it may be a trace of the line of confluence of the osseous eneasing of the primitive mandibular eartilage. But the manmalian unity of the bone is well exemplificd in this portion of jaw.

'T'he extent, shape, and the angle of the long axis of the symphysial surface with that of the horizontal ramus, are the same as in Triconodon mordax (Pl. III, figs. 7 and 10).

Species 2.-Triconodon ferox, Ow. Plate III, figs. 11, 12, 13, 17, 18, 19. Plate IV, fig. 1.

The size of the specimen about to be described might be decmed to represent that of the jaw of a full-grown Triconodon mordax, adnitting the evidence of immaturity shown by the type-specimen (fig. 7). But although the jaw-bone would grow and bring into view the three main cones and hinder talon of the last molar elear of the coronoid process, yet the crowus of the tecth, onee completed, do not grow. Now, the extent of the three molars in sitú in the subject of Pl. III, fig. 11, nat. size, exceeds that of the same teeth in fig. 7 by two millimeters or one linc. 'The extent of the whole molary serics in Triconodon mordax is nine lines, in the present jaw it is ten and a lialf lines.

Does this indicate a mere scxual superiority of size?

It is certain that the molars of the femalc Thylacinus are smaller than those of the malc, concomitantly with her general inferiority of size. I should be unwilling, seeing the general conformity of the dentition in the present and preceding specimens, to refer the subject of fig. 11 to a distinct species, believing rather that it might represent a male of Triconodon mordax, were it not for the difference in the shape of the mandibular ramus itself, to which I shall next ask attention, the present specimen agreeing more closely in this respect with Pleascolotherium than with Triconodon mordax.

There is, however, an important character in which the agreement with the smaller species of Triconodon is closer, and which may be a generic featurc.

Among existing mammals with a dentition for animal food certain marsupials, e.g. Thylacinus, Sarcoplitus, have the articular condyle of the mandible on as low a level as the alveolar tract. This character is repeated in the Phascolotherium of the Stonesfield 
Colite. ${ }^{1}$ But in the present jaw, as in the type-specimen, the condyle projects backward below the level of the alveolar apertures, and the lower border of the ascending ramus, which it terminates behind, does not curve up to the condyle so much as in Phascolotherium.

It represents, in position, the angle of the jaw ; but on the inner side, in the present specimen, is a fractured surface (fig. $11 \mathrm{~B}, a$ ), indicative of a part projecting inward, and which would be the true homologue of the inflected angle of the Marsupial jaw. The articular surface of so much of the condyle as is preserved is smoothly convex, both transversely and vertically.

A deep notch, rounded at the bottom, but narrower than in Pliascolotherium, and also narrower and deeper than in figs. 7 and 10, divides the condyle from the large, lofty, and antero-posteriorly broad, coronoid plate. The depth of the notch gives a pedunculate character to the low-placed condyle in a greater degree than in Triconodon mordax.

The exposed (inner) surface of the coronoid $(e)$ is flat, with a shallow depression at its fore and inuer part, where it passes into the horizontal ramus. Below this depression is the narrow canal, leading from a few lines in advance of the peduncle of the condyle, and sinking, as the 'dental canal,' into the substance of the ramus at a vertical line dropped from a little behind the last molar tooth.

A very feeble and rather broad longitudinal impression $(g)$ is continued from the entry of the dental canal forward along the inner side of the ramus, as far as below the last premolar. This condition of the myloliyoid groove repeats that in Myrmecobius. The lower border of the ramus describes one uninterrupted gentle curve, convex downward from the condyle to the fore end, as in Phascolotherium. The symphysis follows, with a low slope upward and forward, carrying on and terminating the fore part of the curve. This is markedly different from the contour of the symphysial or fore part of the mandible in the two specimens of Triconodon mordax, in which that part of the jaw is preserved (figs. 7 and 10).

The inner alveolar plate projects a little from the sockets before sinking into the inner surface of the ramus. The whole molar series, four premolars, and three true molars are in place, with the base of the canine.

The shape of the jaw, with the same extent of the three molars, in the subject of Pl. III, fig. 12, nat. size, leads me to refer it to the same species (Triconodon ferox), as fig. 11 . It consists of a left mandibular ramus, inner side exposed, with the ascending branch in part shown by an impression, and with the symphysial end crushed and mutilated.

The portion of the bone preserved contains the last three molars, with the fore ends of the upper and lower ridges of the coronoid or those bounding the pterygoid depression.

The first molar is rather smaller than the second, and its mid cusp, being entire, shows

1 Pl. I, fig. 26; and 'Brit. Fossil Mammals,' p. 61, fig. 20, $a$. 
it to rise a little higher than the first and third cusp of the same tooth. In the seeond molar the apex of the mid cusp is broken off, and in the third molar both this and the lind cusp are wanting. Some traces of sockets are visible anterior to the molar series.

'The impression of the angle and lower margin of the ascending ramus shows them to have been slightly inflected. 'Ilie ramus has a slight general eurve, convex downward, from the hind to the fore part, as in the type I'riconodon ferox. 'The lower border of the mandible is moderately thick and rounded.

'T'lie subject of Pl. III, fig. 13, nat. size, is the hinder half of a left mandibular ramus, onter side exposed, with the three molars and last premolar.

'The coronoid process is preserved. In its height, breadth, and baekward curve it resembles that in Plascolotherium, whieh is like that in most zoophagous Marsupials. Unfortunately the lower border of the aseending ramus with the angle is broken off. 'The transwerse rounding of the thiek lower border of the prescrved part of the horizontal ramus is rather oblique, descending from the outer toward the inner surface.

In this portion of jaw the micl eusp is entire in the third molar, showing the three cusps to be of equal licight. The last premolar $(p 4)$ is represented by its main cone and small hind basal cusp); the front one, probably present in the entire tooth, has been broken off. 'The cone, which constitutes the chief part of the crown of the premolar', is subcompressed, pointed, rising higher than the level of the summits of the cones of the suececding molars. A fine groove indents the outer side elose to the front border of the conc. The first molar, mutilated in the present specimen, shows the same degree of inferiority to the sccond molar as in the right ramus (fig. 11), where it is entire.

Although the depth of the ramus below the last molar is markedly greater than in fig. 11, the three molars are not larger nor do they occupy a greater longitudinal extent. I conclude, thereforc, that the subjects of figs. 12 and 13 exemplify a larger and stronger individual of Triconodon ferox.

'The fragment of the right mandibular ramus (Pl. III, fig. 19), with the last molar and a portion of the penultimate molar in situ, shows well some of the characters of the outer surface of the last molar in Triconodon ferox.

The hind lobe of $m 3$ (fig. $19 \mathrm{~A}$ ) has a shallow oblique depression, marking off a low basal talon. 'The outcr and fore part of the base of the front lobe is similarly marked by an oblique eleft defining a low cingulum, beginning at the fore part of that lobe. Its non-cxtension along the base of the tooth to the hind talon shows the aspect presented to he the outer one.

'There is a slight vertical noteh at the hind part of the last cone of the penultimate molar ( $m$ 2), marking off' a better developed basal talon than in $m 3$. 'I'his talon or ridge terminates posteriorly the inner basal cingulum.

'The lobes or cones of the homologous teeth are higher and sharper than in Triconodon 
mordax. In size this third molar somewhat exceeds that in the last-described specimen of Triconodon ferox, but not so much as to justify a reference to a distinct species.

The following exemplifications of the generic characters of upper or maxillary teeth of Triconodon seem, from their size, to have been afforded by $T r$. ferox rather than by $T r$. mordax.

The subject of Pl. III, fig. 18, nat. size, fig. 18 A, magn. 3 diam., and B working surface of teeth, magn. 3 diam., is a portion of a left maxilla, with the last two premolars and the first two molars.

The molars show much wear. A cingulum extends along the outer side of the base of each; it is impressed by many small vertical grooves or notches, and is thickest as it curves toward the summit of the anterior and the posterior lobes at the two ends of the tooth. The three lobes incline inward toward their summits; but these have been much worn down. The posterior fang of the second molar $\left(\begin{array}{l}m_{2} \\ 2\end{array}\right)$ is exposed at the hinder fracture. The main cone of the last premolar $\left(\begin{array}{l}p_{4} \\ 4\end{array}\right)$ has its apex worn away, not broken off; but this extends beyond the level of the working surface of $m 1$ and $m 2$. There is a hind basal cusp, as well as a basal ridge, or 'cingulum ' which ends behind in a slight

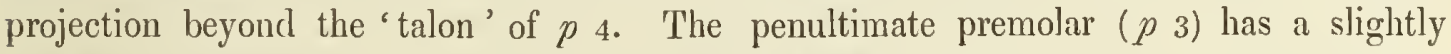
retroverted main cone with a front and hind basal talon, the latter being most prominent. The alveolus and two roots of the second premolar $\left(\begin{array}{l}\left.p_{2}\right) \\ 2\end{array}\right)$ are included in this fragment of upper jaw, showing a decrease of size corresponding to that of the homotypal teeth of the mandible.

A portion of the bony palate is preserved ( $a$, fig. 1S), extending inward from the alveoli of $p 1, p 2$ : this thin, inferiorly concave, bony plate is entire to its fractured margin. There is a depression or smooth groove $(o)$ in the maxillary bone, a short way above the sockets of $p 2$; it may indicate the position of an antorbital canal outlet.

In Pl. III, fig. 17 represents of the nat. size, and fig. 17 A magn. 3 diam., a portion of a right maxilla, with the last two premolars, the first molar and the fore part of the second molar, in situi, the inner side being exposed with a contiguous portion of the bony palate. The teeth agree in size with those in the maxillary specimen of the opposite side last described.

The penuitimate premolar $\left(\begin{array}{l}p \\ 3\end{array}\right)$, in like manner, shows a clief cone, with an anterior and a posterior basal cup, each of the latter being girt by a ridge which almost subsides at the prominent mid-part of the main cone ; the hind basal cusp is the largest. The last premolar $(p 4)$, with increase of size shows plainly the continuation of the cingulum, with a tubercular character, from below the fore and hind talons, across the base of the main cone, with a narrow median interruption, where the main cone seems to be longitudinally impressed. The posterior basal cusp is relatively larger than in $p 3$. The apex of the main cone extends beyond the summit of the contiguous molar cones. In the 
anterior molar the foremost of the three cones or divisions of the crown is less than either of the other two eones. The cingulnm is more interrupted and more feebly developed than in $p 4$, or than along the outer side of the crown of $m_{1}$ (sce fig. $18 \mathrm{~B}, m_{1}$ ); it erosses obliqnely the fore part of the front eone; it also appears on part of the base of the mid cone, and on the fore part of that of the hind cone, but fecbly. 'I'le cones are low, and worn; the transverse breadth of these upper molars is greater than in their lower lomotypes, yet the characteristie extension of the tooth in the antero-posterior direction conenrs, with the trifid crown, in proclaining the genus to which the present and preeeding portions of upper jaw are referable.

'The tendeney to turn, as it were, the outer side of the upper molars to the inner side in the lower molars is exemplified in the partial development of the eingulum, as shown in fig. $17 \mathrm{~A}$ compared with its integrity in fig. $18 \mathrm{~B}$.

Confirmation of the ascription of fig. 17 to Triconodon ferox is afforded by the subjeets of fignres $1,1_{A}, B, C$, Pl. IV. Figure 1 gives the natural size of portions of an upper maxillary of a right mandibular ramus (fig. 1 B, magn. 2 diam.), with the inner surface exposed, and a similar anterior portion of the left mandibular ramus (fig. $1 \mathrm{c}$, magn. 2 (liam.), with the onter side exposed, of the same skull.

A portion of the bony palate projecting from the matrix is crushed down below its level, so as to obseure the inner surface of some of the teeth. The erown of the molar (fig. $1 \mathrm{~A}$, magn. 4 times) shows the thickness of the eingulum traversing the outer side of its base, characteristie of the upper molars of Triconodon. A more interrupted growth of 'cingulum' on the inner side increases the transverse basal breadth. The inferior height of the anterior cone indieates this to be the first molar $(m 1)$. Of the premolars two are preserved, showing a principal cone, a hind smaller one, and the additional basal eusp due to the further extension backwards of the eingulum, as in $p 4$, fig. 17, PI. III.

The portion of right mandibular ramus, in eontact with its maxilla (Pl. IV, fig. 1 B), is mainly instructive in showing a seeond ineisor $\left(i_{2}\right)$ in place; it is the tooth in advance of that shown in fig. 7, Pl. III; it is smaller in size but similar in shape to the third incisor $(i 3)$.

The canine $(c)$ has the usual laniary shape, slightly recurved; the apex is wanting, it appears to be worn down; there is a longitudinal basal indent at the inner side of the crown here exposed. The first premolar and its socket are crushed out of view; the crown of the secund premolar $\left(p_{2}\right)$ is in place, showing the chief cone with a short subvertical fore margin, a long sloping hind margin, provided with a basal cusp, which extends the cingulum. The latter feature is more strongly marked along the inner side of the base of the third premolar $(p 3)$; its fore end, as it circumscribes that part of the base of the main cone, simulates a small basal talon; the hind end similarly projects beyond the true basal cusp or talou at that part of the main cone. The two-cham- 
bered alveolus of the last premolar indicates the usual progressive increase of size. Part of a similar socket, with the hind root and portion of the crown of the first molar $\left(\begin{array}{ll}m & 1\end{array}\right)$, is definable; it is followed by the first and second cones of $m 2$. The basal cingulum is shown in both teeth.

In the fore part of the left ramus, showing the outer surface (Pl. IV, fig. $1 \mathrm{c}$ ), the characters of that side of the crown of the canine are seen; it is more convex than the inner side, and has not the Jongitudinal basal depression. The anterior outlet of the dental canal is beneath the alveolus of the first premolar. Part of the crown of the second $\left(\begin{array}{ll}p_{2} & 2\end{array}\right)$ is preserved. The third $(p)$ shows the height of the main cone, which wants the apex and the right ramus. The last premolar and the first true molar $\left(\begin{array}{ll}m & 1\end{array}\right)$ are represented by the basal parts of the crown. The interruption or partial development of the cingulum is here noticeable. The mandibular rami in the present specimen show the convex lower outline and the gradual curve upward to the incisive alveoli, which appears to be characteristic of Triconodon ferox, or at least to differentiate it from Triconodon mordax.

Species 3.-Triconodon occisor. Plate IV, figs. 2, 2 A, 2 в.

I next enter upon the description of the partially dislocated rami of the same mandible (Pl. IV, fig. 2, nat. size; A and B, teeth magn. 2 diam.), showing the formal characters of the mandible in Triconodon mordax, but belonging to an animal too superior in size to be referable to that species; from which also the present more decidedly and instructively differs in a minor relative size of the first molar $\left(\begin{array}{ll}m l & 1\end{array}\right)$ as compared with the other two molars.

At first sight the left ramus (fig. $2, l$ ) seems identical, answering as it does, in both size and shape, with the type of the genus (fig. 7, Pl. III). But if the first two molars be compared in the two specimens, those of the present show a marked increase of anteroposterior extent, notwithstanding the smaller proportion of $m 1$ to $m_{2}$. This differential character comes out well in the figures of each mandible which are magnified in the same degree in Pl. IV, fig. 2 B, and Pl. III, fig. 7 A respectively. Furthermore, although some signs of immaturity are recognisable in the type of Triconodon mordux, the mandible, here compared, of Triconodon occisor is of a still younger individual; only half of the last molar ( $m$ 3) has advanced into view beyond the base of the coronoid, and not more than two thirds of the crown of the canine $(c)$ and of that of the last premolar $\left(\begin{array}{ll}p & 4\end{array}\right)$ have risen above the socket.

The fully grown animal of the present species would equal in size that of Triconodon ferox, but the shape of the mandible and the proportions of the molars forbid a reference of the present specimen to that spccies.

I cannot, witl a recognition of the above defined characters, withdraw from the 
undesiral)le duty of signifying them by adding another specific name to the present well-marked gemus.

I give my original notes on the type specimen of Tr. occisor.

"Both rami, somewhat mutilated, of the same mandible, the left $(l)$ showing the outer side, the right $(r)$ (good for molars) the inncr side; and the latter more complete, having a fore-ancl-aft extent of coronoid process preserved for nine lines behind the last molar. Part of the inflected ridge or angle $(a)$ is shown. In advance and above this is the entry of the dental cantal (d), the condyle itself is broken away. 'The longitudinal linear groove is secul to terminate near the symphysis. The thicker inner alveolar plate is here well contrasted with the thinner outer wall of the sockets in $l$. The minutely tubercular ridge along the base of the immer sidc of the crown is wcll shown in the first molar" ( $m$ 1, fig. 2 B); " also the vertical gronve close to the anterior border of each cone (most clearly shown in the first and second cones). The hind basal notch or talon comes well out on the outer side of the left $m 1$ and $m 2$ " (fig. $2 \mathrm{n}, \mathrm{Pl}$ IV).

"The last molar is not quite in place, its hindmost conc has not emerged or come forward from its alveolus, where it is cxposed in the right ramus"(fig. $2, r$, and $2 \mathrm{~B}, m 3$ ). "The last premolar" ( $p 4$, fig. $2 \mathrm{~A})$ "lhas not riscn into place; its apex is on a level with the base of the first cone of $m 1$. The third premolar" ( $p 3$, fig. 2 в) " is in place in the right ramus, and shows the basal ridge along its inner side, together with the large posterior talon; the anterior talon is fecbly indicated.

"Both antcrior and posterior talons are more conspicuous and more equal in the sccond premolar" (fig. $2 \mathrm{k}, p 2$ ), "which is much smaller than the third, chiefly through the minor derclopment of the main cone, which is less acute than that of $p 3$. The first premolar $(p)$ l) has a still smaller main cone with an anterior and a posterior cusp. The premolars, like the molars, are inserted each by two roots."

So much of the crown of the canine as has risen into place shows a less recurved shape than in Triconodon ferox. The anterior border of the jaw rises at an open angle with the lower one to the incisive alveoli, as in Triconodon mordax. It does not ascend or curve gradually up as in Triconodon ferox.

Species 4.-Triconodon major, Ow. Plate IV, fig. 3.

In a block of stone, from the part of the Niddle Purbeck marked 'Fenther,' in fig. 4, p. 22, the stone being similar in character with that containing the Swanage Crocodile (Goniopholis), Turtles (Pleurosternon, \&c.) and Fish (Microdus, \&c.), and which the masons were sawing up, their attention was caught by the appearance of a fossil in the line of section. The process was stopped, and the portion of stone with the fossil cut out. It was purchased for the British Museum, and, after careful devclopment of the 
fossil, the part of a right mandibular ramus was exposed, which is represented, of the natural size, in $\mathrm{Pl}$. IV, figure 3.

The preserved molar ( $m 2$ ) is of the Triconodont type ; but the size of the specimen is fully one third larger than the largest of the previously described species of Triconodon. 'The animal to which it belonged would probably be of the size of the 'Native Cat' of Australia (Dasyurus Maugei, Geoffroy). I estimate the length of the lower jaw of Triconodon major, when entire, according to the analogy of Triconodon ferox (Pl. III, figs. 7 and 8), to have been two inches and a half, and the jaw attains that length in the male of the spotted species of Dasyure above cited.

The tooth preserved, which lacks only the apex of the antcrior cone, answers to the second of the three molars in Tr. ferox (Pl. III, fig. 12). It shows the usual absence of continuous cingulum along the outer side of the base of the crown. There is no trace of anterior or posterior talon. The coronal clefts seem to be rather less deep than in the smaller species. The socket and remnant of the first molar shows it to have been, as in Tr. ferox, smaller in proportion to the second molar than it is in Tr. mordax. The last premolar $\left(\begin{array}{l}p \\ 4\end{array}\right)$ shows the same relative antero-posterior extent of crown as in the smaller species : the two fangs supporting the base of the crown are partially exposed, but the rest of the tooth is broken off. The socket for the two fangs of the penultimate premolar $(p 3)$ is preserved, anterior to which the jaw is broken off, exposing the anterior root of that tooth and the cavity of the ramus (fig. $3 a$ ).

The two-celled socket of the molar following the one in place indicates a tooth of equal size ; and the position of the outer buttress-like beginning of the fore part of the coronoid process shows $m 3$ to have been the last. The stone-saw has removed an extent of two lines between the beginning of the coronoid and the rest of the rising branch. This gives a basal fore-and-aft breadth of the coronoid of eight lines; the apex or upper half of the process is wanting. A similar notch between the hind border of the process and the condyle, as in Pl. III, figs. 6 and 10, gives the same pedunculate character to the upper part of the condyle; the joint projects at a lower level than the alveolar outlets. From its lower end a ridge (a) projects outward, but in a less degree than in Dasyurus, defining below the crotaplyte fossa.

The fractured fore part of the jaw exposes the anterior cell or division of the socket of the third premolar, filled with matrix, and the cavity of the ramus itself similarly occupied. The bone has suffered a longitudinal fracture towards its hind part. 


\section{$\S \mathrm{XV}$. Genus-Triacanthodon, ${ }^{1}$ Owen.}

Species 1.-Triacanthodon serrula, ${ }^{2} O w$. Plate IV, figs. 7,7 a, 8,8 a.

'This genus and speeies are exemplified in two slabs, counterparts of the same split block of Purbeek Shale, with the left mandibular ramus of a young individual.

One portion or slab (Pl. IV, fig. 7, nat. size, and $7 \Lambda$, magn. 2 diam.) ineludes the aseending ramus, the last molar tooth in its formative eell, and an impression of the rest of the bone and teeth; tlie otlier portion (fig. 8, nat. size, and $8_{\mathrm{A}}$, magn. 2 diam.) includes the part of the ramus and tecth anterior to the penultimate molar, and the impression of the linder part of the jaw with those of the last two molars. The portion of the ramus ineluding the penultimate molar, which intervened between the fractures in figs. 7 and 8 , had been lost before the speeimen eame into my hands; it is well represented, however, by the impressions of its outer and inner surfaces in the eounterpart slabs.

The fore part of the ramus in fig. 8 shows the outer surface, the hind part in the opposite slab (fig. 7) shows the inner surface, of the mandible.

In the fore part of the jaw the outer ineisor (fig. $8_{\Lambda}, i 3$ ) is preserved; it is small, conieal, thick, outwardly convex, with a sub-obtuse apex; there is a feeble indieation of two shallow longitudinal linear impressions bounding a middle tract of the outer convexity, near the base of the erown. The eanine (ib. $c$ ) is long, large in proportion to the ineisor, strong, sub-recurved, sharp-pointed, with a longitudinal indent near the basal part of the outer side of the crown, indieative of a tendeney to division of the implanted root. The eanine follows the incisor without any diastema. The concave line of the hind border of the crown is arrested three fourths of the way toward the base by a slight hinder projection-a quasi feeble 'talon.'

A very short interval divides the canine from the first premolar $\left(\begin{array}{ll}p & 1\end{array}\right)$. This is small, two-rooted, sub-compressed, with a hind cusp almost equalling the main cone, and with a small anterior basal cusp; the whole crown is low in proportion to its fore-and-aft extent.

The second premolar $\left(p_{2}\right)$, similar in form to, but somewhat larger than, the first, has a more elevated main or mid eone; the front eusp or talon is rather more developed than in $p$.

The third premolar ( $\left.\begin{array}{ll}p & 3\end{array}\right)$ shows a markedly larger size, especially in the relative height and breadth of the main cone. The anterior basal eusp is low ; the posterior cusp

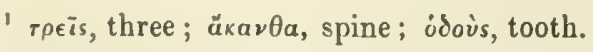

2 Serrula, little saw, suggested by the row of denticles formed by the five three-spined teeth. 
is higher, and it is followed by a minute basal 'talon,' probably the termination of an internal ' cingulum.'

This tooth is followed by $p 4$ or $d 4$, approaching the Triconodont or true molar type; but with the basal cusps, especially the front ones, better developed than in any of the succeeding true molars. The mid cone is also rclatively higher in proportion to the first and third cones; but the whole crown is lower in proportion to its fore-and-aft extent than in the succeeding molars. The apcx of the mid cone reaches only to half the height of the main cone of the antecedent premolars. The crown is entire; no main cone is worn or broken away. If it be the lomologue of $p 4$ in Triconodon it shows widely different proportions and form. The superiority of the middle to the fore and hind cusps favours its reference to the premolar series; unless, indeed, it may belong to the deciduous series; the symbol of $d 4$, in fig. $8_{A}$, is to be taken suggestively in reference to the alternative above proposed. I have not felt justified to hazard this unique and brittle evidence by burrowing after a possible hidden germ of a successional tooth. Behind $p_{4}$ or $d_{4}$ is a tooth $\left(m_{1}\right)$ of the more usual Iriconodont or 'Triacanthodont type, the anterior and posterior cones, especially the latter, rising more nearly to equality with the mid cone : there is neither fore nor hind talon. The crowu of this tooth stands at a higher evel than that of the preceding, but rises not quite to a level with the apex of $p 3$.

The next tooth ( $m 2$ ), of the same type as $m 1$, slightly exceeds it in size; it is equally devoid of trace of 'cingulum' on the outer side here exposed. A minute tubercular prominence at the fore part of the base may be the anterior end of an inner 'cingulum :' there is no trace of hinder talon. 'The next two molars $(m 3, m 4)$ are inclicated by impressions of their crowns in the present slab, that of the lindmost $(m$ 4) being wholly within the impression of the coronoid process. It is preserved in the opposite slab, witl that process (fig. $7 \mathrm{~A}, m 4$ ). The penultimate nolar, with the supporting part of the jaw, as before stated, has been lost.

Before quitting the survey of the slab (fig. S), I may note that the outer wall of the socket of the canine is prominent, and that in the depression between it and the less prominent alveolus of the succeeding premolar the foremost and largest of three outlets of the dental canal opens. Thesc three foramina are in the samc longitudinal line, mid way between the upper and lower borders of the ramus, pretty closely following each other. The outer surface of the bone is finely punctate and longitudinally striate. The outer alveolar border is scrrate through the low angular processes rising into the intervals of the teeth and their fangs; the wall sinks at once from the alveolar outlets a short way, then slightly swells outward before inbending to the thick lower border of the ramus, making the lower half conrex vertically. The symphysial contour forms, as in Triconodon mordax, an open angle with the lower border of the ramus; but this is continued in an uninterruptcd gentle curve to the condyle (b).

In the opposite slab (fig. 7 ) the crown of the last molar ( $m 4$ ) is exposed, incompletely developed, in a formative alveolus at the fore part of the base of the coronoid pro- 
cess; the calcified summits indicate a conformable character with the antecedent molars. In Mlacropms and most diphyodont Placentals the hidden and incomplete condition of the last molan wonld imply, or be coincident with, a like condition of the last premolar.

The coronoid process (fig. $7 \mathrm{~A}, e$ ) is subrhomboidal, is broad, high, reclinate; its apex is continued backwarl to the same vertical line as that touched by the hind part of the condyle which projects below the level of the alveolar outlets. The condyle $(b)$ is pednnculate at its upper part through the oblique decp notch between it and the coronoid. It shows well the cinnivorous mimmmalian convexity, the lower part of which is continued into the lowe border of the ascending ramus. 'This border is inflected, and part of it is retained in the groover impression left on the slab (fig. $\delta_{\mathrm{A}}$, at $a^{\prime}$ ). 'The inflected border, represcuting the 'angle of the jaw,' bounds the shallow longitudinal channel leading to the entry of the dental canal.

Fig. 5.

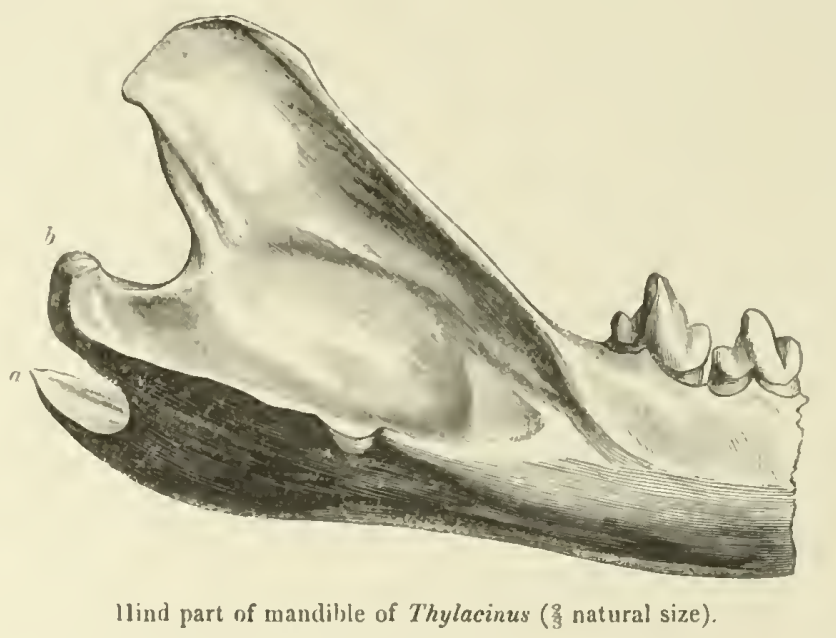

'L'he 'l'hylacine (fig. 5), amongst known living zoophagous Marsupials, oflers the nearest approach to the indications of predatory nature given by the lower jaw and teeth of Triacanthodon. But these indications are exaggerated in the concentrated carnivorous character of those parts in the genus next to be described. 


\section{\$VI. Genus-Plagiaulax, Falconer, 155\%.'}

Species 1.-Plagiaulax minor, Falconer. ${ }^{2}$ Plate III, figs. 9, 9 А, 9 в.

This species is represented by the dentigerous portion of the right mandibular ramus with the teeth in sit $\hat{u}$ (Pl. IV, fig. 9, nat. size; $9 \mathrm{~A}$, magn. 3 diam.; B, molars magn. 6 diam.). The lower border of the hind part with the ascending ramus is broken away.

The teeth are the incisor (i), four premolars $\left(p_{4-2}\right)$, and two molars $(m 1,2)$. The incisor is long, large, laniariform, more rounded or convex externally than in the larger species (see Pl. IV, fig. 11, $A, i$ ); the anterior end is broken off, but the impression left on the matrix shows it to have been pointed, and also indicates a shallow longitudinal groove on the inner side of the tooth, nearer the fore than the hind border $\left(a i^{\prime}\right)$. The length of the exposed part of the tooth or 'crown' equals the fore-and-aft extent of the entire premolar series. The direction of the crown is upward and forward, at an angle of $120^{\circ}$ with the alveolar line of the succeeding teeth : the convexity of the antero-inferior border and a slight concavity of the postero-superior border give the appearance of a curve in the same direction.

The first premolar abuts against the fore part of the second. It rises at a distance from the incisor equal to the breadth of the base of that tooth. It is minute, with a crown longer or higher than its fore-and-aft breadth. Slightly bulging at its base, above the single root, it becomes flat externally with the summit obliquely truncate.

The crown of the second premolar ( $p 2$ ), larger and more compressed, swells out rather more abruptly above the fang, from which protuberance the crown expands and flattens as it rises, and again contracts to abut upon the fore margin of the next tooth. The apex of the crown of $p_{2}$ is marked by three fine short ridges directed from before upward and backward; below these the enamel is smooth and flat to the bulging base. The height of the crown is greater than its fore-and-aft brcadth, the extreme of which is about half way to the angular summit; this sliape is due to a truncation in the same direction as in the first molar, viz. from above downward and forward, which gives to the crown a rhomboidal figure.

The third premolar $\left(\begin{array}{l}p \\ p_{3}\end{array}\right)$ attains greater breadth in proportion to its height, though the latter dimension of the crown still predominates: the thickness of

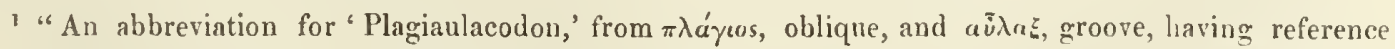
to the diagonal grooving of the premolars,' see 'Description of Two Species of the Fossil Mammalian Geuns Plagiaulax from Purbeck;' by Hugh Falconer, M.D., F.R.S., F.G.S., in 'Quarterly Journal of the Geological Society of London,' vol. xiii, p. 261.

2 Ib., p. 264, and p. 281, fig. 15. 
the crown is but little increased. 'The rhomboidal form prevails; the npper angle being in contact with the npper and anterior angle of the more quadrate crown of the last and largest premolar, and the trenchant border slopes therefrom downward and forward to that of $p 2$. 'T'he lower angle of the rhomboid is formed by the sunooth shining bulge of chamcl above the fang, or the elief anterior fang. Above that the surface expands and flattens, with the slightest degree of concavity lengthwise, and the fechlest indication of a ridge along the hind border. 'T'wo, or at nost three, oblique ridges mark the trenchant smmmit of the crown, whence they run a short way downward and forward.

In the last premolar $(p 4)$, with a slight increase of height of crown, the anteroposterior diameter prevails without inerense of thickness. 'The anterior root, above which is the enamelled swelling, is more plainly a subordinate support, instead of being the ehicf or the sole one. 'I'he onter surface of the crown rises more direetly from the posterior insertion as a flattened tract. A feeble vertical ridge holds the same distance from the anterior thickened border of the crown as does that which, in the preceding premolar, marks the posterior border. 'The flattened part of the crown behind the short vertical rising in $p 4$, thus seems to be a superadderl part of the tooth, and may indicate the tooth, so symbolised, to be a carnassial true molar ; but the test of development cammot, with present evidence, be applied. The oblique ridges, six or seven in number, continued downward and forward from the serrations of the trenchant morgin, are limited to the upper half of the crown. 'The lind part is lower than the fore part; the serrate border sloping from before downward and backward; that horder of the four closely contiguous premolars describes an mbroken convex curve, like the erlge of a cireular saw. 'Tlie four trenchant teeth constitute two thirds of the molary series.

T'he first tubercular molar ( $m$ 1) has an oblong erown, with the long dianeter from before backward. Its vertical diameter is less than half that of the fore part of the antecedent tooth. 'The grinding surface (Pl. IV, fig. 9 B, $m_{1}$ ) is divided by an anteroposterior depression into an outer and an inner division, the inner wall rising lighest; this presents three obtnse cones, the foremost being smallest, and the other two further apart. 'The outer division is cleft into three more equal, smalker, and lower tubercles. Below these the outer surface of the crown is not impresserl or indented, but presents a smooth moderate convexity from before backward. 'The three pairs of peripheral tubercles in this minute lower molar recall the character of those of Stereognathus (Pl. I, fig. 29), though the resemblance is not so close as to the lower molar (Pl. I, figs. 6-12) of Nicrolestes.

'I'le last molar ( $m$ 2) loses in antero-posterior and vertical extent; its middle depressed surface is bronder, and is bonnded by narrow ridge-like low walls of enamel, with feeble indications of a tubercular charaeter, the inner and fore angle being most elevated. In hoth molars the height of the crown is inconsiderable eompared with the other dimensions.

'The onter and fore root of the coronoid process projects external to the alveolus of the last molar, and shows the fractured surface, and the most prominent part of the outer 
surface of the horizontal ramus is thence continued in a gentle curve below the alveoli of the premolars, forward, to the upper part of the socket of the incisor; the prominence is not well defined, but it gives a vertical bulge or convexity to the onter side of the jaw.

The alveolar border rises in well-marked angles into the interspaces of the premolars, or of their roots.

The crown or exposed part of the incisor formed, when entire, two sixths of the total extent of the dental series; the premolars two fifths; the molars one fifth.

Fig. 9, Pl. IV, gives the natural size of the specimen. If the ascending ramus of the jaw be restored after the type of that of the larger species of Plagiaulax (ib. fig. 10), the length of the lower jaw, including Plagianlax minor. the incisor, would be seven and a half lines, as in the woodcut, fig. 6 .

FIG. 6.

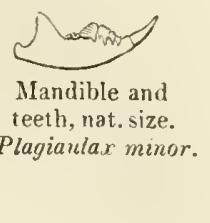

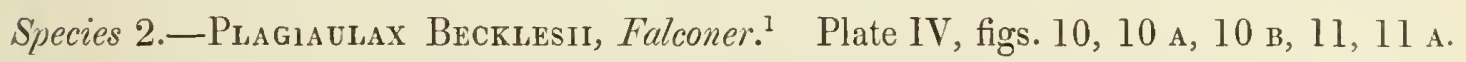

The type of this species is preserved in the counterpart slabs of a split block of Purbeck shale, of which one contains the hind half of the right mandibular ramus, with the impression of part of the fore half (PI. IV, fig. 10, nat. size; $10 \mathrm{~A}$, magn. 3 diam.); the other contains the fore half of the same ramus with the teeth and the impression of the major part of the rest of the bone (ib. fig. 11, nat. size; 11 a magn. 3 diam.). The inner side is exposed of the hind half, the outer side of the fore half.

The fore half contains the incisor (fig. $11 \mathrm{~A}, i$ ) and three premolars (ib. $p 2,3,4$ ); the hind half shows the shallow sockets of two small molars (fig. $10 \mathrm{~A}, m_{1}, m 2$ ).

The condyle of the jaw (figs. $10 \mathrm{c}, 10 \mathrm{~B}$ ) is unusually large, especially in the vertical direction. It extends to the lower border of the ramus, the angle-almost a right onebeing formed by their meeting or intersection at $a$. A narrow tract of fracture indicates the homologue of the angular process to have been thence directly inflected as a thin plate, the base of attachment of which was continned forward below the pterygoid depression, to the entry of the dental canal $(d)$.

The condyle $(c)$ is convex transversely and vertically, the articular surface curving from before backward, downward, and again slightly forward, to the extent of nearly a half circle : its breadth rapidly increases from the upper end to one third down, then gradually decreases to near the angle. The smooth articular surface is best marked upon (and was, perhaps, confined to) the upper broader part of the condyle, the lower boundary, as in Thylacinus, not being defined. The narrowing is chiefly from the inner side; so that the outer contour of this vertical condyle (fig. $10 \mathrm{~B}, \mathrm{o}$ ) is uniformly

$$
1 \text { Op. cit., pp. } 262,278,279 \text {, figs. } 1-5,7-14 \text {. }
$$


(nnvex; the inner conton! (ib. i) is convex at the upper half, concave at the lower one; the imner border is sharply defined, as in Thylacinus. 'The representative of the angular process of the jaw in other Mammals is here directly and abruptly inflected inward, at the level of the lower end of the conclyle, as a horizontal ridge $\left(a, a^{\prime}\right)$, which cxtends forward from the inner side of the lower margin of the ramus to the entry of the dental canal $(d)$, in front of which the ridge curves and rises vertically with some subsidence and blunting to the back part of the molar socket ( $m 2$ ), which is partly within, and is below the anterior part of the base of the coronoid process (b). 'The inflected part of the lower border of the ramus is not much produced, but is most so near the angle, where the margin, broken off from the slab under scrutiny, is preserved in that containing the fore part of the ramus with the teeth (fig. 11). 'The line of the inflected lower border of the jaw runs nearly straight from the terminal condyle to beneath the dental canal.

From the upper end of the condyle the hind nargin of the rising branch ("ramus ascendens,' 'perpendicular portion or ramus,' Anthropotomy) dips down before curving forward and upwarl to rise almost vertically, or with a slight backward curve, to the summit of the coronoid process (b). The concave curve from the condyle is decp and bold, giving a pedunculate character to the joint, at least at its upper part. 'The imner margin of the condyle is produced beyond the level of the inner surface of the rising rauns, circumscribing that surface behind, as does the ridge anterior to the dental canal in front. The apex of the coronoid process, if it were entire, would probably not extend further back in relation to the condyle than in Thylacimus, fig. 5 .

From the summit of the coronoid the anterior margin of that process curves with, at first, a bold convexity, subsiding near the base to change into the gentle concave line by which the process commences, anteriorly, on the outside of the lind socket or hind part of the socket of the last molar tooth.

'The tract of line forming the inner surface of the broar (antero-postcriorly extended) and high coronoid, with that of the 'ramus ascendens' below, is aluost flat on the inner side of the jaw here exposed. It is rertically concave through the production of the inner part of the lower border, near that border, and is very feebly convex in the same direction along the base of the coronoid; in the fore-and-aft direction the flatness of the relatively extensive tract of the inner surface of this part of the mandible is less affected. The inner alveolar wall of the last socket makes an obtuse projection (below $m_{2}$, in fig. $10 \mathrm{~A}$ ), and it is thicker than the outer alveolar wall. In the horizontal plane the inner border of the socket describes a more convex curve than does the outer border. 'The entire borker is obtuse; the socket is a full longitudinal irregular ellipse, and less deep than its length, recalling the shallow bed in which rests the hind tuberenlar of Thylacoleo and Felis. A part of the socket of the anterior molar $\left(\begin{array}{ll}m & 1\end{array}\right)$ is preserved, in front of which is the impression, in slah), fig. 10, of the large premolar $(p 4)$.

'The fore part of the ramns with the tecth is almost as deep as it is long, the deptlo or height of the ramus increasing from the incisive alveolus to the hind fractured part. A 
prominence (fig. $11 \mathrm{~A}, b$ ) a little bclow the hind part of the socket of the last premolar leads backward to the broken origin of the outer part of the anterior border of the base of the coronoid process, and a feebler bulge or vertical convexity of the line extends forward below the premolar alveoli to near the outlet of the socket of the incisor. The concarity (a), decpest at the back part of this portion of jaw, gradually shallows and contracts to end bclow the alveolus of $p_{2}$. The second vertical convexity $(c)$ of the onter surface of the ramus, forming the lower boundary of the concavity $(a)$ is continued into the thick rounded under border of the jaw.

The ramus loses depth as it advances and terminates anteriorly in the socket of the large subcompressed laniariform incisor (fig. 1l,i). The crown of this formidable tooth is directed upward at an angle of $110^{\circ}$ with the line of the premolar alveoli; the tooth as it advances contracts or loses fore-and-aft breadtl, and is slightly curved upward to its pointed extremity. The transverse breadth, which is small, is maintained nearly to the apex. The outer side of the basal third shows a shallow medial longitndinal impres sion, contracting to lose itself in the uniform subconvex lcvel of the rest of the outer surface. This depression recalls that at the corresponding part of the base of the caninc in Triacantlodon ( $p, \mathrm{Pl}$. IV, fig. $8 \mathrm{~A}, c)$. The anterior border of the incisor is blunt to near the apex; the posterior border shows a narrow flat tract with sharp margins; the entire crown is invested by enamel. It is implanted, as far as the socket is exposed, by a single cement-clad root, which slightly contracts as it sinks into the bonc.

The incisor is relatively as long as in Plagiaulax minor (Pl. IV, fig. 9), but is broader antero-posteriorly, less convcx, and less uniformly so extcrnally, more recurved toward the apex; in other words, more fitted for piercing as might become a larger and stronger species.

The three compressed lamelliform premolars progressively increase in height and, in a greater degrec, in fore-and-aft cxtent, as thcy recede in position. 'The crowns of the three teeth $\left(p_{2}, 3,4\right)$ are in very close contact, and are so coadjusted as to give to thcir trenchant border's a continuous convex outline, acting as one great carnassial.

'The first premolar (fig. $11 \mathrm{~A}, p 2$ ) is the least. It arises abont twice its own breadth from the outlet of the incisive alveolus, leaving a distance of that cxtent between it and the incisor. The height of the crown is twice its breadth. The fore part of the base swells into a smootl convexity. The contracting summit bends slightly back and abuts against the middle of the fore part of the second premolar. 'T'he outer side of the upper part of the crown of the premolar $\left(\begin{array}{ll}p & 2\end{array}\right)$ shows an oblique ridge. It appears to be implanted by two fangs, an alveolar process rising to their interspace.

The second premolar ( $p 3$ ) is implanted by a large anterior and a small posterior fing. The outer side of the anterior root swells out at the base of the crown into a smooth convex protubcrance. The outer alveolar wall rises in an angular form between this and the more inwardly inserted small hind root. The crown, narrow transversely, expands from before backward, and then contracts to a subconvex trenchant border. Of this the cutting power 
is enhanced by a fine serration at the hind half, formed by four fine points of enamel, from which, ridges extend obliquely forward and downward, leaving intervening parallel narrow gronves. The lieiglit of the erown of the second premolar is rather more than its foreand-aft breadtl.

In the last premolar $(p 4)$ the increase of size is eonsiderable, as in $P l$. minor. The two roots are nearly equal, the hind one execeding. Both swell out slightly before they coalesce and expand into the erown, but the anterior protuberanec is most marked. 'The fore-and-aft extent of this trenchant tooth exceds its lieight. The scrrate margin is moderately convex. It is formed by eiglit enamelled points, from each of which a ridge extends obliqucly downward and forward, parallel with the eourse of the fonr in the antecedent tootli, and to the same extent down the crown; but both ridges and grooves are more strongly marked in the present premolar. The outer surfaee of the crown is flat, and slopes at once to the trenchant edge, unbroken save by the oblique ridges on its npper half. 'I'le lindmost of these is fecble, and runs below that from the lindmost denticle forning the posterior angle of the crown. 'There is no traee of the short vertical rising noted in $p 4$ of Plagiaulax minor.

As each speeimen is delineated, or outlined, of the natural size, admeasurements are not given in the text. Dividing the length, in a straight line, of the present mandibular ramus, from the apex of the incisor to the back part of the condyle, into nine parts, five of these include the dentition and four the ascending ramus behind the last molar. Of the five parts, inclnding the dentition, a little over four fifths are oecupied by the incisor and premolars, and the rest by the two molars. The teeth ocenpying the four fiftlis of the dentary tract are expressly and very effectively modified for picreing and cutting: those lodged in the lind fifth of the alveolar tract we may infer, by analogy of other specimens, to have been two small and low tubcreular molars adapted for pounding.

'The picreing, holding, and tearing power is limited to onc large sub-creet, sub-recurved, laniariform tooth, which by position in the jaw is technieally an ineisor. The cutting or dividing function is allotted to three teetl, so proportioned and eoarljusted as to act as one large carnassial, working by a sub-convexly curved, trenclaant, and finely serrate edge, as a shear-blade on a tooth, or aggregate of tecth, of probably like carnassial form or character in the upper jaw. The strengthening oblique ridges and resultant serration of the cutting edge secm well adlapted to the division of the tough and dry integument of Saurians.

The position, shape, direction, and relative size of the condyle, with the size, shape, and duration of the coronoid process, indicate the power and line or dircetion of work of the mandible, which by the analogy of the Thylacine (fig. 5) and Ursine Dasyure (fig. 20) $\mathrm{I}$ conclude to have been the work mainly of biting and eutting, with a little crusling or ponnding of the divided substances before their final deglutition. The conparisons, howerer, with the jaws and teeth of other mammalian species will be deferred till the descriptions of the specimens of Plagiaulax are completed. 


\section{Plagiadlax Becklesil (?). ${ }^{1} \quad$ Plate IV, figs. 12,12 a, 12 B.}

The specimen (Pl. IV, fig. 12, nat. size, 12 A, magn. 3 diam., B, grinding surface of molars, magn. 3 diam.) referred to this species ${ }^{1}$ is a fragment of the right mandibular ramus with the beginning of the fore part of the base of the coronoid process (fig. 12 A, $c$ : : it includes two tubercular molars in sitû, with the inner side exposed, and the impression of the obliquely ridged trenchant crown of a prcmolar (ib. $p 4$ ) in relative superiority of size to the tuberculars corresponding with that indicated by the tooth in place $(p 4)$ and the molar alveoli in the preceding specimen (ib. fig. $10 \mathrm{~A}$ ). To the species represented by that specimen I should refer, without doubt, the present fragment, but that the distance from the hind margin of the last premolar to the back of the socket of the hind molar is relatively greater in the present specimen; yet not to such a degree as to forbid the reference, with some indication of doubt, of the present specimen to the Plagiaulax Becklesii. Accepting this determination, we can complete herewith the description of the mandibular dentition of that species.

The penultimate molar (fig. $12 \mathrm{~A}$ and $\mathrm{B}, m \mathrm{l}$ ) presents a low oblong crown, the foreand-aft extent exceeding by one fourth the transverse diameter. The outer half is worn lower than the inner half of the grinding surface, and the outer side of the higher inner border is worn vertically smooth to a shallow groove, traversing the working surface from before backward, and dividing the inner from the outer part of that surface.

The inner surface, swelling out above the two roots of the tooth, presents a low obtuse conical rising anteriorly, with an anterior basal low ridge. The posterior lialf of the inner side of the crown is lower, and presents two small risings, divided by a shallow longitudinal indent. The outer and lower worn-down side of the crown shows two or three feeble risings.

In the last molar (ib. $m$ 2.) the inner half of the crown is higher than the outer one, toward which it also presents a smooth, straight, sheer, or vertically worn, surface. But it is on a lower level than $m$, the enamel being detached or broken away, which gives the appearance of the tooth having been worn down more nearly to the fangs than is the penultimate molar. This, however, is the result of accident. Sufficient of the inner half of the molar remains to show the vertical surfacc presented to the lowcr outer half; and such surface, indicative of vertical abrasion by an upper molar, would be, probably, as high as in the penultimate molar $(m 1)$, had the enamel of the imner half of the crown been preserved in $m 2$. The outer half of the crown retains its enamel covering; has a convex outline from before backward, with an almost flat, shightly concave, working surface. The outer and fore part of the base of the coronoid is external to the posterior two thirds of the last molar.

' By Dr. Falconer, loc. cit., p. 279, figs. $7-10$. 
Small as is this fragment, some nseful inferences may be drawn from it. Firstly, that the two molars in silli were small, not to say minute, in relation to the entire mandible; and ocenpiced not mueh greater extent-if any-of the dental series than do the alveolar indications of such molins in the former specimen (fig. $10 \mathrm{~A}$ ). Secondly, that the line of action in which they worked npon the upper molars was more vertieal than horizontal; conld hardly have been transverse, seeing the shecr wall by which the imner half of the crown rises above the outcr lialf. 'The two molars are plainly of the character of the tubereulars terminating the carnassial scries of flesh-feeders, adapted for pounding and squecing ont the juice of imperfeetly divided animal tissnes; not fitted, for the rotatory grinding actions by which vegetable substances are reduecd, with salivary adinixture, to a pulp) ; but taking that share in the dividing work which the larger of the two small mandibular molars does in Thylacolco carnifex.

Puagiaulax Becklesil, Falconer. Plate IV, figs. $13 a$, A, $13 b$, B.

'This species is, again, represented by the fore part of the right mandibular ramus witl the implanted basc of the broken incisor (i), part of the first $\left(p^{2} 2\right)$, the sccond $(p 3)$, ancl the fore part of the third $\left(\begin{array}{l}p \\ 4\end{array}\right)$ premolars. The inner side of the specinen is represented in Pl. IV, fig. 13, nat. size, $13 \mathrm{~B}$, magn. three diam.: the outer side of the specimen is represented in fig. $13 a$, nat. size, $13 \mathrm{~A}$, magn. three diam. In both figures the parts wanting, but preserved in the preeeding specimens, are restored in outline.

The symphysial surface (fig. $13 \mathrm{~B}, s, r$ ), extcnds upward and forward at an angle of $147^{\circ}$ with the lower line of the mandible $(r, a)$. It is indented behind, the part $(s)$ above the entering noteh suddenly expanding. A linear groove cxtends from the notch forward aeross the symphysial surfacc, dividing the upper broad from the lower narrower part of the artieular surface. The inner surface of the ramus is slightly swollen behind the upper part of the symphysis by the corresponding wall of the long soeket of the laniariform fiolit tooth $(i)$, and the vertical convexity of that swelling changes to a coneavity as the inner surface descends to the thick rounded lower margin.

'The crown of the second premolar ( $p 3$ ) swells out on the inner side (fig. $13 \mathrm{~A}$ ) above the roots, with a eoncavity or notcli, which divides the swollen base into two smooth protuberances, the anterior being the most prominent. Above this the imner surface is flat to the trenehant margin, not defining a eingulum. The flat imer surfaee of $p 3$ is traversed hy four linear ridges extending from above downward and forward, each ridge being continued from the summit of the low projection, the suecession of which gives a fine serrate character to the trenehant border of the tooth.

The ramus lins been fractured across the third premolar $(p 4)$, showing the length of the implanted fang (fig. $13 \mathrm{~B}$ ); the degree of outswelling of the base of the erown both 
externally and internally, and the proportion of the transverse basal breadth to the height of the crown. In this section the tooth is spear-shaped.

Externally as well as internally the lower swollen border of the crown is notched, indicative of the division of the root, and the part in front of the notch is more prominent than the one behind; it is also lower placed. The outer side of the crown (fig. $13 \mathrm{~A}, p 4$ ) is flat from the base to the cutting edge, and no indent marks the base of the crown as a cingulum.

The small anterior premolar $\left(\begin{array}{ll}p_{2} & 2\end{array}\right)$ repeats the character of the fore part of the succeeding premolars, in the smooth enamelled tuberosity by which the crown rises from the root. The narrow crown slopes backward, and is applied like a buttress against the fore part of the next premolar.

The grooves are limited to the upper half of the outer surface of the crown of $p 3$ (fig. $13 \mathrm{~A}$ ), but descend a little lower on the inner surface (fig. 13 B). The anterior denticle of the serrate cutting edge bounds the foremost short groove; the second ridge commencing below the first denticle runs along a greater proportion of the cutting edge before terminating in the second denticle. The third ridge beginning near the fore margin of the crown extends obliquely upward and backward to the third denticle near the hind part of the cutting edge. The fourth ridge terminates in the hind angle of that edge. The groove below the fourth ridge is completed by a fifth, parallel with the others, and terminating a little below the hinder angle of the crown.

In the third or last premolar $\left(\begin{array}{l}p \\ 4\end{array}\right)$ four grooves on the upper half of the outer surface have directions nearly parallel with those of $p 3$. The foremost denticle at the anterior angle of the crown bounds the first short groove. The four succeeding ridges all begin at or close to the anterior margin of the crown.

The accentuation of the outer surface of the fore part of the mandibular ramus is well shown in this fragment. A low ridge ( $t$, fig. $13 \mathrm{~A}$ ), one fourth of the depth of the ramus from the alveolar margins, bounds above a shallow depression at the middle third of that surface which narrows to a point forward beneath the fore part of the first premolar $(p 2)$. Anterior to this point, or angular end of the depression, is a single well-defined circular outlet of the dental canal $(d)$.

The incisor is subcompressed. The section of the base of the exserted crown is a long ellipse with the anterior and posterior rounded ends similar in breadth; but the inner medial side is rather flatter than the outer one.

Plagiaulax Becklesil (?). Plate IV, figs. 15, 15 a.

To this species I refer, with doubt, a specimen of part of the crown of the incisor, a small part of the anterior premolar $\left(p_{2}\right)$, the penultimate $\left(p_{3}\right)$ and major part of the last premolar $(p 4)$ apparently of the left side, imbedded in their natural relative positions in a portion of the Purbeck shale, with the outer surface exposed (Pl. IV, fig. 15, nat. size. 15 A, magn. 3 diam.). 
'l'he cumel of the apical half of the crown of the ineisor, liere preserved, shows a fine longitndinally wrinkled clarneter. 'T'le seetion or fracture of the crown indicates its inner side to have had a shallow longitudinal groove. The basal part of the crown has left a partial impression indicating the diastema between it and the premolars not to have been so long as at first sight appears.

Part of the root of the small anterior premolar $\left(\begin{array}{l}p_{2} \\ 2\end{array}\right)$ is preserved. The penultimate premolar $\left(\begin{array}{l}p \\ 3\end{array}\right)$ shows the usual four oblique ridges on the upper part of the crown. Six ridges are disecrnible on the corresponding part of that of the broader last premolar $\left(\begin{array}{l}p 4 \\ 4\end{array}\right)$. The width of the interspace of the two diverging roots of this tooth, and the transverse brealth of the base of the crown, are well shown in this specinen. It has belonged to an animal quite as large as the type of Plagiaulax Becklesii, and it most probably belongs to that species. 'This specimen does not appear to hare ecme under the notice of Dr. Faiconilr.

Species 3.-Piaglaulax Falconeri, Owen. Plate IV, figs, 16 and 16 a.

This species is represented by the fore part of the right mandibular ramus, with the incisor and premolars, showing their outer surface; followed by the impression of two smaller molars, and part of the aseending ramus (Pl. IV, fig. 16, nat. size, $16 \Lambda$, magn. 3 diam.). The preserved part of the jaw is rather less deep than in Plagianlax Becklesii; the incisor is less broad in proportion to its length, especially at the base; it is also more eonvex on the outer side, and devoid of the longitudinal channel there (fig. $16 \Lambda, i$ ); but it is similar in length, position, currature, and laniary charaeter. The longitudinal ridge or prominenee ( $t$, fig. $16 \mathrm{~A}$ ) of the ramus (answering to $t$ in fig. $13 \mathrm{~A}$ ) is here situated half way between the alveolar outlets of the premolars and the lower border of the ramus; it is further from that border in Pl. Becklesii (fig. $11, a, b$ ), and is less definitely marked; the longitudinal channel below is less prolonged anteriorly. A single outlet of the dental canal opens at a line dropped from the middle of the diastema between the ineisor and premolars.

The first premolar ( $p_{2} 2$, fig. $7.6 \mathrm{~A}$ ) is larger than in Pl. Beclilesii; its crown developes the smooth protuberanee abore the fang, before flattening and expanding; at two thirds toward the apex it contracts thereto. The apex shows one short ridge dividing two grooves; it rises to the anterior angle of the crown of the succeeding premolar; the form of the crown is rhomboidal. The upper and postcrior border is in contact with the anterior border of the next tooth. 'The upper and anterior border slopes forward and downward from the apex; the two lower borders converge, as they descend, to the basal protuberance. The height of the crown is one third more than its fore-and-aft breadth. The sniall lind root is visible at its base.

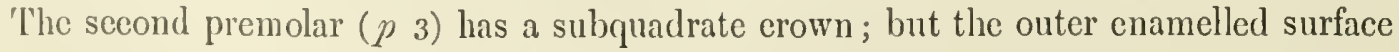
is rhomboidal; the lorrer apex being formed by the basal protuberance. The upper and 
posterior border is applied to the next tooth $(p 4)$, the anterior angle of which is reached by the apex of the present tooth. The upper and anterior border of the rhomb forms the free trenchant part of the crown and slopes down to the angle of the antecedent

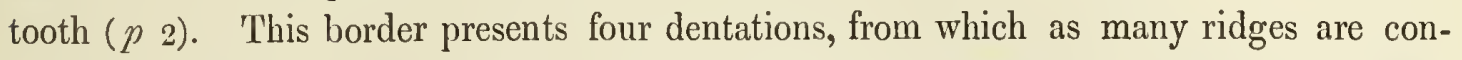
tinued downward and forward, but subsidc before they reach the middle broadest part of the crown. The beginning of the posterior root is shown. This tooth is less than its homologue in Pl. Becklesii (fig. $11 \Lambda, p 3$ ).

The last molar (fig. $16 \mathrm{~A}, p 4$ ) presents the usual subquadrate form, with the hinder root the largest. Eight denticles arm the trenchant border, from which the ridges traverse in the usual oblique course the upper half of the crown. There is a slight protuberance above each root, the rest of the crown being flat. A milute short vertical ridge is on the fore half of the crown, below the oblique ridges; and a similar short vertical ridge may be discerned near the hind part of the penultimate molar $(p 3)$, recalling the structure seen in Plagiaulax minor; and of which there is no trace in Pl. Becklesii. An impression of the bituberculate inner wall of the crown of a small molar $\left(\begin{array}{ll}m & 1\end{array}\right)$ is visible on the matrix behind the last premolar; it is followed by the impression and also part of the inner wall

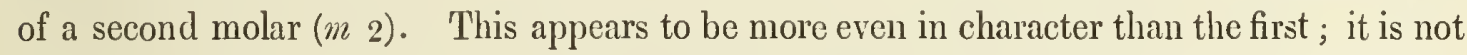
developed into two tubercles so large and well marked; it is of the same, generically, small size. Beyond the last molar rises the impression of part of the beginning of the coronoid process $(b)$.

Dividing the dental series of this specimen from the tip of the incisor to the back part of the last molar into fifteen parts, the incisor occupies five parts, the premolars five parts, the diastema two parts, and the molars ( $m 1$ and 2 ) three parts.

If the only differences between the present specimen and the type of Plagiaulax Becklesii had been in the less robust mandible and more slender incisor, such characters might have been interpreted as sexual; but the difference of the configuration of the outer surface of the jaw, and more especially in the proportions of the premolars, point to a derivative stage which would support a distinct specific entry in Zoological Catalogues. It is instructive to discern in the differences supporting a Plagiaulax Falconeri evidence of an intermediate position between Pl. Becklesii and Pl. minor. In size the present species, which I dedicate, as of right, to the Founder of this most singular and interesting genus, is the same or but very little inferior to the type of Pl. Becklesii.

The specimen (fig. 16) does not appear to have come under the notice of Dr. Falconer.

Plagiaulax medius, Owen. (Cut, fig. 7, p. 86, and fig. 12, p. 90, magn. 4 diam., after FALCONER.)

'The subject of fig. 14, p. 289, of Falconen's ' Original Memoir' (loc. cit.), I have failed to find after rigorous and reiteratcd search in the series of specimens of the Becklesian Collection transmitted to me for description. It was not in that portion including the 
subjects of all the other illustrations of his 'Nlemoir,' marked as 'returned' by the anthor. 'T'he foregoingr specimen (Pl. IV, fig. 16), not deseribed by FALConer, comes the nearest to it, and at first I suspected that it might be such original from which the ascending ranus and condlyle had been accidentally brokcn away. But Fatconer deseribes his specimen as "l'ig. I, Plaginulax Beelilesii. The left ramus of the lower jaw, nearly perfect, showing the outer surface, magnified 4 diameters," (loe. eit., p. $280^{1}$ ). But the subject of $11 y$ Pl. IV, fig. 16, is clearly the fore part of the right ramus of the lower jaw; it differs also in the proportion of the premolars, in the relative depth of the ranus supporting them, and more decidedly in the shape, size, and direetion of the ineisor.

Dr. Falconen refers the specimen, fig. 14, p. 2S0, of his original Memoir, tom. cit. and fig. 1, Pl. XXXIV, of the mulercited work, to his Plagiaulax Becklesii, and it will be observed, in the copy of that figure, in Cut 12, p. 90, that the premolar $(p 2)$ bears the same proportion to $p 3$ as in the type of Plagiaulax Becklesii, PI. IV, figs. 11, 11 A.

The mandibular ramus with the incisor of Plagiaulax minor, restored according to the analogy of Playiaulaw Becklesii, is, as we liave seen, $7 \frac{1}{2}$ lines in length (fig. 6, p. 76). 'The original of the fig. 14, p. 280, of FALCoNeR's 'Memoir,' magn. 4 diam., must have been 8 lines in length (fig. 7); it is nevertheless referred to Plagiaulax Becklesii (Pl. IV, figs. 10-14), which is 14 lines in length (fig. S).

'Trusting, as we may confidently do, to the accuracy of FALCoNer's figure, it will be seen that this differs not only, notahly, in size from the type of the species to which that minute and enreful Observer refers it, bnt in the size of the premolar teeth. 'The series of three in the type of Plagiaulax Beeklesii (fig. 8) has a longitudinal extent of 3 lines, but in Plagiaulax medius (fig. 7) of $2 \frac{1}{4}$ lines. 'The shorter incisor (ib., i), tapering from the exposed part of the base to the apex, might be interpreted as a stage in the development and protrusion of the tooth; and this probably led Dr. FaLConer to suggest that "the specimen would seem to have belonged to a young individual of Pl. Becklesii."

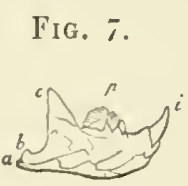

Plagiaulax medius. The subject of Falconer's Plagiaulax Becklesii, fig. 14, loc. cit., reversed and reduced to the nat. size.

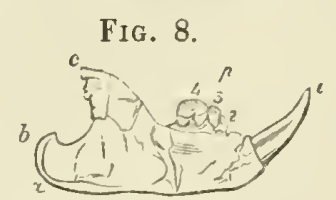

The type of Plagiaulax Becklesii, F. Nat. size.

But the crowns of the premolars are fully formed and in place, that of the anteriol one ( $p$ 2) appearing to have bcen worn. Nothing that is known of the change of the dentition of the Marsupialia would support the infercnee that the premolars in fig. 7 were of the deciduous series, destimed to be displaced by permanent ones of the size of those

1 See also 'Palxontological Memoirs and Notes of the late Hugh Falconer, A.M., M.D., \&c.,' 8vo., 1868 , vol. ii, p. 417 , pl. xxxiv, fig. 1 .

2 I oc. cit., p. 2il, and 'Palæontological Memoirs, \&c.,' 1868, vol. ii, p. 421. 
in Plagiaulax Becklesii, fig. 8. Repeated researches have failed to bring to light any other instance of a vertically replacing tooth ('dent de remplacement,' Cuv.), save that 'premolar,' by development as well as by shape, which displaces the second or the first and second of the primary or deciduous molar series in the Poephaga. ${ }^{1}$

This premolar ( $p$ 4, figs. 13, 14, p. 92), which assumes an antero-posteriorly extended trenchant and vertically ridged character in IIypsiprymnida, may be the homologue of $p 4$ in Plagiaulax, but the proof from developmental character is wanting. I deem it most unlikely that any of the premolars in fig. 7, p. 86 should be destined to be displaced and replaced by a vertical successor of larger size and similar character. There then remains the possibility, assuming the trenchant, serrate, ridged teeth in Plagiaulax medius to be permanent or non-deciduous primary ones, that they belonged to a female Plagiaulax Becklesii, in which the incisor was not fully risen into place. The difference in the shape of the coronoid process $(c)$ may depend upon some marginal defect of that plate in the small and delicate fossil. ${ }^{2} \quad$ The condyle $(c)$ may likewise have lost so much of its prominence as would have brought it to the vertical parallel of the angle of the jaw $(a)$, as in fig. 8 and $\mathrm{Pl}$. IV, fig. 10.

If the parts as figured by Dr. FALconer were natural, they would indicate, with difference of size, a differcuce of shape of jaw, which, as compared with that of the type Plagiaulax Becklesii, should be interpreted as specific. They undoubtedly show the same low position of the condyle, viz. depressed below the level of the molar alveoli--lower, indeed, than in the type-specimen (fig. S, p. S6). The figure also shows the wide emargination between the base of the coronoid $(c)$ and the condyle $(b)$, like that which is seen in the mandible of Thylacinus (fig. 5, p. 74), and to which the tern ' neck' or 'peduncle' of the condyle is sometimes applied.

From the seemingly more distinct and prominent angle (fig. 7, a) a ridge is continued forward and upward, bounding below the external crotaphyte hollow, at a higher level than the inverted angle and lower margin of the jaw bounds the internal or pterygoid hollow in Plagiaulax Becklesii (Pl. IV, fig. 10). ${ }^{3}$

In the well-preserved 'ascending ramus' of the jaw of Plagiaulax Becklesii (Pl. IV, fig. $10,10 \mathrm{~A}$ ) there is no trace of a solution of continuity effecting a communication between the cxternal and internal crotaphyte depressions near the entry of the dental canal, as

' Owen's "Fossil Marsupialia from the Caves of Wellington Valley," May 8, 1838, in Mitchell's "Three Expeditions into the Interior of Eastern Australia,' 8vo, vol. ii, p. 360, pl. 30. 'Classification of the Marsupialia,' 'Proceedings of the Geological Society of London,' Jan. 8th, 1839.

2 Dr. Falconer, who describes this fossil, in a P.S. to his original paper, as "a fifth specimen of Plagiaulax" received since that paper was written, states, "The true molars, if present, are concealed by the flap formed by the anterior margin of the coronoid process. This part of the jaw has been slightly crushed."-Loc. cit. (1857), p. 271 , op. cit. (1868), p. 421.

3 "The base of the coronoid is occupied by a deep depression bounded on the lower side by a raised ridge, which sweeps round from the inferior part of the condyle, to be continued into the anterior margin of the coronoid process."-Falconer, loc. cit., 1857, p. 271, tom. cit., 1868, p. 421. 
in the pocphagous and rhizophagous Marsupials. Dr. FALConer states, "So far as can be seen" (in fig. 7) "the depression would scen to be more limited" than in Ihypsiprymnus, where the "crotaphyte depression terminates in an excavation common to it and the dentary canal." 1

I conclude, therefore, that, in this 'fifth specimen,' as in the type of Plagiaulax Becklesii, the ascending plate or 'ramus' is entire, as in Dasyurus and Thylacinus, with a like carnivorous character of coronoid and condylc.

\section{$\S$ XVII.-TAXoNouIC DEDUCTIONS.}

In the non-production of an angular process of the mandible downward and backward below a condylc low-placed as in Plagiaulax, in the inflection of the part corresponding to the angular process in placental Carnivora and its continuation with a similarly inflected lower bordcr of the 'ascending ramus,' with a corresponding outwardly produecd ridge deepening and bounding below the outer crotaphyte depression, I see, with 1). FaLconer, characters of the mandible of Plagiaulax which "are clearly marsupial.".

In this ancient extinct marsupial genus the mandibular dentition is :-

$$
i \overline{1-1}, c \overline{0-0}, p \overline{4-4} \text {, or } \overline{3-3}, m \overline{2-2},=\overline{14 \text { or } 12} \text {. }
$$

In this formula the 'premolars' are defined by 'shape.'

Now, the Marsupialia show two leading modifications of the anterior mandibular teeth: in one, several pairs of incisors intcrvene between the right and left canines; in the other, one pair of incisors of large size are present, and no canines. The first condition characterises the 'polyprotodont section,' the second the 'diprotodont scction.' ${ }^{3}$ 'The existing representatives of the lattcr group of pouched Mammals are confined to the Australasian area. Some of the former group are American.

In both sections there are modifications of dentition, digestive organs, and limbstructures, which in an interesting degree run parallel with each other; the arboreal diprotodont Phalangers and Petaurists, e.g., with the Opossums and Phascogales; the saltatory Bandicoots and Choeropods with the Potoroos and Kangaroos: the gradatory carnivorous Polyprotodonts have no known existing Diprotodont correlatives. PlagiauI $x x$ belongs to the diprotodont section of Marsupiatia, and the next step is to determine, so far as the mandible and mandibular dentition may support a deduction, to which of the minor groups or families of that section it shows the nearest affinity.

\footnotetext{
1 Loc. cit., p. 271, and tom. cit., p. 421.

2 Loc. cit., p. $2 \pi$ l, and tom. cit., p. 421.

${ }^{3}$ OWEN 'Anatomy of Vertebrates,' vol. iii, p. 293.
} 
No existing Diprotodont offers the mandibular formula of Plagiaulax. In the Plialangers a subtrenchant tooth (fig. 9, $p 4$ ), in contact with the true or tubercular molars, and witl a crown reaching to the same level, is reckoned as the last or hindmost premolar, and as the homologue of the similarly devcloped and situated tooth in Phascolarctos and in most "Poephaga." I view the last and largest of the promolars of Plagiaulax as the homologue of this tootli, and symbolise it as $p 4$.

In Plealangista Cookii (fig. 9) three small teeth intervene between the last premolar $\left(\begin{array}{l}p \\ 4\end{array}\right)$ and the incisor (i). Two of them are held to be $p 3$ and $p$ 2- the homologues of those so symbolised in Plugiaulax FIG. 9. Becklesii (fig. S). With respect to the anterior small tooth, it may be questioned whether it be the homologue of $p \mathrm{l}$, in Plagiaulax minor, or the rudiment of a lower canine. At any rate, as regards number of mandibular teeth between the incisor and the true molars, it is only in the Carpophagous family of Diprotodonts that specics are known corresponding with the species of Plagiaulax. In Petaurus (Belidens) flaviventer four denticles intervene between the functional premolar and the incisor. ${ }^{2}$

Some zoologists have founded subgeneric divisions, with names, on the difference in number of the small premolars, and would, on like grounds, place in distinct genera Plagiaulax Becklesii and Plagiaulax minor. A better ground for such distinction is afforded, among cxisting Carpopliaga, by the small volant species, Petaurus (Acrobata) pygmans, in which the true or tuberculate molars are reduced to three on each side of both jaws; whilst between these and the incisor in thc lower jaw are interposed four teetlı; add thereto the shape of the last premolar, which has exchanged the trenchant for the acuminate character. Nere form, however, of one or more premolars is not enough to determine the reference to, or the removal from, such a group as Carpophaga of a species proved by more important characters to belong to that group or to one of like value in the diprotodont scries.

In somc Poeplaga, for example, the tooth answering to $p 4$ in Plagiaulux resembles it in size and trenchant shape, being also grooved; yet the Poephaga depart further than do most Carpophaga, in having no tooth interposed between $p$ 4 and the large procnmbent incisor of the lower jaw.

The Hypsiprymnida or Rat-Kangaroos, with a ridged and trenchant $p$, have it followed by four molars with massive triturating crowns. Of these the first three have "a

1 This term, applied in 1839 to the diprotodont family including Hypsiprymnus, Macropus, and their subgenera, is preferable to the subsequently propounded one, Macropodu, of Van der Hoeven; because the latter is equally applicable in its descriptive sense to the long-legged saltatory Polyprotodonts. See Owen, Classification of the Marsupialia, in 'Transactions of the Zoological Society of London,' 4to, vol. ii, p. 315.

2 See Art. Marsupialia, 'Cyclopædia of Anatomy,' vol. iii, 1841, p. 264, fig. 89. 
yuadrate form, presenting four equidistant blunt tubercles, whieh are joined in pairs by trinsterse ridges, but with these ridges less clevated than the points of the tubercles: there

Fig. 10.

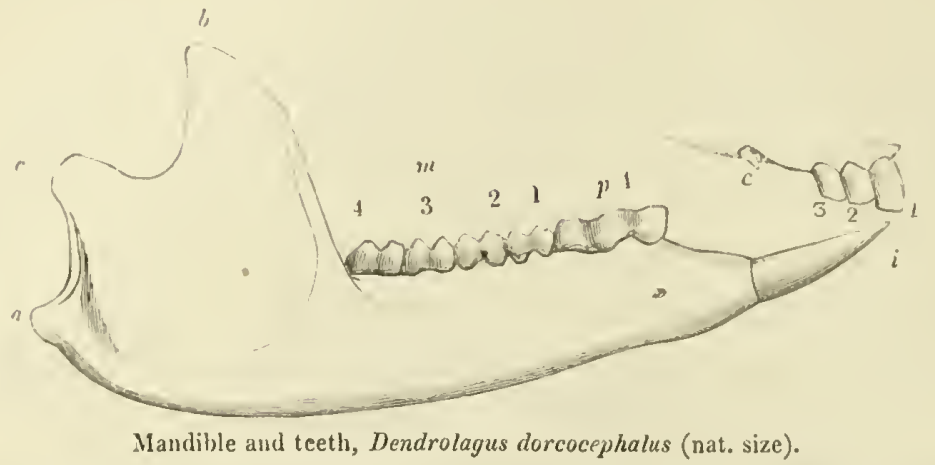

is a slight trace of the band of the tootl (" eingulum' of nyy "Odontography") "on the front and baek part of each molar, as in Macropus. 'The hindermost molar is generally small, almost round." I

In those vegetable-eating Marsupials the molar teeth adapted to sueh diet are never fewer and commonly more in number than in the most typical placental IIerbivora. In relation, apparently, with the drier and tougher vegetable fibres of Australia, the premolar is trenchant, and in the smaller Poephaga is strengthencd by vertical grooves and ridges. In one of the New Guinea 'Tree-Kangaroos (Dendrolagns dorcocephalus, fig. 10) this trenchant tooth is proportionally larger than in the Australian Potoroos and Bettongs, but the light-giving teeth-the true molars - are conformable with the macropode type.?

Fig. 11.

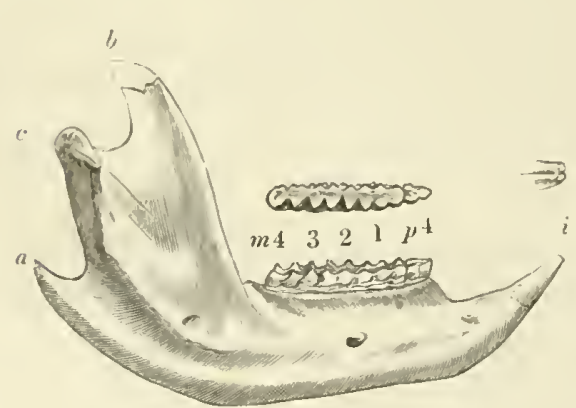

Mandible and mandibular teeth, $\frac{1}{2}$ nat. size, Phascolarctos fuscus.

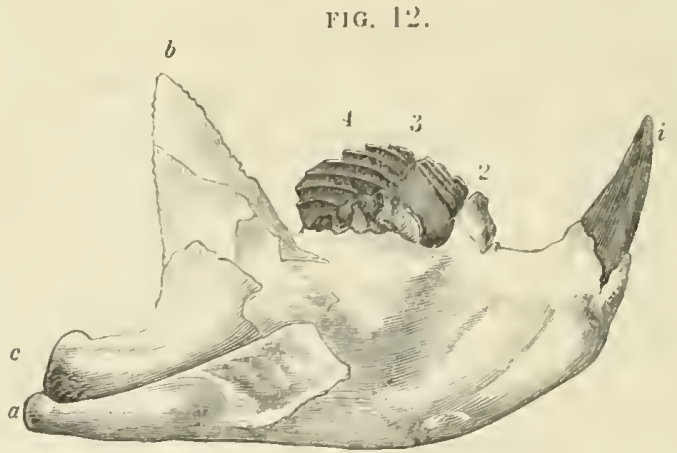

Mandible and mandibular teeth, Plagiaulax (medius, mihi) Becklesii, Falc., magn. 4 diam. (after Falconer). ${ }^{3}$ Rerersed.

A greater contrast in the Diprotodont series is seen in the mandible and mandibular teeth of the Koala (Plascolarctos, fig. 11) and Plagiaulax, fig. 1:.

'Waternouse, "A Natural History of the Mammalia (Marsupialia)," 880, 184., p. 194.

= Ib., p. 182, pl. 10, figs. 5, $5 a$.

3 'Quarterly Journal of the Geol. Soc.,' vol. xiii (1857), p. 280, fig. 14; also 'Palæontographical Memoirs, \&c.', vol. ii, p. 416, pl. 34, fig. 1. 
The premolar (fig. 11, $p_{4}$ ) is reduced in size, and begins to assume the triturating structure and breadth. In the true molars the four lobes have each the shape of a threesided pyramid, with the inner side of the inner pair of lobes undulated or indented in a manner recalling the ruminant type of grinders.

The lower incisors in Phascolarctos and Iypsizrymmus show, as in Rodents, an abraded surface (fig. 11, i) indicative of habitual and long continued gnawing actions. The mandible, by its lofty condyle (ib. $c$ ), its short, narrow, recnrved coronoid (b), and the low relative position in which the inflected angle $(a)$ is produced, concurs with the herbivorous type of dentition in all Carpophaga and Pocplaga.

In Halmaturus the mandibular incisor is procumbent; its long pointed crown is depressed, rather expanded or spatulate, with an outer trenchant edge, the inner side more or less flattened by pressure against its fellow, and the upper side showing, for some extent behind the point, the plane of attrition produced by action against the three opposing incisors of the premaxillary. The trenchant premolar, though relatively larger and more compressed than in Macropus, especially in such large extinct Wallabees as Halmaturus Atlas, forms but a small part, one nintll, of the dental series. It is followed by four molars with large cubical bilophodont crowns, with superadded longitudinal and transverse ridges. Each inolar averages three fourths of the fore-and-aft extent of the trenchant premolar. ${ }^{2}$

In Hypsiprymmus the long pointed incisor (fig. 14, i) is likewise procumbent, but is trihedral. 'The outer side is convex across, the inner and the upper sides are narrower' and are flat, but are not divided by so sharp an angle as that which bounds the outer facet. The upper surface of the incisor shows a plane of attrition from action upon the upper incisors for one third of the extent from its apex, and the enamel is wanting on this surface. 'The trenchant premolar (ib. $p$ 4) has a low crown with a straight cutting subserrate edge. The outer and inner sides meet at a much less acute angle than in Plagiaulax. 'The inner side shows five or six vertical ridges, the first and last being broad. The outer side is worn smooth in old individuals. This tooth forms one seventh of the longitudinal extent of the entire dental series. It is succeeded by four molars (m 1-4) with large cubical massive crowns, the grinding surface of which, characterised as describcd by Waterhouse, ${ }^{2}$ become, by age, worn down to a flattened, more or less irregular, triturating surface, exemplifying the habitual horizontal, rotatory, or alternate crushing action of the mandible upon the upper jaw.

There is but little variation in the rise from horizontality of the lower incisor in the known Potoroos (fig. 14) and Bettongs (fig. 13); in none is the upper contour of the exserted part of the tooth (i) raised above the parallel of the alveolar border of the lower molars.

In a skull of the Brush-tailed Bettong (Bettongia penicillata, fig. 13) now before me, the scalpriform character of abrasion of the upper surface of the pointed ends of the

$$
\text { ' 'Odontography,' pl. 101, fig. } 3 .
$$

2 Op. cit., p. 194. 
incisors extends half way towarel their base. 'The ridges and grooved trenchant premolars
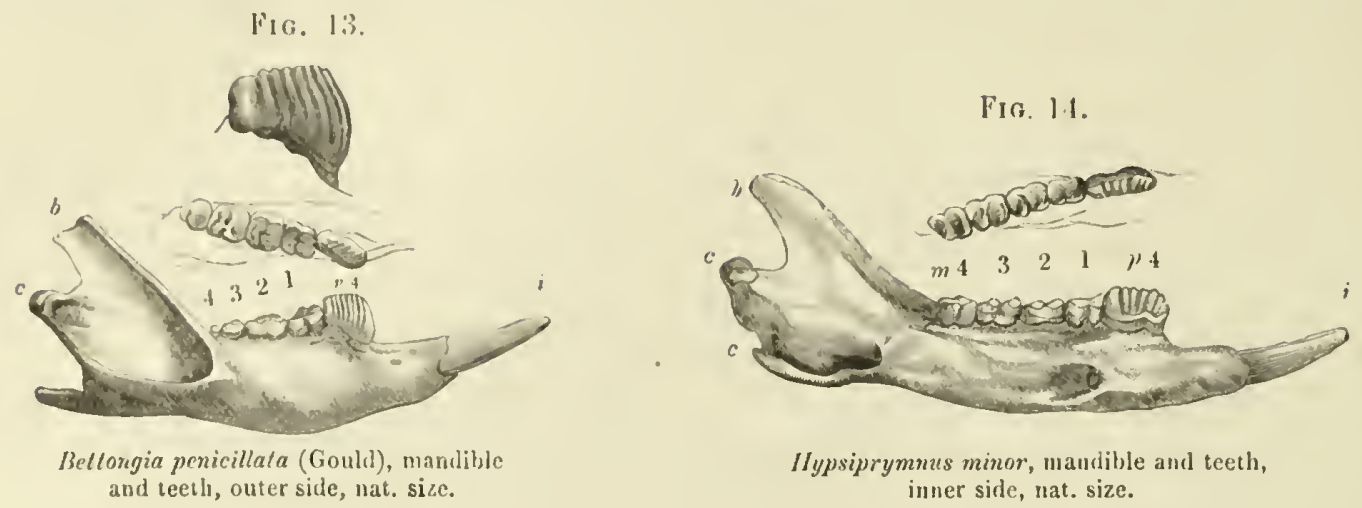

oceupy rather more than one sixth of the dental series. 'They are followed by four molars

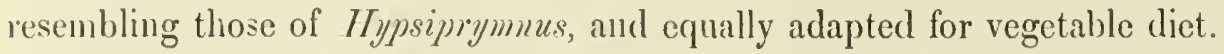

"The premolar in $U$. Gilbertii is but little longer than the foremost true molar, whilst in $/ /$. murims it is equal in length to the first true molar tooth added to that of the second."- I" aterhouse, op. cit., p. 230.

In all Marsupial Poephaga the mandible presents eorresponding modifieations for the morements required in the cropping and mastication of vegetable food. 'The major part of the eondyle is horizontal; and extended transversely, flattened, or with a feeble conrexity from before backward, which is its least diameter (Pl. IV, fig. 10, c). 'The condyle (figs. 13, 14,c) is raised above the level of the grinding teeth, about equidistant from the inflected angle below (ib. a) and the summit of the eoronoid proeess above. This process (ib. b) is relatively narrow, short, and mueh inelined backward. 'The vertical line from its summit to the condyle is less than lialf the same diameter of that part of the lanms. A wide vaenity at the fore and onter part of the 'ascending branch' receives the dentary canal from the inner surface, and is continued forward into the substance of the liorizontal ramus.

In the absence of this external vacuity or perforation, and in the presence of every character of jaw and tectl showing adaptation for animal diet, Plagiaular (fig. 1:) liffers from the Potoroos (I/ypsiprymmus), Kangaroos (IIncropus), and every other known recent or extinet form of pocphagons Marsupialia.

We should have no ground for surprise if, in the long ages sinee the diprotodont condition was furst manifested, forms now exemplifying it had departed too far from the primitive type to be zoologieally associated therewith more nearly than as Marsupials with lower incisors linited to a single pair. If we ask:-where is the living Marsupial that retains the typieal number of premolars with a reduction of the true molars to two and of the incisor to one, on each side of the lower jaw ? - the answer is 'Nowhere.'

In the case of the Amplitherium or of the Spalacotherimm, \&c., with the exeessive ummber of molars, Mr. Waterhouse's discovery of Myrmecobius indicated the Marsupial 
still retaining that anomalous character of dentition which the small Mesozoic quadrupeds manifested in a land geographically now that of England.

So, with regard to the Plagiaulax with its defective molar formula, we must also travel to the antipodean continent of Nyrmecobius to find the forms most nearly allied, in dentition, to the Purbeck genus. But even there they are no longer amongst the existing Iarsupials.

The incisors of Thylacoleo (fig. 15, i) in size, position, direction, and shape closely resemble those in Plagiaulax, much more closely than does the lower incisor of any poephagous, carpophagous, or rhizophagous species of Marsupial : the crown is completely shcatlied by enamel. But the laniary modifications are exaggerated or carried further out in Thylacoleo; the tooth is more compressed, its hindcr trcnchant edge is finely serrate, as in Machairodus; the crown is slightly recurved, as in Plagianlax Becklesii and P\%. Falconeri; and the outer surfacc shows a very shallow and wide longitudinal dcpression at its basal half.

The last premolar $(p 4)$ is trenchant, and occupies two fiftlis of the longitudinal extent of the dental series; it is preceded by three small and early shed premolars; it is followed, as in Plagiaulax, by two small, tubercular molars ( $m 1$ and 2$)$, which, together, arc limited to one sixth of the dental series. The first of these, again, indicates the more strictly carnivorous character of Thylacoleo by the elevation and compression of the fore part of the crown, detracting in the same degree from its triturating powcr and character. The second lowcr molar is low,

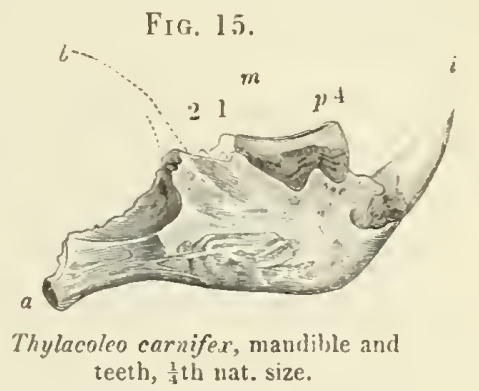
tubercular, one third the size of the first molar, implanted by one short thick root. We know that the two small teeth succeding the carnassial in the lower jaw were opposed to a single transiersely extended tubercular molar above, in Thylacoleo.

The large carnassial premolar in Thylacoleo (fig. $15, p 4$ ) forms the same proportion of the dental serics as do the close-set three or four trenchant premolars in Plagiaulax. The antcro-posteriorly cxtended crown of the 'Thylacoleo's premolar has the enamcl at the basal part of the inner surface vertically and fincly undulated, one cannot say grooved or ridged. The worn margin demonstrates the trenchant or shear-blade mode of working upon the similarly shaped and developed upper carnassial. The smooth even surface slopes obliquely down the onter sidc of the lower and the inner side of the upper carnassial in Thinlacoleo, showing the same relation of these teeth to one another transversely, as in the Lion and other Fclincs.

In Tryylacoleo the outer wall of the mandibular ramus bulges out, as in Plaginulax, below the soekct of the premolar. The outer crotapliyte depression is entire and impcrforate. The dentary canal begins at a corresponding part of the imuer or pterggoid dcpression. From the continuation backward and slightly dowwward of the lower border 
of the outer crotaphyte depression, and from the concomitant extent of the fractured base i) the colonoid process in the least muntilited mindihle of Thylacoleo, which has yet reached me (fig. 15), I infer a breadth and generil development of the coronoid process, and a position of the comblyle corresponding, more or less, with those characteristic of Playiantax, Sarroplitus, and Thylacynus.

'Tlie rentition of the upper as well as of the lower jaw of Thylacoleo being ascertained, its formula gives :-

$$
i \frac{2-2}{1-1},\left(\frac{1-1}{0-0}, \frac{1-4}{3-3}, m \frac{1-1}{2-2} ;=2 S .\right.
$$

'T'hns, so fan' as the dentition of Playianla.e is known, it more closely resembles that of Thylacoleo than of any other Marsupial.

From the elaracteristic rednetion in size and number of the molar tecth, I have associated them as members of a 'pancirlentate' family or Section of Diprotodonts.

In this section may be discemed an interesting illustration of the Law or 'I'endency from the General to the Particular as species approach the present time in geologieal position.

'I'he extinct pouched Camivore of the Neozoic period his the functional or earnassial premolars reduced to a single tooth on each sicle of the lower jaw; the extinet pouched (iaminore of the Mesozoic period retained, in one species, three premolars of the carnassial type, in another species four-the normal nmmber-on each side of the lower jaw.

'The parallel runs very close with that which the placental Camivora show within the limits of 'lertinry time; as when, e.g., we compare the Niocene Hyanodon and its three lower carnassials witl the modern Iryana, where they are reduced to one; or when we comprare the Miocene Amplingyon with its three upper tubereulars with the modern Ursus, where they are redneed to two.

'I'lie alleged 'well-ascertained' conchision as to the horbivorous nature of Plagiaulax allowed only the contrast with the rich and well-adapted series of grinding teeth in the Poeplagya and placental Ilerbivores to be thought of, and blinded the Objector to the suggestive instance of ancient adhesion to type which the carnassials of Plagiaulax, viewed as a Carnivore, foree upon the attention.

Because certain saltatory vegetable-feeding Marsupials have one trenchant and vertically ridged mandibular premolar, oecupying a small proportion of the entire molary series, it is not admissible that three or four trenchant and obliquely ridged mandibular premolars, forming a large proportion of the entire molary series, afford adequate grounds for conchuding the limbs to be 'macropodal,' and the beast to be herbivorous and a "Marsupial form of Rodent." 2

$A$ life's experience in the labour of restoring, from fragmentary evidenees, an extinct

1 Falconer, 'Quarterly Journal of the Geol. Soc.,' vol. xiii, p. 276; also, 'Palæontographical Memoirs, Sec.' vol. ii, pp. 421, 427.

${ }^{2}$ Ib., ib., rol. xviii, p. 349, and 'Pal. Mem.,' rol. ii, p. 425. 
species has left me under the conviction that what has been above submitted to Palæontologists in the attempt to determine the affinities of Plagiaulax is near the truth: and that having the lower jaw and its entire dentition to work from, the Palæontologist ought to be able to indicate, approximatively, its place in the Natural System.

I should not have presumed so far if my material had been a solitary premolar; supposing even that the last and largest of the series had been the sole indication of what we now know as Plagiaulax.

If it had resembled a premolar of a Rat-kangaroo as much as it differs from one; if its crushing edge had been straight and vertically notched, instead of being curved and obliquely notched, or 'serrate;' if its ridges had been vertical instead of oblique; no inference as to the number and kind of teeth with which such premolar had been associated, in the otherwise unknown Oolitic beast could be safely or scientifically drawn; still less could the Palrontologist be justified in jumping at the conclusion that the old user of this solitary evidence of its dental tools had been a saltatory herbivore! If one desired to have it believed that a Nacropodal or Poephagous Miarsupial had existed in Triassic or Oolitic antiquity, he might incleed sulsstitute for scientific reasoning confidence of assertion. ${ }^{1}$

With a fossil premolar as like that of Hypsiprynmus as the last premolar of Plagiaulax is unlike,-I will not insult the common sense of Zootomists by citing the microlestian denticle (Pl. I, fig. 16) as a parallel case,-the competent Palæontologist riewing such premolar would call to mind instances where similar premolars are associated, in the Mammalian class, with very different molars, canines, and incisors. A premolar does a part, but not the whole. nor commonly the main work, of the preparation of the food for deglutition and digestion, \&c. A premolar may show, as in Hypsipryunus and Playiaular, an admirably fitting instrument for dividing by cutting or by sawing. But such a fossil instrument cannot, by itself, teach the nature of the substances to the division of which it was applied by the living animal; still less can it justify a conclusion as to the kind of locomotion with which the beast carried itself to its food or prey.

The great master and founder of Palæontology has been held by some to have hazarded orer much in estimating the amount of inference that could be drawn from a solitary fossil tooth. But this at least all subsequent cxperience has confirmed, that he selected the class of teeth which best justifies his axiom. I proceed, next, to consider the physiological deductions which may be drawn from our knowledge of these light-giving elements in the dentition of Plagiaular.

1 Thus, Mr. Boyd Dawkins affirms :- "The presence of the Macropoda (Van der II. = Poëphaga, Owen) is proved by the discovery of the Kangaroo-rat allies : namely, in the Purbeck beds, of the Plagiaulax, the true affinities of which have been so amply demonstrated by Dr. Falconer ('Quart. Journ. Geol. Soc.,' vol. xiii, p. 261 ; vol. xriii, p. 348); in the Rhatic bone-bed, of the Microlestes of Frome and Diegerloch, closely allied, according to Professor Owen, to Plagiaulax ('Palæont.,' p. 305); and, lastly, in the strata below the bone-bed, by the discovery of the Hypsiprymnopsis Rhaticus of the Watchet shore." "Quarterly Journal of the Geological Society of London,' vol. xx (1864), p. 412. 


\section{§ XVili. Pursiological Deductions.}

From the shape of a tooth may be inferred its work; a pointed one to pierce, a trenchant one to cut, a broad knobhed or ridged crown to bruise. But the kind of substances to be piereed, cut, or ground demands otlice considerations than that of mere shape to determine. 'The chief of these is the kind of tecth with which the piercers, the cutters, or the pounders may be respectively associated, more especially the first two. If the Palsontologist has no other part of the skeleton than a jaw with tecth to work from, the guiding principle of correlation is eorrespondingly limited in its applicability. Cuvier's choice of tooth or class of teetl as being of highest correlative ralue, or as throwing most light on the food and hahits of an unknown and extinct Mammal, still commends itself to my experience as the best.

Guicled by lis rule, ${ }^{1}$ my first attention was paid to the molar tecth of Plagiculax. 'l'hese are too few, too small, and occupy too short a space in the dental series to perform the effective kind and amount of mastication required for the preparatory act of digestion of regetal,le substances.

Known only as they exist in the lower jaw, the analogy of Thylacoleo teaches that they would not be in greater, were more likely to be in less number, in the upper jaw ; accordingly, the inference of their functional relations to food may be legitimately drawn.

Every known instance of a like condition of tulsercular molars points to the modifications of the rest of the dental series for predatory life and animal diet. And this, as regards the mandibular dentition of Plagiaulax, we have seen to be the case in every species and varicty.

A pair of teetli, placed favorably at the fore part of the jaw, manifest the length, strength, sub-compressed, snlb-recurved, pointed form of the laniaries of the Carnivore, and suggest the applieation to scizing, piercing, lacerating, slaying. The major part of the alveolar tract is occupied by tecth of the trenchant carnassial or sliear-blade type.

'There are few instances in which the sagacity of Cuvier in directing primary attention to the 'dents molaires' is better exemplified than by the small extinct Mesozoic Marsupial uncler consideration.

The Musk-deer lias a pair of canines almost as formidable for lethal purposes as the npper ones of Machairodus. The Gorilla has canines in shape and proportion like those of the ordinary large Camivora; the Baboon adds to them the secondary feline characters of longitudinal grooves and the trenchant ridge; but the tyro taking these tecth only for his gnide or basis of physiological reasoning wonld be led astray.

The light-giving tecth in each case, by their massive cubical crowns, complex confignration and structures, number, and large proportion contributed by them to the

1 "La première chose à faire dans l'étude d'un animal fossile est de reconnoître la forme de ces dents molaires ; on determine par la s'il est carnivore ou herbivore."-Cuvier, 'Recherches sur les Ossemens fossiles,' 4 to (1822), tom. iri, p. 1. 
dental series, bespeak plainly the secondary or subsidiary function of the associated long and large laniaries, as weapons, viz. of defence or of sexual combat.

The true molars tell a similar story in every species of carpophagous and poephagous Marsupial. Detached lower incisor's of the Kangaroos are long, pointed, and sharp-edged ; in the Bettongs and Potoroos their tapering ends begin to manifest scalpriform modifications.

The procumbent, in many Kangaroos almost horizontal, position of these teeth warns against the conclusion that they were made to pierce as weapons, offensive or defensive: closely looked to and compared with true laniaries, such as those in Potamogale (figs. 16, 24) Thylacoleo (figs. 15, 18), and Plagiaulax (fig. 12), characters of shape and structure, besides those of direction or position, are discemed in the incisors of Poephagans (figs. 10, 13,14 ) which relate to other ends than stabbing and tearing; to uses which require opposing teeth of a different character and in greater number than in pancidentate Marsupials.

The premolars of Plagiaulax are plainly made to cut; the strengthening of the blade by enamel-ridges, and the serration of the cutting edge, due to their oblique course, suggest an occasional application to tougher tissues than merely muscular. In the trenchant and vertically grooved premolars of Potoroos and Bettongs the margin is notched, but it las not the true serrate character which the oblique and unequally bordered dentations give to the cutting edge of the carnassials of Plagianlax. The three or four such premolars in this genus combine their oblique serrate margins into a curved line like that of part of a circular saw; the notched edge of the single premolar in Hypsiprymnus is straight.

The many and large molar teeth and procumbent sub-scalpriform incisors associated with the trenchant premolars of Potoroos and Bettongs, show the kind of substances these were destined to cut. We know it to be tough, dry regetable substances, such as the coarse grasses of the Xanthorrlicea, the tegument of the Cycadeons Macrozamia, rootfibres, \&c.

The few and suall molar teeth and suberect laniariform incisors associated with the serrate premolars of Plagiaulax show that they operated upon animal tissues; the evidence of the many and varied kinds of small Saurians coexisting with Plagiaulax significantly indicate the tough integument which sucl modified carnassials woukd be well fashioned to divide.

Trenchant premolars need not the ridged and serrate structure "for chopping up fruits or succulent vegetables ;" the very perfection and strength given to the carnassials of the little saurivore indicate the nature of the mutritive substances they operated on, and the needlessuess of supplemental pounding or masticating teeth in greater number or of greater size than Plagiaulax possessed. Roots and grass "chopped up" by the premolars of

${ }^{1}$ Flower, Prof. Wm. Henry, F.R.S., "On the Affinities and probable Habits of the Extinct Australian Marsupial, Thylacoleo carnifex, OWEN," in 'Quarterly Journal of the Geological Society of London,' vol. xxiv (1868), p. 318. 
Rat-kangaroos would hardly, in that state of division, be fit for swallowing; accordingly we fund a provision of not less than sixteen square and broad-crowned, ridged, and tuberculate grinders, superadded to the trenchant teeth, in order to pound up the chopped roots and grass, and to well blend those dry vegetable cuttings with abundant salivary secretion, in order to prepare a bolus fit for deglutition and subsequent digestion.

\section{$\$$ XiX. Objections to the Carnivority of Plagiaulax examined.}

'The procumbent pair of lower incisors in Poephaga oppose the upper surface, not the cnd of the tonth, to three pairs of upper incisors, of which the foremost is longest. By the analogy of Thylacoleo the suberect pointed pair of lower incisors in Plagiaulax would be crossed by a correspondingly developed and deflected pair of laniariform incisors; and, if these were followed by others in the premaxillary bones, they would probably be rudimental and limited, as in Thylucoleo, to a single pair.

'The functional incisors in both jaws would act as in Thylacoleo, the lower ones like a

FIG. 16 .

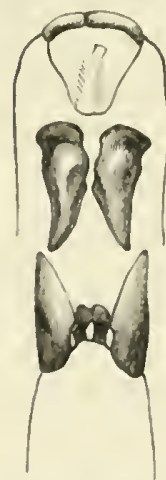

Front view of upper and lower incisive laniaries, Potamogale relox; twice nat. size. ${ }^{3}$ pair of hayonets, cemented side by side, with the muscular forces of hoth mandibular rami concentrated on the thrust. A like advantage in lethal stabbing power is gained by the same "collateral arrangement in the axis" of the perforating stroke, in many of the Ferines ("Carnassicrs") of the Cuvierian system. It is interesting to note, however, that these instances occur in the orders ("Insectivores, Marsupiaux') which I have proposed to place, through cerebral characters, on lower steps in the Mammalian series; the lissencephalous and lyencephalous conditions of brain seeming to me of greater taxonomic value than the "possession of claws and of three kinds of teeth." " With lower intelligence the power of the killing tecth is heightened; and a like relation is not unfrequently exemplified.

Observation of the liabits and actions of the lissencephalous Otter (Potamogale, Dn Chaillu), with approximate or "collateral" laniaries (fig. 16), slows them to be as efficient, to say the least, in the capture and slaughter of its prey, as are the divaricate lamiaries in the gyrencephalons Otter (Lutra). The Hedgelog

1 Falconer, "On the disputed Affinity of the Mammalian Genus Plagiaulax from the Purbeck Beds," in 'Quarterly Journal of the Geological Society,' vol. xviii (1862), p. 352 ; also, "Palæontological Memoirs," vol. ii, p. 43.5 .

2 "Les Carnassiers forment une réunion considérable et rariée de quadrupèdes onguiculés, qui possèdent les trois sortes de dents." Cuvier, 'Regne Animal,' tom. i, ed. 1829, p. 110. But see, Owes, "On the Charactrrs, Principles of Division, and Primary Groups of the Class MLammalia," in 'Proceedings of the Linnean Society', Feb., 18.57 ; also, "Anatomy of Tertebrates," 8vo, rol. ii, p. 296.

3 I am indehted for the drawing from which cut fig. 16 was taken to Prof.Allyax, F.R.S., of the University of Edinburgh, where the unique skeleton of that rare genus is preserved. 
(Erinacens) adds young Rabbits to its miscellaneous and lower animal diet, and kills them as effectually by its approximate laniaries as does the Stoat by its divaricate ones. Breeders of poultry will hardly be prepared to endorse the epithet "mild" applied by Prof. Flower to "the ferocity and destructive power" of the Rat as compared with the Ferret $;^{1}$ if the application of their respective lethal weapons upon defenceless birds be the subject for consideration. No doubt, in combat, the Terrier or the Ferret gets the better of the carnivorous rodent. We may admit that Triconodon mordax, the contemporary of the Plagiaulax minor, might have overcome and devoured that little predatory Diprotodont; but this would afford no ground for denying the power of the latter to pierce and slay, by means of its approximate laniaries, the comparatively defenceless Saurilli, Macellodi, Nuthetes, ${ }^{2}$ and other diminutive lacertines.

In the Insectivora, as in the Marsupialia, there are two local conditions of the teeth which are adapted "to pierce, retain, and kill." In some, e.g. Gymnura, Dasyurus, the laniaries answer, in position, to the canines of gyrencephalous Carnivora, and 'are leld well apart through the interposition of a line of incisors:' in others, e.g. Potamogale (fig. 16), Solenodon, Erinaceus, Scalops, Urotrichus (fig. 17), Plagiaulax, Thylacoleo (fig. 15), the laniaries are approximate, or are separated at their base by only a single pair of minute incisors (fig. 16).

FIG. 17 .

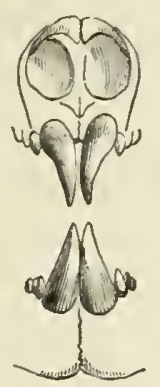

Front view of upper and lower laniaries, Urotrichus talpoïdes, magn.
FIG. 18.

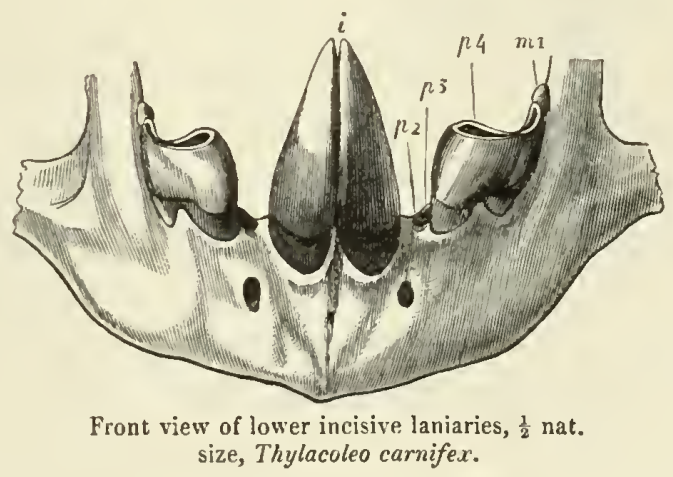

The transfcrence of the laniary form and function from the canines to the incisors, the development of the latter locally characterised teeth into lethal weapons, is the rule in the lissencephalous members of Cuvien's 'Carnassiers.' Whether, however, the laniaries, which "are kept well apart" in Moschus, as in Felis, or which are approximate in Plagiaulax" as in the many predaceous species above cited, be really used to pierce, hold, and kill other animals for food, cannot be determined in an extinct species "by a facile observation of mere form," ${ }^{3}$ but by the laws of physiological correlation. Referring to the molars of

1 'Quarterly Journal of the Geological Society,' vol. xxiv (1868), p. 318.

2 Owen, 'Quarterly Journal of the Geological Society,' vol. x (1851), p. 420.

3 Falconer, 'Quarterly Journal,' \&c., p. 358, 'Palæontological Memoirs,' p. 441. 
Moscluns, we shonld he justified, if we knew that animal solcly by its petrified jaws and dentition, in concluding that its canines, notwithstanding their fomidable development and their position as "held well apart," with " the points of penetration doubled, the dilacerating and killing powers multiplied," "were, nevertheless, not used for predaceons enrk, hut merely as weapous of sexual combat and defence. Similarly, a reference to the molars of Plagiaulax and Thylacoleo teaches that the approximate laniaries, "placed collaterally in the axis of the jaws, one on each side, ahove and below,", were related to caruivorous labits.

As beautiful as they are truc are the laws of correlation rightly discerned. With the carnivorous type of dentition of Plagiaulax are associated the characters of the carnivorous type of mandible (fig. 12). With the herbivorous teeth of IIypsiprymmus go the high-placed condyle, the small sloping coronoid, and the extension of jaw below the condyle for adequate inuplantation of the pterygoid muscles chicfly concerned in the working of molars framed for grinding vegetable substances (figs. 13 and 14).

In my memoir on the Aye-aye 1 had to note that the mandibular condyle was "sessile,

FIG. 19.

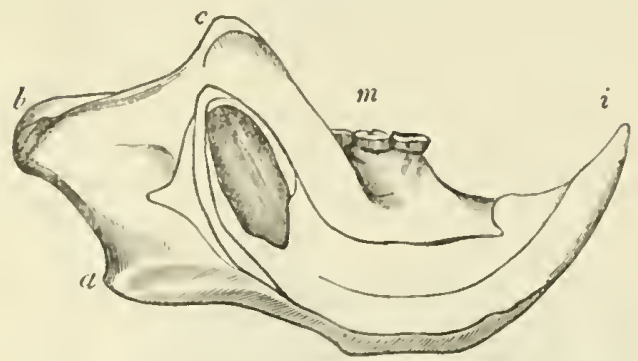

Cheiromys: mandible and teeth, the incisor exposed: nat. narrow, rather long, convex both across and lengthwise, and placed on the level of the grinding tecth," and I remarked that "the sessile condyle contrasts strongly with the pedunculate one, especially in the small extinct ferines (Plagiaular and T'riconodon) of the Purbeck beds, a concomitant difference being shown in the rentition; trenchant teetl, grooved as in the lower carnassials of Thylacoleo, take the place of the flat-crowned molars of Cheiromys."3

Prior to this discovery no such low position of the mandibular condyle was known, "in any herbivorons or mixed-feeding Mammal," supposing the Aye-aye to be such.

DE BuAINVILLA had stated that the condyle was " nearly at the posterior extremity of the entire jaw," "and he might have affirmed it to be quite there; but of its relative position to the alveolar series neither the text gave information, nor did the figure of the skull with the co-articulated mandible permit of a certain conclusion on that point. Dr. FAlconer reprodncing the same view of the detached mandibular ramus of Cheiromys which I lıad given in pl. 20 , figs. 7, 8, of my memoir (see fig. 19), onits any notice of that figure. He cites only the work which I published the year before I received the unique

'Falconen, 'Quarterly Journal,' \&c., p. 352, 'Palæontological Memoirs,' p. 435.

2 Ib., ib., p. 352 ; ib., p. 435.

3 'Transactions of the Zoological Society of London,' vol. v, pt. 2, 4to, 1863 (read January 14 and 28, 1862), pp. 50, S1.

4 "Presque à l'extremité postérieure de toute la mâehoire," 'Osténgraphie, Mémoira sur l'Aye-aye, J. 19. 
specimen of Aye-aye, and then turns upon me the weapon with which I had furnished him." "The author of "Palæontology' states that it is a "character unknown among any herbivorous or mixed-feeding animal." "I again refer my reader," pursues Dr. FALconer, "to the figure (fig. 20) of the lower jaw of the Aye-aye. In it the articular surface of the condyle, although directed subvertically, or at the most diagonally, is wholly below the grinding plane of the molars. It looks still more depressed in Plagiaulax Becklesii; but this is, in part, owing to the inflected margin of the angle being broken off in the fossil, while it is entire and salient in the recent form, thus elevating the condyle above the lower plane of the ramus, and leading to an appearance of a greater amount of difference than exists in nature." 2

I will presently refer to the grounds assigned for concluding Cheiromys to be a herbivorous or mixed-feeding genus; and, referring to the description of the mandible in Plagianlax Becklesii (p. 77) for the evidence of non-extension of the angle beyond the lower end of the condyle in that species, I will now offer a few remarks bearing upon the relative value of the molar teeth, and the position of the condyle of the mandible in the interpretation of the habits and food of an extinct Mammal.

Position of condyle relates to the force with which the mandible is worked, shape and pedunculation of the condyle to the direction of the working force.

The flattened or less convex articular surface favours the rotatory movements; the more convex, especially transversely extended, and pedunculate or subpedunculate condyle indicates the ginglymoid articulation with greater extent of divarication or wider gape, and more habitual movements in one plane, or linited more or less thereto. 'The rotatory grinding movements of the mandible are commonly associated with a high position of the condyle and regetable diet; the vertical biting movements are commonly associated with a low position of the condyle and animal diet. But the advantage of a long lever afforded by a lofty coronoid process and low-placed condyle may co-relate with powerful biting and gnawing actions, as in the working of the maximised scalpriform teeth of Cheiromys.

These instruments are wielded by the powerful and farorably formed jaw with a force which enables the Aye-aye to rapidly erode or gouge away the hardest timber. 'To infer it to be a vegetable-feeder from the scalpriform teeth, and the associated low condyle, and other mandibular modifications, is to assume the ligneous fibre to be gnawed by the animal for food. But, were the species extinct, the molar tecth would teach that this could not be; few, small, flat-crowned, or tuberculate, they plainly point to operations on nutritive substances from the animal kingdom.

A captive Aye-aye, it is true, endured a regimen of rice for two months before it died. And this fact is cited to prove it to be a herbivore! ${ }^{3}$

1 'Memoir on Aye-aye,' op. cit., pl. xx, figs. 7, 9; 'Palæontological Ilemoirs,' vol. ii, pl. 34, fig. 13.

2 'Quarterly Jourual of the Geol. Soc.,' vol. xviii (1862), p. 361 ; also, 'Palæontological Memoirs and Notes,' 8 vo, 1868 , vol. ii, pp. $445,446$.

$s$ "One of the live specimens procured by Somnerat lived in captivity two months fed on boiled rice. 
But were the maximised chisel-teeth, with a low-placed mandibular condyle and biting power of jaw, needed to divide the stems of rice or the stalks of dates or of bananis?

Soxwirat, besides specifying the compulsory food on which his captive Aye-aye perished, describes the long, slender, naked, middle digit, and states: "Il s'en sert pour tirer des trous des arbres les vers qui sont sa nourriture." I I understand this to mean that larve ('vers') are its natural or staple food. 'The affirmation may have been made from Soxvernat's observations on Cheiromys in a state of nature, or on the reports of natives of Madagascar, or on both authorities.

Dr. SANDwiru adds to his account of the substances on which he fed his Aye-aye a detailed statement of obscrvations of its power of detecting, exposing, and extracting the xylophagous larvæ, which it eagerly devoured, confirmatory in an inuportant and instructive degree of Soxwerat's statcment of its food in a state of nature $:^{3}$ nor is other testimony to the same fact wanting. ${ }^{2}$ And to the acquisition of such animal food the dental and mandibular machinery of Cheiromys are as perfectly adapted as was the same machinery in Plagiculax to the different kinds of animal food whieh that extinct Marsupial captured and fed upon.

'l'he large front teeth in Cheiromys are curved in segments of circles (fig. 19, $i$ ), the depth of the tooth exceeding the breadth; the working surface is elongated, in breadth equalling that of the base of the tooth, with a front convex enamelled border, forming the apex of the gouging tool.

With what molars are thcse scalpriform teeth associated? Few, small, tubercular (fig. $19, m$ ): fitted for squeezing the soft animal nutriment out of the tegumentary covering of a caterpillar; not adapted for trituratory mastication of such vegetable food as calls for the more complex and massive molars of the Kangaroos, Potoroos, and Koalas, or of the xylophagous Voles and Beavers.

In another part of the polemical paper advocating the macropodal affinities of Playiaulax, the angular process of the jaw as a salient apoplyysis is stated to be wanting in that genus, and an argument for its herbivority is based upon the assertion that " this process is a very constant character of the carnivorous jaw," and that " it is well developed in the minute insectivorous Myrmecobius."

'I'o this I reply, that the angular process is not present in Stenorliynclues and some The species of IIypsiprymnus are strictly vegetable-feeders." FalCoser, 'Quarterly Journal of the Geological Society,' vol. xviii (1862), p. 364; ' Palæontological Memoirs,' 8vo, 1868, vol. ii, p. 449. “Dr. Sandwitr fed his captive Aye-aye upon bananas and dates." Ib., ib., p. 450. By parity of reasoning the Kite (Home, "Lectures on Comp. Anat.," 4to, vol. i, p. 271) and Sea-gull (OwEx, "Physiol. Catalogue of Mus. Coll. Surgeons," 2nd ed., 8vo, p. 151) might be cited as herbirorous. This and the passage on the rice-feeding were read to the Zool. Soc., Jan. 14th, 1862.

1 "Voyage aux Indes Orientales," \&c., Paris, 4to, 1782, and Ed. 8ro, 1806, vol. iv, p. 122.

2 Owex, "On the Aye-aye," 4to, 1863, p. 25.

3 Falcoxer, 'Quart. Journ. Geol. Soc.,' vol, xviii, p. 363 ; 'Palæont. Memoirs,' p. 448. 
otlier Seals ; nor is it peculiar to the mandible of Carnivora even "as a salient process ;" and, furthermore, as such, it is not wanting in Plagiaulax; only, it is directed inward immediately below the condyle in that Marsupial, not, as in Myrmecobius from a part of the jaw continued downward below the condyle.

The differences which the Marsupialia present in the position, form, and degree of inflection of the angle of the jaw are noted in the works cited below." "The condyle of the jaw is nearer the plane of the inferior margin of the ramus in the Thylacine, (fig. 5,

FIG. 20.

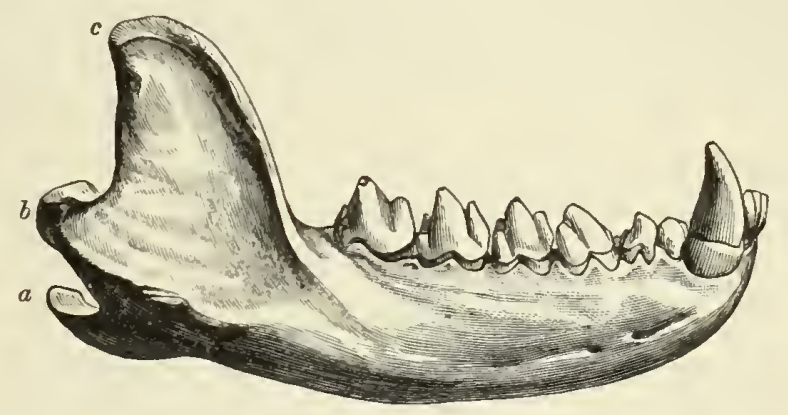

Mandible and teeth, Dasyurus ursinus.

p. 74) and Dasyure (fig. 20), than in the Opossums; and, consequently, when the inflected angle is broken off, the curve of the line continued from the condyle along the lower margin of the jaw is least; in this particular again the Phascolothere rcsembles the Thylacine." 2 The Plagiaulax repeats this characteristic of the most carnivorous members of its order, but with still less degree of curvature.

One othcr proposition seems of sufficient weight, in relation to the scientific standing of the Objectors to my conclusions as to the habits and affinities of Plagiaulax, to call for notice; although its very suggestion betrays a sense of the insecurity of the grounds on which the herbivorous and saltatory nature of Plagiaulax has been contended for.

The species of this genus are affirmed to have been animals too small, too feeble, to have preyed upon others, especially when much larger than themselves.

Whoever has witnessed the well-known zoological phenomenon of the pertinaceous pursuit and fatal attack of a IIare by the diminutive Weasel would pause, howevcr, before venturing on such ground.

Dr. Falconkr, ${ }^{3}$ selecting for his example the most diminutive of the species of Plagiaulax, remarks:- "The entire length of the specimen, including the six molars and premolars, together with the procumbent incisor (according to the metrical line $e$ ), does not exceed 4 of an inch, of which the six clicek-teeth united make only about two and

1 'Geological Transactions,' 2nd series, vol. vi, p. 50; 'Zoological Transactions,' vol. ii, p. 392 ; 'Cyclopædia of Anatomy,' Art. MLarsupialia, vol. iii, p. 275.

2 'Hist. of British Fossil Mammals,' 8vo, 1810, p. 65.

3 Falconer, opera cit., pp. 363 and 448. 
a laif lines ( 25 inch). I ask any zoologist or comparative anatomist to look at it, and say whether the dental apparatus of this extremely miunte creature is competent to perform the duties required of a predaceous carnivore.

"Magnitude in this case is an important ingredient, as it necessarily involves mensure of force. Could P. minor have preyed on small Mammals and Lizards? Is it not more probable that this pigmy form was itself an object of prey in the Purbeck Famma?" 1

'I'o this I reply that the original, now before me, of "fig. 15, Plagiaulax minor, of the 'Quirterly Jominal of the Geological Socicty of London' for August, 1557 (vol. xiii, p. 251)," reproduced in the subsequent polemieal paper of Dr. F ' LCover, in 'Quarterly Journal,' \&c., for June, 1862 (vol. xviii, p. 367), and copjed in pl. 34, fig. 2, of the Postlumous Work 'Palæontological Menoirs' (1.416), shows two molars and four premolars; the incisor is neither ehisel-shaper nor procumbent; but rises with a slight curve to its FIG. 21. pointed apex at an angle of $120^{\circ}$ with the line of the molar alveoli (fig. 21 ). The length of the dental series from the apex of the laniariform incisor to Mandible and teeth, the hind part of the sccond molar is seven sixtcenths of an inch, precisely the nat. size, Plagiau- length of the dental series in Urolrichus lalpoïdes-a transitional Shrew five
la.x minor.

inches long, from the snout to the tip of the tail, with a skull one inch in length, and a pair of lower pointed incisors (fig. 17) upcurved at the same angle as in Pl. minor, but relatively less and shorter (fig. 22, A).

I an not cognizant of any grounds afforded by Zoology which forbid the supposition that a Mammal of five inches in length, with the carnivorous type of dentition of Plagiaulax, may have been able to capture and kill the diminutive species of Lizard (Saurillus, ${ }^{2} \&$ \&.) abundantly associated with Plagionlax in the Purbeck shales. Comparntive anatony suggests that the modifications of the dentition of Plagianlax minor, as compared with the similarly sized Shrew (Uro/richus), would give the Purbeck Marsupial both the disposition and power to attack and prey upon animals of a larger size and higher organization than worms and insects. But the question of the carnivority of the genus Plagiaular, if weighed by 'magnitude as a measure of force,' is not fully or fairly tested by the exclusive example of the most diminntive species.

In Plagiaulax Falconeri (PI. IV, fig. 16) the extent of the dental scries, lower jaw, is nine sixteenths of an inch: in Plagiaulax Beclilesii (ib., figs. 10, 1], 12, and fig. 8, p. 86), it is ten sixteenths of an inch.

'The entire lengtl of the mandible in this species, inclusive of the incisor, in a straight line, is one incli three sixteenths; the depth of the ramus at the back part of the large carluassial is five sixtecnths of an inch.

In the Wensel (Mustela vulgaris, fig. 22, c) the extent of the dental series, lower jaw, is cight sirteenths of an inch; the entire lengtl of the mandible, inclusive of the

1 Falcoser, op. cit. Ib., p. 363 ; ib., p. 448.

2 OWEx, 'Quarterly Journal of the Geological Socicty,' No. 40, 1854, p. 420. 
incisors (fig. 20, D, p. 178) is $\frac{13}{16}$ ths of an inch; the depth of the ramus is $\frac{2}{16}$ ths of an incl. In an opossum (Didelplys murina, ib. $c$ ) the extent of the mandibular dentition is $\frac{10}{16}$ ths of an inch. The application of these proportions to the question of the food and habits of the small British oolitic paucidentate Marsupial and of the great Australian pleistocene analogue will be carried ont at the conclusion of my illustrations of that strange extinct marsupial Carnivore originally designated by the name of 'Pouched Lion' (Thylacoleo).

With these indications of the marsupial Mammals which formerly existed in lands now contributing to the soil of Britain, I close the Prefatory Chapter and proceed to the proper subject of the work, namely, the 'Fossil Mammals of Australia.'

\section{Order MARSUPIALIA.}

\section{Suborder POL yProtodon'tia.}

\section{Genus Sarcophitus.}

Species Sarcophilus (Dasyurus) ursinus, Harris. ${ }^{1}$

I HAVE received portions of the cranium and of both upper and lower jaws, with teeth, of this species from the 'Breccia Cavern,' Wellington Valley (Plate XIII. fig. 2; Plate XV. fig. 2: Cut, fig. 20, p. 103, $\frac{2}{3}$ rds nat. sizc). Some arc identical in size with the corresponding parts of the cxisting spccics therewith compared: two fossils of the lower jaw are rather larger; but the teeth in them wcre of the same size as in the recent animal.

At the present day the Ursine Dasyure exists in Tasmania. No living spccimen has yet bcen discovered in Australia.

\section{Specics Sarcoplitus (Dasyurus) laniarius, Ow.}

This larger specics, first determined from remains brought by the discoverer of the Wellington Valley and its caves, ${ }^{2}$ is representcd by several spccimens exhumed in the 'Statc Exploration' of those caves; ${ }^{3}$ such fossils wcre nore numerous than those of the smaller Ursine species. From the examples of Sarcophilus laniarius are selected the subjects of figs. 1-6, Plate V. Besides the diffcrence in size, the following modifications of structure are noticeable. The larger and deeper digital pit, $a$, fig. 1, on the inner or

1 'Trans. of the Linnean Society,' 4to, rol. ix. pl. xix. 7.

"Major (afterwards Sir Thомаs) Mrtcheli, "Three Expeditions into the Interior of Eastem Australia, Sro, 1338, vol. ii. p. 363, pl. 31. figs. 3-5.

${ }^{3}$ See p. 239. 
palatal side of the penultimate upper molar; the better and broader ossification of the medial border, ib. $b$, of the palatal vacuity (comp. fig. 2, Plate XIV.). In the under jaw the relatively broader and deeper symphysis, Plate $V$. figs. 5 and $6, s$; the wider interval between the two predental foranina, $d d^{\prime}$, fig. 6, and the more backward position of the hinder one, fig. $7, c$, bencath the fore part of the antepenultimate molar (comp). fig.r. 20, p. 103).

Genus 'Thy lacines, 'Temminck.

Thylacinus cynocephalus, liarris.

Of this species the eave-fossils yicld specimens not differing in size and structure from the corresponding parts of the existing species (Plate XII. fig. 2; Plate XIII. fig. 3; Plate XV. fig. 3 ; Cuts, fig. 5, p. 74).

\section{Thiylacinus major, Ow.}

In the Palæontological Appendix to Mircnele's work I noticed (p. 363) and figured (plate 31. fig. 7) the "anterior part of the right ramus of the lower jaw," and remarked, "the position of the tectl in the specimen (xi. $c$, fig. 7 ), which are wider apart, leads me to doubt whether it is the lower jaw of Das. laniarius, or of some extinet marsupial Carnivore of an allied but distinet species."

At the date (1 \$36) of this note no skull or skeleton of the large carnivorous 'Tasmanian Marsupial, described and called Didelphis cynocephala by Mr. Harmss, ${ }^{1}$ had come under my obscrvation. I have since ${ }^{2}$ had the mcans of determining the identity of certain carc-fossils with IIArRis's spccies, and to recognize the subject of "plate 3l. fig. 7," ahove-cited, and other fossils since reccived, from Mitcnelu's Breccia Cavcrn, as having helonged to a larger species of Thylacinus, now seemingly extinct both in Australia and 'lismania.

The jaws of the 'Thylacine are relatively longer than in the Sareophile, the type number of teeth are present; and the anterior ones, $d 1, d 2, d 3$, are separated by intervals, not in contact as in the Sarcophile. 'T'he crown is more compressed and pointed in the 'l'hylacine.

In 'Thylucinus major the upper canine (Plate V. figs. 7, 7') is proportionately larger in comparison with the lowcr onc than it is in I'hylacinus cynoceplaalus : the other osseous and dental characters, so far as they are at present represented by fossils, indicate chiefly a supcriority of size as compared with the still existing Tasmanian species.

The former presence of both marsupial carnivorous genera in Australia excmplifies

${ }^{1}$ Tom. cit.

2 'Cyclopxdia of Anatomy' Art. Marsupialia, rol. iii. (1841), p 258, fig. 80. 
the light thrown by Palæontology upon ancient geography. The inference, at least, is legitimate that, with the northern extension of geographical range of the genera Thylacinus and Sarcoplitus, there coexisted a corresponding continuation of dry land, uniting the now distinct island of Tasmania with the Australian continent. The ancient representation of these genera by larger and more formidable species agrees with the co-existence, to be demonstrated in the course of the prescut work, of larger herbivorous Marsupials than now exist in either Australia or Tasmania.

\section{PLATE V.}

Fig. 1. Palatal surface of fore part of the skull of Dasyurus laniarius.

Fig. 2. Onter side view of the prcmaxillary and part of the maxillary of do: 2'. 'Transverse section of the canine.

Fig. 3. Outer side vicw of part of the maxillary of do.

Fig. 4. Outer side view of mandible and tceth of do.

Fig. 5. Inner surface of symphysis mandibulæ and teeth of do.

Fig. 6. Outer surface of the same fossil.

Fig. 7. Crown of upper canine of Thylacinus major: $7^{\prime}$. Transverse section of do.

Fig. 8. Outer side view of hind part of mandible and teeth of Thylacinus major.

Fig. 9. Outer side view of forc part of mandible and teeth of Thylacinus major.

Fig. 10. Inner side view of part of the mandible and tceth of Dasyurns mordax.

Fig. 11. Outer side view of part of mandible and tceth of Perameles tenuirostris.

Fig. 12. Outer side view of fore part of mandiblc of Phalangista sicca.

Fig. 13. Portion of right maxilla and teeth of Hypsiprymmus spelaus.

Fig. 14. Outer side vicw of mandible and tecth of Hypsiprymnus speiceus.

Fig. 15. Outcr side view of mandible and teeth of Bettongia cuneata.

\section{Suborder DIPRO'TODONTIA.}

\section{Section SARCOPIIAGA.}

Genus Thirlacoleo, Ow.

Species Thylacoleo carnifex, Ow.

The first indication of this genus and specics was the largc, two-fanged sectorial tooth, the subject of figs. 10 and 11, plate 32 of Mitchell's work above cited. I could not, at that date, determine the affinities of the Australian mammal yielding such a tooth; and for somc years it was open to any palæontologist to offer an intcrpretation 
of the speeimen, which was deposited, with the rest of MLtcnent's cave-fossils, in the Museum of the Gcological Society of London.'

I subsequently received the fragment of lower jaw (Plate VI. fig. 12), in whieh I recognized the homologne of the problematieal eave-fossil in situ, followed by a small tubereular tooth and the débris of a seeond still smaller one, which seemed to terminate the mandibular series of teetlı. 'The speeimen was from the bed of a tributary of the Condamine. Here secmed to be, from this recent drift-deposit in Australia, the eorrelative, on a gigantic seale, of the diminutive mesozoic British fossil, figured in Cnt 6, p. 77. In Potoroos (Plate V. figs. 14, 15, and Cuts, figs. 13 \& 14, 1. 92) the molars sueceeding the sectorial tooth are many, are tubercular, and relatively larger than in Thylacoleo and Plagiaulax.

With the mandibular drift-fossil was assoeiated the maxillary fragments (Plate VI. figs, 9,10$)$ containing the sectorial molar, the left of which I inferred to have opposed the lower homotype (fig. 1:) ; for in that tooth the smooth surface due to attrition sloped from above downward and ontward; in the upper scetorial the similar but nore cxtensive worn surfaee sloped from its edge upward and inwarl. It was plain that these teeth had played upon each other like shear-blades. The resemblance to the sectorial or 'earnassial' teeth of the plaeental Carnivora was patent and strong. It was further earried out by the presence of one small upper tubereular tooth (figs. $9 \&$ $10, m$ l) following the great sectorial blade--not set, however, directly behind it, but, as in Felines (figs. 4, 7, 5), on the inner side of the hinder end, with the long axis of the crown at right angles with that of the great sectorial. Here seemed to be an indieation of a placental exeeption to the grade of mammalian life elaracteristic of the indigenous Australian quadrupeds.

Of the right maxillary and scetorial, fig. 1, Plate VI. gives the outer side vicw, showing the long and strong, deeply implanted anterior root, $a$, and the base of the more longitudinally extended hinder root, $b$ - the first supporting the fore part of the crown, which is convex externally, the second the larger proportion of the erown, whieh is longitudinally coneave externally, all this outer part of the crown being covered by a plate of enamel. The outlet of the suborbital canal $(c)$, and part of the suture between the maxillary and malar $(d)$ descending from the lower border of the orbit, are shown in this fragment, and seemed to support the 'plaecntal' affinity. A similar view of a corresponding part of the right maxilla of a IIy ana spelcea is given in fig. 2. In this cxtinct placental Carnivore the outlet of the suborbital canal is shown at $c$, and the malomaxillary suture at $d$. In the sectorial tooth the anterior root $(a)$ is long, thick, deeply implanted, and descends from its apex to the erown of the tooth with a slight inclination baekward, as in fig. 1. The part of the erown which it supports is convex ontwardly. The division of the longer hinder part of the erown, supported by the broad lamelliform root $(b)$, into three parts by the two vertical grooves $(e, f)$ is more definitely marked;

\footnotetext{
1 'Proceedings of the Geological Society of London' for April 1831.
} 
yct, though faintly shown, they may be recognized at $e$ and $f$ in fig. 1 . In the great extinct Cave Lion of Europe ('Felis spelcea, fig. 3, betwecn 1 \& 2, Plate VI.), the sectorial, with a similar divergence of the two roots for firmer implantation of the tooth, shows less excess of size of the hinder root; the crown is more definitcly divided than in the Hycna into three lobes; and part of the middle and more prominent one, as well as the anterior lobe, is supported by the long, thick though smaller anterior root. But the inncr enlargement ( $t$, fig. 4 ) of the fore lobe more resembles that marked $t$ in fig. 3 (of the second row) in being a tubercle, than it is in the Hycona (fig. $5, t$ ); and, so far, figs. $3 \& 4$ indicate a more strictly flesh-feeding animal than fig. 5 . The close correspondence, however, of the line or direction of wear, the polished smoothness interrupted by a few distant vertical linear risings in figs. $3 \& 5$, indicated a similarity of the substances to be operated upon and identity in the mode of mastication, exercised by the Hycena and the great Australian Carnivore.

The vertically worn surface in Felis (fig. 4) is less even or continuous, being interrupted by angular projections, the chief of which ( $y$, fig. 4 ) answers to the less developed one ( $g$, fig. 5), which has no corresponding one in fig. 3. The tubercle $(t)$ in Iycena, however, distinguishes it more essentially from the Australian fossil (fig. 3); while the feeble rudiment of that enlargement in the genus Machairodus (figs. 7, $8, t$ ) makes this extinct European Feline approach nearest in carnassiality to the Thylacoleo. The demonstration, in short, of the carnivorous character of the Queensland fossils, and consequently of the problematical Cave-fossils, was so plain and complete at the close of the comparisons, of which the most essential are illustrated in Pl. VI., that the only doubt engendered was as to whether the Australian carnassial and tubercular teeth belonged to a marsupial or to a placental extinct form of Carnivore. But the dcgree in which the subjects of figs. 1, 9, 10, 12 exceed in the size and carnassiality of the sectorial tooth, justified the inference of the more ferocions and flesh-fceding habits of the Australian Carnivore.

\section{DESCRIPTION OF' 'THE PLATE.}

\section{PLA'TE VI.}

Fig. 1. Outer side view of a portion of a right superior maxillary bone, with the sectorial molar tooth of Thylacoleo carnifex, Ow.

Fig. 2. Outer side view of the corresponding part and tooth of the great extinct Hycana (Iy)cena spelaa, Goldfuss).

Fig. 3 (upper row). Outer side view of the upper sectorial molar, in a fragment of the superior maxillary bone of the great extinct British Lion (Felis spelca, Goldfuss).

Fig. 6 (3 bis, second row). Inner side view of the sectorial and tubercular molars of fig. 1 (Thylacoleo carnifex). 
Fig. 4. Inner side vicw of the scctorial and tubercular molars of fig. 3 (npper row) (Felis spelac $u$ ).

Fig. 5. Inncr side view of the scetorial and tubcrcular molars of fig. 2 (Iyscna spelce ).

Fig. 7. Inner side view of the left upper sectorial and tubcreular molars of the Sabretoothed Lion (Machairodus (Felis) cultridens, Cuv.).

Fig. S. Working surface of the same teeth.

Fig. 9. Working surface of the left upper scetorial and tubercular molars of Thylacoleo carnifex.

Fig. 10. Inncr side vicw of the same tectl.

Fig. 11. Onter side view of the left lower sectorial molar of the extinct British Lion (Felis spelaa).

Fig. 12 Outer side view of the left lower sectorial and tubcrenlar tectli of the 7hyyacoleo carnifex.

Description of a mutilated Skula of Thylacolco carmifex, and Comparisox of it with tilat in Placental and Marsupial Carnivora.

This fossil was discovered by IV. Adexer, Esq., in the bed of a lake, 80 miles southwest of Melbournc. Thic lake is shallow and becomes almost dry in autumı; its bed is then covered with a deposit of common salt of cxccllent quality. The wholc of this part of the country is volcanic: a contiguous decper salt lake appears to have becn the cratcr of an cxtinct volcano.

The fossil is the cramial part of the skull (Plates XI. XIII. XIV. and XV. fig. 1), similar in size and in the development of the temporal ridges and fossæ to that of a Lion. It included the large sectorial tooth implanted, witl a small tubercular tooth, in a portion of the right superior maxillary bone, including part of the orbit and lacrymal bone (Plate XI. fig. 1, $p$ 4, and fig. 2). These tceth werc the homologucs of the snbjects of Plate VI. figs: 1, 3, 9, 10; and the small proportion which the brain-case or cranial cavity (Plate X.) bore to the rest of the skull, with the extcrnal position of thc lacrymal

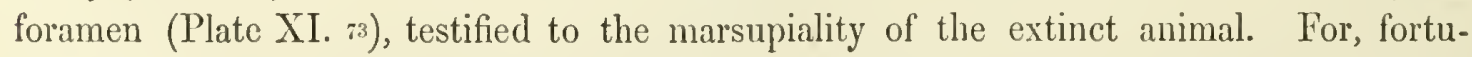
natcly, the nasal process of thic maxillary in thic dctached facial portion of the skull of this Thylacolco fitted a surface at the forc part of the cranium in such a way as to demonstrate that it formed part of the same skull, completing the lower lialf of the orbit (Plate XI. fig. $1, o^{\prime}$ ), of which the upper half $(o)$ remains in the cranial portion of the skull.

The value of this additional evidence of Thylacoleo, besides thc demonstration it afforded of the true affinities of the genus, consisted in thc confirmation it added of characters previously deduced from fragmentary specimens, and of the constancy of such characters. 
The upper sectorial tooth of the fossil (Plate XI. figs. 1 and $2, p_{4}$ ) is larger than that of the largest Lion or Tiger which I have seen, and than that of the great extinct Lion (Felis spelcae, Plate XIV. fig. 4, $p_{4}$ ). Its antero-posterior extent is 2 inches 3 lines, that in Felis spelcea being 1 inch 7 lines. The greatest diameter of the upper tubercular tooth (Plate XI. fig. 2, $b$ ), which is at right angles to that of the sectorial one, is $7 \frac{1}{2}$ lines, that of the Lion (Plate XIV. fig. $4, m_{1}$ ) averaging 6 lines.

The upper sectorial tooth of the Felines is divided into a 'blade' and 'tubercle, the latter being developed from the inner side of the base of the fore-part of the crown, and being supported by a fang which makes an extension of the socket inwards at right angles to the rest of the socket. A portion of the fossil tooth has been broken away at this part (Plate XI. fig. 2, $p_{4}$ ), but apparently little more than the enamel; and the socket certainly shows no inward extension indicative of a 'tubercle' so large and distinct as in the Felines (Plate XIV. fig. $4, p_{4}$ ): the crown of the sectorial in Thylacoleo is thicker here than in the rest of its extent, and has been slightly convex on the inside as on the outside of this part of the tooth; but there appears to have been no distinct lobe or tubercle, and I conclude that the crown of the upper great sectorial in the Thylacoleo consists exclusively of the 'blade.' The trenchant edge of this is not notched as in the Felines where it is trilobate (Plate XII. fig. 1, $p_{s}$ ), but is even and uniform, describing a very feeble concarity lengthwise (Plate XI. fig. 1, $p_{4}$ ). In the specimen it has been worn to a sharp edge by the play of the blade of a similar sectorial obliquely upon its inner side. The outer side of the crown is convex vertically, wary lengthwise, being in this direction gently concave at the mid-part, convex at each end, with minor undulations of the surface near the base. The imner side of the crown is gently concave vertically at its mid-part, slightly undulated, but mainly convex lengthwise. The anterior border of the crown is formed by a subdentate ridge, sloping with a slight convexity downward and backward, in vertical extent 1 inch: the crown gradually decreases in this diameter to its back part, which ends in the form of a low protuberance. The tooth is strongly inplanted by, apparently, an undivided base coextensive with the crown. I have not thought fit to mutilate the unique fossil to determine the depth and precise character of this implautation. The thickest part of the tooth is 8 lines.

The tooth which most nearly corresponds with the sectorial of Thylacoleo is the penultimate upper molar of Sarcophilus (Dasyurus) ursimus (Plate XIV. fig. 2). In this tooth the 'blade' forms the chief part of the crown; it is concave externally, convex internally lengthwise; its edge is entire, slightly concave; but it is associated with an anterior lobe and antero-internal tubercle, wanting in the fossil.

The tubercular tooth (ib. fig. 1, $m$, Plate XI. fig. 2,b) in Thylacoleo is on the inner side of, and at right angles with the sectorial tooth, but is almost half an inch in advance of the hind end of that tooth: in Felis (Plate XIV. fig. $4, m$ ) it is close to that end. In Thylacoleo this tooth consists of a principal portion next the sectorial, and a small lobe (Plate XI. fig. 2,b) forming the inner or 'mesial' end of the crown: the principal part 
rises to a low obtuse point, with a middle longitudinal depression between two conrexities, on the outside: the inside slopes forward gradually to the base so as to represent, and act as, a crushing surface. Besides being relatively larger, this 'tubercular' tooth is more deeply and firmly implanted than in the Lion, whence is due its preservation in the present fossil, a circumstance which is rery rare in Felis speloce. In no Feline does this tootl present the accessory lobe, as in Thylacoleo. In the presence of this lobe at the inner end of the crown, the last small molar in Srarcophilus presents a closer resemblance to the same tooth in Thylacoleo; but the principal lobe is more pointed and trenchant in the small existing marsupial carnivore; and the whole tooth is so situated that its outer end is visible in a side view. 'The firm implantation of the last small molar, and its shape, are significant of the affinity of Thylacoleo to Sarcophilus.

In the Felines the outer wall of the maxillary above the socket of the sectorial tootl is perforater by the large antorbital foramen: it is not so perforated in Thylncoleo. 'The canal for the suborbital nerve and ressels is relatively smaller in Thylacoleo (Plate XI. fig. 2,c), and must open some way in advance of the socket of the penultimate tooth, as it does in Sarcophilus. From that socket to the orbit the outer surface of the maxillary is smootli and even, first gently concave, then as gently convex: it does not show the zygomatic protuberance which intervenes in Sarcophilus. The vertical extent of this part of the maxillary is 2 inches, being nearly the same as in the Lion. 'The border of the orbit is sharper and more produced, especially at the lower and fore part (ib. fig. $\left.1, o^{\prime}\right)$. than in the Lion.

Sufficient of the palatal part of the maxillary is preserved in this fragment to afford a very significant character of the nature and affinities of the Thylacoleo. In most Marsupialia. and in all the carnivorous species, the bony palate is interrupted by large vacuities opposite the antepenultimate and penultimate molars. In all placental Carnivorr the hony palate is here entire; it shows, at least, only a small oblique nervo-rascular foramen at the suture between the palatine and maxillary; and the roof of the mouth is extenderl by bone some way behind the last molar tooth. In the present specimen of the Thylaroleo is preserved the smooth rounded outer border (Plate XI. fig. 2, and Plate XIV. fig. 1,d) of a large palatal vacuity opposite the hinder half of the penultimate tooth, and at a distance of 14 lines from it transversely. Such a vacuity extends opposite the penultimate and antepenultimate molar in Sarcophilus (Plate XIV. fig. 2).

I now proceed with the description of the larger, cranial, portion of the present fossil, before returning to another character in the smaller portion which I regard as decisive of its niarsupial affinities. 'The cranial part of the skull shows a broad and low occipital surface (Plate XV. fig. 1); the sides (Plate XI. fig. 1) excavated by large temporal fossæ $\left({ }^{2} \tau^{\prime}\right)$, with their ridges meeting at a low and short parictal crest (Plate XVI. $t^{\prime}$ ); the upper surface expanding, in front of this, to a very broad, almost flat interorbital region, 11. The post-orbital processes. 12, with the zygomatic arches, 27, and part of the basis cranii, are broken away. The extreme lengtl of this portion of skull is 8 inches; the least breadth of the cranium, at the temporal fosse, is 2 inches 2 lines. 
The upper border of the occipital foramen (Plate XV. fig. 1) is as broad as in the Felis spelcea, and broader than in most of the existing species of Lion or 'Tiger'; it does not present the pair of processes that characterize it in those large placental Carnivora. As the occiput rises from this border it slopes forward with a slight concave curve to the ridge, ${ }_{3,8}$ (Plate XIII. figs. 1, 3, 8), dividing the occipital from the upper plane of the skull: transversely the occiput is concave in the middle and slightly convex on each side, with a surface marked by musculo-tendinous insertions; the median depression is partly bisected by a vertical ridge (Plate XV. fig. $1, f$ ), on each side of which there is a venous foramen. The breadth of the occiput on the level of the upper border of the foramen magnum is 5 inches; its height from the same border 2 inches 2 lines. In Felis spelce the breadth of this part is 3 inches 4 lines; its height being 2 inches 8 lines. The Sarcophilus (Plate XV. fig. 2) much more nearly resembles the Thylacoleo in its low and broad occiput.

The major part of the basioccipital is broken away (Plate XIV. fig. 1); the anterior portion, which has coalesced with the basisphenoid (ib.5), forms with it, not a platform extending horizontally forward, as in placental Carnivora, but a bent surface forming a curve convex downward as it extends forward; this character is seen in the Iasyurus macrurns and in many Kangaroos; but the convexity at the junction of the basioccipital and basisphenoid, 5 , appears to have been greater in the Thylacoleo. The base of the left occipital condyle, 2, remains; and in the fossa anterior to it, are the orifices of three precondyloid foramina $(g)$, as in the majority of Marsupialia, including the Dasyari; they unite to form a single hole internally in the Thylacoleo. In the placental Carnivore the precondyloid canal is single at both ends, and commonly opens externally into the jugular foramen (Viverrida, Hyana, Felis), or close to it, as in the Dog.

The jugular foramen $(i)$ is bounded behind by a notch in the exoccipital, forming the margin turned towards the tympanic, 28, and which margin is extended further in advance of the precondyloid foramina than in the Dog or any placental Carnivore in which those foramina do not communicate with the jugulars; in this respect the Drsyuri and many other marsupials resemble the Thylacoleo.

The bones composing the complex framework of the organ of hearing are strikingly different in the placental and marsupial Carnivora. In the Cat, Dog, Hyæna, Civet, Otter, Bear, the tympanic bulla is formed by the inflated petrosal with which the true tympanic bone has coalesced; in the marsupials the petrosal remains comparatively small, and is confined chiefly, if not wholly, to the function of a capsule of the internal organ of hearing; the tympanic bulla is excavated in the inflated base of the alisphenoid; and the tympanic bone itself continues a free and distinct ossicle, which, in the Dasyures and Thylacine, is a small thick semicylindrical canal with smooth obtuse margins, and its concavity looking backward and upward.

On the right side of the fractured base of the fossil skull in question, the small compact petrosal (Plate XIV. fig. 1, 16 ) is exposed; it is similar to that in the Lasyurus. being grooved longitudinally at its inner and under side, the lower border of the groove forming a sharp edge, above which, on the inner side of the petrosal, the foramina 
anditoria interna pierce the bone. On both sides the tympanic sinuses in the alisphenoid, 6, are exposed; and their concordance with those in the Dasyuri is very clearly exemplified on the left side, in which the tympanic bone, ${ }_{28}$, is preserved, showing its characteristic shape and relative position behind and external to the alisphenoid bulla, 6 .

The canal of the meatus ( $k$ ) external to the tympanic, is excavated in the outwardly prodnced base of the zygoma, behind the postglenoid process $(l)$, for an extent resembling that in the Dasyuri, but much greater than in the Dog or other placental Carmivora.

Another character distinctive of the marsupial order is the position of the entocarotid canal $(m)$, which perforates the outer and back part of the basisphenoid, ${ }_{5} *$ : this orifice is lodged in a fossa between the basioccipito-sphenoid and the bulla auditoria in Thylacims and Dasyurus (ib. fig. $2, m$ ), and it presents exactly the same position, and perforates the same part of the basisphenoid, in Thylacoleo.

In the genus Felis the entocarotid enters the base of the skull at the fore-part of the foramen jugulare, notching the part of the petro-tympanic bulla at the fore-part of that foramen. In the Hyæna, as in the Viverrines, the entocarotid notches or perforates the tympanic bulla in advance of the jugular foramen close to the side of the basioccipital: it perforates the same part of the tympanic bulla in the Otter and other Mustelines.

The foramen ovale pierces the base of the alisphenoid immediately anterior to the bulla in the marsupial Carnirora, and is divided by a ridge from the carotid canal in the Dasyuri; it presents the same relations in Thylacoleo (Plate XIV. fig. 1,n), and the base of the ridge (ib. $s$ ) also remains to show the existence of that character.

The interval between the foramen orale (Plate XI. fig. 1, $n$ ) and foramen rotundum (ib. $p$ ) is relatively much greater in the marsupial than in the placental Carnivora. In the genus Felis, they are separated from each other only by the base of the ridge or rising of bone extending from the ectopterygoirl towards the glenoid cavity, and the foramen is on the same transverse line with the anterior boundary of that articulation; in the Hyæna, Vivernines, and Dog, it is a little in advance of the same boundary; in the Otter it opens externally into a fossa common to it with the foramen lacerum anterius (or for. ophthalmicum). In the Thylacine and Dasyures the foramen rotundum is distinct both within and without the cranial carity from the foramen lacerum anterius, and is far in advance of the glenoid carity. It presents the same relative position in the Thylacoleo (Plate XI. fig. 1, p).

In Felis the foramen rotundum is larger than the foramen opticum; in Dasyurus it is much smaller; and this is the case also with the Thylacoleo (Plate XI. fig. 1), although the foramen opticum $(q)$ is relatively smaller than in the Dasyurus ursinus.

* "The carotid canals pierce the body of the sphenoid, as in Birds, and terminate in the skull rery close together behind the sella turcica." - Zoological Transactions, vol. ii. (October, 1838), p. 390. See also Mr. Turver's careful and minute account of the "Foramiua at the Base of the Skull" in Zoological Proceedings, May, 1818, p. 64. 
In the marsupial Carnivora the basisphenoid is relatively longer than in the placental Carnivora, and, at its posterior part, it sends a ridge downwards from that part of each lateral margin which is not underlapped or covered by the base of the alisphenoid, the suture of which long continues distinct. These ridges, with the alisphenoid, render the whole under surface of the basisphenoid canaliculate, or concave transversely: the basisphenoid is flat beneath in the placental Carnivora, and that part of the base of the skull is made canaliculate by the development of the ectopterygoid plate from the alisphenoid: these plates exist likewise in the marsupials, but, as they extend backwards to join the alisphenoidal bullæ, they diverge from the basisphenoid ridges and are external to them.

Sufficient of the base of our fossil skull remains to demonstrate this characteristic marsupial structure: the basisphenoid, though convex lengthwise beneath, is concave transrersely by the production from the lateral margins of its hinder part of the same ridges $(r, r)$ as those of the Thylacine and Dasyures, and in the degree of concavity more resembles the latter: the commencement of the outer ectopterygoid ridge $(s)$ of the alisphenoid is preserved, diverging as it extends backwards from its anterior junction with the basisphenoid ridge.

The sutures between the alisphenoids and basisphenoid still remain, indicating the great antero-posterior extent of the former, and the degree to which they underlap the basisphenoid, learing only a strip $2 \frac{1}{2}$ lines broad exposed at its junction with the presphenoid, 9 ; and gradually diverging as they extend backward, the basisphenoid, 5 , being one inch and a half in breadth at their hinder borders.

The characters of the base of the cranium here displayed by the Thylacoleo, and the greater retention of the typical elementary construction of the skull, would be sought for in vain in any mammalian Carnicora, save those of the marsupial order.

In the placental Carnivora, the superoccipital region, defined below by a boundary line drawn across the upper ends of the condyles, is almost as high as it is broad, and in rising from the foramen magnum it curres slightly backward. In the marsupial Carnivora the same region so defined is much broader than it is high, especially in the Dasyures (Plate XV. fig. 2); in these the occiput is rertical; it inclines a little forward from the foramen magnum in the Thylacine. All these characters are repeated in the Thylacoleo; the occiput being relatively as broad as in Sarcoplitus, and the superoccipital sloping more forwards than in the Thylacine before it rises rertically to the occipital crest; thus departing in a greater degree from the placental type, and manifesting, as might be expected from the superior general size of the skull, in a more marked manner, the inferiority of development of the brain. In every natural group or family of the warm-blooded Vertebrata the brain is proportionally less as the animal is larger, and its osseous case makes a smaller part of the entire skull.

In the marsupial Carnivora the brain is relatively much smaller than in the placental Carnivora, and the lateral walls of the cranial cavity make a smaller protuberance or convexity at the temporal fossæ. In the remarkable skull under comparison, the sides of the cranial cavity make no protuberance whatever into the temporal fossæ ; they have 
been moulded solely in obedience to the pressure of the enormous temporal muscles, and present a uniform concavity towards the temporal fossc. 'The cranial walls here (Plate XIII. fig. 1, $2 z^{\prime}$ ) show as little indication of the brain within as in a cold-blooded reptile: amongst the mammalian Carnivora the Thylacoleo is unique in this respect; and in the diminutive relative size of its cerebral organ, it is approached only by the Thylacine and the largest existing species of Dasyure.

In the Das. ursimus the apparent breadth of the cranial chamber is here greater than it actually is, by reason of the swelling out of the squamosal abore the root of the yggoma through the extension therein of tympanic air-cells; and similar air-cells are exposed on the right side of the fossil Thylacoleo (Plate XI. fig. 1,c); but I know of no species of placental Carnivore in which the squamosal is so modified.

Another equally instructive marsupial character is exhibited by the bony outlet of a vein (ib.s), which conducts part of the blood from the lateral sinus to the outer and back part of the cranium: this venous foramen is situated behind the root of the zygoma and above the meatus auditorius in the 'llyylacine (Plate XII. fig. 2, s) and Dasyures. A similar diverticular vein is present in certain placental Carnivora, and has its external outlet behind the glenoid cavity and in front of the meatus auditorius, as $e . g$. in the Dog and Otter; there is a small venous outlet on the outside of the tympanic bulla in the Cat and Hyæna; but in no placental Carnivore is such a renous foramen present behind, or piercing the ridge continued backward from the root of, the rygoma.

In the Thylacoleo this renous foramen $(s)$ is present in nearly the same relative position as in the marsupial Carnirore, posterior, viz., to the commencement of the ridge or hind root of the zygoma; in the Dasyure it is below the upper margin of the ridge; in the 'Thylacine it is posterior to the beginning of the ridge; in the Thylacoleo it is posterior and superior to the beginning of the ridge. Thus in the same degree in which the Thylacoleo departs in this particular from the largest existing marsupial Carnivora, it differs from the placental Camivora, in all of which the foramen, besides its other differences of position, is quite below the zygomatic ridge in question.

The interorbital part of the upper surface of the cranium (Plate XIII. fig. 1, 11) is remarkable in the marsupial Camiror' for its great breadth, especially as compared with that of the cerebral portion of the cranium; the transverse diameter of this part at the middle and highest part of the upper border of the squamosals is, in the Dasyurus msimus, less than half the same diameter of the narrowest part of the interorbital portion of the cranium. In the Tiger, Lion, and Felis spelcea the diameter of the interorbital space is one-serenth less than that of the cranium of the Thylacoleo, taken across the same part as in the Dasyurus. In the Thylacoleo the least diameter of the interorbital surface is 2 inches 10 lines; the diameter of the cranium opposite the middle of the upper border of the squamosals, ${ }_{27}$, is 1 inch 3 lines.

The broad interorbital platform of the Thylacoleo, with a broad and shallow depression, and two slight lateral convexities at its anterior half, passing posteriorly into an almost flattened surface, decreasing to the point where the temporal ridges $\left(t^{\prime}\right)$ meet above the 
parietal, forms, in contrast with the contracted cerebral part of the cranium, a conspicuous marsupial character of the skull.

In the Thylacoleo the squamosal (Plate XI. fig. 1, ${ }_{27}$ ) extends forward in the temporal fossa nearly half-way between the root of the zygoma and the postorbital process, and two-thirds of the way upward, 27 , between the root of the zygoma and the parietal ridge; its contour is almost semicircular. In the Felines the squamosal extends a very little way, if at all, in advance of the base of the zygoma, and does not ascend half-way from that part to the parietal ridge (Plate XII. fig. 1, ${ }_{27}{ }^{\prime}$ ). It is only in the marsupial Carnivora that we find those proportions of the squamosal which characterize the Thylacoleo.

On the inner wall of the right orbit the fronto-lacrymal suture shows that the lacrymal bone, $z_{3}$, was of large size, that it formed the anterior half of that wall, and extended upon the upper part of the skull, forming apparently the anterior superorbital protuberance, besides extending forward upon the facial part of the skull, as far as that part anterior to the orbit has been preserved in the fossil. The lacrymal bone presents the same relative dimensions and extent in the largest existing Dasyurus (D. ursimus). in which the lacrymal duct pierces, not the orbital, but the facial, plate of the lacrymal bone, and is consequently outside the orbit.

In the Lion, the Felis spelce (Plate XII. fig. 1), and other placental Carnivora in which the lacrymal bone is best dereloped, it is almost confined to the orbit, its most forward portion forming about the middle third of the anterior margin of the orbit, where it developes a slight protuberance; its orbital plate, moreover, does not attain that part of the inner wall of the carity where it is so conspicuous in the Thylacoleo and Dasyurus, but extends backward along the lower part of the inner wall to join the orbitosphenoid. The lacrymal foramen, ${ }_{3}{ }^{\prime}$, is within the orbit.

The Thylacinus (Plate XII. fig. 2), which retains the marsupial proportions of the lacrymal bone, has an intraorbital perforation, besides two antorbital ones, $7^{\prime}$ : in most marsupials there are only the two antorbital lacrymal holes, and in the Dasyuri there is only one lacrymal foramen, which is outsicle and in frout of the orbit; the Thylacoleo (Plate XI. fig. $1,{ }_{7^{3}}$ ) resembles the Dasyuri in its single antorbital perforation of the lacrymal bone, and this is one of the decisive marks of its marsupiality.

The postorbital process has been fractured on both siles; but on the left sufficient is preserved to slow that the hind and front sides meet at a right angle, and form a ridge at its under part.

Sufficient of the articular surface (Plate XIV. fig. 1,s) for the lower jaw is preserved on the left side of the skull of the Thylacoleo, to show that it had a greater anteroposterior extent than in Felis speleea, and was flatter at its fore-part, the margin there not being so produced: the same character is shown in Desyumus ursinus. The postglenoid process is fractured.

I am indebted to Mr. Samuel Stctchidre, F.L.S., for a cast of a portion of a right ramus of a lower jaw of a large Carnivore, a fossil which he obtained at Hodgson's Creek, Darling Downs, during his geological survey of that district of Australia in the year 1853. 
'This portion (Plate XI. fig. 3; Plate XIII. figs. 4 and 5) fortunately includes the carnassial and tubercular teeth, and by the correspondence of these in shape and size with the answerable teeth $\left(p_{s}, m_{1}\right)$ in the upper jaw of Thylacoleo (Plates XI. and XIV. fig. 1), I believe it to belong to the same species.

'The lower carnassial tooth consists only of the 'blade,' which is thickest anteriorly, with an even trenchant edge, describing a slight concavity lengthwise, and obliquely abraded by the play of the upper tooth upon the outer side of the edge. 'The outside of the tooth (Plate XI. fig. $3, p_{4}$ ) is convex lengthwise, and also vertically at the forepart: the inside (Plate XIII. fig. $4, p_{4}$ ) is concave lengthwise, except near the fore-part; rertically it is convex at the base and concave above, the base being slightly grooved vertically. 'The anterior margin of the tooth, which is the highest, is bounded by a vertical ridge. The length of the crown is 1 inch 8 lines; the height at its fore-part is 9 lines; the thickness at the same part is 6 lines: the height and thickness of the crown diminish toward the back part. The small tubercular tooth (Plate XI. fig. 3; Plate XIII. figs. 4 and $\left.5, m_{1}\right)$ is immediately behind the preceding: it consists, more distinctly than the one above, of an anterior principal lobe and a small posterior one; the anterior lobe is convex on both sides, subconical, with a worn obtuse summit. The antero-posterior extent of the crown is 7 lines; the same extent of both the teeth just equals that of the upper sectorial, and the lower tubercular is so situated as to play, in lateral movements of the jaw, upon the upper tubercular. Behind the tubercular in place there is the socket of a rudimental one, which cannot have exceeded 3 lines in its longest diameter (ib. $m_{2}$ ). From this socket the coronoid process begins to rise, sloping upward and backward. It is broken off within half an inch of its origin. 'The fore-part of the fossa for the implantation of the temporal muscle is preserved, showing by its depth the strength of that muscle; the anterior boundary of the fossa is vertical and convex forwards. The ramus of the jaw preserves the same depth from the last socket to the fore-part of that of the sectorial tooth. The symphysis (Plate XIII. fig. $4, s$ ) begins behind, at a vertical line dropped from a little in advance of the middle of the sectorial, $p_{4}$; it is of a wide oval form. To judge from the cast, but little of the jaw appears to have been broken away from the fore-part of the symphysis. The upper and forepart shows the alveolus and base of a tooth (Plate XI. fig. 3,c) which has projected obliquely upward and forward. It is separated by an interspace of 3 lines from the sectorial, and would seem to be the sole tooth in advance of it. If the ramus be really produced at the upper part of the symphysis further than is indicated by the present cast, it may have contained one or more incisors, and the broken tooth in question may be the lower canine. If, however, this be really the foremost tooth of the jaw, it would appear to be one of a pair of large incisors, according to the marsupial type exhibited by the Macropodidee and Phalangistide. However this may ultimately prove to be, the molar series in each ramus of the lower jaw is reduced to the enormous sectorial and the two small tuberculars; and it would seem, therefore, in the upper jaw, to be reduced to the single sectorial and single tubercular on each side. It is possible that a canine 
may have existed in the upper jaw as much longer and larger than that below, as the upper canine is in the extinct Machairodus. But sufficient is demonstrated in the abovedescribed fossils to make known the most anomalous dental system in carnivorous Mammalia, whether placental or marsupial.

There is an interesting resemblance between the known dentition of the lower jaw of Thylacoleo and that of the small extinct mammal from the Purbeck strata called Plagiaulax by Dr. FALCONER*; and the resemblance would be closer should the broken tooth in the lower jaw of Thylacoleo here described prove to be the foremost one. Certainly no other known mammal shows two posterior tubercular teeth so similar to those in Plagiaulax minor, in their relative size to each other, to the trenchant tooth in front and to the ramus of the jaw, as does the Thylacoleo.

The anterior orifice of the dentary canal (Plate XI. fig. 3,o) appears, in the cast, to have been in the fossa, on the outside of the jaw, between the socket of the sectorial tooth and the one anterior to it. As much of the lower border of the jaw as is preserved is straight. Not enough of the back part of the jaw remains to indicate the form or direction of the angle. But the lower jaw of Thylacoleo must have been singularly short in proportion to its depth and breadth, and a like extreme shortness of the muzzle or facial part of the skull may be inferred.

With the above-described portions of the cranium of the Thylacoleo, I received from my friend Dr. Hobsor a portion of a sectorial tooth with one of the fangs. It was so similar in the character of the crown to the great sectorial in place, that I had no doubt about the genus to which it belonged, but only as to whether it was a smaller anterior sectorial of the upper jaw, or the sectorial of the lower jaw. Mr. Stutcinury's specimen has settled that doubt. The tooth (Plate XI. figs. 4, 5 and 6) is the hinder half, with the hinder fang of the left sectorial of the lower jaw. The characteristic markings and undulations or grooves of the enamel, and the thickness of this substance where it is exposed by the abrasion of the trenchant edge, are carefully shown in the figures.

In existing carnivorous mammals the ferocity of the species is in the ratio of the 'carnassiality' of the sectorial molar, $i$. $e$. of the predominance of the 'blade' over the 'tubercle;' and this ratio is shown more particularly in the upper sectorial, in which, as the tubercular part enlarges, the species becomes more of a mixed feeder, and is less devoted to the destruction of living prey. From the size and form of the carnassials of Thylacoleo, especially of the upper one, we may infer that it was one of the fellest and most destructive of predatory beasts.

The metacarpal bone (Plate XIII. figs. 6, 7 and 8) is here figured, as it resembles in its shape that of a large carnivorous animal, and may possibly belong to the Thylacoleo. The figures preclude the necessity of verbal description. It is from a freshwater deposit in Darling Downs, Australia.

On the occasion of a visit to London, in 1848, by the able comparative anatomist and palæontologist M. Paul Gervais, at the period when the supposed marsupial character

\footnotetext{
* Proceedings of the Geological Society, March, 1857.
} 
of the Pterodon or Ilyenodon of the Miocene deposits of Auvergne, Gard, and Vaucluse was under discussion, I took the opportunity to point out to M. Gervass certain characters deducible from the 'formmen caroticum' and 'foramen lacrymale' bearing on this question, and illustrated my conclusions by reference to the then unique carnivorous fossil which I had a short time before received from Australia.

'The estimable author of the 'Zoologie et Paléontologie Françaises,' 4to, 1848-52, enters the genus Thylacoleo in the 'Table of Fossil Mammalia according to their geographical arrangenent*; and in his remarks on those of Australia (Nouvelle-IIollande), he writes, "Ses dépôts pliocènes ou pleistocènes ont fourni des Grands Kangaroos, un gr'and Wombat $\uparrow$, diverses autres espèces congénères de celles d’à présent, les genres de Itiprotodun et Notothérium qui étaient aussi des Marsupiaux, nais dont les allures et la taille approchaient de celles de nos grands pachydermes diluviens, et le Dasyurien, plus grand que le Lion, que M. OwEx nomme Thylacoleo \$."

I cite this passage in testimony of the date of my determination of the marsupial nature of the great carnivorous Australian fossil, and of the imposition of its generic name; because the portion of the lower jaw with the carnassial and tubercular teeth of the same extinct species, which was obtained by my friend Mr. STutchisury during the period in which he was fulfilling his valuable duties as "Geological Surveyor" of the colony of Australia, is alluded to under the name Schizodon in a Report to the Colonial Secretary, clated "Darling Downs, 1st October, 1853."

If this generie name had had priority of the one given by me to the same extinct grenus, it must have been suppressed, since Schizodon had been previously applied in 1829 to a genus of fishes, which still retains it, by AGAssi\% $\S$; to a genus of mammals by Mr. Wateriodse, in 1842; and, slightly modified as Schizodles, to a genus of molhusks by Mr. King. Of course the two latter applications, like that by Mr. Stutcil$B L R Y$, must fall into the subordinate rank of synonyms.

The additional fossil of the Thylacoleo discovered by Mr. Stutchibur is a very welcome one. It was not, indeed, sufficient to guide the Colonial geologist to an idea of the order of Mammalia to which it belonged; and Mr. Stutcibury concludes his brief notice of the fossil by the remark, "Its affinities lad better be left for future discussion, as it is probable that further search may bring to light more remains illustrative of this very singular animal $\| . "$

Such remains had, however, been obtained by Mr. ADExer, and had been transmitted to ine cight years previously; and the chicf conclusion as to the affinities of the animal to which they belonged, had been indicated by the term Thylacoleo, i. e. Marsupial or

* Op. cit. vol. i. p. 190.

+ That, riz., which is alluded to as being "at least four times as large as either of the known existiug species," in iny Memoir on the existing Species of Phascolomys, of July 1845, Truns. Zool. Soc. vol. iii. p. 306.

$\ddagger$ Op. cit. vol. i. p. 192.

§ Selceta Genera et Species Piscium Brasilieusium, 4to, 1829. II Papers relative to Geolugical and Mineralugical Surreys, 1\$53, p. 10. 
Pouched Lion*, which conclusion was based on the characters and comparisons of those fossil remains detailed in the foregoing pages.

The concurrence in them of so many cranial characters found only in the Marsupialia, will be deemed, I apprehend, demonstrative of the marsupial nature of the Thylacoleo; and, amongst existing Marsupialia, the Sarcophilus or Dasyums ursinusat present the largest existing species of its genus-seems to me to have the nearest affinities to the Thylacoleo, although the interval be still very great between them.

\section{Description of the Plates.}

\section{PLATE XI.}

Fig. 1. Side view of the cranium and part of the upper jaw of the Thylacoleo carnifex : -nat. size.

Fig. 2. Inside view of part of the upper jaw, showing both the sectorial and tubercular molars of ditto.

Fig. 3. Outside view of part of the lower jaw of the Thylacoleo carnifex.

Fig. 4. Inside view of part of the left lower carnassial tooth of the Thylacoleo camifex.

Fig. 5. Outside view of the same specimen.

Fig. 6. Upper view of the same specimen.

\section{PLATE XII.}

Fig. 1. Side view of the skull of the Felis spelaca (from European Bone-cave):-half nat. size.

Fig. 1 a. Outline of the sutures between the nasals, 15 , and frontal, 11 , and between the superior maxillary, 22, and the frontal, 11 , showing the backward extension of the maxillaries, which distinguishes the Lion from the Tiger:-nat. size.

Fig. 2. Outline of the skull of the Thylacinus Harrisii:-nat. size.

\section{PLA'TE XIII.}

Fig. 1. Upper view of the cranium of the Thylacoleo carnifex:-two-thirds nat. size.

Fig. 2. Upper view of the cranium of the Dasyums (Sarcophitus) ursinus:-nat. size.

Fig. 3. Upper view of the cranium of the Thylacinus Harrisii:-nat. size.

Fig. 4. Inside view of part of the lower jaw of the Thylacoleo carnifex:-nat. size.

Fig. 5. Upper view of the same fossil.

Fig. 6. Side view of a metacarpal of a carnivorous quadruped; from Australian pleistocene.

Fig. 7. Proximal end of the same.

Fig. 8. Distal end of the same. 


\section{PLA'TE XIV.}

Fig. 1. Base view of the mutilated fossil cranium of the Thylacoleo carnifex:-nat. size.

Fig. 2. Base view of the cranium of the Dasyurus (Sarcophilus) ursinus:-nat. size.

Fig. 3. Base riew of the cranium of the Thylacinus IIarrisii:-nat. size.

Fig. 4. Part of the palate, with the sectorial $(p 4)$ and tubercular $(m 1)$ molars of the Lion (Felis Leo):-nat. size.

\section{PLATE XV.}

Fig. 1. Occiput of the Thylacoleo carnifex:-nat. size.

Fig. 2. Occiput of Dasyurus (Sarcophilus) ursinus:-nat. size.

Fig. 3. Occiput of Thylacinus Harrisii:-nat. size.

Fig. 4. Occiput of Felis spelaca:-nat. size.

The letters and figures are explained in the text. 


\section{DESCRIPTION OF AN ALMOST ENTIRE SKULL OF THE Thylacoleo carnifex,}

\section{FROM A FRESHWATER DEPOSIT, DARLING DOWNS, QUEENSLAND.}

Since the foregoing pages on the genus Thylacoleo went to press I have been favoured by Edward Hill, Esq., of Sydney, New South Wales, through the kind offices of his brother-in-law Sir Daxiel Cooper, Bart., with a small collection of fossil remains from that part of the freshwater deposits of Darling Downs through which the river Condamine has cut its bed.

Among these fossils were parts of a broken skull, at once recognizable, by its carnassial teeth, as belonging to the large carnivorous marsupial exemplified by the subject of Plate XI. of the present work.

On readjusting these fragments, I was gratified to find that they formed a more perfect skull than the one which first indicated the genus and species, and not only confirmed the marsupial character of the fossil, but supplied particulars of much value in determining the affinities of Thylacoleo in the marsupial series.

In previously reconstructing so much of the skull of the Thylacoleo as is figured in that Plate and Plates XIII., XIV.\& XV. fig. 1, I had, for the facial portion there preserved, only the guide of a small surface on the nasal process of a detached maxillary bone which fitted to about half an inch of the fractured surface of the fore part of the cranium (Plate XI. fig. 1, ${ }_{3}$ ). I was glad, therefore, to have the accuracy of that "fit " confirmed by the more perfect state of the skull here described.

In comparing the upper carnassial tooth of Thylacoleo with that of Felis in the preceding section, I had to regret that a fracture with some loss of the tooth in the marsupial carnivore prevented the precise determination of its degree of difference from that of the placental feline in regard to the "tubercular" part of the carnassial; but a close inspection of the tooth in the fossil led me to infer that "little more than the enamel" had been broken away (p. 111). The perfect condition of both right and left carnassials at the fore part of the crown in the present instance (Plate XVII. $p_{4}$ ) enables me to state that, in the place of the tubercle, there is only a low vertical ridge of enamel, about a line in breadth, without any additional inner root at the fore part of the tooth: the large carnassial of Thylacoleo consists exclusively of the "blade." This is more worn than in the original specimen described. A smooth and polished surface is exposed by attrition, sloping from within downward and outward, and meeting the inwardly bent outer enamelled surface at an angle of about $50^{\circ}$. The worn surface is deeper at the fore and hind parts of the tooth than at the middle, agreeably with the antero-posterior concavity of the outer surface. The hindmost part of the worn surface, which is 4 lines across, slopes rather outwardly from the rest, at a low angle 
defined by a linear boundary. I conclude that this surface is formed by the attrition of the small tooth succecding the carnassial in the lower jaw, and marked $m 1$, fig. 3, Plate XI. The more extended anterior surface indicates that the lower carnassials pass within the upper ones when the mouth is shut. The whole abraded surface shows a play of the teeth for trenchant action like that of the blades of shears, in a more striking degree than in the carnassials of Felines. 'The fore part of the camassial, here 7 lines in brealth at the base of the crown, is formed by a ridge of enamel, acquiring, as it approaches the working surface, a line in breadth; from this the crown quickly expands to its greatest breadth, which is defined by a similar vertical ridge on both the outer and inner sides of the tooth. The enamel-tract between the anterior and outer ridges is convex; that between the anterior and inner ridges is flat. The outer surface of the enamel belind the ridge shows several slight linear vertical impressions, between which the enamel slightly bulges out, at the basal part of the crown, the grooves subsiding halfway toward the trenchant border; the enamel is also finely wrinkled. 'The vertical extent of the enamel decreases from the fore to the hind end of the crown. I have nothing more to add from this second specimen to the description of the upper carnassial of Thylacoleo given at p. 111. The breadth of the palate between the fore parts of the carnassials is 3 inches 5 lines, and between the hind parts 3 inches 10 lines, showing the slight convergence of the antero-posteriorly extended crowns of the carnassials anteriorly.

In the portion of upper jaw first described, the fore part had been broken away immediately in fiont of the alveolus of the carnassial tooth; but enough of the bone on the outer side of the socket remained to determine a differential character between Felis and Thylacoleo in favour of the marsupiality of the latter. From the state of the first specimen I could only say that the suborbital or antorbital canal "must open some way in advance of the socket of the penultimate tooth, as it does in Sarcophilus" (p. 312). The present specimen sliows that the anterior opening of the canal (Plate XVI. ${ }_{21}$ ) is about 3 lines in advance of the alveolus of that tooth (here the carnassial, $p_{4}$ ), 10 lines above the alveolar border of the maxillary, and 6 lines behind the maxillo-premaxillary suture. The foramen is vertically elliptical, $3 \frac{1}{2}$ lines in long diameter, and $2 \frac{1}{2}$ in short diameter. The corresponding foramen in Felis Leo may be 10 lines in long diameter and 6 lines in short diameter. This difference indicates the minor extent of sensitive surface and (ribrissal?) appendages in Thylacoleo as compared with Felis, and corresponds with the singular relative shortmess of the muzzle in Thylacoleo, which the present instructive fossil exemplifies.

In this specimen the right occipital condyle is entire: it forms outwardly a strong oblique convexity, broadest abore, contracting as it bends round the outside of the foramen magnum forward and inward; toward the foramen the condyle is slightly concare lengthwise (Plate XVII. 2). The lower ends of the condyles are about 5 lines apart, the upper ends 1 inch 3 lines. 'The foramen magnum is 1 inch in transverse, and $7 \frac{1}{2}$ lines in vertical diameter: it looks backward and a little downward. About 4 lines in advance 
of the foramen the basioccipital (Plate XVII. ${ }_{1}^{1}$ ) begins to show a median longitudinal ridge, formed, or left apparently, by a pair of smooth excavations of the under surface of the basi-occipito-sphenoid, the anterior half of which is bounded externally by the thick obtuse ridges developed from the sides of the basisphenoid (ib.5). The depressions and dividing ridge are present, but more feebly marked, in Felis; the basisphenoidal ridges, which prolong backward the pterygoid walls (ib. $\left.{ }_{24}\right)$ of the postnarial canal, are not developed in Felis: the breadth of the basis cranii between the tympanics is much greater in Thylacoleo than in Felis. The suture between the basioccipital and basisphenoid is obliterated. The pterygoids $\left(i b .{ }_{24}\right)$ are of great length; their bases almost meet beneath the presphenoid, but gradually diverge as they extend backward, uniting suturally with the sides of the basisphenoid as far back as the low thick ridges $(i b .5)$ which are the sole representatives of the "pterygoid processes" of the sphenoid. The bodies of the cranial vertebræ describe the same curve, convex lengthwise downward, as in the first specimen. The basisphenoid, anterior to the median ridge, is gently concare transversely; and this concavity becomes deepened, by the junction of the pterygoids, as the centrums advance, the pterygoid plates arching from the junction downward and outward, to form the sides of the posterior continuation of the bony nostrils or respiratory passage. The conformity in this part of the cranial structure of Thylacoleo with that in Thylacinus (Plate XIV. fig. 3) is very close.

The paroccipital (Plates XVI \& XVII. s) is broken, but seems not to have extended far below the level of the occipital condyle; it articulates externally with the mastoid ( 8 ), which is not coextensive therewith vertically. Together they form a low, thick, obtuse, rough, subtrihedral pyramid, with the base downward and the outer side excarated.

The median vertical superoccipital ridge (Plate XVIII. fig. 2, ${ }_{3}$ ) and the lateral depressions are better dereloped in the present specimen, with the more abraded carnassial teeth, than in the one first described, indicating the longer subjection of the bone to the action of the nuchal muscles.

The cranial nervures and vascular foramina are as in the first specimen, with which also the tympanic (Plate XVII. 28) agrees in its small size and relative position.

Nearly the whole of the articular surface for the mandibular ramus (Plate XVII. ${ }_{27}$ ) is preserved on the right side of the present specimen; it is 1 inch 6 lines in transverse, and nearly 1 inch in antero-posterior extent; concave transversely, moderately convex from behind forward at its horizontal part, this facet changing or deepening to the concave only where it is continued upon the post-glenoid plate: this is deeper than in the Lion, and much thicker; it is on the same transverse line as the tympanic, and is divided by the narrow fissure below the meatus auditorius externus from the mastoid.

There was sufficient of the articular surface in the first-described fossil to show that it had a greater antero-posterior extent than in Felis, with some minor characters of difference in which it more resembled that part in the Ursine Dasyure. So much of this significant part of the skull being preserved in the present fossil as is formed by the zygomatic process of the squamosal demonstrates the wide difference from the semi- 
cylindrical transverse canal characteristic of the ginglymoid joint of the lower jaw in placental Carnivora. 'The surface, though of great transverse extent, was probably carried out further in that direction by the malar bone (to judge by the analogy of the Dasyurus (Plate XIV. fig. 2) ; but this part of the zygoma has been broken away. There is a striking sinilarity, indeed, in the kind of mutilation which the fossil skull from the freshwater deposits at Colungoolac (Plate XIV. fig. 1), and that from the same formations channelled by the Condamine (Plate XVII.), has undergone. 'The occipital condyles, zygomatic arches, and postorbital processes have suffered, differing only in the degree in which these projecting parts have been broken away during the apparently similar cosmical violence to which both fossils have been sulject. Besides the postglenoid ridge (Plate XVII.l) in Thylacoleo, there is a narrower boundary wall descending in the inner or mesial end of the articular surface, nearly as low as the posterior one; it renders the surface concave in the transverse direction; and against this "entoglenoid process" (ib.e) abuts the apex of a thick obtuse triangular mass of bone, with the base turned toward the descending basisphenoid ridge, but separated from it and from the end of the pterygoid by a groove. 'This convex portion of bone (Plate XVII. 6) appears to be developed from the base of the alisphenoid, and to have contributed to the tympanic cavity, like the second "bulla ussea" in Perameles*; it was broken away on both sides in the first-described skull, but the pneumatic cavity by which it was excavated is partly shown on the left side (Plate XIV.6); its base is perforated by the "foramen ovale."

In the present skull the cranium has been broken across lengthwise, and almost horizontally, exposing the extension of the air-sinuses (Plate XVIII. fig. 4) from the nose to the occiput, raising the outer table of the cranium nearly 2 inches above the inner one at the middle of the intertemporal ridge, and showing the small cerebral cavity restricted to the lower and hinder half of the cranium. The length of this cavity is 4 inches, its breadth 3 inches, its height 2 inches. Neither falx nor tentorium was ossified. The anterior boundary of the "sella" is indicated by a transverse rising produced into a pair of small retroverted "clinoid" processes, but there is no depression below the level of the cranial surface of the basisphenoid. The rhinencephalic compartment is relatively large.

In all the characters of the cranium shown and described in the original specimen the present fossil corresponds therewith. The posterior palatine vacuity, indicated by the smoothly convex inner border of the roof of the mouth parallel with the hind half of the sectorial tooth (in Plate XIV. fig. 1, d), is shown in the present skull (Plate XVII. $d$ ) to be the fore part of the wide and advanced "palato-nares;" they are divided, mesially, by the presphenoid rostrum and romer, and are bounded, laterally, by an extension of the palatal process of the maxillary and of the palatine to the pterygoid. 'This extension (ib. so), flat below, convex above, contracts to a diameter of eight lines opposite the middle of the posterior nostril, then increases in breadth, and loses in depth as it

\footnotetext{
* Cyclopadia of Anatomy and Physiology, rol. iii. Art. Larsupialia, fig. 96.
} 
passes into the pterygoid wall of the wide and deep pterygo-sphenoid basicranial longitudinal median canal. Each posterior bony nostril is longitudinally orate, with the great end forward, 2 inches in longitudinal and rather more than 1 inch in transrerse diameter, with the plane of the opening inclined from without upward and inward, and, more feebly, from before upward and backward. The bony roof of the mouth is thus much reduced in length, a dimension which is surpassed by its breadth between the great carnassial teeth. Its posterior border is thin, and sharp where it forms the fore part of the palatal nostril, and gradually thickens, becoming smoothly convex at the outer side of that aperture. The bony palate is perforated by a pair of apertures about 1 inch in advance of the hind border, and $1 \frac{1}{2}$ inch from the anterior end; that on the left side (Plate XVII. a) is elliptic, about 5 lines by 3 lines in its two diameters; on the right side the bony palate is partly broken away: these answer to the incisive or prepalatal foramina, and are on the line of the suture of the premaxillary with the maxillary palatal processes. The breadth of the palate, which is nearly 4 inches between the hind ends of the carnassials, is reduced to 1 inch 3 lines anterior to the small openings above-mentioned, and rapidly contracts to a breadth of 3 lines between the large sockets of the anterior teeth, which here, descending, convert the fore part of the palate into a deep groove.

The most welcome and instructive part of the present fossil skull is the fore part, giving evidence of the anterior teeth, and of the formation, position, and aspect of the external nostril. This orifice (Plate XVIII. fig. 1) is formed by the premaxillaries (22) and extremities of the nasals (15). A characteristic of most of the facial sutures in Thylacoleo is their finely undulated or subdentate structure. This is shown between the maxillary (Plate XVI. ${ }_{21}$ ) and malar (26), between the maxillary (21) and premaxillary (22), and between the nasals (15) and premaxillaries, though not in the median suture between the nasals themselves. These bones (Plates XVI. \& XVII. figs. 1\& 3, 15) slightly expand at their fore ends, where their free margin is thick and obtuse and forms the upper third of the external nostril. The premaxillaries form the sides of the opening by a similar margin, which rapidly expands at the lower half, to form or be continued, sloping forward, into the alveoli of the pair of incisor tusks $\left(i_{1}\right)$. The inner or medial border of each alveolar outlet (Plate XVII. $i_{1}$ ) is continued downward below the level of the contiguous bony palate for about 4 lines, forming the sides of a groove or canal at that part about 3 lines in breadth, which expands as the palate extends backward between these alveoli. At the middle of the lower boundary of the extemal nostril the premaxillaries rise into a slight prominence; the lateral borders of the nostril are slightly concare vertically (Plate XVIII. 22); the form of the nostril (ib. fig. 1) is transversely elliptic, its plane almost vertical with the lower border a little adranced; the anterior margin of the nasals is, through fracture, not quite entire. The vertical diameter of the nostril is 1 inch 2 lines, the transverse diameter 1 inch 10 lines. The rertical extent of the premaxillary is 2 inches 7 lines; the antero-posterior extent of the upper part of the premaxillary (or of the naso-premaxillary) suture (Plate XVI. between ${ }_{15} \&{ }_{22}$ ) is 2 inches; the maxillo- 
premaxillary suture ( $i b$. between ${ }_{21} \& 22$ ), as it descends, runs forward, reducing that dimension of the bone at the middle of the nostril ( $\left.{ }_{22}\right)$ to $1 \mathrm{inch}$, whence it expands to 1 inch 8 lines, where it contributes to the alveolar border of the upper jaw and to the bony palate; the pair of incisive or premaxillary palatal foramina, before described (Plate XVII.a), open upon the suture of the premaxillary with the palatal plate of the maxillary.

Each premaxillary has three alveoli ; the outlet of the foremost (Plate XVII. $i_{1}$ ) is oral, witl the larger end forward, 1 inch in long diameter, $7 \frac{1}{2}$ lines across the widest part: this socket rises for nearly 2 inches in the substance of the bone, inclining a little backward and outward to its closed end the long axes of the outlets converge forward. The outlet of the second incisor (ib. $i_{2}$ ) is a full ellipse, 4 lines by $3 \frac{1}{2}$ lines in the two diameters; that of the third incisor (ib. $i_{3}$ ) seems to have been of similar size. The breadth of both premaxillaries posteriorly is 2 inches 10 lines; anteriorly, across the first alveoli, 1 inch 8 lines; the length of the premaxillary part of the bony palate is 1 inch 7 lines. The maxillary (Plate XVI. ${ }_{21}$ ) swells outward as it leaves the premaxillary to form the socket of the great carnassial $\left(p_{4}\right)$, above which it rises to join the malar ${ }_{26}$ ), the lacrymal (13), the frontal (11), and the nasal (15) bones. Anterior to the root of the carnassial it is perforated by the small antorbital foramen. Behind the carnassial socket the bone extends outward and backward for $1 \frac{1}{4}$ inch, forming the lower and fore part of the temporal fossa, and there terminating by a free obtuse convex border $\left(i b .{ }_{21}^{\prime}\right)$, of similar rertical extent, below the malo-maxillary suture. The corresponding part of the posterior border of the maxillary in Felis is concave. On the inner side of the hinder end of the carnassial socket is that (Plate XVII. $m_{1}$ ) for the small tubercular tooth, which was preserved in the first-described specimen; the long axis of its outlet forms an open angle with that of the carnassial socket, at the fore part of which the alveolar border of the maxillary is excavated by either a similar socket for a tworooted tooth, or by two contiguous sockets for two small single-rooted teeth (ib. $p$ s). I think the first the more likely explanation, in which case the long axis of the outlet of this socket forms an open angle with that of the carnassial one, extending therefrom inward and forward, instead of inward and backward like the posterior socket. The extent of such axis is 6 lines, the first subcircular orifice being rather less, the next rather more than 3 lines in diameter. The fore part of this socket is near the lower end of the maxillo-premaxillary suture, and the state of the alveolar and contiguous palatal part of the jaw here precludes any clear determination relative to a canine; such a tooth (ib. c), of small size, conical and obtuse, had been cemented to this broken part of the alveolar border, in the line of the small posterior incisors.

The posterior part of the maxillary is concave as it rises from the border to form the fore part of the temporal fossa, and then bulges out into that fossa as a smooth conrexity, on the inner side of which is the hinder opening of the suborbital canal (Plate XVIII. fig. 3,o). Above this convexity the lower and fore part of the orbit impresses that part of the maxillary which supports the lacrymal, which, forming that part of the 
rim of the orbit and extending backward, adds to the depth of the depression. The rim subsides above the lacrymal, and the upper part of the orbit is continued convexly upon the upper part of the skull parallel with the posterior ends of the nasals and contiguous part of the frontal $(i b .11)$. The superorbital ridge is resumed by the outstanding and down-bending process of the frontal (Plate XVI. 12), which, being broken away on both sides of the skull, exposes the large air-sinus with which it was excavated. The rimless upper part of the orbit is 10 lines in extent. The orbit is relatively smaller than in Felis, deeper anteriorly, and more significantly different by its wall not being pierced for the lacrymal canal, the entry of which $\left(i b .{ }_{13}\right)$ is situated externally, as shown in the first-described specimen of Thylacoleo. The length of the nasal bones (Plate XVIII. fig. $3,{ }_{15}$ ) is 3 inches 6 lines; their least breadth, conjointly, is 1 inch ; they slightly expand at both ends, but most so posteriorly, where they are 2 inches across. Their median suture remains; that of the frontals is in great part obliterated, and the conjoined frontals (ib. $\left.{ }_{11}\right)$ enter the posterior interspace of the nasals. The fronto-nasal suture is undulatory. The nasal processes of the maxillaries do not extend so far back as the nasals, which terminate angularly, but with the apex largely rounded off.

The upper cranial surface of the frontals (Plate XVIII. fig. $3,{ }_{11}$ ) contracts backward to the intertemporal ridge (ib. $t$ ); the boundary between frontal and parietal is not shown. At the anterior expanded part of the frontals the external surface forms a pair of low convexities divided by a median longitudinal shallow channel, but deeper and with the convexities better marked than in the first specimen. These convexities give a contour line to the upper part of the skull (Plate XVI.) resembling that in the Brown Bear, which also the skull resembles in the breadth of the naso-maxillary part. The upper and hinder parts of the cranium correspond with those which were characterized in the former paper.

The dentition of the upper jaw, as indicated by alveoli in the present specimen, includes, on each side, three incisors (Plate XVII. $i, 1,2,3$ ), followed by three or four other teeth: of these, one is the great carnassial $\left(p_{4}\right)$, another the small transversely oblong tubercular $\left(m_{1}\right)$ : the seat of doubt is between the carnassials and incisors. To one of the doubts expression has been already given-whether, viz., the carnassial was preceded by one small two-rooted premolar $\left(p_{3}\right)$, or by two smaller and single-ruoted teeth. A canine appears to be represented by the tooth with a subcircular, conical, obtusely worn crown, under 3 lines in diameter, supported on a thicker base (ib. c). Future specimens may clear up this part of the dentition of Thylacoleo. It is certain that the anterior incisor (ib. $i_{1}$ ) bore a relation of size to the carnassial similar to that of the canine tusk in Felis to the carnassial. Of the two small premaxillary teeth which succeeded the front tusk, neither is preserved.

The size of the laniary canine in Felis being here transferred to the first incisor, its function as killer was similarly provided for by its approximation to the moving power, through the extreme shortness of both upper and lower jaws, especially anterior to the chief molar teeth. In Felis the small incisors are very little in advance of the canine; 
this large tooth is almost at the fore part of both upper and lower jaws; and in Thylacoleo the relative position of the incisor-tusk to the enormous temporal fossa is such as to give it the adrantage of a harder or closer grip during the action of the powerful temporal iuuscles.

In the preceling section so much of the characters of the lower jaw, and its teeth, of Thylacoleo were given as could be deduced from the cast of a portion of that bone, figured in Plates XI. \& XIII. figs. 3, 4, \& 5, pp. 117 \& 118.

The carnassial and succeeding tubercular teetl, being in place, served to refer this fossil to the same species as that indicated by the upper jaw (Plate XI. figs. 1 \& 2). A socket for a second smaller "tubercular" was evident, behind the one in place. The chief doubt remained in regard to the fore part of the mandibular ramus; the plaster cast did not admit of any certain conclusion as to the extent to which the original might there have suffered fracture; part of the symphysial surface and the base or socket of a large obliquely produced tooth could be made out, and this "seemed to be the sole tooth in advance of" the carnassial. Accordingly I wrote, "If the ramus be really produced at the upper part of the symphysis further than is indicated in the present cast, it may have contained one or more incisors, and the broken tooth in question may be the lower canine. If, however, this be really the foremost tooth of the jaw, it would appear to be one of a pair of large incisors, according to the marsupial type exhibited by the Macropodide and Phalangistidee" (p. 118).

The perfect condition of the upper jaw of the chief subject of the present paper determined the alternative, and proved the Thylacoleo to be the carnivorous modification of the more common and characteristic type of Australian Marsupials, having the incisors of the lower jaw reduced to a pair of large, more or less procumbent and approximate, conical teeth or "tusks."

I have been faroured by Mr. Gerard Krefrt, the able Curator of the Australian Museum, Sydney, New South Wales, witlı a "photograph" of the outer side, and an outline sketch, natural size, of the inner side, of a portion of the right mandibular ramus of Thylacoleo carnifex in that Museum, which presents the same general resemblance, in the kind and degree of mutilation, to the original of the cast described in Part I., which the cranium from the "Condamine River" presents to the one from "Colungoolac." It is fortunately, however, a little more complete-sufficiently so to demonstrate that the large socket (Plate XVIII. figs. $5 \& 6, i$ ) is of the foremost tooth of the lower jaw. It also exhibits two small approximate alveoli, or the divisions of an alveolus, for a two-fanged tooth, corresponding in size and in relative position to the carnassial, with the similar socket or sockets noticed in the description of the upper jaw (Plate XYII. $p_{3}$ ). There are evidently no smaller incisors behind the large one of the lower jaw, nor any other teeth between the large incisive tusk and the small tooth or teeth on the inner side of the fore part of the great lower carnassial. The portion of lower jaw in the Sydney Museum also shows the socket for the minute tubercular tooth (Plate XVIII. figs. $\left.5 \& 6, m_{2}\right)$ behind the posterior double-rooted one $\left(i b . m_{1}\right)$. The 
"foramen mentale," the anterior boundary of the depression for the insertion of the large temporal muscle, and the form of "symphysis closely resemble all these characters as shown by the cast of the mandible first described. Mr. Krefret has dotted the depth to which the socket of the lower incisive tusk descends in the symphysial part of the jaw (ib.fig. 6, $i$ ): it is somewhat greater than that of the upper tusk.

The length of the dental series of the upper jaw, in a straight line, is 4 inches 3 lines; that of the lower jaw is 3 inches 3 lines.

From present data the probable formula of Thylacoleo is : $-i \frac{3-3}{8}, c \frac{1-1}{8}, p \frac{2-2}{2-2}, m \frac{1-1}{2-2}=24$. Of the incisors of the upper jaw, the first is a large tusk; of the premolars, the first is small, probably two-fanged, the second a very large carnassial. The first molar is small and two-fanged in both jaws, the second is restricted to the lower jaw, is still smaller, and is single-rooted.

Besides the full confirmation which the additional fossils, here described, give of the marsupiality of Thylacoleo, its closer affinities in that Order are shown to be, not to the existing Carnivorous Marsupials, e. g., Sarcophilus, Dasyurus, Thylacinus, Didelphys, but to the Diprotodons, Nototheres, Koalas, Phalangers, and Kangaroos. It may, I think, be said that the skull above described is one of the most singular and interesting mammalian fossils hitherto discovered.

Admeasurements of the Shull.

Length . in. lin.

Length of the facial part anterior to the orbit . . . . . . . 30

Breadth at the preserved posterior part of the zygoma . . . . . . 72

Breadth at the preserved anterior root of the zygoma . . . . . . . . 69

Breadth of the cranium between the temporal fossæ . . . . . . . . 23

Length of the bony palate, from the fore border of the palato-nares . . . 211

Breadth of the bony palate at the same part . . . . . . . . . 36

From the fore end of premaxillary to the hind border of the palato-nares . 49

From the hind border of the palato-nares to that of the occipital condyles . 56

Length of the temporal fossa, including the orbit . . . . . . . . . 72

Breadth of the interorbital space across the antero-superorbital ridges . . 310

Breadth of the interorbital space behind the antero-superorbital ridges . . 30

Least breadth of the foramen magnum . . . . . . . . 011

Least height of the foramen magnum . . . . . . . . . . . 07

Breadth between the upper ends of the condyles . . . . . . . . . 14

Breadth across the broadest part of the condyles . . . . . . . . 25

Breadth across the paroccipitals. . . . . . . . . . . . 42

Breadth across the mastoids . . . . . . . . . . . . . . 53

Vertical diameter, or depth of the upper jaw, at and including the fore part of the carnassial tooth . . . . . . . . . . . . . 40 
Vertical diameter, or depth of the mandible, at and including the fore part of the carnassial tooth . . . . . . . . . . . 30

Other admeasurements are noted in the text.

\section{PLATE XVI.}

Side view of the cranium of the Thylacoleo carnifex: nat. size.

\section{PLATE XVII.}

Base view of the skull of the Thylacoleo carnifex: nat. size.

\section{PLATE XVIII.}

Fig. 1. Front view of the skull of the Thylacoleo carnifex.

Fig. 2. Back view of the same skull.

Fig. 3. Upper view of the same skull.

Fig. 4. Air-cells of the diploë above the cavity for the brain.

Fig. 5. Outer side of part of the right mandibular ramus, with the carnassial $\left(p_{4}\right)$ and first molar $\left(m_{1}\right)$; the second molar, $m_{2}$, is indicated in outline.

Fig. 6. Inner side of the same portion of mandible: the second molar $\left(\mathrm{m}_{2}\right)$ and the incisive tusk, with the first molar, $m_{1}$, carnassial, $p_{4}$, and incisive tusk, $i_{1}$, of the upper jaw, are indicated in outline.

All the figures in this Plate are half the natural size.

The letters and figures of each Plate are explained in the text. 


\section{DESCRIPTION OF MAXILLARY, MANDIBULAR, AND DEN'TAL FOSSILS OF THE Thylacoleo carnifex; WITH REMARKS ON OBJECTIONS TO THE AUTHOR'S DETERMINATION OF THE NATURE AND HABITS OF THE SPECIES.}

THE relations of the extinct Australian Marsupial, which forms the subject of the two preceding sections of the present work, to the members of the pouched Order characterized by a single pair of incisor teeth in the lower jaw have been generally admitted. But, since the communication of this comprehensive and briefly expressed view of the affinities of Thylacoleo in a paper read to the Royal Society of London, June 15th, 1865*, several eminent and experienced investigators of Fossil Remains have endeavoured to determine to which of the groups specified at p. 131 the Thylacoleo was most closely or immediately allied. Some have been led to the belief of its having been a Kangaroo, some have deemed it a Potoroo or Rat-Kangaroo, others would rank it with the arboreal Phalangers or Koalas; but all concur in repudiating its carnivorous character, have rejected the distinct section of Diprotodont Marsupials, of which Thylacoleo and Plagiaulax are exemplars, and have sought, with more or less ingenuity, to invalidate the conclusions which I had been led to deduce from the parts of the fossilized remains of those paucidentate Marsupials which, at that date, had been submitted to my examination.

The relevancy of such objections to my determination of Plagiaulax is considered in the 'Prefatory Notice,' pp. 88-106. In the present Section I propose to append to the description of the Thylacolean fossils received since 1865, a like consideration of the arguments, objections, and imputations to which my papers on Thylacoleo have given rise.

In these, the substance of which is embodied in the two foregoing sections, I inferred, from the size and position of the socket of the anterior tooth, from the structure of the root of the tooth therein implanted, and, above all, from the characters of the associated and completely preserved teeth, that such front tooth must have been laniariform, i.e. subcompressed and pointed, adapted for piercing, holding, and lacerating, like the canine of a Carnivoret.

To this the late laborious and experienced palæontologist, Dr. FALConer, objected that, in referring to my paper, he finds " that the body of the tooth, of which the shape and direction are adduced as terms of comparison, together with the fore part of the symphysis, is wanting" $\$$.

* Published in the Philosophial Transactions, 1856, p. 73.

+ Philosophical Transactions, 1859 , p. 318; ib. 1866, pp. 79, 80 .

$\ddagger$ Quarterly Journal of the Geological Society, June 1862, vol. xviii. p. 353; also ' Palæontological Memoirs 
To my statement, "that there is a socket close to the symphysis of the lower jaw of Thylacoleo, which indicates that the canine may have terminated the dental series there, and afforded an additional feature of resemblance to the Playiaulax"*, Dr. FALCONER remarks :- "In all this, it will be seen, the argument is within the domain of conjecture; the tooth oscillates between canine and incisor; and not merely so, but the principles which are followed as guides in this walk of investigation are set aside, to give place to the illusory indications of mutilated external form.... If palæontological investigations were conducted in this manner there would be no limit to conjecture; the landmarks we profess to follow would be disregarded, and disorder would face us everywhere. But, happily, science furnishes unerring principles, which provide the corrective. I need harlly add that the argument drawn from Thylacoleo has, in my view, no bearing on the incisors of Plagiaulax, and gives no support to the carnivorous inference" $\uparrow$.

This rebuke, being doubtless kindly meant and penned in the interests of palæontology, I have hitherto borne in silence, hoping that less fragmentary fossils of Thylacoleo would ultimately reach me; and sustained, I must own, by a confident belief that they would confirm the inferences drawn from the position of the alveolus, suggesting the alleged feature of resemblance of Thylacoleo to Plagiaulax.

Nevertheless, the portion of mandible figured in Plates xI. \& xIII. of the Phil. Trans. for 1859 being represented by a plaster cast, and the figures $5 \& 6$ in Plate IV. of the Plil. Trans. for 1866 being from photographs, I could not feel surprised that arguments in favour of the herbivorous nature and affinities of both Thylacoleo and Plagiaulax should have met with acceptance and support from some Anatomists, Naturalists, and P'alæontologists, as, for example, those referred to below ${ }_{\text {w. }}^{\text {. }}$

I have again been favoured, through the kind offices of Sir Daniel Cooper, Bart., with a collection of fossils obtained by his friend, Mr. Sт. JEAx, of Gowrie, from the freshwater deposits of that locality, in Darling Downs, Queensland, Australia, which collection included the alveolar portion and certain tecth of the right upper jaw (Plate VII. figs. 1-5), and the major part of the left ramus of the lower jaw with certain teeth (Plate VIII. figs. 1-5) of a full-grown Thylacoleo carnifex.

'The teeth in the upper jaw are:-the anterior incisor with the terminal half of the crown broken away $\left(i_{1}\right)$, the carnassial $\left(p_{4}\right)$, and three antecedent small and simple obtusely conical tecth $\left(p_{1,2,3}\right)$.

and Notes,' by the late Hegir Fatcoxer, F.R.S. \&e., 8vo, 1868, vol. ii. p. 437. [In future referenees I shall use the numbers $\mathrm{X}$. and XI. to signify the above rolumes.]

* Owex's 'Palæontology,' Sro, 2nd ed. (1861) p. 432.

† X.p. 3.5. ; XI. p. 438.

$\ddagger$ E. g. Mr. Boyd Dawrivs, F.R.S., in Quarterly Journal of the Geologieal Soeiety of London, vol. xx. 1864, p. 412 ; Mr. Gerard Krefft, "On the Dentition of Thylacoleo carnifex, Owen," Annals and Magazine of Natural History, 3rd series, vol. xriii. 1866, p. 148; Professor W. H. Flower, F.R.S., "On the Affinities and probable Habits of the extinct Australian Marsupial, Thylacoleo carnifex, Owex," in Quarterly Journal of the Geologieal Soeiety of London, March 1868, rol. xxiv. p. 307. [This volume and paper I shall refer to as No. XII.] 
The teeth in the lower jaw are the root and base of the crown of the incisor (i), and the entire carnassial $\left(p_{4}\right)$.

I was thus still driven, as far as these specimens went, to an inferential conclusion as to the form of the crown of the anterior incisor, both above and below. But, since preparing for the Royal Society (Philosophical Transactions, 1871, p. 213) a description of the specimens, I have been favoured by photographs and fossils of both these teeth nearly complete, and also with a plaster cast of the entire lower incisor, now in the Museum of Natural History at Sydney, New South Wales, through the kindness of the Trustees of that Museum and of their able Curator, Mr. Gerard Krefft, Corr. M.Z.S.

The teeth transmitted and the subjects of the photographs were obtained from the Breccia-cave in Wellington Valley*, in the course of recent assiduous researches conducted by Alex. M. Thomson, D.Sc., Reader on Geology, Sydney University, and by Mr. Kreffe, in 1869 , aided by the liberal grant of $£ 200$ voted by the Local Parliament of New South Wales in favourable response to the Memorial which I addressed to the Colonial Secretary, February 23rd, 1867

Whatever interpretation may ultimately be accepted in palæontology of the habits and affinities of Thylacoleo, additional and valuable materials for such interpretation have thus been added to the subjects of former descriptions: an account of these additions, with their bearing on the arguments that have been opposed to my conclusions, is given in the present section.

Upper Jaw and Maxillary Teeth.-The specimen of this part of the skull (Plate VII.) includes almost the entire premaxillary (figs. $\left.1-5,{ }_{22}\right)$, with its alveolar $\left(a, a^{\prime}\right)$, nasal $(n)$, and palatal $(p)$ portions.

The alveolar portion contains the socket $(a)$ of the anterior large laniariform incisor $\left(i_{1}\right)$, that of a much smaller incisor $\left(i_{2}\right)$ opening close to the first, and, after an interval of two lines, the front half of the socket $(c)$ of a small canine (fig. 9), the division of which socket is made, or rather indicated, by the premaxillo-maxillary suture $\left(s, s^{\prime}\right)$ : this third socket is rather larger than the second, and is more outwardly placed.

The nasal portion of the premaxillary forms anteriorly, above the deep socket of the first incisor, a thick obtuse margin (fig. 4, 22 ), convex transversely, concave vertically and also laterally toward the nasal cavity (ib. $n$ ); it becomes much thinner above the socket, then regains thickness at its upper part, where the plate arches inward to join the nasal bone. A ridge $(r)$ for the attachment of the inferior "turbinal " divides the fore part of the nasal chamber into an upper $(n)$ and a lower $\left(n^{\prime}\right)$ passage.

The palatal process (figs. $2 \& 3, p{ }_{22}$ ) is thick and short; it projects forward about four lines in advance of the first large alveolus (fig. 1, $p$ \$), is grooved above, lengthwise,

* Discorered by Colonel Sir Tmomas MitcheLl, C.B., F.G.S., and described in his work, 'Three Expeditions into the Interior of Eastern Australia,' 8vo, vol. ii. 1838.

+ See page 239 of the present work.

$\ddagger$ As shown in the subject of fig. 1, Plate xviII. 
where it forms that part of the floor of the nostril, $n^{\prime}$; and it is also grooved or channelled longitudinally at its under part, which channel (figs. $2 \& 3,2^{\prime}$ ) gains breadth and deptli as it passes backward; but it is broken away after contributing an inch to the median palatal suture (ib. $p$ ).

The facial plate of the premaxillary repeats the characters of that figured in Plate XVI., and the suture $\left(s, s^{\prime}\right)$ with the maxillary has the same crenate character and course.

'The outlet of the socket of the first incisor is $9 \frac{1}{2}$ lines in fore-and-aft diameter, 6 lines in transverse diameter; the outer wall is outwardly convex, the inner one straight. The depth of the socket is $1 \frac{1}{2}$ inch; it contracts to the closed end. 'The outlet of the second socket (fig. $3, i_{2}$ ) is circular and small, $4 \frac{1}{2}$ lines in diameter; it is also shallow, rapidly contracting to the closed end.

The outlet of the third socket (figs. $2,3, c$ ) is larger, deeper, and elliptical, $4 \frac{1}{2}$ lines in long (fore-and-aft) diameter, 4 lines in transverse diameter; it is separated by a diastema of two lines and more from the second, and its hind wall is formed by the maxillary (21), the proportion being the same as that which the maxillary contributes to the premaxillary for the lodgment of the canine in Thylacinus. Besides this contribution to the third socket, the portion of maxillary of Thylacoleo here preserved shows three sockets of small tubercular premolars (ib. $p_{1,2,3}$ ) and the major part of that of the great carnassial tooth (ib. $p_{4}$ ).

A portion of the outer alveolar plate (figs. $1 \& 5,{ }_{21}$ ) is preserved, and also a portion of the palatal plate (figs. $2 \& 3,{ }_{21}$ ), showing its concavity near the carnassial.

The socket succeeding the third $(c)$ is on the inner side of the hind or maxillary part of that socket, showing that the tooth it contained (figs. $2 \& 3, p_{1}$ ) held the same relative position to the third tooth (ib. $c$ ) as does the anterior premolar to the canine in Lutra; thus adding another to the extremely few instances simulating, in Mammalia, the double row seen in certain lower Reptiles and Fishes. The outlet of this socket is subcircular, 4 lines by $3 \frac{1}{2}$ lines, and is 3 lines distant from the outer surface of the maxillary.

The next (fifth) socket $\left(p_{2}\right)$ is nearer the outer border of the alveolar process, one line and a half behind the back part of the third socket; it is circular, three lines in diameter. It is immediately succeeded by a sixth socket $\left(p_{3}\right)$ of similar size and shape, situated more outwardly as well as posteriorly, the alveolar wall curving from the premaxillo-maxillary suture outward and backward to the prominent fore part of the socket of the great carnassial $\left(p_{4}\right)$.

'This socket extends backward almost at a right angle with those of the three small antecedent teeth (fig. 3); its length from before backward is 2 inches 1 line; its greatest breadth near the fore part is 7 lines.

No part of the socket of the small tubercular molar shown in Plate XI. \& Plate XIV. fig. 1 is preserved in the present portion of the upper jaw ; but this satisfactorily demonstrates the rest of the dentition of its side of that jaw, as respects size, kind, and number 
of teeth, and thus supplies what was less perfectly shown in the subject of Plate XVII. I may add that photographs, and specimens of this tooth $\left(m_{1}\right)$ from the breccia-cave, illustrate the constancy of character in the solitary spelæan example of the true or tubercular molar series from the upper jaw of Thylacoleo.

Of the first incisor $\left(i_{1}\right)$, nearly one inch projects from the outer wall of the socket in the subject of fig. 1, Plate VII. ; the inner wall (fig. 2, ib.) extends two lines lower down the tooth. The dimensions of the outlet of the socket give those of the corresponding part of the tooth, which very closely fits and adheres to the socket. The anterior border of the exposed part of the incisor shows a moderate curve convex forward; the posterior border, three lines below the socket, shows, after a slight basal convexity, the beginning of a curve concave backward. The exposed base of the tooth retains for four or five lines below the socket a coating of cement beneath which the enamel emerges. This is thicker toward the back than at the fore part of the crown, but nowhere exceeds half a line. Much of it is broken away from the base of the crown here preserved; and at the outer and back part of the base of the crown the enamel presents a free rounded edge, for two lines vertically, as if it were there interrupted. The dentine is extremely dense; the diameters of the broken part of the crown, which I take to be about halfway from the pointed end of the crown, are 7 lines by $5 \frac{1}{2}$ lines; the dentine here presents, in transverse section, a narrow oval form, broader before than behind, and more convex outwardly than on the inner side.

Of the second incisor $\left(i_{2}\right)$ one can infer from its socket that it had a root about 5 lines in length, tapering to an obtuse point, and a crown measuring 4 lines in diameter at its base.

The third tooth which has been displaced from the somewhat larger socket opening upon the premaxillo-maxillary suture, and which makes a slight prominence on the outside of the alveolar tract, at a short distance from the second, I conclude to have been a canine $(c)$; the fang, or implanted part, has been 9 lines in length, slightly curved, tapering to the end.

The tooth remaining in the socket (Plate VII. figs. $2 \& 3, p_{1}$ ) on the inner side of the hind part of the canine $(c)$ has the summit of the enamelled crown broken away; the diameters of the base of the crown are 4 lines and 3 lines. The root is firmly fixed in the socket: I regard this as the first premolar $\left(p_{1}\right)$. Its internal position, its implantation in the maxillary at. some distance from the suture with the premaxillary, and its continuation of the oblique line of the succeeding premolars, weigh with me against regarding it as a canine, according tothe hy pothesis of the tooth (c, Plate VII. figs. 1-3) being a third incisor, as in some hypothetical restorations referred to in the sequel.

Thesecond premolar $\left(p_{2}\right)$ in situ in the specimen (Plate VII. figs. 1, 2, 3) is somewhat smaller than $p_{1}$, with a very short enamelled crown, forming a low ridge extending from the outer side to nearly the inner side, and there meeting and blending with a second low ridge at right angles, close to the inner border of the crown. The enamel is limited to forming the low-ridged cap or summit of the tooth; the rest of the tooth 
projecting from the socket is covered by cement. The length of the cement-clad root is given in the figure of, I believe, the homologous tooth in Plate VII. fig. 14.

The third premolar ( $\left.p_{3}\right)$, also preserved in the specimen (Plate VII. figs. 1-3), is rather larger in size, has a similar extremely low and slightly prominent crown, with the same ridge rumning from the outer to the inner side, crossed by the shorter ridge at right angles near the inner side of the crown, to which the longer ridge extends, leaving the shorter ridge chiefly conspicuous behind it. The vertical extent of the cement-covered and cnamelled part of the second and third premolars projecting beyond their sockets does not exceed 3 lines. This specimen resolves the doubt expressed with regard to their empty sockets in the specimen figured in Plate XVII. p. 128*, and demonstrates that each socket contains its own small simply implanted tooth, and was not a division of a socket lodging a larger two-fanged premolar.

Beyond the third premolar the fore part of the crown of the maximized carnassial $\dagger$ (Plate VII. figs. $1 \& 2, p_{4}$ ) extends downward 10 lines. The shape, structure, vertical grooving, and dimensions of this tooth agree with those in the specimens described in the previous Sections.

'The trenchant margin of the upper carnassial is worn, as usual, obliquely from without upward and inward, the cutting-edge of the enamelibeing external (Plate VII. fig. 2, $p 4$ ). This edge does not run straight, but sinks to form a low angle at the end of a wellmarked external vertical groove (ib. $o$ ), marking off rather more than one-third of the hind part of the crown, which answers to the similarly but better defined hind lobe of the feline upper carnassial. 'The smoothly worn surface is thus divided into two parts, the anterior one being broadest anteriorly at the thickest part of the tooth, while the posterior gains breadth as it recedes toward the hind end of the crown. But the indications of rescmblance to the feline carnassial, especially to that of Machairodus (Plate VII. figs. 15, 16), do not end here. 'The inner surface of the crown, about one-fourth of the way from the fore to the hind margin, projects and terminates in a ridge ( $v$, figs. $2 \& 3$, Plate VII.), which expands to the base of the crown, representing the more developed ridge or vertical swelling of that part of the carnassial in Machairodus (fig. 15,v), from the broadening base $\left(\vartheta^{\prime}\right)$ of which the tubercle of the upper carnassial, wanting in Machairodus as in Thylacoleo, is developed in Felis. An opposite rertical ridge on the outer side of the crown in Thylacoleo (fig. 1, $p_{4}, u$ ) represents the most prominent part of the middle lobe of the carnassial in Felines (fig. 16, $u$ ), whence the outer, surface bends inward to the angle or groove dividing that lobe from the hind one. The outer surface in Thylacoleo bends in the same direction to the corresponding angle or groove (o, figs. 1 \& 3), then curves outward to the hind end of the crown. This is very low and subobtuse, as is the corresponding end of the carnassial in Felines. But the fore part of the crown, in

* "At the fore part of the carnassial socket the alveolar border is cxcavated by either a similar socket for a two-rooted tooth, or by two contiguous sockets for two small "single-rooted tceth."

† No evidence has jet been had that this or the antccedent permanent tccth had displaced deciduous predecessors; the adopted symbol $p$ is to be taken with this reservation. 
Thylacoleo, rises with a backward inclination to the highest, or vertically longest, part of the crown, from which a well-marked ridge traverses or forms the anterior margin of the crown (figs. $2 \& 3, z$ ). The anterior root is longer but narrower, antero-posteriorly, than the posterior one, as in the upper carnassial of Felines.

In Hypsiprymnus minor (Plate VII. figs. 17, 18) the premolar has a straighter edge, not bilobed; the outer side of the crown is indented with the four or more parallel grooves and ridges, at the apical half; the inner side is uniformly and obliquely worn, in degree according to age.

Mandible and Mandibular Teeth.-The portion of lower jaw (Plate VIII. figs. 1-5) from the deposit at Gowrie includes 6 inches in longitudinal extent of the left ramus, viz. from the fore part of the symphysis $(s)$ to the fore part of the strongly inflected angle $(a)$. This latter character is acceptable as confirmatory of the marsupial nature of Thylacoleo, in a way more intelligible or convincing to some than the cranial and maxillary characters adduced in support of that induction in the original Memoir (Philosophical Transactions, 1859); although I am not aware that the marsupiality of Thylacoleo has been, by any objector, called in question.

The fossil is massive, heavy, much petrified; it retains the fang and base of the crown of the anterior and sole incisor (i), the entire carnassial $\left(p_{4}\right)$, and the two fangs of the anterior molar (fig. $3, m_{1}$ ).

The small and simple socket of the second molar is indicated $\left(m_{2}\right)$; and two or three small and very shallow alveoli (Plate VIII. figs. $2 \& 3, p_{3}, p_{2}$ ) intervene between the incisor-socket and the inner side of the anterior fourth part of the carnassial. From the condition of the upper small premolars it may be inferred that there were two or three similarly small functionless and speedily lost teeth between the carnassial and the laniariform incisor of the lower jaw, occupying the sockets ( $p_{3,} p_{2}$, figs. $2 \& 3$ ).

Assuming these to be three in number, the first and second are on nearly the same transverse line, so close together that the broken thin partition (?) gives the appearance of a single socket.

The entire length of the alveolar tract is 3 inches; from the back part of the last socket to the hind fractured end of the present fossil is 3 inches. As the extent from the fore part of the upper carnassial to that of the glenoid cavity in the skull figured in Plates XVI. \& VII., measures 5 inches 10 lines, it may be inferred that such must have been nearly, if not quite, the extent of the mandible from the fore part of the lower carnassial to the fore part of the condyle; consequently the entire length of the mandible would not be less than 7 inches. We may reckon that 1 inch, at least, is wanting from the broken hind part of the specimen figured (Plate VIII.); and we may certainly infer that a greater proportion of the mandible was allotted to the joint and to the muscular forces working that instrument than to the dental weapons with which it was armed; concentrated as they here are, as in the fellest Carnivora, for fatal efficiency.

The symphysial contour (ib. figs. $1 \& 2, s, r$ ) rises from the lower border of the horizontal 
ramus at an angle of $120^{\circ}$. The vertical diameter of the ramus anterior to the carnassial tooth is 1 inch 10 lines; it is the same anterior to the origin of the coronoid plate; and, save that the upper border is undulated by the alveolar opening, it runs parallel with the lower one. The outer wall swells out to lodge the anterior root of the carnassial, the vertical swelling subsiding at the lower fourth of the jaw. The dental canal has two small outlets anterior to the swelling. The outer wall becomes slightly concave lengthwise between the socket of the carnassial and the origin of the coronoid, which is broad and thick anteriorly $(c)$, where it divides that concavity from the deeper one behind for the insertion of the large crotaphyte muscle ( $f$, figs. 1 \& 3 , Plate VIII.).

The specimen shows only the fractured base of the coronoid plate, the length of which in a straight line is 2 inches 6 lines; its direction is curved with the convexity inwards (fig. $3, c, c^{\prime}$ ): the fore part, formed by the buttress-like development of the outer wall of the ramus $(c)$, is 7 lines in thickness; it rapidly decreases to $1 \frac{1}{2}$ line, and returns to $2 \frac{1}{2}$ lines in thickness at the hinder part $\left(c^{\prime}\right)$. The osseous tissue at the fore part of the coronoid is compact and dense. Toward the hind part is exposed the dental canal (fig. $2, d$ ), broken across where it was traversing the base of the coronoid; the canal here is narrow tranversely. A narrow longitudinal groove between the base of the inflected part of the "ascending ramus" and the part of the dental canal $(d)$ exposed by the fracture is continued as a shallow impression with a slight curve downward and forward, and then straight for a little way, becoming obliterated below the vertical parallel of the last molar $\left(m_{2}\right)$. This is the only indication interpretable as a "mylohyoid groove."

The course of the fracture at the base of the coronoid from its thick fore part is backward and downward. The lower border of the ramus forms a thick ridge at the lower end of the symphysis, and subsides into a rounded or convex tract, gaining breadth as it recedes, and becoming flattened as it expands by the increased production of the angle of the jaw (Plate VIII. fig. 4, $a, a^{\prime}$ ). The crotaphyte fossa (ib. fig. $1, f$ ) is not continued forward into the substance of the horizontal ramus, as in Potoroos and Kangaroos.

The symphysis (ib. fig. $2, r, s$ ) is subtriangular, the lower and longer side being rather convex, the upper side almost straight ; the base, which is turned backward and downward, is bilobed, the upper lobe, with the convex contour, being the longest. The length of the symphysis is 2 inches; the basal depth is 1 inch 5 lines. 'The upper part of the symphysis forms a slightly concave tract or platform, 9 lines in breadth at the fore and inner part of the carnassial, which increases as it recedes, sloping downward and backward (ib. fig. 3, s). It is bounded externally by the sockets of the incisor (i) and of the premolar teeth $\left(p_{1-4}\right)$ in continuous series. There is no true diastema between the laniary and the carnassial ; the three closely aggregated empty sockets of probably as many singlerooted, small, soon shed, functionless premolars occupy the intervening tract and something more, viz. by encroaching on the inner side of the fore part of the socket of the carnassial (Plate VIII. figs. $2 \& 3, p_{2}, p_{3}$ ). Behind the symphysis the inner wall of the ramus (fig. 2) is moderately convex vertically, concave in a less degree lengtliwise at the lower 
part, where the curve becomes deepened posteriorly by the inbending of the angle $(a)$. This part gains in thickness as it extends inward; the inner surface of the part preserved in the specimen described is vertical, and in that direction measures 6 lines (fig. 2, $a$ ). The fractured end (fig. 5, $a$ ) shows the three-sided character of this part of the angle, the upper and under surfaces converging to the thin horizontal plate (ib. $b$ ) connecting the angle with the part supporting the coronoid and condyle (ib. $c^{\prime}$ ). The fore part or beginning of the neck of the condyle may be indicated by the smooth tract (fig. 3, $e$ ), which would then define the hind border of the coronoid process; or this narrow tract may indicate a minute transverse perforation of the ascending ramus. On the first notion the preserved fore-and-aft extent of the part relating to the support of the condyle $\left(e, c^{\prime}\right)$ is 10 lines.

Before the completion of the present work I hope to receive from some liberal and fortunate collector of Australian fossils a specimen of the lower jaw of Thylacoleo with the whole of the rising branch complete, showing both the shape and position of the condyle. Seeing that in Bettongia (p. 170, fig. 18), Hypsiprymnus (p. 170, fig. 17), Phascolarctos (p. 153, fig. 6), and all the marsupial vegetable feeders with a high-placed condyle, there is a corresponding course of the base of the coronoid from before upward and backward, whilst in Thylacinus (p. 155, fig. 11) and Sarcophilus (p. 155, fig. 12), with a low-placed condyle, the base of the coronoid runs straight backward, I take ground for inferring a similar or relatively lower position of condyle from the slope of the base of the coronoid from before downward and backward, as indicated in the present jaw of Thylacoleo, and deem it not improbable that it may have approached in both respects the Plagianlax; thus exemplifying in the form of the mandible, correlatively with the dentition, the higher degree of carnirority in these extinct marsupial and diprotodont genera.

Photographs and Cave-specimens of Maxillary Teeth.-After completing the description and figures of the foregoing specimens of maxillary and mandibular structures and teeth of the Thylacoleo, I was faroured by receiving (May 20th, 1870) from the Colonial Secretary's Office, Sydney, New South Wales, a series of Photographs of Fossil Remains, and some duplicate specimens, obtained by Dr. A. M. Thomson and Gerard Krefrt, Esq., from Limestone Caves in Wellington Valley, under the circumstances detailed in the Section on Diprotodon, p. 239.

I have subsequently been favoured by the Trustees of the Museum of Natural History, Sydney, and the able Curator, Mr. Gerard Krefrt, with a second series of Photographs, some of them duplicates of the above, others of fossils since acquired from the same breccia-caves. The Trustees of the Sydney Museum have also transmitted to the British Museum duplicate specimens of these cave-fossils.

From this rich series of photographic illustrations and specimens I select for description and figures the following, which supplement and almost complete our knowledge of the permanent or fully developed dentition of Thylacoleo carnifex.

The tooth in "Photograph No. 28" (Plate VII. figs. 6, 7 ) is the anterior incisor, left 
side, npper jaw. It has its crown a little worn at the point; it is plainly "canine" in function as in shape. The enamelled part of the crown which projects beyond the cement measures 1 inch 2 lines along the anterior curve. This is convex lengthwise, angular transversely, being traversed at the fore part by a low ridge ( $r$, fig. 7, Plate VII.); the posterior border beyoud a slight basal convexity is feebly concave lengthwise, rather flattened across, but chiefly bounded by a longitudinal ridge of enamel near the outer side: this ridge is feebly notched; the thinner enamel is continued from it, obliquely to the immer sile of the crown, where the thicker enamel, of less longitudinal extent than the onter enamel, also developes a trenchant posterior ridge. 'The entire length of the tooth following the curve is 2 inches 3 lines: the fore-and-aft breadth of the base of the crown is 8 lines; the transverse breadth 5 lines: it accords, therefore, closely with the anterior incisor preserved in the portion of jaw above described (Plate VII. figs. 1, 2, $\left.3, i_{1}\right)$. The photograph (No. $28 b$ ) of the outer side of the answerable tooth shows a greater extent of preserved fang, though not quite entire at the end; the serration or notching of the long outer hind trenchant ridge or edge of the enamel is better marked than in the specimen. Together they concur in demonstrating the effective laniary character of the foremost tooth of the upper jaw of Thylacoleo.

A tooth in the photograph No. $28 c$ of upper tecth of Thylacoleo accords with the inclications, as to form of fang and basal breadth of crown, afforded by the alveolus symbolized in figs. $2 \& 3$, Plate VII., as of the second incisor $\left(i_{2}\right)$. I have therefore added a copy of it, fig. 9, in that Plate. It shows a root tapering to an obtuse point, 5 lines in length, and a crown 4 lines in diameter at its base, short, subconical, and obtuse, and may well be $i_{2}$ with a rather longer root from a less aged individual Thylacoleo: the crowl of this tooth must project close behind the base of the crown of the front incisor.

The tooth (Plate VII. fig. 10) from the photograph No. $28 c^{\prime}$, with a fang 10 lines in lengtl, fitting by its fore-and-aft breadth such a socket as that marked $c$ in figs. 1, 2, 3, Plate XI., answers to the indications there given. Another subject of the same photograph (fig. 11) is a more perfect canine of the opposite side, its bend of fang being contrary to that indicated by the right upper socket $(c)$ in fig. 1, Plate VII.

Accordingly, I conclude the canine, $c$ (Plate VII. figs. $9 \& 10$ ), to have a small subobtuse subcompressed crown, with a convex front outline from before backward, where it meets the hind shorter border of the crown at an angle which seems to form the rather blunt point of the tooth. The length of the enamelled crown is 4 lines, taken in the tooth's axis along the middle of the crown; the fore-and-aft breadth of the crown is 6 lines; the fang is an inch in length and rather curved, contracting to an obtuse point.

Amongst the duplicate cave-teeth are the crowns with portions of the fang of two such canines; the best-preserved fang is similarly curved (Plate VII. fig. 12), with a subtrihedral transverse section; but this form is more strongly marked in the short enamelled crown, the outer and inner sides mecting, anteriorly, at a trenchant border, strongly curved to 
the apex, which bends beyond the hind side (ib. fig. 12, $b$ ); this is flattened transversely, and is feebly concave lengthwise. The enamel has much less vertical extent here than along the anterior trenchant convex side of the crown. The outer side is slightly convex, and marked in one specimen by a longitudinal linear groove (ib. fig. 10); in the other by two grooves (ib. fig. 11), recalling those in the upper canines of Felis; the inner side (fig. 12,a) in both teeth shows two longitudinal grooves, and a ridge of enamel behind the hindmost groove.

Of the three succeeding small teeth which I have assigned to the premolar series (ante, p. 134), I recognize, in the cave-specimens, by the similarity of their very short crown and straight root, those answering to $p_{2}$ and $p_{3}$ in the upper jaw (Plate VII. figs. $13 \& 14)$; but there is a photograph of a larger tooth, though less than the canine, which in size at the base of the crown corresponds witl the $p_{1}$ in place (id. ib.) on the inner and hinder side of the canine. This tooth has a low conical crown, 3 lines long by $4 \frac{1}{2}$ in basal antero-posterior breadth. The premolar (fig. $14, p_{2}$ ) has a root 10 lines in length, curved near the end to which it contracts.

The two smaller succeeding premolars in place in the unique jaw (Plate VII. figs. 1-3) I have not thought proper to displace; the photographs, which plainly show the same very short extent of enamelled crown, give to an example of $p_{2}$ a straight fang of 7 lines in length, and to one of $p_{3}$ a similar fang 8 lines in length; both taper to an obtuse point. Amongst the duplicate teetl transmitted is a $p_{2}$ with half an inch of the solid straight fang, and the crown of a $p_{3}$ corresponding with that in the upper jaw (Plate VII. fig. 3).

The photographs include three specimens of the great carnassial $\left(p_{4}\right)$ with an enamelled crown 2 inches in fore-and-aft basal extent, 9 lines in greatest vertical extent. The subject of one figure shows the two roots; the foremost of which is 1 inch 6 lines long and 1 inch in fore-and-aft breadth, where it becomes free; the hind root or division is 1 inch in length and about the same in fore-and-aft extent; its greatest transverse thickness is 6 lines, and it contracts to an obtuse hinder border. Both roots are shown to be strongly marked, as in the tooth in situ (Plate VII. figs. 1 \& 2), by fine subwavy longitudinal strix near their extremities, adding to the closeness of attachment to the alveolar periosteum. The characters of this huge carnassial in the fossil specimen are so closely repeated as to render figures of these photographs unnecessary.

A side view and a view of the grinding-surface of the small tubercular molar are given in the photograph No. 7 : a similar specimen I have worked out of the breccia (Plate VII. fig. $\left.3, m_{1}\right)$. This tooth closely resembles that shown on the inner side of the hind end of the great carnassial in Plate XI. fig. $2, b$ and in Plate XIV. fig. 1.

It is evident that the five small teeth between the upper laniary $\left(i_{1}\right)$ and the carnassial ( $p_{4}$, figs. 1-3, Plate VII.) can have had but insignificant functional relations. They could not be opposed to mandibular teeth, if even their homotypes had been present or retained in the lower jaw. But of these there seem to have been but two, or at most 
three, developed, of very small size, on the inner side of the fore part of the lower carnassial; and I have scen no specimens of mandible in which they are retained.

Photographs and Cave-specimens of the Mandible and Mandibular Teeth.-The following are the most instructive photographs of portions of the mandible with teeth of Thylacoleo from the Breccia-care of Wellington Valley, in the series above referred to.

No. 10 gives two views of a portion of the right ramus (the outside view is given in Plate IX. fig. 1). It is similar to the fossil from Queensland above described (Plate VIII. fig. 1), but more mutilated at the back part. The chief value of the specimen photographed is the retained incisor (i), from which only the apex of the crown is wanting, by an oblique fracture from above and behind downward and forward. In a photograph of a more inutilated mandible (ib. fig. 2), the inner wall of the alveolus of the incisor is broken away as far as the vertical line dropped from the fore part of the carnassial $\left(p_{4}\right)$. 'The outer wall remains a few lines in advance of this in the subject of figure 1 , but sufficient of the cement-covered root of the tooth is exposed to show a commencing contraction toward its implanted end. The incisor is directed upward at an angle of $130^{\circ}$ with the long axis of the ramus, and the crown shows a curvature with the convexity forward and downward as in the lower laniaries of Thylacinus; the hind border is not straight or convex like the answerable upper border in the same tooth of Bettongia and Hypsiprymnus, but is serrato-trenchant and slightly concave lengthwise. A photographic view giving the transverse breadth or thickness of the incisor would have been instructive; but the portion of the tooth retained in the mandibular ramus figured in Plate VIII. fig. 1, $\ddot{i}, a$, shows the more essential distinction from the long procumbent lower incisors of the herbivorous Marsupials in the degree of lateral compression of the crown and its proportion to the antero-posterior breadth, which in the laniary of Thylacoleo is intermediate between that in Machairodus and Felis.

The two anterior outlets of the dental canal are present, and in the same position in the cave-fossil (Plate IX. fig. 1,0) as in the Queensland specimen (Plate VIII. fig. 1, 0). The postero-inferior emargination of the symphysial surface is repeated on the inner surface of the ramus of the subject of fig. 1, Plate IX., as in Plate VIII. fig. 2, $r$.

All the characters of the carnassial tooth $\left(p_{4}\right)$ in the Quecusland specimen are closely repeated; the crown is abraded in the same direction and to the same extent.

The crown of the first molar $\left(m_{1}\right)$ is preserved in both the cave-specimens photographed, showing its raised, anterior, subtrenchant lobe, and its small low hind tubercular talon. On the outer side of this tooth is shown the subvertical surface formed by attrition against the hind part of the upper carnassial. The proportions of the anterior and posterior roots of $m_{1}$ are indicated in the photograph of the inner side of the subject of fig. 1, Plate IX. The socket of the minute $p_{3}$ (ib.) plainly appears on the inner side of that for the anterior root of $p_{4}$ in the same photograph; but the shallower and larger ones of $p_{2}$ and $p_{1}$ have left no impression-were probably obliterated in the 
fossil. There can be no doubt as to the specific identity of the Wellington Valley cave-fossils with those of Thylacoleo carnifex from Melbourne (Lake Colungnolac) and from Queensland (Gowrie Creek).

The second fossil of Thylacoleo from the breccia-cave, the subject of the photograph No. 29 of the series, is a smaller portion of the fore part of a right ramus, with the entire incisor, the carnassial, and first molar in situ. The whole length of the base of the incisor is exposed, and the obtuse termination of the closed and contracted end of the root (Plate IX. fig. 2). The fractured state of the bone also shows portions of the fore and hind roots of the carnassial $\left(p_{4}\right)$, the latter apparently the larger, contrary to that in the lower carnassial of Felines, which is not the homologous tooth, although with a similar adaptive modification of crown. The length of the incisor is 3 inches 3 lines, that of the enamelled crown appears to be about 1 inch 8 lines; the anteroposterior breadth of its base is 9 lines. The position, direction, and curvature of the incisor in this specimen accord with those in the photograph copied in fig. 1, Plate IX., and with the restoration based on the direction of the empty socket in the subject of Plate XVIII. fig. 6. The vertical extent of the fore part of the carnassial $\left(p_{4}\right)$ is 1 inch 9 lines, that of the enamelled crown being $7 \frac{1}{2}$ lines.

All the evidences yielded by the specimen (figs. 1-3, Plate VIII.), by the casts (Plate XI. fig. 3), and by the photographs (Plate IX. figs. $1 \& 2, p_{4}$ ) concur in showing the closer resemblance of this sectorial tooth to the carnassial of the large placental Camivores (Plate VIII. figs. 9 \& 12) than to the sectorial premolar in Rat-Kangaroos (ib. figs. $8 \& 10$ ). The crown of the tooth (fig. 11) is bent lengthwise, with the convexity outward, the concavity inward; and this is chiefly at the hinder half of the tooth (fig. $3, p_{4}$ ). The fore part of the crown is the thickest, and that by the prominence of the inner surface at the anterior fourth, which makes a low obtuse ridge $(r$, fig. 11 , Plate VIII.) divided by a depression or channel from the anterior ridge $(\alpha)$ or border of the crown, which represents the prebasal ridge ( $a$ ) in the carnassial of the Hycena (fig. 12). The broader part of the trenchant surface (b, fig. 11) is anterior, as in Hyana (b, fig. 12). The trenchant margin does not extend in a straight line, but is subconcare, though less so and more continuously than in Hycena. The effect of these curves of the cutting part of the blades in Thylacoleo, as in Felis and Hycona, is to make them meet at successive parts in the act of cutting, not by simultaneous opposition of the entire cutting-edges of the opposed blades. The vertical undulation of the enamel is finer, less marked, in the lower than in the upper carnassials, and is confined to the basal part of the inner surface, not to the apical half of the crown as in Hypsiprymmus (fig. 10).

In the cast of a specimen of a right mandibular ramus with the carnassial less worn than in the specimen Plate VIII. figs. 1-3, the abraded surface is interrupted midway, indicating a bilobed character of the unworn margin, as in the lower carnassial of Felines; the abraded surface in the cast expands from the unworn part of the dividing notch forward toward the anterior end of the tooth and backward to the posterior end (Plate VIII. fig. 11). The subject of figure 6, Plate VIII., is a specimen worked out of the 
breccia transmitted by the Trustees of the Australian Museum, and slrows the proportions of the two roots of $p_{4}$, lower jaw.

The Photograph No. 7 includes views of five examples of the large laniariform lower incisors, both outer and inmer surfaces of the most entire specimen being given.

No. 1 shows the outer side of a left lower incisor wanting only the tip of the crowll. The closed contracted end of the root is truncate. The length is 3 inches 4 lines, the greatest breadth from before backward 9 lines.

No. 3 in the photograph is of the inner side of a similarly entire right incisor (Plate IX. fig. 4). The ridge $(d)$ defining the inner side from the narrow posterior facet of the crown is clearly given in this photograph, which appears to be the incisor removed from the socket of the subject of fig. 1, Plate IX., the same mutilation of the summit of the crown being shown. 'The implanted end of the root contracts in the same degree, and shows the same truncation, as in the subject of figs. 5 \& 6, Plate IX.

Photograph No. 43 gives, somewhat reduced, the inner side of the fore part of the riglit ramus, showing the symphysial surface, the carnassial, and the first molar. The extent and shape of the symphysis, as in Plate VIII. fig. 2, are here repeated with the same vertical extent and lower contour of the fore part of the mandible. Photograph No. 37 is of the outer side of the same specimen, on the same scale, showing the trenchant part of the crown of the first molar $\left(m_{1}\right)$ as in Plagiaulax. A view of the carnassial in situ, in a small fragment of the left ramus, showing the oblique external smooth wear of the trenchant tootl, is also given in photograph No. 43 .

These evidences are acceptable as testifying to the constancy of the characters of the lower jaw and dentition in Thylacoleo carnifex.

Cave-specimens and Cast of Inferior Incisor.-I have been favoured by Mr. KREFFT with a cast of the entire inferior incisor of Thylacoleo, from the breccia-cave in Wellington Valley; and since penning my notes on this cast and the photographs, an entire lower incisor and portions of others have come to hand in the series of cave-specimens worked out of the masses of breccia transmitted from the Wellington caves.

The incisor (Plate IX. figs. 5, 6, 7) is long, subcompressed, subrecurved; the crown is pointed, trenchant anteriorly. The entire tooth is about equally divided into crown (fig. 5, $a^{\prime}, b$ ) and fang (ib. $f$ ); but the enamelled part (e), when the root-cement is scraped away, is longer than at first appears; for the cement encroaches upon the enamelled crown in angular prolongations from the root, and further on the inner (fig. 6, c) than on the outer (ib. fig. 5) or hinder part (fig. 7 ) of the tooth. The crown becomes threesided a little below the apex $(e)$; the outer side (fig. $5, a$ ) is broadest, and is transversely convex, the posterior border forming that of the crown. The imner side (fig. 6 , $a, d)$, of less breadth, is flat, but is divided by a longitudinal ridge $(d)$ into two facets, the hinder one being the narrowest and inclining transversely to the hinder border $(n)$. Toward the base of the crown the hind surface $(h)$ becomes feebly concave between these marginal posterior ridges. 
Thus the perforating part of this tooth is strengthened by four longitudinal enamel ridges, in which the serrate or finely undulated or wrinkled character is more or less manifest, especially on the trenchant anterior border, defining the outer (fig. 5) from the inner (figs. $4 \& 6, i)$ surfaces of the crown, also on the supplementary ridge $(d)$ on the inner facet $(i)$.

As the fore-and-aft breadth of the crown increases from the apex downward, the stronger convexity of the antero-external part is limited to the fore part of that facet, the hinder part of the facet becoming less convex or almost flattened, and at the base of the crown even feebly concave, where the cement (fig. $5, c$ ) encroaches on the enamel. A similar concavity marks the onter part of the base of the laniariform incisor of Platgiaulax, FalcoNer, X. fig. 1, p. 366 ; XI. pl. 33. fig. 1, a. The anterior subserrate ridge is the longest, the postexternal ridge subsides a little sooner in approaching the base, the postinternal ridge is next in length, and the supplementary inner ridge is the shortest. The enamel-case of the crown is entire, but is thickest upon the more convex anterior part of the antero-external facet, and where it forms the ridges (see the section, Plate IX. fig. 8).

The posterior facet at the apical part of the crown meets at a right angle the inner side, but lower down it slopes from the postinternal ridge, backward as well as outward. to meet the outer facet at $b$. This gives a more trenchant character to the subserrate ridge or border $(d)$ between these surfaces.

The effective cutting power of the postinternal ridge, where the angle between the posterior and internal surfaces of this three-sided bayonet-like tooth becomes a little open, is enhanced by the prominence of the ridge, supplemental strength being given to the piercer by the added postinternal ridge. The cement-clad root (Plate IX. figs. $5,6 \& 7, c, f)$ gradually contracts to its subtruncate closed extremity.

In the specimens of lower laniary above described, as in the cast and photographs of that formidable tooth of Thylacoleo, evidence is given of its conforming in its limited or temporary growth, as in its shape, proportions, and structure, with the canine of the Felines, but with superadded modifications strengthening and perfecting it for its work as a piercer, holder, and lacerator.

Thus, through the cooperation of a liberal and enlightened Legislature and Administration, and of esteemed friends and fellow-labourers, in Sydney, New South Wales, ample evidence has been got of both upper and lower laniary incisors, as well as of the rest of the dentition of Thylcicoleo carnifex.

It is with pleasure, though without surprise, that I have been enabled to confirm the inferences expressed in my former papers, on such elements of that dentition as I then only knew " in part."

Whether the "principles which are followed as guides in this walk of investigation were" therein "set aside, to give place to the illusory indications of mutilated external form" * I cannot determine, because Dr. FALCONER does not define the principles to which 
he refers. It is certain that the indications of the mutilated parts of my original specimens have not proved "illusory."

But such indications were not the sole grounds of my conclusions; I was also guided by a principle. It is that laid down by Cuvien in the van of his immortal work of Restoration of the extinct Mammals of the Paris Basin.

The aberrations of some contemporary labourers in this field show that it will bear repetition:-_ "La premic̀re chose à faire dans l'étude d'un animal fossile est de reconnoître la forme de ses dents molaires; on détermine par-là s'il est carnivore ou herbivore"*

These test-tecth were fortunately entire in the upper jaw of the skull of Thylacoleot, and in the cast of the lower jaw originally described \$.

The major part of the molar series was represented by one large and most efficient carnassial, followed by a single small tubercular above, which was opposed to a semitubercular molar and a second more minute tubercular tooth below.

Here was no molar machinery for the mastication of vegetable food, but a maximized modification of the teeth for the division of fleshy fibre, and so much of the tubercular form added for the final crush or squeeze of gristle or other tough part escaping the shears, as exists in the most carnivorous of the placental mammals.

Location of Laniaries.-From these facts, with faith in the Cuvierian principle, I inferred a concomitancy of laniary teeth at the fore part of the jaw "to pierce, retain, and kill" $\$$ the prey, whether such laniaries held the relative position to a suture technically determining them to be either "incisors" or "canines." It is now determined that these laniaries are, as was inferred in the Second Section\|, incisors. A co-adapted pair at the fore part of the lower jaw were opposed to a slightly separated pair in the upper jaw.

To this demonstration applies the following objection against the inference as to function:-

"Throughout the Mammalia, where teeth perform the functions of canines to "pierce, retain, and kill,' they are held well apart through the interposition of a line of incisorsthe end being obvious: the points of penetration are doubled, the grasp is strengthened by widening the base, and the dilacerating and killing powers are multiplied "T.

'To this I reply that, were a pair of bayonets cemented side by side and the forces of two brawny arms concentrated on the thrust, their perforating and lethal power would be increased. I fail to see how such "collateral arrangement in the axis" of the piercing force "would place them at a disadvantage to the end to be attained"**.

Dr. FALCOXER admits that "a Rat when seized can inflict a smart wound on the hand" $\uparrow$. I can add experience of loss of young poultry showing by the wounds on their legs how they had been brought down from the perch, and by wounds on the neck how they had

* Reeherches sur les Ossemens Fossiles, 4to, tom. iii. (1822) p. 1.

+ Philosophical Transactions, 1859, Plate xı. figs. 1 \& 2.

$\mp$ Id. ib. fig. 3 .

$\S$ Owex's 'Palæontology,' 8ro, 1860, p. 320.

\|I See, also, Philosophieal Transactions, 1866, p. 80.

I X. p. 352 ; XI. p. 435.

** Id. ib.

+† Id. ib. 
been killed, and then more or less devoured by the nocturnal murine omnivorous Rodent. thus demonstrated to have acted in this carnirorous fashion by virtue of the pair of scalpriform incisors " arranged collaterally in the axis," \&c. But my objector's odontological knowledge seems not to have included the fact, that there are several genera and species of Curier's "Carnassiers" in which incisors having the size, form, and office of laniaries* are not "held well apart through the interposition of a line of 'other" incisors" $p$.

The European Otter (Lutra) shows, indeed, this divaricate arrangement, but an African Otter (Potamogale, Cut, fig. 1) does not; a co-adapted pair of laniaries $\left(i_{1}\right)$ at the fore part of the upper jaw were opposed to a slightly separated pair in the under jaw $\left(i_{2}\right)$.

In the Insectivora, as in the Marsupialia, there are two types of the teeth which are dereloped and shaped "to pierce, retain, and kill," in other words, two local conditions of "laniaries." In some, Gymnura $\S$, Centetes $\|, e . g$., the laniaries answer to the 'canines' of Carnivora, and are separated by interposed 'incisors' in both upper and lower jaws, as they are in Sarcophilus and Thylacinus; in other Insectivora the laniaries are approximated, and are formed by 'incisors'; as, e.g. in Solenodon T, Erinaceus**, Scalops, Urotrichus, and other Soricidce generally, in which a juxtaposed pair at the fore part of the mandiblett oppose a corresponding pair at the fore part of the upper jaw. These incisors usurp the

Fig. 1.

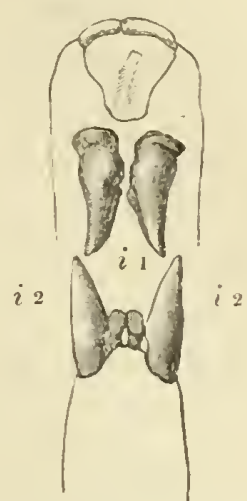

Laniary ineisors, front riew, Potamoyale ielox: twice nat. size $\ddagger$.

functions of the canines in Gymnura, Talpa, \&c. The transference of the laniary form and function from the canines to the incisors, the development of these latter into the dental instruments "modified to pierce, retain, and kill," is the rule, or is found in the majority of Insectivora. In the Japanese Mole-shrew (Urotrichus talpoïdes) \$中 " the incisor is long, conical, and pointed;" it is groored on the inner side: "the lower canine is small, its office being transferred to the incisor" $\$$. This large laniary tooth may be

* "Technical eanines vary as mueh in shape, proportion, and function as do technical 'ineisors;' are sometimes, indeed, implanted by two roots instead of one." See 'Odontography', pl. 110. fig. 3 (Mole).

$\dagger$ X. p. 352 ; XI. p. 435

¥ For the subject of this Cut I am indebted to the author of the instructive Memoir on Potamogale, Zool. Trans. vol. ri. p. 1, Professor AlLasax, F.R.S., of the University of Edinburgh, where the unique skeleton of the Potamogale is preserred.

\$ Owex's 'Odontography,' pl. 111. fig. 4, $a, b$.

॥ Ib. pl. 110. fig. 6 .

T 'Odontography,' pl. 111. fig. 1 (the front riew (b) may be compared with that of Thylacoleo in XII. p. 312 , fig. 2).

** Ib. pl. 110. fig. J.

†† Sorex.— "In the lower jaw there is, as is known, one very elongated pointed ineisor on each side." "The eanine is a small conieal tooth, the smallest of the lower jaw."-Mrvart, "On the Osteology of Inseetivora," Journal of Anatomy and Physiology, rol. ii. p. 11.

¥¥ Catalogue of Bones in the British Mruseum, 8ro, p. 109.

\$irart, ut suprù. 
the homologue of the laniariform $i_{2}$ in Potamogale; but the pair of developed incisors in Urotrichus are what Dr. FALCONER would have described as "approximated and placed collaterally, as in the placental Rodents"*; i.e. they are in contact, side by side (Cut, fig. 2 ). In the large $\Lambda$ frican Ferine (Carnassier, Cuv.), with the habits and food of the Otter, discovered and called Potamogale by Du Cirallud, the first incisor of the upper jaw (fig. $3, i_{1}$ ) "closely resembles a large projecting canine" $\uparrow$. In the lower jaw "the first is rery small. The second incisor is high, conical, curved; it is sharp-pointed, and resembles a canine" $\$$. "The condyle is borne on a distinct neck" $\$$. The low position of the condyle (b), associated with these laniariform incisors in Potamogale

Fig. 2.
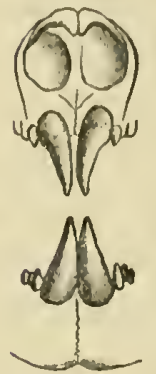

Front view of laniary ineisors, magn., Urotrichus talpoüles, Texurnck. (fig. 3), is not alluded to either by Allman (l. c. p. 11) or by Mivart (l.c. p. 127). It is important in association with the position and juxtaposition of the laniaries in this large fish-hunting Ferine, with regard to the moot question of the carnivority of Thylacoleo and Plagiaulax.

In Myogate, as in Solenodon, the first upper incisor "is much larger and more vertically extended than in any other tooth in the skull. Its crown is triangular,

Fig. 3.

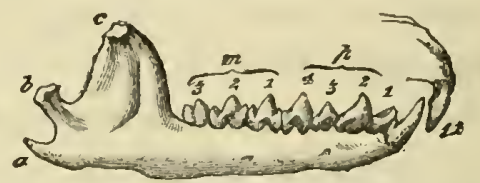

Side riew of upper laniary and mandibular dentition, Potamogale velox, nat. size (ex AlLMan, loc. cit.). it is in contact with its fellow of the opposite side, and predominates more than does any other form yet reviewed, except, perhaps, that of Sorex. It is opposed mainly to the second incisor of the lower jaw, the first being much smaller...... This second incisor is exceedingly large, pointed and conical" $\|$. "The canine is a small obtusely pointed tooth $q$," as in Thylacoleo. In Solenodon, Potamogale, and Myogale the laniariform incisors of the lower jaw, to which those in Urotrichus and Sorex may be homologous, are divided from each other, at their base, by a very small pair of anterior incisors; but the extent of separation is slight, and cannot affect in any appreciable degree their piercing power.

Indeed, to concentrate is to give force, to divide is to weaken. If it be not carried too far, divarication may aid in the secondary work of holding the pierced prey: but for the primary lethal operation, the base for the grasp of the biting muscles is as broad in Thylacoleo as in Felis. An estimate of the concentrated force of these cnormous muscles upon the pair of lower laniaries approximated as one piercing, lacerating organ, with the

* X. p. 352; XI. p. 435.

† Alumsix, "On the Charaeters and Affinities of Potamogale," Trans. Zool. Soe. rol. ri. (1866) p. 6. I am indebted to the accomplished author of the above-eited interesting Monograph for the drawing whieh is the subject of the Cut, figure 1. $\ddagger$ Ib. p. 7 .

§ Ib. p. 11. (Compare this "pedunculate" character with that in Playiaulax, figure 10.)

Mrrart, op. cit. Journal of Anatomy and Physiology, vol, ii. p. 124.

- Id. ib. p. 125. "Scalops. The first incisor is rery large, and is opposed to one nearly as long in the lower jaw. where the eanine is wanting, or represented by a most minute and rudimentary tooth."-Ib. 
superlative degree of carnassiality of the premolar, suggested the expression of the pouched Lion having been "one of the fellest and most destructive of predatory beasts"*.

Had Dr. FALCoNer been aware of the genera and species of Cuvier's Carnassiers, with laniariform or canine-like teeth ' approximate,' he would scarcely have advocated the herbivority of Thylacoleo by statements and remarks open to so facile and obvious a refutation.

The Curator of the Museum of the Royal College of Surgeons, and now Hunterian Professor, cognizant by his duties of a greater range of zootomical facts, nevertheless adopts the argument from divarication of the laniaries in the Carnivora known to Dr. FalcoNer, and salves the exceptions by affirming " the modus operandi of the Hedgehog in snapping up and devouring a beetle is totally different from that of a Cat in seizing and killing a Rat or a Rabbit" $\dagger$. And one may conclude that the Thylacoleo, from the nearer resemblance of its laniaries and of the jaw working them to those of the Cat, would show, also, some difference from the Hedgehog in the snapping or seizing of its prey. But Professor FLowER, in a question of such importance to Physiology as the reconstruction of Thylacoleo, should have defined the 'total difference' between the mode of application by the Hedgehog of its 'approximate' laniaries and that of the application of the Cat or Stoat of their ' divaricate' ones in the killing of a young Rabbit: for the Hedgehog invades the burrows of the prolific rodent to devour the offspring; it is by no means exclusively insectivorous.

Was the well-armed mandible, with its low and advantageous joint for a strong grip. applied by Potamogale in piercing, holding, and killing its fish in so different a fashion from that of the like mandible in Lutra, as to lend any countenance to the assumption that the juxtaposed long terminal incisors of the lissencephalous Otter were put to the service of an herbivore-to the same service as they are in the Koala, e.g.? Yet, if Professor FlowER's argument and diagrams \$ mean any thing, they mean this!

The Thylacoleo's approximate incisors $\oint$ are relatively as long, as sharp, as laniariform as are those of Potamogale; and if we turn to the teeth (Plate XIV. $p_{2-4}, m_{1,2}$ ), which tell us truly the use to which such incisors were put, they speak directly and plainly that it was for capturing and killing a higher prey than fishes.

Comparison of the Teeth of Thylacoleo with those of Phascolarctos.-The light thrown by the large carnassial and small tubercular teeth on the application and function of the laniaries of Thylacoleo is sought to be obscured by conjectural figures of the structure of those laniaries and of the jaw that works them.

In fig. 2 (XII. p. 312), entitled "Thylacoleo carnifex restored," Professor Flower represents the incisors with truncate summits, like those of an herbivorous marsupial. This restoration is reproduced in Cut, fig. 4. The carnassial of Thylacoleo (ib. $p$ ) has features

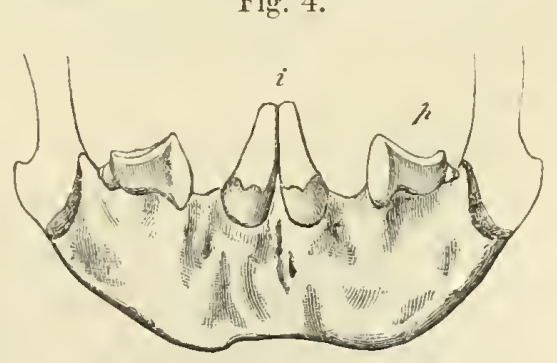

Front view of mandible and tecth (Thylacoleo), as restored, one-third nat. size, by Professor Flower (XII. p. 312, fig. 2).

* Philosophical Transactions, 1859, p. 319. † XII. p. 318. ‡ XII. p. 317, \& pp. 312, 313, figs. 2, 4, 5.

$\S$ These teeth are represented too broad in proportion to their length, or too short in proportion to their breadth, in XII. fig. 2. 
too broad and pronounced to be misunderstood. The herbivorous Marsupial selected

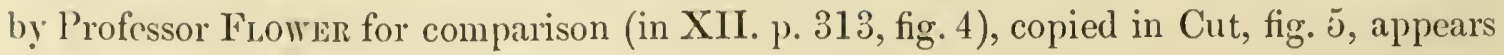
to have a similar camassial $(p)$; but this appearance is due to the foreshortening of the series of the grindingteeth of the Koala.

My business here is simply to set forth the facts which gruide to a right conclusion, and to put them as correctly as I am able. The incisors of Thylacoleo are neither truncate nor flattened by attrition at their ends; their character, from nature, is given, of the natural size, in the front view of the mandible (Plate IX. fig. 3). They may be blunted by use, or the point may be broken off,

Fig. 5.

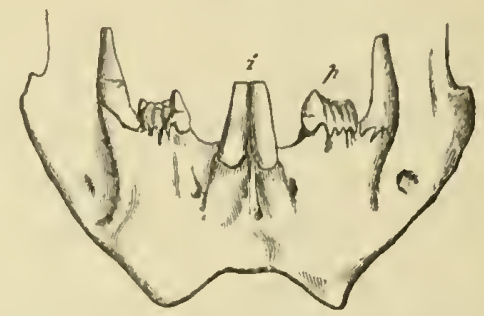

Front riew of mandible and teeth (Phascolaretos), three-fourths nat. size (after Professor FLower, XII, p. 313, fig. 4). as in figures 1, 4, Plate IX., from the photograph No. 10. The laniaries of an old Lion usually show the same effects of usage. Professor Flower gives a front view of the incisors of Phascolarctos, and a side view of the incisors of Hypsiprymnus; but a view of the working surface, from which the best idea can be formed of the use to which such incisors, in the two Marsupial herbivores, are put, is not given. I have supplied this omission in the upper figure of Cut $6, i$, where the working surface of the lower incisor of the phytophagous diprotodont Marsupial may be compared with that of the zoophagous one (Plate IX. fig. 7).

Returning to Curier's test of the diet of an extinct animal, which test gives the use of the long anterior teeth, whether canines or incisors, of such animal, I may recall attention to the single, small, - one may truly say, viewing the enormous carnassial against which it abuts-minute tubercular in the upper jaw of Thylacoleo (Plate VII. fig. 3, $m_{1}$ ).

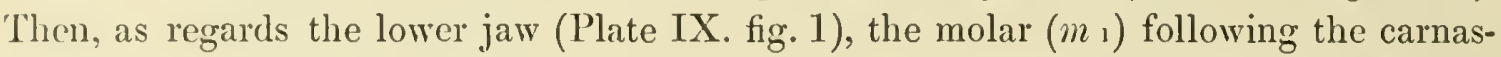
sial $\left(p_{4}\right)$ has the anterior half of the crown compressed transversely, the sides converging to a trenchant margin: this approximation to the form of its homologue in Felines, from the close and extensive abutment of the tooth against the upper carnassial, forms a continuation of the shear-blade structure, and gives the lower blade an extent equal to that of the larger carnassial above. The tubercular part of $m$, below forms a mere basal talon to the carnassial part of that tooth, whilst $m_{2}$ is a truly minute tubercular, and, seemingly, soon lost.

The demonstrated structure of the laniaries of Thylacoleo is in harmony with the zoophagous work which the molar teeth are plainly designed to transact.

Now, being solely desirous to test Cuvier's principle in reference to the approximate pair of long incisors of Phascolarctos, I subjoin what is essential to such test, and what Professor Fluwer omits, viz. a side view of the dentition of the Koala, reduced one-half, together with a view of the grinding-surface of the molar teeth, natural size (Cut, fig. 6), corresponding with those of the Thylacoleo shown in Plate XI. fig. 3, Plate XII. fig. 3.

The tooth $\left(p_{4}\right)$, probably homologons with the carnassial of Thylacoleo, and that which most resembles, or rather least differs from, it in the shape of the crown, occupies less than one-eighth of the dental series in Phascolarctos, in Thylacoleo it occupies nearly 
one-half; in Phascolarctos it forms one-fifth of the molar series, in Thylacoleo it forms two-thirds of that series; these proportions are masked in the foreshortened view, fig. 5 .

The premolar in the upper jaw of the Koala $\left(p_{4}\right.$, fig. 6) presents a flat surface, with a breadth of crown two-thirds of the length, the surface being slightly raised by a border of thick enamel at the periphery, and by a plicate island of enamel in the middle. It is a true pounder of vegetable substances, with the structure of a typegrinder of an herbivore. Such contrast in proportions, structure, form, and function with $p_{4}$ in Thylacoleo*, as is presented by the tooth $\left(p_{4}\right)$ of Phascolarctos, would not be surmised by an uninstructed comparer of the imaginary restoration of Thylacoleo (fig. 4, copied from XII. fig. 2) with the corresponding view of its alleged herbivorous analogue and ally (fig. 5, copied from ib. fig. 4).

Mandibular Characters of Camivorous and Herbivorous Marsupials.-A highplaced condyle is associated with the rotatory morements of the jaw in herbivorous Marsupials (fig. 6, $b$ ) as in herbivorous Placentals. Professor FLower's restoration

Fig. 6.

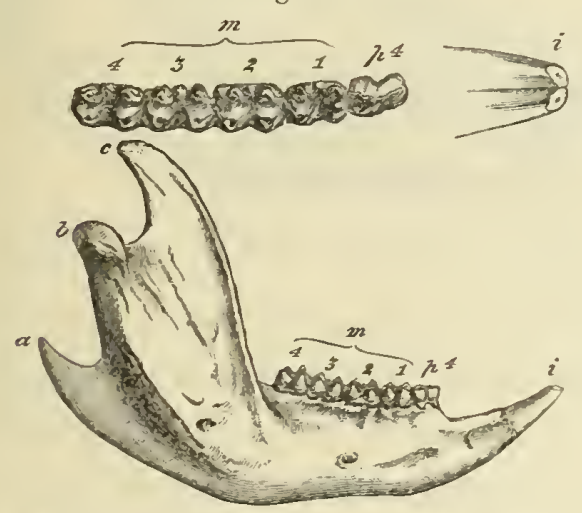

Mandible of Koala (Phascolarctos fuscus), one-half the natural size, and grindingsurfaee of teeth, natural size, from nature.
Fig. 7 .

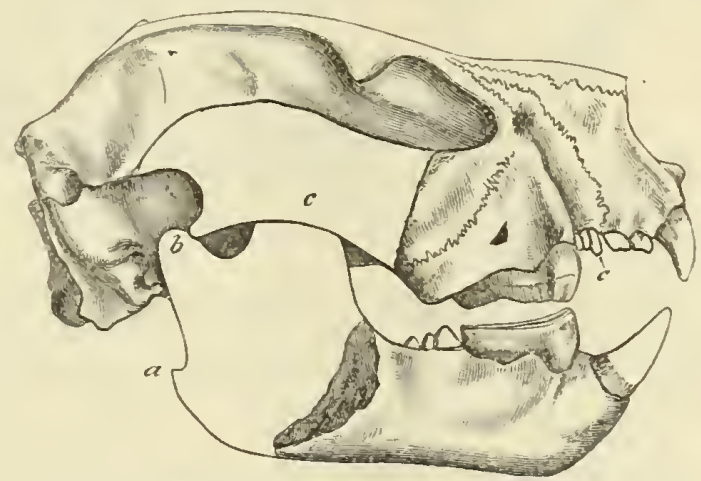

Skull of "Thylacoleo carnifex, restored," one-fourth natural size (after Flower, XII. p. 312, fig. 1).

(fig. 7 , copied from XII. p. 312, fig. 1) gives a similar position to the mandibular condyle $(b)$ in Thylacoleo, and the angle $(a)$ is there indicated after the pattern of the lower jaw of the Koala (fig. $6, a$ ).

The first fossil mandible of Thylacoleo which permits a deduction to be made of the relative position of the parts in question (Plate VIII. figs. 1 \& 2, and Cut, fig. 8), demonstrates the fallacy of the restoration in fig. 7, and shows a structure harmonizing with powerful vertical morements of the mandible, not with the horizontal grinding required for the comminution, and mixing with abundant saliva, of vegetable matters.

Fig. 8.

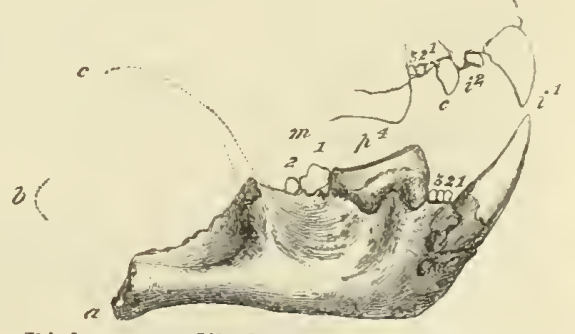

Pight mandibular ramus, mutilated behind, from nature, one-fourth natural size (Thylacoleo).

* Figured in Platc xI. figs. 1 \& 2, Philosophical Transactions, 1859. 
'The fact is patent; but the inference has been called in question.

Dr. Falcostar writes, in June 1862, "Next, as regards the depressed position of the condyle-below the level of the grinding-tecth. 'The author of 'Palæontology' states that it is 'a character unknown among any herbivorous or mixed-feeding animal.' I again refer my reader to the figure (pl. 34. fig. 13) of the lower jaw of the Aye-aye"*. 'This figure is essentially the same as that in my Memoir read before the Zoological Society, January 14th, 1862 (fig. 9). Prior to that date the depressed position of the condyle to the level of the grinding-teeth (fig. 9, b) was a character unknown in any herbivorous or mixed-feeding animal; it is still so unknown as depressed below that level, such as we sce it in Plagiaulax (fig. 10). Dr. Falconer, proceeding with his evi-

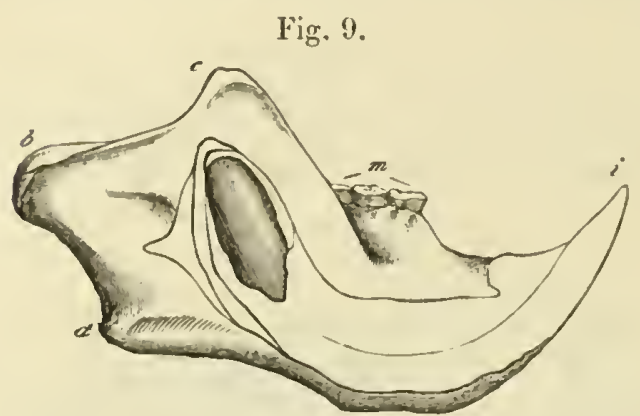

Handible of Chiromys Hadagascariensis, natural size (Zool. Trans. rol. r. pl. 20. fig. 9, Memoir of January 14, 1862).
Fig. 10.

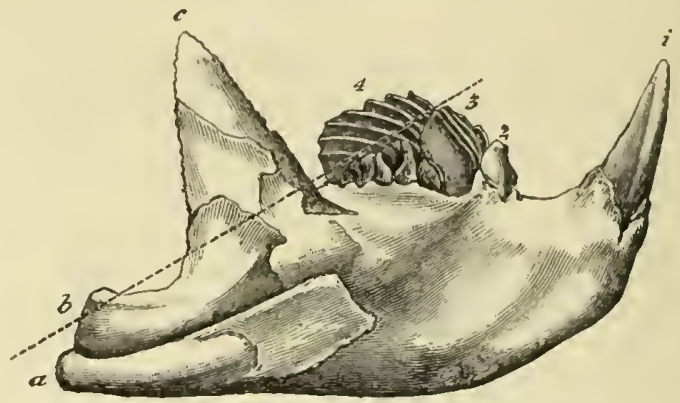

Iandible of "Plagiaulax Becllesii, magnified four diameters" (after Falconer, XI. pl. 34. fig. 1).

dence of the herbivority of the gnawing Lemur and his comparison of its mandible with that of Plagiaulax, admits that "the condyle looks still more depressed in Plagiaulax Becklesii; but this is, in part, owing to the inflected margin of the angle being broken off in the fossil, while it is cntire and salient in the recent form, thus elevating the condyle above the lower plane of the ramus, and leading to an appearance of a greater amount of difference than exists in nature" $\downarrow$.

Here we are at issue on a matter of fact. I affirm that the condyle ( $b$, fig. 10) in Plagiaulax would not be so elevatcd above the lower plane of the ramus if the angle ( $a$, fig. 10) were entire and salient, because the saliency has an inward, not a downward, direction. The correspondence in this respect, as well as in the low position of condyle, of Plagiaulax with the carnivorous Thylacoleo, Dasyures, and 'Thylacines, and its difference from the herbivorous marsupials (fig. 6) and larvivorous Lemur (fig. 9) is as clearly demonstrated in the Purbeck fossils, as if the inflected angle had received no fracture whatever.

For other differences of mandibular structure and configuration between Plagiaulax and Chiromys, invalidating Dr. FALCONER's argument in favour of a common herbivorous or rodent nature associated with a common depressed position of condyle, I refer to figs. $9 \& 10$.

In reference to the subject of the latter illustration, Dr. FALCONER has remarked, "Pro* X. p. 361 ; XI. p. 445. + X.p. 361 ; XI. p. 446 . 
fessor OWEN meets the argument in my paper by the assertion that the condyle of Plagiaulax is 'pedunculate, as in the predaceous marsupials.' If so, I invite him to adduce the instance, bearing in mind that the question here is one of degree*".

The virtual acceptance of this "invitation" had been given years before in the instance of the Phascolotheret, which, like Plagiaulax, is an extinct marsupial carnivore from an oolitic deposit.

The required structure is shown in the Cut (fig. 11,b) of the articular extremity of Fig. 11.

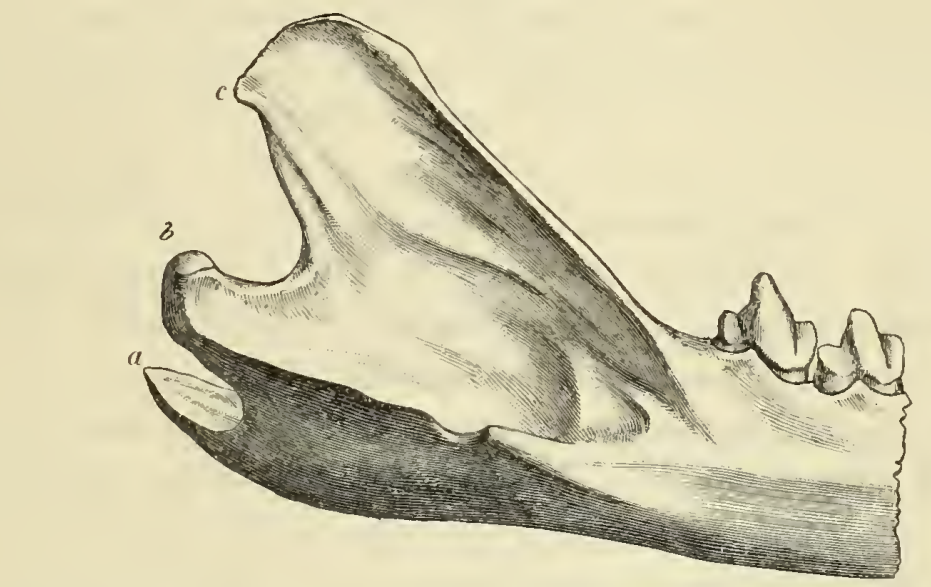

Articular end of mandible, Thylacinus cynocephalus: two-thirds nat. size.

the mandible in Thylacinus cynocephalus\$. In nearly the same degree is the condyle pedunculate in Potamogale (fig. 3, p. 150), and in a somewhat less degree in Sarcophilus (fig. 12, b).

Fig. 12.

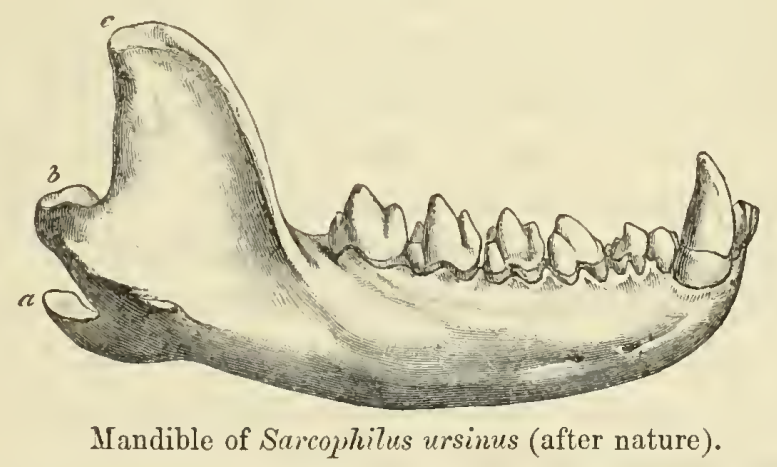

I may assume that the extent of condylar prominence and position in the instances cited will be admitted to have justified, as, indeed, they formed the basis of, the assertion of the community of the "pedunculated condyle," such as it is shown in figs. $10 \& 11$ at $b$.

* X.p. 362 ; XI. p. 447.

+ Transactions of the Geological Society of London, 2nd series, vol. vi. (1839) p. 58, pl. 6.

$\mp$ See 'Descriptive Catalogue of the Osteological Series contained in the Museum of the Royal College of Surgeons of England,' 4to, 1853, p. 347. nos. 1903-1908. 
It will be observed that, in the Thylacine-the most carnivorous of modern Marsupials-the depth of the notch between the condyle $(b)$ and coronoid $(c)$, or what I)r. FALconen indicates by the term "pedunculate," is relatively greater than in Sarcophilus. The two recede in this respect progressively further from the Koala and the Aye-aye. If Plagiaulax had shown less degree of "pedunculation" and a higher position of the condyle than in Thylacinus or Sarcophitus, and had, in these respects, approached nearer to Chiromys or Phascolarctos in mandibular modifications, an inference of corresponding atproximation in diet, or herbivorous application of jaw, would have been legitimate. I claim the same quality for my conclusion, that as the carnivorous characters of the lower jaw are maximized in Plagiaulax (fig. 10) with strong indications of the same structure in Thylacoleo (fig. S), so the carnivority of both genera is the more plainly demonstrated.

It is not, however, a solitary character, but an association of characters, which establishes this conclusion. In Sarcophitus the inner wall of the ramus above the symphysis, as in Thylacoleo, is broad, nearly horizontal, gaining breadth as it recedes and extending back to the third premolar. The symphysis is more extensive, and unites together more firmly the rami of the jaw in Sarcophilus and Thylacinus than in Poëphaga. In the Kangaroos it permits the scissor-blade movements of the horizontally flattened procumbent incisors. In Bettongia the symphysis does not reach backward to the socket of the single premolar. Thylacoleo and Plagiaulax resemble the existing marsupial C'armivora in the extent of the mandibular symphysis, and in the firmness of the union of the parts so joined together.

Position of condyle relates to the force with which the mandible is worked, shape and pedunculation of the condyle to the direction of the working force.

The flattened or less convex articular surface favours the rotatory movements; the more convex, especially transversely extended and pedunculate or subpedunculate, condyle indicates the ginglymoid articulation with greater extent of divarication or wider gape, and more habitual morements of the jaw in one plane, or limited more or less thereto. 'The rotatory grinding movements of the mandible are commonly associated with a high position of the condyle and vegetable diet; the vertical biting movements are commonly associated with a low position of the condyle and animal diet. But the advantage of a long lever afforded by a lofty coronoid process (figs. 10,11, 12, c) and low-placed condyle (ib. $b$ ) may correlate with powerful biting and gnawing actions, as in the working of the naximized scalpriform teeth of Chiromys (fig. 9,i).

Here, however, the coronoid $(c)$ is comparatively low: the condyle (ib. $b$ ) is narrow; its convex curve is chiefly longitudinal, or from above downward; there is no constriction or neck; the supporting part of the articular surface is continued directly upward and forward to the coronoid $(c)$, and almost as directly downward and forward to the angle $(a)^{*}$.

In similarly placed condyles for biting, piercing, lacerating, and killing actions of the

* Owex, 'Monograph on the Aye-aye,' 4to, 1863, p. 20.pl. 8. figs. 7,9 (also 'Transactions of the Zoological sincietr,' vol. v. pt. 2. pl. 20. figs. 7, ?). 
mandible, and where such condyles are associated, as is the rule, with laniariform not with scalpriform anterior teeth, the condyle is more prominent; the part of the ascending ramus supporting the condyle curves toward the coronoid process, in a course at first more or less deeply concave, then vertical or recurved; and a similar well-marked concavity divides the condyle from the angle of the jaw, save in the most decidedly zoophagous of the Marsupialia (Sarcophilus, Thylacinus, Plagiaulax), in the latter of which the convex condyle forms, as it were, the upper and back part of the angle itself.

The condyle in Plagiaulax (fig. 10, $b$ ) projects a little below the horizontal level of the alveolar series; in Chiromys and Carnivora it is on that level. But if the mandibular condyle in Plagiaulax agreed in all characters with that of the rodent Lemur, this would not show Plagiaulax to be a vegetable feeder. The direct testimony of the insectivorous or rather larvivorous habits of the Aye-aye is too strong and too sure to be done away with by the enforced food on which a captive individual may have been compelled artificially to subsist.

However, for the instruction of any physiologist or palæontologist who may still deem the position of the condyle in Chiromys to throw light upon the food and nature of Plagiaulax and Thylacoleo, it may be stated that in every secondary mandibular character Plagiaulax differs from Chiromys, and resembles Sarcophilus, Thylacinus, and Phascolotherium*. The supporting part of the condyle sinks below the transversely extended upper part of the convex articular surface, before curving forward and upward to the coronoid, leaving an entering notch between that process and the coronoid which, in the type specimen of Plagiaulax Becklesii (fig. $20 \mathrm{~F}$, p. 178), closely corresponds in form with that in Thylacinus and Phascolotherium.

The fractured line of the angle of the jaw is not beneath the neck of the condyle, but on the inner side of the inferior border of the rising ramus passing to the lower end of the condyle. 'That part of the angle which has been broken off did not extend, as Dr. Falconer states, below the condyle as in the Aye-aye, but to the inner side thereof, as in Sarcophilus, Thylacinus, and Phascolotheriumt.

Whoever may have watched a living Thylacine or Ursine Dasyure must have been struck with the width of its gape. The extent of such motion of the mandible is due to the freedum of the joint (figs. 11, 12, 6 ) and its distance from the moving lever $(c)$. The like or even greater relative backward position of the condyle must have equally or more favoured "the power of separating the jaws in front essential to a predaceous animal having laniary teeth," like those of the Thylacoleo and Plagiaulax (fig. 10), "constructed to pierce, retain, and kill" \$. And we have direct proof in the sessile condition of the condyle in the Aye-aye that the power of separating the jaws was more restricted in that carnivorous and rodent Lemur.

* British Fossil Mammals, 8ro, 1846, p. 65.

† It is this "broad" part of the condyle which gives it the "ovate or pyriform outline" (XI. p. 445). In Thylacinus and Sarcophitus a part of the articular surface also extends down from the back of the condyle.

$\ddagger$ XI. p. 447 . 
Testimony as to the native food of the Aye-aye.-The advantage to the forcible action of the jaw by the backward position of the condyle is recognizable, whether the fore teeth of the jaw be fashioned for "biting," i.e. piercing as a dagger and becoming infixed in a prey, or for "croding" hard wood, as a gouge or chisel.

Modifications of the mandible might be expected to be associated with the different actions and applications of the fore teeth, aided or advantaged by the carrying back the condyle and lengthening the lever of the biting powers.

Prior to 1861 such backwardly placed as well as low-placed condyle was not known in ally real or alleged herbivorous or mixed-feeding animal. The anatomy of Chiromys added, in that year, the interesting and instructive exception (admitting the Aye-aye to be a mixed feeder). If it had been contended that the lower-placed condyle shown in Plagiaulax, and deducible in Thylacoleo, was absolute, independently of other characters and considerations, in demonstrating the carnivorous nature of these marsupials, the discovery of the structure of the mandible of the Ayc-aye would have placed a seeming objection and a feasible argument in the hands of an advocate of the non-carnivorous character of Thylacoleo and Plagiaulax. If it were proved that the Aye-aye is a vegetable feeder, not to say herbivorous, the same advantage would be his who had interpreted the fossil remains of Thylacoleo and Plagiaulax, notwithstanding the low-placed condyle, as those of vegetarians, having their nearest affinities " to the marsupial herbivores, such as Halmaturus, Hypsiprymnus, and Phascolarctus"*.

But the only testimony we have at present of the natural food of Chiromys shows it to be "carnivorous" in the sense of subsisting on the flesh or insect-tissues of wood-boring larvæ; all the peculiarities of its structure are physiologically or teleologically intelligible only on this basis. Huxter, it is true, made his captive Sea-gull subsist wholly on grain $\phi$, and induced a Kite to eat and thrive on bread alone $\$$.

Save for loyalty to truth in the abstract one might be willing to accept the evidence adduced by Dr. Falcover $\oint$ of the food given to captive Aye-ayes as proof of its being naturally a vegetable feeder; but I believe the position of the mandibular condyles to be related to the powcrful working of the pair of incisors. Such work is not necded for dividing the stems of rice or the stalks of dates or bananas. Nor are the Aye-aye's conditions of condyle present in Hypsiprymnus or in any other vegetable feeder. No one can admit the Ayc-aye to be a strict vegetarian who gives credit to the subjoined testimony :-

"It so happened that the thick sticks I now put into his cage were bored in all directions by a large and destructive grub, called here the Moutouk. Just at sunset the Aye-aye crept from under his blanket, yawned, stretched, and betook himself to his tree, where his morements are lively and graceful, though by no means so quick as those of

* X. p. 352 ; Xi. p. 435 .

+ Hoмe, 'Lectures on Comparatire Anatomy' 4to, vol. i. p. 271. Owex, 'Catalogue of the Physiological Series, Museum of the Royal College of Surgeons,' 2nd ed. 8 ro, p. 151, prep. no. 523.

† Hoxter, 'Animal Economy', Owex's Ed. 8ro, 1837, p. 112.

$\S$ X. p. 36t; XI. p. 449. 
a Squirrel. Presently he came to one of the worm-eaten branches, which he began to examine most attentively; and bending forward his ears, and applying his nose close to the bark, he rapidly tapped the surface with the curious second digit, as a Woodpecker taps a tree, though with much less noise, from time to time inserting the end of the slender finger into the worm-holes as a surgeon would a probe. At length he came to a part of the branch which evidently gave out an interesting sound, for he began to tear it with his strong teeth. He rapidly stripped off the bark, cut into the wood, and exposed the nest of a grub, which he daintily picked out of its bed with the slender tapping finger, and conveyed the luscious morsel to his mouth. I watched these proceedings with intense interest, and was much struck with the marvellous adaptation of the creature to its habits, shown by his acute hearing, which enables him aptly to distinguish the different tones emitted from the wood by his gentle tapping; his evidently acute sense of smell, aiding him in his search; his secure footsteps on the slender branches, to which he firmly clung by his quadrumanous members; his strong rodent teeth, enabling him to tear through the wood; and lastly, by the curious slender finger, unlike that of any other animal, and which he used alternately as a pleximeter, a probe, and a scoop"*.

SoNNERat, besides specifying the compulsory food on which his captive Aye-aye perished in two short months, not being able longer to sustain life thereon, describes the long slender naked middle digit:- "il s'en sert pour tirer des trous des arbres les vers qui sont sa nourriture" $\uparrow$. I understand this to mean that larvæ-"vers"-are its natural or staple food. The affirmation may hare been made from Sonnerst's observations on Chiromys in a state of nature, or on the reports of natives of Madagascar, or on both authorities. It is a better testimony of its natural "nourriture" than the compulsory diet of confinement, and ought to be quoted in a consideration of the present important question.

For to what condition is Comparative Anatomy reduced if we reject the testimony which Dr. Falconer does not cite, and admit, upon the testimony he does cite, that Chiromys is a vegetable feeder! Were the scalpriform teeth enabled, through the low position of a terminal condyle, to gouge out the hard woody fibre for food in order that the animal might masticate such fibre? Only upon this hypothesis could Chiromys be cited as an exception to the correlation of such position of mandibular joint with animal diet. But xylophagous habits involve complex ever-growing molars, like those of the Voles, the Beavers, and Capybaras. A reference to the molar teeth of the Aye-aye at once indicates its true diet, and the part played by the lower jaw and its chisels in obtaining it. Observation of the living animal in its native woods vindicates the Cuvierian principle, and gives the rational explanation of both dental and maxillary inachinery. Instead of being an exception, the low condyle enters into the rule of its association with the getting of food of an animal nature.

* Letter from Dr. Sandwitr, quoted in "Owex on the Aye-aye," Trans. Zool. Soc, rol. v. pt. 2. 1863, p. 37.

† Tojage aux Indes Orientales, \&c., Paris, tto, 1782, p. 122. 
Now let us return to the application of the Aye-aye's mandibular structure to the explanation of that in Thylacoleo and Plagiaulax. "The large front teeth in Chiromys are curved in segments of circles, the working surface is elongate, in breadth equalling that of the base of the tooth, with a front convex enamelled border, forming the obtuse apex of the gouging surface" *.

With what molirs are these scalpriform teetl associated? Few, small, tubercular. Adapted for squeezing the soft animal nutriment out of the tegumentary covering of a caterpillar, not adapted for trituratory mastication of such vegetable food as calls for the more complex and massive molars of the Kangaroos, Potoroos, and Koalas. With what kind of teeth is the low-placed and backwardly placed condyle of Thylacoleo and Plagiaulax associated? and what may be the diet indicated by such association? For the response to these questions the palæontologist, guided by the Cuvierian principle, refers to the great carnassial and the small tubercular molar teeth.

Comparison of the Mandibular Condyle in Thylacoleo, Plagiaulax, and Rodentia. - In placental Rodents the mandibular condyle is longitudinally horizontal, transversely convex; its long diameter is from before backward; it represents the section of a cylinder. The glenoid cavity of Thylacoleo shows that its condyle has been convex from before backward or longitudinally, and with its long diameter transverse; not limiting the jaw, as in Rodents, to horizontal morements chiefly to and fro, but adapting the jaw to hinge-like vertical motion, needed for the due action of the terminal laniaries and the large carnassials.

The mandibular condyle in the more ancient and smaller Marsupials with a closely analogous dentition is demonstrably similar to that which is here inferentially ascribed to the condyle of Thylacoleo. It is in Plagiaulax convex longitudinally, or from before backward, and that in so great a degree that the most prominent part of the convexity looks backward. "Its long diameter is disposed subrertically, and the outline is ovate or pyriform, the broad end being uppermost" $\uparrow$. This broad end is the transversely extended part of the convex condyle\$. Dr. FALCoNer, nevertheless, affirms that the form of condyle presented by Plagiaulax is "common in the placental Rodents" $\$$; yet is constrained to add, "with the difference, liowever, that in the latter the condyle having to work backwards and forwards in a groove, its articular surface is disposed longitudinally" $\|$.

But this difference precludes an ascription of community of form of condyle between Plagianlax and Rodentia; and in so far as the difference is such as to enable the con. dyle in Plagiaulax to work the jaw upward and downward, or vertically, it lends itself to those actions which the jaw has to perform "among the Carnivora."

The kind and degree of difference which the mandibular condyle presents in Chiromys and in Plagianlax, already pointed out, in like manner illustrates its application in the

* Orex, 'On the Aye-ayc,' 4to, 1863, p. 25. $\uparrow$ X. p. $360 ;$ XI. p. 445.

$\ddagger$ Owev, Monograph on British Mesozoic Mammalia, pl. 4. fig. 10, A, c \& B.

$\S$ X.p. $360 ;$ XI. p. 445.

If Id. ib. 
latter to predatory actions, and is consequently and concomitantly associated with a difference of form of the entire mandible: that part in Plagiaulax conforms with the lower jaw in Sarcophilus and Thylacoleo in as marked a degree as it differs from the mandible in Chiromys, in placental Rodents, in Phascolarctos, and in Hypsyprimnus.

Comparison of Incisors of Diprotodont Paucidentata with those of Chiromys and Rodentia.-Thylacoleo and Plagiaulax, it is affirmed, "agree with Chiromys in the collateral position and upward direction of their strong incisors"*. Doubtless; but they differ in the character of the terminal surface indicative of the kind of work to which those incisors were respectively put in Thylacoleo and Chiromys. Admitting the Aye-aye to be "as rare and aberrant among existing Mammalia" $\uparrow$ as are Thylacoleo and Plagiaulax" among fossil Marsupials, yet the Aye-aye shows on its lower front teeth a long smooth sloping surface, the result of the scraping, cutting, chisel-like action of the opposed scalpriform incisors\$.

Thylacoleo and Plagiaulax preserve the pointed termination of the lower incisors, or if they be blunted or broken, they show no signs of habitual attrition. Chiromys combines a compressed form with peculiar fore-and-aft breadth of the incisor, which has its thick enamel limited to the front border and to a contiguous portion of the sides, but coextensive in length with the deeply implanted tooth. The lower incisors of Thylacoleo and Plagiaulax have the proportion of transverse to fore-and-aft breadth, and the continuous sheath of enamel (Plate XIII. fig. 8) limited to the exposed crown, which are characteristic of the laniaries in Potamogale and Felis: consequently the crown or exposed part of the long and large incisor of Thylacoleo and Plagiculax is that alone which is curved, and the division into crown and root is recognizable. The entire scalpriform incisor of Chiromys, like that of true Rodents, is curved in the segment of a circle $\S$ and the tooth (fig. 9, $i$ ) preserves its diameters of depth and breadth from the end of the worn, sloping, eroding surface of the crown (i) to the base of the implanted part, and this part is much longer, with a concomitantly longer socket, than in Thylacoleo and Plagiaulax. The above-defined broad and striking differences between the lower incisors of Chiromys and those of Plagiaulax and Thylacoleo militate strongly against the conclusion of Plagiaulax and Thylacoleo being Marsupial forms of Rodent, or "Rodent types of Marsupial" $\|$, and are decisive against the alleged "clear eridence of their phytophagous and rodent plan of construction" $\%$.

Dr. Falconer pursues his argumentation as follows:- "Let us now consider Owen's inference as to the function of these teeth. It is expressed thus: "The large front tooth is formed to pierce, retain, and kill ; the succeeding teeth are like the blades of shears, adapted to cut and divide soft substances like flesh,' \&c. Professor OWEn has elsewhere described the premolar of Iyypsiprymnus as trenchant**, and I have shown above

* X.p. 364 ; XI. p. 449.

+ Id. ib.

$\ddagger$ Owes, 'On the Aye-aje,' \&c., pl. 20. fig. 3.

$\S$ "The incisors are long, large, much compressed, regularly curred in segments of equal circles, the upper pair describing onc-fourth, the lower pair one-half of such circle."-OwEx, op. cit. p. 55.
II X. p. 349 ; XI. p. 431.
T X.p. 353 ; XI. p. 436.
*** Odontography, rol. i. p. $3 \triangleleft 9$. 
that the tooth is essentially alike in Plagiaulax," (as Professor Flower contends that it likewise is in Thylacoleo*). "If, therefore," proceeds Dr. Falcoser, " the function is to be deduced with such facile certainty from the mere form, the premolar of Hypsiprymnus ought also to be carnivorous. But we know that the genus is so strictly herbirorous that the family to which it belongs lias been regarded as representing in the Marsupialia the Ruminants of the placental Mammals. With this fact before us, is it likely that the premolars of Plagiaulax and Thylacoleo "were applied to cut and divide flesh'?"

'T'o this I reply; consider the difference of the molar tecth following the trenchant one in Plagiaulax and Hypsiprymnus respectively, and the true solution will be given $\$$.

Interrupted and continuous applications of Teeth.-The decluction of the carnivorous nature of the extinct Marsupials in question was drawn not from shape merely, but from correlation of teeth. The "arbitrariness," if such quality be predicable of the conclusion, is applicable to the guiding principle, not to the palwontologist confiding therein. If reference to confirnatory and collateral facts was omitted in the Papers of 1859 and 1869 , it was under the belief of their being the common property of the interpreters of fossil remains.

In the adaptively modified dentition of the class Mammalia the differently shaped tecth are put, some to occasional and interrupted, others to continuous use. The incisors of the child biting a piece of bread and butter exemplify the first functional character; the molars which pound the piece bitten off, the second. These incisors are trenchant or sharp-edged like the premolar of a Bettong or the carnassial of a Cat; their action in the human subject leaves a clean semicircular border of the bitten slice. The tecth, of whatever kind, incisors, premolars, or molars, which have the continuous work show its effects by an abraded surface. Those which have the occasional and interrupted work show little or no indication of such. The laniaries of Carnirora, when they have pierced and lacerated the prey, have done their work; the gnawing off of the pieces of flesh adapted for the imperfect tubercular mastication and for deglutition is effected by continuous action of the sectorial blades, the mouth being turned sideways to the food, as may be seen in the Felines and other Carnivore which have the largest and best-shaped carnassial teeth. Such action and application of these teeth are exemplified by the clean-worn, smooth, oblique surface sloping in the opposed blades down their opposite and opposed sides.

"The same functional character, relating, that is to say, to "time" or "prolongation of use," is indicated by the incisors. Those in Thylacoleo and Plagiaulax show no evidence

* XII. p. 310. "The great eutting premolar of Thylacoleo bears no real comparison with the carnassial tooth of the Carnirora, but with the eompressed premolar of the IIypsiprymni."-Ib. p. 316.

+ X. p. 356 ; XI. p. 440.

$\ddagger$ Dr. FAlcoser, indeed, does strengthen his attack by ealling in the argument from correlation; but he selects a different tooth from that of the Curierian prineiple:- "When this eonelusion as to the herbivority of Plagiumlax" and Thylucoleo "from similar trenehant charaeters of premolars with those of IIypsiprymnus is coupled with the obriously phytophagous type of the incisors, the conviction will be confirmed."-X. p. 357; XI p 440. 
of mutual continuous attrition. In Rodents, whether placental or marsupial, the oblique surface of wear or use in both upper and lower pairs of the large front teeth has suggested the comparison with the chisel, and the term "scalpriform." Such incisors have a trenchant margin as the human incisor has; but the superadded sloping surface of attrition in the Rodent indicates the continuous as distinguished from the occasional application of such front teeth. The Lemurine Aye-aye presents the same character as a guide to the inference of function of incisors, and at once exemplifies the difference of such function and that of the homologous pairs of pointed unworn teeth in Thylacoleo and Plagiaulax.

It is proper, in pursuing comparisons for the purpose of arriving at truth, that, besides the front view of the incisors of the Koala*, we should contrast their working surface (fig. $6, i$ ) with that in the corresponding teeth of Thylacoleo. A comparison of Cut, figure $5, i$ with figure 3, Plate IX., will show that the one has the continuous or frequent action, the other the intermittent and occasional. It is evident that the six incisors of the upper jaw, as well as the lower pair, in the Koala, work much and continuously in cropping and gnawing off the vegetable food which the large, numerous and complex grinders (fig. $6, \mathrm{~m}$ ) pound to pulp for the bolus of deglutition.

A minor but sufficiently conspicuous degree of attrition characterizes the narrower upper and the lower procumbent incisors of the Bettongs and Rat-Kangaroos.

In the Bettongia penicillata, with such worn incisors and with all the molars in place and showing habitual use, the trenchant premolar retains its vertical groovings to the cutting-edge of both the outer and inner sides. They have been used to divide the grass-blade or the leaf-stalk, or other tough part or fibre of the vegetable food; but the more important and continuous work of mastication has had grinders in number, size, massiveness, and complexity of horizontal area fitted to perform it. Old age is attended with seeming exceptions to this rulc in both human incisors and hypsiprymnal premolars, which then show the wear or work of a life.

Independently of the correlative guide, the worn surfaces of the Thylacoleo's carnassials show, like those of the Lion's, and like the scalpriform incisors of the Rodents, that their work and office were of the continuous kind; which, with their shape and position in the jaw, was for flesh-cutting, not for wood-cutting, or leaf-cutting or grass-cutting; for the succeeding few and small tuberculars could do nothing to the purpose with slices of such vegetable substances.

How far this deduction of function from mere form may be "facile" or "arbitrary" it is not for me to say; but it by no means authorizes any one to infer, because the correlation of the premolars of Thylacoleo and Plagianlax with few and small tuberculars and large laniaries favours their carnassiality, that "the premolars of Hypsiprymnus ought also to be carnivorous" $\uparrow$. All that the mere form of that tooth shows is, that it cuts. What manner of substances were so cut can be inferred from the asso-

* Exclusirely given by Professor Flower in his advocacy of the herbivority of Thylacoleo, XII. p. 313, fig. 4.

† X. p. 357 ; XI. p. 440 ; also XII. p. 318. 
ciated teeth, more especially those defined by Cuvien as the fittest to yield the required information.

\$15. Work of Nolars in Herbivora. - Vegetable substances need for their assimilation not only dividing but crushing and reduction to pulp by commingling of salivary secretions during the grinding process. Hence large salivary glands are associated with numerous broad-crowned grinders. Palæontology is not left in so helpless a condition as it is made to appear in the following passage:- "There is no reason to suppose that the large trenchant premolars [of Thylacoleo] were not as well adapted for chopping up succulent roots and vegetables as for 'dividing the nutritive fibres' of animal prey"*. But my task has been to show, not only for what they were adapted, but what they did "chop up." "It may have been," proceeds the writer, "some kind of root or bulb; it may have been fruit"*. And so it may, according to the conditions of life and organization imagined by Professor Flower, but not according to those of the Creation open to our observations and comparisons. No known herbivorous Mammal is limited to teeth for slicing or "chopping up" vegetable food.

There is no difference, indeed, between X. and XII. on the main question at issue between them and me; but they are at variance between themselves on one point. Dr. Falcoxer was unable to resist the proofs of carnivority from the demonstrated molar dentition of Thylacoleo; but, having committed himself to a different interpretation of the like dentition in Plagiaulax, he defended his position with an ingenuity worthy of a better cause, and which excited in the author of XII. and others the sentiments expressed by the epithets " masterly," "amply demonstrated," \&c.

Professor Flower, however, with the unmistakable evidences of essential conformity between the dentition of Plagiaulax and Thylacoleo, consistently applied himself to show that Thylacoleo was as good an herbivore as Plagiaulax. He says, "Dr. Falconer, in his anxiety to show that Plagiaulax could not have been carnivorous, has endeavoured to scparate it as much as possible from Thylacoleo, laying great emphasis on all the points of divergence that could be found between them. He was evidently under the impression that the latter had been proved to be a carnivorous Marsupial, without staying to inquire into the arguments on which the assumption rested" $\uparrow$.

Family relations of Thylacoleo and Plagiaulax in the Marsupial Order.-Of the cxisting groups of pouched Herlivora Professor Flower, in his paper on the Affinities of the extinct Australian Marsupial, which is "branded with such a direful title as Thylacoleo carnifex" "w, inclines to select the Macropodidee as the one to which that Marsupial belonged; and, therein, more especially the Iypsiprymni or Rat-Kangaroos, in which he "sees at once in the great cutting premolar a miniature of that of Thylacoleo"\$.

In a "Postscript" he derives encouragement of his views from "some remarks "On the Dentition of Thylacoleo carnifex, Ow.' by Mr. Gerard Krefrt, the able Curator of the Australian Museum, Sydney, in the Ann. \& Mag. Nat. Hist. vol. xviii. ser. 3, p. 148,
* XII. p. 318.
$\dagger$ Ib. p. 308.
$\ddagger$ Ib. p. 314 .
$\S$ Ib. p. 310. 
1866;" accompanied by "a conjectural restoration of the then unknown anterior part of the skull and incisor teeth," which, Professor FLowEr proceeds to assert, "subsequent discoreries have in great measure confirmed"*.

I may here remark that, as my "Description of an almost entire Skull of the Thylacoleo carnifex," was "Received June 8,-Read June 15, 1865 " (Phil. Trans. 1866, p. 73), the anterior part of the skull and incisor teeth were not unknown in September 1866, nor at the date of Mr. KREFFT's paper, May 24, 1866. The degree of confutation which the restoration of the skull, according to the herbirorous hypothesis, has subsequently received, may be estimated by the comparison of fig. 7, p. 153 and fig. 13, with Plates VII., VIII. \& IX., and more especially with Plate X. of the present Work.

Mr. KREFFT in this communication, and in its conjectural illustration (fig. 13), inclines to refer Thylacoleo to the Carpophaga ${ }^{\dagger}$, deeming it "not much more carnivorous than the Phalangers of the present time+".

But in the "List of the Fossils from the Caves of Wellington Valley," appended to the 'Report to the Trustees of the Australian Museum regarding the examination of those Caves,' Mr. KRefFt writes:- " 5 . Teeth and bones belonging to the gigantic KangarooRat named Thylacoleo carnifex by Professor OwEx."

Of the same opinion I infer to be Mr. Boyd Dawkiss, F.R.S., from the following Fig. 13.

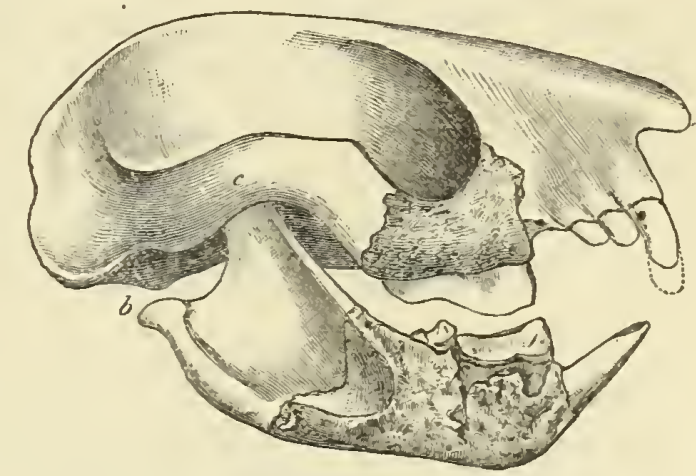

Restoration of the skull and teeth of Thylacoleo, by Mr. KRefFr, on the herbirorous hrpothesis. (Ann. \& Mag. Nat. Hist. 1866, vol. xriii. pl. xi.) passage in his instructive paper "On the Rhætic Beds and White Lias of Western and Central Somerset:"- "The presence of the Macropoda (Van der H.) (=Poёphaga, Owrs) is proved by the discovery of the Kangaroo-Rat allies,-viz. in the Purbeck beds, of the Plagiaulax, the true affinities of which have been so amply demonstrated by Dr. FALCorve $\oint$; in the Rhætic bone-bed, of the Microlestes of Frome and Diegerloch, closely allied, according to Professor Owex, to Plagiaulax (Palæont. p. 303); and, lastly, in the strata below the bone-bed, by the discovery of the Hypsiprymnopsis Rhaticus of the Watchet shore"ll.

To the evidence and question of the affinity of Thylacoleo and Plagiaulax to existing groups or families of the Marsupialia I next address myself.

The pouched Mammalia show two taxonomic modifications of the anterior mandibular

* XII. p. 319.

† For the definition of this Family, see "Classification of the Marsupialia," Trans. Zool. Soc. rol. ii. p. 322.

¥ Ann. \& Mag. Nat. Hist. 1S66, xriii. p. 149.

§ Quart. Journ. Geol. Soc. vol. xiii. p. 261, vol. xriii. p. 348.

II Id. ib. vol.xx. 186t,p. 412. But sce the examination of the grounds of the determination of this rhætic fossil as the tooth of a Potoroo, in the 'Prefatory Notice,' pp. S-10. 
teeth: in one, several pairs of incisors intervene between the canines; in the other, one pair of incisors of large size are present and no canines. 'The first condition characterizes the "polyprotodont section," the second the "diprotodont section"*. 'The existing representatives of the latter group of Mursupialia are confined to the Australasian area; some of the former group are American.

In botl sections there are nodifications of dentition, of digestive organs, and limbstructures, which in an interesting degree run parallel with each other; - the arboreal diprotodont Phalangers and Petaurists, $e . y$., with the Opossums and Phascogales, and the saltatory Bandicoots and Chceropus with the Potoroos and Kangaroos; while the gradatory carnivorous Polyprotodonts have no known existing diprotodont correlatives.

But my knowledge of mammalian organization does not autlorize me to assert that the diprotodont type of Marsupialia could not be so modified as to subserve carnivorous habits. I recognize no suficient ground for the confidence that predatory dentition must be associated with three or more incisors antecedent to the canine, or "by the interposition of a line of incisors" between the two canines of either the upper or lower jaw.

Dr. FalCoNer, in reference to the known Marsupial genera, asserts:- "In all the carnirorous genera and species, fossil or recent, of which the dentition has been accurately determined, there are three or more incisors, followed by a canine, on each side of the jaw, above and below; and the empirically observed result is consistent with a rational interpretation of the arrangement, in reference to their food and the means of procuring it. On the other hand, in all the existing strictly phytophagous genera, there is only a solitary incisor (being that next the axis) on either side of the lower jaw, and no conine" $\uparrow$. I shall presently inquire how far this alleged generalization applies to known existing species, premising that it can only be affirmed as bearing on the interpretation of the fossil remains of Thylacoleo and Plagiaulax, by demonstrating the inaccuracy of my determinations of the dentition of those extinct gencra, and by resting on the foregone assumption that no Marsupial genus can or could be carnivorous unless it had the canine or caniniform tooth preceded by three or more incisors, and that "a solitary incisor," however shaped and associated with other teeth, must make a "strictly phytophagous Marsupial."

My encleavours, and whatever success may have attended them, in the interpretation of animal structures, have depended mainly on careful aroidance of antecedent assumptions of the extent of sccondary modifications with which a dentition primarily fashioned for animal food might be associated. I leare my mind open, for example, to deduce consequences from observing the modifications of size, shape, and direction of the "solitary incisor on either side of the lower jaw," and the form, size, and number of the premolars, and more especially of the true molars associated therewith. To think or reason otherwise would be simply to argue in a circle, as thus:- "All carnassial Marslipial genera have incisors as well as a canine; ergo, no Marsupial genus with a laniari.

\footnotetext{
* Ores's 'Anatomy of Tertebrates' rol. iii. p. 293.
}

† X. p. 351; XI. p. 434. 
form tooth not preceded by incisors can be carnirorous. All phytophagous Marsupial genera have a pair of developed incisors, approximated and placed collaterally in the lower jaw as in placental Rodents; ergo, a Marsupial fossil mandible with such incisors must be of an herbivore." But it is affirmed:- "the incisors of Plagiaulax are framed, in regard to number, order of suppression, collateral position, and relation to the premolars, in exact correspondence with the type of the Marsupial herbivores, such as Halmaturus, Hypsiprymnus, and Phascolarctos, and wholly at variance with the Carnivorous type"*. And if considerations of the shape of the incisor, modification of its working end, angle of its projection, degree of curvature of the tooth, evidence of its temporary growth or otherwise be set aside, the same may be affirmed of the lower incisors of Thylacoleo.

Any one enjoying a sense of confidence in the impossibility of a modification of the diprotodont type of Marsupial dentition for carnirorous habits may well dispense not only with a consideration of all those characters of the teeth in question which truly point to their function, but also of the modifications of size, shape, and number of the molar teeth associated with such pair of lower laniariform incisors.

I am not cognizant of any facts subversive of the Cuvierian principle as to the teeth which should first be observed in an unknown fossil by the palæontologist in quest of the nature of its food, and I cleave to the belief of their primary importance as throwing light on the problem to be solved.

I have qualified Dr. Fulcover's generalizations even when restricted to existing Marsupials, as "alleged." Let me recall to the recollection of his followers some of the instances which invalidate the general averments adduced to show that Thylacoleo and Plagiaulax must be herbirorous because diprotodont.

The small insectivorous Marsupial Tarsipes combines with its two "well-dereloped, long, slender, and pointed lower incisors" $\$$, minute molars unfitted, as in Plagiaulax and Thylacoleo, for mastication of vegetable food. Its simple alimentary canal, only exceeding the entire length of the animal by about one-half, is "destitute of cæcum" the small Polyprotodont Phascogale $\oint$. "When intent upon catching flies it would sit quietly in one corner of the cage, eagerly watching their movements" $\|$.

According to the "fundamental principles which comparative anatomy supplied" to Dr. Falconen "for his guidance" (but which principles he nowhere defines), Tarsipes, like Thylacoleo and Plagiaulax, having "a pair of developed incisors approximated and placed in the lower jaw collaterally," should have been "phytophagous."

Let us test the contrasted conditions of the generalization as to incisors by another appeal to living Nature. "The Root-feeding Dalgyte"थ, or Australian "Native Rabbit" (Peragalea lagotis), is a miscellaneous eater. The specimen in the Zoological Gardens

\footnotetext{
* X.p. 352 ; XI. p. 435.

† WATERhorse, 'Natural History of Mammalia' (Marsupialia), p. 342.

$¥$ Op. cit. p. $3+3$.

\$ Owex, Art. "Marsupialia," Cyclopædia of Anatomy, vol. iii. p. 300, fig. 122 (Phascogale flavipes).

\|| Gould, 'Mammals of Australia,' rol. i. (Tarsipes rostratus).

T Gocld, 'Mammals of Australia,' rol. i. Introduction, p. xrii.
} 
was dicted on bread and milk. "In its native grassy haunts its food consists of inseets and their larra, and the roots of trees and plants"*, for the mastication of which its broad flat grinderst are well adapted. Nevertheless the eanines proper are separated in the upper jaw by not fewer than ten incisors, and in the lower jaw by six incisors \$.

'The cloven-footed Choropus, equally polyprotodont, but with digital characters more closely resembling those of the Artiodactyle Ungulates than in any other marsupial genus, is not carnirolous. The condition of the molars assoeiated with the "three or inore incisors followed by a canine on each side of the jaw," elearly points to that faet. 'The accomplished naturalist and explorer of Australian haunts of animal life thus testifies of Chceropus castanotis:- "As its dentition would indieate, its food consists of insects and their larve, and of regetable substanees of some kind, probably the bark of trees and tuberous roots" $\$$.

In faet the parallel and convergent modifications of all those struetures which truly influenee and indieate the food and habits of the animal have been noticed by all who have devoted the requisite attention to the Marsupial order. Gould well remarks, "IIysiprymni grub the ground for roots, and live somewhat after the manner of Peramelirles, with which, however, they have no relationship" ||; meaning within the ordinal limits—the one group being "diprotodont," the other "polyprotodont," with modifications of the two subordinal types bringing them to elose similarity, if not identity, of locomotion, diet, and mode of obtaining food.

In the case of a fossil mandible of either genus the palæontologist, referring to the molar teeth, would be led to the like inference as to food and habits, although he would see in one a pair of large approximate incisors and no canines, in the other canines with small incisors interposed.

Fig. 14 .

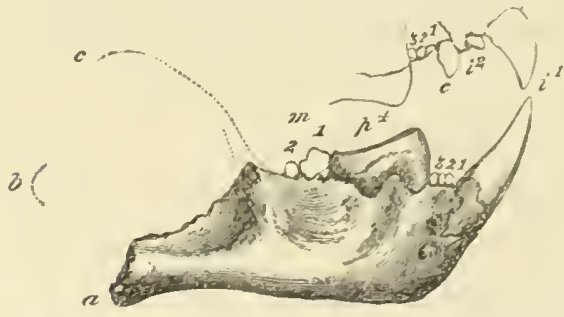

Mandible and teeth, Thylacoleo, reduced to one-fourth nat. size.
Fig. 1.5.

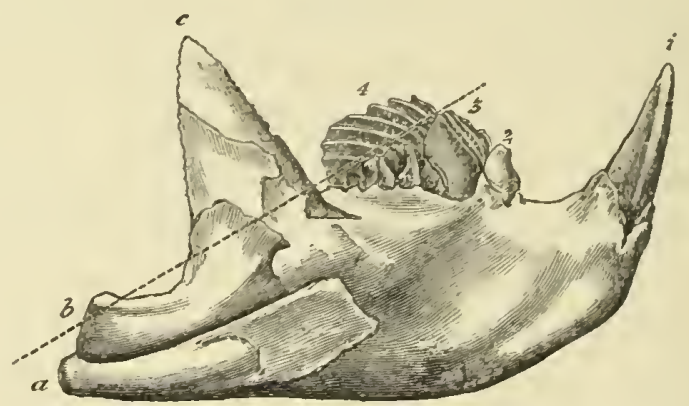

Mandible and tecth, Plarjumlax, magnified 4 diameters. (After Falcones, Quarterly Journal of the Geologieal Society, vol. xiii. $185 \bar{i}$, p. 280, fig. 14.)

Thylacoleo (fig. 14) and Plagiaulax (fig. 15) more closely resemble each other in

* Goctd, tom. rit. (I'eragalea largotis).

+ Cyelopædia of Anatomy, rol. iii. (1841), Art. "Marsupialia," p. 274, fig. 96.

‡ Ib. Art. "Marsupiaiza," ut suprì.

§ Goctd, 'Mammals of Australia,' rol. i. (Chceropus).

Id. ib. Introduction, p. xis. 
their dentition and shape of mandible than they do any other family of diprotodont Marsupials*. From the characteristic reduction in size and number of the molar teeth I hare associated them as members of a "paucidentate" family or section.

To which of the existing families of Diprotodonts is the paucidentate one most nearly allied? Thylacoleo best lends itself to the solution of this question, its maxillary as well as mandibular dentition being now, I may affirm, accurately determined. It is highly probable, from the close conformity of Plagianlax to Thylacoleo in the peculiarly and extremely modified dentition of the lower jaw, that the maxillary teeth also resembled those of the larger diprotodont carnivore. Of this the dental formula is:-

$$
i \cdot \frac{2-2}{1-1}, c \cdot \frac{1-1}{0-0}, p \cdot \frac{4-4}{4-4}, m \cdot \frac{1-1}{2-2}:=30 .
$$

No existing Diprotodont offers a like formula. That of the Poëphaga departs further than in most other diprotodont families, because there is no tooth interposed between the incisor and sectorial in the lower jaw, and in most Kangaroos not more than two are developed between the front incisor and sectorial in the upper jaw on each side, the two interrening teeth being incisors-both projecting anterior to the maxillo-premaxillary suture. Hypsiprymmus and Bettongia have a small canine in that suture, and two incisors between the larger front incisor and the sectorial in the upper jaw, but no teeth in that interspace in the lower jaw (figs. 17, 18). Of the more important true molar teeth (id. ib. $m_{1-4}$ ), the first three have "a quadrate form, presenting four equidistant blunt tubercles which are joined in pairs by transrerse ridges, but with these ridges less elevated than the points of the tubercles; there is a slight trace of the band of the tooth" ('cingulum' of my 'Odontography') "on the front and back part of each molar as in Macropus. The hindermost" (fourth) "molar is generally small, almost round. Cases occur in which the last molar tooth is absent; and, what is more extraordinary, I have obserred an extra tooth on each side of the upper jaw in a species of Hypsiprymuи"

Thus in these mixed feeders, but with the regetable diet predominating, the molar teeth adapted to such diet are never fewer and commonly more in number than in the most typical placental Herbicora. In relation, apparently, with the drier and tougher regetable fibres of Australia, the premolar is trenchant and strengthened by vertical grooves and ridges. In one of the New Guinea Tree-Kangaroos (Dendrolagus dorcocephalus) this trenchant tooth ( $p$, fig. 16) is proportionally larger than in the Australian Potoroos and Bettongs, but the light-giving teeth (the true molars) "are conformable with the Macropus type" $\S$.

* Dr. Falcoser asserts, "Thylucoleo and Plagiculax maj be regarded as being as wide apart among the Marsupials as the two former (Machairodus and Moschus) are among placental Mammals."-X. p. 358; XI. p. 442.

$\dagger$ I hold by this term, preferring it to the subsequently propounded one, Hacropoda, of Fax der Hoetex, because the latter is equally applieable in its descriptive sense to the long-legged, saltatory Polyprotodonts.

$\ddagger$ Waternorse, 'A Natural History of the Mammalia' (Marsupialia), Sro, 1545, p. 194.

§ Ibid. p. 182, pl. 10. fig. 3. In my 'Odontograph5' I showed that the "maximum of derelopment of the trenchant premolar was attained in the arboreal Potoroos of New Guinea (Hypsiprymnus ursinus and Hyps. dorcocephalus), in the latier of which its antero-posterior extent nearly equals that of the three succeeding molar 
There is 110 grreater contrast in the Diprotodont series than that presented by the molars in the Poëpherya and the P'ancidentute-the Kangaroos and Potoroos on the one hand, the Thylucoleo and Playiaulax on the other. A trenchant tooth may exist for other purposes than that of cutting vegetable matter, notwithstanding the stress laid by Messis. Falcoxis, Frower, and Boyn Dawkins on the degrees of resemblance subsisting between the sectorials in the Pancidentata and P'oëphaga. The differences which are pointer out in the present paper outweigh the resemblances in number and importance, irresnective of the characters given by the rest of the dentition.

Fig. 16.

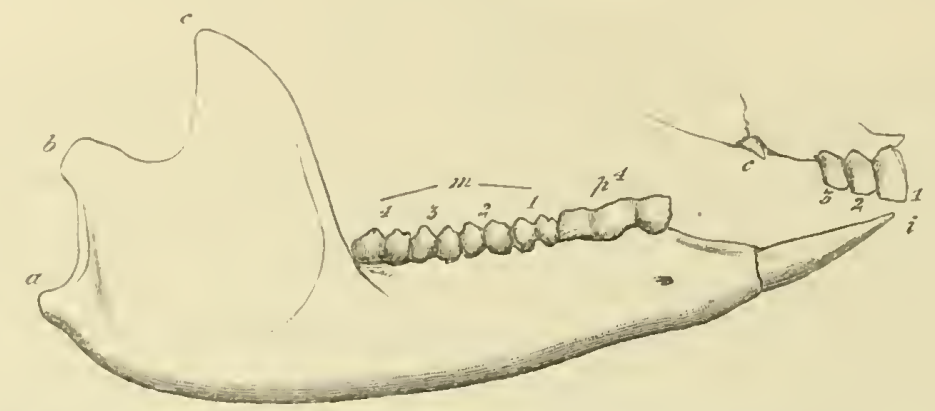

Hacropus (Denulrolugus) dorcocephalus, mandible and tecth, nat. size.

First, as to relative size. With all the additions of poëphagrous species made to our \%oological Lists since 1840, I still find the Macropus dorcocephalus* (fig. 16) to present the nearest approach to Thylacoleo in the relative magnitude of the trenchant premolar (ib. 14 ). Including with that tooth the four succeeding molars, as the "molary scries," the premolar constitutes nearly two fifths of that series: in Thylacoleo (fig. 14) the pre molar $(p+s)$ constitutes sevell-tenths of the molary series.

Fig. 17.

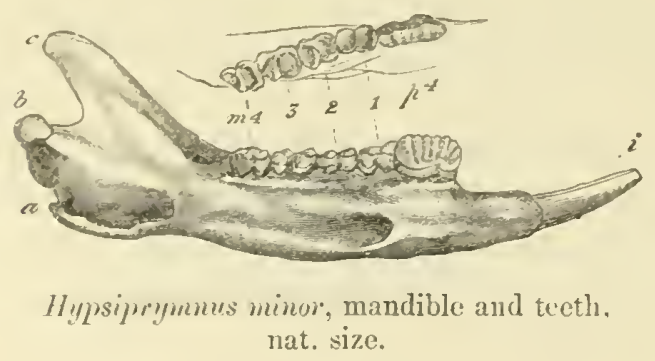

Fig. 18.

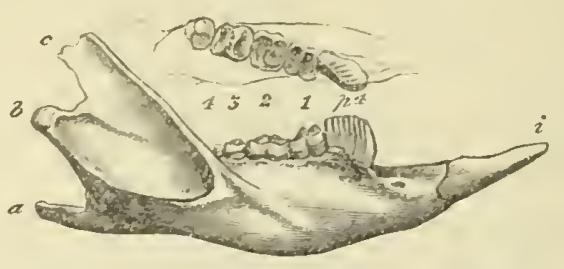

Bettongiu penicillutu, mandible and teeth, nat. size.

In some Potoroos, Hypsiprymnus minor, II. Grayi, e. g. (fig. 1T), the premolar ( $\mu^{\prime 4}$ ) a little exceeds in fore-and-aft extent the two succeeding molars $\left(m_{1} \&_{2}\right)$, but in most it

teeth" (p. 3ธ\%). Dr. Falcoxer misquotes this as a "statement that in tro Potoroos of New (iuinea its anteroposterior extent nearly equals that of the three sueceeding molars."-X. p. 358; XI. p. 442. I3ut in 1)endrolarpus ursinus, D. inuslus, and D. Brunii the proportion of the premolar does not exceed that of IIypsiprymnus Grayi.

* The many and small gradations which those additions hare made known, in retained rudimental or functionless canines, in hairivess of muzzle, of tail and other parts, in shape of ears, in proportion of fore aud lind 
falls short; and in Bettongia penicillata (fig. 18) it is reduced to the extent of one and a half of the succeeding molars, or to one-fourth of the entire "molary series."

A comparison more closely bearing upon the use to which a sectorial premolar has been applied is that of the relation of its fore-and-aft length with the length of the "diastema" or interval between it and the incisor; for the jaws of marsupial Herbivora are commonly characterized by length, and those of Carnivora by shortness.

Long as the premolar is in Dendrolagus dorcocephalus, the slender jaw is prolonged to as great an extent before it gives exit to the procumbent incisor; this interval is never less, usually more, than the fore-and-aft length of the trenchant premolar in all Poëphaga. In Thylacoleo the interval between the fore border of the homologous lower premolar and the outlet of the incisor's alveolus is one-fourth the fore-and-aft extent of such premolar.

The contrast between Thylacoleo and herbivorous Diprotodonts, in the proportion of the trenchant premolar of the upper jaw to the succeeding molars (which in the great carnivore are reduced to one, Plate VII. fig. $3, m_{1}$, as in Felis), is still more striking and decisive as to the use of such premolar than in the lower jaw. With the predominance of antero-posterior over vertical extent of crown in the trenchant border, and in the proportions of the two roots of the lower one, the resemblance of the premolar of Thylacoleo to that in any poëphagous or herbivorous Diprotodont ceases. It has not the parallel ridges and grooves which characterize the homologous tooth in the Potoroos (Hypsiprymnus, Bettongia, Potorous, \&c.).

In the upper sectorial premolar of Thylacoleo, the two best marked ridges are the one defining the anterior border (Plate VII. figs. 1-3, z), and the one terminating the inner prominence of the swollen fore part of the tooth (ib. $v$ ) answering to the somewhat more dereloped ridge in the upper carnassial of Machairodus (ib. figs. 15, 16, v).

The slight outswelling of the base of this ridge (Plate VII. figs. 2, 15, $v^{\prime}$ ) I regard as a rudimental homologue of the internal tubercle of the upper carnassial in Felis. Thus the carnassial in Machairodus (Drepanodon) offers an instructive intermediate modification of that tooth between Felis and Thylacoleo. I am the more impressed by the degree of resemblance through adaptive modification of the sectorial premolar in the carnivorous marsupial, seeing the differences that might be expected, as, indeed, some do exist, in homologous teeth, developed for the same office, in two such different routes of derivative modification as are exemplified by the Narsupial and Placental series of mammalian structures.

One vertical ridge on the outer and broader fore part of the crown (Plate VII. fig. 1, $p_{4}, u$ ) feebly represents the second lobe of the feline carnassial; it is divided by a shallow vertical depression from the part (ib. $z$ ) representing the anterior lobe of that tooth*

limbs, in length or eurrature of claws, \&e., have afforded the "Gattungsmacherei" grounds for IIalmaturus, Lagorchestes, Heteropus, Petrogale, Osphranter, Dentrolagus, Hypsiprymnus, Bettongia, Potorous, Dorcopsis, \&c.

* This structure is better marked in an upper earnassial of Thylacoleo from the breccia-care, of which photographs of the outer and inner sides werc transmitted to me in the scries abore noted. 
The rest of the outer surface is feebly undulated, and that more toward the base than the upper part of the crown. On the inner side, the basal undulation, through vertical risings and sinkings of the enamel, is more feebly marked*. The chief vertical indent on the outer side of the crown of the 'Thylacoleonine upper carnassial is near the posterior third (Plate VII. figs. 1, 3, o), and answers to the deeper vertical notch in Machairodus (ib. fig. 15,o) and Felis which defines the posterior lobe of their upper carnassial. It is interesting to note that this notch is less marked in Machairodus than in Felis, and also that the concavity of the outer side of the carnassial from before backward (i. $e$. from the outer ridge representing the second or middle lobe in Machairodus and the hind end of the crown) represents the more angular concavity due to the deeply vertical groove on the outer part of the carnassial in the above placental Carnivora.

Professor Flower (XII. p. 309) states that " the resemblance of the great premolar of Thylacoleo to the "carnassial" of the true Carnivora is merely superficial ;" and he specifies among the differences, "especially the absence of any distinct inner lobe or tubercle" (in the upper molar) "supported by a third fang" (ib. p. 310). He was, probably, not cognizant of the example afforded by one of the extinct true Camivora of the absence of the inner lobe or tubercle, or, rather, its reduction to a ridge, the lower swollen base of which (Plate VII. fig. 15, $v^{\prime}$ ) may be compared to "a less cleveloped homologue of the inner tubercle in the normal species of Felis"

Dr. Falcoxir, indeed, repudiates this partial homology, and affirms "of the upper carnassial of his Sewalik Machairodus" that "neither the anterior lobe nor the middle one bears the slightest indication of bearing an internal tubercle" (XI. p. 456); and this further evidence of transitional structure between the Feline and Thylacoleonine carnassials will probably be acceptable to Professor Flower, though it is enunciated, as I think, in exaggerated terms.

The well-defined rertical ridges and interrening grooves on both outer and inner surfaces of the crown of the sectorial premolar of the Potoroos vary in number in different species, but are countable and pretty constant in such species, rising from four to eight or more; they are best marked on, and sometimes limited to, the apical half of the crown, the enamel at the base being smooth and eren. 'The fore part of the Potoroo's sectorial is not broader (is usually narrower) than the hind part, and the cutting-edge runs straight or nearly so.

The transverse expansion of the fore part of the lower carnassial of Thylacoleo, representing the thicker anterior lobe of the carnassial of the Felines, the fore-and-aft convexity of the outer surface of the crown, and the concavity of the inner surface answering to that which defines the two lobes of the blade in Felines are better marked than

* Dr. Falcoxer, quoting my original deseription of the earnassial in Thylacoleo as being "slightly grooved vertically on the inner side," correetly proceeds : "these indentations disappear about halfway up towards the edge, where the surface becomes retieulately rugose, being preeisely the reverse of what occurs in the last premolar of Hypsiprynmus" (X. p. 356, XI. p. 440).

$\uparrow$ Owex, British Fossil Mammals, tto, 1846, p. 178. 
are those correspondences in the upper carnassial, and are unmistakable. A broader well-defined prominence on the fore part of the inner surface of the crown of the lower sectorial (Plate VIII. fig. 11, $r$ ) leaves a part anterior to it (ib. $a$ ) representing the anterior basal talon, chiefly marked or extended upon the inner surface of the fore part of the crown in the lower carnassial of Felis and Hyoena. The indications of vertical elevations of enamel are more feeble in the lower than in the upper sectorial, and are chiefly seen at the basal part of the inner surface. The notch at the middle of the trenchant border in the less worn lower carnassial (Plate VIII. fig. 11) clearly indicates divisions resembling, though more feebly marked, the anterior and posterior lobes of the homologous tooth in the placental Carnivora (ib. fig. 12).

The absence of the anterior transverse expansion, and the straight line described by the trenchant border, in the lower sectorial of the Potoroos, is, at least, as strongly marked in the lower jaw (ib. figs. 8, 10,13) as in the upper one (Plate VII. figs. 17, 18). In juxtaposing the specimens of the homologous teeth in Thylacoleo and any Potoroo for a true deduction of comparative similarity and difference, "one sees at once that the great cutting premolar of the Hypsiprymni or Rat-Kangaroos is" not "a miniature of that of Thylacoleo"*. And, if it were, the function of such sectorial could not be deduced from mere shape, but from the nature of the other teeth wherewith it is associated, and the modifications of the jaws by which such dentition was worked.

The varieties of form above defined, inasmuch as they modify the surface of a carnassial tooth, may be said to be 'merely superficial;' but I am at a loss to know how that disparaging epithet affects the question. Professor Flower offers no testimony of a 'deep-seated' structure common to the sectorials in Poëphaga and Paucidentata, and different from those in placental Carnirora. He will find one if he examines microscopical sections of the teeth in question $\uparrow$. But it is one which Thylacoleo shows in common with Thylacinus and Sarcophilus, and it is a marsupial modification, not a macropodal one.

The student in reading of the "great cutting premolar of the Rat-Kangaroos" must bear in mind that the epithet is relative. Where such tooth is greatest in those vegetarians it is small in comparison with its homologue in Thylacoleo. The difference of shape, direction, term of growth, and of every character meaning function is still greater and more obvious in the incisors of the Diprotodonts compared than in the sectorials; and the degree and kind of difference shown by Thylacoleo testifies to the carnassiality of the main representative tooth of the molary series.

Against the association of that great carnivore with the Poëphaga "(= Macropoda, V.d.H.)," there are opposed not only the differences above demonstrated in the homologous sectorial teeth, but the absence of the third pair of upper incisors and the presence of premolars in advance of the sectorial one in both jaws of Thylacoleo. It will

* XII. p. 310.

t It is that represented in Plate 102 of my 'Odontography;' showing the extension of dentinal tubules into the enamel. 
be admitted by candid readers of botlı my Papers on that genus that I have been reticent of conjecture or assumption; but I venture to say that when the limbs of Thylacoleo are restored they will not be "macropodal," not minimized at the fore part and maximized at the hind part of the body, for bipedal saltatory actions to bear it swiftly away from carnivorous pursuers, or to carry it far abroad from pasture to pasture and from scrub to scrub in quest of vegetable food, but that they will agree in the main with the limbs of Leo, Thylacinus, and Sarcophilus.

Pursuing the comparison of Thylacoleo with other Diprotodonts, we may at once dismiss the arboreal Phascolarctidce, with a trenchant premolar (at least in the young Koalas), on the same grounds as those on which the Poëphaga are rejected from the association. 'The fallacious resemblance in the comparative views given in XII. pp. 312, 313, figs. $2 \& 4$, of the skulls of the Koala and of the Thylacoleo (as restored by Professor Flower), vanishes when they are turned from the front to the side view, as in figs. $6 \& 8$, p. 153.

The sectorial of Phascolarctos forms one fifth of the molary series, and mainly through " the greater relative size than in other vegetable-feeding Diprotodonts of the four following molar teeth"*. The incisor formula differs by excess, as the premolar formula docs by defect, compared with the dentition of Thylacoleo, and this in the same way and degree as in Kangaroos and Potoroos.

We must pass to another family of Diprotodonts to find the two minute (I termed them "functionless") premolars in advance of the last which retains its sectorial use and equality of length with the succeding molar. In Phalangista ursina, Ph. maculata, and $P h$. chrysorrhoa the functional premolar is preceded by two rudimental premolars. In Phalangista Cookii (fig. 19) three minute teeth interrene between $p 4$ and $i$, in the lower jaw, as in that of Thylacoleo: in the upper jaw, where the canine is minute and protrudes at the maxillo-premaxillary suture, two small premolars intervene between it and the homologue of the upper carnassial of Thylacoleo. The same degree of correspondence in numerical formula is represented by some Petaurists \$; but I have failed to find any species of "Carpophaga" $\S$ in which threc premolars appear between the functional one and the canine, or any spe-

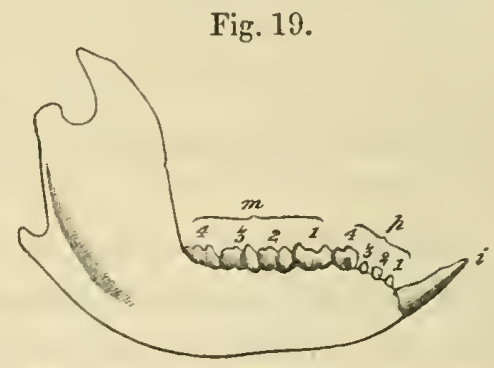

Mandible and teeth, Phalangista Cookii, nat. size. cies in which the upper incisors are reduced to two on each side. That a tendency to deviate by such reduction was amongst the inconstant characters of organization of diprotodont Marsupialia is exemplified by the Wombats, in which no incisors are dereloped behind the large upper anterior pair. Thylacoleo shows an interesting intermediate stage of the incisive formula, viz. $i \cdot \frac{2-2}{1-1}$, between the $i \cdot \frac{1-1}{1-1}$ of Rhizophaga\| and the $i \cdot \frac{3-3}{1-1}$ of all other existing families of Diprotodonts.

* OWfar, "Classification of Marsupialia," Trans. Zool. Soc. (1839) p. 326.

$\uparrow$ Loc. cit. p. 323 .

士 E. g. Petaurus (Belideus) flaviventer, Cycl. of Anat. Art. Marsupialia, tom. cit. p. 264, f. 89.

OWEx, "Classification of Marsupialia," ut suprà, p. 322.

"I Ibid. p. 329. 
Of all known Marsupialia, recent or fossil, Plagiaulax, so far as its dentition is accu rately determined, is most closely allied to Thylacoleo. In the lower jaw the true molars are similarly reduced to two of small size and tubercular form. One cannot suppose that they were opposed by more tuberculate molars above; the analogy of Thylacoleo (Plate X.) would point to ferver. A character, indeed, of the first of the inferior molars of Plagiaulax, overlooked by Dr. FALCONER, would indicate that it worked sectorial-wise, like the fore part of the anterior lower molar of Thylacoleo, upon the back part of the blade of a large upper carnassial; I allude to the smooth vertical wall-like surface of the inner side of the outer half of the crown of $m 1$, in Plagiaulax*.

Taking the same range of the molary series for comparison as in Thylacoleo and existing Diprotodonts, in reference to the character of size of the last trenchant premolar, the tooth equals in antero-posterior extent one-half of that series in Plagiaulax. But in this more ancient Diprotodont the premolars anterior to the last large one have not undergone the extreme degradation which they show in the tertiary fossil (Thylacoleo) and in some existing Diprotodonts of Australia. They are modified, in Plagiaulax, for sectorial function, and are so combined with the last and largest sectorial as to work with it as one instrument, obliquely ridged and notched at the convex cutting-margin, like a section of a circular saw. I have already $\uparrow$ pointed out the advantage of this modification of carnassial in dividing the integuments and other tissues, tougher and drier than those in Mammals, of the lacertian members of the cold-blooded class which so abounded with the small carnivorous Marsupials in the same Mesozoic period and place.

If it be admitted that, so far as the lower jaw and its dentition show, Plagiaulax (figs. 10 $\& 15)$, with its two or three reduced anterior premolars, its suddenly enlarged hind premolar, its disproportionately small and few (two) tubercular molars, and its large laniariform upcurved incisor, comes nearest to Thylacoleo (figs. 8 \& 14), it is plain, from the antecedent comparisons with existing Diprotodonts, that there are no grounds for inferring the Macropoda to have been derived from the Paucidentata, or these from Rat-kangaroos.

What we do learn from consideration of the fossils in question is, the fact of an additional and most interesting modification of the Diprotodont section of the Marsupial order or subclass, unknown before the discovery of these fossils. We further learn that such modification, which, from the extreme reduction of the true molar series, I have been led to take as the character of a "paucidentate" family of Marsupials, was already established at the Purbeck period; yet with modifications interestingly exemplifying the tendency to the "more generalized condition of structure" as compared with the newer tertiary extinct form.

But I am here met by another objection. Dr. FALCONER, attacking the principle of the tendency to transition in organisms from generalized to specialized structures as they approach in geological position the present time, writes:- "Among other arguments, they insist that the earliest Eocene Mammalia, both carnivorous and

\footnotetext{
* 'Prcfatory Notice,' \&c., pp. 76, 81; Plate IV. figs. 9, 12.

† 'Prefatory Notice,' \&c., p. 97, Plate IV. figs. 9, 12.
} 
herbirorous, possessed, in most cases, the full complement of teeth ; while forms characteristic of later times, such as the Felidx and Ruminantia, are remarkable for special suppression of these organs. If the generalization were really of as wide an application as has been claimed for it, we ought to find evidence of closer adherence to the general archetypic model the further back we recede in time. But so far is Plagiaulax, at present the oldest well-ascertained herbivorous mammal yet discovered, from giving any countenance to the doctrine, that it actually presents the most specialized exception, so to speak, from the rule to be met with in the whole range of the Marsupialia, fossil or recent. It had the smallest number of true molars of any known genus in that subclass, six at least of the normal number of incisors being also suppressed" *.

But Plagiaulax, riewed as a member of the same predaceous group of Marsupialia as Thylacoleo, affords an interesting instance of adherence to the law above disputed. The extinct pouched carnivore of the tertiary period shows a single carnassial tooth on each side of the lower jaw; the extinct pouched carnivore of the oolitic period retained in one species three premolars of the carnassial type, in another species four (the normal or type number) on each side of the lower jaw. The parallel runs very close with that which the placental Carnivora show within the limits of tertiary time; as when we compare the miocene Hycenodon and its three lower carnassials with the modern Hyona, where they are reduced to one, or when we compare the miocene Amphycyon with its three upper true tubercular molars with the modern Ursus, where they are reduced to two, or the modern Felis, where they are reduced to one. If, also, the oolitic Phascolothere, although it is known (to me) only by half its lower jaw and the teeth of that moicty or "ramus," be compared with the modern Opossum, represented by the same part, the more generalized type is conspicuous in the absence of the degree of differentiation of the individual teeth in the oolitic fossil jaw which characterizes the homologous teeth in Didelphys. The canine is marked by only a slight superiority of size from the antecedent teeth, which are of similar shape, and divided from each other by similar intervals, in Phascolotherium. In Didelphys the canine is marked by greater relative size and difference of shape from the close-set group of small incisors commonly anterior to it. The seven molars in Phascolotherium show gradational differences of size, but none of shape; sare some simplification of the two smallest, which are the first and the last of the series of seven teeth. In Didelphys the last four molars are abruptly and markedly differentiated from the three preceding ones, so that zoologists distinguish the four as "true molars" from the three which are their "false molars." Phascolotherium does not lend itself to this distinction

* Quart. Journ. Geol. Soc. vol. xiii. p. 270 ; XI. p. 427 .

+ This well-known fact in comparative odontology is here repeated in reply to the question addressed by Professor Hexuey, in his eharaeter of adrocate of ' Cniformitarianism,' to the London Gcologieal Society, speaking for the then President, Mr. Leosard Horver: "in what eireumstance is the Phascolotherium more embryonie, or of a more generalized trpe, than the modern Opossum?"-Quarterly Journal of the Society, vol. xriii. (1862) p. li. This is a mode of fence eoncealing indiridual knowlcdge and assuming general ignoranee of facts running counter to a riew adroeated by the rhetorician. 
A still more generalized type of dentition is shown by the multiplication of slightly differentiated teeth in the genera Amphitherium, Amphilestes, Spalacotherium, Peralestes, Stylodon, \&c., of the lower and upper oolites. One solitary form (Myrmecobius) alone remains at the antipodes with minute and slightly differentiated teeth, in number exceeding the type one in most modern Mammals, and recalling that in lower and wider vertebrate groups.

The two or three smaller but functional premolars in advance of the large lower carnassial in the mesozoic Plagiaulax are reduced to two or three more minute functionless and speedily lost premolars in the neozoic Thylacoleo.

This fact invalidates the averment of "the contradictory bearing of the dental system of Plagiaulax upon the assumption that the earliest Mammals had the full complement of teeth:" which averment Dr. FALCoNer reiterates and "calls special attention to," in X. p. 365, XI. p. 451. For if, in place of assuming Plagiaulax to be the earliest mammal, and, as such, with the full complement of teeth, or "the oldest well-ascertained herbivorous mammal," it be viewed as no more than it is, viz. a geologically earlier form than Thylacoleo with a dentition similarly modified for carnivority, the degree of difference between the two members of the Paucidentata is affirmatory instead of contradictory, in relation to the rule in question, rightly stated.

Relation of Size to Carnivority.-One other argument against the predatory way of life of the subject of the present and preceding Sections remains for notice, although its very suggestion implies a sense of the insecurity of the grounds on which the herbivorous habits and affinities of Plagiaulax and Thylacoleo have been advocated.

They are affirmed to have been animals too small, too feeble, to have preyed upon others, especially when much larger than themselves.

Whoever has witnessed the well-known zoological phenomenon of the pertinacious pursuit and fatal attack of a hare by the diminutive weasel would pause, however, before venturing on such grounds of objection.

Dr. FALCONER, selecting for his purpose the most diminutive of the species of Plagiaulax, affirms: "The entire length of the specimen, including the six molars and premolars, together with the procumbent incisor (according to the metrical line $e$ ), does not exceed 4 of an inch, of which the six cheek-teeth united make only about two and a half lines ( 25 inch). I ask any zoologist or comparative anatomist to look at it, and say whether the dental apparatus of this extremely minute creature is competent to perform the duties required of a predaceous carnivore. Magnitude in this case is an important ingredient, as it necessarily involves measure of force. Could P. minor have preyed on small Mammals and Lizards? Is it not more probable that this pigmy form was itself an object of prey in the Purbeck fauna?"*

To this I reply, that I have now before me the original of fig. 15, Plagiaulax minor of the Quarterly Journal of the Geological Society of London for August 1857, xiii. p. 281, reproduced in the subsequent paper of Dr. FALCONER in Quarterly Journal \&c. for June 1862 (X. p. 367), and copied in pl. 34. fig. 2 of the posthumous work (XI. p. 416).

\footnotetext{
* X. p. 363; XI. p. 448.
} 
The specinen (fig. 20, $\mathrm{A}$ ) shows two molars and four premolars; the incisor is neither chisel-shaped nor procumbent, but rises with a slight curve to its pointed apex at an angle of $120^{\circ}$, with the line of the molar alveoli. The length of the dental series from the apex of the laniariform incisor to the hind part of the second molar is seven-sixteenths of an English inch, precisely the length of the dental series in Urotrichus talpoïles (ib. B), a ferine mammal, 5 inches long from the snout to the tip of the tail, with a skull 1 inch in length, and an approximate pair of lower pointed incisors upcurved at the same angle to the molar line as in Plagiaulax minor, but relatively less and shorter.

Some Opossums, e.g. the murine and dorsigerous Philanders (fig. $20, \mathrm{c}$ )* have the mandible intermediate in size between that in Plagiaulax minor $(\Lambda)$ and in Plagiaulax Becklesii $(\mathrm{F})$; it is both shorter and weaker than in the latter species. A naturalist and good observer (Dr. CARTER Blake, F.G.S.) has expressed to me his surprise at witnessing, while in Central America, the disproportion of size between those mouse-like predaccous Marsupials, and the Lizards and Suakes on which they prey.

Fig. 20.

$\wedge$

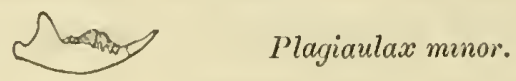

B
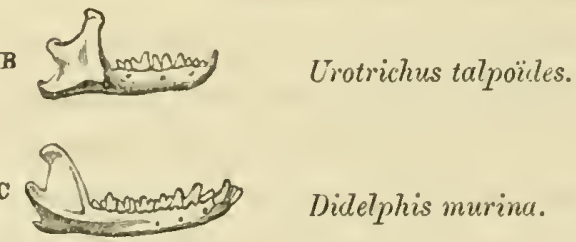

D
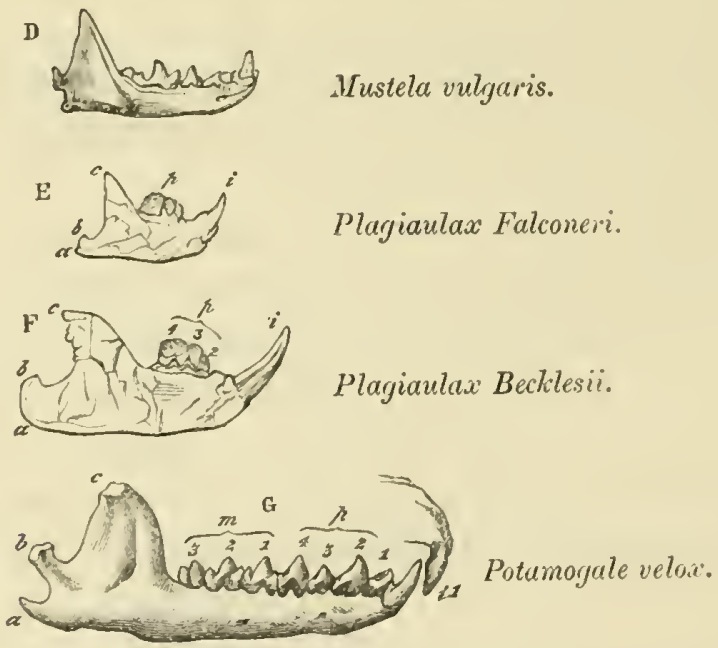

The above figures of the mandible and mandibular teeth are of the natural size.

I am not cognizant of any grounds afforded by zoology which forbid the supposition that a mammal of five inches in length, with the carnivorous type of dentition of Plagirulax, may have been able to capture and kill the diminutive Lizards (Saurillus, Ma-

* In D. Corsigerc, from tip of incisors to condyles, 10 lines; in D. murina $11 \frac{1}{2}$ lines. 
cellodus, Nuthetes*, \&c.) abundantly associated with Plagiaulax in the Purbeck shales. Comparative anatomy suggests that the modifications of the dentition of Plagiaulax minor, as compared with the similarly sized Shrew (Urotrichus, fig. 20, в) and Opossum (Philander murinus, ib. c.), would give the Purbeck marsupial both the disposition and power to attack and prey upon animals of a larger size and higher organization than worms and insects. But the question of the carnivority of Plagiaulax, if weighed by "magnitude as a measure of force," is not fully or fairly tested by the exclusive example of the most diminutive species.

In Plagiaulax Falconeri (Ow. $\uparrow$, fig. 20, E) the extent of the dental series, lower jaw, is six-sixteenths of an inch; in Plagiaulax Becklesii, Fr. (fig. 20, F) it is ten-sixteenths of an inch. The entire length of the mandible in this species, inclusive of the incisor, in a straight line, is 1 inch two-sixteenths; the depth of the ramus at the back part of the large carnassial is five-sixteenths of an inch.

In the Weasel (Mustela vulgaris, Cuv., fig. 20, D) the extent of the dental series, lower jaw, is eight-sixteenths of an inch; the depth of the ramus at the back part of the large carnassial is two-sixteenths of an inch.

With the greater relative depth and consequent strength of the jaw of Plagiaulax a greater size and strength of both laniary and carnassial teeth are concomitant. The condyle, which is on the level of the dental series in the Weasel, is below that level in Plagiaulax. Every modification of the small marsupial by which it departs from the little blood-thirsty Placental is in the direction of greater carnivority.

In Phascogale penicillata the extent of the dental series, lower jaw, is fourteen-sixteenths of an inch. It has four true molars in such lateral series, with relatively smaller laniaries and still smaller sectorial premolars than in Plagiaulax; the mandibular condyle is raised a little above the dental line; the carnivorous adaptation of both jaw and teeth is less marked than in the Purbeck marsupial. But what is the testimony in regard to the habits of the existing pouched carnivore no bigger than a rat?

Gould, who would be the last to repeat testimony to which zoology and comparative anatomy ran counter, writes "Phascogale penicillata, small as it is, comparatively, is charged with killing fowls and other birds" \$.

I can bear personal testimony, and that to my own loss, of the attack and slaughter of nearly full-grown Shanghai pullets by Mus decumanus. Comparative anatomy lends more aid to the credibility of the predatorial powers of the carnivorous marsupial than of the equally small rodent; but that both of them do attack and destroy animals more than twice their size and weight is a zoological fact.

* Owen, 'Quarterly Journal of the Gcological Soeiety,' 1854, rol. x. p. 420.

† 'Prefatory Notice of the Fossil Mammalia of the Mesozoic Formations,' p. 84, Plate IV figs. 16, 16 A.

‡ "Mammals of Australia," fol. Introduction, p. xviii. Mr. Waterhoose remarks, "In the Phaseogales, where the two forcmost of the lower incisors are large, their inereascd development is, as it were, at the expense of the posterior incisors, which are rery small, and the eanine which follows them is but moderately developed."-Nat. History of the Mammalia, vol. i. (1845) p. 256. 
Thougl magnitude may be, in one sense, a measure of force, it by no means neces sarily implies the application of such force, and consequently is any thing but "an important ingredient" in the question of the carnivority of Mus, Mustela, Phascogale, and Plagiaulax.

But whatever bears on the interpretation of the singular dentition of the small "paucidentate " marsupial, logically applies to the larger one.

Mr. KREFet gives drawings of sections of the "lower incisor of Thylacoleo, Nototherium, Diprotodon, Thylacinus, and Sarcophilus," also of what he terms the "upper incisor and lower incisor of Felis tigris,.... showing the relative size of the teeth in these animals, and proving sufficiently that the Thylacoleo was far inferior in strength to a modern 'Tiger, and no match for ponderous Diprotodonts and Nototheriums"*.

If the carnassial tooth were selected instead of an incisor, it would show on the above basis that Thylacoleo was "far superior in strength and carnivority to the modern Tigers and Lions." But I would submit that the test of relative size of a single tooth, if even the answerable or homologous one were recognized by the tester, is not a decisive or sufficient one in the present question.

It is evident that Mr. KREFrT's figures $7 \& 8$ are sections of the canine, not the incisor, of the 'Tiger. But if that tooth in the Hippopotamus were exemplified by a similar section, it would be no element, or a very deceptive one, in concluding as to strength or carnivority. The canines of Moschus and other like instances will at once suggest themselves to the competent Comparative Anatomist.

To the assertion of the "gigantic herbivorous Nototherium" \&c. being "many times as large as the Thylacoleo" $\dagger$, I will oppose a few matters of fact and mensuration. The length of the skull of the largest species of Nototherium (N. Mitchelli) is 1 foot 6 inches \$; that of the skull of Thylacoleo carnifex is 10 inches 8 lines: were the occipital ridge and spine entire in the specimen measured (Plate X.) it might be set down at 11 inches. It will be within the bounds of accuracy to say that the Notothere was twice as large as the Thylacoleo, not more. The skull of the Diprotodon is 3 feet in length ; it is, lowever, large in proportion to the trunk and limbs; bulk for bulk, the animal was probably not much larger in comparison with the Thylacoleo than is the Giraffe in proportion to its destroyer the Lion. The disproportion between the Wolverene (Gulo luscus) and its prey the Reindeer must be greater than that which the dimensions of the known fossils of Thylacoleo and Diprotodon suggest. 'The length of a Lion's skull before me is 1 foot; that of the skull of a South-African Giraffe is 2 feet 2 inches. If we next compare, not a single tooth merely, but the whole lethal tooth-weapons of Thylacoleo and Felis tigris,

* "On the Dentition of Thylacoleo carnifex (Ow.)," in Annals and Yagazine of Natural History, Third Series, rol. xriii. 1866, p. 148.

† Professor FLower, F.R.S., howerer, adopts the argument from size, and rejects the hypothesis " that Thylacoleo was the destrojer of the gigantie herbivorous Mlarsupials (many times as large as itself) with which its remains are found associated, the Diprotodons and Nototheres."-XII. p. 318.

‡ OwEx, "On some Outline-drawings and Photographs of the Skull of Nototherium," Quarterly Journal of the Geologieal Society of London, vol. xv. p. 173, pl. vii. (1858). 
we get the following results. The length from the fore part of the laniary to the hind part of the carnassial, upper jaw, is in Felis tigris 3 inches 7 lines; in Felis spelaea 4 inches; in Thylacoleo carnifex 4 inches 3 lines. In the lower jaw the proportions are reversed; but the difference affords no reasonable ground for inferring such inferiority of strength or destructive power as to support the inference that Thylacoleo was incapable of playing the same part in relation to the Nototheres and Diprotodons as the Lion now performs in relation to the Buffaloes and Giraffes.

The remains of the large extinct Herbivora of the Pleistocene period in Britain, which have been found in the limestone-cares of Weston-super-Mare, Torquay, Pickering, \&c., are held to have been parts of animals which have fallen a prey to the contemporary Carnivora, now also extinct. The caves of the limestone-district of Wellington Valley, Australia, reveal phenomena of extinct animal life closely analogous. I infer that the fossils, always more fragmentary than those from the tranquil freshwater deposits, of the Diprotodons, Nototheres, large Kangaroos, and Wombats, surpassing in size any existing species, were remains of animals which had fallen a prey to contemporary Carnivora, and by them had been dragged into the care.

Now, no predaceous species bearing such proportion to the Diprotodon and Nototherium as the spelæan Lion, Bear, and Hyæna bore to the Mammoths, Rhinoceros, Oxen, \&c., has hitherto been detected in Australian bone-cares, save the Thylacoleo camifex. To its associated fossils, the Thylacine or the Dasyure (Sarcophilus), the objection of defective strength and bulk might be specious, but, as applied to the Thylacoleo, it is absurd.

In the main the descriptions or definitions of the characters of the fossil remains of Thylacoleo and Plagiaulax by my antagonists and myself are the same; and the chief difference herein is that I interpret the fractured surface of the angle of the jaw in a specimen of Plagiaulax as indicative of that part being bent inward immediately below the neck of the condyle as in Sarcophilus and Thylacinus, whilst Dr. FALcoxer contends that the part broken away descended below the condyle as in the mandible of the Aye-aye. And so, with regard to Thylacoleo, I interpret the evidences of its fossil mandible as indicative of an agreement with that in existing Marsupial Carnivora in the form and proportions of the coronoid process and in the position of the transversely extended condyle. Messrs. KrefFt and Flower restore the mandible of Thylacoleo, in regard to these light-giving structures, according to the analogies of the carpophagous Phalangers and Koalas and the poëphagous Potoroos, assigning to the upper jaw the same incisive formula, for dissenting from which I have given reasons.

I cannot find better words to express my conviction of the state of the question as now analyzed and tested than those of the gifted and lamented Palæontologist, whose criticisms, as reproduced in his posthumous work, reiterated, as it were, from the grave, have overcome the reluctance which, till now, has kept me silent. In those words, therefore, I venture to remark, that, if my inferences and conclusions be favoured by acceptance, it will not imply that my opponents had "fallen into errors of obserration and descrip- 
tion"*, so much as it will expose "the fallacious train of reasoning which had led them astray" $\dagger$.

Should Thylacoleo be permitted to rest, after the facts and inferences from the fossil evidences at my command, in the section of diprotodont Marsupials, with P'lagiaulax, amongst the predaceous feeders on flesh, and not with IIypsiprymnus amongst the harmless Ilerbivora, it will only be further proof of the worth and truth of the principle which Corras laid down as our guide in such dark routes in Palæontology.

Already, since writing the above, evidence has reached me, in the last Packet from sychey, which I shall probably be not the only one to hail as undesigned witness to what I deem the truth of the matter.

Amongst the fossils obtained by Professor 'Thomson and Mr. Krefret from the brecciacaves of Wellington Valley were several ungual phalanges, some of which, equalling or surpassing those of a Lion, were compressed, the vertical exceeding the transverse diameter, and being considerable in proportion to the length: these phalanges are curved and pointed, but the point is more or less blunted or broken, apparently after interment. They supported a claw, and in most there are traces more or less plainly discernible of a bony sheath which bound or strengthened the attacliment of the base of the claw. 'These specimens, at present, I know only by photographs of the natural size.

Plate X. fig. 12 is of one of these ungual phalanges, 1 inch 9 lines in length, 1 inch 8 lines in basal depth. The articulation (a) occupies the upper half of the basal surface ; it is concave and divided by a median vertical ridge, adapting it to the pair of convexities on the distal end of the penultimate phalanx. A strong tubcrous process (b) for the insertion of the flexor tendon projects from the lower part of the basal half of the bone. A ridge $(c)$ anterior to the joint may indicate the attachment of the sheath broken away.

Figure 14 gives an under view of this phalanx, showing the breadth of the apophysial part of the base, and the compressed character of the decurved claw-bearing part of the phalanx.

Figure 11 is a side view of a similar phalanx, 1 inch 8 lines in length, 1 incl in basal depth. The upper part of the articular surface $(a)$ is more produced, or better preserved, than in figure 13 ; and the indication of the sheath $(c, c)$ is more considerable and begins more in advance. The insertional tuberosity (b) also extends rather more forward.

In the next photograph (ib. fig. 12) the bony basal claw-sheath $(c, c)$ is evidently preserved; its anterior margin is 1 inch 3 lines in adrance of the lind part of the phalanx; but this, as well as the under surface of the back part, appears to be mutilated. One half or side of the sheath has been broken away, exposing the core of the claw $(d)$, the pointed termination of which is better preserved than in the preceding specimens.

From these specimens may be inferred a spelæan animal with subcompressed decurred pointed claws, equalling or exceeding those of the Lion or Tiger in size, but supported by phalanges resembling those of Thylacinus, Dasyurus, and the Opossums in being non-retractile, or wanting the characteristic low position of the joint in the sheathed

$$
\text { * X. p. } 350 \text {; XI. p. } 433 .
$$$$
+\mathrm{Id} \text {. ib. }
$$ 
claw-bones of placental Felines, but resembling those phalanges, rather than the nonretractile ones of the Marsupials above mentioned, in the proportion of depth to length and breadth.

A claw may be adapted to pierce, retain, and lacerate (as, for example, the large sheathed one of Myrmecophaga jubata), and be used as a weapon against a mammal of equal or superior size only in defence (as when the great Anteater causes the death of its assailant the Jaguar by the tenacity of its grip). So, likewise, may the claws of the Megatherioids have been put to such occasional defensive uses against their probable assailant the Machairodus neogreus, although, as in the Anteater, the habitual service of the claws may have related to insects or vegetable diet.

One is guided in a conjecture as to the uses of claws by the evidence afforded by the associated fossils of the animals which, if unguiculate, would have had claw-bones of the size of those under consideration.

No evidence of a Megatherioid or other Edentate animal has been had from any care or fossiliferous deposit in Australia. The shape of the ungual phalanges in Kangaroos and Wombats is known. The ungual phalanges (Plate $\mathbf{X}$. figs. 11-14) are too small for Nototherium and Diprotodon, if even one were to entertain the idea of those huge Marsupial Herbivora having had sheathed, compressed, decurved, pointed claws, like those which the plalanges in question plainly bore. These phalanges are as much too large for the Thylacinus and Sarcophilus. But there is no other associated Carnivore corresponding in size with that of the animal indicated by them, save the Thylacoleo.

It is open to any one to repeat, with respect to these phalanges, the remark which has been made on the fossil metacarpal of the carnivorous type from Australia (Plate XIII. figs. $6,7,8$ ), the size of which is such, as the articular surfaces ( $a$ in figs. $11,12,13 \& 14$, Plate $\mathrm{X}$.) show, to have entered into the formation of the paw terminated by such clawphalanges, viz. "That the metacarpal bone figured in Phil. Trans. 1859, Plate Xir. belonged to the same animal as the skull is only conjectural"*.

All that has been above advanced in searching out the nature of the ungual phalanges made known to me by photography is conjectural; but if a Palæontologist or Comparative Anatomist is willing to lend friendly aid in such difficult gropings after the things of the past, he should point out in what particulars he deems the grounds of the conjecture to be defective.

A great proportion of the fair edifice of Palæontology still rests upon a scaffolding of wise and well-founded "conjecture." 


\section{'Table of Iocalities of Thylacoleo carnifex, showing:-}

\begin{tabular}{|c|c|c|}
\hline Where found. & By whom. & Date. \\
\hline 13receia-cavern, Wellington Valley, New South Wales* & Sir 'Thomas Mitehell, C.I3. & 1836 \\
\hline Lakic Colungulae, 80 miles S.W. of Melbourne, Vietoria $†$. & William Adeney, Esq.. & 1845 \\
\hline ILodgson's Creek, Darling Downs, Queensland... & Samuel Stutchbury, Esq. & 1853 \\
\hline Eton Vale, Darling Downs, Queensland . & Edward S. Hill, Esq. ... & 1863 \\
\hline St. Jean Station, Darling Downs, Queensland & M. Satehe St. Jean & 1865 \\
\hline Breccia-earern, Wellington Valley $\ddagger$. & Prof. T'homson and Gerard Krefft, Esq.. & 1869 \\
\hline
\end{tabular}

* Appendix to Mrirchell's 'Three Expeditions into the Interior of Eastern Australia,' 8vo, vol. ii. 1838. Upper and lower incisors of Thylacoleo are figured in Plate 32, figs. 4-10 (compare the restoration of fig. 6 with fig. 6, Plate IX. of the present work); figs. 10,11 give two riews of the lower earnassial tnoth. I did not feel justified, in 1837, in proposing a generie name on those data.

† This diseovery of remains yiolding satisfactory generie charaeters, whieh were then made known as of Thylacoleo, is noticed in Dr. Hobsos's letter, quoted p. 110. In subsequent correspondence with the diseorerer 1 received the following observations on the mineralogieal and geologieal characters of the loeality :-

$$
\begin{aligned}
& \text { "Choeolyn, Timboon, Vietoria, Australia Felix, } \\
& \text { 16th August, } 1855 .
\end{aligned}
$$

"If you look at a map of Victoria jou will pereeive a Lake situated almost due west from the town of Geelong named, probably, Lake 'Timboon. The true aboriginal name of this Lake is 'Golongolue,' euphonized by the Government Surveyors to Colungulae. My property is situated on the eastern bank, whieh in all the lakes about leere is the highest. The lake is salt, having no outlet, and is surrounded by banks of reddish clay eovered with light black soil rising on the eastern side to 30 or 40 feet with an undulatory surfaee. The margin of the lake is indented here and there with eapes of basaltie boulders, rery hard and heary, although exeecdingly eellular. Between the water-line and the cliff lies a narrow beach, and about the winter watermark in many places may be seen fragments of a peculiar ealeareous conglomerate, often mueh resembling coprolites. Where this is seen, if you look above you at the clay-cliff, you will pereeive a narrow white stripe, in some places only a few feet from the surfaee. I believe the conglomerated and disjointed stratum on the beaeh to be this same stratum brought down by the long-eontinued aetion of the waves and weather in ages bygone. Examining the conglomerate elosely, you will find that almost every fragment eontains more or less fossil bones, generally small broken pieces, and by erawling along the cliff you will find a bone now and then protruding. On the beach in 1843, when I first arrived, disjecta membra overspread many yards of surfaee, mostly belonging to the Kangaroo and Wombat. The blaeks ealled them old men's bones, and some said they were the remains of the Bunyip (a fabulous animal said to live in many of these lakes). I have given away hundreds of these speeimens; but some that I could not identify, having here no means of eomparison, I preserved for those who I believed possessed sound scientific knowledge. Among these were the speeimens I sent to you through Dr. Honson. I had long scarched drring leisure hours for fossil teeth belonging to the large bones, and suddenly perecived those sent among the broken eonglomerate, and for a time they excited great euriosity. I have not till lately found any more teeth, which made me regret the more the loss (as I feared) of those sent you. Some of these specimens of fossils are fincl 5 petrified, others are not, but are enelosed in a hard ealeareous matrix, the bone presenting a more recent or rather chalk-like appearance. Of these latter I have some before me, which I will endeavour to send you soon. Referring to the former part of this letter, allow me to mention that the hard eellular boulders appear to me to be the water-worn remains of submarine volcanoes, subsequent to the formation of whieh the whole western distriet appears to hare been raised and thiekly inhabited by animals. Violent voleanie aetion has again taken plaee, destroying these animals; and still subsequent eruptions have broken up the erust in which they were imbedded, eorering them with voleanie mud and the eountry with fragments of broken lava. All 
action has again ceased, and verdure has covered the oldest volcanoes, which form the picturesque crateriferous hills which now surround me.

(Signed)

"Obediently yours, "William Adenex."

‡ The subjoined extract from the Correspondence on the renewed Exploration of the Wellington Valley bone-breccia caverns, by the aid of the Grant roted by the Local Parliament of New South Wales in 1869, relates chiefly to the discovery of Thylacoleonine remains:-

\section{"Australian Museum, Sydney, New South Wales, October 30th, 1869.}

"Dear Professor Owen,--I received jour letter of August 2nd, and would have replied to it before had I not been absent at Wellington. I have been very successful, though I did not make any very great discovery. I found plenty of Thylacoleo remains, in particular teeth, and forward photographs thereof. Besides these I brought back remains of almost all our known genera, except perhaps Phascolarctos; nor did I discover any Bats, and no Hydromys. The photographs of the Thylacoleo-set of teeth will gire you a good idea of the animal's dentition; they were all discovered together and by my own hands. It was probably a complete skull; but the soil was soapy, stiff, and the ground had been given up as no good; when I went into it again, and after taking a foot of clay off and finding nothing but limestone nodules which assumed (pardon the expression) the shape of bones, I drove my pick slap into it with a will, and broke probably the skull into a hundred fragments. Here is a photograph of what was rescued; the two little upper premolars I did not find; there are also two in the lower jaw just behind the large third one. I mark their position-Plate II. Plate 3 gires you a view of the last tubercular molar in the lower jaw. The canine of the upper jaw is of a good size but of very peculiar form, so are the 2nd and 3rd incisors; all the teeth are Thylacoleo's, and of all I have duplicates.

(Signed)

“Gerard KrefFr."

[The tooth here called 'canine' is the anterior, first, or canine-shaped incisor.-R. 0.$]$

\section{Description of the Plates.}

\section{PI,ATE VII.}

Fig. 1. Portion of right upper jaw-bone (maxilla) and teeth, outer side view.

Fig. 2. Portion of right upper jaw-bone (maxilla) and teeth, inner side view.

Fig. 3. Portion of right upper jaw-bone (maxilla) and teeth, under view with workingsurface of teeth: the relative size and position of the tubercular is shown at $m_{1}$.

Fig. 4. Portion of right upper jaw-bone (maxilla) and teeth, front view.

Fig. 5. Portion of right upper jaw-bone (maxilla) and teeth, hind view.

Fig. 6. Crown of a less worn upper laniary $\left(i_{1}\right)$, outer side; from a breccia-cave.

Fig. 7. Upper laniary $\left(i_{1}\right)$, front view; from a breccia-cave.

Fig. 8. Part of crown of upper laniary $\left(i_{1}\right)$, inner side view ; from a breccia-cave,

Fig. 9. Second incisor $\left(i_{2}\right)$, outer side; from a breccia-cave.

Fig. 10. Right upper canine (c), outer side; from a breccia-cave.

Fig. 11. Left upper canine $(c)$, outer side; from a breccia-cave. 
Fig. 12. a, right upper canine $(c)$, inner side: $b$, ib. hinder side; from a brecria-cave.

Fig. 13. First upper premolar, outer side; from a breccia-cave.

Fig. 14. Second upper premolar, side view; from a breccia-cave.

'The foregoing figures are from Thylacoleo carnifex, nat. size.

Fig. 15. Sccond npper carnassial, Machairortus, inner side view, nat. size.

Fig. 16. Second upper carnassial, Machairodus, working-surface, nat. size.

Fig. 17. Right upper premolar, inner side view, nat. size, Iypsiprymnus.

Fig. 1S. Right upper premolar, working-surface, nat. size, IIypsiprymmus.

\section{PLATE VIII.}

Fig. 1. Left mandibular ramus, wanting the "rising branch," outer side view; ib. $\ddot{\imath}$, a section of fractured laniary.

Fig. 2. Left mandibular ramus, wanting the "rising branch," inner side view.

Fig. 3. Left mandibular ramus, wanting the "rising branch," upper view, witl workingsurface of carnassial.

Fig. 4. Under view of beginning or fore part of the inflected angle.

Fig. 5. Back view of fractured ditto.

Fig. 6. Lower carnassial tooth $\left(p_{4}\right)$, outer side, with fangs exposed.

The foregoing figures are from Thylacoleo carnifex, nat. size.

Fig. 7. Lower carnassial, outer side, Machairodus, nat. size.

Fig. 8. Left lower premolar, outer side, Hypsiprymmus, nat. size.

Fig. 9. Left lower carnassial, inner side, Machairodus, nat. size.

Fig. 10. Left lower premolar, inner side, Hypsiprymnus, nat. size.

Fig. 11. Working-surface of lower carnassial, Thylacoleo, less worn than in fig. 3, nat. size.

Fig. 12. Working-surface of lower carnassial, Iyycena, nat. size.

Fig. 13. Working-surface of left lower premolar, IIypsiprymnus.

The line I indicates the total length of the mandible of Thylacoleo when entire.

\section{PLATE IX.}

Fig. 1. Horizontal ramus of right mandible, with teeth, outer side view, nat. size; from a "photograph." (Original, a cave-specimen in the Museum of Natural History, Sydney, New South Wales.)

Fig. 2. Fore part of mandibular ramus, showing depth of implantation of laniary (i), and part of socket of carnassial $\left(p_{4}\right)$; from a "photograph." (Id. ib.)

Fig. 3. Front view of mandible and teeth; the bone in outline: from original fossils.

Fig. 4. Right lower incisor, inner side view ; from a "photograph." (Original, a cavespecimen in the Museum of Natural History, Sydney, New South Wales.) 
Fig. 5. Right lower incisor, from a breccia-cave in Wellington Valley, outer side view.

Fig. 6. Right lower incisor, from a breccia-cave in Wellington Valley, inner side view.

Fig. 7. Right lower incisor, from a breccia-cave in Wellington Valley, back view.

Fig. 8. Right lower incisor, from a breccia-cave in Wellington Valley, transverse section, one-third from apex of crown.

Fig. 9. Right lower incisor, from a breccia-cave in Wellington Valley, transverse section of base of crown.

The subjects of the foregoing figures are from Thylacoleo carnifex, nat. size.

Fig. 10. Left mandibular ramus and teeth, Bettongia, nat. size.

Fig. 11. Inner side view of a sheathed ungual phalanx (claw-core exposed by the removal of part of bony sheath) of an unguiculate mammal.

Fig. 12. Outer side view of a similar ungual phalanx, with more of the bony sheath preserved.

Fig. 13. Side view of a similar ungual phalanx; sheath mutilated.

Fig. 14. Under view of the same phalanx.

(From "photographs:" the originals in the Museum of Natural History, Sydney, New South Wales, were obtained from the same breccia as the subjects of figs. 1 and 2, and are from a large carnivore, probably of the same species.)

\section{PLATE X.}

Section of the skull of Thylacoleo carnifex as at present known, showing the cerebral cavity and the entire dentition from nature, nat. size. Owing to the crowding of the abortive premolars $\left(p_{1,2,3}\right)$ to the inner side of the functional one $\left(p_{4}\right)$, a complete view of the dental system cannot be had from the outer side of the jaws: if illustrated from that point of view it must be more or less diagrammatically; this Plate is, therefore, added, to be contrasted, as to number and relative size and position of the teeth, with the restorations which have been published in support of the herbivorous hypothesis of Thylacoleo. I have refrained from completing anatomically the articular part and ascending ramus of the mandible: one cannot doubt but that, ere long, an entire mandibular ramus of Thylacoleo carnifex will be obtained. The section of the cerebral cavity. confirms the ascription of the extinct carnivore to the Lyencephalous subclass. The cerebellum, as in Dasyurus, rises wholly behind the cerebrum, with apparently the interposition of part of the mesencephalon The prosencephalon $(p r)$ is very small when its proportion to the entire skull is compared with that in the Lion or Tiger. The rhinencephalon $(r h)$, projecting and conspicuous anterior to the cerebrum, is characteristically large. A "sella" $(h)$ is plainly indicated at the part of the basi- 
sphenoid where that cavity is "indicated only by the internal orifices of the entocarotid canals" in Thylacinus*. The chiasmal fossa is shown at $u$ : the precondylar foramen at p.c.

The symbols, letters, and numerals are explained in the text.

\section{List of Woodcuts.}

Fig. 1. Laniaries of Potamogale, front view.

Fig. 2. Laniaries of Urotrichus, front view.

Fig. 3. Mandible and upper and lower laniaries, side view, Potamogale.

Fig. 4. Mandible and teeth of Thylacoleo, as restored by Professor Flower, front view, one-third nat. size.

Fig. 5. Mandible and teeth of Phascolarctos, front view, three-fourths nat. size, after Professor Flower.

Fig. 6. Mandible and teeth of Phascolarctos, side view, half nat. size: grinding-surface of molars, nat. size, after nature.

Fig. 7. Skull of Thylacoleo carnifex, as reduced and restored by Professor FLower.

Fig. 8. Mandible of Thylacoleo carnifex, one-fourth nat. size, after nature.

Fig. 9. Mandible of Aye-aye, with incisor exposed, nat. size.

Fig. 10. Mandible of Plagiaulax Falconeri, Ow., magnified 4 diameters.

Fig. 11. Mandible of Thylacinus cynocephalus, after nature.

Fig. 12. Mandible of Sarcophilus ursinus, after nature.

Fig. 13. Skull of Thylacoleo carnifex, as reduced and restored by Mr. KREFFT.

Fig. 14. (Repetition of fig. 8.)

Fig. 15. (Repetition of fig. 10.)

Fig. 16. Mandible and teetl, Dendrolagus dorcocephalus.

Fig. 17. Mandible and teeth, Hypsiprymnus minor.

Fig. 18. Mandible and teeth, Bettongia penicillata.

Fig. 19. Mandible and teeth, Phalangista Cookii.

Fig. 20. Mandible and teeth, recent and fossil carnivores, nat. size.

* Descriptire Catalogue of the Osteological Series, Mus. Coll. Chir., \&c., 4to, p. 349. 


\title{
Suborder DIPROTODONTIA.
}

\author{
Section Poephaga.
}

Family GRAVIGRADA.

Genus Diprotodon.

Species Diprotodon australis.

§1. Introduction.-Ix a letter dated May 8th, 1838, addressed to Sir Thomas Mitchell, F.G.S., Surveyor-General of Australia, giving results of an examination of a series of Fossil Remains from caves in 'Wellington Valley,' and published in his 'Three Expeditions into the Interior of Eastern Australia,' vol. ii. 8vo, 1838, one of the specimens was described as follows:-

"Genus Diprotodor. I apply this name to the genus of Mammalia, represented by the anterior extremity of the right ramus, lower jaw, with a single large procumbent incisor (IX.), fig. 1, pl. 31. This is the specimen conjectured to have belonged to the Dugong, but the incisor resembles the corresponding tooth of the Wombat in its enamelled structure and position (see fig. 2, pl. 31, and a section of the Wombat's teeth in fig. 7, pl. 30). It differs, however, in the quadrilateral figure of its transverse section, in which it corresponds with the inferinr incisors of the Hippopotamus. 'To this Diprotodon, or to some distinct species of equal size, have belonged the fragments of bones of extremities marked $\mathrm{X}, \mathrm{X} a, \mathrm{X} b$ " (p. 362).

I reproduce the original figures (Woodcut, figs. $1 \& 1 a$ ) representing the specimen of half the natural size, and the section of the incisor of the full size, on which the genus was founded; but which specimen I now know to be that of a young individual.

Extraordinary as seemed the magnitude of the beast which this tooth indicated, at a period when the largest known mammal of Australia was a Kangaroo, it gave only half the size of the full-grown Diprotodon australis.

In ignorance of this fact I was led astray by the first evidences (femur and molar teeth) $1 a$

Fig. 1.

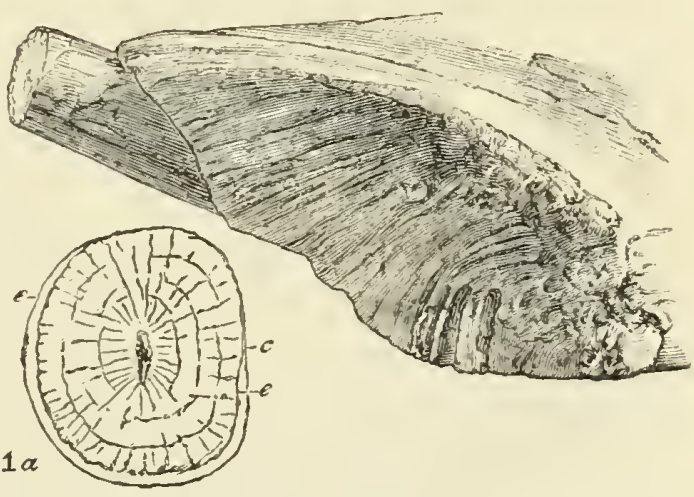
of the mature animal which were transmitted to me from freshwater deposits in another and remote locality of Australia; and, for a short time, I believed them to belong to a Proboscidian, referring them, in 1843, on the authority of a drawing of part of a jaw and teeth transmitted to me by Sir Thomas Mitchell, to the Dinotherian section of that order*. 
But I was not long under this delusion, and in 1844 realized grounds for the following rectification:- "Having since received specimens of portions of lower jaws with teeth identical in structure with the fragment figured in my first communication to the 'Annals of Natural History' (p. 9, figs. 2 \& 3), I find that the reference of that portion of tooth to the genus Dinotherium was premature and erroneous. 'The extinct species to which it belonged does indeed combine molar teeth like those of Dinotherium with two large incisive tusks in the lower jaw; but those tusks incline upwards instead of downwards, and are identical in form and structure with the tusk from one of the bonecares of Wellington Valley, described by me in Sir 'Triomas Mitciell's 'Three Expeditions into the Interior of Australia,' vol. ii. 1838, p. 362, pl. 31, figs. 1 \& 2, as indicative of a new genus and species of gigantic mammalian animal, to which $I$ gave the name of Diprotodon australis" *.

Of no extinct animal of which a passing glimpse, as it were, had thus been caught, did I ever feel more eager to acquire fuller knowledge than of this huge Marsupial. No chase can equal the excitement of that in which, bit by bit, and year after year, one captures the elements for reconstructing the entire creature of which a single tooth or fragment of bone may have initiated the quest; in the course of which one finally realizes, with more or less exactitude, the picture which the laws of correlation had led one to frame of an animal which may have passed out of existence long ages ago $\downarrow$.

Appeals to friendly correspondents in Australia had met, in 1845, with so much success as enabled me to give the entire dental formula of the lower jaw, viz. $i, 1, c, 0, m, 5 ;=6$ : and also to indicate a second genus of large herbivorous Marsupial (Nototherium) only inferior in size to Diprotodon $\$$.

further evidences fell in at longer intervals, and I was occasionally flattered with the hope of obtaining an entire skeleton, as by the subjoined extract from my old ally in researches of Australian 'Loology, Dr. George Bennetr, F.L.S., of Sydney, New South Wales.

Copy of part of a letter from George Bennett, Esq., F.L.S., dated Sydney, September 18th, 1863, referring to a skeleton of Diprotodon.

"... I I have some expectation of getting you more of the bones of the Diprotodon; my son George, who is now on a station in Queensland, writes me as follows:- 'I have been along the bank of a creek called 'King's Creek,' and searched it very minutely: I have found several bones, and also the place where the whole of a skeleton is imbedded in the ground. The bones are immense, some of the vertebræ are about 12 or 14 inches in length. I have now one of the smaller vertebræ, and it measures 6 inches in diameter.

* Annals and Magazine of Natural History for October 1844.

+ I hazarded the expression, in 1843, of such an ideal picture, as " of a heary terrestrial quadruped, like the Mastodon, with thick and stout extremities adapted to the support and progression of a massive frame."-Annals and Magazine of Natural History, rol. ix. p. 332.

$\mp$ "Report on the Extinct Mammals of Australia, and on the Geographical Distribution of Pliocene and Postpliocene 3 ammals in general," Reports of the British Association, 8ro, 1845. 
The head of the same skeleton was sent some years ago to Sydney. The shepherd who discovered the head is here still, and it was he who showed me the place. When I can get time and men in that direction I will dig it out and then forward it by degrees to you.'

"Since I received this account," proceeds Dr. Bennert, "I have seen Mr. W. B. Тоoтh, the owner of the station, and he informed me that he has a large blade-bone, and that when he visits the station and has the men at leisure, he will gradually dig out the skeleton as perfect as possible and forward it to me. Mr. ' $\mathrm{I}$. left on the 15th of this month for the station. I suggested to him to preserve every bone however small, which he has promised to do. On my receiving only a few at a time I will immediately transmit them to you, as I expect it will take some time to excavate the whole skeleton, as men cannot be spared at all times from a large sheep station."

I have long (perhaps too long) deferred entering upon the work of the present coms munication, hoping to complete the materials for the entire reconstruction of the Diprotodon. But the quick lapse of time, its inevitable effect on mind and body, and the venial impatience of the possessors of nondescript bones of the great Marsupial, combine to put an end to delay, and I proceed, therefore, to the description of the parts of this extinct animal at present at my command.

§ 2. Skull.-It is probable that the specimen in the British Museum (Plate XIX. figs. 1, 2, 3), purchased at the sale of a series of Australian Fossils sent to London from Sydney by a Mr. Bord, and stated to have been obtained from the bed of a creek at Gowrie, near Drayton, Darling Downs, Queensland*, may be the " head " referred to in the letter above cited.

The chief dimensions of this skull are given in the 'Table of Admeasurements' of parts of the skeleton of Diprotodon, p. 573.

The skull shows the general marsupial character of that part in its degree of depression or flattening from above downward, in the small proportion devoted to receive the brain, and in the large proportion given to the olfactory chamber and precranial airsinuses.

The occipital region (Plate XIX. fig. 1, , fig. 3), instead of being vertical, as in Macropus (ib. fig. 5) and most existing Marsupials, slopes forward from the terminal condyles at an angle of $45^{\circ}$ with the basicranial axis.

The basioccipital (ib. fig. 3,1 ) forms by a thick border convex vertically, slightly concave transversely, the lower part of the rim of the foramen magnum (ib. o) an inch in extent, separating in the same degree the lower ends of the occipital condyles (ib. 2, 2). These ends may be contributed by the basioccipital element, but the sutures between it and the exoccipitals are obliterated.

* "All the above fossil remains are from King's Creek, Darling Downs, being the same locality whence the entire skull of the Diprotodon was obtained some years ago."-W. S. MacLEaY, in "Report on Donations to the Australian Museum during August, 1857.' See also "Owen, On Nototherium," in Proceedings of the Geological Society of London, March 1858, p. 158. 
'The basioccipital, as it adrances, expands and gains a thickness of nearly an inch of compact and minutely cellular bony tissue.

'The occipital condyles (Plate XIX. fig. 3,2), an inch apart below and $2 \frac{1}{2}$ inches apart above, have their lower extremity obtuse, about an inch broad, curved inward and forward; they expand as they ascend, diverging to a breadth of 2 inches at their upper ends. 'The vertical convexity of each condyle describes a semicircle, the extent of the articular surface following this curve being 6 inches. 'The outer border is longer than the inner one, so that the upper margin of the condyle rises obliquely from within outward. 'The narrow lower ends of the condyles rise or project more abruptly from the intervening basioccipital borkler of the foramen magnum than in Macropus. Each condyle is here impressed by a rough surface or shallow notch at its inner surface, indicative of tendinal insertion. A low narrow ridge extends from the outer part of the lower end of the condyle, forward, and may indicate the lateral extent of the basioccipital at this part. 'The transverse convexity of the condyle is greater, less angular, especially at the lower' half, than in Macropus. 'The oblique base or upper end of the condyle projects proportionally nore from the non-articular part of the exoccipital. A similar better definition or greater prominence characterizes the outer margin of the condyle; the inner margin forming the sides of the foramen magnum is sharper and better defined than in Mrcropus: these borders are also less divergent as they rise. The inner, non-articular side of the condyle is slightly concave, rough, subtuberculate. The outer border of the articular part is sharp, and projects over the immer non-articular side of the condyle. In their posterior terminal position and degree of proninence the occipital condyles of Diprotoron resemble those in Dinotherium.

The foramen magnum (ib. fig. 3, o) is bounded above by the arched obtuse border of the exoccipitals, which bones rapidly gain thickness as they extend from the foramen. I assume that the exoccipitals met above the foramen, as in many Marsupials; or, if not mecting, had their interspace filled by the superoccipital, as in Phascolarctos: they left here no notch, such as one sces in Macropus Bennettii. 'The upper border of the foramen magnum is non-emarginate in Macropus major; but it is relatively of greater extent in that Kangaroo, through the greater divergence of the condyles, and it is less arched or concave transversely than in Diprotodon. 'Two precondyloid foramina open upon each exoccipital, opposite the junction of the lower and middle thirds of the condyle, from which the hindmost foramen is distant 9 lines, the next 1 inch 2 lines; cach foramen is about 4 lines in diameter. An irregular or tubercular ridge curves over the fossa of the precondyloid foramina, expanding to be lost on the paroccipital. This process (ib. figs. $1 \& 3,4$ ) is tuberous, thick, and short; it is not so much produced as in Macropus.

The foramen magnum is more evasé than in Macropus, i. e. it expands fumnel-wise to its outlet. backward, and especially above and below; it has more the character of a short (neural) canal than a foramen, through the antero-posterior extent of its wall or rim. It is transversely elliptical, 2 inches 5 lines in long, 1 inch 3 lines in short, dia- 
meters. It opens directly backward, the plane of its outlet being vertical. On each side of the inlet of the foramen magnum a wide and deep impression of a sinus curves downward to the jugular foramen at the inner side of the base of the paroccipital. The inner openings of the precondyloid canal are in a slight depression on each side the foramen magnum, a little nearer together than the outlets.

In the almost entire skull the upper border of the foramen magnum and contiguous part of the superoccipital surface are wanting. In the part of the occipital of another skull that surface is preserved to an extent of $2 \frac{1}{2}$ inches in advance of the upper border of the foramen, and for a breadth of 6 inches. This surface slopes forward from the foramen and condyles as in the entire skull; it is externally smooth and transversely undulating, showing a shallow medial concavity between two broad gentle convexities, which fall outwardly into concavities bounded by the oblique bases of the condyles. Nearly the lower half of the superoccipital surface is preserved in the fragment: the upper half, present in the skull, shows a strong medial vertical ridge (Plate XIX. fig. 3, 3), and is bounded above by the ridge between the superocciptal (3) and parietals (7), continued outwardly upon the mastoids (8). The cranial air-sinuses are continued backward into the super- and ex-occipitals, not into the basioccipital. On each side the mid-ridge ( 3 ) is a shorter vertical ridge. The mastoid (8) makes a much less projection than the paroccipital (4); it is confluent above with the petrosal, as in other Marsupials; not preserving its primitive distinction from that sense-capsule as in the Babyroussa*.

The brain being small in Marsupials, and the disproportionate smallness of its case to the rest of the skull increasing, as in other natural groups of mammals, with the general bulk of the species in such group, this character is a striking one in the skull of Diprotodon. Like its carnivorous contemporary the Thylacoleot, the brain-case makes 110 convexity or out-swelling into the temporal fossæ; the inner as well as the outer and hind walls of these long and large lateral vacuities are concave, and form parts of a general though not uniform excavation.

The broad and low triangular superoccipital surface, strongly sloping forward as it rises from the condyles, contracts above to its apex, and is continuous there with a (sagittal) ridge of the coalesced parietals (ib. fig. 1, z) extending forward to the interorbital region. There the upper surface of the cranium begins to expand, and to swell into a pair of low convexities (ib. fig. 1, 1 ) which roof over the frontal sinuses. The outer wall of this pneumatic part of the cranium has been crushed down by posthumous pressure or injury in the entire skull.

The nasals (Plate XIX. figs. 1, 2, 15), in continuing forward from the frontals the upper line of the skull, rise gently toward their terminations, which again curve downward, giving a sigmoid contour to that part of the cranial profile in a degree peculiar to the present species. The vertical diameter of the facial part of the skull at the ter-

* Owen, 'Anatomy of Vertebrates,' 8vo, vol.ii. p. 469; and ' Catalogue of the Osteology, in the MIuseum of the Royal College of Surgeons,' 4to, no. 3345, p. 557.

$\uparrow$ Plates XI. \& XVI. 
mination of the nasals rather exceeds that of the cranial part at the parietal region; it is also greater than the beginning of the facial part of the skull in advance of the orbits and molar alveoli, whence there is a gain both in depth and breadth as it approaches the anterior terminations; but the uniformity of this diameter of the skull along the medial line, from the superoccipital forward to the premaxillo-nasal part, viewerl sideways or in direct profile, is a remarkable characteristic of Diprotodon.

The part of the maxillary (Plate XIX. fig. 1, ${ }_{21}$ ) lodging the molar series of teeth $(d 3-m 3)$ breaks the lower line of the profile, descending below it along the middle third of the length of the skull. The zygomatic arch is deep, long, but proportionally less conrex outwardly, or less expanded, than in Thylacoleo. Its base (ib. figs. $1 \& 3,{ }_{27}$ ) seems as if continued from the whole side of the occipital plane, contracting rapidly at the upper border as the arch sweeps outward and forward; the superoccipital crest being continued into the upper border of the arch, and this apparently without break or abrupt rise in any part of that border*. The frame of the orifice of the "meatus auditorius" (ib. fig. $1,{ }_{28}$ ) projects downward from the hind part of the lower border of the base of the \%ygoma, indicative of the tympanic. Immediately in front of this descends the postglenoid process $(a)$ of the squamosal, and in advance of this is a second downward projection or convexity due to the "eminentia articularis" $(b)$, which is here, as in Marsupials, a process of the malar (26). From this part the lower border of the zygoma runs forward nearly parallel to the upper one, but with a slight concavity, as far as the maxillary element of the zygoma, which sends dowu a strong, moderately long, obtuse, subcompressed nnasseteric process (ib. $21^{1}$ ) - a cranial feature which is peculiar to herbirorous Marsupialst.

The orbit (ib. fig. $1, r$ ) is a relatively small vertically oral carity, communicating widely behind with the temporal fossa (ib. 7). The external nostril (ib. figs. $1 \& 2, n$ ) is terminal, subvertical, rather expanded, and divided in great part by an upward extension of the medial nasal plate of each premaxillary (ib. figs. $1 \& 2,22^{2}$ ), which plates, being in close contact, form the lower part of a long "septum narium" at the outlet of the nasal cavity, recalling its condition in the extinct Rhinoceros tichorhinus. There is a narrow and short descending ridge at the coadapted medial borders of the nasals, which seems to have been continued into the septum by cartilage rather than by bone. I have alluded to the analogy which the structure of the external nostrils in Diprotodon suggest to those of an extinct Pachyderm, but the truer and closer resemblance is found in the Marsupial group. The carity of the nose is divided by a complete bony septum to within one-fourth of the outer opening in Macropus and Phascolomys \$, advancing, in one species of Wombat, as in Nototherium, nearer to that outlet.

* Some mutilation of the hind part of this upper border in both zygomata begets reserve in definitcly pronouncing as to its normal outline.

+ The descending masseteric process in Glyptodonts, Sloths, and Megatherioids is formed by the malar bone exclusirely. Owes, 'Anatomy of Vertebrates,' vol. ii. p. 405, figs. 273, 274, 26, $a$.

$\doteqdot$ "On the Osteology of the Marsupialia," Zoological Transactions, fol.ii.p. 391. Anatomy of Vertebrates, vol ii. p. 348. 
The base of the masseteric process of the maxillary (Plate XIX. fig. 1, ${ }_{21}^{\prime}$ ) is a vertical outstanding ridge, beginning below about an inch above the fore part of the last molar alveolus, or above the interspace between the last and penultimate sockets, according to the age of the individual. It becomes thinned as it rises and projects, and then suddenly expands to form the fore part of the zygoma and to send down the process. This is slightly twisted upon itself outward and backward, concave on the hinder and inner surface, convex at the opposite surface; the fore part of the vertical base of the zygomatic process of the maxillary is smooth and concave.

The alveolar border of the maxillary contracts and terminates obtusely behind the last molar ( $m$ 3, Plate XXII. fig. 2). It articulates with the palatine, leaving a hinder angular interval into which the lower and fore part of the pterygoid is wedged. 'The outer part of the concare hind border of the bony palate curves from the pterygoid inward and forward to opposite the mid-division of the last molar: the palatines appear to complete, with the maxillaries, the hind part of the roof of the mouth, without leaving a vacuity.

Portions of the maxillary and palatine of two other individuals are equally without indications of any wide postpalatal racuity opposite the interspace between the last and penultimate molars. In advance of this interval the bony palate, due here to the maxillaries exclusively, extends so as to give a breadth of the palate between the penultimate molars of $4 \frac{1}{2}$ inches.

Anterior to the masseteric process the outer alveolar wall of the maxillary is undulated by the rertical prominences, indicative of the large and thick roots of the molar teeth. The alveolar border contracts as the teeth advance in position and decrease in size, and becomes a ridge anterior to the first molar in place (usually the second of the series $\left(d_{4}\right)$ in full-sized Diprotodons). This antalveolar or diastemal ridge (Plate XIX. fig. 1, x) curves upward and inward, approaching its fellow, then arches downward and terminates at the back part of the socket of the third incisor, where the maxillo-premaxillary suture begins. At the wider hind part of the interval, between the antalveolar ridges, there seems to have opened an anterior or prepalatal canal leading to the fore part of the nasal cavity, the orifice being elongate. In advance of this the deep and narrow channel between the fore part of the diastemata is entire. Above these ridges, the outer plates of the maxillaries swell outward as they ascend to form the lateral walls of the antorbital part of the nasal chamber, arching inward again abore to join the nasal bones (15).

The maxillo-nasal suture seems to have a relatively greater extent than in Phascolomys; but owing to the short facial or antorbital part of the skull, as compared with Macropus, it is of much less relative extent than in that genus. The antorbital foramen (ib. figs. $1 \& 2,21)$ is longest vertically.

Each premaxillary (Plate XIX. figs. $1 \& 2,{ }_{22}$ ) is deeply excavated by three alveoli, the foremost the longest, largest, and most curved. The inner walls of these alveoli rise as a strong vertical crest $\left(22^{\prime}\right)$ dividing the lower part of the nasal outlet. The incisive alveoli succeed each other from before backward; and, owing to its superior size, 
the outer border of the first projects further from the midline than does that of the last. Viewed from the palatal aspect the two series of incisive alveoli converge backward. instead of forward as in the Kangaroo and most other quadrupeds. 'The malar bone (Plate XIX. fig. 1,26) ascends from its junction with the maxillary to join the lacrymal $(-3)$ at the fore part of the orbit, by a very narrow curved strip or process; its main body is suspended in the zygomatic arch, of which it constitutes the anterior half, and the lower part, as far as, and including, the "eminentia articularis." The suture between the squamosal and malar elements of the zygoma is almost straight, extending from behind the orbit obliquely backward and downward to the glenoid cavity, of which articular surface the malar "eminentia," here more flattened than usual, contributes the fore part. This articulation (ib. fig. 4) is most extended transversely to the skull's axis ; its hinder half (ib. ib. ${ }_{27}$ ) is concave from before backward, its fore part (ib. ib. ${ }^{26}$ ) convex, but becomes flattened or a little hollowed on the "eminentia."

The lacrymal (ib. fig. 1, $7_{3}$ ) is perforated by the canal, marsupial-wise, in advance of and external to the orbital cavity.

§ 3. Mandible.-A transversely extended subconvex condyle (Plate XXVII. figs. 3 \& 4) adapts itself to the cavity offered by the base of the zygoma. 'The condyle is $5 \frac{1}{2}$ inches in transverse extent, 1 inch 9 lines from before backward; it is, in that direction, most convex. The condyloid process is supported by a three-sided neck quickly contracting to 1 inch 9 lines in transverse diameter (ib. fig. $3, n$ ); it is broadest and flattened behind, contracted in front to the ridge-like beginning of the "coronoid" plate (ib. figs. $2 \& 4, r$ ), which extends forward near the outer side of the neck. The condyle is more extended inward (ib. fig. 4, c) than outward (ib. ib. $c^{\prime}$ ) of this advancing rertical coronoid plate. The flat surface at the back part of the neck is continued into a suddenly expanded hinder facet of the ascending ramus, formed by the outward production of the hind wall or boundary of the outer depression for the insertion of the temporal muscle, and by the inward production (Plate XIX. fig. 3,e) of the hind wall or boundary of the deep inner concavity of the ascending ramus, where opens the large entry (Plate XXVII. fig. 2, o) of the dental canal. Below this orifice the concavity extends downward through the concomitant extension of the inner plate or hind wall to the lower border of the horizontal ramus, where it gradually subsides. The hind wall of the outer depression of the ascending ramus (Plate XIX. fig. 1,e) follows the contour of that of the inner depression, but sooner subsides; the interspace is a continuation of the broad hind flattened facet which. as it descends, gets a more outward aspect. Beyond the subsidence of the outer plate it gives the appearance of a bending inward of the angle of the jaw (ib. fig. 3, $e^{\prime}$ ), and that to a degree which is characteristic of Marsupials. The outer or crotaphyte depression of the ascending ramus (Plate XIX. fig. $1, f$ ) gradually gains the ordinary level of the outer surface of the horizontal ramus, and does not undermine the ascending branch to communicate with the inner concavity as in Macropus. In the shape of the condyle Diprotodon resembles Phascolomys, in which the intercommunicating canal of the ascending ramus is much reduced. 
The anterior border of the ascending ramus is straight and subvertical ; it is thickened at its lower part to be continued into the convex outswelling of the horizontal ramus outside the last molar (Plate XIX. fig. 1, $m 3$ ), a distance of an inch intervening between the alveolus of this molar and the convexity rising and thinning into the fore part of the coronoid plate $(f, f)$. The alveolar border is continued into an obtuse ridge or prominence (Plate XXVII. fig. 2, $p$ ), 2 inches behind the last alveolus; from which prominence the ridge subsides and expands, retrograding to form the internal border of the entry of the dental canal (ib. ib. o).

The horizontal ramus gains slightly in depth as it advances from the last to the first molar socket (Plate XIX. fig. 1, $d 3$ ). Two and a half inches below this socket, and a little in advance, is the vertically elliptic outlet of the dental canal (ib. 32). Below this orifice the ramus bulges out into a rather rough tumefaction, then slopes and contracts upward and forward to complete the socket of the huge procumbent lower incisor (i). From the socket of $d 3$ the alveolar border sinks and expands into the upper part of the socket of the incisor. The under border of the horizontal ramus is smoothly and broadly convex transversely. The inner surface sinks sheer from the openings of the molar alveoli, and curres inward below the anterior ones to the symphysis (Plate $\mathbf{X X V}$. fig. $2, s, s^{\prime}$ ). The fore part of the mandible below the incisive alveoli, expanding to the tuberous outswellings above-mentioned, has a broad, subquadrate form, recalling the shape of that part in the Hippopotamus (Plate XIX. fig. 2, $t, t$ ).

The symphysis (Plates XXV., XXVI. fig. 2,s,s) begins behind, at a line dropped vertically from the front lobe of the third molar $(m 1)$; it is 6 inches in length, 4 inches in depth in the full-grown animal. It gains in vertical direction more than in length during the growth of the mandible, with reference apparently to the provision of a sufficient lodgment of the progressively increasing incisive tusk. (Compare Plate XXV. fig. 2, $s, s$ with Plate XXVI. fig. 2, $s, s$.)

The large size of the dental canal exposed by the posterior fracture of the ramus of another mutilated mandible indicates the ample supply of ressels and nerves which minister to the growth and nutrition of the incisive tusk; the depth of the symphysis of the jaw corresponds with the tusks, which it helps to support; contributing to the required strength for the operations of those eroding implements, with space for the deep implantation and for the lodgment of the large persistent matrix of each tusk (Plate XXVII. fig. 5). 'The direction of the symphysis is oblique, from below upward and forward; its upper margin is nearly straight, its lower one convex; the rough articular surface stands out a very little way from the vertical plane of the inner surface of the ramus.

In comparing the symphysial part of the jaw of Diprotodon with that of any other large quadruped carrying a single incisor in each ramus there are well-marked differences. The symphysis in the Sumatran Rhinoceros and in Acerotherium is less deep and is proportionately broader; the great length of that part in the Mastodon longirostris, and its deflection in Dinotherium more conspicuously differentiate them. In the remark- 
ably large proportion of the symphysis in Diprotodon to the size of its molar teeth there are no quadrupers which so nearly resemble it as the Notothere and the Wombat; but in this existing Marsupial the symphysial part of the jaw is broader in proportion to its depth. The long and narrow symphysial junction in the Kangaroo is peculiar for the yielding movements allowed to the rami upon each other, which is betrayed by those of the long procumbent depressed incisors in the living animal*.

\$. Dentition.-The dental formula of Diprotodon is:- $i \frac{3-3}{1-1}, c \frac{0-0}{0-0}, m \frac{5-5}{5-5}=28$. Of the upper incisors the first or anterior pair.(Plate XIX. figs. 1 \& 2, $i 1$; Plate XX. figs. 1-6) are large curved scalpriform teeth, of which $I$ have not found indications of cessation of growth in any specimen. The skull above describer and figured (Plate XIX.) has been that of an aged male, judging from the size and degree of attrition of the teeth which are retained; but the anterior incisors above, like the pair below, are continued to the bottom of their deep alveoli without contraction, and with the retention of a widely open pulp-cavity (Plate XX. fig. 6). It is obvious that these strong anterior incisors (ib. figs. 1-4) worked with the evergrowing power of the "dentes scalprarii" of the Wombat, the Aye-aye, and the Rodents.

In the above skull the length of $i 1$, following the convex curve of the tooth, is 11 inches; its circumference is 4 inches 9 lines; the breadth of the oblique abraded working surface is 1 inch 9 lines; the longitudinal extent of that surface is 2 inches; but this raries in other specimens. An extent of $8 \frac{1}{2}$ inches (following the outer curre of the tooth) is lodged in the socket of the premaxillary.

I made a transverse section of a fragment of the skull of a Diprotodon, including the fore part of the premaxillaries and their scalpriform teeth (Plate XX. fig. 5). Such section of the tooth $(i 1, c, d, e)$ is irregularly threc-sided, with the angles broadly rounded off. 'The inner side, or that next the fellow tooth, is the narrowest; the front or enamelled side is the broadest: this side is trarersed lengthwise by a wide and shallow mid channel; the opposite side is grooved by a narrower and rather deeper channel, running along its outer half; and the inner more prominent half of this side (the concave one lengthwise) also shows a narrow and feeble impression near the mid-line of the tooth, and a broader more shallow impression nearer the angle, dividing the hinder from the inner surface. This surface, 1 inch 3 lines across (ib. fig. 2), is generally somewhat convex, but wary through two or three low obtuse longitudinal ridges, with interrening shallow channels. A fossil fragment of a similarly sized tooth yielding such transverse section as that shown by this remarkable scalpriform incisor would, according to present experience, determine the genus of Mammal to which it had belonged.

The enamel coating the anterior convex curve of the tooth is continued over the major part of the outer rounded surface, terminating abruptly along a line (ib. fig. 5, $e^{\prime}$ ) external to the outer longitudinal ridge $(c)$ of the posterior surface. In like manner the enamel is continued orer the rounded angle between the anterior and inner or medial sides of the incisor, and terminates abruptly at $e$, fig. 5, after covering about one- 
third of the inner surface. The hinder and two-thirds of the inner sides of $i 1$ are thus uncoated by enamel, the dentine $(d)$ showing there only a thin coating of cement $(c)$.

'The surface of the enamel is longitudinally striate and punctate (Plate XX. figs. $3 \& 4$ ); the fine pits being chiefly but not wholly between the striæ; so that in some parts the surface seems to be minutely reticulate or reticulo-punctate. The surface of the dentine to which the enamel was applied shows a similar but less marked character. The cement $(c)$ is thickest where it overlaps the terminal edges of the enamel.

The second upper incisor (Plate XIX. fig. 1, $i 2$; Plate XXIII. fig. 7) is slightly curved, but in an opposite direction to the first, the anterior longitudinal outline being concave: the degree of this bend seems greater through the oblique attrition of the tooth from behind downward and forward. The transverse section of this incisor is subcircular. The length of the exposed part of the tooth is 3 inches; the circumference is 3 inches 6 lines; but this slightly diminishes to the margin of the socket, and more so to the inserted end. The fore-and-aft extent of the abraded working-surface of the tooth (ib. fig. 8) is 1 inch 6 lines. The length of the entire tooth does not exceed 4 inches.

The third upper incisor (Plate XIX. fig. 1,i3), of similar form, is smaller. The length of the exposed part is 2 inches 10 lines; its circumference is the same; the foreand-aft extent of the worn surface is 1 inch. This surface runs upon the same level as that of the second incisor. The crown of the large lower incisor, besides applying its trenchant edge against that of the broader front incisor, scraped upon both the smaller incisive teeth. Probably, by reason of the age of the individual and the extent of tooth worn away, the original enamelled crown has gone, and both $i 2$ and $i 3$ are here represented only by their cylindrical cement-covered portion.

A specimen of a detached second upper incisor is in the same condition: the enamelled crown is worn away, the root contracts to its implanted end, which shows a small remnant of a conical pulp-cavity 8 lines in depth and the same in width, as in fig. 7 , Plate XXIII.

The second and third incisors of Diprotodon were teeth of limited growth, and with the enamel confined to and thus defining a crown as in the Kangaroos; whilst the front incisor was a scalpriform tooth as in the Wombats, in which the second and third incisors are not developed. The extinct Diprotodon thus exemplifies an interesting intermediate or transitional condition of the upper "dentes primores" unknown in any existing form of Marsupialia.

In the upper jaw of the skull above described (Plate XIX.) the molar series is in place, with the exception of the first small tooth $(d 3)$. The other four teeth occupy, on each side the jaw, a longitudinal alveolar extent of 7 inches 4 lines. The homologies of these teeth with those in Macropus are indicated by the symbols used in my 'Anatomy of Vertebrates,' vol. iii. fig. 296, where the grounds for such use are given, and in fig. 1, Plate XIX. of the present Memoir. Scarcely a trace of the socket of the first small molar $(d 3)$ remains in the skull; the other molars progressively increase in size to the last $(m 3)$, which has a minor breadth of the hind lobe than in $m 2$. The line of the 
working surfaces of the four molars describes a slight convexity downwards (Plate XXII. fig. 1); the exterior line is also slightly convex (ib. fig. 2); the interior line is concave in a less degree; the right and left series are moderately convergent anteriorly. The interspace between the hind lobes of the last molars $(m 3)$ is 4 inches 1 line; that between the front lobes of the first molars $(d 4)$ is 3 inches 1 line; these dimensions give the breadth of the palate between the right and left teeth above symbolized.

All the molars in place have an enamelled crown divided into two transverse lobes (Plates XXI., XXII. $a, b$ ), with accessory basal ridges $(f, g)$, and are inserted by cementclad contracting roots as in Macropus. The summits of the transverse lobes are abraded in all the molars of the specimens figured; but least so in the hind lobe of the subject of $m$ 3, fig. 2, Plate XXII.

The socket of the first small molar (fig. 1, $d 3$ ) is partially preserved in the entire skull ; it consists of two cavities, the hindmost the largest, the tooth having only two roots. In the subject of Plate XXI. figs. $1 \& 2$, the crown of $d 4$ is ground down nearly to the bottom of the cleft $(h)$; the fore-and-aft extent of the grinding-surface is 1 inch 2 lines; its transverse extent across the hind lobe is the same. Across the fore part of the base of the tooth is a low ridge $(f)$, to the level of which the anterior lobe $(a)$ is almost worn. The corresponding ridge at the back part of the tooth is continued along both the outer and inner borders $(g, g)$ of so much of the back part of the hind lobe as is not ground down; the whole of the surface projects beyond the level of the worn surface of the following molar (fig. 1, $m$ ). The transverse cleft is deepest at its outer and inner ends; a ridge of enamel descends from each of these ends of the anterior lobe, and, meeting a corresponding projection of the oppposite lobe, it partially closes the entry of the valley.

The anterior basal ridge is strongly developed in $m 1$, especially at its inner end; the interspace between it and the anterior lobe widens toward the inner side of the tooth $(f)$. The anterior lobe is worn down nearly to the level of the ridge; the surface describes a transverse irregular ellipse; that of the posterior lobe is narrower: in both a mid linear tract of osteo-dentine $(o, o)$ is exposed. The narrow hind basal ridge $(g)$ is continued upon the hind lobe as in $p 4$, and that lobe projects clear beyond the level of the grinding-surface of $m 2$. The antero-posterior and transverse diameters of the workingsurface of $m 1$ are each 1 inch 6 lines.

The anterior basal ridge $(f)$ is strongly developed in $m 2$, and the antero-posterior diameter of the tooth ( 1 inch 9 lines) rather exceeds the transverse diameter. The front lobe $(a)$ is worn down to within 5 lines of the basal ridge. The minor degree of abrasion of the hind lobe shows the curve of the grinding-surface, concave backward, which is lost as the thicker part of the lobe is reached. The hind basal ridge $(g)$ is feebly developed.

In the last molar $(m 3)$ the hind lobe is markedly less than the front one, by its more rapid loss of transverse dimension: it is rather narrower in this line at its base, as it is in fore-and-aft extent. The last upper molar of Diprotodon may be readily determined by its posterior contraction. In some individuals the hind surface of the hind lobe 
is less evenly concare transversely; I have seen it almost canaliculate. The loss of breadth of this lobe is chiefly from the outer side, and the lobe is lower than the front one, the level of the grinding-surface reaching halfway toward that of the front lobe. The fore-and-aft extent of the base of the tooth is 2 inches; the transverse extent of the worn surface of the front lobe is 1 inch 6 lines; that of the hind lobe is 1 inch 3 lines. The anterior ridge (fig. $4, f$ ) is continuous with a feeble rising of the enamel at the outer and the inner borders of the front surface of the anterior lobe. The posterior basal ridge (Plate XXII. fig. $3, g$ ) is more directly and conspicuously continued into the ridge along the inner border of the posterior surface of $m 3$.

Wherever sufficient of the lobes remains, their profile, especially the outer one, describes a curre concare forward (Plates XXI., XXII. fig. 1). The inner and anterior angle of each tooth, due to the more prominent part of the front basal ridge, projects inward, a few lines beyond the inner surface of the tooth in advance (ib. ib. fig. 2). Thus there is not only a zigzag disposition in the vertical but in the transverse arrangement of the upper molars, though in the latter it be but slightly marked. The enamel is about a line in thickness, and shows strongly the reticulo-punctate or rugous surface at the less exposed parts of the crown.

The upper molars are implanted by fangs which acquire twice the length of the enamelled crown: they are at least three in number, save in the first small and early deciduous tooth ( $d 3)$. The base of the anterior division of the tooth bifurcates as it descends, slightly contracting in the socket, and thus forming two fangs in the same transverse line. The base of the posterior division, if it bifurcates in any molar, is divided later and to a less extent. It gradually contracts, and is longitudinally excavated at the side next the other fangs.

Figure 4, in Plate XXII., gives a view of the two anterior fangs $(m, n)$ of the last molar; fig. 3 , ib., shows the single posterior fang $(l)$ of the same tooth. Plate XXIII. fig. 3 shows the sockets and implanted ends of the fangs of the antepenultimate and last molar teeth. The outstanding antero-posteriorly compressed zygomatic process of the maxillary $\left(n^{\prime}\right)$ is here opposite the hind lobe of $m 2$.

In the series of upper molars of Diprotodon there are varieties as to size, and as to order or degree of wear, the former variety being more constant. Both are exemplified in the specimens figured in Plate XXI. figs. 2 \& 3. In fig. 3, a portion of the left upper jaw with the last three grinders, $m 1$ shows both lobes and the anterior ridge worn down to a common field of dentine $(d)$ and osteo-dentine $(o, o)$ : the summits of $m 3$ are partially abraded. In fig. 2 , in which the last molar $(m 3)$ shows an equal degree of abrasion, the antepenultimate molar $(m 1)$ is not worn to the same degree as in fig. 3; the anterior lobe is ground down near to the basal ridge $(f)$, but this remains untouched; the valley between the two main lobes is not obliterated. What is still more unusual, where the last molar has come into use, the second molar ( $p 4$, fig. 2, Plate XXI.) preserves its lobes hardly worn down to the bottom of the valley, and the two fangs of the first molar $(d 3)$ remain in their alveolus. 
A cursory comparison of the two foregoing specimens suggests that $m 1$ (fig. 3 , Plate XXI.) may have been destined to be pushed out by a vertical successor, which, in place in the larger specimen ( $m$ 1, fig. 2, Plate XXII.), shows of course a less degree of abrasion. But this is not the case. I have in vain sought for evidence of any premolar, in either upper or lower dental series of Diprotodon: it differs from Macropus and resembles Phascolomys in this particular. All the teeth, like the last three grinders in the type diphyodont dentition, belong to the first set. The variety as to degree of attrition in unolars of the same series is due to some modified habit of mastication: the difference ill respect of size I ascribe to sex, the smaller grinders belonging to the female, concomitantly with a general inferiority of bulk, as is scen in Macropus. The following adineasurements exemplify the difference of size in molar teeth, which is probably sexual :-

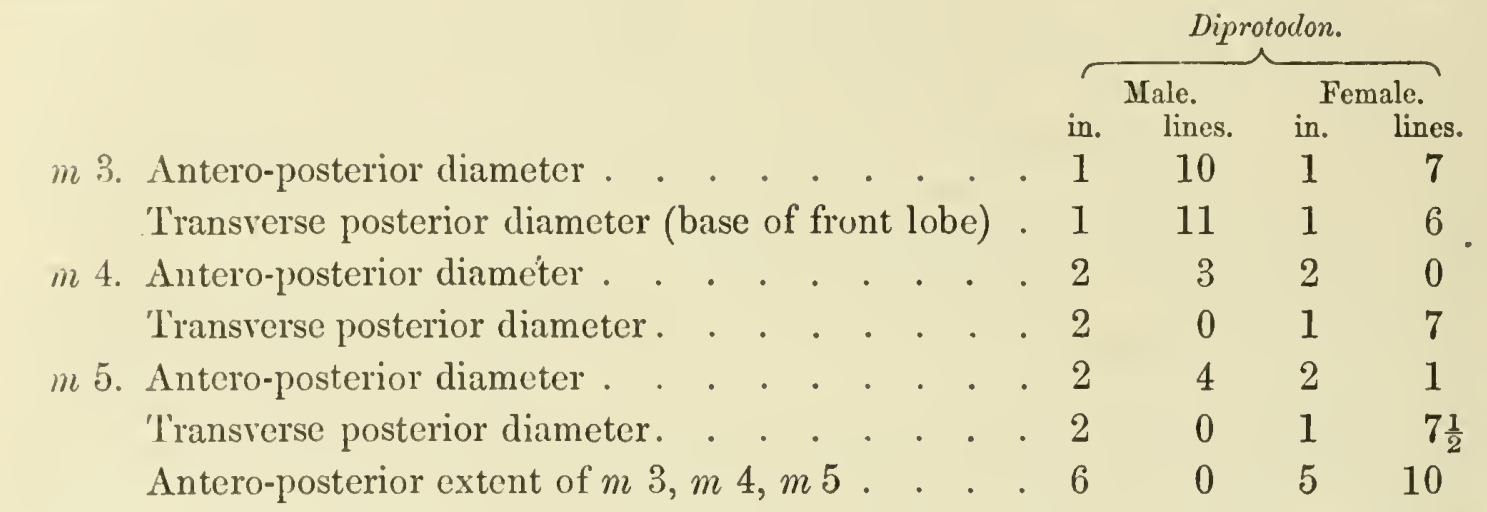

The forms and proportions in which the four constituents of the molar teeth of Diprotodon are combined, are exemplified, in the vertical longitudinal section of the last three upper grinders, in Plate XXVII. fig. 1. The enamel $(e)$ gains thickness as it recedes to a certain extent from the summits of the lobes, giving more resistance or grindingpower as the tooth wears down; but the enamel thins again at the base of the lobe; it gains a little more thickness as it is reflected, so to speak, over the basal ridges, beyond which it extends from three to four lines before thinning off, and ceases upon the body of the tooth before its division into fangs. 'The usual general direction of the dentinal tubules is well displayed, as in most fossil teeth. As the dentine becomes exposed and abraded, the pulp-cavity is defended by the coarser calcification of the remaining matrix near the field of abrasion, and from 2 to 3 lines of osteo-dentine is interposed between that field and the pulp-cavity. In each lobe of the tooth most worn $(m 1)$ the cavity is reduced to a linear trace. In the anterior lobe of $m 2$ it is more expanded; and it retains width in both lobes of $m 3$. In each tooth the pulp-cavity has received a lining of dark-coloured spar in the course of fossilization. The cement is thickest upon the back part of the hind root $(c)$, whence it extends upon the posterior basal ridge: this partial excess of cemental development assumes a characteristically definite figure in such sections as the one described.

The lower incisors (Plates XIX., XXVI. \& XXVII. $\ddot{\imath}$; Plate XXIII. figs. 4, 5, 6) are 
nearly straight; the very slight degree in which they deviate from that line tends to an upward curve (Plate XXIII. fig. 4).

The length is 10 inches, the circumference 5 inches 6 lines. The longitudinal extent of the worn surface in those of the skull (Plate XIX.) is 3 inches; its transverse breadth is 1 inch 4 lines. The transverse section of the entire tooth (Plate XXIII. fig. 6) is oblong; in some it presents an irregular oval with the small end upward. 'The outer side at its lower two-thirds is usually prominent; the inner side is more even or flat, in some instances feebly convex; in one specimen very slightly concave along its middle third. The outer side is more constantly traversed by a narrower shallow longitudinal channel, rather above the middle of that side. The enamel (Plate XXIII. figs. 5, $6, e$ ) is continued from the border of this channel round the lower part of the incisor, to about onefifth of the extent of the inner side (ib. $\left.e^{\prime}\right)$ : its terminal borders are abrupt on both sides, with the rather thick cemental covering of the unenamelled part of the circumference extending over the enamel borders. The surface of the enamel is finely ridged lengthwise and reticulo-granulate; the minute studs of enamel being, however, more conspicuous than the holes; although these are not absent.

About two-thirds of the tooth is lodged in the socket, which extends backward a little beyond the symphysis, but without causing, as in Rodents, a prominence of the inner wall of the ramus (Plate XXVI. fig. 2); in this respect Diprotodon resembles Macropus and Phascolomys. The line of the socket forms an angle of $147^{\circ}$ with the basal line of the mandibular ramus. The pulp-cavity (Plate XXVII. fig. $5, p$ ) is a long cone widely open at the base. The pair of tusks run almost parallel, slightly approximating so as to come into contact at their working ends.

The form of the lower incisor, described as it is shown in the most perfect specimen of the lower jaw of a full-grown example, is subject to some variety. Being a tooth of unlimited growth, it increases with the size of the jaw. In young specimens the outswelling of the outer side, or the contraction of the upper third of that side, is either not apparent or not so conspicuous, and the transverse section of the incisor yields a full oval, as in that of the young Diprotodon from the Wellington Valley Cave* (Cut, fig. 1 a), and, slightly modified, in the one of similar age from Darling Downs, Queensland (Plate XXVI. fig. 1, a).

But under all these slight varieties, which I cannot regard as specific, there prevail the same essential characters of structure, disposition of enamel, \&c., pointed out in my original Memoir as differentiating Diprotodon from Halichore, Hippopotamies, and other Mammals with tusks of similar size *.

A diastema, between three and four inches in extent, rises gently as it recedes from the incisor (Plate XXV. ̈) , to the first molar $(d 3)$, and more so, as the molar series becomes completed and pushed out for use as in Plate XIX. fig. 1, and Plate XXVI. fig. 2.

Of the first molar tooth $(d 3)$ I have no specimen. Its existence was indicated by traces of its socket in the portion of mandible obtained by Dr. E. C. Hobson, from a gravel-

* Mrtchell's ‘ Three Expeditions into the Interior of Australia,' 8vo, 1838, vol. ii. p. 362, pl. 31. figs. 1 \& 2. 
bed in the "Melbourne district," described in my "Catalogue of Fossils in the Museum of the Royal College of Surgreons' (4to, 1845), p. 308, no. 1491 ; and such trace of socket showed the tooth to have been implanted by two fangs. The corresponding divisions of the socket of $d 3$, with the fangs in situ, are better preserved in the specimen figured in Plate XXVII. fig. 5, and Plate XXVI. figs. $1 \& 2, d 3$. Dr. Hobson, shortly before his death in 1848, transmitted to me a sketch of this tooth in situ, in a fragment of the lower jaw of a young Diprotodon (Cut, fig. 2), according to which the anterior as well as the posterior lobe of $d 3$ is in the form of a transverse wedge; there is a basal ridge along both the fore and hind parts of the crown, the latter being the broadest; in short, 13 presents, in miniature, the bilophodont type of the succeeding molars. From the attrition of the two lobes it may be inferred that the opposing molar above was also transversely two-ridged. That the tooth (fig. 2) answers to the one which occupied the socket $(d 3)$ in Plates XXVI. \& XXVII. fig. 5, is shown by correspondence of size. The fore-and-aft extent of the socket in both is 9 lines, the breadth of the division for the anterior fang is 4 lines, of that for the posterior fang $4 \frac{1}{2}$ lines; the alveolar wall $\mathrm{ex}$ tending transversely between the two divisions exceeds a line in thickness; each fang is subcircular at its fractured end, with an indent at the side turned toward the other fang, indicative of a longitudinal groove into which the walls of the socket enters, giving a firmer implantation to the tooth.

In the portion of mandible (Plate XXVI. \& XXVII. fig. 5) the penultimate molar (m 2) had not risen completely into place, and the posterior lobe was barely touched by masticatory work. In the mandibular ramus (Plate XXVII. fig. 2), with the last molar ( $m 3$ ) in place and both ridges showing wear, the two divisions of the socket of $d 3$ are retained, without trace of tooth. The fore-and-aft extent of the socket is 9 lines, that of the hind fossa or division is $3 \frac{1}{2}$ lines, that of the front one $2 \frac{1}{2}$ lines, and that of the intervening bar is $2 \frac{1}{2}$ lines at its prominent part.

In the younger jaw the second molar (Plate XXVI. figs. $1 \& 2, d 4$ ) has both lobes the crown about half worn down; the fore-and-aft extent of the crown, including the anterior and posterior basal ridges, is 1 inch 6 lines. The anterior basal ridge is thickest at its outer part, and here the enamel has been worn off in mastication. The flat fore side of the front lobe rises 5 lines above the ridge. The abraded surface (Plate XXIV. fig. 3. a) of this lobe is $S$ lines in transverse and 4 lines in antero-posterior extent, the mid part being increased in this direction by an outswelling of the hind surface there of the lobe. The outswelling of the front slope or surface of the hind lobe is situated more outwardly: the abraded surface (Plate XXIV. fig. $3, \zeta$ ) of this lobe is narrower from before 
backward, broader transversely, than that of the front lobe. A low and short ridge of enamel $(h)$ closes both outer and inner ends of the intervening transverse valley. The length or vertical extent of crown between the end of the valley and the division into fangs is 5 lines on the inner side and 4 lines on the outer side of the tooth. The middle of the hind surface of the hind lobe swells out; and as both outer and inner ends of the hind basal ridge $(g)$ bend up the corresponding parts of the hind lobe, its hind surface shows two shallow depressions divided by the above-named rising: in these depressions the reticulo-punctate character of the enamel is most strongly marked. The hind basal ridge is thicker than the front one $(f)$, and thickest at its middle; its enamelled margin is irregular, it rises higher than, and seems to overlap, the front basal ridge of the fol. lowing tooth. The cement upon the exposed part of the crown of $d 4$, between its enamelled lobes and implanted fangs, is thick. The fangs are two in number, broadest transversely, slightly divergent, canaliculate on the contiguous sides.

In the jaw of an older Diprotodon the second molar (Plate XXIV. fig. 4, $d 4$ ) shows both lobes abraded to their common base, exposing the osteo-dentine $(0)$ obliterating the cavity of the fang. A small part of the enamel of the front basal ridge $(f)$ shows its position as blended with the front lobe. The line of enamel of the worn hind surface of the hind lobe $(b)$ forms an open angle, of which the apex shows the end of the prominence joining the middle of the hind basal ridge $(g)$, and dividing the remnants of the pair of depressions between that ridge and the hind lobe. The fore-and-aft extent of the worn surface of this molar is 1 inch $6 \frac{1}{2}$ lines; that of the base of the crown is 1 inch 8 lines; the breadth of the hind part of the worn surface is 1 inch. The alveolar border rises into an angle between the origins of the fangs.

In Plate XXIV. fig. 2 shows the working-surface of the crown of $d 4$, of rather smaller size than those above described, and probably from a young female Diprotodon. The summit of the anterior lobe is so far worn as to expose a transverse curved line of dentine, concave forward, beginning to expand where attrition has reached the prominent part of the hind surface of the lobe. The summit of the posterior lobe $(b)$ has just been touched. The proportions of the basal ridges $(f, g)$ are well shown. The reticulo-punctate character of the enamel is well marked. This tooth was from the freshwater deposits of the Province of Victoria, near Melbourne. The outer side view of this tooth is given in figure 1 .

From the same locality I received the third molar $(m 1)$ of the same Diprotodon (Plate XXIV. figs. 5 \& 6): its almost untouched lobes are more compressed than in the Tapir and Dinothere, and their lamelliform summits rise higher beyond their basal connexions than in the Kangaroo; the median connecting ridge which extends between the two transverse eminences longitudinally, or in the axis of the jaw in the molars of the Kangaroo (ib. fig. 14), is very feebly indicated by the outswelling, shown in figs. $3 \& 7$, at the back of lobe $a$, in the Diprotodon. The anteriorly concave curve of the summits of the transverse lobes, in fig. 6 , is more regular, equable, and greater than in the 'Tapir (fig. 15), the Dinothere, or the Kangaroo. The two fangs, the contiguous 
surfaces of which present the deep and wide longitudinal groove, as in the Tapir, Dinothere, and Kangaroo, are connected together at their base by a ridge coated thickly with cement, and extending longitudinally between the beginnings of the opposite grooves in Diprotodon.

'The third molar in the young specimen (Plate XXV. figs. $1 \& 2, m 1$ ) has both lobes partially abraded ; the fore-and-aft extent of the tooth is 1 inclı 10 lines, the basal breadtl of both lobes is the same, viz. 1 inch $1 \frac{1}{2}$ line. The reticulo-punctate or "worm-eaten" character is strongly marked on the enamel of the fore part of the front lobe; this is slightly concave transversely at its upper part, the outer and inner borders inclining forward to receive the upward continuations from those ends of the anterior transverse ridge $(f)$. The middle of the lind surface of the front lobe (Plate XXIV. fig. 7,a) is prominent, making the masticatory surface widest at that part. The prominence $(b)$ from the opposite surface of the hind lobe looks more like an infolding of the outer border of that lobe, a character exaggerated in most Kangaroos; the inner border of the hind lobe is slightly produced backward as well as forward. The hind surface of the hind lobe does not show the mid prominence. 'The hind transverse basal ridge $(g)$ is highest and thickest at its middle; the ends of this ridge are less distinctly continued upon the corresponding borders of the hind lobe than in $m 2$. The slight backward curve of the lobes appears in the profile view of $m 1$, fig. 5 .

In the older jaw the lobes of $m 1$ (Plate XXIV. fig. 8) are worn down nearly to their bases. The front transverse ridge rises a little above the hind one of the antecedent tooth; about 5 lines extent of the fore part of the front lobe rises above the ridge. 'The anterior enamel-line of the worn surface is nearly straight, the posterior one forms a low angle answering to the prominence of that surface of the lobe. 'The valley between the two lobes is most shallow and narrow at its middle. 'The abraded surface of the lind lobe is transversely elliptical, 1 inch $4 \frac{1}{2}$ lines in transverse diameter, and 8 lines in the opposite diameter; its hind border is worn down within 3 lines of the posterior basal ridge $(g)$, which abuts against the next tooth above its anterior ridge.

The fourth molar $(m 2)$ in the younger specimen (Plate XXIV. figs. $9 \& 10)$ has a line of dentine exposed on the summit of the front lobe $(a)$, but the enamel is not worn off that of the hind lobe $(b)$. The transverse concavity of the fore part of the front lobe is well marked at the present early stage of attrition: the convexity of the back part increases towards the base of the mid prominence. The ends of the front basal ridge $(f)$ rise a little way upon the outer and inner borders of the front lobe. 'The transwerse concavity of the fore part of the hind lobe is narrowed, as it descends, by the reciprocal and progressive inbending of the outer and inner borders of the lobe upon the front surface, as this approaches the base of the lobe. The height of the hind lobe from the middle of the valley is 1 inch 3 lines; the antero-posterior extent of the middle of the base of the lobe is 10 lines. The posterior basal ridge $(g)$ resembles that of $m 1$, bearing the same proportion to the front ridge. 
In the older specimen (ib. fig. 11) the two lobes of $m 2$ are half worn down; the abraded surface of each is gently bent with the concavity forward; the transverse extent of such surface is 1 inch 7 lines; the fore-and-aft extent of the tooth is 2 inches 4 lines. The abraded surfaces slope from before downward and backward.

In the last molar of the same lower jaw the summit of the hind lobe, on which a narrow tract of dentine is exposed, measures 1 inch 4 lines in transverse extent, that of the more worn front lobe being 1 incl 6 lines. The transverse extent of the base of each lobe is the same, viz. 1 inch 7 lines. The summit of the hind transverse ridge $(g)$ is continuous with a short low rising upon the back part of the hind lobe. The antero-posterior extent of the tooth is 2 inches 5 lines.

There is less difference between $m 2$ and $m 3$ of the lower jaw than in the upper one. Owing to the direction of the plane of attrition, the front surface of each worn lobe is higher than the back surface; the front lobe, when unworn, rises a little higher than the back one. The fore part of each tooth rises more abruptly, and in a greater degree above the back part of the tooth in advance; thus the line of attrition of the entire molar series is zigzag. The general curve of the grinding-surface of the four molars is slightly concave from before backward, as, above, it is convex. The contour of the outer sides of the lower series of molars is slightly convex; that of their inner sides is almost straight.

In the mandible belonging to the skull (Plate XIX. fig. 1) the outer part of $m 2$ is worn to its base, and a larger proportion of $m 3$ alone remains in the left ramus*. The fore-and-aft extent of $m 3$ is 2 inches 5 lines: the same extent of the abraded surface of the front lobe is 9 lines, its transverse extent being 1 inch 7 lines. The enamel at this part of the tooth is fully a line in thickness.

In a fragment of the left mandibular ramus of an old Diprotodon are the last two grinders (Plate XXIV. figs. 17, 18), similarly worn down but better preserved. In $m 2$ (fig. 17) a portion of the enamel at the inner end of the valley $(e)$, and the enamel of the hind part of the base of the hind lobe with the contiguous basal ridge alone remain ; the rest of the surface is polished dentine and osteo-dentine with the external cement. In $m 3$ (fig. 18) the enamel is worn away from the fore and outer part of the front lobe; the front basal ridge is rounded off; the outer boundary of the valley connecting there the front and hind lobes is smoothed down, and the middle of the hind transverse ridge is touched. Both lobes are worn down nearly to the bottom of the valley. At the middle of each of the smooth concave plates of dentine, a central tract of osteodentine $(0)$ is defined. The antero-posterior extent of $m 2$ is 2 inches 4 lines; that of $m 3$ is 2 inches 5 lines; the greatest transverse diameter in each is 1 inch 7 lines. This Diprotodon had probably died of old age. The outer alveolar border has grown upward with the rise of the fangs and base of the teeth to bring them into grinding contact with those of the upper jaw.

In the crown of the last molar not wholly emerged from the formative alveolus of the

* The form and position of these teeth are given, in outline, from better preserved and less worn specimens. 
young Diprotodon (Plate XX1V. figs. 12, 16), the unworn summit of the hind lobe is irregularly and minutely wrinkled, not divided into small mammilloid tubercles as in the Dinothere. In the largest existing species of Kangaroo (Macropus major and M. laniger, e. g.) the lower molars have no posterior basal ridge. It is interesting to find that this is present in a still larger extinct species (Macropus atlas, Ow., fig. 14, g), but it is narrower than the anterior basal ridge. In the lower molars of Diprotodon the posterior basal ridge is not only constant, but is broader than the anterior one.

- The sum of the characters of the teeth of Diprotodon, and the observed varieties and modifications due to sex, age, and other conditions, have been given in detail and fully illustrated. The most common evidences of extinct Mammals are detached teeth; and it seemed desirable to afford sufficient and satisfactory means of determining those of the genus Diprotodon, as thereby the knowledge of its geographical distribution in the Australian Continent at the period of its existence may be the more speedily acquired.

A retrospect of the dentition exhibited in the series of specimens above described and illustrated brings to view a combination of characters now shown apart in the marsupial herbivorous genera Macropus and Phascolomys; but the Macropode characters prevail in number and importance. The small upper incisors ( $i 2$ and $i 3)$ with definable crown and fang and concomitant limitation of growth, the same genetic character of the molars with the bilophodont type of their crown, testify to the closer affinity of Diprotodon to Hacropus. 'The large, scalpriform, ever-growing first pair of incisors of the upper jaw, with the shape, structure, and corresponding genetic character of the lower pair of incisors, are resemblances to the Wombat's dentition; and the same affinity is exemplified in the number of the molar teeth.

In the Macropode group, although not more than five grinders are ever in place in one alveolar series of either jaw, seren may be developed. Of these teeth two have no homologues calcified in either Phascolomys or Diprotodon; these are the small anterior teeth symbolized in my 'Anatomy of Vertebrates' (rol. iii. p. 3S0, fig. 296) as $d 2$ and p.3 (Cut, fig. 4). It may be objected that, for certainty on this point, one ought to have specimens of jaws of Diprotodon of an earlier age than that represented in Plates XXV1. \& XXVIl. My experience in marsupial dentition begets confidence, however, that, had a true "replacing tooth" been developed in Diprotodon as in Macropus, its crown-germ would have been detected beneath the tooth marked $d 3$, in the subject of the above-cited Plates. 1 also believe that, had a $d 2$ ever been calcified and in use, as in the Kangaroos and Potoroons, some trace of its alveolus would have remained, in this young jaw, instead of the continuous, eren subtrenchant margin which the diastema of the subject of Plate XXVI. presents between $d 3$ and $\ddot{i}$.

Since the Wombats in their molar dentition offer precisely the same differences as to number and succession of grinders which Diprotodon presents, we may have the less reserve in accepting the evidences of the further resemblance which the molar series adds to the incisive one. The extension of the genetic character of the scalpriform incisors 
to the molars is the marked distinction of Phascolomys in the Marsupial series; for, with continuous growth, go length of tooth without loss of breadth, depth of implantation with, commonly, curvature of socket, and continuation of enamel to the widely open base of the tooth. I have no evidence that the first and smallest of the series of five grinders in Phascolomys is a premolar or replacing tooth, and view it, therefore, as one of the first developed calcified series. It is analogous, in function, in retention, and long-continued use, to a premolar of the placental type-dentition. The succeeding four grinders in both Phascolomys and Diprotodon are equally members of the first set of teeth; and the last three are homologous with those that are not displaced by vertical successors in diphyodont Placentalia. The symbols, therefore, $d 3, d 4, m 1, m 2, m 3$, express, in my opinion, the homologies of the functional molar teeth of Diprotodon with those, e.g., so marked in Hyrax, Hippopotamus, and Sus*. For convenience of comprehension of the teeth symbolized in Plates XIX.-XXVII. I subjoin woodcuts of an instructive phase of dentition in the Hog (fig. 3) and Kangaroo (fig. 4).

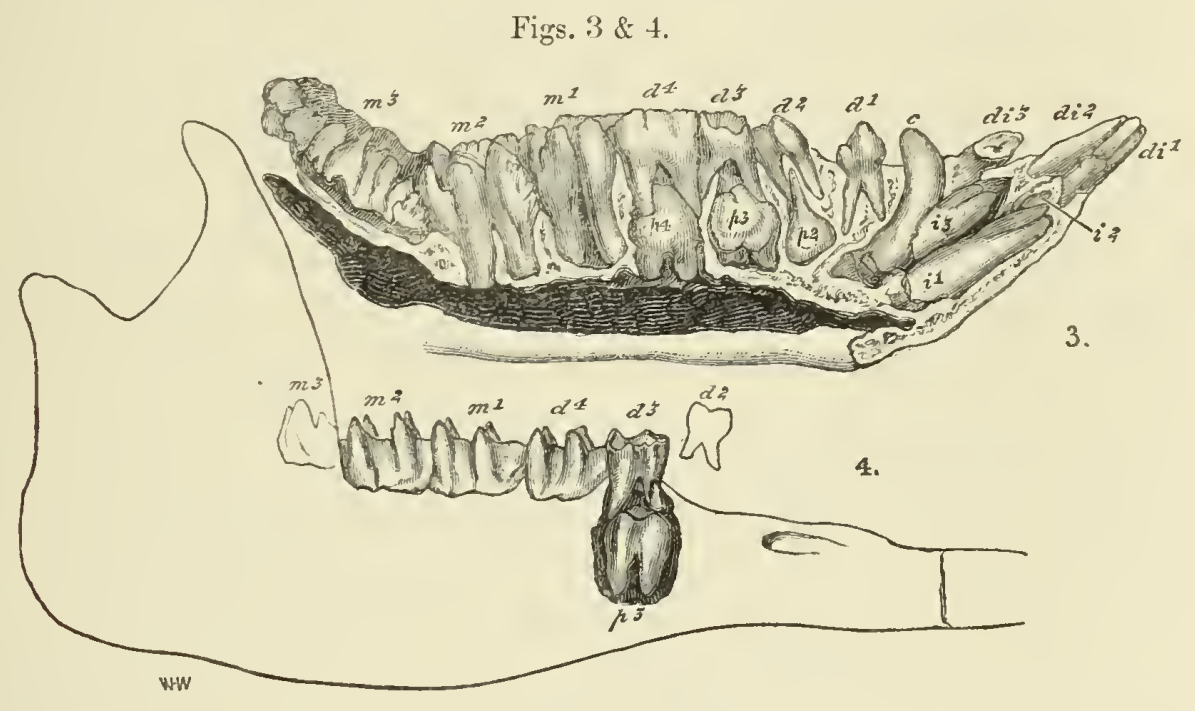

$\S 5$. Spinal Column.-Of the atlas there is a portion of the left moiety (Plate XXVIII. fig. 2) showing the deep articular cavity for the occipital condyle of the same side, between which and the diapophysis is the outlet of a canal $(a)$ about 3 lines in diameter, which traverses the neural arch from within outward behind the upper part of the cavity for the condyle. The surface $\left(z^{\prime}\right)$ for the articular process of the axis is slightly concave ; between its upper part and the ridge leading from the hind margin of the neural arch to that of the diapophysis there is a deep and wide groove for the passage of the vertebral artery into the neural canal. The above-described fragment yields evidence that, as in Macropus, Phascolomys, Phascolarctos, and some other Marsupials, the ring of the atlas (if indeed it were completed below by bone in Diprotodon) presented only the perforation

* In my 'Anatomy of Vertebrates,' vol. ii. p. 465, fig. 312 ; vol. iii. p. 346, fig. 276; p. 357, fig. 287 ; p. 377, fig. 294. 
(for the anterior spinal nerve or a division of it) on each side of the base of the neural arch, the vertebrarterial canal being, as above described, an open groove. In the atlas of proboscidian and of other large placental Manmals, which the present fossil resembles in size, the diapophyses are widely bored by the vertebral artery, which usually perforates also the fore part of the neurapophysis*.

I recognize, therefore, in the portion of the atlas vertebra, here referred to Diprotodon, marsupial characteristics; compared with that of the Kangaroo, its diapophyses are relatively shorter, thicker, terminally more obtuse, not so much expanded or depressed at that part, upon the whole more resembling those in the Wombat and Koala

The axis or vertebra dentata (Plates XXVIII. fig. 1, \& XXIX. figs. 1, 2, 3) is entire, save the ends of the diapophyses, which have been broken away. The length of the body, with the odontoid process, is 6 inches 3 lines, the height of the vertebra is 8 inches 4 lines, the breadth across the anterior articular surfaces is 5 inches 9 lines. The size of this vertebra thus equals that in the largest Rhinoceros or Hippopotamus, and in length that of a full-sized Elephant. The hind surface of the centrum (Plate XXIX. fig. 3,c) is flat, rather rough, transversely elliptic, with a tendency to an angular or octagonal outline. 'The under surface (ib. fig. 2) expands as it advances to develope the bases of the parapophyses (ib. $p p$ ); contracting in advance of these it again expands into the anterior articular processes (ib. and fig. 1, $z, z$ ). A low hypapophysis (ib. fig. 2, hy) of a subtriangular form projects from the middle of the under surface towards the fore part. The anterior articular surfaces (Plates XXVIII. \& XXIX. fig. 1, z) converge to the base of the coalesced body of the atlas, called " odontoid" process. This element (Plate XXVIII. fig. 1, $c a$, and Plate XXIX. fig. 2, ca), 2 inches in length, 1 inch 6 lines in breadth, and of similar depth, is convex transversely and longitudinally below; it has a pair of slightly concave roughened surfaces, meeting above, along the anterior sloping half (Plate XXVIII. fig. $1, m$ ), behind which the upper surface rises into a low broad tuberosity (ib. $t$ ), bounding anteriorly a smoothish elliptical surface (ib. $r$ ) occupying the upper part of the rest of the odontoid. A broad deep irregular depression (ib. o) divides this surface of the odontoid from the anterior articular surfaces of the axis. These surfaces (ib. and Plate XXIX. fig. $1, z, z$ ), of a full oval shape, 3 inches in diameter, are moderately convex. The neurapophyses (Plate XXVIII. $n$ ), after developing the diapophysis (ib. $d$ ), contract to a fore-and-aft extent of 1 inch 9 lines, then expand backward to develope the postzygapophyses $\left(z^{\prime}\right)$, in advance of and between which the neurapophyses converge and coalesce to form the base of the neural spine (ib.ns). This expands both forward and backward,

* Osteologieal Catalogue of the Museum of the Royal College of Surgeons, 4to, 1853, p. 475, no. 2678, 'Atlas of Elephant' (by misprint the vertebral artery is called "medullary"); p. 509, no. 2945, "Atlas of Rhinoceros bicornis,' " the rertebral artery perforates the diapophysis and then also the neural areh;" p. 566, no. 3404, Hippopotamus amphibius, " the transrerse proeesses are perforated by the rertebral arteries."

+ I am led to believe, after fresh study of Diprotodont fossils, that the one ascribed to a calcaneum in my 'Catalogne of Fossil Mammalia in the Museum of the Royal College of Surgeons ' may be a fragment somewhat rolled and worn of the atlas rertebra. 
as it ascends, to an obliquely truncate summit nearly 5 inches in fore-and-aft extent; narrow and ridge-like at the mid part, expanding and obtuse at the fore and hind angles, the latter being the thickest; from each side of this angle a low ridge (Plate XXVIII. fig. $1, g$ ) descends obliquely forward, subsiding upon the lateral surface of the spine. The neural canal is 2 inches 3 lines in width, and rather less in height, especially behind. where the vertical diameter is 1 inch 6 lines. A wide groove leads outward and downward from the canal between the postzygapophyses and the back part of the centrum. The upper (neural) surface of the centrum is impressed at its middle with a deep pit, to which a groove learls on each side; the smooth surface has been broken away before and behind the pit, indicative of its having been crossed lengthwise by a bony bar, which would have converted the lateral groove into a pair of foramina.

Of the quadrupeds resembling in size the Diprotodon, the Proboscidians have the axis most like that of the Australian giant, but the following differences present themselves. In Elephas the odontoid is absolutely, as well as relatively shorter; the anterior articular surfaces are less uniformly convex and less convex in any direction; the neural spine is relatively lower, much thicker transversely, with a subquadrate termination or upper surface, canaliculate along the mid line, and deepening to produce a posterior bifurcation. The centrum has no hypapophysis. In Macropus, on the other hand, we find the hypapophysis is repeated both as to size and position; the odontoid process also offers a like development, with resemblance in such details as the disposition and proportions of the pair of upper terminal surfaces for ligamentous attachment, and the posterior smooth surface for the transverse ligament. The neural spine is, however, more produced anteriorly and less so behind.

In my 'Osteology of Marsupialia,' I noted, as a result of observations on the skeleton of Macropus major, that "in the Kangaroo both the dentata and atlas have the transverse processes grooved merely by the vertebral artery"*. I have since observed in Macropus laniger the circumscription of the groove by the development of a slender parapophysis, as in Diprotodon. A similar vertebrarterial canal occurs in Phascolomys and Phascolarctos. The neural spine of the axis in the Wombat resembles in shape that in the Diprotodon, but is rather more produced behind. The hypapophysis is, lowever, a mere medial low ridge; that in the Kangaroo is significantly more like the process in Diprotodon. In both Macropus, Phascolomys, and Phascolarctos a pair of conspicuous foramina near the hind part of the upper (neural) surface of the centrum lead to canals converging as they sink in the osseous substance to a common (venous) passage; these are not present in Proboscidians; a few minute irregular venous foramina may be seen on the corresponding surface of the axis vertebra.

The third (Plate XXIX. fig. 4) and two consecutive (Cut. fig. 5, c 3, c4) cervical vertebræ resemble by their shortness those of the Wombat rather than of the Kangaroo; they are by no means, however, so compressed from before backward as in the Proboscidians.

* Trans. Zool. Soc. vol, ii. p. 394 ; see also Art. Marsupialia, Cycl. of Anat. p. 276. 
In Diprotodon the length of the third cervical centrum is 1 inch 10 lines, the breadth of its hind articular surface is 4 inches 3 lines, the height of the vertebra is 8 inches. The centrum is without hypapophysis, the vertical extent of the hind surface (Plate XXIX. fig. $4, c$ ) is 2 inches 9 lines; the two extremes of the transverse ellipse are almost angular. The base of the parapophysis (ib. and cut, fig. 5, p) extends from near this angle forward for $1 \frac{1}{2}$ inch along the side of the centrum. The upper surface of the centrum shows a large medial venous orifice. Both margins of the rising neurapophyses are deeply notched for the "conjugational foramina," and send off a small diapophysis (ib. l) to circumscribe above the vertebrarterial canal. The neural spine (ib. ns), 4 inches in height from the roof of the neural canal (ib. $n$ ), is compressed from before backward, simple, obtusely rounded at the end, strengthened by a low medial ridge, both before and behind, along its basal half. There is no such development of neural spine in the third cervical of Proboscidians; in the larger herbivorous Marsupials it is as conspicuous as in Diprotodon, but with altered shape; that in the Wombat most resembling the one in Diprotodon, but being relatively lower.

The fourth cervical (Cut, fig. 5, c 4) much resembles the third; but, as in the Kangaroo, has a shorter spine, resembling, however, in shape that of the third, being compressed from before backward instead of from side to side as in Macropus. The slight increase of size is in breadth, chiefly of the centrum, not in length or height. The neural canal is wider and a little ligher; more space is made for the myelon as it traverses the more flexible part of the neck. 'The large venous foramina and vertical canal are repeated on the upper part of the centrum; the corresponding pair of foramina now also blend into a common fossa, as in the Wombat.

In the fifth cervical (Cut, fig. 5, $c 5$ ) the neural spine gains in antero-posterior and loses in transverse thickness; the vertical ridges are stronger, especially the one behind; it appears to have been shorter than in the fourth vertebra*. The centrum and neural canal have increased, chicfly transversely; there is very little increase of length. The parapophysis has gained in rertical extent.

In the series of mutilated vertebræ belonging to Mr. Bord's specimen of Diprotodon are two dorsals (Plate XXIX. figs. 5-8). They show the impressinns for the free articulation of the ribs both before and behind (ib. figs. $6 \& \tau, p l, p l^{\prime}$ ), and are remarkable Fig. 5.

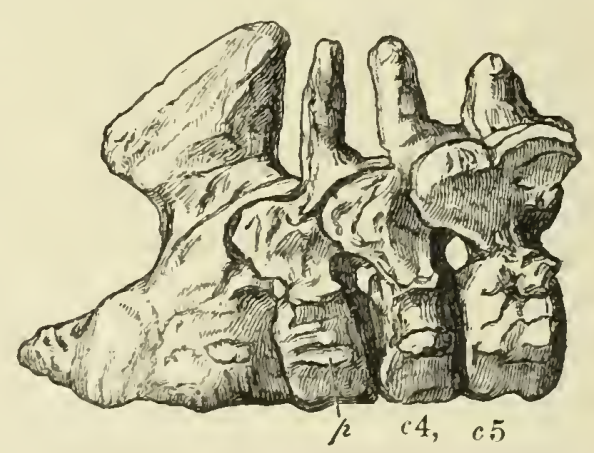

Second to fifth cervical rertebræ, one-sixth nat. size; Diprotodon. for the retention of the short proportion of the cervicals, and for the terminal bifurcation of the antero-posteriorly compressed spine (ib. figs. $5 \& 8, n s$ ). They are not consecutive vertebræ, but were not far from one another in the anterior part of the dorsal series.

* It is so in the sketch sent me by Sir Thomas MIrchele from Sydney (Cut, fig. 5); but, amongst the damages to the specimens in their passage to London, the summit of this spine has been knocked off. 
As in this region the vertebræe in many Mammals decrease in breadth before regaining the size which then goes on augmenting to the lumbar region, I first take for description that (Plate XXIX. figs. $5 \& 6$ ) which with a broader centrum has a shorter as well as broader spine. The fore-and-aft extent of the centrum is 2 inches at its lower part; it slightly decreases towards its upper surface. The breadth of the centrum is 4 inches 10 lines, above which this dimension is increased by the share contributed by the neurapophyses (ib. fig. $5, n, n)$ to the body of the vertebra $(c)$; the sutural lines indicative of this share are plainly traceable on the terminal articular surface (ib. fig. $5, c$ ), from which the epiphysial plate has become detached. As the ends of both diapophyses and neural spines are broken off, the following dimensions of the vertebra are not the full ones, viz. of breadth 8 inches 6 lines, of height 9 inches 6 lines. 'The width of the neural canal is nearly 4 inches, its height is fully 3 inches. Both articular surfaces of the centrum are nearly flat, the anterior one in a very slight degree convex; but both surfaces are epiphysial, with coarse furrows and lines affecting a radiate disposition, the extent of which rugosity indicates the complementary plate to have overlapped both elements of the vertebral body, viz. the neurapophysial (fig. $5, n, n$ ) and the central one (ib. $c$ )*.

A prominence on the upper third of the side of the body indicates the lower boundary of the neurapophysis, and this part of the body holds the main part of the impressions $\left(p l, p l^{\prime}\right)$ for the head of the rib, of which impressions the hinder is the larger. The contour of the articular surfaces of the body is semicircular. The neurapophyses, after contributing their share to the vertebral body, extend upward, outward, and a little forward, contracting into subcylindrical pedicles which suddenly expand to send off the diapophyses (ib. figs. $5 \& 6, d$ ), prezygapophyses $\left(z\right.$ ), and postzygapophyses $\left(z^{\prime}\right)$. Before developing the latter processes the neurapophyses begin to bend inward, still ascending; then they contract, especially from before backward, converge, and coalesce to form the base of the antero-posteriorly compressed and laterally expanded spine (ns). The base of this spine is strengthened both before and behind by a low broad median ridge; its terminal divisions diverge as they rise. The undivided base forms a low obtuse eminence between them (fig. $5, n s$ ).

The prezygapophysis (fig. $6, z$ ) projects forward as a semicircular shelf, the flat articular surface looking upward, with a very slight inclination downward and outward; the postzygapophyses $\left(z^{\prime}\right)$, of somewhat smaller size, are supported each by a buttress of bone descending from the hinder and outer angle of the spine, and expanding with a prominent convexity to the articular surface. 'The upper surface of the centrum, between the neurapophysial bases, shows the large venous fossa.

In the other dorsal vertebra (Plate XXIX. figs. 7,8 ) the diapophysis is entire on the left side (fig. $8, d$ ), and expands into a protuberance with an articular surface (fig. $7, d$ ) 1 inch 9 lines by 1 inch 3 lines, for the tubercle of the rib on its lower half. The neurapophysial parts of the centrum are traceable, and make a more definite rising at

* This is the usual character of epiphyses completing compound bones, as, e.g., at the proximal end of the three confluent metatarsals in the bird, at both ends of the two confluent metacarpals in the ruminant, \&c. 
the upper part on each side the small intervening proportion of the centrum proper (ib. fig. 8, c). Posteriorly they also slightly project (fig. $7, n$ ) beyond the flat surface of the centrum (ib. c); and a smooth tract of the neural canal (fig. 8, $n^{\prime}, n^{\prime}$ ) is continued backward upon each of these prominences. The fore surface of the centrum is in a very slight degree convex; both surfaces are epiphysial or rough, with the usual tendency to a racliate disposition of the fine furrows. 'The postzygapophyses $\left(z^{\prime}\right)$ are somewhat more prominent than in the former dorsal (figs. $5 \& 6$ ), and the neural spine slopes a little backward. This process is narrower transversely than in fig. 5, and is longer prior to its bifurcation (fig. $8, n s$ ). Its strengtliening ridges, especially the anterior one, are more developed; the bifurcation of the summit is repeated in this as in the foregoing vertebra, with slight divergence of the terminal prongs, both of which have lost their summits.

In the whole range of the Mammalian series I know of no dorsal vertebræ with characters like the subjects of figures $5-S$. Where vertebræ are notable for their shortness and lamelliform type they are confined to the region of the neck, as, e. g., in Proboscidia and Cetacea; but the dorsal series, in these, promptly resumes the ordinary proportions of length of centrum. Similarly, where the transversely bifurcate character of the neural spine is met with (e.g. Elephant, Man), it is restricted to one or two of the cerrical series; in Diprotorlon only is it known to exist in a dorsal vertebra. What modification may ensue or at what distance from the neck in other or posterior dorsal vertebræ iny present materials do not enable me to state. I infer that the more usual proportions are acquired in the posterior dorsals from the slight increase presented in the following specimen, and from those which certain of the lumbar vertebræ present.

'The specimen referred to, which forms part of the collection in the Muscum of the Royal College of Surgeons, consists of the centrum only.

It measures 2 inches 3 lines in antero-posterior diameter, 3 inches in vertical diameter, and 4 inches 9 lines in transverse diameter. Both articular extremities are flat; the epiphysial plates are anchylosed; but where they are broken away the radiating rough lines, characteristic of the epiphysial surface, indicate that the union was tardy and had been recently effected before the animal perished. This vertebra differs by its compressed form and the flattening of the articular ends from the dorsal vertebræ of the ordinary placental Pachyderms, but resembles in these characters the dorsal vertebræ of the Proboscidians; in these, however, the breadth of the vertebral body is not so great as in the fossil. From the cetaccan vertebræ the present fossil is distinguished by the large concave articular surface at the upper and anterior part of the side of the body for the reception of part of the head of a rib; this costal surface, which is not quite entire, appears to have been about $1 \frac{1}{2}$ inch in diameter. The neurapophyses are anchylosed to the centrum, but the internal margins of their expanded bases are definable, and have been separated by a tract rather less than 1 inch in breadth, of the upper surface of the centrum; at the middle of this surface there is a deep transversely oblong depression. A similar depression is present in some dorsal vertebræ of the Megatherium and in the 
anchylosed lumbar vertebra of the Mylodon; but the bodies of the dorsal vertebræ in the great extinct Bruta are longer and narrower in proportion to their breadth than in the present fossil. In the Kangaroo the upper surface of the body of the dorsal and lumbar rertebræ is perforated by two rascular canals, which pass down vertically and open below by a single or double outlet. In the Wombat the middle of the upper surface of the bodies of the dorsal and lumbar vertebræ exhibits a single large and deep depression, which in the dorsal vertebræ has no inferior outlet, and in this character they closely resemble the present fossil. The dorsal rertebræ of the Wombat are, however, longer in proportion to their breadth.

Thus the present mutilated rertebra alone would support the conclusion that there had formerly existed in Australia a mammiferous quadruped, superior to the Rhinoceros in bulk, and distinct from any known species of corresponding size. It is interesting and instructive to find one well-marked character in it, viz. the median excaration on the upper part of the body, repeated in the same vertebræ of one of the largest of the existing Marsupialia.

The remaining eridences of vertebræ in the Boydian or purchased series of Diprotodont Fossils in the British Museum consist of five centrums and two pairs of detached terminal epiphyses of those elements.

The centrums, in the absence of any costal or hæmapophysial depression, in their increased length and greater expanse of the neural canal, are referable to the lumbar series. Three retain the coalesced bases of the neurapophyses, yet these do not develope diapophyses in the extent to which they are preserved.

The foremost of these lumbar centrums shows a length of 2 inches 4 lines at its lower part, increasing to 2 inches 8 lines at its upper part; the others, with slight general gain of size, show the same proportions. Thus the one which seems the last of the series has a length of 3 inches 3 lines at the lower part, and of 3 inches 8 lines at the upper part of the centrum. Thus we may infer that the part of the spine from which these rertebræ have come was habitually bent in Diprotodon with the concavity downward. The degree of increased length in the last over the longest of the other three centrums indicates two or three missing rertebræ intervening between those to hand. The Kangaroo has six lumbar vertebræ, the Koala eight, the Wombats only four (Phascolomys vombatus) or five (Phascolomys latifrons). Six lumbars is the rule in Marsupialia, and I incline to view Diprotodon as amenable thereto, rather than as repeating the exceptional formula of Phascolomys*.

In the foremost of the fire fossil lumbar centrums a small protuberance from the upper and fore part of one side indicates the rudiment of a diapophysis; it is not present on

* As I was led to note in my 'Osteology of Marsupialia,' loc. cit., p. 396, the number of free trunk-rertebræ is significantly constant in that order, whatever be the difference of costal formula ; thus, Phascolarctos has 11 costal, 8 lumbar, =19; Petaums, 12 costal, 7 lumbar, =19; Macropus, Phalangista, Perameles, Myrmecobius, Phascogule, Didelphys, Dasyums, Sarcophilus, Thylacinus, have severally 13 costal, 6 lumbar, =19; Phascolomys vombatus has 15 costal, 4 lumbar $=19$. 
the other side; it may be a rertebra, as is sometimes seen in the Kangaroo and other mammals, transitional between the dorsal and lumbar series, having the characters of a rib-bearer on one side and not on the other. A trace of roughness on the side of the fossil centrum corresponding to the protuberance on the other side, may indicate there a ligamentous attachment of a rudiment of the last free rib. The present vertebra, whether interpreted as the last dorsal or first lumbar, shows the small extent to which those vertebre gained in length as they receded in position. The antero-posterior diameter at the under part of the centrum is 2 inches 5 lines, at the upper part 2 inches 10 lines; the breadth of the anterior surface is 4 inches 10 lines, the vertical diameter of the same surface is 3 inches 9 lines. The epiphysial plate adheres to this surface; it is concentrically marked, thinning off to the centre, where it leaves a vacuity transversely oblong, 1 inch 4 lines by 1 inch in its diameters. From the opposite surface the epiphysis has been detached, showing the radiate disposition of the ruga of the diaphysial surface, and the proportions contributed by the bases of the neurapophyses to the rertebral body.

In the next rertebral body, of similar dimensions, the anterior epiphysis is adherent, but with the line of suture conspicnous; it is from 3 to 4 lines thick at the periphery, and thins off toward the centre, where it leaves a vacuity of about 1 inch in diameter. The surface, for 1 inch at the periphery, is moderately convex, the rest is flat. The free surface of the centrum is greatly and equably concave lengthwise. At the middle of the neural surface is a transversely oblong venous fossa, 9 lines by 6 lines in diameters. 'This centrum adheres by matrix to the succeeding one, which, repeating the characters above noted, retains about 1 inch of the neurapophysial pedicles or lamellix. Each at its origin has a fore-and-aft extent of 2 inches, contracting to 1 inch 8 lines at the fractured end; it rises nearer the fore than the hind end of the centrum. The extreme thickness ( 1 inch) is toward the fore part of the pedicle. The transverse diameter of the neural canal at the broken ends of the pedicles is 3 inches 6 lines. The venous fossa is repeated in this as a single median one; but in another lumbar centrum the entry is divided by a median longitudinal tract of the neural surface, as is commonly the case in the Kangaroo.

In the third of these the left pedicle is preserved to a height of 2 inches, expanding then to an antero-posterior extent of 2 inches 3 lines, and a transverse one of 1 inch 5 lines; at the lower contracted part of the neurapophysis these diameters are, respectively, 1 inch 9 lines and $1 \mathrm{inch}$. Yet the whole of the outer surface is smooth without trace of outstanding transverse process; whereas in both Kangaroo and Wombat that process comes off at the junction of the neurapophysis with the centrum. We may therefore infer that the neural arch of the lumbar series was loftier in Diprotodon, as we have already seen it to have been in the two anterior dorsal rertebræ preserved. 'The epiphysis is wanting from the hind surface of the third lumbar described, and the sutures of the neurapophyses with the centrum are there exposed. They project a little beyond the epiphysial surface of the centrum. 'The largest and hindmost of the present series of lumbars (Plate XXIX. 
figs. 9,10 ), the length of the centrum of which has been noted above, shows a breadth of hind surface (fig. 10) of 5 inches 9 lines, its height being 4 inches; the antero-posterior extent of the base of the pedicle is 2 inches 6 lines; about 9 lines extent of the centrum extends backward beyond it.

The smaller pair of epiphysial vertebral plates (ib. fig. 12), cemented together by the matrix, have come, according to their size and shape, from the cervical series; they are transversely elliptical, 4 inches 6 lines in long diameter, and 3 inches in short diameter. The thicker free or peripheral margins $(12, a)$ diverge from each other, and they thin off to a central vacuity $(12, c)$. The larger pair (ib. fig. 13) appear to be from the lumbar series; they measure 4 inches $7 \frac{1}{2}$ lines across, and 3 inches 8 lines down the middle; their central vacuity is transversely oblong, measuring 1 inch 3 lines by 1 inch. These detached vertebral epiphyses are completely petrified.

The terminal epiphyses of the bodies of dorsal and lumbar vertebræ remain distinct, and come off in pairs attached by intervertebral substance in Kangaroos which have arrived at full growth. I presume that the same circumstance occurred in the course of decomposition or maceration of the carcass and skeleton of Diprotodon; hence the presence of such separate pairs of epiphyses receiving co-attachment from the matrix after separation from their proper centrums*.

Of the ribs, though few are entire, so many have reached me as suffice to show that,

* Since the reception of the specimens of rertebræ above described, I have becn favoured with two drawings, of the natural size, of a side view and end view of a lumbar vertebra of a Diprotodon, from St. Ruth's Station, Condamine River, Queensland, by Dr. Fr. Campbell. In these drawings sufficient of the neural arch is preserved to show the base of the diapophysis extending outward, at 1 inch 6 lines above the level of the upper surface of the centrum. The breadth of the centrum is 5 inches, its rertical diameter 4 inches; the brcadth of the neural canal is 3 inches 6 lines, the fore-and-aft extent of the centrum at its upper third is 2 inches 10 lines. An oblique broad low ridge or rising of the outer surface of the pedicle rises to the lower part of the base of the neurapophysis.

The two drawings, of side and front riews, of this rertebra have becn made carefully, and I believe accurately, as regards admeasurements, by Mr. CAMpBelL's son, who found the vertebra, and whose letter to his father on the subject is as follows:-

$$
\text { (Copy.) }
$$

$$
\text { "St. Ruth, 25th May, } 1865 .
$$

"The enclosed drawings I send to you to amuse you a little till I come down, speculating as to what the huge animal was. I hare the bone and some more, now in my possession. A large top jaw with a few pieces of tecth sticking in it, and what looks like a blou-hole in the top--some smaller shank bones, or something of the sort-all fossil. They ring like cast iron when knocked together : too heavy to bring down with me:-they are of a dark brick colour. I will try and make drawings of the rest if I have time before I come down. One of the vertebro of a Bull looks very small indeed alongside this great bone.

$$
\text { (Signed) "Hugh Campbell." }
$$

In the letter inclosing his son's drawings Dr. C. writes:- "The bones he mentions in the letter and whose likeness is also inclosed hercwith, I regret to say he was induced to part with to a gentleman to whom he was under particular obligations of friendship, and who had expressed a great desire to possess them." Should the present notice ever meet the cyes of the possessor of these fossils he may be assurcd that it would give me pleasure to make them subscrient to the advancement of a knowledge of Diprotodon. 
as in Marsupials and most Mammals, they vary in length, curvature, degree in which the groove for the intercostal ressels and nerve is excavated, distinction of head and tubercle, and relative position of the latter (Plate XXXV.).

'The longest specimen measures 2 feet 1 inch, following the convexity of its curve. 'The tubercle is low, $3 \frac{1}{2}$ inches from the head; the intercostal groove is shallow, and chiefly defined by a ridge-like production of the posterior border at the upper fourth of the rib, 3 or 4 inches in extent. Beyond this the rib loses thickness and gains breadth, the latter dimension reaching to $1 \frac{1}{2}$ inch about one-third from the broken end.

Another specimen presents a greater degree of curvature. 'The tubercle is better dereloped, has a more definite articular surface, extending upon the neck of the rib. 'I'he broadest part of the rib ( 1 inch 9 lines) is at the upper third of the bone. 'This rib had a more anterior position in the chest than the former; the extent preserved, following the convexity of the curve, is 1 foot $6 \frac{1}{2}$ inches.

A third specimen with head, tubcrcle, and intercostal groove well marked, is less curved than the former, and is larger than either of the above described. A length of 1 foot 4 inches is preserved. 'The fractured end is elliptic, 1 inch 9 lines in long diameter, 1 inch in short diameter; but the rib midway between the end and the head attains a breadth of 2 inches. 'This lias come from nearer the middle of the chest.

'The only entire specimen is a posterior rib, with the tuberosity relatively small and rough; the head large, intercostal groove almost obsolcte; body of the rib straight along its distal half, which gradually expands, with loss of thickness to a breadth of 2 inches 2 lines. 'The length of this rib, following the convex curve, is 1 foot 8 inches. The lower extremity shows the roughened surface for the attachment of the costal cartilage.

'The costal fragments yield little more than the character of size. The vertebral end of one, which includes the tubcrcle, has a circumference below that part of $3 \frac{1}{2}$ inches. Another fragment has a circumference of $4 \frac{1}{2}$ inches; a third fragment is nearly 6 inches in circumference; a fourth fragment shows a flatter shape.

From the shortness of the costigerous vertebre and the size of the ribs, their interspaces must have been narrow.

Assuming with much confidence that the dorso-lumbar series in Diprotodon included nimeteen vertebræ, I assign one more pair of ribs than in the Kangaroo, and reckon fourteen pairs in the dorsal series (Plate XXXV.).

$\S 6$. Scapula. - The scapula is represented in the Boydian collection of Diprotodont remains by an almost entire specimen of that of the left side (Plate XXX.), and by a fragment of the one of the right side.

It is narrow in proportion to its length, and chiefly peculiar by the production of the subspinal plate anteriorly (ib. a), whereby the usual proportions of the triangular mammalian scapula are reversed, the part answering to the base (ib. $b$ ) being the apex, and 
the articular end of the bone (ib. $a, c$ ) the base of the triangle, which is elongate and irregular.

The articular or glenoid cavity (ib. d) presents the usual oval shape with the small end upward (ib. fig. 3); the concavity is deepest lengthwise, and the apical part is most produced. The outer border beneath the acromion $(e)$ has been broken off, indicative of its prominence, which is better preserved in the articular cavity of the fragment of the right scapula, showing its resemblance to that part in Macropus. This border subsides, becoming thick and convex as it approaches the small or coracoid end of the cavity. The lower border is continued into a rugged triangular surface beneath (fig. $3, a$ ) for the attachment of the long head of the triceps; the upper apical part is produced, beak-like; beyond the base of the coracoid (c). The inner margin is low near the apex, but less obtuse than the corresponding part of the outer one; it is more produced as it descends; but this margin subsides gradually into the subscapular one.

The spine (ib. fig. $1, f$ ) begins by a gradual elevation of the lower or hinder half of the hinder surface of the "base" $(b)$, which elevation contracts as it rises from that surface to a thickness of $1 \frac{1}{2}$ inch. The free border, of this thickness, is also flat; the spine gradually rising as it advances, describes a slight curve toward the upper or anterior $\operatorname{costa}(g)$; the lower margin of the free border becomes most produced, and, as the spine expands into the acromion (e), this margin also expands and becomes rough for muscular attachments, and in the present specimen forms the most prominent part of the acromion; but the end of this process is broken off. From a pencil-sketch of this scapula made by Sir Thumas Mitchell when it arrived at Sydney (Woodcut, fig. 6, not reversed), the acromion ( $e$ continued to expand

Fig. 6 .

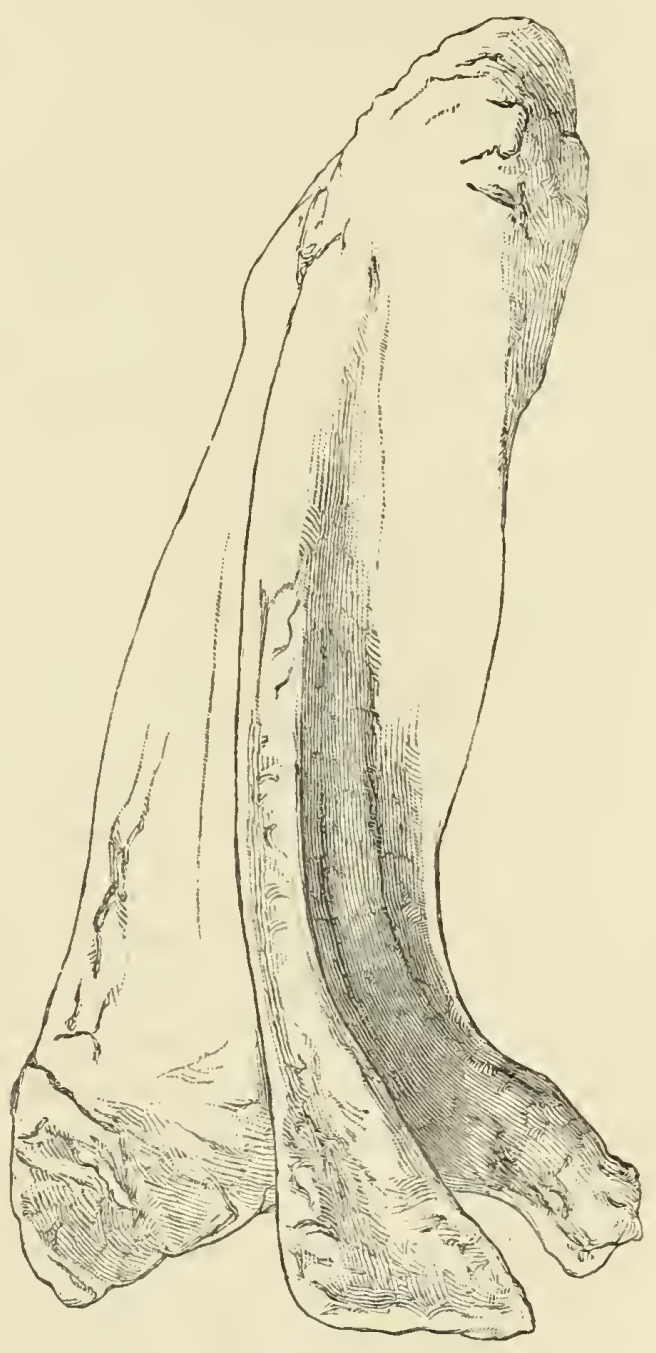

Scapula of Diprotodon: one-fifth nat. size. to an obliquely truncate end, having the upper or fore angle most produced, and, as it were, slightly twisted towards the coracoid (c) (fig. 1, Plate XXX.). As the spine (ib. fig. $2, f^{\prime}$ ) rises from the scapular plate, it becomes compressed or thinner beneath the free margin, and presents a smooth concave surface to each scapular fossa $(i, j)$. 
The coracoid process (P'late XXX., c), arising from a vase of 3 inches in extent, is subcompresser, with the outer surface concave as it extends toward the end of the process, which, however, is broken off. The upper or front "costa" (ib. $g$ ) describes a strong concave curve as it recedes from the coracoid; the middle third of its extent (ib. $g^{\prime}$ ), which was probably convex and produced, has been broken away. Where it is again entire (ib. $g^{\prime \prime}$ ) it describes a gentle concavity, and forms the outer border of a sudden thickening of that part of the basal end of the scapula. The upper or basal threc-fourths of this anterior border of the bladebone are curved "dorsad," so as to bound or form the (transverse) hollow of the supraspinal fossa (ib. fig. 1, $i$ ). The part broken from the upper costa $\left(g^{\prime}\right)$ may have made the breadth of the fossa, as in the Kangaroo and most Marsupials, greater at its mid part than appears in this fossil.

The subspinal fossa (ib. $j$ ) increases in breadth from the basal $(b)$ to the articular end ( ( ) of the scapula, singularly reversing its proportions in other Mammals. In the Koala (Phascolarctos) this fossa retains its breadth through an extension of the lower costa nearer to the glenoid cavity than usual*. The corresponding extension is proportionally greater in the scapula of the Megatherium; but in Diprotodon it is continued as far forward as the neck of the scapula, with an increase of thickness, and a bend toward the "dorsum" of the scapula, increasing the depth of the concavity of this part of the subspinal fossa. 'The border of the plate (ib. $a, a^{\prime}$ ) produced below or behind the glenoid cavity $(d)$, and having the same aspect, is very thick, concave lengthwise, convex across, with a rough slightly projecting insertional surface at its middle: a more rugged surface appears also at the angle $a$, where it joins the lower or hinder costa, but this is the seat of some mutilation of the fossil.

This costa $(a, b)$ loses thickness as it recedes from the angle for one-fourth of its extent; it regains a certain thickness and ruggedness for another fourth $(k)$, where it is also bent toward the subscapular plane; it then continues drawing nearer to the origin of the spine and finally thickens as it is lost in the obtuse contracted basal end $(b)$ of the bladebone.

The long and narrow subscapular surface (Plate XXX. fig. $1 l$ ) presents a gentle concavity lengthwise, with a corresponding convexity across the middle, rather increased at the two ends; the mid convexity is clianged to a concarity by the in-bending of the part $(k)$ of the lower costa above mentioned. The smooth subscapular surface is broken only by the thick short triangular elevation (ib. $m$ ) extending from near the upper or fore angle of the base.

The singular, not to say unique, development of the "glenoidal" part of the inferior costa $\left(a, a^{\prime}\right)$ or subspinal plate, was doubtless correlated with some peculiarity of use or application of the fore limb. As to the general shape of the scapula, I cannot suppress expressing the interest with which I have viewed in this old extinct Marsupial or implacental form of Mammal the retention of so much of the archetypal or pleurapophysial proportions which one sees without surprise in inferior Vertebrates such as Mono tremes, Birds, Reptiles, and Fishes.

* This peculiarity is figured in the 'Cyclopædia of Anatomy', Art. Marsupialia, p. 281, fig. 106. 
The total length of the above described scapula is 2 feet 3 inches; the extreme breadth is 1 foot 2 inches; the long axis of the glenoid cavity is 6 inches, the short axis 4 inches 2 lines; the height of the spine at the base of the acromion is 4 inches.

Fragments of scapula, from the bed of the Condamine River, west of Moreton Bay, Australia, in the Museum of the Royal College of Surgeons, placed with some doubt in the series of Diprotodont remains in my 'Catalogue of Fossil Mammalia' (4to, 1845, p. 298), can now be certainly referred to Diprotodon australis. One of these fragments (no. 1471) includes 4 inches of the interior part of the origin of the spine. "The thickness of the neck of the scapula is 2 inches 9 lines; that of the base of the spine is 1 inch. The indication of the sudden rising of this thick spine from the plane of the scapula distinguishes it from that bone in the Rhinoceros, and its thickness is greater than in the largest Hippopotamus; it is also relatively greater in comparison with the neck of the scapula than in the Elephant" (p. 298). The specimen was thus differentiated, in 1845, from all known Mammals of corresponding or approximate bulk, and is now seen to conform in the particulars cited with the bladebone of Diprotodon.

A portion of the glenoid cavity and neck of the scapula of a large Mammalian quadruped (no. 1472), from the same Australian deposits, shows similar dimensions to those in the entire scapula of Diprotodon australis.

$\S 7$. Humerus.-In Macropus the articular head of the humerus is subhemispherical, looks a little backward as well as upward (the bone being held vertically), and overhangs the back part of the shaft. The inner and outer tuberosities rise above the head, in front of it. The inner tuberosity is thicker and shorter than the outer one, which extends ridge-like obliquely from without inward and forward where that end projects, forming the outside of the deep groove, dividing it from the inner tuberosity; the groove expands and shallows as it descends, and is soon lost in the fore part of the shaft.

The inner tuberosity is supported on a columnar development of the fore and inner part of the shaft. From the fore end of the oblong outer tuberosity the "deltoid" ridge extends halfway down the middle of the fore part of the shaft, being more or less prominent in different species. In all the ridge attains its greatest breadth and prominence at its lower part before its sudden subsidence. At the outer side of the shaft above the developed termination of the deltoid ridge, projects a short, thick, longitudinal ridge, with a rough obtuse surface. Thus the fore part of the upper half of the humerus is divided into two facets, the inner one deepening upwards to the inter-tuberous or bicipital groove; the outer one broader and flatter, between the outer and the deltoid ridges. The back part of the upper half of the humerus is also, but less definitely, divided into two longitudinal tracts; the outer one flattened or slightly concave transversely where bounded by the outer ridge; the inner one gradually contracting, with increased transverse convexity, to be continued into the ridge leading to the ento-condyloid tuberosity. The shaft of the humerus is more bent, with the concavity backward, than usual; the distal end not being turned forward in the degree which gives the ordinary sigmoid shape to this bone in unguiculate mammals. 
The humerus in Marsupials is not described in either editions $(1805,1835)$ of the 'Leçons d'Anatomic Comparée.' But in the 'Ossemens Fossiles' (4to, tom. iv. p. 284) Cuvier notes the precaution requisite in the examination of the distal articular surface of the humerus in Marsupials on account of its resemblance to that in Carnivora. In the posthumous Sro edition of the 'Ossemens Fossiles,' tom. vii. p. 276 , after the generalization as to the perforation of the inner condyle in Carnivor a, is added: "ainsi que chez les 1)idelphes et dans tous les animaux à bourse." So likewise De Blainville states that the imner condyle of the humerus is perforated, "chez tous les Didelphes sans exception," using the term in his peculiar taxonomic sense as equivalent to the Marsupialia of other zoologists. I have, however, pointed out exceptions to this rule in certain Dasyures (Dasyurus Maugei), Phalangers (Ph. Cookei), and Petaurists*.

So much it seemed requisite to premise, because the imperforate condition of the inner condyle also characterizes the bone in Diprotodon, differentiating it from the humerus in Macropus and Phascolomys, without, however, affecting the marsupiality of the great extinct Herbivore. 'To the description of this bone in Diprotodon I now proceed.

The humerus (Plate XXXI.) is more nearly straight than in other Marsupials, and is remarkable for the feeble development of the riilges for muscular attachments. At a glance one sees its relations to the restricted offices of support and locomotion with much less subserviency than in the smaller existing Marsupials to more varied applications of the fore limb.

The head of the bone (ib. figs. $1 \& 2, a$, and fig. 3) rises above the tuberosities $(b, c)$, forming a very large proportion of the upper end (fig. 3). It has the usual degree of convexity, with a full oval contour, the long axis being transverse, and the smaller end next the outer tuberosity; it overhangs the back part of the shaft at its inner two-thirds (fig. 1), but in a less degree than in the Kangaroo. 'The inner tuberosity (b) is represented by a low broad, rough ridge, extending from the imner side along the fore part of the periphery of the head to near the small outer end of the articular ball; here it is interrupted by a wide but very shallow representative of the "bicipital groove." The outer tuberosity (figs. $1 \& 2, c$, fig. $3, e$ ) projects in a greater degree from the outer side of the base of the head.

The broal, low, rounded angle between the fore and outer sides of the humeral shaft, continued from the fore end of the outer tuberosity (fig. 2,c), representing at first the outer side of the bicipital groove, descends and assumes rather more of the character of a muscular ridge at the mid length of the shaft (fig. $2, d$ ) before subsiding.

The homologue (ib. $e$ ) of the short external ridge in MLacropus here projects as strongly from that side of the bone, but on the same transverse parallel with the lower, best developed part of the deltoid ridge $(d)$. Consequently the external ridge $(e)$ is relatively lower placed than in the Kangaroos; it is also relatively shorter, lengthwise, and stands out more abruptly at its upper part.

The representative of the deltoid ridge divides the fore part of the shaft unequally, and the broader division or tract (fig. $2, f$ ) is internal, the narrower division or tract $(i b . g)$

* Osteology of Marsupialia, loc. cit. p. 400. 
being turned so as to form rather the outer facet or side of the upper half of the humeral shaft. Another peculiarity of the present humerus is a well-defined oval rough surface (Plate XXXI. fig. $1, h$ ) at the outer side of the back part of the shaft, one-fourth of the way down; this surface measures 2 inches 2 lines lengthwise, by 1 inch 2 lines across; the lower half of its periphery is most prominent. A low ridge, about an inch in length, in Macropus major, seerns to answer to this process.

The shaft expands transversely and becomes flattened from before backward at its lower third as far as the distal articulation (fig. 4), which resumes antero-posterior thickness with reduction of transverse extent. The ento-condylar ridge (figs. $1 \& 2, i$ ) is much produced, though relatively less than in Macropus; the upper and lower borders meet at an open angle; the ridge is very thick; it extends more than 2 inches from the ulnar condyle; it is imperforate.

The ectocondylar ridge $(k)$ is longer than the inner one $(i)$, but is less prominent; it is also angular in form, but more openly so. The upper and longer side, commencing 6 inches above the radial condyle, is narrow and slightly turned forward; the lower side rapidly expands to nearly the fore-and-aft breadth of the radial condyle, along the radial or outer border of which the ectocondylar ridge subsides. The middle of the distal expansion of the shaft, above the articulation, is remarkable for the size and depth of the anterior fossa (fig. $2, l$ ) ; the posterior or olecranal depression (fig. $1, m$ ) is comparatively feebly marked.

The radial $(n)$ and ulnar $(o)$ condyles are more convex and more equal than in Macropus; they are divided by a narrower and deeper trochlear channel.

The radial condyle is the longest; its outer and hinder marginal contour describes part of a circle, and is not encroached upon, as in Macropus, by the rough surface from the ectocondylar tuberosity. The ulnar condyle, which begins in Macropus to subside or give way to augment the intermediate concavity, here retains its hemispheroid form (ib. fig. 4, o). It is interesting to note this resemblance to the distal articulation of a femur in the humerus of an animal low in the Mammalian scale.

The hind or "olecranal," supracondylar depression (fig. 1, $m$ ) is shallow, limited in situation to above the ulnar condyle, and the narrow intercondylar channel, and not extending to above the radial condyle.

I have not been able to find the orifice of a medullary artery: the distal portion of the left humerus, broken from the rest of the bone near the middle of the shaft, $11 \frac{1}{2}$ inches from the distal end, shows a depression near the middle of the fractured surface half an inch across and not quite an inch deep; and this, if it be not an accidental excavation in the dense cancellous structure, is the sole indication of a medullary cavity. Such cavity is wanting or small in the gigantic extinct Sloths. It is, again, with interest that I view this sign of low organization in the great extinct Marsupial mammal*.

Ulna.-Of the ulna I have hitherto received only the proximal half (Plate XXXV. ${ }_{s 5}$ ),

* Description of the Skeleton of Mylodon robustus, 4to, 1842, p. 82. Memoir on the Megatherium, 4to, 1860, p. 49. 
and with the olccranon not quite entire; it is a strong but low trihedral process, smooth and concave on the imner side, roughish and flattened behind; with a smooth almost horizontal triangular surface at the upper part. The breadth of the base of the olecranon is 3 inches 10 lines; the circumference of the base is 13 inches. 'The articular surface answering to the "greater sigmoid cavity" is concave, longer and deeper from before backward than from side to side. From its npper and outer part a less concave articular surface is continued upon the inner side of the base of the olecranon. 'The lower part of this surface, which may have afforded the "lesser sigmoid cavity" to the radius, is broken away. The rough tract for syndesmotic junction with the radius (ib. ${ }_{54}$ ) extends down the outer side of the shaft inclining obliquely forward: it is about an inch in breadth. 'There is a small but well-marked tuberosity and depression, on the outer or radial side of the ulna, $1 \frac{1}{2}$ inch below the "greater sigmoid cavity," answering to a corresponding process in the Wombat. 'The elongation of the olecranon in that burrowing Marsupial, augmenting the lever for working the fore paw, does not exist, and was not needed in the gigantic gradatorial Diprotodon. The portion of ulna above described indicates a massive and powerful fore arm, and has encouraged me to indicate the continuation of the ulna, as a distinct bone, to the carpus, in my restoration of Diprotodon (Plate XXXV.). 'The canal for the medullary artery enters the bone on the inner side (that next the radius) below the "sigmoid" articular cavity, and the canal is directed inward and a little upward. This fossil was obtained in the bed of the Condamine River, west of Moreton Bay, by Sir 'Tiomas Mitchell, C.B.

\$ 8. Pelvis. - In a collection of bones from fluriatile freshwater deposits at Eton Vale, Darling Downs*, in the usual massive or weighty, semipetrified condition of fossils from those beds, were fragments of a large pelvis, readjustible to the extent of giving a great part of the sacrum and ilia, both acetabula, the acctabular portion of cach ischium to the extent of 7 or 8 inches, and about 5 inches of the acetabular end of each pubis.

The sacrum consists of two vertebræ (Plate XXXII. $s s_{1}, s_{2}$ ), uniting with the ilia (ib. ${ }_{22}$ ) by a terminal expanse of the transverse processes (ib. fig. 1, $p, p l_{2}$ ), coequal with the antero-posterior extent of the entire sacrum, and giving to that bone a subquadrate form one-third broader than it is long. Much of the anterior articular surface of the body of the first sacral (fig. 1, $s_{1}$ ) is preserved, and a smaller proportion of the posterior surface of that of the second sacral (ib. $s_{2}$ ). Both surfaces show the usual mammalian Hatness and concentric lineation for union by intervertebral sclerous substance with contiguous centrums: the rougher surface shows the loss of the epiphysial plate. The transverse diameter of the fore part of the first centrum is 5 inches; the vertical (neurohæmal) diameter is 3 inches. 'The transverse diameter of the hind end of this centrum, giving that of the fore end of the succeeding anchylosed centrum $\left(s_{2}\right)$, is 3 inches 5 lines. The hæmal $\uparrow$ surface of both centrums (Plate XXXII. fig. $1, s_{1,2}$ ) is flat, subquadrate, the

* These fossils, collected in the above-named loeality by Edward S. HrLl, Esq., were liberally presented to the British Museum by Sir Daxiel Coorer, Bart., in 1864.

t In noting the position and aspect of the parts of this pelvis aceording to anthropotomical description, 
contour being straight lengthwise, the coalesced ends making no projection forward or hæmad.

The upper and anterior border of the first centrum, however, is abraded, as is the lower and anterior border of the second centrum; both being entire, would give a slight concavity to the longitudinal contour of the hæmal surface. The length of the sacrum is 5 inches 8 lines, that of the anterior centrum being 3 inches 3 lines. The rib-part (Plate XXXII. fig. $1, p$ ) of the broad and thick transverse process of the first sacral recedes slightly as it expands, passing outward to join the ilium $\left(b, p, 6_{2}\right)$, with a slight curvature convex hæmad. The greater part of the hæmal surface of the process is flat transversely, becoming slightly concave at its hind part; lengthwise it is here convex from before backward. The line of the confluence with the ilium, indicated by a slight eminence (ib. fig. $1, b, p, p$ ), is feebly curved with the convexity outward. The sacro-iliac symphysis is 8 inches in length following the curve; the origin of the sacral rib or transverse process has a fore-and-aft extent of 3 inches 9 lines. The direction of the origin of the process in both vertebræ is oblique, from near the neural surface of the centrum anteriorly to the hæmal one posteriorly. The hind border of the origin of the first transverse process forms the fore margin of the wide anterior outlet of the intervertebral canal $(i)$, which expands into an infundibuliform channel backed by the succeeding transverse process $\left(p l_{2}\right)$.

The neural position of the fore part of the transverse process (fig. 1, $p l 2$ ) of the second sacral makes the aspect of the nerve-outlet $(i)$ obliquely hæmad and backward; the long diameter of the outlet is $1 \frac{1}{4}$ inch; the mass of nerves therefrom emerging has deeply grooved the upper or fore part of the great sciatic, or sacro-ischiatic notch $(\mathrm{m})$. The outlet thus intervening between the bases of the transverse processes is circumscribed externally by the confluence of the expanded ends of those processes, forming the articular surface of the sacrum with the ilium.

The tuberosity (Plate XXXII. figs. 2, 3, $z^{\prime}$ ) representing the confluent zygapophyses of the first and second sacrals is on the inner side and anterior to the posterior outlet (ib. fig. $2, j$ ) of the intervertebral nerve-canal, and partly overhangs a smaller outlet $(g)$ of a canal passing backward to open into the large intervertebral canal. The fractured base of the left postzygapophysis (ib. $z^{\prime \prime}$ ) of the second sacral is preserved, close to the outer end of the hind margin of the neural arch.

The neural spine of the first sacral (ib. figs. $2 \& 3, n_{1}$ ) is coextensive at its base with the summit of the arch, has a fore-and-aft extent of 2 inches, a transverse breadth of 1 inch 2 lines. The summit of the spine is broken away at the height of about 1 inch,

the surface of the sacrum and ilium turned toward the pelric cavity is " anterior" or "forward;" but in the ordinary posture of the quadruped it would be "inferior" or "downward." In the nomenclature of Dr. BarcLAY such surface would be "central" and look "centrad," the opposite surface "peripheral" and looking "peripherad ;" or those surfaces might be "sternal" and "dorsal" respectirely. I spall use the term "neural" and "neurad" in the sense of Barcliy's "dorsal" and "dorsad" and of the anthropotomist's "posterior," and the term "hæmal" and "hæmad" in the sense of "sternal" and "sternad." Fore or anterior, and aft, hind, or posterior will be used to denote the relations of the parts toward the head or the tail of the quadruped. 
and there the spine is 1 inch in thickness and 1 inch 7 lines in fore-and-aft extent. The anterior orifice of the neural caul (Plate XXXII. fig. 3) is 3 inches 5 lines in transverse dianeter, but only 1 inch vertically between the centrum $(c 1)$ and summit of the neural arch ( $n s 1)$; and this dimension is rather lessened at the middle of the canal by a slight rising along that part of the neural surface of the centrum. A medial vertical ridge with a depressionon each side marks the fore part of the base of the thick neural spine $\left(n s_{1}\right)$. 'The fractured base of the prezygapophysis $(z)$ of the first sacral measures 2 inches 4 lines by 1 inch 5 lines.

A partial ossification extends from the base of the neural spine of the first to that of the sccond sacral (ib. fig. $2, n s_{1} \&_{2}$ ), bisccting a deep triangular depression, which, how(ver, does not communicate with the neural canal; a continuous ossification from the first to the second sacral neural arch forms a smooth unbroken ceiling to the canal. 'I'he posterior outlet of the neural canal (ib. $n^{\prime}$ ) of the second sacral is transversely extended, ;) incles 6 lines across, 10 lines in height on each side the mid rising of the ccntrum. A greater proportion of the neural spine $\left(n s_{2}\right)$ of the second sacral than of the first is broken away; the remaining base gives 1 inch 8 lines in fore-and-aft extent, 10 lines in greatest brealth, which is at the hind part; the fore part is ridged with a small depression on each side. 'The irregular ossification is continued from the median ridge to the antecedent spine.

Of both ilia a large proportion has been preserved. The acetabular part $(d, t)$ swells out from the body of the bone, before (fig. 1) and behind (fig. 2), and developes a tuberosity (d) oblong lengthwise, triangular transversely, at the upper or anterior part of the brim of the cavity. In advance of the acetabulum the ilium contracts, especially from the neural to the hamal aspect, or is depressed and lamelliform; but continues thickest medially to form the junction with the sacrum, and contracts laterally to a smoothly rounded concave margin (ib. figs. $1 \& 2, n$ ). About the sacro-iliac symphysis the medial and anterior border, or "crista" of the ilium $(c)$ contracts to a thickness of $1 \frac{1}{2}$ inch, and where it is entire is convex and roughened. At the fore part of this symphysis is an oval foramen, 1 inch by 9 lines in diameters (ib. fig. $3, f$ ), the outlet of a canal communicating with the capacious intervertebral canal. The frec portion of the ilium is lamelliform, arches outwardly, the thin outer or hinder border $(n)$ describing a bold concave curve. Save for two inches near the symphysis of the right ilium, the crista is broken away. 'The hæmal surface of the iliac plate (fig. 1,62) is almost flat. 'Transversely, it is convex one-third of the extent from the fractured margin $(c)$, concave to the opposite outer margin $(a, n)$, both curves being feeble; lengthwise it bccomes concave toward the acetabulum. 'The hæmal tract $(p, p)$ of the sacro-iliac symphysis forms a low broad smooth convex ridge, enlarging and slightly rising as it approaches the acetabular part of the ilium, but subsiding before this begins to expand; this ridge, or tract, feebly represents the "linea ileo-pectinalis." It seems to be suddenly resumed by a process $(e)$. at the junction of the ilium with the acetabular end of the pubis (64). I infer, at least from its bcing broken off on each side of this pelvis, that it projected far enough to be called 
a "process" rather than a "tuberosity." The fractured base is oblong, $1 \frac{1}{2}$ inch by 9 lines. The process so indicated answers to that called "ilio-pubic" in Poëphaga*.

The neural surface (Plate XXXII. fig. 2, ${ }_{62}$ ) of the free part of the ilium is almost as flat as the hæmal surface; lengthwise the general slight convexity changes to a concavity as it approaches the acetabulum ; transrersely the surface becomes gently convex towards the thin concave border $(n)$.

The neural surface of the ilium is divided into a rough and a smooth part; the latter is exterior, narrow, extending about $1 \frac{1}{2}$ inch from the external border $(n)$, becoming gradually narrower to within 4 inches of the precotylar tuberosity $(d)$, where the smooth tract ends; the rest of the neural surface of the iliac plate is chiefly roughened by coarse grooves and low ridges, mostly inclining lengthwise with more or less obliquity, indicative of coarse and strong muscular attachments.

At the inner and back part of the sacro-iliac symphysis an angular tuberosity, answering to the "posterior inferior spine," unites with a larger rough tuberosity from the transverse process of the second sacral vertebra, together forming a large "sacro-iliac" tuberosity (ib. $u$ ), overhanging the deep and wide groove at the fore or upper part of the great sacrosciatic notch $(m)$. The plane of the long curved lamelliform ilium is thus almost horizontal, or with surfaces looking neurad and hæmad; the long axis of the bone forms with that of the sacrum an angle of $35^{\circ}$ (Plate XXXV. 62, s).

Of the ischium (Plate XXXII. figs. 1, 2, 4,63) the spine is represented by a slightly prominent surface (l), roughened at its upper and lower margins, of an oval form, 2 inches by 1 inch in diameters, the long one being in the direction or axis of the ischium, and the small end of the oval is forward. Between the upper part of the "spina ischii" and the neural margin of the acetabulum is a low subcircular rugous tuberosity (fig. 2, q) 1 inch in diameter. The back or neural wall of the acetabulum contracts as it retrogrades, the part contributed by the ilinm being broader than that by the ischinm.

The acetabular part of the innominatum contracts transversely, and expands in the neuro-hæmal direction from the line $m, d$ to the line $l, t$.

The ischium as it is produced backward beyond the acetabulnm contracts, but is rounded and thick posteriorly, and is thinned off only anteriorly where it forms part of the margin of the "foramen ovale." The ischia diverge from each other at this part, instead of retrograding parallel with each other as in Macropus; but to what extent is not shown in the present specimen.

The great sacro-sciatic notch (figs. $1 \& 2, m, l$ ) presents a deep and wide groove $(m)$ at the fore part, overhung by the produced hind part of the sacro-iliac symphysis $(u)$, which symphysis is here obliterated by anchylosis. Below the groove the back part of the acetabulum makes convex that part of the margin of the notch, which margin is again concave slightly to the tuberosity representing the ischial spine $(l)$.

* Osteol. of Marsupialia, tom. cit.p. 403: the sharcs taken respectively by the ilium and pubis in the formation of the ilio-pubic process is shown in the 'Cylopædia of Anatomy,' 8vo, vol. iii. (18+1), Art. Marsupialia, p. 284, fig. 110 (Itypsiprymmus). 
In both "imnominata the pubis (64) is broken off close to the acetabulum. The diameters of the fractured surface are 2 inches 6 lines and 1 inch 5 lines, the latter breadth being near the back part of the bone which gives a subtriangular section. The anterior apex is formed by a rough ridge, which rises from the hxmal part of the pubis about 2 inches from the ilio-pubic process (Plate XXXII. fig. 1,e), leaving a shallow groove between the ridge and the acetabular margin.

'The acetabulum (ib. fig. $4, t$ ) is a nearly liemispherical depression, $5 \frac{1}{2}$ inches by $5 \frac{1}{4}$ inches across the opening, nearly 3 inches in depth; its rim is smoothly rounded and less thick between the pubic ridge (64) and the "antero-inferior" iliac spine $(d)$; thicker and rough from this to the posterior or ischial part $\left({ }^{\prime}{ }^{\prime}\right)$; this, as it bounds the acetabulum posteriorly, curves uprard, gradually subsiding to form the outer wall of the "cotyloid notch" or groove $(y)$ conducting the ressels to the synovial and adipose mass about the expanded, rough, slightly depressed surface for the origin of the "ligamentum teres." This surface $(x)$ is oval, 2 inches 8 lines by 1 inch 3 lines in diameters; the cotyloid groore is 10 lines wide. The aspect of the acetabulum is outward and more obliquely downward and backward than in Macropus, through a greater development of the iliac, and especially of the pubic, walls.

'The sacrum is in the line of the lumbar vertebræ, upon which.line the ilia are directed obliquely forward and neurad at the angle above given (Plate XXXV.).

'The condition already noted of the materials for the recomiposition of the present pelris allows not of determination of the form and extent of the "brim of the pelvis," assuming, as is most probable, that this was naturally entire; nor does it give the extent, form, and direction of the ischio-pubic symphysis which I conclude to have existed. The transverse diameter of the pelvic cavity between the acetabular origins of the pubic bones (ib. fig. $\left.1,{ }_{64}\right)$ is 1 foot, between the ischial spines $(l, l) 7$ inches. From the portion traceable of the "foramen ovale" I infer it to have been relatively large, as restored in Plate $\mathrm{L}$.

The ischia are divergent in the extent to which they are preserved. Although the tuberosity and terminal part of the ischium are wanting, the hinder articular surface of the second sacral centrum (Plate XXXII. fig. 2, s 2) permits a conclusion that the ischia rere free from any direct union with the vertebral column.

The remains of no quadruped so large as that indicated by the above-described pelvis, sare those of Diprotodon, have been discorered in the freshrater deposits of Darling Downs. Yet it would betray an undue confidence in the proportion of present acquisitions of fossil remains to the entire extinct mammalian population of Australia, to infer specific relationship from sameness of locality, or even some degree of juxtaposition of parts of a skeletorl. It is incumbent, therefore, to state the results of the comparison of the pelvis in question with those of known genera of Mammals which have led me to the conclusion that it is marsupial and referable to the largest known species of the pouched order.

'The most conspicuous feature of the pelris, without doubt, is unlike the corresponding part in any known marsupial, and so much more resembles that in the Elephant as to 
have supported the view first suggested by the flattened form of the femur next to be described, if more instructive characters had not been shown deducible from the pelvis in question.

The ilia, though not quite entire along the "labrum" (Plate XXXII. figs. $1 \& 2, c)$, are sufficiently so to support the inference that they were short, broad or expanded, with a flattened surface rather than a fossa, directed hæmad or downward, and in a minor degree forward. Such a lamelliform ilium is not presented by any existing genus of Marsupial, but is found, besides the Proboscidians, in Megatherioids, Sloths, Apes, and Man.

From the Elephant's the ilia of the present species differ in the much less production of the angle terminating in the antero-superior spine $(a, a)$, which, in Proboscidians, extends outward and bends down in an almost hooked form to near the parallel of the acetabular outlet.

In the Megatherium and Mylodon the ilia are proportionally more expanded and outwardly extended than in the Elephant. The ilia of the Sloths (Bradypus, Cholopus) come nearer to the proportions of those in Plate XXXII. ; but the antero-superior angle is rounded off, and the position and aspect of the iliac planes are different. There is, however, a more marked, definite, and weightier distinction between the present pelvis and that of other Mammals with expanded lamelliform ilia. Leaving the human and simial pelves out of the comparison, that of the Elephant includes four sacral vertebræ, and the Sloths, both arboreal and terrestrial, have the sacrum unusually prolonged to effect the second junction with the innominate bones at the ischial tuberosities, thus converting the "great sciatic notch" into a foramen.

In the present pelvis the sacral vertebræ are but two in number. Now this, as a rule, is the number to which the sacral vertebræ are restricted in Marsupialia; and it strikes me as the more significant of the affinity, so indicated in the present pelvis, because it is associated with a modification of the ilium which, in the placental series, goes with at least double that number, and commonly with many more sacral vertebræ, five or six, e.g., in the Sloths and Megatherium, and as many as eleven vertebræ anchylosed in a mass in the Mylodon. A still more decisive mark of Marsupial affinity in the pelvis in question is the evidence of an ilio-pubic process (Plate XXXII. fig. 1,e,e); and this also points to the particular family of Marsupialia to which the large quadruped under consideration is more nearly related. Only in the Kangaroos is this process so developed as to be subject to such violence as has broken it away on both sides of the present pelvis. In all other Marsupialia it is indicated, if at all, by a mere tuberosity. The concurrence, therefore, of a bisegmental sacrum with the ilio-pubic process decides me to restrict further comparison with the pelvis of the Kangaroos (Macropus).

I take the difference of form of the iliac bones, which is very great, between Macropus and Tiprotodon-for if we arrive at the Marsupial genus with a diprotodont dental formula by the pelvic route we may be absolved of rashness in drawing the obvious conclusion-to depend on the corresponding differences in the mode of locomotion deducible 
from the structure and proportions of the limb bones. Diprotodon, by the equable and massive developinent of fore and hind limbs, must have progressed on dry land, like the Elephants and Megatherioids, with a regular, quadrupedal, gravigrade pace, though no doubt less sluggishly than either Mylodon or Megatherium. It is evilent that it could not depend on the hind limbs alone for rapid escape from enemies as do the Kangaroos. The powerful exertions those singular marsupial animals impose upon their long legs in the successive bounds by which they rapidly traverse the plain, eall for the provision of long muscles and of strongly eontracting ones, indicated by the long, strong, three-sided, and three-ridged ilia, in which both sides of the prism destined for muscular attachments are deeply hollowed. The corresponding pelvie muscles in Itiprotodon must have been relatively shorter, less thick, but broader, and, in relation to the thigh bone, arranged and disposed more or less as in the Elephant.

Amongst minor differences between Macropus and Diprotodon in the anatomy of a part of the skeleton in which they agree in more essential characters, I note that the outer margin of the sacral apophyses (Plate XXXII. fig. $1, p l_{1}, p l_{2}$ ), uniting with the ilia at $p, p$, do not curve hæmad as in Macropus, making that surface transversely concave.

The outlet of the anterior canal communicating with the wide intervertebral nervepassage, answering to that marked $g$ in Diprotodon (ib. fig. 2), is relatively smaller and more in advance of the soldered zygapophyses uniting together the two sacrals in Macropus. The "spine of the ilium" in Macropus is represented by a relatively narrower and less prominent surface than in Diprotodon, is further from the ischial spine, nearer the middle of the back wall of the acetabulum in Macropus. The breadth of this wall is almost equal in the Great Kangaroo, and the hind contour of the acetabular brim is almost parallel with the coextensive inner and hinder border of the innominatum.

The ischium, as it is produced backward beyond the acetabulum, is relatively more compressed and lamelliform in Macropus than in Diprotodon, and, most probably, is relatively longer. In the acetabulum itself the vascular groove and the ligamentous depression are relatively deeper in Macropus than in Diprotodon.

\$ 9. Femur. - The femur is remarkable for the length, breadth, and depth of the proximal end, including the "head," "neck," and "trochanters," for the rise of the head above the great trochanter, for the fore-and-aft flattening of the shaft, and for the extent in the same direction of the inner condyle chiefly due to the prominence of its narrow anterior tuberous end.

The chief dimensions of this bone are given in the 'Table of Admcasurements,' p. 574.

'The " head" (Plates XXXIII. \& XXXIV. fig. 1, $a$ ) is egg-shaped, the great end hemispherical with the articular surface produced upon the upper part of the neck, contracting and representing the small end of the egg (Plate XXXIII. fig. 1,b). 'There is no pit for attachment of a ligamentum teres; the sole indication of any special addition to the fibres of the capsule of the joint is a rough shallow indent of an angular form, encroaching on the ball from the under part of its periphery (Plate XXXIV. fig. 1,c). 'The fore-and-aft diameter of the head is $4 \frac{1}{2}$ inches; the transverse extent to the end of the supracervical 
apex is 6 inches: this production is more conspicuous at the fore (Plate XXXIII. fig. 1, $b$ ) than at the back part (Plate XXXIV. fig. 1). The margin of the articular surface is slightly prominent, through the sudden contraction of the rough surface of the neck; but this is chiefly at the fore part (Plate XXXIII. fig. 1, d), towards which aspect the head slightly inclines. At the back part of the neck, just beyond the head, there is a low ridge $1 \frac{1}{2}$ inch long (Plate XXXIV. fig. $1, e$ ) parallel to the margin of the articular surface.

The rugged surface of the great trochanter commences at the middle of the upper part of the neck, with a moderate elevation and a border convex towards the head (Plate XXXIII. fig. $2, f$ ) ; its fore-and-aft breadth here is $3 \frac{1}{2}$ inches, but the process expands as it recedes from the head, sloping downward to a breadth of 4 inches 10 lines; its outer expanded termination is subbilobed, the posterior lobe (ib. $h$ ) being most produced outward; the anterior one (ib. $g$ ) is continued furthest down the shaft.

Anteriorly the great trochanter is defined by the abrupt rising of the rugged surface from the smooth surface of the neck along a curved line (ib. fig. 1, $i, i$ ), which bends round the lower part of the anterior lobe (ib. fig. $1, g$ ), : this is continued upon the fore part of the shaft near its outer margin for an extent of 5 inches from the upper surface of the lobe; the posterior lobe (Plate XXXIV. fig. $1, h$ ) extends a shorter way down the outer surface of the femur, and is defined, or rises, very abruptly from the smooth tract of that part of the shaft. The posterior part of the trochanter projects as a thick oblong tuberosity (ib. fig. $1, k$ ) above the trochanterian depression (ib. $l$ ): the mouth of this depression is 3 inches 8 lines in length, 1 inch in breadth, opening parallel with the lower margin of the neck, and is 3 inches in depth. Beyond the depression the posterior margin of the trochanter is less defined from the femoral shaft than is the anterior one. The neck of the femur (Plates XXXIII. \& XXXIV. $m$ ) begins by hardly a less diameter than the head from above downward, and augments in that direction as it extends outward; it is rapidly compressed from before backward, as it recedes, especially where it is continued into the trochanterian fossa (Plate XXXIV. fig. 1, l); its upper margin is slightly concave from within outward, convex from before backward, 2 inches broad in that direction; the lower margin is 2 inches 6 lines. This margin is not uniformly convex across, but is remarkable for the production of its hinder half into a long narrow elliptical rough ridge, representing the small trochanter, which is 6 inches in length and $1 \frac{1}{2}$ inch across the middle (Plate XXXIII. fig. $1, n$ ).

The lower ends of this and of the anterior tuberosity of the great trochanter are on the same transverse parallel, at which the proper shaft of the femur may be said to commence. This is defined by a gentle concave curve in both outer and inner sides, the least transverse diameter being 4 inches 5 lines. At the upper half of the shaft the fore-and-aft thickness decreases from the outer to the inner border, which is reduced to 2 inches before rounding off. This border gains in thickness as it approaches the lower end.

The outer side of the compressed shaft preserves a thickness of about $2 \frac{1}{2}$ inches along 
its middle two-thirds, expanding above and below to the ends of the bone. The fore surface of the shaft is smooth, the hind surface shows a shallow narrow longitudinal depression (Plate XXXIII. fig. 2, o; Plate XXXIV. fig. 1,o), and near the outer border, $3 \frac{1}{2}$ inches above the outer condyle, it is $2 \frac{1}{2}$ inches in length. A subcircular feebly marked rough surface or patch (Plate XXX1V. fig. 1, p) is discemible near the middle of the back surface, not quite halfway down the shaft.

'The rotular surface (Plate XXXIII. figs. 1, 2, 4, r) of the distal end, defined by a low lising from a slightly clepressed fore part of the lower end of the shaft (ib. fig. 1, q), is made strongly concave transwersely by the forward production of the narrow tuberous end (ib. $s$ ) of the fore part of the inner condyle $(t)$, from which it is divided by a channel $\frac{1}{2}$ an inch wide (ib. fig. $4, x$ ) continued to the intercondylar pit $(u$ ) from the inner surface of the distal end of the shaft. 'The large rotular surface, thus concave transversely, convex from before backward, is broadly continuous with the articular surface of the outer condyle (ib. figs. $1 \& 4, v$ ). The fore-and-aft extent of the inner condyle, including the rotular part, is 8 inches; the same diameter of the outer condyle is but 4 inches 7 lines. 'The transverse diameter of the back part of the inner condyle is 3 inches 6 lines; that of the outer condyle is the same; the transverse diameter of both condyles (Plate XXXIV. fig. 1, $t, v$ ), including the intervening depression $(u)$, is 7 inches 6 lines. 'The form of the articular surface is very different here, in the two condyles; the inner one $(t)$ shows a full convexity in both directions, the transverse contour becoming flattened toward the outer border. The outer condyle $(v)$ is slightly concave transversely along two-thirds of its middle part, the outer convex border being somewhat produced; the outer condyle is also less convex from before backward than the inner one. There can hardly be said to be a popliteal depression; the rertical line of the back of the shaft is continued directly into the intercondyloid groove $(u)$, the sides of which are formed by the production of the back parts of the condyles.

'The inner surface of the distal end of the shaft developes a strong ridge (Plate XXXIII. fig. 5,w), extending above 4 inches from the back part of the inner condyle toward the rotular division of the same. 'The outer supracondylar surface is more even and is slightly concave, divided by a moderate rough prominence (ib. fig. 1,y) from the smooth outer part of the shaft.

'The outer side of the shaft, for a short way below the great trochanter, joins the hind surface at an angle, simulating a low ridge continued from the end of the hind lobe of that process, and subsiding into the rounded smooth convexity of the onter part of the shaft; but there is no "linea aspera." I cannot detect in this femur any orifice of a medullary artery. The fractured surface of the shaft of a left femur does not indicate any medullary cavity. But in the shaft of another femur, corresponding with the above in size and shape, the transverse being to the antero-posterior diameter as two to one, there is a conspicuous orifice for the medullary artery, at the back part and a little above the middle of the shaft, toward the inner side; the canal slopes upward, to a small spheroid medullary carity, with dense walls 1 inch in thickness (Plate XXXIII. fig. 3). 
The femur, like the pelvis, of Diprotodon presents the greatest resemblance in general form and characters to the corresponding bone in Proboscidia. The head is deroid of the ligamentous pit; the shaft is straight and antero-posteriorly compressed; there is little* or no medullary cavity.

Passing to particulars of structure, there appear several more or less well-marked differences.

The head rises higher above the neck and trochanter in Elephas; it has a more directly upward aspect, the neck is shorter, the great trochanter is absolutely, as well as relatively, of less extent in Elephas. The trochanterian depression is less deep, and opens nearer the exterior surface of the trochanter. A ridge is continued downward from the border of the depression, which, with a second ridge continued downward from the outer part of the trochanter, bounds a flat facet forming the outer surface of the upper half of the shaft: there is no such definite facet in Diprotodon. At the upper and fore part of the trochanter in Elephas there projects a tuberosity midway between the head of the femur and the outer part of the trochanter, and the neck rising to support this tuberosity is somewhat convex transversely: there is no trace of this tuberosity in Diprotodon, and the forc part of the neck is concave transversely. The small trochanter, which in Elephas, as in Diprotodon, is a long longitudinal ridge, is situated lower down in Proboscidia. The ridges continued from the great trochanter upon the shaft represent, in that order, "lineæ asperæ," of which there is no trace in Diprotodon.

The differences become more marked at the lower end of the bone. The rotular surface or pulley is absolutely as well as relatively narrower in Elephas; it has a more anterior aspect, is supported on an anterior production or expanse of the femur; the sides of the pulley are parallel, subequally developed; there is no production of the inner one as in Diprotodon. The outer as well as the inner part of the rotular articular surface is distinct from that surface in the corresponding condyle. Both condyles are convex and equally prominent behind in Elephas; in which genus there is no transverse hollowing of the outer condyle, giving a trochlear character with production of the outer border of that condyle as in Diprotodon. The intercondylar groove is deeper and narrower in Elephas than in Diprotodon.

Omitting the notes of comparisons of the femur of Diprotodon with that in other large quadrupeds, the essential correspondence throwing truc light on the determination of the species to which it belongs, and the affinity of that species, is found in the Poëphaga or Macropodida exclusivcly. It is there only that one finds the transverse excavation of the surface of the outer femoral condyle, producing the contrast of a trochlear character of surface with the uniform convexity or ball-like prominence of the inner condyle. In the Great Kangaroos (Macropus major, M. laniger) the character is exaggerated, the channel is deeper, and its outer border is more produced. The rotular surface is broad, with unsymmetrical sides in Macropus, the inner border being sharpest, though less produccd anteriorly than in Diprotodon.

* See Osteological Catalogue of the Museum of the Royal College of Surgeons, 4to, p. 481. 
Macropus further agrees with Diprotodon and differs from Elephas in the continuity of the articular surface, giving that of the synovial cavity, of the rotular and condylar joints; but in Macropus the inner as well as the outer condyle is so continuous. 'The intercondylar groove is relatively wider in Macropus than in Diprotodon, and, the condyles being more backwardly produced, it is deeper. 'The longitudinal ridge-like small trochanter is placed higher in Macropus as in Diprotodon than it is in Elephas. The attachment of that muscle, which leaves a circular rough patch at the back of the femoral shaft in Diprotodon, is developed into a tuberosity in Macropus. The trochanterian depression is very deep in Macropus as it is in Diprotodon. The great trochanter is bilobed exteriorly in Macropus, but with a deeper and differently directed dividing chamel than in Diprotodon.

I discern in the foregoing correspondences the essential marks of affinity, and view the greater elevation of the trochanter major in Macropus, the greater length and cylindroid form of the shaft of the femur, the greater relative antero-posterior extent of the distal end, and especially of the outer condyle, with the stronger indications of muscular attachment, as adaptive characters in the smaller Marsupial related to its more rapid and vigorous modes of locomotion.

$\$ 10$. Tibia.-The tibia, of the general dinensions given in the Table of Admeasurements, p. 243. I conclude, by the agreement in size and character of the upper articular surface (Plate XXXIV. fig. 4) with the lower one of the femur (Plate XXXIII. fig. 4), to belong to the same leg, viz. the right one, of Diprotodon.

The external upper articular surface (Plate XXXIV. figs. 3 \& 4,a) is gently undulated, with a transverse convexity adapted to the corresponding concavity on the outer femoral condyle, and with the concavities, though slight, answering to the convexities of that condyle. The inner articular surface (ib. fig. $4, b$ ) is larger, and presents a uniform concarity to the convex inner femoral condyle. The ridge or spine (ib. figs. 2, 4,c) between the articular surfaces extends 2 inches from behind forward and a little outward; it is from (i) lines to 10 lines thick, and is roughly excavated above. The rough part of the upper surface of the tibia (ib. $d$ ), in advance of the articulations, is more extended transversely from behind forward. 'The breadth of the upper surface exceeds by two-fifths the foreand-aft diameter. The articular surface for the head of the fibula (ib. fig. $3, e$ ) is continuous with the outer articular surface $(a)$, and extends from its outer and hinder margin at a rather acute angle or nearly a right angle, 1 inch 4 lines down the shaft, the breadth of the surface being 1 inch 6 lines. In advance of this surface projects the external tuberosity $\left(f^{\prime}\right)$, from which a thick (epicnemial) ridge-like rising of bone (ib. fig. $2, g, g$ ) extends in front of the upper end of the tibia for about $5 \frac{1}{2}$ inches. This ridge or prominent tract is longitudinally striate or scratched, as if it were an ossified ligamentous attachment. At the middle of the fore part of the tibial head a narrow ridge (ib. fig. $2, h$ ) is continued from the transverse one 2 inches down the shaft, like the procnemial ridge in birds, but much less produced. From the junction of the "epicnemial" ridge with the outer tuberosity a narrow "ectocnemial" ridge (ib. $i$ ) 
extends for an inch or two down the shaft. Beneath the outer tuberosity is a rough shallow cavity (Plate XXXIV. fig. $3, k$ ), and a similar but smaller one (ib. $l$ ) impresses the shaft a little way below the fibular articular surface. An internal tuberosity (ib. figs. $2 \& 4, m$ ) is feebly marked below the contracted inner end of the inner articular surface.

The shaft of the tibia rapidly contracts to a transverse diameter of $2 \frac{1}{2}$ inches at the middle third of its extent, where it is trihedral, with the angles rounded off. It appears to be twisted with the inner malleolus turned forward; but this is very feebly marked, not projecting below the distal articular surface. At the outer and back part of the lower half of the shaft is a rough longitudinal prominence (fig. $3, n$ ), 4 inches by 1 inch, seemingly for ligamentous attachment of the corresponding part of the shaft of the fibula. At the inner and back part of the shaft a low narrow fibrous ridge runs parallel with the inner border of the fibular ridge, defining therewith an oblique shallow canal, 9 lines in width.

A slightly raised border of bone (figs. $2,3, p$ ), from 1 to 2 inches distant from the lower articulation, seems to indicate the original line of junction of the epiphysis. Malleoli cannot be predicated of the distal end of this tibia (ib. fig. 5). At the inner periphery of the articular surface, instead of a prominence there is a notch (ib. $q$ ), from which a groove $1 \frac{1}{2}$ inch long and 5 inches wide extends outward and forward into the joint; the rough convex border of the articulation external to this, corresponding in position to the fore part of the upper end of the tibia, appears to represent an internal malleolus. On each side the entering groove $(q)$ the distal articular surface is slightly convex; in the rest of its extent it is nearly flat; its form is oblong, with the long axis at right angles to that of the upper articular surface, $i$.e. from before backward instead of from side to side.

In a portion of the shaft of a tibia, obtained by Sir Thomas Mitchell from the bed of the Condamine River, the upper part of the ridge between the outer and hinder surfaces shows the orifice of a medullary arterial canal, which expands as it slightly descends. No medullary cavity, however, is shown in this fragment. The compact part of the wall of the shaft is half an inch thick, and a moderately close cancellous structure extends inward to the centre of the shaft.

A subtrihedral portion of bone, including the distal end and accompanying the above portion of tibia, I believe to be part of the fibula; it is 7 inches in circumference. The centre of the shaft is occupied by a close cancellous texture. The articular extremity is much abraded; a trace of the epiphysial suture remains; and I find that this islong conspicuous in the fibula of the Wombat. I have given what I conjecture to be the proportions of the fibula in my restoration of the skeleton of Diprotodon, Plate XXXV. ${ }_{67}$.

In the singular form of the tibia of Diprotodon are presented Marsupial characters exclusively. "The outer articular surface is continuous with that of the head of the fibula"*, as in the Wombat and Koala; "the shaft of the tibia is twisted as in Opossums, Dasyures, Phalangers, and Petaurists, as well as in the Koala and Wombat" + . 
"The internal malleolus is very slightly produced in any Marsupial"*, save in the Wombat and Kangaron.

"l'he fibula is complete and forms the external malleolus in all Marsupials;" and such may be inferred to be its condition from the evidences of attachment shown in the tibia of Iiprotodon. Only, iustead of "the close contact and attachment ensuring a due degree of fixity and strength"* in the Kangaroos, I infer from the articular surfaces on the tibia for the fibula and for the foot that this "enjoyed a movement of rotation analogous to the formation and supination of the hand"*, as in all save the saltatory Marsupials; and we may infer a corresponding modification of the foot approximating Diprotodon to Phascolomys.

$\S 11$. Conclusion.-Thus in the series of Mammalia which characterizes the Australian continent we have evidence of the former existence of a species as large as the Megatherium - that strange extinct animal which similarly crowns the series of Bruta correspondingly characteristic of the South American Continent.

It is interesting to note the similarity in size, number, and form of working-surface of the molar teeth in the extinct Marsupial and Bradypodal giants; so much so that, notwithstanding the different dental structures and conditions of growth, one cannot resist the inference of a correspondence of diet. But whereas in Megatherium the front teeth are wanting, and the prehension of the vegetable food was allotted to limbs and tongue, in Diprotodon instruments allied to those by which the Beaver and Wombat gnaw the ligneous fibre were magnified to the proportions of the body to be provided for. The Marsupial inonster brought down the tempting foljage by erosion of the trunk, not by the strong hawl of a forcible grasp. Accordingly, the limbs show not those abnormal proportions which distinguish the Megatherioids; they manifest, especially the hind ones with the pelvis, in the Diprotodon, forms and proportions recalling those of the Elephant, and suggestive of analogous uses and mode of progression. The fore limbs may be inferred by the modifications of the distal articulation of the humerus, and by what is known of the ulna, to have enjoyed the rotatory as well as flexile movements. Herein the Diprotodon resembles the Megatherium rather than the Elephant; but the truer inference from the retention of the rotatory and probably unguiculate structure of the fore paws is that, as in the existing herbivorous Marsupials, they were needed for the manipulations of the pouch.

'The resemblance in the Diprotodont and Megatherioid dentitions, guiding to the recognition of function or adaptive purpose, are underlain, as above hinted, by differences of textural and genetic conditions. Diprotodon combines enamel with dentine, osteodentine, and cement; Megatherium has no enamel. In Diprotodon the molars have a limited period of growth; in Megatherium that period was limited only with life.

The Australian giant adds to number, relative size, and shape of crown, of its molars, in which it accords with the existing macropodal marsupial dwarf of that land, the further correspondence in the coronal enamel and the divergent roots of the grinders.

\footnotetext{
* Osteology of the Marsupialia, Toc. cit. p. 405.
} 
Similarly, the American phytophagous giant added to a bilophodont working-surface of its few and small molars, the peculiar texture and rootless condition of the long deeply implanted ever-growing dental mass, characteristic of the molars of the existing dwarfsloths of its continent.

When only the large curved pair of upper scalpriform incisors of Diprotodon were known, to which the subcompressed lower pair are opposed, an alliance of Diprotodon to Phascolomys was suggested. The subsequent evidence of a nearer affinity to Macropus instructively exemplifies the superior value of the molar teeth as indicators of the nature of an extinct animal*.

It is true that in the proportions of the limbs, especially in those of the tibia and its distinction from the fibula, as in some other particulars of the osteology of Diprotodon, it resembles more the Wombats than the Kangaroos; but the more weighty and essential correspondences are with the Macropodidce; the equipedal modifications are adaptive and necessitated by the bulk of the extinct marsupial herbivore. The most elastic imagination could hardly stretch to the association of the disproportionate hind limbs of the Kangaroo with a trunk equalling that of a Rhinoceros; for according to that pattern, Diprotodon must have towered to a height of 30 feet. The departure from the type of its diminutive modern allies is, again, interestingly analogous to that which occurs in the herbivorous Bruta. The bulk and weight of body in Megatherium precluded the proportions of length and slenderness, with terminal prehensile instruments, in the limbs, by means of which its diminutive congeners and contemporaries have been enabled to withdraw themselves from an unequal conflict into the safe shelter of lofty trees. In like manner the bulk and weight of Diprotodon militated against its enjoying the privilege of the elongate saltatory limbs to which its small congeners and contemporaries the Kangaroos have owed their safety, or of the scansorial ones by which the Koala climbs out of danger.

The analogies traceable between the extinct herbivorous giants of the two remote tracts of dry land are full of interest and instruction. I may add that, as swift and continuous course and power of climbing are privileges checked or regulated by the mass and weight to be hurried along or dragged aloft, so likewise is the faculty of burrowing and concealment under ground. The Diprotodon was as impotent to avail itself of the means of escape to which the comparatively diminutive Wombats owe their present existence, at it was of the interposition of space, which the Kangaron by a succession of long leaps, rapidly puts between itself and its pursuers.

Subject to this explanation the combination of Wombat- and Kangaroo-characters may be adduced as exemplifying that more generalized structure in Diprotodon from which, or from some earlier still more generalized marsupial type, may have diverged the

* Agreeably with the rule laid down by the great Founder of Palæontology; "La première chose à faire dans l'étude d'un animal fossile, est de reconnoître la forme de ses dents molaires; on détermine par-là s'il est carnivore ou herbivore, et dans ce dernier cas, ou peut s'assurer jusqu'à un certain point de l'ordre d'herbirores auquel il appartient," Cuvier, Ossemens Fossiles, 4to, vol. iii, 1812, p. 1 (Premier Mémoire). 
thrce existing families with special modifications, respectively, for burrowing, climbing, and leaping. Or, to borrow a figure from another lypothetical school, I might remark that the orders, or other natural groups, of placental Manmalia represented by members of the marsupial series have been indicated by different zoologists *, and with no material divergence of opinion; but not until now has evidence been received of a Marsupial representative of the proboscidian group.

In certain Mastodons there is a pair of incisive tusks below as well as above: the proboscidians maximize the rodent type as Diprotodon does the Marsupial one. The brain of the Elephant is essentially "lissencephalous," inasmuch as the cerebrum does not exteud upou the cerebellum. This position of one primary mass of brain in front of the other is, as stated in the definitions of the subclasses of Mammalic in the cerebral system $\uparrow$, a more constant and important character than convolution of surface, which in both Iy- and Liss-encephala relates to the bulk of the species and of the brain. So, on the other hand, if a smooth cerebrum overlaps the cerebellum as in the Marmoset, it is essentially "gyrencephalous." The terms suggested by the superficial character which prevails, with exceptions, are arbitrary, but the most convenient for expressing the more constant characteristics of the brain therewith associated.

In the extinction of Diprotodon, as of Megatherium, there seems to be an additional exemplification of the fruitful and instructive principle which, under the phrases "contest for existence," or "battle of life," embodies the several circumstances, such as seasonal extremes, generative power, introduction of enemies, \&c., under the influence of which a large and conspicuous quadruped is starved out, or falls a prey, while the smaller ones migrate, multiply, conceal themselves, and escape.

We infer from the fact of remains of young and inexperienced Diprotodons occurring in Australian Caverns with those of Thylacoleo, that the large Marsupial herbivore had its enemy in, and occasionally fell a victim to, the large Marsupial Carnivore; as at the present day the Kangaroo is laid in wait for by the 'Thylacyne, or 'Native IVolf', and by the Dasyure, or 'Native Cat.'

We may speculate upon the possible relation of the first introduction of the Human kind into Australia, and of the subsequent insulation of that land from the rest of the Papuan Continent, to the final extinction in the so restricted territory of all the characteristic Mammals which happened to surpass in bulk the still existing, swift-retreating, saltatorial and nocturnal Kangaroos.

* "On dirait, en un mot, que les marsupiaux forment une elasse distincte, parallìle à eelle des quadrupìdes ordinaires et divisible en ordres semblables; en sorte que si on plaçait ees deux elasses sur deux colonnes, les sarigues, dasfures et péramèles seraient, ris-à-ris des earnassiers inseetirores ì longues canines, tels que les 'tenrees et les taupes; les phalangers et les potoroos, ris-à-ris des hérissons et des musaraignes; les kangaroos proprement dits, ne se laisseraient guère comparer à rien; mais les phascolomes devraient aller vis-à-ris des rongeurs." - Ctrier, Règne Animal, ed. 1817, tom. i. p. 171. "Les ornithorhynches et les éehidnés y formeraient un groupe parallèle à celui des édentés."-Op. cit. ed. 1829, tom. i. p. 174.

t OWEx, "On the Characters \&c. of the elass Mammalia," Proceedings of the Linnean Society, 1857. 
It is true that reliable evidence has not reached us of the contemporaneity of Man with Diprotodon in Australia. No human tooth or bone, no weapon fashioned by man, has hitherto been detected in the breccia-caves, or has been picked up in the lacustrine beds in South Australia, Queensland, and Melbourne, from which the largest and oldest Diprotodonts have been exhumed, mostly under conditions of petrifaction, suggestive of interment in those deposits during a vastly longer period than the Mammoths and Rhinoceroses have lain in our own brick-fields.

A human skeleton, or part of it, picked out of the deposits forming the bed of a tributuary of the Condamine, and yielding the same results of chemical analysis as are recorded of a Diprotodont fossil at p. 242, would be one of the much needed decisive and satisfactory evidences of the antiquity of Man. To promote the investigation in the Australian Continent which the present phase of the ancient history of our own species so much requires, I rentured some time ago to address the Legislature of New South Wales, and with results, as respects the aid and encouragement of such researches, which are given in the subjoined notes*.

The range of Diprotodon australis, during the period of its existence, in the Australian Continent is shown by the evidence at present possessed to have been wide.

* "London, British Museum, 23rd February, 1867 .

"SrR,-The enlarged and liberal riers of your administration embolden me to suggest that a eareful and systematic exploration of the Limestone-cares of Wellington Valley, discorered by the Colonial Surveyor in or about 1832, would be a work worthy of your eneouragement.

"The fossil remains whieh were then obtained from the eares rerealed the important and suggestire fact that the marsupial type of strueture prevailed in the ancient and extinct as in the existing quadrupeds of Australia.

"Besides the great aecession of such eridences as would aecrue to the MIuseum at Sydney from sueh cxploration, most instructive eridenee may be expeeted bearing upon the antiquity and origin of the aboriginal races of Australia. Such contribution to human knowledge, initiated and supported by New South Wales, would be gratefully appreciated by all who in this hemisphere are deroted to the progress of scienee, and would redound to the honour of your present constitutional Gorernment.

"I rould willingly derote time to the determination and description of such specimens, or duplieates, as, so aequired, might be transmitted to me for that purpose, or be liberally sent for deposition in the British MIuseum; and these descriptions would be punctually transmitted to the Museum at Sydney, as materials of its Catalogue, or to such address as you might be pleased to indicate, in reference to a systematic deseription of the Wellington Valley Bone-cares.

"I feel confident, from personal conferenee on the subject with the late Sir Tromas Mircnelt, who eonfided to me the fossils he was able to bring orer for description in his work published in 1838, that the results of the proposed exploration, in the hands of one qualified, would amply repay a grant, say of $£ 200$ or $£ 300$, if placed on the estimates and sanctioned by the Assembly.

(Signed) "Richard Owen, F.R.S."

"The Hon. Hexry Parkes, \&c., Colonial Secretary, New South Wales." 
Table of Localities of Diprotodon australis, showing:-

\begin{tabular}{|c|c|c|}
\hline Where founcl. & By whom. & Wate. \\
\hline Breceia-eavern, Wellington Valley* & Sir Thomas Mitchell, C.13. & $18: 36 ;$ \\
\hline Tributaries of Condamine liver, Darling lownst & Sir 'Thomas Mitelell, C.13. & $18+2$ \\
\hline (Quaternary gravel, Mlount Macedon, Melbourne + & E. C. ILobson, M.1). & $1843-45$ \\
\hline Tributaries of Condamine liver, Darling Dowus & Ludwig Leichlrardt, XI.D. & $18+4$ \\
\hline Freshwater beds, Mount Macedon, Melbourue \| & 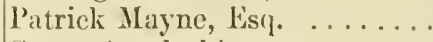 & $18+4$ \\
\hline lBone-eaves, Wellington Valley ............. & Count Strzelecki .... & $18+4$ \\
\hline King's Creek, Darling Downs & Mr. Turner & $18+7$ \\
\hline Gowric, Darling Downs 9. & Fred. Neville Isaac, Esq. & $18+9$ \\
\hline Galtendauldai, Jelrille Plains & Wni. Buchanan, Esq. & 1851 \\
\hline Creeks, Marling Downs & Henry Hughes, Esq. & 1856 \\
\hline Gowrie, Darling Downs. & John E. Allport, Esq. . & 1860 \\
\hline Welcome Springs, South Australia*** & Fred. Geo. Waterhouse, Jisq. & 1861 \\
\hline Valley of Condamine t†... & J. H. Ifood, Esq. & 1861 \\
\hline Portland Bay, South Australia & James S. Wilson, Esq.. & 1860 \\
\hline Hergott's Springs, Mount $A$ ttraction, 500 miles $\mathrm{N}$, of Idelaide ++ & William Burrett, Esq. & 1861 \\
\hline Eton Vale, middle of Darling Downs & Edward S. Ilill, Esq. & 1863 \\
\hline St. liutl Station, Tributary of Condamine River & Hugh C'ampbell, Esq. & 1865 \\
\hline St. Jean Station, Queensland. & II. Satche St. Jean & 1865 \\
\hline Clifton Plains, Darling Downs & F. Nieholson, Esq. . & $1866 ;$ \\
\hline Breceia-cavern, Wellington Valley & Gerard Krefft, Esiq. . & 1866 \\
\hline
\end{tabular}

To this letter I was faroured with the following reply :-

(Copy.)

"Colonial Secretary's Officc, Sydney, New South Wales, 16 th June, 1869.

"Sir, - With referenec to your letter of the 23rd of February, 1867, recommending that the Gorerument of this Colony should eause a eareful and systematic exploration to be madc of the Limestone-caves of Wcllington Valley, I have now the honour to inform you that the sum of $£ 200$ has been roted by the local Parliament for carrying out your suggestion, and that the Curator of the Australian Museum has been charged with the duty of making the necessary exploration.

"I have the honour to be, Sir,

"Your most obcdient Serrant,

(Signed)

" Johx Roberissox, Colonial Secretary."

"To Profcssor Owen, F.R.S."

I was gratified by reading in 'The Times' of December 1st, 1869, a notice from the Sydney Correspondent of that Nerrspaper to the effect that "the Wellington Bone-eaves have bcen explored by Dr. 1. M. Thouson and Mr. KrefFt of the (Sydney) Museum, with astonishing and unexpected results."

* See description of these Bone-caves by their discoverer in his "Thrce Expeditions into the Interior of Eastern Australia,' 8ro, vol. ii. 1835.

+ Sir T. MIten EL places the locality in lat. $28^{\circ} \mathrm{S}$., long. $150^{\circ} \mathrm{E}$.; and of the Condamine, he writes: " This stream is remarkable from forming large basins at some places and losing its course in swamps at othcrs, and at other parts again cutting its course in a decp channel, through dcep beds of alluvium, in which these bones [of Diprotodon] are thus brought to light."-Letter dated January 3, 1842.

$\ddagger$ Dr. Horson, in transmitting these specimens, sent a sketeh of the locality with the following Note:-

"The country from II elbourne is voleanic the whole way; indeed the bank which borders the estuary on which the town is built is the commencement of rast elevated plains of rolcanic origin, corered with vesicular lava, scorix, interrupted by decp rarines, which show on their stecp sides, in many places, a regular columnar basaltic arrangement. Of this nature is the entire country betwixt Mount Macedon and Melbourne, gradually rising, but so slightly as to be almost impereeptible, till fou arrive at the volcanic hills that immediately surround Mount Maccdon, which is, I beliere, composed of granite on its top, and of schistose slates on its side. 
The fossils from Mount Macedon are less petrified than those from Darling Downs: the osseous substance crumbles away if not supplied with gelatine, like the fossil bones and tusks from our brick-earth in England.

"Amongst the secondary hills which skirt the base of Mount Macedon there is a considerable circular plane, which is more elevated in its centre than at its circumference, and which will be better explained by a diagram:-

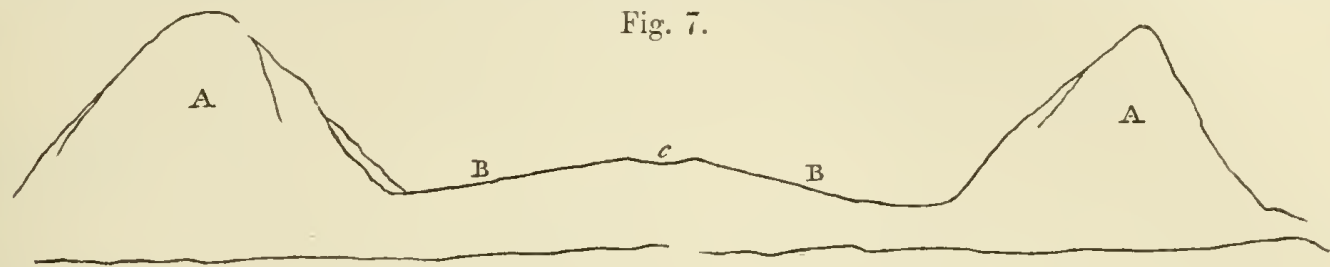

A, A. Volcanic Hills surrounding the plain.

B B. The plain.

c. A swamp or bog in which are found the bones at a depth of $4 \frac{1}{2}$ feet. After digging through a solid peaty soil for 3 feet you then arrive at a stratum of gravel about 18 inches thick, in which the bones are deposited. This layer of gravel rests upon a bed of firm clay, which is unfossilfferous.

"The bog or marsh in which the bones are found is about four acres in extent, and appears to contain bones at every point. I opened two pits at 150 yards distance from each other and found bones in both, in the same stratum of gravel."-Lctter dated January 1st, 1845.

$\S$ The following valuable Note on the formations of the locality accompanied the transmission of the fossils, by the gifted and unfortunate explorer of that part of Australia:-

“The Darling Downs are extensive plains, formed by broad shallow valleys, without trees, covered only with grass and herbage, which grows luxuriantly on the rich black soil, in which concretions of carbonate of lime are frequently found. Ranges of low hills, forming long simple lines with sudden slopes and flat-topped cones, accompany these valleys, and have an open forest formed of various species of rather stunted kucalyptus. All these hills are formed by a basaltic rock, containing frequently crystals of peridote, and being oftcn cellular, sometimes real scoria. The base of the rock is, however, feldspathic; and, as the peridote is frequently absent, the rock becomes uniformly grcy, forms a white globule before the blowpipc, and is therefore to be classed amongst the trachytes or phonolites. The plains are filled by an alluvium of considerable depth, as wells, dug $50-60^{\prime}$ deep, have been sunk within it. The plains and creeks in which the fossil bones have been found are 'Mr. Hodgson's Creek,' 'Campbell's Creeks,' 'Mr. Isaac's Creck,' and 'Oaky Creek." They pass all into and through immense plains on the west side of the Condamine, into which they fall. The bones are either found in the bed of the creck, particularly in the mud of dried up water-holes, or in the banks of the creeks in a red loamy breccia, or in a bed of pebbles, containing many trachytic pebbles of the coast range from the west side of which these crecks desecnd.

"In the banks of the creeks you find at first the rich black soil of the plain, about 3 ' thick, then layers of clay and of loam, here and there, particularly at 'Isaac's Creek,' with marly concretions of strange irregular forms. The masses of these concretions are often of considerable thickness, though not extending far horizontally. The loam contains small broken pieces of ironstone (breccia) and is equally local. Below these the bed of pebbles lies. The bones found in the breecia are generally near the concretions, but not with them, or they oecur amongst the pebblcs. $\Lambda$ very interesting fact is the presence of univalve and bivalve shclls, which live still in the neighbouring water-holes, in the same beds, in which the bones are found. They are either intimately united with the bones by a marly cement, or they occur indepcndently. The greatest depth in which bones are found is 12 '. At 'Oaky Creek' we found them at the surface. Besides the bones of the gigantic animal, there are lower jaws and different parts of the skeleton of four other Kangaroos, many of them little different from the living ones, and probably identical with those of Wellington Valley. It secms to me that the conditions of life can have very little changed, as the same shells live still in similar water-holes. The want of food can 
I subjoin the analysis of bones and teeth of Diprotodon australis, from the beds of the rreeks, Darling Downs, by Walter Fligit, 1D.Sc., Assistant in the Department of Mincralogy of the British Museum.

\author{
"Laboratory, Mineral Department, British Mruseum, \\ 21st Jinuary, 1870.
}

"Iliar Sir,-I have the honour to lay before you a Report on the ehemical examination of a portion of a jiw-bone of the Diprotodon, which was received from Professor Owex at the end of last jear.

"The method, derised by M. Scubuek-Lestris, and deseribed by him in the 'Comptes Rendus,' vol. lxix. p. 1207, was cmployed in this inquiry, and the following analytieal determinations were made.

"1.2462 gramme of bone, treated with 108 cub. eentims. of hydrogen ehloride, of specifie grarity 1.04 (from 5 to $6^{\circ} 13.10 x$ ) , for twenty-two hours at ordinary temperatures, left a residue which, after haring been dried at $100^{\circ} \mathrm{C}$. till it ceased to lose weight, amounted to 0.1953 gramme, and, after ignition, to 0.1772 gramme. liy this treatment the ealcium phosphate, carbonate, and fluoride iron phosphate, \&e., as well as the 'soluble osscine ' of SCHEURER-KiESTXEk, are taken up by the aeid, and there remain 14.259 per eent. of insoluble mineral matter (eliefly siliea coloured red with iron peroxide) and $1 \cdot 452$ per ent. loss of weight by ignition, which in the memoir alluded to is taken to be insoluble osseine.

"The pounded bone, however, when heated did not change in eolour to ans great degree, nor emit the expeeted chriracteristic odour. A nitrogen determination was next made with the following result. $0 \cdot 541$ gramme of bone, heated with soda-lime, and the resulting platinum ammonium chloride ignited, gare 0.002 gramme of platinum. This amount of the metal eorresponds with 0.00028 gramme of nitrogen. Assuming that gelatine contains 17.5 fer cent. of nitrogen, the abore nitrogen corresponds with 0.0016 gramme of osseine, or 0.295 per cent.

"The bone thercfore eontains about $\frac{1}{4}$ per ecnt. of osseine altogether; and the loss of weight, amounting to 1.452 per ecnt., and regarded by Scheurer-hestner as due to insoluble osscine, must be aseribed to a further loss of water which was not expelled at the temperature of $100^{\circ} \mathrm{C}$.

" 1 s the amount of matter insoluble in hydrogen ehloride appeared unusually large (14.259 per cent.), it was thought that the aetion of the aeid might not hare been eomplete. In spite of my failing to detect phosphoric acid in this portion, I nerertheless thought it advisable to subject a further quantity of the bone to the action of a corresponding amount of aeid of the same strength for a longer period. 1.0468 gramme of bone digested with 90.5 eub. centims. of hydrogen ehloride for sixty-eight hours at ordinary temperatures, left a residue weighing 0.1418 gramme, which, when ignited, was redueed to 0.1341 gramme. In this ease, then, 12.81 per rent. of mineral matter remained undissolsed, whilst the loss by ignition amounted to 0.735 per ecnt.

"With a riew to determine the water present in this bone, 2.5046 grammes were heated for several hours, first at $100^{\circ} \mathrm{C}$. and after at $120^{\circ} \mathrm{C}$. ; the water lost amounted to 0.0932 gramme, or $3 \cdot 721$ per eent. After icnition and treatment with ammonium carbonate, the total loss was 0.1446 , or $5 \cdot 774$ per eent. Subtracting

scarcely be the cause of their disappearing, as floeks of sheep and eattle pasture orer their fossil remains. But as such an herbirore must hare required a large body of water for his sustenanee, the drainage of these plains, or the failing of those springs, the caleareous waters of whieh formed the eoneretions in the banks of the ereeks, has been probably the eause of their retiring to more farourable localities, and I should not be surprised if I found them in the tropieal interior, through which I am going to find my way to Pt. Essington."-Letter dated "SydncF, 10th July, 1s 4 ."

"Found about 6 feet below the surface in sinking a well."-Note by Mr. Marse.

" "In the 'red bank" of this [Isaae's] creck."-Note by Mr. Isauc.

** Found about $>$ feet belor the surface in sinking a well, lat. $137^{\prime} 50^{\prime \prime}$ S., long. $39^{\prime} 35^{\prime \prime}$ E.-Note br Mr.

F. G. Waterhorse.

$+1+$ "From 100 feet below the surface, in dirging a well, in the ralley of the Condamine Iirer."-Note by Ir. HoOD.

$\mp+$ "They were taken from a bed of sand and quartz eonglomerate, at a depth of about 5 feet." -Note by Mr. lierrett. 
from this number the amount of osseine present $(0.295$ per cent. $)$, there remain 5.479 per eent., the proportion of water present in the bone.

"It may be mentioned that the bone contained a considerable quantity of vivianite, which gave to portions of its interior a dull blue colour.

"Analysis of Substances filling cavity of tooth of Diprotodon [Pulp-cavity of lower incisor,

Plate XXVII. fig. 5, ̈̈.-R. 0.].

"The nitrogen in a portion of the abore, which had been dried for many hours at $1 \mathrm{C} 0^{\circ}$, was determined by the usual method.

" 0.9814 gramme of substance, heated with soda-lime, gave 0.0071 gramme platinum, which corresponds with 0.001 gramme nitrogen.

"Regarding this nitrogen as present in the form of osseine, and employing the number obtained by FremY $(17.5$ per cent.) in his analysis of the gelatine of beef-bone as correctly represcnting the percentage of nitrogen in osseine, we find the substance from this fossil tooth to contain 0.58 per cent. of osseine.

"When heated in a tube it became slightls darker in colour, and emitted a faint empyreumatic odour.

"It was found to be composed of

Iuch carbonate lime,

Some phosphate lime,

Ifuch silica, iron oxide, \&c.,

Some water not remorable at $100^{\circ}$,

The small portion of organic matter alrcady mentioned.

"I am, dear Sir,

"Your obedient Serrant,

"To Professor Story-Mraskelyxe, "Walter Flighr."

Keeper of the Mineral Department, British Yuseum."

Table of Adueasurejents.

Skull.

Length from occipital condyle to fore end of premaxillary

Breadth betwcen outer sides of zygomata.................. 160

Depth to lower border of mandible at the orbit .............. $110 \quad 10$

Depth to outlet of socket of upper $m 1$, at the orbit.............. 100

Breadth of occiput........................... 110

From lower border of foramen magnum to middle of superoccipital ridge . $\quad \begin{array}{llll}0 & 9 & 9\end{array}$

Breadth of cranium at middle of temporal fossa and at the level of the

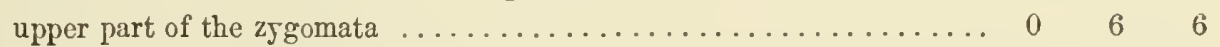

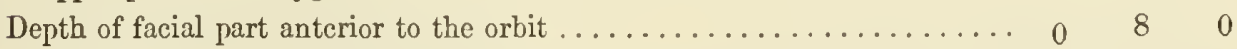

Depth of facial part at forc end of nasals.................. $010 \quad 10$

Depth of zygoma at the lower cnd of the malomaxillary suture ........ 0 4 40

Length of mandible from back of eondyle to outlet of incisive sockets $\ldots . .26400$

Depth from summit of coracoid process $\ldots \ldots \ldots \ldots \ldots \ldots \ldots \ldots \ldots \ldots 1140$

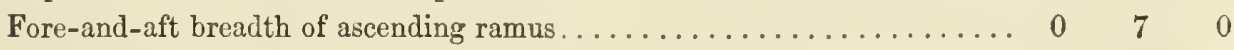

Depth of horizontal ramus at the socket of $m 1 \ldots \ldots \ldots \ldots \ldots \ldots 00450$

Length of symphysis ........................... $0.6 \%$

Greatest depth of symphysis ....................... 0 . $3{ }^{6}$

Length of upper incisive alveolar series $\ldots \ldots \ldots \ldots \ldots \ldots \ldots \ldots \ldots 00446 \ldots$

Length of upper molar alveolar series $\ldots \ldots \ldots \ldots \ldots \ldots \ldots \ldots \ldots, 0 \quad 8 \quad 6$

Length of lower molar alreolar series . .................. 0 90 


\section{Vertebre.}

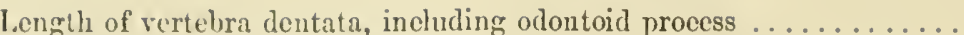

Height of rertebra dentata, inchding odontoid process $\ldots \ldots \ldots \ldots \ldots \ldots 0048 \quad 4$

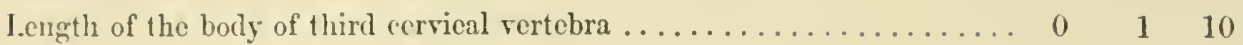

Brealth of the body of third cervical rertebra $\ldots \ldots \ldots \ldots \ldots \ldots \ldots, 0 \quad 4 \quad 3$

Height of third eerrieal rertebra ....................... $088^{0}$

Length of the body of an anterior dorsal vertebra $\ldots \ldots \ldots \ldots \ldots \ldots \ldots 0 \quad 2 \quad 2 \quad 0$

Breadth of the body of an anterior dorsal vertebra ............. $04 \quad 4 \quad 10$

Height of the same vertebra ..................... $010 \quad 10$

Length of the body of an anterior lumbar vertebra .............. $042^{2} 4$

Length of tho body of a posterior lumbar rertebra ............... 00303

Breadth of tho body of a posterior lumbar vertebra............. $0 \quad 5 \quad 0$

Longitudinal extent of sacrum ...................... $06^{6} \quad 0$

\section{Scapula.}

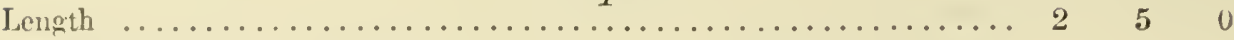

Breadth, across the humeral end $\ldots \ldots \ldots \ldots \ldots \ldots \ldots \ldots \ldots \ldots \ldots 120 . \ldots$

Breadth, of base, at subsidence of spine $\ldots \ldots \ldots \ldots \ldots \ldots \ldots \ldots \ldots 6060$

\section{Humerus.}

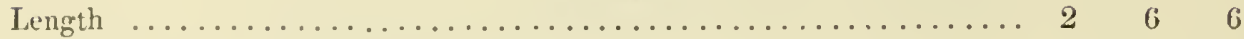

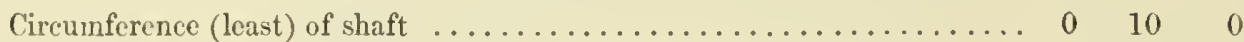

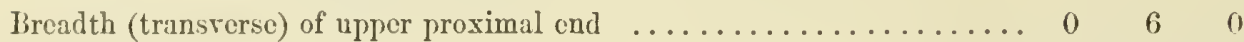

Breadth (transrerse) of lewer end . . . . . . . . . . . . . . . . . 0 . 9

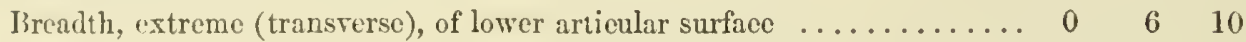

Breadth (fore-and-aft) of radial condyle $\ldots \ldots \ldots \ldots \ldots \ldots \ldots \ldots \ldots, 0 \ldots 30 \ldots$

Breadth (fore-and-aft) of nlnar condyle .................... 0 . 340

Breadth (fore-and-aft) of intermediate trochlea ............... $0{ }^{1} 11$

Pelvis.

Breadth across fore part of ilia ...................... $288^{2} 0$

Breadth aeross antero-inferior iliae spines $\ldots \ldots \ldots \ldots \ldots \ldots \ldots \ldots \ldots, 1 \quad 9 . \ldots$

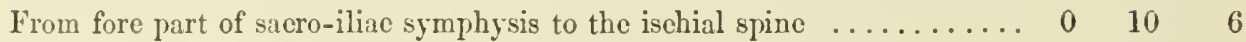

From hind part of sacro-iliae symphysis to the ischial spine ........ 040

Breadth between ischial spines...................... 0 6 6

\section{Femur.}

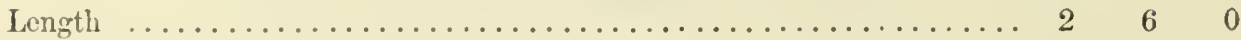

Circumference (least) of shaft $\ldots \ldots \ldots \ldots \ldots \ldots \ldots \ldots \ldots \ldots \ldots, 100,0 . \ldots$

Breadth (transrerse) of upper end $\ldots \ldots \ldots \ldots \ldots \ldots \ldots \ldots \ldots \ldots \ldots 1{ }^{2}{ }_{6}$

Breadth (extreme transverse) of lower end ................... $088_{6}$

Circumference of head $\ldots \ldots \ldots \ldots \ldots \ldots \ldots \ldots \ldots \ldots \ldots \ldots \ldots, 2 \quad 0$

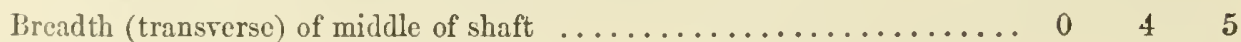

Breadth (fore-and-aft) of middle of shaft $\ldots \ldots \ldots \ldots \ldots \ldots \ldots \ldots, 0 \quad 2 \quad 6 \ldots$

Breadth (fore-and-aft) of inner condyle $\ldots \ldots \ldots \ldots \ldots \ldots \ldots \ldots \ldots \ldots 0,7 \quad 9$

Titia.

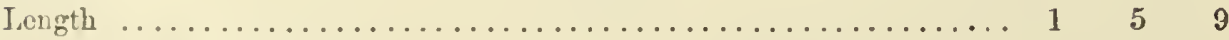

Cireumference (least) of shaft $\ldots \ldots \ldots \ldots \ldots \ldots \ldots \ldots \ldots \ldots \ldots \ldots, 0 . \ldots, 8 \ldots \ldots$

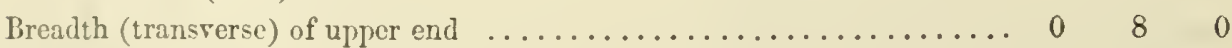

Breadth (greatest) of lower end $\ldots \ldots \ldots \ldots \ldots \ldots \ldots \ldots \ldots \ldots \ldots, 0 \ldots 50$ 


\section{Description of the Plates.}

\section{PLATE XIX.}

Fig. 1. Side view of skull of Diprotodon australis:-one-fifth nat. size.

Fig. 2. Front view of skull of Diprotodon australis:-one-fifth nat. size.

Fig. 3. Back view of skull of Diprotodon australis:-one-fifth nat. size.

Fig. 4. Proportions of malar ${ }_{26}$ ) and squamosal $\left.{ }_{27}\right)$ forming glenoid cavity:-one-fifth nat. size.

Fig. 5. Side view of skull, in outline, of Macropus laniger:-one-fifth nat. size.

\section{PLATE XX.}

Fig. 1. Outer side of first incisor, upper jaw :-nat. size.

Fig. 2. Inner side of first incisor, upper jaw :-nat. size.

[An extent of an inch of the tooth is wanting at the place of fracture.]

Fig. 3. Outer or enamelled side of working extremity of a first incisor.

Fig. 4. Outer or enamelled side of working extremity of a first incisor from another individual.

Fig. 5. Section, vertical and transverse, of premaxillary alveoli, with the first incisors, $i 1$, in situ: $i 2$, end of the socket of the second incisor; $i 3$, part of that of the third incisor.

Fig. 6. Basal or inserted end of first incisor; the margin mutilated.

Fig. 7. Basal or inserted end of second incisor.

All the figures are of the natural size.

\section{PLATE XXI.}

Fig. 1. Outer side riew of the right upper molars, in situ, of probably a female Diprotodon.

Fig. 2. Grinding-surface of ditto.

Fig. 3. The three last molars of another Diprotodon.

Fig. 4. Grinding-surface of crown of last molar $(m 3)$ of a larger, probably male, Diprotodon.

Fig. 5. Front view of the same tooth.

Fig. 6. Back view of the same tonth.

All the figures are of the natural size. .

\section{PLATE XXII.}

Fig. 1. Outer side view of the right upper molars, in situ, of a large, probably male. Diprotodon.

Fig. 2. Grinding-surface of ditto, with part of bony palate.

Fig. 3. Hind surface of last molar $(m 3)$ of another Diprotodon.

Fig. 4. Front surface of the same tooth.

All the figures are of the natural size. 


\section{PLATE XXIII.}

lig. 1. Outside view of last upper molar $(m 3)$ of a small, probably female, Diprotodon. lig. 2. Outside view of last upper molar $(m 3)$ of a larger, probably male, Diprotodon.

Fig. 3. Sockets and ends of roots of penultimate and last upper molars.

Fig. 4. Outside view of lower incisor [an extent of an incl is wanting at the place of fracture].

Fig. 5. Working surface of exposed end of lower incisor.

Fig. 6. 'Transrerse section at its emergence from the socket.

Fig. 7. Side view of second upper incisor $(i 2)$.

Fig. S. Working surface of the same tooth.

\section{PIA'TE XXIV.}

Molar teeth of the lower jaw.

Fig. 1. Outer side view of second molar $(d 4)$ of a young Iliprotodon.

Fig. 2. Working surface of second molar $(d 4)$ of a young Diprotodon.

Fig. 3. Working surface of second molar of an older, probably female, Diprotodon.

Fig. 4. Working surface of second molar of an old, probably male, Diprotodon.

Fig. 5. Outer side view of third molar $(m 1)$ of a young Iiprotodon.

Fig. 6. Working surface of third molar ( $m 1$ ) of a young Diprotodon.

Fig. 7. Working surface of third molar $(m 1)$ of an older, probably female, Dimrotodon. Fig. S. Working surface of third molar $(m 1)$ of an old, probably male, Diprotodon.

Fig. 9. Outer side view of fourth molar $(m 2)$ of a young Diprotodon.

Fig. 10. Working surface of fourth molar $(m 2)$ of a young Diprotodon.

Fin. 11. Working surface of fourth molar $(m 2)$ of mature, probably male, Diprotodon.

Firg. 12. Outer side view of crown of germ of fifth molar of a young Diprotodon.

Fig. 13. Front view of fifth molar of a mature Diprotodon.

Fig. 14. Working surface of penultimate lower molar of Macropus Atlas.

Fig. 15. Working surface of penultimate lower molar of a Malayan Tapir.

Fig. 16. Working surface of crown of incomplete fifth molar of a young Diprotodon.

Fig. 17. Working surface of penultimate molar $(m 2)$ of an old Diprotodon.

Fig. 18. Working surface of last molar ( $m 3$ ) of an old Diprotodon.

Figures 1, 2, 5, 6, 9, 10, 12, 16 are from the same individual.

All the figures are of the natural size.

\section{PLATE XXV.}

Fig. 1. Portion of right mandibular ramus with last two molars.

Fig. 2. Hinder fractured end of the same, showing inflected angle, $e$, of a mature Diprotodon. 


\section{PLATE XXVI.}

Fig. 1. Outside view of anterior part of mandible and teeth $(i 1, d 4, m 1)$ of an immature Diprotodon: the first molar $(d 3)$ is given in outline. $1 a$, section of incisor, $\ddot{i}$.

Fig. 2. Inside view of anterior part of the same mandible and teeth $(i 1, d 3$ restored in outline, $d 4, m 1)$.

\section{PLATE XXVII.}

Fig. 1. Section of upper molars $(m 1, m 2, m 3)$ of a mature, not old, Diprotodon; nat. size.

Fig. 2. Inside view of mandible and teeth of ditto: reduced to one-sixth.

Fig. 3. Back view of mandibular condyle: reduced to one-sixth.

Fig. 4. Front view of ditto: reduced to one-sixth.

Fig. 5. Section of anterior part of mandible and incisor tusk of an immature Ihiprotodon; nat. size.

\section{PLATE XXVIII.}

Fig. 1. Axis, or vertebra dentata:-nat. size.

Fig. 2. Portion of atlas vertebra:-nat size.

\section{PLATE XXIX.}

Fig. 1. Front view of axis.

Fig. 2. Under view of axis.

Fig. 3. Back view of axis.

Fig. 4. Back view of third cervical vertebra.

Fig. 5. Back view of an anterior dorsal vertebra.

Fig. 6. Side view of the same dorsal vertebra.

Fig. 7. Side view of a succeeding dorsal vertebra.

Fig. 8. Back view of the same vertebra.

Fig. 9. Side view of the body of a lumbar vertebra.

F'ig. 10. Back view of ditto.

Fig. 11. Under view of ditto.

Fig. 12. Epiphyses of the body of a cervical vertebra: $a$, edge- or side-view.

Fig. 13. Epiphyses of the body of a lumbar vertebra: a, edge-view.

All the figures are one-third the natural size.

\section{PLATE XXX.}

Fig. 1. Inner or subscapular surface of the left scapula.

Fig. 2. Outer surface or "dorsum" of the left scapula.

Fig. 3. Articular end, with glenoid cavity of the left scapula.

One-third the nat size. 


\section{PIATE XXXI.}

Fig. 1. Back view of left humerus.

Fig. 2. Front view of left humerus.

Fig. 3. Proximal end of left humerus.

Fig. 4. Distal end of left humerus.

Fig. 5. Inner side view of clistal third of a right humerus.

One-third the nat. size.

\section{PLA'IE XXXII.}

Fig. 1. Under or "hæmal" view of the pelvis.

Fig. 2. Upper or "neural" view of the sacrum and right half of the pelvis.

Fig. 3. Front view of the sacrum.

Fig. 4. Acetabular carity. [See 'Admeasurements' in text for scale of reduction.]

\section{PLATE XXXIII.}

Fig. 1. Front view of femur.

Fig. 2. Outside view of femur.

Fig. 3. Section of middle of shaft of femur.

Fig. 4. Lower articular end of femur.

Fig. 5. Inside view of lower end of femur.

One-third nat. size.

\section{PLATE XXXIV.}

Fig. 1. Hind view of femur.

Fig. 2. Front riew of tibia.

Fig. 3. Outside view of tibia.

Fig. 4. Upper end of tibia.

Fig. 5. Lower end of tibia.

One-third nat. size.

\section{Plate XXXV.}

Restoration of the skeleton of Diprotodon australis:-one-twelfth nat. size.

[Amongst the indigenous Australian plants introduced in this Plate are the grass-tree (.Yanthorrhea), and the Cycadeous genus Macrogamia.] 


\title{
Suborder DIPRO'TODONTIA.
}

\author{
Family GRAVIGRADA.
}

\section{Genus Nototherium.}

$\S 1$. Introduction.-THE recognition of the genus which is the subject of the present Section was subsequent to that of Diprotodon. So much of the molar teeth as remained in the mutilated mandibles* transmitted to me, in 1842, by Sir Thouras Mirchell, C.B., from the bed of the Condamine River, indicated their transversely two-ridged character, and suggested at first sight that the fossils might belong to some smaller species of Diprotodon. Closer scrutiny, however, showed them to be parts of full-grown animals, and that they could not be the young of any larger extinct Herbivore.

Moreover, sufficient of the symphysial or anterior part of one of the mandibular fossils remained to demonstrate the absence of any incisor developed as a tusk or defensive weapon $\phi$, such as coexisted with the bilophodont molar teeth in the lower jaw of Diprotodon. The small portions of the enamel on the remaining bases of the molars (for the crowns of all had been more or less broken away) showed a smoother surface than that at the corresponding parts of the molars in Diprotodon. I was therefore led to recognize with much interest, in the fossils transmitted by my esteemed friend on his return to his duties as Surveyor General of the Colony of Australia, after the publication of the work $\$$ containing the first notice of Diprotodon, evidence of another genus of extinct herbivorous marsupials, second only in bulk to that first discorered, and I proposed for the smaller genus the name of Nototherium $\oint$.

Further comparison of the mandibular fossils referable to such genus indicated them to have belonged to two species, to one of which (Woodcut, fig. 1, p. 250) I was glad to attach the name of its discoverer (Nototherium Mitchelli); the other I proposed to call Nototherium inerme, as it afforded evidence of the absence of large incisor tusks. Whether any, or of what proportion, or in what number, incisors might hare been present in the missing fore part of the fractured symphysis could not, of course, be determined; that which remained only gare the negative evidence as to incisors of the relative size and shape and persistent growth characterizing the Diprotodon $\|$.

* Owes, "Report on the Extinet Mammals of Australia, \&e.," in Reports of the British Association for the Advaneement of Seienee for 1844,8 ro, p. 223 , plates $3 \& 4$.

+ Ib. p. 231.

¥ 'Three Expeditions into the Interior of Eastern Australia,’ vols. i. \& ii. 8ro, 1838.

$\S$ vóros, south, $\theta$ npiov, beast, 'Catalogue of the Fossil Mammalia and Ares in the Museum of the Royal College of Surgeons,' London, 4 to, 1845, p. 314.

|| "The lower fraetured surfaee exposes the dental eanal extending obliquely from without inwards below the soekets of the anterior molars and then bifureating; the outer and larger division terminating at the mental foramen, and an inner and smaller one extending forwards nearer the symphysis, but without any trace of a large ineisor " (op. cit. p. 319). 
In the year $1845 \mathrm{I}$ received from the accomplished and determined, but unfortunate explorer of Australia, Ludwig Leichinad, a fossil mandibular ramus of a young Notothere, showing the germ of an incisor which, in adult specimens subsequently acquired, proved to be a tooth of temporary growth with crown and fang distinct, as in Macropus,

Fig. 1.

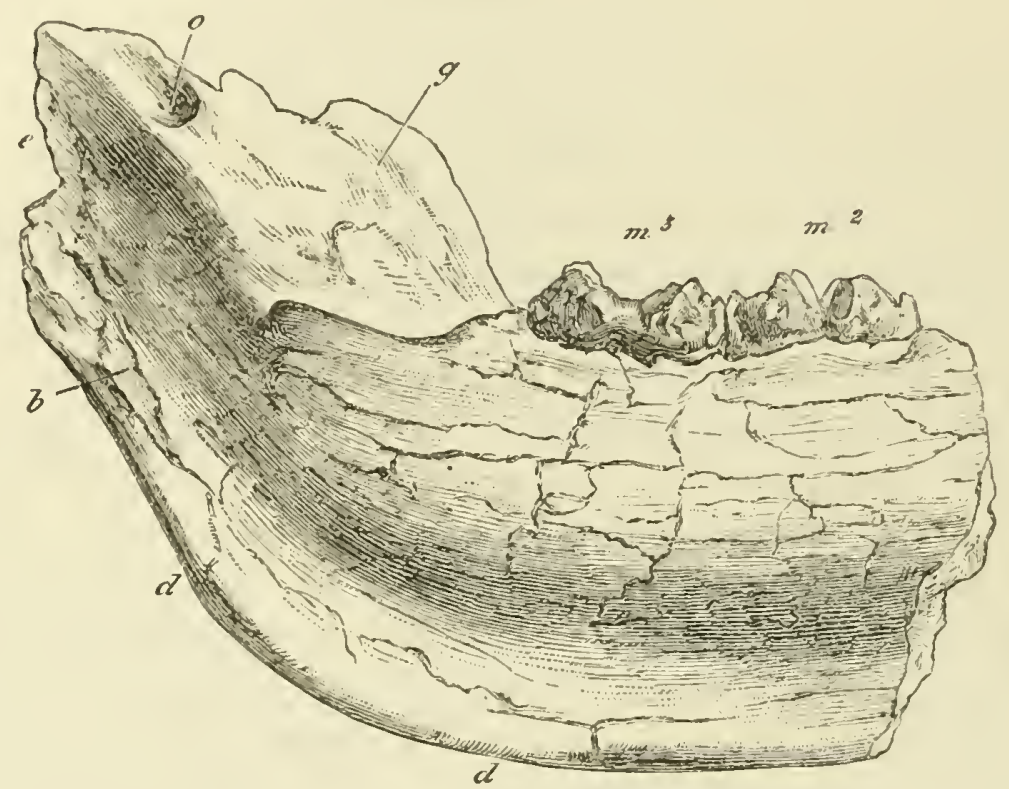

Inner side of hind half of left mandibular ramus of Nototherium Nitchelli ( $\frac{1}{2}$ nat. size), " On Extinct Mammals of Australia," Reports of the British Association for the Adrancement of Science, rol. for 1844, pl, iv. fig. 3.

as will be shown in a subsequent part of the present section. One of these adult specimens included both rami, contributing satisfactory additional evidence of the characters of Nototherium Mitchelli. It was part of the series of fossils collected at King's Creek, Darling Downs, in 1845, and transmitted to London by Mr. Bexjanis Bord, where it was purchased by the Trustees of the British Museum, along with the cranium and lower jaw and other instructive parts of the skeleton of Diprotodon, described and figured in the preceding section, pp. 189-248.

A portion of maxilla with upper molar teeth of Nototherium Mitchelli also formed part of this purchased series.

In 1856 there was discorered in the same locality the skull, wanting the lower jaw, of Nototherium Mitchelli. 'This unique and valuable specimen came into the possession of Frederic Netille Isaic, Esq., by whom it was presented to the Australian Museum, then in course of formation in Sydney, New South Wales.

Willidis Silarpe Maclear, Esq., F.R.S., originator of the Quinary System and author of works and monographs which gare great stimulus to the progress of philosophic zoology, published a notice of this remarkable fossil, naming it Zygomaturus trilobus, in a "Report on Donations to the Australian Museum during August 1857," which appeared in a Sydney newspaper of that date. 
Photographs of the skull, made by the direction of the then Governor of Australia, Sir William Denison, K.C.B., were transmitted to Sir Roderick I. Murchison, Bart., P.G.S., for presentation to the Geological Society of London. These photographs were placed in my hands, with the request to report upon them*. I had some time previously received from my friend George Benvetт, Esq., F.L.S., of Sydney, outline drawings of the same skull, from which materials I recognized it to belong to the genus Nototherium, and in all probability to the larger species, $N$. Mitchelli, of which the lower jaw, from the same formation and locality, had been previously received and added to the British Museum. I had written, on receipt of the 'Sydney Morning Herald' containing Mr. Maclear's Report and Notice of his Zygomaturus, to the author, suggesting the probability that his subject might prove to belong to the Nototherium, and expressing the wish for the opportunity of making the requisite comparisons by means of a cast of the skull ; and I received a friendly and favourable reply in a letter dated 9th March 1858, in which Mr. W. S. MACLEAY writes :- " Every month a list of donations received is published in our local newspapers, and it is true that in one of such monthly lists I lately wrote on this 'Zygomaturus' a few words which you appear to have seen. They are, however, principally intended to please the donor, and to induce him to send us more specimens. The name, from the 'tail' or process of the zygoma, was given on the principle we adopted of cataloguing every thing, were it only for the purposes of correspondence and exchange."- " You ask for a cast of the skull of the Zygomaturus, and I am glad to think that, long ere you receive this letter, you will have had in your hands a cast that Mr. WANT, a Trustee of our Museum, took home for the British Museum."

The characters afforded by this cast and by the outlines and photographs of the original specimen dispelled all doubt, in my mind, as to the skull and upper jaw and teeth belonging to the same species as the lower jaw of Nototherium Mitchelli, also discovered in the bed of King's Creek, Darling Downs.

But there were many points in relation to sutures and foramina which could only be determined by inspection of the original specimen. It could scarcely be expected, however, that a donation of such unique rarity would be despatched for that purpose from the Antipodes. But the Trustees of the Australian Museum have kindly directed photographs, on a larger scale than those originally sent by Governor Denison, to be prepared and transmitted to me; and they have also liberally caused casts to be made of the principal specimens of bones and teeth of Nototherium subsequently acquired for the Australion Museum, which casts, with photographs of the originals, have likewise safely come to hand.

These and other evidences of the present genus, received at different times from various sources and localities in the Australian continent, will be duly acknowledged in the descriptions of such about to be given; and I proceed to give the results of the examination of the evidences at my command of the cranial structure of Nototherium.

$\S 2$. Skull.-The singular shape and proportions of this part of the skeleton will be

* Quarterly Journal of the Geological Society, vol. xv. 1859, p. 168. 
recognized at a glance of Plates XXXVI. and XXXVII. 'The occipital region (Plate XXXVTI. fig. 1) represents the upper half of a transverse ellipse, being arched above; the straight line, or section, below is interrupted by the paroccipitals $(4,4)$, which descend on each side of the condyles $(2,2)$, albout 2 inches below the level of the foramen magnum, 0 ; the mastoids $(8,8)$ and squamosals $(27,27)$ bound the region externally. The breadth of the occiput at its base is 13 inches, the leight at the mid line 7 inches. The surface inclines forward (Plate XXXVI. fig. 1, 3) especially at its mid third (Plate XXXVII. figs. 1 \& 2, 3), but becomes vertical, or nearly so, as it arches outward. The surface is broadly undulate transversely, being concave at the nicl third, convex at the two outer thirds. Nearly the whole of this surface is roughened by ridges and insertional impressions of nuclial muscles, the sharpest and most prominent of which is the medial vertical one (ib. figs. $1 \& 2,3$ ), extending from near the upper border of the foramen magnum to the transrerse ridge bounding the occiput superiorly: this ridge describes a low arch transversely; lengthwise it extends toward the upper surface of the cranium, describing an open angle with the truncate apex forward (ib. fig. 2). 'The condyles form the lower two thirds of the foramen magnum, save at the interval of seven lines between their lower ends (ib. fig. 3, 2, 2). From these they direrge as they rise with a vertical convexity, greatest at the lower half of the condyle, and more gradual toward the upper and outer end. The transwerse convexity is more regular, and affects the hinder, outer, and under parts of the joint. 'The length of each condyle is 2 inches 7 lines, the extreme breadth is 1 inch 3 lines, the distance between the upper ends is 4 inches 6 lines. 'The surface towards the foramen is almost flat in the least diameter, gently concave or rather undulating lengthwise. 'The plane of the occipital foramen is vertical; its shape is a full ellipse, with the least diameter transverse; this gives 1 inch 8 lines; the long diameter is 2 inches.

A broad groove or channel, directed from below upward and outward, divides the condyle from the base of the paroccipital (4). This broad process inclines forward before it descends, its hinder plane being anterior to that of the convex part of the occiput above. 'The obtuse termination of the process is continued, with a curve upward and outward, by a thick and rugged ridge into the mastoid process ( 8 ), which, with the squamosal, bounds the occipital region laterally. The outer margin rises from the mastoid with a slight convexity for four inches before curving inward to the upper arch of the occipital ridge. A fracture of the outer table on the right side of the occiput exposes the extension to this part of the cranial walls of the air-cells continuous with larger cavities in advance.

The base of the huge zygomatic arch is continued (Plate XXXVI. fig. 1, 2-), with a slight sinking inward, from the whole vertical extent of the mastoid ridge and fiom a part of the superoccipital ; the lower end being formed by the tympanic, which is defined by a slight notch from the end of the mastoid process.

The parietal walls (il. $z$ ) extend from without inward and forward. From the short alisphenoid the parietal plate arches upward, with a strong convexity forward at its lower half (Plate XXXVII. fig. 3, $;$ ); this subrertical part of the cranial walls forms the hind boundary of the vast subquadrate oblong vacuity combining orbit and temporal 
fossa (Plate XXXVII. figs. $2 \& 3, t$ ). The parietal or parieto-temporal wall (Plate XXXVI. fig. 1,7 ) is divided from the occipital plane (Plate XXXVII. fig. 2, s) by the superior or superoccipital arched ridge; it is divided from its fellow or opposite wall above by a flattened tract about an inch broad (ib. fig. 2, 7), near the superoccipital (ib. fig. 2,3 ), but which expands as it advances from the parietal (7) upon the frontal (11) region. The parieto-frontal part of the cranium forms less than the middle third of the breadth of the entire skull as here completed by the enormous zygomatic arches. The frontal roof of the cranium, retaining its flatness transversely, gains a breadth of five inches, with a slight downward slope in profile (Plate XXXVI. fig. 1), and then (ib. 11) more abruptly arches down to the origin of the nasals (ib. ${ }_{15}$ ), an arch being continued outward, on each side of the naso-maxillary pedicle, to the tuberosity $(s)$ representing the antorbital or lacrymal process. There is a transverse depression above the origin of the nasal bone (Plate XXXVII. fig. 2, 15). The vertically conrex outswellings of the frontal above and alongside this depression indicate the enormous air-sinuses within. 'The inner side or walls of the orbito-temporal vacuities sink sheer from the upper parieto-frontal tract to the outswelling of the maxillary molar alveoli (ib. ${ }_{21}$ ), with a slight inclination inward. The greatest posterior depth of this cranial precipice is $6 \frac{1}{2}$ inches.

At the junction of the alisphenoid with the parietal, near the bottom of the back wall, is a tuberosity. The diameter of the sphenoido-parietal part of the cranium is $4 \frac{1}{2}$ inches; that of the skull at the corresponding part across, or including the zygomatic arches, is 16 inches! 'The cranium proper, from this singular constriction, gradually expands as it advances to the superorbital part of the frontals. If the cranial cavity concurred with its outer walls in shape it would be triradiate, two corridors extending along the transversely extended and antero-posteriorly contracted occipital part, and a third passage running forward from the mid line toward the face. But the singular departure in the outer walls from the normal shape of the brain-case is mainly due to a vast diploë of air-cells. The proper cerebral carity makes no outward show, and it is insignificantly small in proportion to the entire skull.

Viewed from below (as in Plate XXXVII. fig. 3), the condyles (2,2) are divided by a deep notch ; their lower ends descend a little below the level of the basioccipital ( 1 ). This presents a rugged triangular tract in advance of the foramen, the apex being continuous with a sharp ridge longitudinally bisecting the surface of the basisphenoid. On each side of the tuberous tract and ridge is a wide and moderately deep depression, extending from the lower end of the occipital condyles forward to the pterygoid plates or posterior aperture of the nares. These "basioccipito-sphenoidal depressions" are bounded laterally by a small tuberosity, by the inner surfaces of the occipito-petrous prominence, and by a ridge inclining mesiad to the hind part of the base of the pterygoid plate.

The basioccipito-sphenoidal part of the "basis cranii" is $3 \frac{1}{2}$ inches in length, and 3 inches in breadth posteriorly. Its plane forms with that of the "basis faciei," or bony palate, lengthwise, an angle of $130^{\circ}$; the basis cranii sinking, the basis faciei rising, as they advance. 
The fore part of the tympano-mastoid ridge (Plate XXXVI. fig. 1, 8, 12) appears to form the smooth flat hind wall of the articular surface for the mandibular condyle, unless the squamosal should abut against the mastoid beneath the petrotympanic: the cranial bones of this part are evidently modified by original antero-posterior compression. This postglenoid process or wall is $2 \frac{1}{2}$ inches transversely, and probably was of great vertical extent when entire; it is directed from within outward and rather forward. The articular surface has the same clirection, and consists of a hind groove (Plate XXXVII. fig. 3, g) and a front bar, i.e. it is divided from before backward into a strong convexity and a decp concarity; both are slighly concave transversely; in that direction the extent of the surface is $3 \frac{1}{2}$ inches; from before backwards it measures $1 \frac{1}{2}$ inch. The malar $(26)$ descends to bound the outer part of the articular bar, to which it contributes a share of the articular surface. The outer end of the groove opens freely upon the base of the zygoma, which it slightly indents; the inner end is blocked by the descending part of the rugged petrosal.

The palatal part of the premaxillaries (Plate XXXVII. fig. $3,{ }_{22^{*}}$ ) is feeblyconcave, 1 inch 5 lines across at the interval between the sockets of $i_{2}$ and $i_{3}$, then contracting to a breadth of 1 inch at the middle of the diastema (ib. $d$ ) between the incisors and molars: the length of this toothless tract is 2 inches 9 lines in a straight line. It is formed by a well-defined ridge gently curved inward until near the socket of the anterior molar, which part of the alveolar tract bends abruptly downward, 9 or 10 lines, below the ridge (Plate XXXVI. fig. 1, ${ }_{21}, d_{3}$ ). The palate is deep transversely between the right and left anterior molars (Plate XXXVII. fig. $3, d_{3,21^{\circ}}$ ), their interval in a straight line being 1 inch 10 lines. As the palate expands its transverse concavity decreases; its greatest breadth between the penultimate molars $\left(m_{2}\right)$ is 2 inches 9 lines. Length wise the intermolar part of the bony palate (ib. $\left.20^{*}, 21^{*}\right)$ is, anteriorly, gently concave, then convex, and again concave; it extends about an inch beyond the last molars, is bounded behind by a thick low rough ridge, a median forward continuation of which divides the back part of the bony palate into two shallow rough depressions or channels leading outwards to behind the last alveoli. 'The bony palate appears to be entire; its length from the interspace of the alveoli of the front incisors $\left(22^{*}\right)$ is 11 inches 6 lines, from between the alveoli of the front molars to the hind border it is 7 inches 6 lines.

'The huge and extraordinary zygomatic arches (Plates XXXVI. \& XXXVII. ${ }_{27},{ }_{26},{ }_{21}$ ) extend straight forward in parallel lines for more than half the length of the entire skull (Plate XXXVII. figs. 2 \& 3), then bend abruptly downward and arch transversely inward to abut against the middle third of the alveolar plates of the maxillaries, a thick

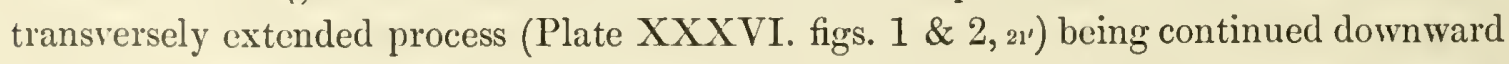
from the angle of the inward curvature. From the hinder origin or " pier" ${ }_{27}$ ) each arch gains, as it advances, a vertical extent of 4 inches 3 lines; then contracts to one of 3 inches, again expanding slightly in the vertical direction, and greatly in the transverse one, before the inward twist to form the maxillary pier or abutment. The inner surface of the arch is smooth and slightly concave; the outer surface is rough, convex, and outswells 
into two large protuberances, one at the part $(e)$ anterior to that supporting the joint for the lower jaw, the other and larger (fig. $2, f$ ) at the angle formed by the down-bending of the arch to the orbital floor; the latter is most prominent and best defined. The floor of the orbit (ib. fig. 1, r) is of comparatively small extent, limited to the inner or mesial half of the inwardly bent part of the zygoma, of a triangular form, indicative, with the inner orbital concavity leading to the antorbital process $(s)$, of the small relative size and low position of the eyeball; with this position the foramen opticum corresponds. The extent of the anterior inwardly bent part of the zygoma is 5 inches. From the lower angle of the bend is continued downward the process $\left(21^{\prime}\right)$ for an extent of 3 inches, with a twist, making its sides look forward and backward, its borders outward and inward. Its breadth is $2 \frac{1}{2}$ inches, its termination subtruncate; from its inner border to the alveolar part of the maxillary, between the penultimate and antepenultimate molars, is 3 inches 6 lines, giving the span of the arch extending transversely from the anterior root of the zygoma to the masseteric process, the end of which reaches below the level of the upper grindingteeth (Plate XXXVI. fig. 1, 21'). The anterior root of the zygoma is three-sided: one, the upper horizontal surface, forming the floor of the orbit, has a fore-and-aft extent of 2 inches; the anterior and posterior surfaces converge to a thick lower border, which is above the interval between $m_{1}$ and $m_{2}$, terminating about 10 lines above the outlets of the sockets of those teeth. The antorbital foramen (ib. ${ }_{21}$ ) is vertically elliptic, 10 lines in long and 6 in short diameter, situated 1 inch 9 lines in advance of the orbit, and about 2 inches above the outlet of the anterior molar $\left(d_{3}\right)$. The antero-posterior extent of the maxillary alveoli, in a straight line, is $\tau$ inches; their outlets describe a gentle convexity downward as well as outward, the right and left series diverging from the anterior pair to the fourth and incurving slightly at the last pair (Plate XXXVII. fig. $3, d_{3}, m_{3}$ ). The outer roots of the contained molars cause corresponding prominences of the sockets, giving an undulatory surface to that part of the upper jaw (Plate XXXVI. fig. 1). This extends, perhaps in conjunction with the palatine bone, about an inch beyond the last molar, with an upward slope.

The breadth of the hind part of the palate here is 3 inches 3 lines. The posterior nares form a triangular aperture, with the base above the palate, 2 inches 3 lines broad, thence contracting as it extends obliquely upward and backward to a point at the fore end of the basisphenoid ridge; the length of the aperture from this point is 4 inches 6 lines. The aperture is bounded laterally by the pterygoid plates.

If, as in the skulls of Mammals generally, we regard the part anterior to the orbits as the facial division, which is often the longest, the corresponding part in Nototherium offers the strangest and most anomalous form and proportions in the mammalian class. It looks like a mere pedunculate appendage to the rest of the skull. Instead of tapering to the end, as is usually the case, it expands forward from its base of attachment both vertically (Plate XXXVI. fig. 1, ${ }_{15}, i_{1}$ ) and transversely (Plate XXXVII. fig. 2, ${ }_{15}, 22^{\prime \prime}$. The vertical diameter at the base, or from the depression at the root of the nose to the fore part of the maxillary alveolar process, is 4 inches 9 lines; the same diameter at the 
fore end, from the tips of the nasal bones (15) to the first incisive alveoli $\left(i_{1}\right)$, is 6 inches 6 lines. The breadth of the face at the outsides of the antorbital foramina is 2 inches 6 lines; the same dimension across the nasal processes of the premaxillaries (22") is 6 inches. The length of the facial part of the skull from the antorbital foramen (Plate XXXVI. fig. $\left.1,{ }_{21}\right)$ to the fore part of the premaxillary $\left(22^{\prime}\right)$ is 5 inches 8 lines.

'The nasal bones (15) appear to expand as they advance, chiefly transversely, for four fifths of their extent, then abruptly contract, from their outer borders, to terminate in a slightly deflected obtuse apex: their mesial suture appears to lie in a longitudinal chink or depression at the anterior third (Plate XXXVII. fig. 2, ${ }_{15}$ ), but the chink does not extend to the conjoined apices. The sides of the most expanded part of the external uostril, contributed by the premaxillaries, swell into low and large, rather rough, tuberosities $\left(22^{\prime \prime}\right)$; between these the upper surface is almost flat, like a platform.

The premaxillaries (22), which unite with the nasals (15), as in Phascolarctos (Plate XXXVI. fig. 3) and Phascolomys (ib. fig. 4), send their nasal processes upward, outward, and forward, where they expand and terminate, each in a tuberosity which projects below and a little in advance of the one above mentioned. These tuberosities, with the mesial prominence of the apices of the nasals, give a trilobate character to the upper boundary of the external bony nostril in Nototherium (fig. 2), exaggerating that in Phascolomys (fig. 4).

The premaxillaries (22) contract and descend, below the nasal processes, as vertical plates; slightly expanding again, below, to form the alveoli of the incisors, especially of the larger anterior pair: the outer surface of these alveoli appears to have been coarsely rugous. 'The inner walls of the alveoli rise, conjoined, as a vertical plate of bone, 3 inches abore the outlets, and extend backward in close contact to form or support the beginning of the "septum narium." The space between the premaxillary septal plates and the superincumbent ends of the nasals is little more thian an inch, which gives the rertical diameter of the nostril at that part; its transrerse diameter is 4 inches. The antero-posterior extent of the alveolar part of the premaxillary is 2 inches 6 lines. The fore-and-aft diameter of the outlet of the first incisor is 1 inch 2 lines; the transierse diameter is 10 lines. The outlets of the smaller second and third incisors are subcircular; each has a diameter of 6 lines.

The cranial characters above described from casts, drawings, and photographs, I have been enabled to test by actual fossils of portions of the upper jaw and skull.

The first of these is a fragment of a right maxilla with two molars $\left(m_{1}, m_{2}\right)$ in situ. It shows part of the front pier of the maxillary arch, including its posterior surface, which springs from the alveolar plates on the vertical parallel with the interval between the two lobes of $m_{1}$, at its lower end, and extending as it rises with a curve convex backward to orerhang part of the hind lobe of the same tooth. Sufficient of this maxillary zygomatic process remains to exemplify the difference between Nototherium and Diprotordon in the antero-posterior extent or thickness of this "pier;" it is characteristically greater in the smaller Herbivore, and of itself would save the palæontologist from 
being led astray by the close general resemblance of the upper molars of Nototherium with those of Diprotodon. The present fragment being from a young specimen, the dental lobes show well their vertical curve concave forward, and the transverse curve of the edge of the wedge concave backward. I availed myself of this fragment to expose the front roots of the anterior molar and the hind root of the posterior molar; but these, with other dental characters, will be noted in the section on the teeth of Nototherium. The present specimen afforded the subject of fig. 8 in Plate XLIII.: it shows a part of the convex roof of the alveolar tract which projects into the orbito-temporal vacuity, and the contiguous groove for the superior maxillary nerves and vessels.

The second cranial specimen is a larger proportion of the left maxilla with three molars in situ ( $\left.d_{4}, m_{1}, m_{2}\right)$, part of the socket of the first ( $\left.d_{3}\right)$, and the base of the crown of the last $\left(m_{3}\right)$ rooted in its socket.

A portion of the bony palate extends with a slight upward curve, inward, from the sides of the sockets of $d_{3}, d_{4}$, and more distinctly inward from those of $m_{1}$ and $m_{2}$. A breadth of 1 inch 6 lines is preserved (opposite $d_{4}$ ): the fracture reduces the breadth to 6 lines as it extends backward to the alveolus of $m_{3}$. So much as is preserved of the bony palate confirms the inference of the entireness of the bony roof of the mouth deducible from the cut and photograph of the entire cranium, as far back at least as the sockets of $m_{3}$, right and left. The hind part of the origin of the zygomatic process of the maxillary is here at the vertical parallel of the interval between $m_{1}$ and $m_{2}$, consequently rather further back than in the former fragment. The worn surfaces of $m_{1}$ and $m_{2}$ show the present to have come from an older individual, as will be subsequently pointed out in detail. An extent of 3 inches of the massive maxillary pier, as its origin extends from behind obliquely upward and forward, is here preserved; the thickness of the process is 1 inch 3 lines. The height of the alveolar process or tract at the last two molars is 2 inches 9 lines. The transversely convex or arched roof of these sockets is, relatively, less broad and prominent than in the Wombat; its extent and proportions resemble more the corresponding part in the Kangaroo, conformably with the common character of three-rooted teeth of limited growth, which contrasts with that of the large undivided bases of the corresponding molars in Phascolomys, retaining their formative matrices, and making a proportional prominence outside the "superior maxillary channel." This channel in Nototherium describes a curve convex outward as it courses forward to perforate the antorbital part of the maxillary and emerge upon the outer surface of that bone (as the 'antorbital foramen,' 21, fig. 1, Plate XXXVII.).

The third portion of the skull of Nototherium includes part of the right maxillary with three molars $\left(d_{s}, m_{1}, m_{2}\right)$ in situ, and part of the right palatine bone (Plate XLIII. figs. $6 \& 7$ ). The teeth are more worn than in the preceding specimen: the fossil is part of an aged individual; the teeth, moreover, show a superiority of size compared with those of the last described fragment, answering to the difference one sees between the molars of the full-grown male and female Kangaroos.

The hind surface of the maxillary pier of the zygomatic arch here lies vertically 
parallel with the fore half of the front lobe of $m_{2}$ : an extent of 3 inches 3 lines is preserved of the origin of the pier as it passes forward and upward, where the fracture of the maxillary traverses the interval between the sockets of $d_{3}$ and $d_{4}$. The bony palate arches upward and inward from the immer walls of the sockets of $m_{1}$ and $m_{2}$, in as great a degree as from those of the socket of $d_{4}$. The extent preserved, in a straight line from the outlets of the alveoli, is 2 inches. The palato-maxillary suture begins at the inner or mesial fractured surface of the bony palate opposite the hind lobe of $m_{1}$; near the interval between $m_{1}$ and $m_{2}$ it extends outward and backward with an oblique curve to near the inner side of the outlet of the socket of $m_{2}$. Its relative position to the molars agrees with that of the palato-maxillary suture in Phascolomys latifions; in Macropus rufius the suture begins, mesially, at the transverse parallel of the interval between $m_{2}$ and $m_{3}$, at least in an example with those molars in place and use.

'The palatine bone, like the maxillary alveolar tract, has been broken at the part behind $m_{2}$, the broad single posterior root of which is exposed. But at the fractured surface of the palatine there occurs, just opposite or parallel with the back part of $m_{2}$, in small tract of the natural smooth unbroken surface of the palatine, indicating a posterior palatal vacuity, on the parallel of $m_{3}$, as in Phascolomys. The thickness, vertically, of the fore part of the bony palate here preserved is $1 \mathrm{inch}$, of the lind part half an inch.

In the younger, probably female specimens, the same admeasurements give 6 lines and 2 lines.

Contrasting the difference of size, shape, and relative position of so much of the maxillary zygomatic process and bony palate as is preserved in the two specimens just described, one is at first inclined to deem them to have come from different species of Nototherium; and three species of the genus are indicated by mandibular characters.

But in reference to the progressively backward extension of the zygomatic process of the maxillary, this may be coincident with the progressive growth of the alveoli of the hinder molars, as these teeth come into use; in like manner, as their crowns are pushed down to the line of wear in the ratio of the abrasion of their wedge-shaped ridges, so the alveoli will cling to and follow the roots, growing as they lengthen, and giving a curre or concavity to the palatal surface not present or needed in the less worn condition of $m_{1}, m_{2}$, and $m_{3}$, in younger individuals.

With the foregoing evidences of the cranial characters of Nototherium we may safely proceed to bring them out, or add to their saliency, by comparison with those in other extinct and in existing Marsupialia.

The skull of Nototherium is shorter in proportion to its breadth and depth than in Diprotodon, and differs in the singular way in which the maxillary or facial part is bent up upon the cranial part, exemplified in figure 1, Plate XXXVI., and by the angle, before noted, which the bony palate forms with the basis cranii. The shortness is mainly due to that of the antorbital extent of the skull; the diastema between the incisors and molars is relatively as well as absolutely less than in Diprotodon. The Notothere resembles the Koala (ib. fig. 3) and Wombat in the small proportion of the skull in advance of 
the orbits; the Diprotodon is more like the Kangaroos in the length of this part. The terminal expanse and lateral tuberosities of the upper half of the bony nostril is a peculiarity of Nototherium; but it is instructive to note them in both Phascolarctos and Phascolomys (Plate XXXVI. fig. 4); the fore part of the bony muzzle is expanded laterally by an outward swelling of the front border of the premaxillary (ib. 22) where it joins the nasal (ib. 15 ).

In the form, especially breadth, of the external nostril the Notothere resembles the Wombat, while the Diprotodon is more like the Kangaroo in this respect; but no known existing Marsupial shows the septal plates developed from the premaxillaries at the entry of the nasal passages, as in both Nototherium and Diprotodon. The Wombats make the nearest approach to this peculiarity.

The Notothere surpasses the Diprotodon in both the absolute and relative size of the zygomatic arches. This difference is very striking when a front view of the cranium (as in figure 2 of Plate XXXVI.) is compared with the similar view given of the Diprotodon's skull in Plate XIX. fig. 2.

This most extraordinary feature in the cranial organization of the present large extinct Herbivore leads me to submit the following remarks.

The zygomatic arches are relatively stronger and wider in Proboscidians than in Ruminants and Solipeds; they are widest and thickest in the bilophodont Dinotheres, the temporal fossæ being of corresponding capacity. Still more dereloped are these arches in the Manatees, the Tapirs, and the bilophodont Megatheres, especially in the vertical extension of the bone giving attachment to masticatory muscles. It would seem that the working of opposed double-ridged grinders required greater strength and more direct horizontal pull of the masseteric muscular fibres than the working of the more complex but flatter molars of the Ox, Horse, Rhinoceros, or Elephant. The phytophagous Marsupials have the grinding-surface of their many massive molars raised into prismatic cones or transverse ridges, and their skull is remarkable for the great strength, size, and span of the zygomatic arches. The descending process from the fore and under part of the arch, for extending the origin of the premasseter muscle, adds to the zygomatic complexities and characterizes the Poëphaga among existing Marsupials. This osteological feature is not found in any gyrencephalous Herbirore; but it exists, with a different relation to the constituent bones of the arch, in the lissencephalous Sloths, Megatherioids, and Glyptodonts. In the Nototheres the zygomatic derelopment reaches its maximum, with the dependent process extending from the maxillary element of the arch as in other Marsupials. The muscular force operating on the mandible, both for biting and chewing, was very great, indicative of unusual resistance in the alimentary substances to be ground down. The grip of the front incisors brought by the shortness of the face and jaw within the power of the crotaphyte muscles in a degree proportional to the proximity of the inserted movers must have been like that of a rice.

\$ 3. The Mandible. A. Nototherium Mitchelli.-The mandible (Plate XXXVIII.) discovered in the bed of King's Creek, a tributary of the river Condamine, Darling 
Downs, which was purchased of the collector by Mr. BExJums Bord, and subsequently, with the rest of Mr. Bord's collection, acquired by the British Museum, is from the same formation and locality as the skull above described, which fell into Mr. Is.ic's hands.

This mandible agrees so closely, not only in the shape, structure, and other characters of the teeth, saving the difference of upper and lower, but also in the dimensions of these and of the proportion of the jaw-bone preserved, that it might well have been part of the sanle indiviclual; it certainly belongs to the same species.

Comparing the type specimen of Nototherium Mitchelli, Ow.*, with the answerable part of the above-mentioned mandible, the correspondence in size and configuration is such as to support the reference of the present more complete specimen to that species.

The depth of the mandible behind the last molar is 3 inches 9 lines in the first described, it is 3 inches 8 lines in the present specimen; the thickness of the mandible below the last molar is 2 inches 6 lines in both specimens. The antero-posterior extent of the two last molars in the original fragment with mutilated crowns is 3 inches 4 lines; in the more perfect mandible (Plate XXXVIII. figs. 1 \& 2 ; Plate XLIV. figs. 1 \& 2, $\left.m_{2}, m_{3}\right)$ it is 3 inches 6 lines; from the back of the last molar to the entry of the dental canal (Plate XXXVIII. fig. 2, o) is 2 inches 9 lines in both specimens. The place and degree of inflection of the under margin and angle of the jaw (ib. $a \& d$ ) are the same in both.

Referring on these grounds the mandible (Plate XXXVIII. figs. 1 \& 2) to Nototherium Mitchelli, the cranium and upper jaw answering to that lower jaw must be referred to that species.

'The mandible in question consists of the two rami mutilated at both ends, but fortunately retaining their natural confluence at the symphysis, of which a longitudinal extent of 3 inches $S$ lines is preserved (ib. figs. $2,3, s$ ); this gives the angle of divergence of the horizontal rami from the place of confluence (ib. id.). It shows that the interval between the right and left mandibular condyles agreed with that between the articular cavities in the skull (Plate XXXVII. fig. $3, g, g)$; and that the distance of the condyle from the fore part of the first molar $\left(d_{3}\right)$ was the same as that, viz. 12 inches, from the fore part of the first molar to the joint for the condyle in the upper jaw.

So much of the ascending ramus as is preserved, which closely corresponds with that in the type jaw, shows the same oblique direction of the curve (Plate XXXVIII. fig. 1, $a, b, \pi)$ by which the lower border graduates into the lind one of the rising branch: the curve changes slightly on rising to the level of the alveoli, being then feebly concave above the anterior inflected part of the lower margin; it becomes convex where the border is again inflected, and abore this the hind border of the ascending ramus, after contracting, expands transversely, apparently to support the condyle. The angle or anterior

* "Report on the Extinet Mammals of Australia, \&c." in Report of the British Association \&c. for 1864, p. 13, pl. 4 ; and Cut, fig. 1, p. 42 (suprì). 
inflection (Plate XXXVIII. $d, d$ ) is but slightly bent inward, with a thick and smooth border; the longitudinal extent of this inflected part is about $4 \frac{1}{2}$ inches, closely repeating, as far as it is preserved, the characters of the more perfectly preserved angle of the type specimen (Cut, fig. 1, $d, d$ )*. An oblique longitudinal wide and shallow channel intervenes on the inner side of the ramus between the inflection (Plate XXXVIII. fig. $1, d, d$ ) and the low tuberous termination $\dagger$ of the postalveolar ridge (ib. \& fig. 2, t), about an inch and a half behind the socket of the last molar $\left(m_{3}\right)$. This channel is continued backward with a partial interruption, caused by the forward extension of the inflected angle or hind border of the ascending ramus (ib. fig. 2, $a, e$ ). This part is broken away in the type specimen.

In no part of the oblique channel (ib. $\zeta$ ) occupying and mainly forming the inner surface of the ascending ramus of the jaw is there any trace of inlet of a dentary canal; in this respect, as in the somewhat unusual position of that inlet or entry, the present mandible agrees with the type fragment\$. Some nerve or vessel has left its impress along the middle of the channel, but has quitted it for contiguous soft parts without penetrating the bone.

The outer surface of the ascending ramus rises from the line of the anterior inflection (d) with a feeble vertical concavity, speedily changed to a convexity curving outward to the thick obtuse lower boundary (Plate XXXVI. \& Plate XXXVIII. fig. 1, $h$ ) of the ectocrotaphyte depression (ib. $f^{\prime}$ ). The fore part of this depression is formed by the corresponding part of the rising ramus (ib. and fig. 2, q), which commences opposite the hind part of the last molar $\left(m_{3}\right)$, and at a distance outside it of 1 inch 3 lines. The base of the "coronoid" plate (Plate XXXVIII. fig. 2, $q, h$ ) describes a curve, concave outward, of which base an extent of 5 inches (in a straight line) is preserved. The process is broken off in both rami; it was thickest at the fore part of its base (Plate XXXVIII. fig. 4, q), which here gives half an inch. The dental nerves and ressels groove the inner and back part of the base of the coronoid before penetrating it obliquely in the same position (at $o$, figs. 1 \& 2) as that in the type specimen (Cut, fig. 1,o).

Between the postinternal alveolar process (Plate XXXVIII. figs. 1, 2, $t$ ) and the base of the coronoid process, is an irregular shallow channel (ib. $u$ ), narrowing as it passes backward to the dental canal $(o)$. The depth of the mandibular ramus at the back of the last tooth-socket is 4 inches, the thickness of the ramus at the fore part of the origin of the coronoid process is 2 inches 6 lines.

The interspace between the right and left last socket is 3 inches 6 lines. The breadth of the mandible, taken anterior to the origin of the coronoid process, is 7 inches 8 lines; whence the jaw gradually expands to the condyles. We may estimate its breadth at the outsides of these, from the cavities (Plate XXXVII. fig. $3, g,{ }_{27}$ ) receiving them, to have been 1 foot, or thereabouts.

The outer surface of the horizontal ramus (Plate XXXVI. fig. 1, 32, q) is smooth, very convex vertically where it advances from the ascending ramus, but rising with a slight

* Op. cit. pl. 4. figs. $3 \& 5, a$.

$\dagger$ Loc. cit. figs. $2 \& 3, b$.

$¥$ Loc. cit. fig. 3 . 
concavity to the outlets of the sockets; the convexity subsides as the jaw advances and the surface ascends more vertically to the outlets of the three anterior molars (ib. $d_{3}, d_{4}$, $m_{1}$ ), but it continues the vertically convex curve to the lower border. The thickness of the ramus before inbending to the symphysis is 2 inches; its height where it joins its fellow at $s$ (Plate XXXVIII. fig. 2) is 3 inches 5 lines. At the lower and back part of the symphysis is a transverse roughish crescentic depression (ib. fig. $3, v$ ) for muscular insertion. The general longitudinal lay of the outer surface of the horizontal ramus is a feeble convexity forwards as far as below the second molar $\left(d^{\prime}{ }_{4}\right)$, where it begins to change to a concavity leading on to the symphysial part (fig. 1, ${ }_{2}-k$ ), containing, anteriorly, the sockets of the incisors. On the vertical parallel of the fore part of the first molar socket, about halfway between the upper and lower borders of that part of the ramus, is an outlet of the dental canal (ib. ${ }^{2}$ ); it is subcircular, 5 lines in long diameter.

The imner surface of the horizontal ramus (Plate XXXVIII. figs. $1 \& 2, i$ ) sinks sheer below the outlets of the last socket, and with a slight vertical convexity from that of the penultimate molar; it is at first feebly concave, then convex to the back part of the symphysis, and the surface is uniformly concave at the upper part of the symphysis (ib. fig. $\left.2, s^{*}\right)$, between the three anterior sockets of the right and left sides. The longitudinal lay of the inner wall of the ramus is feebly convex posteriorly, changing to a concavity deepening into the back and upper part of the symphysis. 'This junction of the right and left rami is completely ossified without a trace of the primitive separation shown in Plate XL. figs. 2, 3, 4, s, $s^{\prime}, s^{*}$; herein contrasting strongly with the condition of the joint in the Kangaroot.

The hind surface of the symphysis (Plate XXXVIII. figs. $2 \& 3, s$ ), vertically convex and smooth, is on the rertical parallel with the back lobe of third molar $\left(m_{1}\right)$, near, but not quite extending, to the interspace between its socket and that of the fourth molar $\left(m_{2}\right)$. The upper surface of the symphysis (ib. fig. $2, s^{*}, s$ ) between the three anterior molars $\left(m_{1}, d_{4}, d_{3}\right)$ is a rather deep smooth longitudinal canal, the margins of which begin to be encroached on by a diastemal ridge (ib. $k$ ), continued forward from the socket of $d_{3}$ with a slight curve convex inward.

The antero-posterior extent of the five molar alveoli is 7 inches 5 lines. The breadth of the anterior division of the first socket is $3 \frac{1}{2}$ lines, of the posterior division 5 lines; the depth is shown in the jaw of the young Nototherium (Plate XL. fig. 5, l). The sockets of the other molars increase in breadth to the anterior division of the last, which is 1 inch 1 line across. The alveolar plate rises in an angular form at the intervals of the sockets, and at those of the diverging roots of each tooth on both outer and inner sides of the jaw.

At the fractured part of the symphysis are parts of the bottoms of a pair of incisive alveoli; that on the left side gives a transverse breadth of 9 lines and a vertical one of about 1 inch; but the lower wall is broken away from the base. A still smaller portion is preserved on the right side.

$\dagger$ Owex, Osteology of the Harsupialia, 'Anatomy of Vertebrates,' vol. ii. p. 350. 
The indications suffice to show that the incisors were not developed as tusks, of size and proportions fitted for offensive or defensive purposes, as in Diprotodon; their base and socket not extending backward beneath any of the molar alveoli, at least in the adult. Not more than an inch and a half of the toothless part of the symphysial end of the lower jaw has been preserved in the present specimen, and that only on one (the left) side.

Accepting the evidence from size and proportion in the preserved parts of the present mandible and its dentition, in proof of its appertaining to a full-grown individual of the same species as the skull above described, the length of the part of the lower jaw with its incisors, in advance of the molar series, can be estimated and restored from that of the premaxillary and its incisors anterior to the molar teeth in the upper jaw. This estimate gives from the fore part of the anterior molar socket of the mandible to the tips of the pair of lower incisors an extent of at least four inches and a half.

Complete as is this lower jaw compared with previously received specimens, including the one originally described, the relative extents of the sockets and protruded parts of the lower incisors would have remained to be determined.

Fortunately a mutilated mandible, but with the symphysial end nearly if not quite entire, has been received by the Trustees of the Australian Museum, Sydney, and a plaster cast of this specimen has been prepared and transmitted, with their characteristic liberality and promptitude, to the 'Trustees of the British Museum.

In this specimen an extent of the jaw forming the sockets of the pair of incisors (Plate XXXIX., $k, \ddot{)}), 2$ inches 6 lines anterior to the first molar (ib. fig. $3, d_{3} \& s^{*}$ ), has been preserved; but at this distance, the incisors with, perhaps, some small part of the fore part of their sockets have been broken off. The symphysis dwindles vertically and transversely to the condition of mere sheaths of the two approximate teeth, such sheath in no part of the fractured surface exceeding three lines in thickness, and where the bone comes nearest to the fracture it thins off to a fine edge (ib. fig. 4). As far as a cast can be trusted, part of the natural outlet of the sockets is shown below the teeth (ib. fig. 2, $s^{\prime}$ ), the alveolar wall having extended further forward at their upper part

The vertical diameter of the fractured or partially fractured end of the symphysis at the mid line is 1 inch 6 lines; the transverse diameter is the same. The broken surface, including the roots of the incisors (Plate XXXIX. fig. 4, nat. size), is of a subquadrate form, with a mesial groove above $\left(s^{\prime}\right)$ and a slighter one below.

The lower contour of the mandible is continued, without interruption, but with gradual loss of convexity, from the inflected border (fig. $1, d$ ) to the outlet of the incisors (i).

At the upper part of the symphysis the ridge (fig. $3, k$ ), of which the beginning or hind part was noted in the description of the preceding specimen (Plate XXXVIII. figs. $1 \& 4, k$ ), is here seen to converge toward its fellow for the extent of an inch, then to be continued straight forward, broadening and subsiding. The pair of ridges form the sides of the smooth channel $\left(s^{*}\right)$, grooving the upper surface of the symphysis, and

+ See Plate XXVI. fig. $2, s$, where the same form of incisive alveolar outlet is shown in the mandible. 
gradually shallowing to the fore end. Posteriorly the channel rapidly widens to the intermolar space, then gradually expands, preserving or gaining depth to the lind border of the symphysis $(s)$. The entire length of this confluent tract of the mandibular rami is 5 inches 10 lines; the thick rounded lind border is on the vertical parallel with the hind lobe of the third molar $\left(m_{1}\right)$. It is satisfactory to find this character of the former mandible of Nototherium Mitchelli (Plate XXXVIII. fig. 2, s) here repeated. The under part of the hind end of the symphysis shows the insertional depressed surface (Plate XXXIX. fig. 2, $v, v$, of similar size and shape to that in the subject of Plate XXXVIII. fig. 3,v). 'The symphysis is subcompressed anterior to the molars, but the transverse diameter diminishes less gradually than the vertical one.

'The present mandible is of a full-grown and, from the wear of the tecth, rather aged individual. The last three molars and a portion of the second are in place in the right ramus : the first, second, and part of the third molars remain in so much as is preserved of the left ramus.

The fore-and-aft extent of the molar alveoli is 6 inches 10 lines; that of the three hindmost is 5 inches 2 lines. I give this measurement, as well as the first, to show the close correspondence in size of the present with the preceding mandible of Nototherium: the present specimen is rather smaller; the bone is rather more slender; the rertical diameter, for example, of the ramus anterior to the foremost molar-socket is 2 inches 4 lines, in the subject of Plate XXXVIII. it is 3 inches; the vertical diameter behind the socket of the last molar in the subject of Plate XXXIX. is 2 inches 10 lines, in that of Plate XXXVIII. it is 3 inches 9 lines, in the type jaw $t$ it is 3 inches 8 lines. With the closer conformity in the molar series, I infer the more slender proportions of the present mandible to be sexual, and to indicate its having come from a female Notothere.

Rather more of the base of the coronoid process (Plate XXXIX. figs. $1 \& 3, q, 0$ ) is here preserred than in the subject of Plate XXXVIII.; it occupies the same proportion, and shows the same shape and curve as in that jaw; the dental canal perforates its hind part in the same position and with the same obliquity. The postalveolar process, broken as in the former mandible, and as it usually is in these Australian fluviatile fossils, holds the same relative position to the last molar tooth as in the male jaw. 'The smooth oblique channel between the fore part of the coronoid and the last alveolus has a breadth of 9 lines in the female, instead of 12 lines as in the male specimen. The anterior inflected angular border repeats the characters of the part in that specimen, but is not entire; the exceptionally perfect condition of the part in the type mandible gires consequently valuable eridence of this character.

The commencement, an inch above the anterior angular inflection, of the posterior inflected margin (Plate XXXIX. figs. 1 \& 5,a) and the corresponding outswelling at the outer part of the ascending ramus (ib. fig. $5, h$ ) indicate more definitely than in the first described mandible the part from which the neck of the condyloid process

$$
+ \text { Loc. cit.; and Cut, fig. } 1
$$$$
\ddagger \text { Loc. cit.; and Cut, fig. 1, } d \text {. }
$$ 
has been continued. The breadth of the back part of the jaw here is 2 inches 2 lines.

The anterior outlet of the dental canal is, as in the former mandible, on the same vertical line as the fore part of the first molar; but it is placed rather lower down: it is of similar size and shape.

A third example yieldiug Nototherian mandibular characters is also from the freshwater deposits of Darling Downs; it was discovered at Eton Vale by Edward S. Hilu, Esq., and was presented to the British Museum by Sir Daniel Cooper, Bart. It is part of the left ramus of an adult and seemingly male jaw, and includes the sockets of the last three molars with the penultimate and last of these teeth in place, but mutilated. It retains a similar proportion of the ascending ramus to that in the two preceding jaws, but with more of the fore part of the base of the coronoid process. The vertical diameter of the ramus behind the last molar socket is 3 inches 9 lines; the thickness of the jaw below that socket is 2 inches 7 lines.

From the hindmost socket to the orifice of the dental canal is 2 inches 8 lines. The postalveolar process with the base in the Nototherian position is, as usual, broken away, like most projecting parts in these rolled and transported drift-fossils. The fore part of the coronoid rises to 1 inch and 9 lines above the dental orifice, but at that height has been fractured. The antero-posterior extent of the two last sockets is 3 inches 6 lines, as in the first described mandible, with which all the other characters of the present specimen correspond so far as they are shown. I refer it, therefore, to a large old male of Nototherium Mitchelli. The marks of torrential action are very plain in this water-worn fossil : it is massive and heavy from some mineral infiltration.

A fourth rolled and mutilated specimen from the same locality, contributed by the same liberal donor, retains the last three molars and the socket of the second, with the hind part of the symphysis, showing the same vertical relative position to their molar $\left(m_{1}\right)$ as in the former specimens of Nototherium Mitchelli. The teeth, so far as they are preserved, agree in size, shape, and proportion with those of that species. The ascending ramus has been broken away behind the last alveolus and the beginning of the base of the coronoid process. The dental canal is here exposed an inch below that part of the process, and half an inch from its outer side.

The fore-and-aft extent of the three last sockets is 5 inches 5 lines. The depth of the ramus at the interspace between the last two sockets is 4 inches 2 lines in a straight line; below the interval between the penultimate and the antepenultimate molars it is 4 inches 3 lines. In the first described mandible the same admeasurement is here 3 inches 9 lines; in the type jaw it is 3 inches 7 lines; in the second and supposed female jaw it is 2 inches 10 lines. Between this and the mandibular fragment under description the difference of depth of the horizontal ramus seems too great for mere sexual variety; yet the three last molars are not at all larger than, or in any appreciable degree different from, those in the subject of Plate XXXIX. But, besides the greater depth, the outer surface of the jaw is rather less convex vertically beneath the 
third molar $\left(m_{1}\right)$ than in the three preceding specimens. Nevertheless I cannot feel that I have grounds for propounding any distinction of specific value for the Notothere yielding the present fossil. The fracture through the hind part of the symphysis exemplifies the complete bony confluence of this part, and the non-existence therein of the wide alveolus of a large scalpriform tusk. 'The transverse fracture anterior thereto at the interval between the first and second molars exposes the dental canal, of 4 lines diameter, situated 2 inches below the outlet of the socket, and $1 \frac{1}{2}$ inch above the lower surface of the symplysis.

The fifth mandibular specimen of Nototherium Mitchelli is from the freshwater beds traversed by Gowrie Creek, Darling Downs; it was there collected by IIExrr Huanes, Esq., by whom it was presented to the Natural-History Society of Worcester. This specimen is chiefly valuable for the more perfect and less worn condition of certain of the molar teeth. It consists of a right ramus mutilated (as most of these fossils from river-beds are) at both ends. The relative position of the back part of the symphysis and of the entry of the dental canal, with the general size and proportions of the best preserved parts of the ramus, show the specimen to have belonged to the Nototherium Nitchelli; and it agrees most closely with the more perfect mandible in the Australian Iuseum at Sydney, which I have referred to the female of that species.

The subject of Plate XL. is an instructive specimen of a mandibular ramus and den. tition of a young Notothere; it was transmitted to me, in 1847 , by the enterprising and unfortunate explorer of Australia, LuDWiG LEICIHIARD, to whom I had been previously indebted for the account of the geology of the locality yielding this and other remains of extinct Marsupials (p. 241).

I incline to refer this specimen, from the size of the incisor and of the three anterior molars, to Nototherium IFitchelli. The generic indications in the present fossil will be noted in $\S 4$, on the teeth of Nototherium: the characters of the bone exemplify mainiy those of immaturity. It consists of a right ramus, which, being figured of the natural size in Plate XL., precludes the need of noting dimensions. The antero-posterior extent of the three anterior molar-sockets will be seen to agree with that in the mature mandible, Plate XXXIX.

The ascending ramus has been broken away, exposing the formative alveolus of the penultimate molar (figs. $3 \& 4, m_{2}$ ) and the like cavity at an earlier stage of the last molar (ib. $m_{3}$ ). Provision has been made in this cavity for the lodgment of the anterior lobe of a tooth of equal transverse diameter (14 lines) with that of the tooth $\left(m_{3}\right)$ in place and use in the largest examples of the present species. The dental canal (fig. 3, o) exposed by the hinder fracture presents a semielliptic form, 9 lines transversly and 3 lines from before backward. The canal undermines, as it were, the shell of the last formative alveolus, and it contracts as it inclines toward the outer wall of the ramus in its forward course.

The contour of the lower border of the ramus from the hind fracture to the symphysis (Plate XL. figs. $1 \& 4, e, s^{\prime}$ ) is a more open curve than in the adult; it is feebly inter- 
rupted between the inflected border $(d)$ and the hinder inflection or angle $a$; the slight concavity between $d^{\prime}$ and $a$ being less apparent in the adult jaw. The ridges (fig. $1, h, q$ ) bounding the ectocrotaphyte depression $(f)$ are naturally feebler, less pronounced, in this young jaw; the base of the anterior one $(q)$ rises from the transverse parallel of the hind lobe of the penultimate molar $\left(m_{2}\right)$. The postinternal angle of the formative alveolus of the last molar appears to represent the postalveolar process of the mature mandible.

The oblique channel (answering to $u$ in figures of the adult jaw) between the coronoid and postmolar processes here runs from that lodging the fore lobe of the penultimate molar to near the middle of the outer part of the interspace between the lobes of the antepenultimate molar $\left(m_{1}\right)$; it thus preserves its general relative position to the last grinder "in place" and use, and doubtless was still more advanced when $m_{1}$ was "en germe."

Such changes in the relative position of parts, and differences of general shape, of the mandible in the adult and young Notothere are dependent on, or concomitant with, the growth called for to sustain in action the full complement of teeth in the adult. No inference of specific difference can be deduced from the relative position of the hind part of the "symphysis mandibulæ" $(i)$ in this young jaw to the front lobe of the second molar $\left(d_{4}\right)$; because the socket of that tooth would move forward in the course of growth, whilst the symphysis extended its grasp of the fore parts of the two rami prior to the ultimate obliteration of the syndesmotic joint in the adult. At the present immature stage this articulation remains. The surface (fig. $4, s^{*}$ ) is vertical, flat, with roughish rugæ, mostly directed from above downward and forward, gaining in prominence, through deepening of the intervals, along the lower third. It seems as if confluence had already begun at a small part of the upper and posterior border of the articular surface, such portion having been broken away from the left ramus and left adherent and seemingly confluent with the right one. Behind the lower part of the posterior border of the symphysis is the flattened, rough, slightly depressed surface (fig. $2, v$ ) for muscular insertion noted in the older specimens.

The shallow indent or concavity dividing the inflected parts of the horizontal $\left(d^{\prime}\right)$ and ascending ( $a$ ) rami has a more adranced position and a direction more approaching the horizontal than in the mature jaw: in Plate XL. fig. $4, a-d$ is shown to be below the interval between the penultimate and last molars and parallel in extent with the contiguous lobes of these teeth. The inward extension of the bone at $a$, fig. 4, represents a resumption of the inflection of the lower margin of the jaw at its hinder part, from which resumption the bone thins off to be continued backward into the thickened part $(e)$, which contributed to support the broken-off condyle.

This character is retained, but is better marked, in the adult mandible of Nototherium Victorice from South Australia (Plate XLI.); but the incisor tooth in that species has a smaller and more advanced socket than in the present immature jaw, which in this more important character agrees with Nototherium Mitchelli. 
In the removal of the part of the outer wall of the ramus in quest of a possible germ of a premolar or vertically replacing tooth, the base of the socket of the incisive tusk (Plate XI. fig. $\left.5, i^{*}\right)$ was shown to extend beneath the first molar $(d, l)$ as far as the septum, dividing the socket of that tooth fiom the next, lodging $d_{4}$.

'The base of the incisive socket makes a feeble prominence at its upper and inner side at the hind third of the plate, sloping to the symphysial articular surface. The direction of the socket and of its contained incisor is that of the long axis of the symphysis.

'The outlet of the socket (figs. $1 \& 4, s^{\prime}$ ), 1 inch in advance of that of the foremost molar, is subquadrate, 7 lines in vertical and 6 lines in transverse diameter. The anterior outlet of the dental canal (fig. 1, ${ }_{32}$ ) holds the same relative position as in the first described jaw of Nototherium Mitchelli.

The general depth of the present young jaw is of course much less, relatively to the crowns of the teeth in place, than in the adult.

I have been favoured by the Trustees of the Australian Museum, Sydney, with photographs and a plaster cast of the left ramus and back part of the symphysis of the mandible of a mature Nototherium from the freshwater deposits of Darling Downs.

It includes the series of five alveoli of its side, the last three of which support their teeth, which are rather more worn than in Mr. HugnEs's specimen, and rather less so than in the mandible figured in Plate XXXVIII.

The longitudinal extent of the five alveoli is 6 inches 9 lines, as in Mr. Hughes's specimen; that of the last three molars is 4 inches 6 lines, but the hind talon of the last molar seems to hare been broken away; were it entire, as in the first-described mandible, the three teeth would occupy an extent of 5 inches. The inner wall of the crown in each of the three molars has been broken away; but they appear to have equalled in breadth those teeth in the subject of Plate XXXIX., or the female mandibular specimen.

'The inflection of the lower border of the jaw begins, as usual in the adult, on the vertical parallel with the socket of the last molar; the hind part of the symphysis extends to the rertical parallel with the fore part of the third molar $\left(m_{3}\right)$.

The vertical diameter of the jaw below the last molar $\left(m_{3}\right)$, taken at the outer wall of its alveolus, is 3 inches 2 lines; that taken at the third molar $\left(m_{1}\right)$ is 3 inches 1 line.

At the fractured fore part of the cast is plainly shown part of the bottom of the socket of the left incisor, with its longitudinally striate and finely rugous surface. There is not enough of the cavity preserved to show that the missing part (almost the whole) of the socket and incisor differed in shape or direction from those in the subject of Plate XXXVIII. fig. $1, \ddot{i}$.

Agreeing, to the extent to which this cast does, with that of the more complete mandible of the inferred female of Nototherium Mitchelli, in every particular in which the comparison can be instituted, I am unable to point out any character whereby it can be referred to a different species; and I doubt whether a scrutiny of the original specimen would have supplied indications of such distinction. 
Mr. KREFFT has favoured me with a pencil-sketch of the base of the incisor (Cut, fig. $2, i$ ), of the natural size, from the original fossil, showing the exhaustion of the pulp in this tooth of limited growth.

B. Nototherium Victorice, Ow.-In the specimen of the left ramus of the mandible (Plate XLI.), liberally transmitted for my examination by direction of the Trustees of the Museum of Natural History in Adelaide, South Australia, more of the ascending ramus is preserved than in any of the foregoing specimens; and there are differences which deserve to be interpreted as specific.

The specimen was discovered by Mr. Tilgate, of Wentworth, South Australia, in freshwater deposits near Lake Victoria, in that colony.

The posterior orifice or entry of the dental canal (fig. 2, 0 ) is on a level with the outlet of the last alveolus $\left(m_{3}\right)$, not perforating the base of the coronoid above that level as in Nototherium Mitchelli. The inflection of the lower border (ib. $d, d^{\prime}, d^{\prime}$ ) begins on a vertical parallel with the hind lobe of the penultimate molar $\left(m_{2}\right)$, and terminates a little behind the vertical parallel of the last alveolus, before the horizontal ramus bends upward into the base of the ascending ramus. After a subsidence for the extent of an inch and a half, the lower border again begins to be

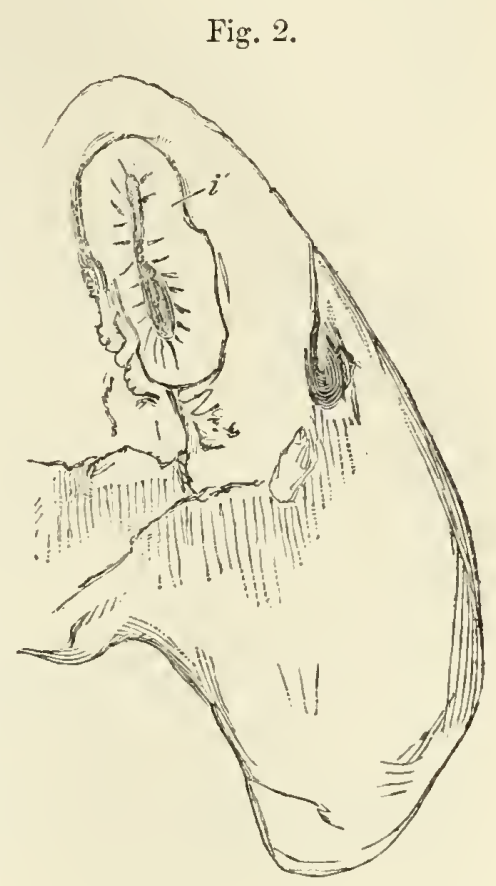

Fractured symphysis of jaw, with base of broken incisor, Nototherium Mitchelli. inflected, suddenly (at $a e$ ), and to a greater degree than at any part of the more posterior inflection in Nototherium Mitchelli (Plate XXXIX. fig. 1,a). The second inflection in the present species, at first as thick as the anterior one (viz. 5 lines), quickly thins off as it recedes to a plate of 1 line in thickness (Plate XLI. $e$ ); which, after the course of about an inch, suddenly expands to form the thick inner part $(n)$ of the broad posteriorly flattened hind surface of the ascending ramus, supporting the condyle $(c)$. Much of this joint is broken away, but both the outer and inner beginnings of its base or "neck" remain, together with the entire extent of the base of the coronoid plate (fig. $1, q, r$ ), the summit of which is also wanting. The concave platform (fig. $2, u$ ) between the fore part of the coronoid process and the postalveolar ridge and process has a breadth of about an inch and a half; the process, as usual, has suffered fracture.

From the back part of the last alveolus to that of the base of the process is 1 inch 5 lines; from the same part to the dental orifice $(0)$ is 2 inches 2 lines: the dental canal runs obliquely forward; only the two anterior thirds of the orifice are defined by a sharp border; the diameter of the orifice is 4 lines. A groove (fig. $2, p$ ) of the same breadth, and about an inch and a half in length, runs forward along the under and inner side of the orifice $(0)$; this groove has a sharp inner border. A parallel ridge is directed 
from the back part of the dental orifice where it is broadest, backward, becoming narrower as it recedes, and subsiding an inch and a lialf from the orifice.

About 3 inches, following the curve, of the back part of the base of the coronoid $\left(r, f^{\prime}\right)$ are preserved; its commencement from the neck of the condyle $\left(r^{\circ}\right)$ is raised much above the horizontal plane of the molar alveoli: the plate here is thin, but its margin is obtuse or rounded; at the hind part of the fracture $\left(f^{\prime}\right)$ it shows a thickness of 2 lines; as it advances it gains one of 3 lines; as the anterior border descends it gradually increases in thickness to 6 lines, near its obtusely rounded basal beginning. 'This (fig. 1, q), as usual, rises, buttress-like, from the outer wall of the mandible, on the transverse parallel of the middle of the last alveolus, and about an inch and a half lower than the outlet of that socket. The course of the base of the coronoid upward and backward is with a slight outward concavity at its anterior half, and is then level; its extent is 4 inches 9 lines; the anterior border of the process is gently convex, to the extent ( 4 inches) to which it has been preserved. 'The breadth of so much of the condyle $(c)$ as is preserved is 2 inches 3 lines; the outer portion shows a small part of the articular surface, convex from before backward.

The ectocrotaphyte depression (fig. $1, f$ ) is smooth and shallow; it is divided from the lower inflected part of the ascending ramus by a change of contour of the smooth outer surface, forming a broad convexity vertically; but this becomes, as it recedes, rather more prominent, thinner, and shows a roughened, as it were worm-eaten, surface (fig. $1, h$ ), and, from a slightinflection at its termination towards the back surface of the ascending ramus, it there indicates the fore-and-aft extent of that part of the jaw as giving, viz. from the fore part of the base of the coronoid, 6 inches. It is possible that a smoother surface of the lind prominent outer and lower boundary of the ascending ramus may have suffered some abrasion in the fossil. There is no perforation of the crotaphyte depression.

The sympliysial end of the present ramus lias been broken away at the fore part of the second alveolus, exposing part of the anterior root of that tooth (fig. $4, d_{3}$ ), and a small part of the bottom of the incisor's socket (i).

The antero-posterior extent of the last three molar sockets is 4 inches 10 lines; a thin plate rises to form the outer wall of their outlets.

The inbending of the inner surface to form the hind part of the symphysis begins at the vertical parallel of the middle of the third molar (fig. 2, $s, m_{1}$ ). 'The lower part of the symphysis shows a pair of transversely crescentic insertional depressions, concave backward (fig. $3, v, v$ ). The depth of the ramus at the interval between the third $\left(m_{1}\right)$ and fourth $\left(m_{2}\right)$ sockets is 2 inches 8 lines: in the female (?) of Nototherium Mitchelli it is 3 inches; in the male (?) it may attain 3 inches 10 lines.

The symplysial joint in Nototherium Victorice has become completely obliterated in the present full-grown specimen; a dense, minutely spongy tissue is included in a thin compact crust of bone.

The inner wall of the alveolar outlets does not rise so high as the outer one; it thins 
off to an edge closely fitting the contour of the base of the crown of the tooth; the inner side of the horizontal ramus (fig. 2) at once descends with a gentle vertical convexity, interrupted beneath the last and part of the penultimate sockets by the concavity due to the inflected lower border $\left(d, d^{\prime}\right)$. The depth of the inner side of the ramus behind the fifth (last) socket is 2 inches 9 lines; in Nototherium Mitchelli it is 3 inches 6 lines.

The portion of the base of the incisor-socket exposed by the anterior fracture (fig. $4, \ddot{i}$ ) gives a vertical extent of 1 inch, a transverse breadth of 4 lines. The bottom is smooth; the side-walls worm-eaten, with a tendency to longitudinal striation. External to this part of the socket, about a line's distance, the dental canal is exposed, of a subcircular section, 3 lines in diameter; about the same thickness of the osseous tissue divides it from the outer surface of the jaw. Two inches behind this part a small orifice pierces the outer surface at the same distance below the middle of the outlet of the alveolus of the molar $\left(m_{1}\right.$, fig. 1$)$.

The colour of the fossil above described from the deposits near Lake Victoria is a rich brownish yellow. The osseous tissue is massive, the bone heavy, but does not adhere to the tongue. The minute cancelli are vacant, not filled up by mineral matter. The dental canal contains the easily displaced lacustrine deposit. The Nototherian fossils from Darling Downs are either of a deeper and duller brown colour, as in the first described jaw (Plate XXXVIII.), or of a greyish mottled stone-colour, as in the third and fourth specimens.

C. Nototherium inerme, Ow.-The fossil(Plate XLII.) on which the species Nototherium inerme is founded consists of a left ramus of the lower jaw, mutilated and abraded as in most of the specimens from the river-beds and deposits of Queensland. The base of the coronoid (fig. 1, $f$ ), with the entry of the dental canal (fig. 3,o) and part of the inflected angle (ib. $b, e$ ), remain at the hind end of the specimen, and the back part of the symphysis (figs. $2 \& 3, s$ ) terminates the fore end. 'The symphysis does not extend backward beyond the vertical parallel of the fore half of the second molar $\left(d_{4}\right)$. 'The dental canal (fig. 3,0 ) begins near the level of the molar, and 1 inch 9 lines behind the last alveolus. In the type mandible of Nototherium Mitchelli, as in the subjects of Plates XXXVIII. \& XXXIX., the orifice of the dental canal is raised above the level of the grinders, and is 3 inches behind the last alveolus; yet the antero-posterior diameter of that alveolus is less in Nototherium Mitchelli than it is in N. inerme. The specific difference of $N$. inerme from both $N$. Mitchelli and $N$. Victorice is also shown in the relative position of the symphysis to the fully developed molar series. 'The absence of any trace of incisive alveolus at the fractured part of the symphysis indicates the tooth to have been relatively smaller, still less of the character of a tusk or weapon offensive or defensive; whence the specific name originally suggested by the present fossil *. The depth of the horizontal ramus is relatively less than in Nototherium Mitchelli, and diminishes in a * 'Catalogue of the Fossil Mammalia \&c. in Mus. Coll. Surg.,' 1845, p. 314. 
greater degree toward the symphysis. The vertical diameter at the back part of the symphysis is 2 inches in Nototherium incrme; in $N$. Mitchelli it is 2 inches 10 lines; yet the fore-and-aft extent of the four last alveoli is 6 inches in the former and 5 inches 7 lines in the latter, the same specimens which afford the difference of depth of ramus yielding the latter admeasurement.

The longitudinal extent in which the lower border of the ramus is inflected (fig. $3, d, d^{\prime}$ ) equals that in Nototherium Victorice; it is also interrupted at a similar part, but apparently less abruptly. 'The dental canal (fig. $3, o$ ) perforates the smooth ridge or longitudinal rising of bone leading from the postmolar process toward the back part of the rising ramus, and, as in other Nototheria and in the Diprotodon, does not communicate with any canal leading to the outer surface of that ramus, as is the case in Phascolomys and the Poëphaga. The anterior outlet of the dental canal is below the position for the socket of the first molar $\left(d_{3}\right)$, which socket would seem to be obliterated and the tooth shed earlier than in Nototherium Mitchelli or in $N$. Victorice. In the forward slope of so much as is preserved of the posterior margin of the ascending ramus and its uninter rupted continuation with the convex curvature leading to the symphysis, in the presence and position of the postmolar process, in the position of the base of the coronoid process exterior to the hindmost molar, in the thickness of the horizontal ramus and the convexity of its outer surface, the present jaw exemplifies its resemblance to that in Phascolomys; but it differs in the absence of the deep excavation on the outside of the ascending ramus, and in the inferior depth of the inner concarity due to the inferior extent of the inward production of the angle of the jaw, which marsupial character reaches its maximum in the smaller existing Poephagous and Rhizophagous families.

D. Comparison of the Mandible.-In comparing the mandible of Nototherium with that of Diprotodon, the chief difference relates, as might be surmised, to the chief dental one, viz. to the development, in the larger marsupial Herbivore, of the mandibular incisors into deeply implanted scalpriform tusks. The part of the jaw supporting and wielding these instruments is accordingly both deepened and widened in Diprotodon, and it is also, on an obvious mechanical principle, strengthened or rendered more massive by the presence of the pair of subsymphysial tuberosities *, of which there is no trace in Nototherium. The horizontal ramus in the smaller extinct genus is less deep in proportion to its breadth or thickness, and it loses depth at the symphysis instead of gaining it there, as in Diprotodont. Consequently the lower contour of the horizontal ramus presents opposite curves in the two genera ; it passes to the symphysis, describing a concarity in Diprotodon and a convexity in Nototherium. These differences are more marked in the adult than in the young animals, becoming more conspicuous in Diprotodon as the incisive tusk acquires its adult proportions.

In all the Nototherian mandibles the lower border is inflected at two parts; the one

* Plate XIX. figs. 1 \& $2, t, t$, p. 197.

$\dagger$ Plate XIX. fig. 1, $t$; and compare Plate XXVII. fig. 2, with Plate XLII. fig. 3. 
in the horizontal portion, the other in the ascending portion, or "ramus." It may well be that this character, which is not present in Kangaroos and Wombats, may be presented by Diprotodon, when a perfect mandible of that animal is obtained; but if the fore part of the inflected border shown in the subject of Plate XXVII. fig. 2 be the beginning of an anterior inflection divided by a non-inflected tract from the posterior inflection, which represents the inflected angle in Macropus and Phascolomys, such beginning is more posterior in position, more nearly where the angular inflection begins in Nototherium. In the adult jaw of $N$. Victorice (Plate XLI.) and in the immature one of $N$. Mitchelli (Plate XL.) the whole extent of the anterior inflection $(d)$ is shown; only, in the adult specimen, the free border has suffered.

The orifice of the dental canal is raised to a level above that of the summits of the last molars in Diprotodon. The largest of the species of Nototherium differs little in this respect; but in $N$. Victorice and $N$. inerme the orifice is brought down to, or near to, the level of the alveolar outlets. In the smaller existing herbivorous Marsupials it is placed still lower, being hidden in an excavation which does not exist in the extinct pouched herbivorous giants.

Of the position of the condyle we can speak only as it is indicated in Nototherium Victorice. Here it is raised high above the level of the molar series, as in all herbirorous Marsupials, but not so much raised relatively as in Diprotodon.

In the curve by which the coronoid process adrances and rises from the fore part of the neck of the condyle, Nototherium resembles Phascolomys more than it does Macropus, in which the process rises in almost a straight line obliquely forward to its pointed apex.

\$4. Dentition.-The dental formula of Nototherium, as of Diprotodon, is $i \frac{3-3}{1-1}, c \frac{0-0}{0-0}$, $m \frac{5-5}{5-5}=28$. The homologies of the molars with those of diphyodont Mammals are given by the symbols $d_{3}, d_{4}, m_{1}, m_{2}, m_{3}$, by which those teeth in the present paper will be signified as they range from before backward*.

The upper incisors, $i_{1}, i_{2}, i_{3}$ (Plate XXXVI. fig. 1, Plate XXXVII. fig. 3), follow one another in the same direction in each premaxillary, the foremost being the largest and the sole pair visible in a front view (Plate XXXVI. fig. 2). The right and left series run nearly parallel, slightly converging posteriorly; the greater interval between the right and left incisors of the second and third pairs is due to their smaller size, and their outer surface ranging with that of the larger exterior pair (Plate XXXVI. fig. $3,{ }_{22}{ }^{*}$ ). In the old Nototherium Mitchelli the first incisor does not project beyond an inch from the socket, the crown being directed downward very slightly forward and outward. The entire tooth (Plate XLIII. figs. 1 \& 2) is 5 inches 1 line long in a straight line, 1 inch $7 \frac{1}{2}$ lines in the greatest (fore-and-aft) diameter, which is about the middle of the root,

- In my Memoir on Nototherium (Quarterly Journal of the Geological Society, rol. xr. 1859), I state, in regard to these molars, that " the first appears to be a premolar and the rest true molars" (p.171). I am now able to adduce [Plate XL. fig. 5] eridence that the first tooth is the homologue of $d 3$ in Mlacropus, and has no vertical successor $=p$ s. 
10 lines in greatest transverse diameter. 'The enamelled crown (ib. fig. 1, $e$ and 1, $b$ ) is 1 inch in length, bevelled off, chisel-wise, from before upward and backward, and shows the partial application of enamel usual in such teeth: the free margin on the outer side of the crown (fig. 1,b) extends further back than that on the inner side (fig. 1,e), and is slightly everted; it is also thicker than on the even inner border. The breadth of the unenamelled back part of the crown at its base is $6 \frac{1}{2}$ lines. Owing to the difference in extent of enamel on the sides of the crown, the abraded surface slopes from without inward and backward, as well as from before upward and backward. The enamel is $\frac{1}{4}$ of a line in thickness at the outer side of the crown; the whole outer surface is smooth. 'The crown is broadly convex anteriorly, rather flatter on the inner than on the outer side. 'The root is thickly covered by cement, and increases in every dimension, chiefly from before backward, as it recedes from the crown, until at a little below its mid length it attains the dimensions above given; it then diminishes to the pulp end. The outer side begins to be impressed by a longitudinal shallow channel about an inch and a half below the crown; and this channel increases in breadth, but not in depth, becoming, indeed, shallower near the pulp end of the root. On the inner side (fig. 1) the longitudinal channel begins somewhat nearer the crown, and sinks deeper as it recedes, besides becoming wider. 'The tooth is compressed and gently recurved, the front margin lescribing a greater convexity lengthwise than is the concavity of the hind margin; the root contracts to an anteroposterior diameter of 1 inch 3 lines; it is slightly excavated by the shallow remnant of the pulp-carity (fig. 1, a). The breadth, owing to the oppo. site lateral channels, is least at the middle of this end, where it contracts to 3 lines; the part anterior to this gives a breadth of $4 \frac{1}{2}$ lines.

Thus the first incisor in Nototherium differs from that in Diprotodon not only in size, both relative and absolute, in curvature, and in shape, but in structure or in kind. It is not scalpriform, not an ever-growing tusk with the enamel continued to the widely open base, but is a tooth of limited growth, consisting of a well-defined crown and fang. In this character the Nototherium resembles the Kangaroos, whilst the Diprotodon shows the Wombat or Rodent type of incisor.

Of the second and third incisors of Nototherium, notliing more is known to me than may be inferred from the sockets indicated in the cast of the skull now at Sydney. These seem to show that Nototherium, like Diprotodon, had them of similar and small size; the third not having its enamelled crown longitudinally extended and trenchant as in many Kangaroos. The longest diameter of the crown would appear to have been 6 or 7 lines.

Of the molars of the upper jaw I have, of Nototherium Mitchelli, the second, third, and fourth in situ, in a portion of the left maxilla; the same tecth $\left(d_{4}, m_{1}, m_{2}\right)$, more worn, in a portion of the right maxilla of an older and larger Notothere; and the third and fourth in situ in a fragment of the right maxilla of a younger specimen. The entire molar series of both sides is shown in the cast of the skull in the Australian Museum (Plates XXXVI.\& XXXVII.), and the left series in the cast of the left maxilla of another 
individual, probably female. Photographs of both these specimens, now in the Museum of Natural History, Sydney, New South Wales, have been transmitted to me by direction of the Trustees of the Museum.

Of Nototherium inerme I have the entire molar series of both sides of the upper jaw; with sufficient of that part of the skull to demonstrate its generic concordance with the more complete specimen of the skull of the type-species in the Museum at Sydney.

From these materials the characters of the upper molars of the present genus can be satisfactorily given.

The series of five molars in the entire skull [Plate XXXVI. fig. 1, Plate XXXVII. fig. 3 (reduced), Plate XLIII. figs. 3 \& 4, nat. size] occupies an alveolar extent of 7 inches 2 lines; it describes a slight convexity downward and also outward, the right and left series converging anteriorly (Plate XXXVII. fig. 3) in a rather greater degree than in Iiprotodon. The interval between the anterior lobes of the right and left last molars $\left(m_{3}\right)$ is 2 inches 3 lines; that between the first small molars $\left(d_{3}\right)$ is 2 inches. As in Diprotodon, the inner end of the front lobe of each two-ridged molar projects inward beyond the inner surface or contour of the antecedent tooth; but the hind lobe does not project so far beyond the level of the front lobe of the succeeding tooth as in Diprotodon.

The first upper molar $\left(d_{3}\right)$ may be said to be two-lobed, but is divided in an opposite direction to that in the rest of the series; viz. into an outer and an inner, rather than a front and a back, lobe. The working-surface is subtriangular in form, the angles obtusely rounded, measuring in fore-and-aft extent 1 inch 1 line in the male Nototherium Mitchelli (Plate XLIII. figs. $3 \& 4, d_{3}$ ); the transverse diameter, posteriorly, is 11 lines. The outer lobe or division is the chief one, and constitutes the outer two thirds and the whole fore-and-aft extent of the tooth; the outer side of its base swells out like part of a cingulum or ridge; the summit is subcompressed, and seems to have been trituberculate; the inner and lower division consists of a larger hind tubercle and a smaller front one. On the whole, therefore, the tooth approaches the subsectorial type of its homologue in the Koala (Phascolarctos, p. 153 , fig. $6, p_{4}$ ); it is implanted by two roots, one behind the other, the posterior being the largest and grooved anteriorly, as if preparatory to further transverse subdivision.

The second molar (Plate XLIII. figs. $3 \& 4, d_{4}$ ) has a subquadrate working-surface, divided into two transverse wedge-shaped lobes $(a, b)$, with an anterior $(f)$ and a posterior $(g)$ basal ridge; the latter is the thickest, and developes a small tuberosity at its outer end. This ridge is continued upon the outer and inner borders of the hind surface of the hind lobe, and further upon the outer than the inner one. A short ridge closes the outer and inner ends of the transverse valley. The antero-posterior diameter of the crown is 1 inch 1 line, as is likewise the transverse diameter of the broadest part of the tooth. The direction of the summits of the two lobes is downward and a little forward; they run across the tooth rather more obliquely than in Diprotodon (Plate XXI. fig. 2, $d_{4}$ ), but with a similar curve of the apical ridge slightly concave backward. The less exposed 
enamel toward the bottom of the valley and near the basal ridges is punctate; but grenerally the enamel is smoother and more polished than in Diprotodon. This molar, like the rest of the upper ones, is implanted by two transversely disposed anterior roots (Plate XLIII. fig. 8), and one long transversely extended posterior root.

The third molar (Plate XIIIII. figs. $3 \& 4, m_{1}$ ) has its ridges extended rather less obliquely than in $d s$, but more so than in $m$ s of Diprotodon. 'The antero-posterior diameter is 1 inch 4 lines; the transverse diameter 1 inch 3 lines. As the lobes are more entire they show better the curve of their summits, concave backward. 'The thicker anterior basal ridge $\left(f^{\prime}\right)$ is continued at botl ends upon the corresponding borders of the anterior lobe. The posterior basal ridge $(g)$ is continued internally to the apex of the posterior lobe, gradually subsiding; externally it curves upon the end of the lobe, and subsides halfiray to the summit.

'The fourth molar (Plate XLIII. figs. $3 \& 4, m_{2}$ ) shows a diminution of breadth of the hind lobe in a greater degree than the corresponding tooth does in Diprotodon; its foreand-aft extent is 1 inch $S$ lines. The transverse breadth of the front lobe is, in the old male (fig. 7), 1 inch 7 lines; in the subject of fig. 4,1 inch 6 lines; that of the hind lobe is 1 inch 5 lines. The imner end of each lobe is made thicker by a backward expansion, rather more marked in $m_{2}$ than in $m_{1}$.

In the last molar (Plate XLIII. figs. $3 \& 4, m_{3}$ ) the slightly abraded summits of the lobes show the more vertical or steeper slope of their fore side, which is convex transversely; also the transverse concavity of the hind side, due to the seeming backward bend, with thickening, of the outer and inner borders, and the curving slope of the hind part of the lobes, which gives them in profile a slight bend forward (fig. $3, m_{3}$ ) as in Dipiotodon.

The fore-and-aft extent of this tooth is 1 inch 8 lines; the breadth of the front lobe is 1 inch 7 lines; that of the hind lobe is 1 inch 3 lines; it contracts more rapidly to its summit than in Itiprotodon. The posterior root of $m_{3}$ is slightly impressed lengthwise at its back part, and deeply so at its fore part.

The origin of the outstanding zygomatic process of the maxillary terminates posteriorly opposite, or on a vertical parallel with, the interspace between the third and fourth molars. In one large old Notothere (Plate XLII. fig. 6) it extends, as before observed, a little further back; in an immature individual its origin hardly extends backward beyond the middle of $m$. . This abutment against the upper molar alveoli is strengthened, as the hind molars take more share in the work of mastication. The base of the process stretches forward and upward as far as the parallel with the first alveolus.

A portion of the left upper maxillary of Nototherium, with $d_{4}, m_{1}$, and $m_{2}$, rather more worn than in the above-described specimen, exemplifies the same relation of the base of the malar process of the maxillary with the alvcoli of the three anterior molars.

In not any of the upper molars is the anterior basal ridge $(f)$ so large relatively as in Dipiotodon.

In the upper jaw of Nototherium Mitchelli, in which the last molar had recently 
come into place and the enamel had been slightly worn along the summit of the anterior ridge, the second molar showed the lobes worn down two thirds of the way toward the valley. In the cast of the right maxilla with the dentine exposed on the lobes of $m_{3}$, those of $d_{4}$ are worn down to the shallowest part of the valley. In the oldest specimen of this species the grinding-surface of this tooth (ib. fig. $7, d_{4}$ ) is reduced to a smooth field of dentine $(d)$ and osteodentine $(o)$, with a peripheral boundary of enamel, $e$. This dental constituent does not exceed a line in thickness at this stage of abrasion.

The dentition of the upper jaw of Nototherium inerme is known to me by a portion of that jaw with the right and left series of grinders and much of the intervening bony palate; but the premaxillaries and upper incisors are wanting, being broken away with the contiguous part of the maxillary close to the molar $\left(d_{3}\right)$; and both this and the second molar $\left(d_{4}\right)$ are mutilated on the left side of the jaw. The right series is represented of the natural size in figure 5, Plate XLIII.

The first molar is relatively smaller and less complex on the grinding-surface than is $d_{3}$ in Nototherium Mitchelli (ib. fig. 4): the transverse and antero-posterior diameters are alike. The outer lobe or division has one coronal prominence upon which a slender triangular tract of dentine is exposed extended antero-posteriorly; a more equal-sided triangular tract is exposed on the shorter inner lobe; an anterior and a posterior basal ridge bound corresponding depressions divided by the confluence of the apices of the outer and inner divisions at the centre of the crown; a short external basal ridge closes the concavity impressed upon the hind half of the outer surface of the crown. One cannot distinguish, with certainty, the worn enamel from the dentinal tracts in the plaster cast of the answerable tooth of Nototherium Mitchelli; nor do the photographs help in this particular; but both concur in demonstrating the differences of size, shape, and proportion of the anterior molar, which I judge to exceed those allowed to sexual or individual variation, without affording ground for inferring generic distinction from the modifications of $d_{3}$, represented in Plate XLIII.

The more constant teeth $\left(d_{4}-m_{3}\right)$ in figure 5 exemplify the Nototherian characters with the inferiority of size, corresponding with the little that is known of the present species. Nototherium inerme, like Not. Mitchelli, has the hind lobe of the last molar contracted in breadth, and the antero-posterior extent of the crown is less than that in the opposing molar $\left(m_{3}\right)$ of the lower jaw.

A greater proportion of the enamel of this worn grinder, in the subject of fig. 5, Plate XLIII., shows the punctate rugous character than in the antecedent teeth.

The specific character of Nototherium inerme is well exemplified by the minor relative size of the anterior molar, $d_{3}$ (Plate XLIII. fig. 5 ), of the upper jaw, as by that of . the incisor in the lower jaw.

Of the dentition of this jaw, I commence the description with those in that of the immature specimen of Nototherium Mitchelli (Plate XL.), consisting of the right ramus of the mandible with the first three molars in place, the germ of a fourth, and part of the formative cavity of a fifth molar. The tip of a procumbent incisor projects 
from a socket, close to the symphysis, where sufficient of the cavity was exposed to show that it expanded as it sank in the substance of the jaw.

Putting aside for awhile the evidence of the nature of this specimen afforded by others since received from Australia, I believe it may be of some interest and instructiveness to show how far its determination can be carried, on the supposition that it is the sole eximple of its genus or order.

The mammalian character is seen at a glance by the complex crowns and rooted implantation of the molars, and by the simple condition of the ramus of the jaw, as of one piece of bone. The nonage of the individual to which the jaw has belonged is recognized at the same moment.

Of Mammalia corresponding in size with the parent of a young one having its newly cut milk-series of tecth in a jaw $S$ inches long, the number of genera is not great; and we may be excused for thinking that most of those which are now represented by living species must be known. Of these we should be led at once to Curier's Pachyderms by the shape and size of the teeth of our young giant. 'The broad complex crowns of the molars show its herbivorous nature. The Tapir alone exhibits the bilophodont type of the second and third milk-grinders, with the conical, partly trenchant, partly crushing shape of the first; but it developes, with these in the mandible, eight small front teeth, of which the outermost pair are canines. A Rhinoceros of Sumatra or Java may show a pair of large tusk-like lower incisors, but they are associated, in the milk-dentition, with a smaller pair of mid incisors*.

'There is another and more significant difference which the present fossil evidence of a large Herbirore presents in comparison with a specimen of the same age, or with the same phase of dentition, of any existing species of like size. In the young Tapir, e.g., with three deciduous molars in each mandibular ramus, and the germ of the next molar lying in its formative cavity deeper and less advanced than in the present fossil, the enamel has been worn from the summits of the first and second milk-molars so far as to expose the dentine, and it is abraded obliquely backward from the summits of both ridges of the third molar.

So also in a young Rhinoceros in which the second and third milk-molars are in place, the first and fourth being still "en germe," the enamel shows masticatory abrasion at the summits of the two chief lobes of $d_{2}$ and $d_{3}$. Corresponding signs of the assumption of regetable nutriment in addition to that afforded by the mother's milk are visible in young Equines and Ruminants with a stage of molar dentition corresponding to that shown by the fossil under consideration.

Now here, although the first, second, and third molars are well in place, and the basal ridges of the fourth have risen to the brim of the socket, the enamel shows only a linear trace of attrition on the ridges of the second molar (Plate XL. fig. $3, d_{4}, h, g$ ), with a rery feeble trace on the anterior ridge of the third molar (ib. $m_{1}$ ); its hind ridge and the crown of the first molar (ib. $d_{3}$ ) are untouched. The inference is that the young 
Herbivore represented by the fossil derived a greater proportion of its nourishment from the mother, and much less from extraneous sources, than do the placental Herbivores at a corresponding stage of immaturity.

In this respect the fossil repeats the molar conditions of a young Kangaroo (Macropus) at the same phase of dentition $\uparrow$. With this phase the existing marsupial herbivore has attained that size and strength as a denizen of the pouch in which it begins to protrude its head to crop, occasionally, a tender leaf or blade of grass while the mother may be browsing or grazing. In the singleness and size of the sloping incisor, in the shape and proportion of the first molar $\left(d_{3}\right)$, as well as in those of the second and third two-ridged grinders, $d_{4}, \& m_{1}$, the fossil more closely resembles Macropus than any other known genus, whether marsupial or placental.

I accordingly here pushed the comparative research a stage further, and removed the outer wall of the jaw, as in fig. 5, Plate XL., to see if the large Australian bilophodont fossil carried its correspondence with Macropus to the extent of showing the germ of a premolar $\left(p_{3}\right)_{+}^{+}$; but of this tooth there was no trace. The length and deep implantation of the two fangs of $l_{3}(l)$, underlain by the expanded base of the procumbent incisor (ib. $\left.i^{*}\right)$, make it very improbable that such germ of a $p_{3}$ could ever be developed in the species represented by the fossil.

Thus the results of the above comparisons, independently of other evidences of Nototherium, would have led to the conclusion that the young Herbivore, notwithstanding its bulk, belonged to a group of Mammals in which the milk-dentition was not so soon brought into use for grazing or browsing as in the Placental series; that it, therefore, was probably a Marsupial; which conclusion the close concordance in number and shape of grinding-teeth with the largest existing Herbirore of that order (the Kangaroo) would have put beyond doubt.

The lower incisor, in the immature example, had pushed its tip, as has been said, about two thirds of an inch from the socket; it is of a conical form, with an obtuse apex, which has been abraded for the extent of 3 lines (Plate XL. fig. $3, \ddot{i}^{\prime}$ ). 'The ename ${ }^{1}$ coats the outer and under part of the tooth, bending up a little way upon the flat inner side, and in an increasing degree as the tookh expands (Plate XL. fig. $4, e$ ): the enamel is not continued to the open base (ib. fig. $5, i^{*}$ ) as in Diprotodon: the line of termination is well defined. A thin layer of cement coats the rest of the tooth's circumference. The fracture of the exposed crown of the tooth gives a subquadrate surface, longest vertically, with the lewer and outer angle rounded off. The two diameters are here 6 lines and 5 lines; but the rertical diameter of the hollow base exceeds an inch, the length of the entire though incomplete tooth being 2 inches 9 lines. It is directed obliquely forward and upward, at an angle of $140^{\circ}$, with the lower border of the ramus; a rather less open one than in Diprotodon.

† Owex, Art. "Teeth," Cyclopædia of Anatomy \&c., fig. 594, B; and 'Anatomy of Tertebrates,' rol. iii. fig. $296, \mathrm{~B}$.

$\ddagger$ Page 209, fig. 4, $p$ s. 
'The socket of the first molar $\left(d_{3}\right)$ begins in this young jaw one inch behind the opening of that of the incisive tooth, which gives the length of the diastema (ib. fig. 1, k) at this stage of dentition. 'The first molar lias an anterior and a posterior lobe. The front lobe is highest, and is a three-sided cone, with one angle in front and rather produced or ridgelike; it is subcanaliculate internally: the two posterior angles are continued into the fore and hind borders of the hind lobe; this is transverse, low, flat, inclined from behind forward and rather downward to the base of the front lobe. Both lobes are convex outwardly, and separated there by a shallow depression; the inner side of the tooth is much lower than the outer one. The fore-and-aft cliameter of the crown is 9 lines, the transwerse diameter posteriorly $6 \frac{1}{2}$ lines; it is implanted by two fangs (ib. fig. $5, l$ ), one behind the other, and each 10 lines in length; the entire length of the tooth, vertically, is 1 inch 6 lines.

The second molar (ib. $d_{4}$ ) assumes the two transversely ridged or bilophodont type, the lobes being in the form of transverse wedges. The anterior lobe is narrower transversely, broader from before backward than the posterior one. The anterior basal ridge $\left(f^{\prime}\right)$ is a continuation of the slightly produced fore margins of the outer and inner sides of the front lobe, at their lower ends, into one another, defining below the slightly cxcavated surface on the fore part of the anterior lobe, the enamel of which is finely rugous. From the junction of the basal with the outer vertical ridge, a similar ridge is continued curving downward and backward, and then rising upon the posterior part of the outer surface of the front lobe (ib. fig. 1, a), defining upon that surface a finely rugous tract of enamel. The inner side of the front lobe (ib. fig. 4, a) has no such ridge. The hind surface of this lobe is less definitely bounded by a backward prominence of the outer border, and a slight vertical ridge or fold of enamel near the inner border. The valley (h) between the lobes has both the outer and inner entry crossed by a short ridge, the outer one being the strongest. The posterior basal ridge $(g)$ is the broadest; its outer and inner ends bend up a short way upon the hind surface of the hind lobe. The line of initial abrasion at the edges of the two lobes is from above downward and backward. Both lobes present in profile a slight curve backward. The length (fore-and-aft diameter) of the tooth is 1 inch 2 lines; the breadth (transverse diameter) of the front lobe is 9 lines, that of the hind lobe is 11 lines. It is broader in proportion to its lengtts than in Diprotodon*. The anterior and posterior basal ridges are narrower, relatively, than in that genus.

'The third molar (Plate XL., $m_{1}$ ) has the two lobes of equal breadth save at the summit, where this dimension rather exceeds in the hind lobe: the front lobe rises higher than the hind one. The front basal ridge is continued more abruptly from the anterior angle of the inner border of the lobe than in $d_{4}$, and it passes outward to the base of the outer end of that lobe, like a "cingulum," without being continued upward into the outer prominence bounding that part of the front surface of the front lobe (fig. $3, m_{1}$ ). This surface, as in the second molar, is finely rugous; it is concave transversely, convex 
vertically. The cingulum rises to a point, forming an angle upon the outer side of the base of the anterior lobe (fig. $\left.1, m_{1}\right)$. The closing ridge of the valley is formed by its continuation backward from the angle, and is limited to the outer entry. The hind basal ridge $(g)$ is thicker than in $d 4$.

The two lobes are not on the same parallel, but rather "en échelon," the hind one rising more mesially or internally, and its inner and fore angle looking forward clear of that of the other lobe. The unworn summits are more bent backward than in $d_{4}$. The fore-and-aft extent of $m_{1}$ is 1 inch 6 lines; the transverse diameter of the base of each lobe is 1 inch.

In the partially exposed calcified germ of $m_{2}$ (ib. figs. $3 \& 4$ ) the summits of the two lobes are not quite parallel, and the hind border of the hind lobe slopes more backward to a well-developed basal ridge.

The smooth shallow cavity behind the alveolus of $m_{2}$ is plainly the beginning of the formative chamber of $m_{3}$, calcification of which had probably not begun.

I regret not to possess specimens of Nototherium showing stages of mandibular dentition between that above described and the subject of Plate XLIV. fig. 3.

This specimen forms part of a collection of fossils from the deposits of Darling Downs made by Hexry Hughes, Esq., and now in the Museum of the Natural-History Society of Worcester, to the Council of which I am indebted for the opportunity of examining, comparing at the British Museum, and figuring instructive evidences of extinct Australian Mammals. The one which is referable to Nototherium is the right ramus of the mandible with the last three molars in situ, the fangs of the second and part of the alveolus of the first molar. The two fangs of the second molar (ib. $d_{4}$ ) show a fore-andaft extent of at least 1 inch 2 lines for the crown of that tooth, with an extreme breadth of eight lines. That a still smaller tooth preceded it is indicated, as before remarked, by a part of its socket $\left(d_{3}\right)$. The shape of that tooth, generically distinguishing Nototherium from Diprotodon, is instructively shown in the preceding specimen (Plate XL.). The antepenultimate tooth, or third counting backward (Plate XLIV. fig. $3, m_{1}$ ), measures 1 inch 6 lines in long diameter, and 1 inch 2 lines across the hinder lobe; the talon $(g)$ at the back of this lobe is as well developed relatively as in the penultimate molar. The ridge $(r)$ or production of the outer and front angle of the back lobe obliquely toward the middle of the front lobe is conspicuous at this stage of attrition; much of the front lobe has been broken away.

The crown of the penultimate molar $\left(m_{2}\right)$ is in length 1 inch 8 lines, in breadth 1 inch 3 lines, in height 8 lines; the dentine is exposed at the summit of each ridge. The two ridges, or bilophodont type, of the molars of Nototherium were indicated rather than demonstrated in the specimens on which the genus was founded. The restoration ventured on in the figures of these fossils* was verified by the molars in the immature jaw subsequently sent by LeIchналDт. The first complete penultimate molar which I had the opportunity of studying showed the base of the crown girt by a "cingulum,"

* "On the Extinct Mammals of Australia," Reports of Brit. Assoc. for 1844, p. 231, plate 3. fig. 1. 
developed behind into a low talon, and interrupted at the outer end and more so at the imer end of the two main lobes, and for a greater extent at the inner than at the outer sides: this character my present series shows to be constant.

'I'he horizontal contour of the crown of the penultimate molar is rather rhomboidal than quadrate; for the hind lobe is more interual in position than the front one, and the ridges run, not in a line directly across the alveolar border, but from without inward and a little backward. The fore part of the outer end of each ridge is a little produced, most so in the hinder one, in which the produced part inclining inward, terminates or abuts below upon the middle of the base of the front ridge: the anterior part of the inner end of each ridge is a little produced forward, in an angular form; the greneral result is that the summit of each ridge is slightly concave forward, convex backward.

'The ฮี amel is for the most part smooth and polished; the delicate strix of growth are well marked when viewed by a pocket-lens on the outer side of the tooth, and the same power brings into view a few punctations on the hinder slope of each ridge: the enamel is rather thicker on this slope than on the front one, and seems more so from being more obliquely abraded from before downward and backward: so exposed, the coronal surface of the enamel is a line in thickness; the tract of dentine abraded in the present tooth is two lines across. 'The hinder talon, or part of the cingulum, is most developed; the front one seems as if destroyed by pressure of that of the preceding molar.

Much of the crown of the last molar (ib. $m_{3}$ ) has been broken away; its base measures, in fore-and-aft extent 1 inch 10 lines, in transverse extent 1 inch $3 \frac{1}{2}$ lines; this is at the anterior lobe, the posterior one is narrower. Each fang is longitudinally excavated at the surfaces next each other; and the outer part of the root, so defined, is thicker than the inner part.

'The next stage of dentition which I have had the opportunity of observing in an original specimen of the present species corresponds with that of the maxillary teeth in the skull (Plate XXVII. fig. 3); it is exemplified in the mandible which is the subject of Plate XXXVIII. The crown of the last molar (Plate XLIV. figs. 1 \& 2, $m_{3}$ ) is worn to within three or four lines of the transverse valley; those of the penultimate $\left(m_{2}\right)$ and antepenultimate $\left(m_{1}\right)$ molars show increasing degrees of attrition: the first and second molars are gone, but their sockets remain in the left ramus: the crowns are restored in outline, in fig. 1 , from the subject of Plate XI.

'The anterior fang of the first molar remains in the corresponding division of its socket: the fore-and-aft extent of the socket is 1 inch, being 3 lines more than in the young specimen (Plate XL. figs. 1 to $5, d_{3}$ ). Now, as the roots of the first molar in that specimen are hollow shells of bone widening to their open base, the crown of the tooth may gain increase of support, by enlargement of the fangs before they become solidified, as in the broken one in the present specimen. The difference of size may likewise be referred to difference of sex; it would be hazardous to predicate a difference of species 
on this ground. In both examples they come near, in size, to the anterior molar $\left(d_{3}\right)$ in the upper jaw of Nototherium Mitchelli.

The socket of the second molar (Plate XLIV. figs. $1 \& 2, d_{4}$ ) has a fore-and-aft extent of 1 inch 1 line, which accords closely with that in Plate XL. figs. 1-5, $d_{4}$ ).

The third molar (Plate XLIV. figs. $1 \& 2, m_{1}$ ) shows both lobes abraded to their base; the enamel still crosses the valley, but that between the hind basal ridge and the hind lobe is worn away and a broad smooth expanse of dentine and osteodentine is exposed, 11 lines by 6 lines in diameter. The fore-and-aft extent of the remaining basis of the crown is 1 inch 6 lines; the breadth of the hind lobe is 1 inch. These dimensions accord sufficiently closely for specific identity with those of $m_{1}$, in the immature subject of Plate XL.

In $m_{2}$ (Plate XLIV. figs. $1 \& 2$ ) the enamel of the hind lobe is worn down to the level of the hind basal ridge, which is partly abraded, but not down to the dentine. The narrower and lower anterior basal ridge is intact, and the enamelled crest of the anterior lobe rises 3 lines above it. The anterior productions $(r, r)$ of the two lobes, rudimentally indicating the linking bars in certain Kangaroos, are instructively marked at the present stage of attrition. 'The posterior basal ridge of this tooth overlaps the anterior one of the next $\left(m_{3}\right)$, the front lobe of which rises 5 lines above that level. The anterior prominence near the outer end of each lobe repeats the short forward angle in the contour of the enamel as here worn down. The corresponding prominence of the hinder lobe $(r)$ inclines toward the middle of the valley; the macropodal affinity, slight as it is, is more strongly marked in Nototherium than in Diprotodon*.

The fore-and-aft extent of $m_{3}$ is 1 inch 10 lines, exceeding by 2 lines that of the opposing molar above (Plate XLIII. fig. $4, m_{3}$ ): in this, also, a macropodal character is repeated. 'The transverse extent of the front lobe of $m_{3}$, fig. 3 , is 1 inch 4 lines; that of the hind lobe is less.

The entire extent of the lower molar series is 7 inches 2 lines, about 2 lines less than that of the upper molar series in the skull of Nototherium Mitchelli (Plate XXXVI. fig. 1).

In the series of sockets of the lower jaw of possibly the same individual, the partition between the fore and hind fangs of each tooth is much thicker than that between the sockets of distinct teeth. The transverse space between the hind lobes of the right and left last lower molars is 2 inches 9 lines; between the front lobes of the first molars 1 inch 5 lines. Each mandibular series describes a very slight curve as it advances forward, with the convexity outward. The base of the socket of the incisor, which does not extend beyond that of the first molar, is 1 inch 2 lines in vertical diameter, 8 lines in transverse diameter.

In the specimen of the mandible with the symphysis entire, or nearly so (known to me by the cast, Plate XXXIX.), the molars show almost the same stage of attrition as in the preceding specimen. The first and second molars are retained on the left side.

* Compare figures 11 \& 18, Plate XXIV. with figures $1,2, \& 3$ in Plate XLIII. 
'The crown of the first $\left(d_{s}\right)$ is worn down to a flattened uniform surface, showing the same posterior breadth as in the entire crown in the immature jaw. The two roots supporting it have now risen nearly half an inch above the socket. 'The dimensions and proportions of the following four grinders closely accord with those in the mandible, the teeth of which are figured of the natural size in Plate XLIII. fig. 3.

In the part of the right ramus of Nototherium Nitchelli with the three last molars and the back part of the symphysis, the molars are worn nearly to the same degree: their antero-posterior extent is 5 inches 2 lines. The left ramus of the same species, more mutilated anteriorly, but with a greater proportion of the ascending branch, shows the last two molars similarly worn. The enamel in these Nototherian specimens is as thick as in Diprotodon.

In a mandibular fragment with the lobes of the last molar worn down to the valley, the anterior root of the penultimate molar is exposed, showing a strong curve convex forward, with a deep anterior longitudinal indent almost dividing the implanted end (Plate XLIV. fig. 8). The fine rugosity of the cement, repeated on the closely clasping wall of the socket, is here well shown.

'The molars (Plate XLIV. figs. 4, 5,6) in the mandible of Nototherium Victoria (Plate XLI.) show nearly the same stage of attrition as in the Worcester specimen of $N$. Mitchelli (Plate XLIV. fig. 3).

As already stated, they are limited to the last three teeth and a fragment of the one in advance. In $m$, the ridge closing the outer entry of the valley ( $h$, figs. $4 \& 5$ ) developes an enamel tubercle; and there is a smaller one at the inner entry ( $h$, fig. 6$)$. Of this there is no trace in the perfect specimen of that molar in the immature jaw of Nototherium Mitchelli (Plate XL.), and only a very feeble indication of such on the outer side. The rudiment of the "link" or ridge $(r)$ from the hind lobe to the middle of the base of the liind surface of the front lobe is well marked in $N$. Victorice. The hind talon $(g)$ closely overlaps so as to interlock with the front talon $(f)$ of the penultimate molar, $m_{2}$. 'The abraded surfaces of the two lobes slope from before downward and backirard. The fore-and-aft diameter of $m_{1}$ is 1 inch 6 lines.

The fore part of the penultimate molar (fig. $4, a, m_{2}$ ) rises half an inch above the overlapping talon $(g)$ of the antecedent tooth, at the outer and inner ends of which the front talon of $m_{2}$ appears. Externally.it curves up to terminate near the base of the fore and outer part of the front lobe; on the inner side it sooner subsides. 'The greater breadth, as compared with $m_{1}$ of the front lobe, is gained chiefly by extension of the inner part. A ridge, beginning at the back part of the outer end of the front lobe, curres down to the outer entry of the valley, derelopes there a tubercle, and curves up the outer side of the hind lobe, whence a similar ridge curves downward and backward to the hind talon; the middle and thickest part of this is undermined by the smooth surface which overlies the front talon of the last molar $\left(f, m_{3}\right)$.

'ihe fore-and-aft extent of $m_{2}$ is 1 inch 9 lines; the transverse breadth of the front lobe is 1 inch $2 \frac{1}{2}$ lines, that of the hind lobe is 1 inch 1 line. The abraded surfaces 
of the summits of these lobes slope, as in $m_{1}$, in the same direction but in a greater degree. The hind root of $m_{2}$ is exposed by the fracture shown in figs. $1 \& 2$, Plate XLI. ; it inclines somewhat backward as it sinks in the socket; its basal breadth at the outlet of the socket is 1 inch; it contracts, in the same direction, to 7 lines; much of its surface shows minute granulate longitudinal striations.

The last molar (Plate XLIV. figs. 4, 5, 6, $\mathrm{m}_{3}$ ) rises above and projects inwardly beyond the preceding, in the same degree as $m_{2}$ does in relation to $m_{1}$. The festoon character of the ridges curving toward the outer entry of the valley and to the hind talon is repeated in greater strength; the outer closing tubercle (fig. $4, h$ ) is less marked than in $m_{1}$, but is conspicuous, as is that in the ridge closing the inner entry (fig. $5, h^{\prime}$ ). I incline to regard these tubercles as constant, and as differentiating the last two molars of the present species from those of Nototherium Nitchelli. A mere linear tract of dentine is exposed on the obliquely worn apices of the transverse ridges of $m_{3}$. 'The fore-and-aft diameter of this molar is 1 inch 10 lines; the transverse extent of the abraded summit of the hind lobe is 10 lines, but that of its base is $13 \frac{1}{2}$ lines, the same diameter of the front lobe being 15 lines. The enamel in Nototherium Victorice is not so thick as in N. Mitchelli; its surface is similar.

When the skull, or upper jaw, of this species may be found in South Australia, it will yield, as in the case of the Queensland specimen, the characters ascribed by MACLEAY to Zygomaturus, with, probably, better marked specific characters than those of the lower jaw.

$\S 5$. Conclusion.-No mandible or mandibular teeth, referable or adaptable to those of the maxilla in the unique subject of Plates XXXVI. \& XXXVII., have yet been discovered, save those which yield the characters of the genus Nototherium. No skull adaptable to the mandible and mandibular teeth of Nototherium has yet been discovered, save that to which the name Zygomaturus was given. The admission, therefore, into palæontological catalogues of two genera of bilophodont Marsupialia of the bulk of Nototherium awaits the discovery of fossils demonstrating the distinctive characters of such.

Taking a retrospect of the dental characters of the genus Nototherium with reference to a comparison with those of the genus Diprotodon, we find that the indications, few and feeble though they seemed in the mutilated mandibles and mandibular dentition first received*, have been supported and the inferences therefrom verified in a striking and unexpected degree by the characters of the rest of the skull and of the maxillary dentition.

The first molar, for example, does not give, in miniature, the bilophodont character of the other and larger molars; its crown answers rather to the outer half of the tworidged grinder with a rudiment of the inner half of the hinder transverse ridge or lobe. This tooth, in fact, exemplifies the final stage of modification converting the longitudi- 
nally trenchant type of the premolar in existing Carpophagous and Poëphagous Marsupials into the crushing character shown in the homologous tooth of the larger marsupial Herbirores. 'The rest of the molar series in Nototherium differs from that in Diprotodon by the smaller size and in the smoother enamel; and, perhaps, in a little stronger indication of the production of the hind part, near the inner end, of the transverse lobes, especially of the front one.

In the incisor series the generic character of Nototherium is strongly marked by the form, structure, and nature of the front upper incisor, as before described: and in this character we see a nearer approach of Nototherium to Macropus, while the characters of the front upper incisor in Diprotodon approximate that genus to Phascolomys. But in the number and disposition of the upper incisors, as in the bilophodont molars of limited growth, both the large extinct genera retain the poëphagous character, as contradistinguished from the rhizophagous modification shown by the Wombats among the existing marsupial Herbirores.

The lower incisor of Nototherium shows more of the scalpriform character, at least in the young individual, than does the upper one; but, in the full-grown animal, this tooth is far from having the proportions and deptl of implantation which make it resemble, in Diprotodon, the lower pair of scalpriform teeth of the Wombats. In Nototherium the lower incisor differs from that in Diprotodon in being narrower, with the enamel continued less far or high upon the inner side: this tooth in the young specimen increases more rapidly as it sinks in the socket; but this may be a repetition of an immature character, which is shown, in a minor degree, in the jaw of the young Iiprotodon described and figured in the preceding section*. The widely open base of the growing incisor does not, however, extend backward beyond the first molar; and as this part contracts and solidifies in the adult, the base of the tooth and its socket are moved more forward, and in one species of Notothere $(N$. inerme) to the anterior half of the symphysis in advance of the roots of the first molar.

I have described, in former works, some detached bones $\uparrow$ which from their size might, and probably do, belong to the genus Nototherium; but I have since received eridence of extinct species of nearly equal size, and more nearly akin to the Wombat and Kangaroo families, to which some of the fossil limb-bones from Nototherian localities might possibly belong. I may venture to state that the olecranon of Nototherium is as little produced as in the ulna of Diprotodon.

* Pages 197, 203, Plate XXVII. fig. $\overline{5}, \ddot{i}$.

+ An astragalus, e.g., in "Report on the Extinct Mammals of Australia," op. cit. p. 233, plate 5. figs. 1-6. 
Table of Localities of Nototherium, showing :-

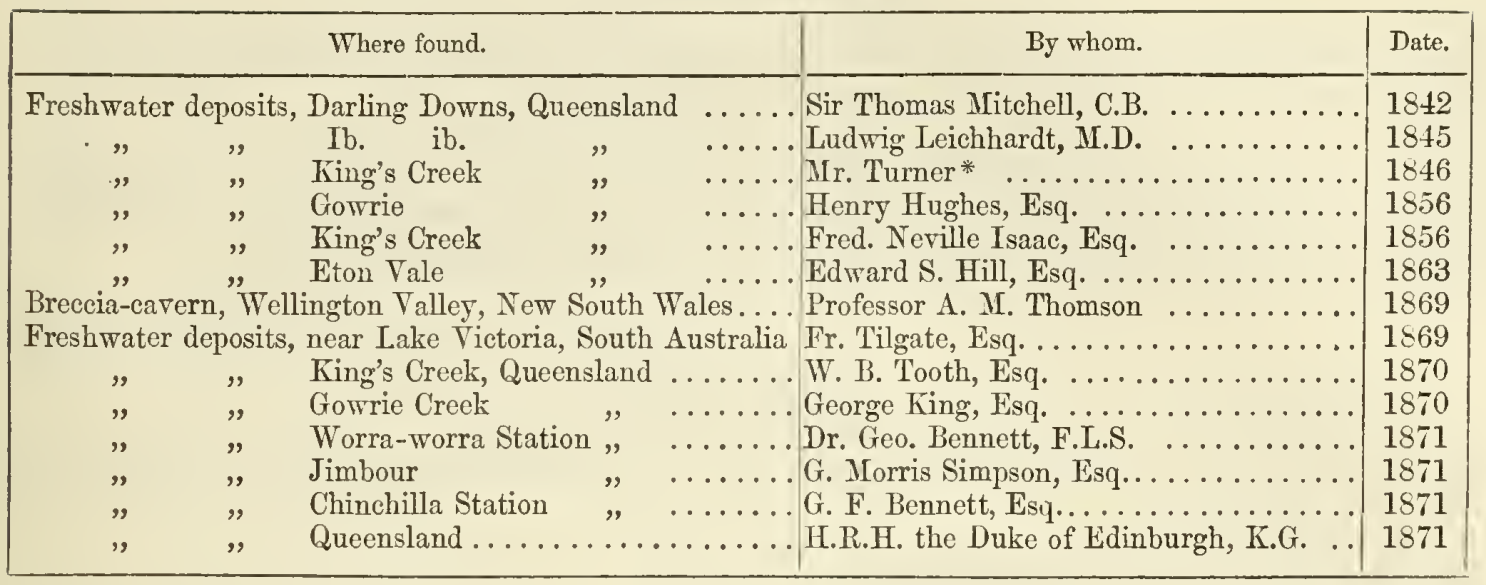

\section{Description of the Plates.}

\section{PLATE XXXVI.}

Fig. 1. Side view of skull of Nototherium Mitchelli:-one third nat. size.

Fig. 2. Front view of skull of Nototherium Mitchelli:-one third nat. size.

Fig. 3. Side view of skull of Phascolarctos fuscus:-one half nat. size.

Fig. 4. Front view of naso-premaxillary end of skull of Phascolomys latifrons:-nat. size.

\section{PLATE XXXVII.}

Fig. 1. Back view of cranium of Nototherium Mitchelli:-one third nat. size.

Fig. 2. Upper view of skull of Nototherium Mitchelli:-one third nat. size.

Fig. 3. Under view of skull of Nototherium Mitchelli:-one third nat. size.

Fig. 4. Back view of skull of Phascolomys platyrhinus:-three fourths nat. size.

\section{PLATE XXXVIII.}

Fig. 1. Oblique side view of mandible of Nototherium Mitchelli (male?):-half nat. size. Fig. 2. Upper view of the same mandible and teeth :- -half nat. size.

Fig. 3. Under view of the same mandible:-half nat. size.

* "In 1845 or 1846, Mr. Turner, Superintendent of a Sheep-station on the Condamine, brought to Sydney a large collection made by himself after various 'freshets' or floods in the creeks of the river had left the fossils bare and protruding from the sides of the gulleys; he disposed of them to a Mr. Benja IIN Boyd, a merchant, who soon after got embarrassed; he sent the fossils to Europe for sale, but suffered our Museum to take casts of all of them." -Letter from W. S. Macleax, Esq., F.R.S., to the author, dated 9th March, $1858 . \quad$ The lower jaw of Nototherium Mitchelli (Plate XXXVIII.) formed part of this collection, which was purchased for the British Museum. 


\section{PLATE XXXIX.}

Fig. 1. Side view of mandible of Nototherium Mitchelli (female?):- half nat. size.

Fig. 2. Under view of the same mandible:-half nat. size.

Fig. 3. Upper view of the same mandible and teeth:-half nat. size.

Fig. 4. Front view of symphysis and broken incisors of the same mandible:-nat. size.

Fig. 5. Back view of part of rising ramus of the same mandible:-nat. size.

\section{PLATE XL.}

Fig. 1. Outer side view of right mandibular ramus and teeth of a young Nototherium Mitchelli.

Fig. 2. Under view of the same ramus.

Fig. 3. Upper view of the same ramus and teeth.

Fig. 4. Inner side view of the same ramus and teeth.

Fig. 5. Outer side view of fore part, with alveoli of the incisor and of the first two molars exposed, of the same ramus.

All the figures are of the natural size.

\section{PLA'TE XLI.}

Fig. 1. Outer side view of part of mandibular ramus and teeth of Nototherium Victoria: -half nat. size.

Fig. 2. Inner side view of the same ramus and teeth:- half nat. size.

Fig. 3. Under view of back part of symphysis of the same ramus:-nat. size.

Fig. 4. Front view of fractured symphysis of the same ramus:-nat. size.

\section{PLATE XLII.}

Fig. 1. Outer side view of mutilated right mandibular ramus and teeth of Nototherium inerme:-half nat. size.

Fig. 2. Upper view of mutilated mandible and teeth of Nototherium inerme:-half nat. size.

Fig. 3. Inner side view of mutilated left mandibular ramus of Nototherium inerme:half nat. size.

Fig. 4. Fractured surface of the symphysis:-two thirds nat. size.

\section{PLATE XLIII.}

Fig. 1. Side view of first incisor, upper jaw, of Nototherium Mitchelli.

Fig. $1 a$. Base of the same tooth. 
Fig. $1 b$. Side view of crown of the same tooth.

Fig. 2. Front view of the same tooth.

Fig. 3. Outer side view of the right upper molars of Nototherium Mitchelli (male?).

Fig. 4. Grinding-surface of the same teeth.

Fig. 5. Grinding-surface of the right upper molars of Nototherium inerme.

Fig. 6. Outer side view of a portion of the right maxilla, with three molars $\left(d_{4}, m_{1}, m_{2}\right)$ in situ, of Nototherium Mitchelli (old male?).

Fig. 7. Grinding-surface of the same molars.

Fig. 8. Front view of an upper molar $\left(m_{1}\right)$, with the two anterior roots exposed.

All the figures are of the natural size.

\section{PLATE XLIV.}

Fig. 1. Outer side view of right lower molars of Nototherium Mitchelli (male); the worn crowns of $d_{3}$ and $d_{4}$ are restored in outline.

Fig. 2. Grinding-surface of the last three tecth of the same jaw, with outlines of that of $d_{3}$ and $d_{4}$.

Fig. 3. Grinding-surface and parts of right lower molars of Nototherium Mitchelli (female?).

Fig. 4. Outer side view of the last three lower molars $\left(m_{1}, m_{2}, m_{3}\right)$, with the mutilated hinder half of the second $\left(d_{4}\right)$, of Nototherium Victoria.

Fig. 5. Grinding-surface of the same teeth (of $d_{4}$ only the hinder half is preserved).

Fig. 6. Inner side view of the same teeth.

Fig. 7. Back view of the penultimate lower molar, with the hind fang exposed in situ, of Nototherium Mitchclli.

Fig. 8. Roots and remnant of crown of a much-worn lower molar of Nototherium Mitchelli.

All the figures are of the natural size.

\section{PLATE XLV.}

Fig. 1. Portion of mandible with three last grinders $\left(m_{1,2,3}\right)$ of Nototherium Mitchelli; inside view: nat, size.

Fig. 2. Outside view of the grinders of the same jaw.

Fig. 3. Upper view or working-surface of the same grinders.

Since the foregoing pages were in type, the Trustees of the British Museum have received, as a Donation from His Royal Highness the Duke of Edinburgh, K.G., the specimen which forms the subject of the above Plate. The fossil, obtained by His Royal Highness in the Province of Queensland, Australia, is part of the collection of interesting and instructive specimens brought home from the Circumnavigatory Voyage of IJer 
Majesty's ship 'Galaten,' under the command of His Royal Highness, and exhibited in the South Kensington Museum. The molar teeth in this fossil are in a more perfect state of preservation than in any other Nototherian jaws which had previously come under my observation; and, being from an individual of the same age as that to which the jaw and teeth of Sototherium Victorice from South Australia belonged, they exemplify more plainly and completely the differential characters of that species and of the Not. Witchelli from the l'rovince of Quecnsland.

The tecth $\left(m_{1,2,3)}\right.$ of Nototherium Mitchelli differ from those of Not. Victoria in the presence of a "cingulum" on the outer side of their base (comp. figs. $2 \& 3, c$, Plate XLV. with figs. $4 \& 5$, Plate XLIV.). In $m$, the cingulum is continued from the prebasal ridge (fig. $2, f^{\prime}$ ) along the base of the anterior lobe to the outer tubercle $(h)$, closing the valley, upon the outer surface of which the cingulum subsides; but it resumes its course behind the tubercle along the outer side of the posterior lobe $(b)$, where it is continued upward along the middle of that side; but from the base of this vertical prominence ( $d$, fig. 2 , Plate XLV.) the cingulum is continued to the postbasal ridge $(g)$, which, like the prebasal one, is a more developed part of the cingulum. In Nototherium Victorice the cingulum is represented only by the pre- and postbasal ridges (Plate XLIV. figs. 4, 5, 6, $f, g$ ), and by the closing tubercles (ib. $h, h^{\prime}$ ) before mentioned (p. 77), at the outer and inner ends of the transverse valley. The penultimate molar $\left(m_{2}\right.$, Plate XLV.) presents the same differential characters. In $m_{s}$ of the present specimen of Nototherium Mitchelli the vertical continuation from the cingulum upon the outer side of the hinder lobe is not present (Plate XLV. fig. 2, $m_{s}$ ); but in Not. Victorice the outer closing tubercle (Plate XLIV. fig. $4, m_{\mathrm{s}}, h$ ) and the postbasal ridge (ib. $g$ ) are both extended, converging, to curve up along the outer side of the hinder lobe of $m_{3}$, without crossing its base, as does the cingulum (Plate XLIV. fig. 2, $m_{3}, c$ ) in Not. Mitchelli. All the molars in Not. Victoria differ from those in Not. Mitchelli by the greater breadth or thickness of the postbasal ridge. 


\section{GENERAL OSTEOLOGICAL CHARACTERS}

$\mathrm{OF}$

\section{EXISTING FORMS OF MARSUPIALIA.}

ThE foregoing sections have been applied to the restoration of extinct forms of Marsupial Mammals of which both species and genus have passed away. In now entering upon that part of my work which deals with the determination of extinct species of genera represented by living ones, it becomes requisite to premise the characters of the petrifiable parts of such species, as grounds of the comparisons by which fossils of the extinct species may be determined and made available for the work of reconstruction.

Before entering upon such specific or generic osteological characters some observations on those of the Order may be acceptable.

$\$ 1$. The Skull.-The form of the skull offers much variety in the Marsupial order, but is remarkable in both extinct and existing genera for the small proportion which is devoted to the protection of the brain, and for the great expansion of the nasal cavity immediately anterior to the cranial one. The breadth of the skull, in relation to its length, is greatest, after Nototherium, in the Wombat and Ursine Dasyure, in which it equals three fourths of the length, and is least in the long-eared Bandicoot (Macrotis lagotis), in which it does not equal one half.

The occipital region, which is generally plane, and vertical in position, forms a right angle with the upper surface of the skull, from which it is separated by a superoccipital crest. This is least developed in Myrmecobius, Petaurus, and Macropus, and most so in Thylacinus and the larger Opossums, in which, as also in the Koala, the crest curves slightly backward, and thus changes the occipital plane into a concavity, well adapted for the insertion of the strong muscles from the neck and back. The upper surface of the skull presents great diversity of character, which relates to the different development of the temporal muscles, coordinate with the varieties of dentition in the different genera.

In the Wombats the coronal surface offers an almost flattened tract, bounded by two slightly elevated and separate temporal ridges; the skull of the Opossum presents the greatest contrast to that condition, for the sides of the cranium meet above at an acute angle, and send upward from the line of their union a remarkably elevated sagittal crest, which, in mature skulls, is proportionally more developed than in any of the 
placental Carnivora. The 'Thylacine and Dasyures cxhibit that crest in a somewhat less degree of development. It is again smaller, but yet well marked, in the Koala and Bandicoots. 'The temporal ridges neet at the lambioidal suture in the P'halangers and l'otoroos; but the size of the muscles in these does not require the development of a bony crest. In most Kangaroos the temporal ridges, which are very slightly raised, are separated by an interspace. 'This is proportionally greater in the Petaurists; and in the smooth and convex upper surface of the skull of Acrobates and Nyrmecobius the impressions of the feeble temporal muscles almost cease to be discernible.

The zygomatic arches, however, are complete in these, as well as in all the other genera, and are usually, indeed, strongly developed; but their variations do not indicate the nature of the food so clearly, or correspond with the differences of animal and vegetable diet in the same degree as in the placental Mammalia. No marsupial animal, for example, is devoid of incisors in the upper jaw, like the ordinary Ruminants of the placental series; and the more complete dental apparatus with which the herbivorous Kangaroos, Potoroos, Phalangers, \&c. are provided, and which appears to be in relation to the scantiel pasturage and the dry and rigid character of the herbage or foliage on which they browse, require a strong apparatus of bone and muscle for the action of the jaws, and the exercise of the terminal teeth. There are, however, sufficiently marked differences in this part of the marsmpial skull; and the weakest zygomatic arches are those of the insectivorous Perameles and Tarsipes. The Hypsiprymni are next in the order of development of the zygomatic arches, which again are proportionally much stronger in the true Kangaroos. 'Tle length of the zygomata in relation to the entire skull, is greatest in the Koala and Wombat. In the former animal they are remarkable for their depth, longitudinal extent, and straight and parallel course; in the latter they have a considerable curve outward. In the carnivorous Marsupials the outward curve of the arch (which is greatest in the Thylacine and Sarcophile) is also accompanied by a slight curve upward; but this curvature is chiefly expressed by the concavity of the lower margin of the zygoma, and is by no means so well marked as in the placental Carnivores. In the Koala and Phalangers there is also a slight tendency to the upward curvature. In the Wombat the outwardly expanded arch is horizontal. In the Kangaroo the lower margin of the zygoma describes a slightly undulating curve, the middle part of which is convex downward. In many of the Marsupialia, as the Kangaroo, the Koala, the Phalangers, and the Opossums, the superior margin of the zygoma begins immediately to rise above the posterior origin of the arch. In the Kangaroos the anterior and inferior part of the zygoma is extended downward, in the form of an inverted conical process, which reaches, in some species, below the level of the grinding-teeth. A much shorter and more obtuse process is observable in the corresponding situation in the Phalangers and Opossums. 'The relative length of the facial part of the skull, anterior to the zygomatic arches, varies remarkably in the different marsupial genera. In the Wombat it is as 6 to 19 , in the Koala as 5 to 14 ; in the l'halangers it forms about one third the length of the entire skull; in the carnivorous 
Dasyures and Opossums it is more than one third. In Perameles, some kinds of Macropus and of Hypsiprymmus, the length of the skull anterior to the orbit is equal to the remaining posterior part; but in Hypsiprymnus myosurus the facial part of the skull anterior to the orbit exceeds that of the remainder; and the arboreal Dendrolagi present a still greater length of muzzle. In most Marsupialia the skull gradually converges towards the anterior extremity; but in Macrotis the skull is remarkable for the sudden narrowing of the face anterior to the orbits, and the prolongation of the attenuated snout, preserving the same diameter for upwards of an inch before it finally tapers to the extremity of the nose. In the Koala the corresponding part of the skull is as remarkable for its shortness as it is in IFacrotis for its length, but it is bounded laterally by nearly parallel lines. The Kangaroo resembles some Ruminants in the prolongation downward of two long paroccipital processes. They are similarly developed in the Koala, but are reduced to short obtuse processes in the Potoroos, Bandicoots, Petaurists, Phalangers, Opossums, and Dasyures.

The basi-, ex-, and superoccipitals remain longer separate in marsupial than placental Mammals, and in some pouched genera do not become, at any period of life, united by continuous ossification.

The temporal bone generally presents a permanent separation of the squamous, petromastoid, and tympanic elements. In the Kangaroo and Wombat the tympanic forms a complete tube, about half an inch in length, with an irregular exterior, and is wedged in between the mastoid and squamosal. In the Potoroo the bony circle is incomplete at the upper part; in the Perameles and Dasyures the bone forms a semicircle, the posterior part being deficient, and the tympanic membrane being there attached to a descending process of the squamosal. In many of the Marsupialia, as the Dasyures, Petaurists, Bandicoots, Potoroos, and Koala, a large bulla ussea is developed in the alisphenoid, increasing the extent of the auditory carity. In Nacrotis, in addition to the preceding, the petrosal forms a second and smaller bulla on each side. In other Marsupialia the petrosal is of small size, generally limited to the office of protecting the parts of the internal ear, and sometimes, as in the Koala, is barely risible at the exterior of the base of the skull.

The direction of the bony canal of the organ of hearing corresponds, as in the placental Mammalia, with the habits of the species: the meatus auditorius is directed outward and a little forward in the carnirorous Dasyures; outward and a little backward in the Perameles and Phalangers; outward, backward, and uprard in the Kangaroos; and directly outward in the Petaurists and Wombat; but the differences of direction are slightly marked.

The squamosal generally reaches halfway from the root of the zygoma to the sagittal ridge or suture; it is most developed in the Wombat, in which its superior margin describes a nearly straight line. 'The zygomatic process of the squamosal is compressed, and much extended in the vertical direction in the Opossum, Dasyure, Phalanger, Koala, and Kangaroo. 'The 'glenoid carity' presents in the marsupial, as in the placental 
Mammalia, various forms, each manifesting a physiological relation to the structure of the teeth, and adlapted to the required movements of the jaws in the various genera. In the herbirorous Kangaroos it forms a broad and slightly convex surface, as in the Ruminants, affording freedom of rotation to the lower jaw in every direction. In the Phalangers and P'otoroos the articular surface is quite plain. In the Bandicoots it is shightly convex from side to side, and concave from behind forwards. In the Wombats it is formed by a narrow ridge, convex antero-posteriorly, considerably extended laterally, slightly concare in the transverse direction, and this ridge is not bounded by any descending process posteriorly, so that the jaw is left free for the movements of protraction and retraction. In the Koala the glenoid cavity is a transversely oblong depression, with a slight couvex rising in front, indicating rotatory movements of the jaw : in the Dasyures it forns a concavity still more elongated transversely, less deep than in the placental Camivora, but adapted, as in them, to a ginglymoid motion of the lower jaw. The joint differs in the absence of an interarticular cartilage in the marsupial Carnivores. In all the genera, save Phascolomys, retraction of the lower jaw is opposed by a descending process of the temporal bone immediately anterior to the meatus auditorius. In all the species, the Petaurists excepted, the malar bone forms the outer part of the articular surface for the lower jaw.

The pterygoids are relatively largest in the Kangaroo, Wombat, and Koala, and present distinct hamular processes. In the Potoroo, Kangaroo, and Wombat the alisphenoid combines with the pterygoid to form a large and deep depression, opening externally. In the Kangaroo, Dasyures, Koala, and Wombat, the alisphenoids articulate with the parietal bones, but by a very small portion in the two latter species; in the Bandicoots and Potoroos the alisphenoids do not reach the parietals.

An obliteration of the sagittal suture occurs in those Marsupials in which a bony crista is developed from the parietals. In the Kangaroos, Potoroos, Petaurists, Phalangers, and Myrmecobians there is a triangular interparietal bone. The frontal bones are chiefly remarkable for their anterior expansion, and the great share which they take in the formation of the nasal cavity. In the Thylacine the part of the cranium occupied by the frontal sinuses exceeds in breadth the cerebral cavity, from which it is divided by a constriction. A postorbital process augments the bony boundary of the orbit in the Thylacine, the Sarcophile, and, in a slighter degree, in the Opossum; it is relatively most dereloped in the skull of the Myrmecobius fasciatus, where the orbit is large; but the bony boundary of the orbit is not complete in any of the Marsupials. In Myrmecobius there is a deep notch at the middle of the superorbital ridge.

'The lacrymal bones vary in their relative size in different Marsupials. In the Koala they extend upon the face about a line beyond the anterior boundary of the orbit, where they show one or two perforations; the facial plate is proportionally greater in the Kangaroos, Potoroos, Phalangers, and Dasyures, in which also this part of the lacrymal bone presents two perforations, but close to the orbit. The 'Thylacine, as compared with the Wolf, presents a greater extent of the facial portion of the lacrymal 
bone, and thus indicates its inferior type. In Myrmecobius the lacrymal bone exhibits its greatest relative facial development.

'The malar bone is very strong, and of great extent, in all Marsupials. Least developed in Macrotis, it here presents a singular form, being bifurcate at both extremities: the 'processus zygomaticus maxillæ superioris' is wedged into the cleft of the anterior fork; the corresponding process of the squamosal fills up the posterior space; the lower division of this bifurcation is the longest. In the Koala, Kangaroos, Potoroos, and Phalangers the malar is traversed externally by a ridge, showing the extent of attachment of the masseter.

The nasal bones vary in their form and relative size in the different genera; they are longest and narrowest in Perameles, shortest and broadest in Phascolarctus. Their most characteristic structure is the expansion of the upper and posterior extremity, which is well marked in the Wombats, Myrmecobius, Petaurists, Phalangers, Opossums, and Dasyures.

The premaxillaries always contain teeth; and the ratio of their development corresponds with the bulk of the dental apparatus which they support. They are consequently largest in the Wombats, where they extend far upon the side of the face, and are articulated to a considerable proportion of the nasal bones, but do not, as in the placental Rodentia, reach the frontal, or divide the maxillary bone from the nasal. In other Marsupials they are further from the frontals.

In Phalangista cookii, some Petaurists, and the Great Kangaroo (Macropus major), the bony palate is of great extent, and presents a smooth surface, concave in every direction towards the mouth; this is pierced by two small posterior palatine foramina, situated at the anterior external angles of the palatine bones, close to the transverse palato-maxillary sutures. The bony palate is also entire in the Dendrolagus ursinus; but in most Poephaga, and in the other families of Marsupialia, there are vacuities in the bony palate.

Cavity of the Cranium. - The parietes of the cranial cavity are remarkable for their thickness in some of the marsupial genera, Phascolomys e.g. In the Sarcophile the cranial bones have a similar thickness. In the Koala the texture of the cranial bones is denser, and their thickness varies from two lines to half a line. In the Kangaroos the thickness varies considerably in different parts of the skull, but the parietes are generally so thin as to be diaphanous; which is the case with the smaller marsupials, as the Potoroos and Petaurists. The union of the body of the second with that of the third cranial vertebra takes place in the marsupial, as in the placental Mammalia, at the sella turcica, which is overarched by the backward extension of the orbito-sphenoids. The optic and prelacerate foramina are blended together, so that a wide opening leads outward from each side of the sella. Immediately posterior, and external to this opening, are the foramina rotunda, from each of which, in the Kangaroo, a groove leads to the fossa Gasseriana, at the commencement of the foramen ovale; the same groove is indicated in a slighter degree in the Dasyures and Phalangers, but is almost obsolete in 
the Wombat and Iioala. The entocarotids entering the suture between the basi- and alisphenoids, usually pierce the basisphenoid and enter the cranial cavity close together, behind the sella, this pituitury fossa being obvious though not bounded by a posterior clinoid late. 'The petrosal in the 'Thylacine, Kangaroo, Koala, and Phalanger is impressed above the meatus auditorius internus by a deep, smooth, round pit, which lorlges the lateral appendage of the cerebellum. 'The corresponding pit is shallower in the Dasyures, and scarcely marked in the Wombats.

In the Kangaroos and Phalangers a thin ridge of bone extends for the distance of one or two lines into the periphery of the tentorial process of the dura mater; and two sharp spines are sent down into it from the upper part of the cranium in Phalangista vulpina. The tentorium is supported by a ridge of bone in the Thylacine; but it is not completely ossified in any of the Marsupialia. 'The rhinencephalic is separated by an obtuse ridge from the prosencephalic division of the cranial cavity. Both primary divisions, with the epencephalic one for the cerebellum and medulla oblongata, succeed one another longitudinally in the Iyencephala as in the Lissencephala; this character would not distinguish an Australian inurine species from a marsupial one.

The olfictory chamber is the largest in the skull, and is divided by a prefrontal bony scptum, continued in some to near the anterior aperture. A longitudinal ridge projects downward from the inside of each of the nasal bones, and is continued posteriorly into the xthmoturbinals, which extend into the part of the olfactory chamber outside of and partly surrounding the rhinencephalic one. 'The convolutions of the mid turbinals are extended chiefly in the axis of the skull; the processes of the subturbinals are arranged obliquely from below, upward and forward. They are extremely delicate and numerous in the Dasyures and Phalangers, but become more simple in the Kangaroo, Koala, and Wombat. 'The chamber' communicates freely with large frontal and maxillary sinuses, and finally terminates by wide apertures behind the bony palate.

'The angle of the jaw is bent inward in the form of a process, encroaching in various shapes and various degrees of development in the different marsupial genera upon the interspace of the rami of the lower jaw. In looking down upon the lower margin of the jaw, we see, therefore, in place of the margin of a vertical plate of bone as in most Placentalia, a more or less flattened surface extended between the external ridge and the internal process or inflected angle. In the Opossums this internal angular process is triangular and trihedral, with the point slightly curred upward. In the Dasyures it has a similar form, but the apex is extended into an obtuse process. In the 'Thylacine the base of the inflected angle is proportionally more extended. In the Bandicoots the angle of the jaw forms a still longer process; it is of a flattened form. extended obliquely inward and backward, and slightly curved upward. In the Potoroos and Phalangers the process is broad, with the apex slightly developed, bounds the lower part of a wide and deep depression on the inside of the ascending ramus. In the Kiangaroos the internal margin of this process is curved upwards, so as to augment the depth of the internal depression above mentioned. 'The internal angular process arrives 
at its maximum of development in the Wombats: it is almost obsolete in Tursipes. In the Koala the process is compressed and directed backward, with the obtuse apex only bending inward; so that the characteristic flattening of the base of the ascending ramus is feebly marked in this Marsupial. In the Thylacine, Sarcophile, and Dasyures the condyle of the lower jaw is placed low down, on a level with the molar series: it is raised a little above that level in the Opossums, and ascends in proportion to the vegetable character of the diet. In all those Marsupialia which have few or very small lower incisors, the horizontal rami of the jaw converge toward a point at the symphysis: the angle of convergence is most open in the Wombats.

§. The Vertebral Column.-The columnar axis of the skeleton is divisible into cervical, dorsal, lumbar, sacral, and caudal rertebræ. The cerrical vertebræ, seven in number, show the usual character of the perforation of the transverse process, due to the union of the outer extremities of par- and di-apophyses with a rudimental rib. I found the pleurapophysis unanchylosed in the dentata of a mature Macrotis. In the Dasyures, Opossums, Bandicoots, and Phalangers the seventh cervical vertebra has only the upper transverse process (diapophysis), and consequently wants the character of the perforation, as in many of the ordinary Mammalia. In the Petaurists, Koalas, Wombats, Potoroos, and Kangaroos the seventh vertebra is perforated like the rest.

The centrum of the atlas is anchylosed, as the 'odontoid process' with that of the axis. The neurapophyses have usually their 'central' or lower ends united by unossified sclerous tissue; and the 'ring' is interrupted below by a longitudinal vacuity or fissure.

In all the Marsupialia the spine of the dentata is well dereloped, in both the vertical and longitudinal directions, but most so in the Virginian and Crab-eating Opossums, where it increases in thickness posteriorly; in these species also the third, fourth, and fifth cervical vertebræ have their spines remarkably long and thick.

In the Koalas and Wombats a short obtuse process is given off from the under part of the transverse process of the sixth cervical. In the Potoroos, Kangaroos, Petaurists, Phalangers, Opossums, and Dasyures this process is remarkably expanded in the direction of the axis of the spine. In the Bandicoots corresponding processes are observed, progressively increasing in size, in the fourth, fifth, and sixth cervical vertebræ.

The number of the dorsal vertebre is greatest in the Tasmanian Wombat, where it is fifteen, with a corresponding number of pairs of ribs; it is fewest in the Koala, which has but eleren, with occasionally a short twelfth pair of ribs. In all the other genera they are thirteen.

In the Koala the length of the spine of the first dorsal hardly exceeds that of the last cervical ; but in all other Marsupials the difference is considerable, the first dorsal spine being much longer; those of the remaining dorsal vertebræ progressirely diminish in length, and increase in breadth and thickness. They slope backward toward the centre of motion, which in Maugés Dasyure is shown to be at the ninth dorsal vertebra, by the verticality of its spine, towards which both the preceding and succeeding spines 
incline. In the Bandicoots (I'cromeles) the centre of motion is at the eleventh dorsal vertchra; in the Potoroos and Kangaroos at the twelfth; in the P'etaurists at the thirtecuth vertebra. In the Phalangers, Opossums, Koala, and Wombat the flexibility of the spine is much diminished, and the centre of motion is not defined by the convergence of the spinous process towards a single vertebra, but they all incline slightly backward.

'The lumbar vertebrix are four in number in the Phascolomys vombatus, eight in the Koala, seren in the Petaurists, and six in other Marsupialia-the total number of "true rertcbrae" being thus the same (nineteen) in all the genera.

'I'he metapophyses, which begin to increase in length in the three posterior dorsal rertebre, attain a great size in the lumbar vertebra, and are locked into the interspace between the anapophyses and postzygapopliyses, except in Perameles, and in the last lumbar vertebrix of all the other genera. 'The diapophyses of the lumbar vertebræ progressively increase in length as the vertebra approach the sacrum; they are most rleveloped in the Wombats, where they are directed obliquely forward. In the Kangaroos, Potoroos, and Bandicoots they are curved forward and obliquely downward. The length of these and of the anterior oblique processes is relatively least in the Petaurists, Phalangers, and Opossums.

'The number of vertebræ succeeding the lumbar, which are anchylosed togetler in the sacral region of the spine, may anount in some kinds of WTombat to seven; but if we regard those vertebrie only as 'sacral' which join the ossa innominata, then there are but three. In the Kangaroos and Potoroos the impetus of the powerful hinder cxtremities is transferred to two anchylosed vertebræ. In Percmeles there is only a single sacral rertebra, the spine of which is shorter and thicker than those of the lumbar vertebra, and turned in the contrary direction, viz. backward. In Myrmecobius there are four sacral vertebræ by anchylosis, two of which join the ilia. In Maugé's Dasyure two sacral vertebra are anchylosed; but it is to the expanded transverse processes of the anteriol one only that the inmominata are joined. 'The same kind of union exists in the Viverine Dasyure; but three vertebræ are anchylosed together in this species. In the Phalangers and Petaurists there are two sacral vertebræ. In Petaurus taguanoides and Pet. macrurus three are anchylosed together, although two only join the ilium.

The transition from the sacral to the caudal vertebræ is obscure in the Vombats; if we limit the sacral to the three which join the ilium, then there remain twelve vertebra for the tail. 'The spinal canal is complete in all but the last three, which consist only of the central element. There are no inferior spines; and as only the six posterior vertebræ, which progressively diminish in length, extend beyond the posterior aperture of the pelvis, the tail is scarcely visible in the living animal. In the Koala the tail is also very short. In one species of Perameles I find eighteen caudal vertebræ, in another twenty-three. In two species of Potoroo there are twenty-four caudal vertebræ; but the relative length of the tail differs in these by one third, in consequence of the different 
length of the bodies of the vertebræ. In Hypsiprymnus ursinus there are more than twenty-six caudal vertebræ. In the Great Kangaroo there are twenty-two caudal vertebræ; in Bennett's Kangaroo there are twenty-four caudal vertebræ. In Phalangista vulpina there are twenty-one caudal vertebræ. Petaurus macrurus has twentyeight caudal vertebræ; Pet.taguanoides twenty-nine, while in the Pet. sciureus there are but twenty. In both these species the bodies of the middle caudal vertebræ are remarkably long and slender. Dasyurus maugci has twenty caudal vertebræ.

In most of the Marsupials which have a long tail this appendage is subject to pressure on some part of the under surface. In the Kangaroos this must obviously take place to a considerable degree when the tail is used as a fifth extremity to aid in supporting or propelling the body. In the Potoroos and Bandicoots the tail also transmits to the ground part of the superincumbent pressure of the body by its under surface when the animal is erect; but it is not used in locomotion as a crutch, as in the Kangaroos. In the Phalangers and Opossums the tail is prehensile, and the vessels situated at the under surface are liable to compression when the animal hangs suspended by the tail. To protect these ressels, therefore, as well as to afford additional attachment to the muscles which execute the various movements for which the tail is adapted in the above-mentioned Marsupialia, $Y$-shaped bones, or hæmal arches (hæmapophyses) are developed, of various forms and sizes, and are placed opposite the articulations of the rertebræ. The hæmapophyses embrace and defend the blood-ressels; and the hæmal spine, continued from their point of union, presents a rariety of forms in different genera for the attachment of muscles.

Of the thoracic ribs, which, with the exception of the Tasmanian Wombat, Koala, and Petaurists, are thirteen pairs, the first is the shortest, and, except in some of the Petaurists, the broadest. In the Pet.macrurus the fifth, sixth, or seventh are the broadest; and the ribs generally have, both in this species and in Pet. sciureus, a more compressed form than in the other Marsupials; but this character does not exist in Petaurus taguanoides. In the Kangaroos they are very slender and rounded, except at the sternal extremities, which are flattened for the attachment of the cartilages: the seven anterior pairs of ribs articulate directly with the sternum. The cartilages of the six false pairs are long and bent towards the sternum, but do not join it; nor are they confluent, but have a gliding motion one over the other. In the Petaurists six pairs out of the twelre, and in the Tasmanian Wombat six pairs only out of the fifteen, reach the sternum.

The sternum consists of a succession of elongated bones, generally six in number. The first bone, or manubrium sterni, is the largest, and presents in many species a triangular shape (from the expansion of its anterior part), and sometimes a rhomboidal figure. A strong keel or longitudinal process is given off in some species from the middle of its hæmal or outer surface; the side next the cavity of the chest is smooth and slightly concave. In the Wombats, Phalangers, and others the keel is produced anteriorly into a strong process, against the sides of which the clavicles abut. The 
first pair of ribs join the produced anterior angles of the manubrium. In the Dasyures, Opossums, Phalangers, and Petaurists the manubrium is compressed and elongated, and the clavicles are joined to a process continued from its anterior extremity. 'The small clavicles of the Kangaroos have a similar connexion. Four sternebers and a xiphisternal complete the breast-bone.

\$3. The Pectoral Extremities.-The clavicles are present in all the Marsupials, excepting the Bandicoots (Macrotis, Perameles) and probably also the Choropus. In the claviculate species they are relatively weakest and shortest in the Kangaroo, strongest and longest in the burrowing Wombat. In the climbing Koala the clavicles are also very strong, but more compressed than in the Wombat, bent outward in their whole extent, and the convex margin formed, not by a continuous curve, but by three almost straight lines with intervening angles, progressively diminishing in extent to the outermost line, which forms the articular surface with the acromion. In Myrmecolius the clavicles are subcompressed, and more curved at the acromial than at the sternal end. In most of the other Marsupials the clavicle is a simple, compressed, elongated bone, with one general outward curvature.

The scapula varies in form in the different Marsupialia. In the Petaurists it forms a scalene triangle, with the glenoid cavity at the convergence of the two longest sides. In the Wombats it presents a remarkably regular oblong quadrate figure, the neck being produced from the lower half of the anterior margin, and the outer surface being traversed diagonally by the spine.

In the Koala the superior costa does not run parallel with the inferior, but recedes from it as it advances forward, and then passes down, forming an obtuse angle, and with a gentle concave curvature, to the neck of the scapula; a small process extends from the middle of this curvature. In the Potoroos the upper costa is at first parallel with the lower, but this parallel part is much shorter; the remainder describes a sigmoid flexure as it approaches the neck of the bone. In the Kangaroos, Bandicoots, Phalangers, Opossums, and Dasyures the whole upper costa of the scapula describes a sigmoid curve, the convex posterior portion of which varies as to its degree and extent. The subscapular surface is remarkable in Perameles for its flatness, but presents a shallow groove near the inferior costa. In most other Marsupials it is more or less convex and undulating.

In the Kangaroos the supraspinal fossa is of less extent than the space below the spine, and the spine is inclined upward. In the Bandicoots and Dasyures the proportions and the supra- and infraspinal surfaces are reversed, and the whole spine is bent downward over the infraspinal surface. In the Potoroos and Phalangers the acromion is, as it were, bent downward, so as to present a flattened surface to the observer; in the Potoroos and Opossums this appearance is produced by a true expansion of the acromion. In the Bandicoots the coracoid process is merely represented by a slight production of the superior part of the glenoid cavity; in the Kangaroos and Potoroos it forms a protuberance on the upper part of the head of the scapula. In the other 
Marsupialia it assumes the character of a distinct process from the same part, and attains its greatest development in the Wombat and Koala, in the latter of which it is forcibly curved downward and inward.

The humerus in the Dasyures resembles that of the Dog tribe in the imperforate condition of the entepicondyle, but differs in the more marked development of the muscular ridges, especially of that which extends upward from the ectepicondyle for the origin of the great supinator muscle; this ridge is terminated abruptly by the smonth tract for the passage of the musculo-spiral nerve. In all the other genera of Marsupials, including Thylacinus and Phascogale, the humerus is perforated above the internal condyle. It is so in Petaurus macrurus and Pet.taguanoides; but in the Petaurus sciureus the foramen is represented by a deep notch; in Phalangista cookii both foramen and notch are wanting. The supinator ridge is much developed in the Petaurus macrurus and Pet. sciureus, and is notched at its upper part; but this notch does not exist in Pet. taguanoides. In the Kangaroos, Potoroos, Wombat, and Koala the ridge extends in the form of a hooked process above the groove of the radial nerve. In all these, and especially in the Wombat, the deltoid process of the humerus is strongly developed: it is continued from the external tuberosity down the upper half of the humerus-except in the Petaurists, where, from the greater relative length of the humerus, it is limited to the upper third. The interspace above the condyles is occasionally perforated in Macrotis and the Tasmanian Wombat. Both condyles are convex anteriorly, the ulnar one is transversely concave behind.

The bones of the forearm are always distinct and well developed; and their adaptation to pronation and supination is complete. The prehensile faculty and unguiculate structure of the anterior extremities appear to have been indispensable to animals where various manipulations were required in the economy of the marsupial pouch. When, therefore, such an animal is destined, like the Ruminant, to range the wilderness in quest of pasturage, the requisite powers of the anterior members are retained and secured to it by an enormous development of the hinder extremities, to which the function of locomotion may be and often is restricted.

We find, therefore, that the bones of the forearm of the Kangaroo differ little from those of the burrowing Wombat, the climbing Koala, or the carnivorous Dasyure, save in relative size. They present the greatest proportional strength in the Wombat, and the greatest proportional length and slenderness in the Petaurists, in which the radius and ulna are in close contact through a great portion of their extent, and thus lend a firmer support to the outstretched dermal parachute. 'They are also long and slender in the Koala. In general the radius and ulna run nearly parallel, and the interosseous space is very trifling; it is widest in the Potoroos. The olecranon is well developed in all existing Marsupials; it is anomalously absent in Diprotodon and Nototherium. In the Pet. taguanoides it is expanded, and truncate at the upper extremity; in the Virginian Opossum and Petaurists we find it more bent forward upon the rest of the ulna than in the other Marsupials. In the Wombat, where the olecranon is the 
strongest, and rises an inch or more above the articular cavity of the humerus, it is extended in the axis of the uhna.

In l'erameles masuta the first and fifth digits of the hand are almost obsolete, the fourth is short and weak, the second and third are of equal length, and alone appear in the fore foot of the living Choropus. All other Marsupials liave a pentadactyle fore paw; in Cheironertes the 'pisiforme' is so developed as to give the appearance of a sixth digit wanting the nail. All the true digits of such paw have so much lateral motion that those on the outer can be opposed to those on the inner side so as to grasp an object. In the Phalangers and Koala the first and second digits are more decidedly opposed to the other three. The inodifications of the carpal and other bones of the fore paw will be given in the special osteologies required in the interpretation of the fossil remains which have at present reached me.

\$ 4. The Pelvic Extremities. - The pelvis is composed of the os sacrum, the two ossa inmominata, and the characteristic supplemental bones attached to the pubis, called the ossa marsupialia.

We seck in vain for any relationship between the size of the pelvis and that of the new-born young, the minuteness of which is characteristic of the present tribe of animals. 'The diameters both of the area and the apertures of the pelvic canal are always considerable, but more especially so in those Marsupialia which have the hinder extremities disproportionately large; in the WVombats also the pelvis is remarkable for its width. 'The pelvis is relatively smallest in the Petaurists. The anterior bony arches formed by the pubics and ischia are always complete; and the interspace between these arches is divided, as in other Mammalia, into the two obturator foramina by an osseous bridge continued from the pubis to the ischium, on each side of the symphysis.

In the Kangaroos, Potoroos, Phalangers, and Opossums the ilia offer an elongated prismatic form; they are straight in the Opossum, but gently curved outward in the other marsupial genera. In the Dasyures there is a longitudinal groove, widening upward, in place of the angle at the middle of the extcrior surface of the ilium. 'The ilia in the Petaurists are simply compressed from side to side. They are broader and Hatter in the Bandicoots, and their plane is turned outward. But the most remarkable form of the ilia is seen in the Wombats, in which they are considerably bent outward at their anterior extremity. In the Kangaroos and Potoroos the eye is arrested by a strong process, given off from near the middle of the ilio-pubic ridge; and this process may be observed less developed in the other Marsupialia.

'The tuberosity of the ischium inclines outward in a very slight degree in the Dasyures, Opossums, Phalangers, Petaurists, and Perameles; in a greater degree in the Kangaroos and Potoroos; and gires off a distinct and strong obtuse process in the Wombats, which not only extends outward, but is curved forward. In the Potoroos the lower part of the ischio-pubic symphysis is produced anteriorly. 'The length of this symphysis, and the straight line formed by the lower margin of the ischia, is a characteristic structure of the pelvis in most of the Marsupials. 
The marsupial bones are elongated, flattened, often more or less curved; they are expanded at the proximal extremity, which sometimes, as in the Wombat, is articulated to the pubis by two points: they are relatively longest, straightest, and most slender in the Bandicoots, flattest, broadest, and most curved in the Koala, and shortest in Myrmecobius, where they do not exceed half an inch in length. In Thylacinus they are not ossified. The cremaster muscle in the male, and its homotype in female, winds round the sclerous or osseous 'internal pillar' of the abdominal ring in its passage to the testicle or to the mammary gland.

The femur is a nearly straight cylindrical bone, having a hemispherical head, supported on a very short neck, especially in the Petaurists, and situated here almost in the axis of the shaft, above and between the two trochanters, which are nearly of equal size. In the Kangaroos and Potoroos the head of the thigh-bone is turned more inward, and the outer or great trochanter rises high above it; in other Marsupials the great trochanter is less developed. In all the species a strong ridge is continued a short way downward from the outer side of the trochanter; and this ridge is so produced in the Wombat as almost to merit the name of a third trochanter. At the distal extremity of the femur the external condyle is usually the largest, the internal rather the longest. The intermediate groove for the patella is well marked in the Bandicoots, where that sesamoid is ossified, but is broad and very shallow in the Phalangers and Dasyures, where the tendon of the rectus muscle is thickened and has but a few specks of ossification; the rotular surface in the Petaurists, Wombats, and Koala, is almost plane from side to side. In Macropodidee the back part of the outer condyle is grooved, but not so deeply as in birds.

The tibia presents the usual disposition of the articular surface for the condyles of the femur; but in some genera the outer surface is continuous with that for the head of the fibula. In the Kangaroos and Potoroos the anterior part of the head is much produced. A strong 'procnemial' ridge is continued down from this protuberance for about one sixth the length of the tibia. In the Koala and Wombat, as in the Opossums, Dasyures, Phalangers, and Petaurists, the shaft of the tibia is somewhat compressed and twisted; but in the Kangaroos, Potoroos, and Bandicoots the tibia is prismatic above, and subcylindrical below. 'The internal malleolus is very slightly produced in any Marsupial, but most so in the Wombat.

The fibula is complete, and forms the external malleolus in all the Marsupials. In Macrotis, it is firmly united to the lower part of the tibia, though the line of separation be manifest externally. In most Potoroos and Bandicoots it is in close contact with the corresponding part of the tibia, but can be separated from that bone. In the Kangaroos the fibula is also a distinct bone throughout; but it is remarkably thinned and concave at its lower half, so as to be adapted to the convexity of the tibia, with which it is in close contact. In each of those genera, therefore, in which locomotion is principally performed by the hinder extremities, we perceive that their osseous structure is so modified as to ensure a due degree of fixity and strength; while in the other 
marsupial genera, as Phascolarctos, Phascolomys, Phalangista, Petaurus, Didelphys, and Dasyumes, the tibia and fibula are so loosely connected together, and with the tarsus, that the foot enjoys a movement of rotation analogous to the pronation and supination of the hand: in the Petaurists, Phalangers, Opossums, and Koala the inner toe, indeed, is so placed and organized as to perform the office of an opposable thumb, whence these Marsupials have been termed Pedimana, or foot-handed. It is to this prehensile power that the modifications of the fibula chiefly relate. In the Wombat, Koala, Petaurists, and Phalangers it expands to nearly an equal size with the tibia at the distal extremity, and takes a large share in the formation of the tarsal joint; but the articular surface is slightly convex, while that of the tibia is slightly concave. The proximal extremity of the fibula is also much enlarged, but compressed, obliquely truncate, and gives off two tuberosities from its exterior surface; to the superior of these a large sesamoid bone is articulated. 'This homotype of the olecranon is present in some other Marsupialia, e. g. Dasyurus macrurus, Didelphys ursina, and Iidelphys plitander.

'The commencement of a degeneration of the foot, which is peculiar to, and highly characteristic of, the diprotodont marsupial animals, is traceable in the Wombats, and may be plainly discerned in the Petaurists, in the slenderness of the second and third toes, as compared with the first, fourth, and fifth. In the Phalangers this diminution of size is still more marked; the second and third toes are also both of the same length, and have no individual motion, being united together in the same sheath of integument as far as the ungual phalanges. In the saltatorial genera of Diprotodonts the corresponding toes, though reduced to almost filamentary slenderness, retain the usual number of phalanges, the terminal ones being armed with claws, which appear as appendages at the inner side of the foot, for the purpose of scratching the skin and dressing the fur. The removal of the hallux commences in the Perameles. In one species the metatarsal supports only a single rudimental phalanx, which reaches to the end of the next metatarsal bone, and the entocuneiform is elongated. In another species the internal toe is as long as the abortive second and third toes, and has two phalanges, the last of which is divided by the longitudinal fissure characteristic of the ungual phalanges in this genus. In Macrotis lagotis the innermost toe is represented by a rudimental metatarsal bone, about one third the length of the adjoining metatarsal. In Choeropus and the poephagous Marsupials no rudiment of the hallux exists. The power of the foot is concentrated in Choropus upon the fourth toe; in Kangaroos and Potoroos the fifth lends its aid, but is shorter than the fourth, which in the Great Kangaroo is upwards of a foot in length, including the metatarsal bone and the claw, which latter resembles an elongated hoof, but is threc-sided and sharppointed, like a bayonet. It is with this formidable weapon that the Kangaroo stabs and rips open the abdomen of its assailant; it will hold a powerful dog firmly during the contest with the anterior extremities, and firmly supporting itself behind upon its powerful tail, deliver its thrusts with the whole force of the hinder extremities. 


\title{
Suborder DIPROTODONTIA.
}

\author{
Family FOSSORIA.
}

\author{
Genus Phascolomis.
}

\section{Osteology of the existing Species.}

\$ 1. The Skull.-The occiput (Pl. XLVI. fig. 1, 2, 3, \& fig. 2) rises vertically from the foramen magnum at the median line, but curres a little backward laterally, where it forms the sides of the broad superoccipital (ib. fig 2,3). The lower and lateral parts of the occiput are formed by the exoccipitals (ib. fig. 2, 2), the mastoids (8), and squamosals $(2 \pi)$. The occiput is higher in proportion to its basal breadth than in Phascolomys vombatus (ib. fig. 3); it is more quadrate in form; it does not curve upward and inward so regularly from the mastoid processes ( 8 ) to the summit, as in Phascolomys latifrons (ib. fig. 4).

The basioccipital (Pl. XLT'III. fig. 1, 1) contributes about half an inch of the thick lower border of the foramen magnum. The exoccipitals (Pl. XLVI. fig. 2, 2) form the lateral borders, developing there the condyles; and the superoccipital completes the middle of the upper border, which is sharp; and as ossification of the latter element does not usually extend so low down as to fill up the whole interspace left by the exoccipitals, the foramen presents a somewhat trilobate or trefoil figure. The foramen magnum has always a greater transverse than vertical diameter; and the exceptions to the trefoil figure show it to be transrersely elliptical, as in figs. 5 \& 6 .

In two skulls of Phascolomys latifrons the occipital part of the mastoid ( 8 , fig. $\bar{i}$ ) ascends above the process $\left(8^{\prime}\right)$, of nearly uniform breadth, to the superoccipital (3), and separates the exoccipital ( 2 ) from the squamosal ( 27$)$. In a third this character obtains on one side; on the other side it is obscure. In Phascolomys platyrhinus (ib. fig. 2) and Phascolomys rombatus (ib. fig. 6) the upper part of the exoccipital (2) usually articulates more extensively with the squamosal (2i).

The characters afforded by the upper surface of the skull differentiate the platyrhine as strongly as they do the Tasmanian Wombat from the latifront species. The temporal fossæ (ib. fig. $1, \tau, 2 \tau$ ) approach each other more nearly, absolutely as well as relatively, in the larger continental species than in the Tasmanian Wombat. The upper third of the fossa is formed by a longitudinal strip of parietal (Pl. XLVII. fig. 1, \& Pl. XLVIII. fig. 1,7 ); and this bends down from the temporal ridge more abruptly in Phascolomys vombatus than in Phascolomys platyrhinus, while in the latter a slight rising or ridge is dereloped from the line of the parieto-squamosal suture. In Phascolomys latifrons the temporal ridges are less marked, and the parietals incline therefrom more outwardly to join the squamosals. The feeble indication of the postorbital process (ib. 12), and the 
well-defined lacrymal tubercle (ib. 73 ) defining the fore and upper part of the orbit, are common to both the bare-nosed species, and distinguish them from Phascolomys latifrons.

The characters of the nasal bones (Pl. XLVII. figs. 1, 3, 4, 5, 15) in regard to shape, size, and connexions are detailed in a succeeding section (pp. 315-319).

'The basal view of the skull of Phascolomys platyrlimus (Pl. XLVIII. fig. 1) shows one of the degrees of variation to which the basioccipital is subject in the depth and breadth of the emargination of the part contributing to the lower border of the foramen magnum. In this skull the emargination is narrow and deep; in a second skull of like size it is less deep and wider. 'The basioccipital is subject to the same variety in Phascolomys vombatus.

In two skulls of Phascolomys latifrons the emargination of the lower border of the foramen magnum is wider, as is shown in the subject of fig. 1, Pl. XLIX., than in the two first-named species. In all the three species, the under surface of the basioccipital has a median longitudinal ridge, which slightly varies in its depth and sharpness; there is a shallow vacuity on each side of the ridge. Each exoccipital, where it coalesces with the basioccipital, develops a tubercle, which, in the platyrhine (Pl. XLVIII. fig. 1, $b$ ) and Tasmanian Wombats, abuts against the petrosal. In Phascolomys latifrons (Pl. XLIX. fig. $1, b$ ) the corresponding (exoccipital) tubercles are more prominent and project freely below the petrosals (16), resembling the pterapophyses of the basisphenoid in birds. The exoccipital is perforated anterior to the condyle by, commonly, two hypoglossal foramina; these are more equal in size in Phascolomys latifrons than in the other two species. There is usually a small vascular foramen external to the upper end of the condyle. The wedge-shaped petrosal (ib. fig. 1, 16) abuts against the side of the basioccipital, with the thin end directed forward. The squamosal (ib. 27 ) expands at the inner side of the mandibular articular surface $(g)$ to form a tympanic cell or 'bulla,' which is large and widely open backward, receiving the inner orifice of the tympanic (ib. 28) in Phascolomys platyrhinus and P. vombatus. In Phascolomys latifrons this pre- or antetympanic cell of the squamosal (Pl. XLIX. fig. 1, 27) is smaller than in the 'Tasmanian Wombat, much smaller than in Phascolomys platyrlinus. External to this cell the squamosal develops, in the bare-nosed Wombats, a vertical ridge, which is wedged into a groove of the tympanic; it is scarcely marked in the hairy-nosed Wombat.

In Phascolomys latifrons (Pl. XLIX. fig. 4) the articular bar of the squamosal $(g)$ is relatively shorter than in the platyrhine or Tasmanian Wombat; and its inner end is notched posteriorly, which receives and is reciprocally received by a notch in the fore and outer part of the tympanic (28). This bone sends forward a thick triangular plate, contracting to the part which is notched for the squamosal, in a way which offers a close and interesting analogy to the 'gomphosis' of 28 with 27 in Birds.

The more marked division of the supratympanic cell in Phascolomys latifrons (ib. fig. $4, l, m$ ), and the greater size and depth of the anterior portion or cavity (ib. l), are among the cranial cliaracters of the species. 
In Ph.platyshinus (Pl. XLIX. fig. 6) and Ph.rmbatus the two divisions of the supratympanic cell are more equal, and the 'gomphosis' of the squamosal with the tympanic is less marked. The malar part (Pl. XLVI. fig. 1, 26) of the zygoma defines the orbit posteriorly by an angular process in both the bare-nosed Wombats; it is not developed in the hairy-nosed species, where the hind boundary of the orbit is indicated by the postfrontal process (Pl. XLIX. fig. 1,12) which is not present or is rudimental in the others.

The numerous irregular venous foramina of the squamosal (Pls. XLVI. \& XLVII. 27) are motable in all the species of Wombat.

The superior maxillary sends outward and backward a process (Pl. XLVIII. fig. 1, 21*) which contributes to and strengthens the anterior pier (ib. 26) of the zygomatic arch; it projects above the alveolus of the third and fourth molar teeth, at a greater height above the molars in Ph. latifions (p. 320, fig. 6, 21*) than in Ph. platyrhinus (ib. fig. 5) or in $P h$. vombatus. In a skull of the larger bare-nosed species, with an upper molar series 2 inches 2 lines in extent, the process rises 7 lines above the outlet of the third molar alveolus. In the skull of a Ph. latifrons with a molar series 1 inch 11 lines in extent, the process rises 10 lines above that outlet. In other words, the outer alveolar plate of the maxillary is deeper below the zygoma in the hairy-nosed than in the barenosed Wombats; it is also more nearly vertical, less inclined mesiad as it descends to the outlets of the sockets.

Phascolomys vombatus resembles Phascolarctus and Hypsiprymus in having the posterior palatal openings large and situated entirely in the palatal bones; and posterior and external to these are two small perforations, not present in the Kangaroos, but which in the Koala and Wombat terminate below a vertical canal opening upon the back and outer part of the maxillary. In the two larger species (Phascolomys platyrhinus and Ph. latifions) the generic characters of the postpalatal apertures are repeated. Of two skulls of Ph. platyrhinus, in the British Museum, the postpalatal apertures are longitudinally elliptical or oblong in one (Pl. XLVIII. fig. 1, $b$ ) and are triangular in the other; in both, the apertures extend more forward and come near to the transverse parallel of the middle of the hindmost socket (ib. ib. m3). In three skulls of Ph. latifrons the postpalatal foramina (Pl. XLIX. fig. 1) are relatively larger, especially longer, than in either the Tasmanian or platyrhine Wombat, and are rounded anteriorly but less broad there than behind: they advance nearer to the fore part of the last molar alveolus, or reach that transverse parallel. The intermolar part of the bony palate is more contracted anteriorly in the bare-nosed (Pl. XLVIII. figs. 1, 4, 21, 21) than in the hairy-nosed Wombats (ib. fig. 5, 21; Pl. XLIX. fig. 1, 21); the narrowest part is between the right and left second molars in Ph. platyrhinus and Ph. vombatus; but in Ph. latifrons there is little difference in the interval between the second $(d 4)$ and that between the first ( $d 3$ ) molars. The palate is slightly arched transversely, and is almost flat in some platyrhine Wombats. In the latifront species it is always more vaulted, or deeper when viewed from below, at the diastemal part (Pl. XLIX. fig. 1, 21), especially at the prepalatal openings (ib. $a, a$ ) than in the bare-nosed species; and the 
diastenal tract is more sharply defincd, laterally, in the liairy-nosed Wombat. 'The' intorbital vacuity is wider, less slit-shaped, in $P$. latifions than in $P$. platyrlinus (Pl. XIVI. fig. 1, 21) and P'l. combatıs.

'I'he cerebral cavity in P'h. Latifions (Pl. XLIX. fig. 5) is, in length, 3 inches 5 lines, and equals one latf the length of the cranium, which is 6 inches 9 lines in the specinen figured. 'The cavity is divided by two vertical ridges into the epencephalic $(c p)$, prosenceplialic $(p)^{\circ}$, and rhinencephalic $(r h)$ compartments. 'l'hese succeed each other lengthwise; but the character is common to the two lower subclasses of Mammalia, in which the (erebrun does not overlap the cerebellum behind or the rhinenceplialon in front. The petrosal (16) contributes a vertical surface to the side of the epenceplialic compartment, which is overarched by the superoccipital and parietal. The acoustic foramen or fossa is subcircular, and is situated below the horizontal ridge bisecting the cranial surface of the petrosal. 'The cerebellar pit above the ridge is wider and more shallow than in Thylacinus and most other Marsupials. The 'vagal' foramen $(c)$ is between the petrosal and the exoccipital. Belind this are the two or three inner orifices of the precondyloid canals $(p)$. The foramen ovale $(o v)$, $3 \frac{1}{2}$ lines in long diameter, perforates the alisphenoid below the tentorial ridge, and opens outwardly anterior to the excavation forming the fore part of the tympanic cavity. A groore runs forward from the foramen orale to the foramen rotundum about 8 lines in advance: at the inner side of this groove the basisphenoid is perforated by the entocarotid. From the inner orifice of this canal a groore runs forward to the common prelacerate and optic fissure (op). The rhinencephalic fossa $(r h)$ is 7 lines in vertical diameter, 5 lines in longitudinal extent. It has a large perforation at its lower and back part leading to the common orbito-temporal fossa; the floor and fore part of the fossa are perforated by the smaller foramina transmitting the olfactory nerves to the xtlimo-turbinals. 'llhe nasal or olfactory cliamber is divided by the coalesced prefrontals which combine with the vomer to form a vertical septum extending from the rhinenceplalic cavity to 8 lines behind the tips of the nasals. The anterior border of the septum is vertical, 1 inch in deptl. In $P /$ platyrlimus the bony septum terminates 14 lines behind the tips of the nasals. The alisphenoid tentorial ridge is less developed in that species. The æthmoturbinals $(e)$ form a mass about an inch in antero-posterior and less in vertical diameter. The mid turbinal is elongate, developed from a ridge descending from the roof of the nisal cavity, a short distance external to the septum, and defining a longitudinal canal traversing the upper part of the nasal meatus. The preturbinal rises from the side of the floor of the chamber. The septum is continued backward by rertical plates of the palatines to the posterior or interual openings of the respiratory passages of the nasal chamber, at the fore part of the interpterygoid fossa. 'The frontal is excavated by three sinuses above the rlinencephalic chamber, and forms there the hind part of the olfuctory division of the nasal chamber. 'The roof of the cranium, at the section, has a close cancellous structure 5 lines thick above the prosenceplalon, 11 lines thick above tlie epencephalon. 
The mandible of the Tasmanian Wombat lias the singular proportions of being as broad as it is long. In the specimen figured (Pl. LIII. fig. 1) the length is 4 inches 6 lines. In one jaw of $P h$. platyrhinus the length is 6 inches, the breadth 5 inches 9 lines. In a second specimen, with a length of 5 inches 9 lines the breadth is 5 inches 3 lines. In a Ph. latifrons with a mandible 4 inches 10 lines in length, the extreme breadth is 4 inches 4 lines. In a second specimen the mandible, with a length of 5 inches, has a breadth of $t$ inches 7 lines (Pl. LIV. fig. 1).

The marsupial characteristic of the inflection of the angle of the lower jaw (Pl. LVI. figs. $1,2,3, a$ ) and the flattening of the lower border or base of the 'ascending ramus,' reaches its maximum of derelopment in the Wombats. The increase of breadth is due to the lower border of the external coronoid or 'crotaphyte' fossa (Pls. LII., LIV. figs. $1,2,3, h)$, which extends as far outward as the mandibular angle does inward. The coronoid process (ib. c) is comparatively slender; its base divides the 'crotaphyte' $(f)$ from the 'angular' $(d, e)$ fossa. The breadth and depth of these bespeak the force of the masticatory (masseteric and pterygoidean) muscles, as the coronoid process indicates the comparative weakness of the biting (temporal) muscles). The latter process is usually undermined by a transterse canal or short tunnel between the two fossæ. The exception of its absence I have hitherto noticed in individuals of the hairynosed Wombat only, and it is rare in Phascolomys latifions.

The postmolar process makes a low angle in the mandible of Phascolomys platyshinus (Pl. LIII. fig. 2) and of Phascolomys latifions (Pl. LIV. fig. 1). The longitudinal canal (ib. ib. $u$ ) between this production of the alveolar border and the base of the coronoid varies somewhat in relative width, a character which aids in the determination of fragmentary mandibular fossils.

The subsymphysial foramina (Pl. LVI., $r, r$ ) are usually closer together in Phascolomys platyshinus (fig. 1) than in Phascolomys latifrons (fig. 3).

Other modifications of the lower jaw in species of Phascolomys will be noted in treating of such fossils in a subsequent section of the present work.

$\$$ 2. Dental Charecters. - The dentition of Phascolomys is unique in the mammalian class; its formula is $i \frac{2}{2}, c_{0}^{0} p_{1.1}^{1.1}, m \frac{4.4}{4.4}=24$; but the teeth symbolized by shape as "premolar" and "first molar" belong, like the other three molars, to the first set, which, so far as I have observed, is not in any proportion deciduous. On the contrary, every tooth enjoys unceasing growth, is consequently rootless, and is curred in the segment of a circle; it has also a partial investment of enamel. This is not the case with the molars of any rodent, or of any other marsupial save the Wrombats. In the upper molars (Pl. XLVIII. fig. 3, e, Pl. XLIX. fig 3,e) the enamel is laid upon the inner, in the lower molars (Pls. LIII. \& LIV. fig. 1) on the outer side. It is coated. with the rest of the tooth's surface, by cement.

The upper incisors in Phascolomys platyrhinus (Pl. XLVIII. fig. 1, $i$, figs. 2, 2') are subcompressed, with a narrow subelliptic transrerse section (fig. $2^{\prime}$ ), of which the long axis is directed from before rather outward and backward. Those of Phascolomys lati- 
fions ('Pl. XLIX. fig. 1, i, figs. 2, 2'), with a fuller subelliptic section, have the long axis directed from before nore outwardly as it extends backward. 'The pair of teeth present is broader surface forwarl; in I'hascolomys platyllimes they present a broarler surface ontward, - the surface in both species being the convex enamelled one; the cnamel in both, also, is longitudinally striate. A larger proportion of the upper incisor is coated with cnamel in J'hescolomys platyrhinus (I'l. XLVIII. fig. 2') than in I'hascolomys latifrons ('l. XLIX. fig. 2'). Commencing in the forner near the hind border, it cxtends along the outside, over the front border, and along the imner side to a longitudinal indent three fourths of the way toward the hind border. The enamel in l'hascolomys latifions, commencing at the hind border, which is rather the outer one, extends over the fore part and upon the imner surface to where it bends to form the hind surface. 'The extent of this hind part of the tooth coated only with cement (Pl. XLIX. fig. $2, c$ ) is greater in I'lascolomys latifions thin is the corresponding unenamelled tract in Phascolomys platyrhimus.

The first npper molar in P'hascolomys platyrhimus (Pl. XLVIII. fig. 1, \& fig. 3, d 3) presents a subtriangular transverse section or working-surface, the base being backward, the apex forward; the inner side is shorter than the outer side, and is indented near the apex by a groove traversing the tooth lengthwise; the outer angle of the base is sometimes, by oblique attrition, produced. The enamel begins anteriorly at the outer part of the apex (fig. 3,e), opposite the groove, is continued inward and backward, and upon the base two thirds of the way toward the outer angle, which, with the outer side of the tooth to near the anterior angle or apex, is coated only by cement (ib. c).

In Phascolomys latifrons the worn surface of the first upper molar (Pl. XLLX. fig. 1 \& fig. $3, d 3)$ is subquadrate; or, if viewed as triangular, the antero-internal surface forms the base, and the postero-external angle the obtusely truncated apex. 'There is a feeble indication of a longitudinal groove, representing that in Phascolomys platyrhinus (Pl. Xl'TIII. fig. 3, g); but it does not mark off an anterior production of the tooth in the bare-nosed species, it simply indents the base or shorter side of the triangle. 'The enamel extends from the base upon the fore and outer part (Pl. XLIX. fig 3, e) and upon the hind part of the tooth, leaving about the same extent of the outer and hinder part unenamelled and coated with cement (c) as in Phascolomys platyrhimus. The chicf distinction is the deeper antero-internal longitudinal groove (Pl. XLVIII. fig. 3, g) marking off a more definite anterior angle or lobule of the grinding-surface of $d 3$ in both the bare-nosed Wombats; by which character a detached tooth might be determined as not belonging to the hairy-nosed species. There is only some difference in size between $d 3$, upper jaw, of Phascolomys platyrhinus and that of Phascolomys rombretus.

The second molar $(d 4)$ assumes a greater proportional size to the first $(d ;)$ in I'hascolomys pletyrhimus than in Phascolomys latifrons; and the succeeding molars repeat the same degree of superiority of size. 'The longitudinal extent of the upper molar series in I'hrescolomys platyrhinus averages 2 inches 1 line; in Phascolomys latifrons it averages 
1 inch 10 lines: the admeasurements are here taken to include the alveolar outlets. In both species there is a slight decrease of size as the teeth recede in position, and chiefly in the hind lobe or division of the last molar ; and in both species the second molar $(d t)$ is distinguished by the marked increase of size, especially transversely, of the hindmost lobe or division. The apex of the front lobe of the third molar $(m 1)$ does not extend so far inward as that of the contiguous lobe of the second molar. The fourth molar $\left(\begin{array}{l}m \\ 2\end{array}\right)$ has a similar relative position to the third; so that the inner contour of the three mid molars is zig-zag, the palate gaining width between each as they recede in position. This character is better marked in the bare-nosed than in the hairy-nosed Wombat. The outer alveolar wall in all the species is deeper than the inner one, and is nearly on a level with the worn or working surfaces of the teeth. The enamel does not extend upon the outer surface, and thins off before it quite attains the angles between the outer and the fore and hind surfaces (Pl. XLVIII. fig. $3, d 4, e$; and Pl. XLIX. fig. $3, d 4, e$ ).

The right and left series of the upper molar's, as may be inferred from the palatal characters, diverge from the second to the last, in a greater degree in Phascolomys platyrhinus (Pl. XLVIII. fig. $1, d t, m$ 3) than in Phascolomys latifions (Pl. XLIX. fig. 1, $d 4, m 3)$.

In a not full-grown latifront Wombat, with a skull 6 inches 2 lines in length, the upper molar series has the same longitudinal extent (1 inch 10 lines) as in a fullgrown individual with a skull 6 inches 9 lines in length. The teeth, including the incisors, have acquired their full size. This fact bears serviceably on the interpretation of fossil Wombats with markedly smaller molar teeth in upper and lower jaws not exceeding in size those of the young Wombat above compared.

The lower incisors of Phascolomys latifions are more distinct in size and shape from those of Phascolomys platyrlinus than are the upper ones. 'The rertical diameter of the transverse section (as in fig. 2, $a$, Pl. LIV.) is the longest, not the transver'se diameter (as in fig. $4, a$, ib.). The outer surface, vertical, and slightly channelled, is divided by a well-marked angle from the lower surface, which is slightly and transversely convex. The enamel corering the lower surface bends orer the angle dividing it from the outer surface and there stops. In Phascolomys platyrhinus the lower enamelled surface bends up upon the outer to near the upper surface, terminating there at an angle or ridge. A narrow longitudinal groove representing the wider outer channel in the hairy-nosed Wombat, divides the enamelled outer angle from the flat upper surface. The transverse section of the incisor may be called triangular in both species; but the base is internal and the apex external in Phascolomys platyrlinus, while the base is inferior and the apex superior in Phascolomys latifrons. The lower incisors are likewise smaller relatively to the jaw and to the molar teeth in the hairy-nosed than in the bare-nosed Wombat; and this character is more strongly marked in the large extinct Wombats indicated in my second Memoir on the osteology of the Marsupialia ${ }^{1}$.

1 Trans. Zool. Soc. vol, iii. (1S+5), p. 306. 
'The first lower molar, on the other hand, is as large in Phascolomys latifrons (II. IIV. fig. 1, $d 3$ ) as in Phascolomys platyrhimus (Pl. LIII. fig. 2, $(13)$; it is consequently larger in proportion to the size of the species, and in proportion to the other molar teeth; it has also a different form. In Phascolomys platyrhimus the transwerse section and working surface of $d 3$ is usually a full cllipse, with the long axis nearly parallel with that of the jaw. In lhascolomys letifrons the section is subquadrate. 'The anterior surface usually shows a feeble longitudinal groove; the outer surface is rather narrower than the other three. The cnamel covering it extends a short way upon the front surface, and then, after an interruption, is resumed upon the antero-internal angle: the outer enamel (xtends minterruptedly over two thirds of the hinder surface. 'The other bilobed or biprismatic molars show litte more than the difference of size, the four (Pl. LIV. $d 4$, $m 1,2,3$, fig. 1) equalling in longitudinal extent three and a half of those in Phascolomys platyrhinus. (Pl. LHI. fig. 2). In all the species the cnamel is wanting on the inner side of the tooth, which is nearly on a level with the inner wall of the alveolus; the outer wall is lower and exposes more of the tooth; the curves of the positions of the prismatic surfaces are reversed in the upper and lower molars.

Mr. Waterhouse, in his instructive paper on the Dentition of the Flying Opossums ${ }^{1}$, pointed out two subgenera as having four true molar teeth on each side of both jaws, and a third subgenus as having three true molars on each side of both jaws; but the observations on marsupial modifications of dentition were not extended further in that paper.

In January 1839 I communicated to the Koologieal Society of London a paper on the chassification of the Marsupialia", which contained the generalized expression of observations on the dentition and other systems, carried out through all the matcrials then at my command. 'This was chiefly in relation to the actual phase of Mammalian

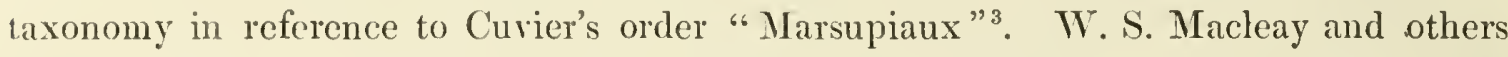
opposed such ordinal group or union of the pouched quadrupeds. The learned ViceSecretary of the Zoological Socicty had published reasons for rejecting the Marsupialia as a distinct group, and for distributing them among different placental orders according to their supposed closer affinities. ${ }^{4}$ The contrary riews set forth by Cuvier and De Blainville ${ }^{5}$ were defective in that kind of evidence which could alone render them convincing; accordingly Mr. Bennett asks, in 1831, "What is there of importance in the structure of the Wombat, except this solitary character of the marsupium, to separate it from the Rodent order?"

1 Proe. Zool. Soe. 1838 , p. 149.

2 Trans. Zool. Soc. vol. ii, p. 315.

${ }^{3}$ Rìgne Animal, rol. i. p. 172 (ed. 1829).

' "Gardens and Menagerie of the Zoological Society" (of London) 'delineated,' 2 vols. 8ro, 1831. By lidward Benmett, Esq., F.R.s., \&c.

Although De Blainrille was able to antieipate the appearanee of the coneluding rolume of the 'Rigne Animal, by a few months, in the issue of his Tabular Sheets of Classifieation, the priority of the proposition of a Marsupial series distinct from, but paralleling, the higher Mammalian orders, is due to Cuvier ("Préface de la première édition, Octobre $1816 ")$. 
The endeavour to reply to this question led me to seek every opportunity of dissecting the brain of Marsupialia, some of the results of which were communicated to the Royal Society in October 1836. Subsequently, in my paper "On the Classification of the Marsupialia" in the Transactions of the Zoological Society, vol. ii. (1839) p. 330, I remarked "that in their cerebral conformation the Marsupialia manifest a close correspondence with the Oripara in the rudimental state of the corpus callosum; the difference which the most closely analogous placental species offer in this respect is broadly marked."

Amongst the other structures there shown to be both common and peculiar to the Marsupialia, I adduced the number of the true molar teeth, as characterized by size and shape, remarking that "in the dental system itself, the varieties of which have been chiefly appealed to as sanctioning the dispartition of the Marsupial order, we find an important peculiarity, by which the carnivorous, omnivorous, and strictly vegetablefeeding genera alike agree with each other, and differ from the corresponding placental Mammalia. In the ordinary Ferce, for example, in the Quadrumana and in the Rodentia, as likewise in the Pachydermata and Ruminantia, the number of grinders developed on each side of each jaw, which are not subject to vertical displacement and succession, is never more than three, while in the corresponding groups of Marsupialia it is always four"

Since the date of this paper (1839) the associated group of Marsupialia has not been sought to be dissevered. It received the valuable sanction of Mr. Waterhouse in his 'Natural History of the Mammalia;' and the generalization as to the number of true molars is given amongst the characters of the order in Part I. of that work, which was issued in 1845 .

1 Trans. Zool. Soc. vol. ii. p. 332. I noted here the exception, previously pointed out by Mr. Waterhouse, in Petaurus (Acrobates) pygmaus, also that of the similarly minute Phalangista gliviformis, pp. 325-333. 


\section{IDESCRIPTION OF THE PIATES.}

\section{PLA'TE XLVI.}

Fig. 1. Side riew of the skull of Phascolomys platyrhinus.

Fig. 2. Back vicw of ditto ditto.

lig. 3. Back view of ditto of Phascolomys vombatus.

Fig. 4. Ditto ditto of Phascolomys latifrons.

Fig. 5. l'oramen magnum, var. of Phascolomys platyrhinus.

liig. 6. Ditto and part of occiput, var. of Phascolomys vombatus.

Fig. 7. Left half of ditto, and part of occiput of Phascolomys latifions.

\section{PLATE XLVII.}

Fig. 1. Top view of skull of Phascolomys platyrhinus.

Fig. 2. Fore end of cranium of Phascolomys platyrhinus.

Fig. 3. Nasal bones, var. of Phascolomys vombatus.

Fig. 4. Ditto, var. 2 of ditto.

Fig. 5. Ditto of Phascolomys latifrons.

\section{PLA'TE XLVIII.}

Fig. 1. Basal view of skull of Phascolomys platyrhinus.

Fig. 2. Upper incisor, side view; and 2', section, ditto.

Fig. 3. First and second upper molars, magnified 2 diameters, ditto.

Fig. 4. Palate, var. of Phascolomys vombatus.

Fig. 5. Ditto, rar of Phascolomys latifions.

\section{PLATE XLIX.}

Fig. 1. Basal view of skull, Phascolomys latifrons.

Fig. 2. Upper incisor, side view; and 2 , section $c-e$, ditto.

Fig. 3. First and second upper molars, magnified 2 diameters.

Fig. 4. Supratympanic cells and tympano-squamosal gomphosis, ditto.

Fig. 5. Vertical longitudinal section of the skull, ditto.

Fig. 6. Supratympanic cells and tympano-squamosal suture, Phascolomys platyrhimus.

All the figures are of the natural size, save where otherwise expressed.

For descriptions of Plates LII. to LVI. see pp. 336, 337. 


\section{Genus Phascolomis.}

\section{Extinct Species resembling the existing ones in size.}

$\$ 1$. Introduction.-To facilitate the comprehension of the characters, deduced from fragmentary fossils chiefly, of the extinct Wombats, I premise a brief recapitulation of those of the skull of the existing kinds which bear most closely on the smaller fossil species to be described in the present section.

I propose, first, to point out, as far as materials permit, the amount of variety to which the same species of Wombat may be subject in the nasal bones, - a requisite preliminary to determining the value of these bones in differentiating recent and fossil species of Phasculomys.

$\S 2$. Nasal bones in Phascolomys vombatus, P'ér.-In an old male Tasmanian Wombat (Phasc. vombatus) the basal breadth equals two thirds of the length of the pair of nasal bones. The outer angles of the nasals, at their base (15), are divided from the lacrymal tubercle (73) by a strip of maxillary (21) 4 lines in breadth, joining to that extent the frontal (11). The sides of the pair of nasals converge forward at the hinder third, then run parallel, gently curving inward, and finally gaining the margin of the nostril, with a slight curve outward. Thus the course of each lateral border of the nasals is undulate. Their tips ( $\left.{ }^{\prime} 5^{\prime}\right)$ extend forward about three lines in advance of the naso-premaxillary suture, and are bevelled off to an obtuse point from without obliquely inward and forward. 'Together these bones form the middle third of the upper border of the external bony nostril. The frontals (11) make a slight projection into the middle of the fronto-nasal suture, which from this shallow indent runs outward and a little forward to the nasal process of the maxillary $(21)^{*}$. The naso-maxillary suture forms the hind fifth part of the lateral border of the nasals; the naso-premaxillary suture runs along the rest of the extent of the nasal bones; $i . e$. to the beginning of their free ends, which are short and subobtuse.

In a second Tasmanian Wombat the nasals (fig. 1, 15 ) differ from those above described in their basal breadth, this being equal to rather more than three fourths of their length, or as 77 to 100, also in the absence of any mesial indent of the fronto-nasal suture, and in the sharper convergence forward of the hinder fourth part of the lateral margins. These margins describe a similar wary course, convex outwards along the middle third, or a little in advance of it. The apices overhanging the nostril are less sharp and prominent than in the last or type specimen.

* This speeimen, figured in the 'Transaetions of the Zoological Society' vol. ii. 1838, shows the usual charaetcrs and is not here repeated: the references to the numerical symbols of the bones, in aid of the deseription, are seen in the subjects of the two Woodcuts showing the varieties. 
In a third younger Phascolomys vombatus (fig. 2) the lateral margins converge more gradually and in an almost straight line from the base to the anterior fourth of the

Fig. 1

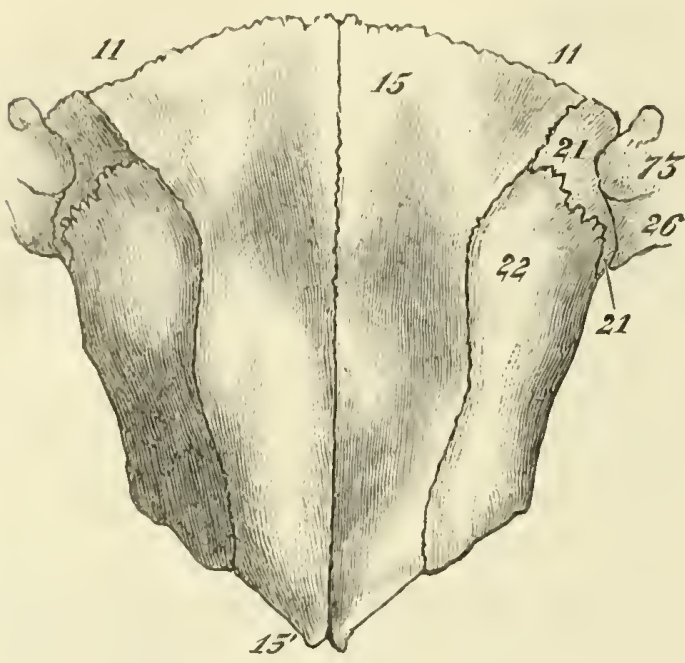

Nasal boncs and their connexions, var. 2, Phascolomys vombatus, Geoffr.
Fig. 2.

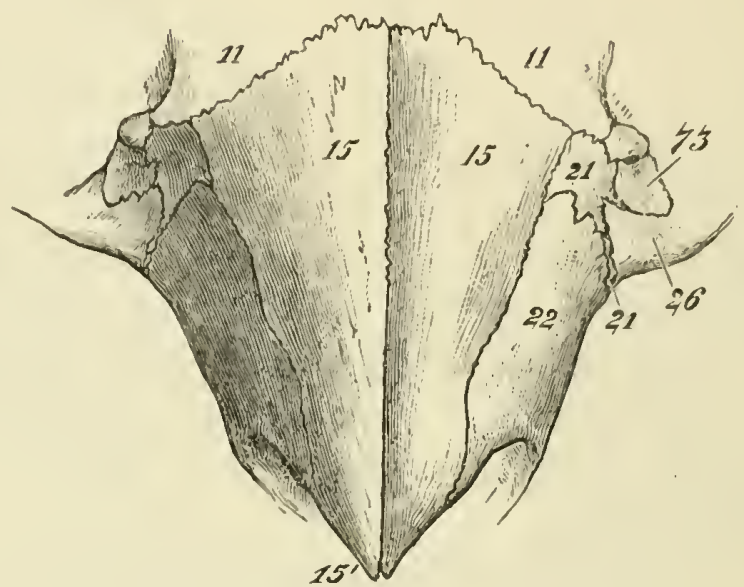

Nasal bones and their connexions, rar. 3, Pluscolomys vombatus, Geoffr.

Fig. 3.

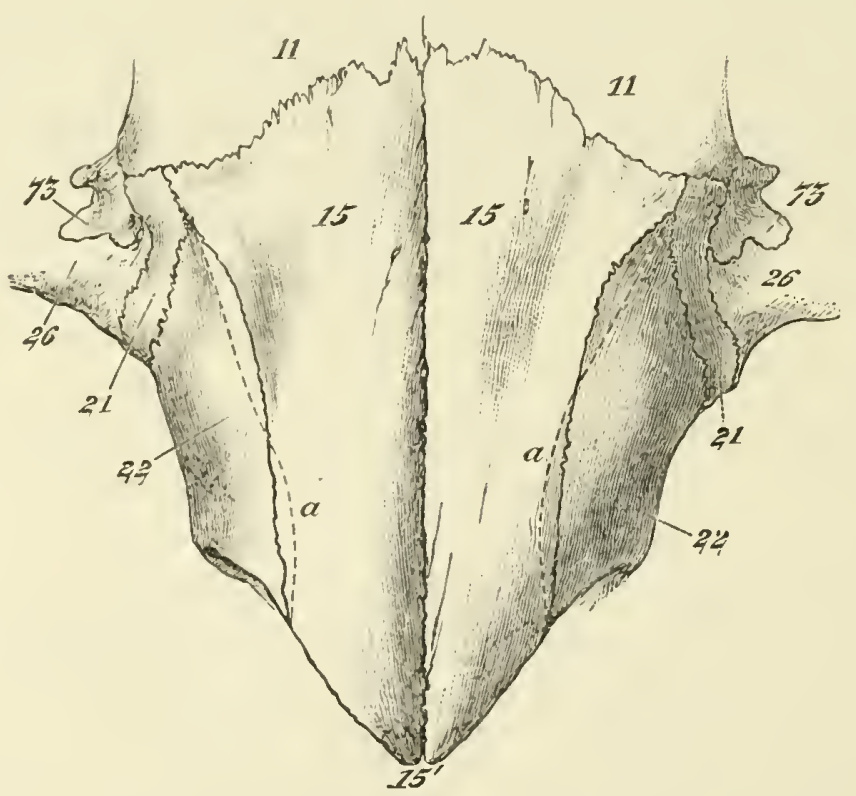

Nasal bones and their connexions, Pluscolomys platyrhinus, 0 w.

nasals, where the margins extend nearly straight to the nostril. The middle sixth part of the fronto-nasal suture is slightly concave; the rest extends outward and more obliquely forward than in the two preceding specimens. The apices of the nasals projecting beyond the premaxillo-nasal sutures are sharp, and form one fifth the length 
of the whole lateral margin of the bone. The basal breadth bears almost the same proportion to the length of the nasals as in the first cited skull.

§3. Nasal bones in Phascolomys platyrhinus, Ow.-The Platyrhine Wombat, in the absence of postorbital processes, the shortness of the naso-maxillary suture, and the deep emargination of the fore part of the nasal process of the premaxillary, is more nearly allied to Phasc. vombatus than either of these species are to Phasc. latifrons; but the nasal bones (fig. $3,{ }_{15}$ ) are relatively broader in the Platyrhine than the Tasmanian Wombat, the outer basal angles approaching as near to the lacrymal tubercles (ib. z3 ) with a greater relative breadth of the skull at that part. In one skull the lateral borders of the nasals have the same undulatory course, but more feebly marked than in the second variety of Phasc. vombatus (fig. 1). In a second the suture between the nasals (15) and premaxillaries (22) runs as in fig. 3 . There is a narrow and irregular intrusion of the frontal at the middle of the fronto-nasal suture, sometimes at the expense of the right (as in fig. 3), sometimes of the left nasal bone. The breadth of the base of both bones equals five sevenths of the length of the nasals in two specimens, and four fifths in a third. The apices ( $\left.{ }^{1} 5^{\prime}\right)$, projecting anterior to the naso-premaxillary suture (22'), are blunter than in the first variety of Phascolomys vombatus. The width or breadth of the nasals, at their base or fronto-nasal suture, begins to diminish at once, as they adrance, by the converging course of the naso-maxillary (15-21) and naso-premaxillary (15-22) sutures. In not any of the three specimens before me is " the width of the nasals continued forward beyond their middles" *. In one variety the course of the naso-premaxillary suture was such as is shown by the dotted line $a$ a in figure 3 . A broader strip of the maxillary $(21)$ divides the malar $(26)$ from the premaxillary $(22)$ in the present species than in Phascolomys vombatus. This is a good and constant character in a comparison of the two species.

$\S 4$. Tasal bones in Phascolomys latifrons, Ow. -The breadth of the fore part of the frontals in the Latifiont or Hairy-nosed Wombat is made to contrast with the narrowness of the rest of the bones by the outward extension of the postorbital processes; the nasals (fig. 4,15 ) present a more regular triangular form, through the prevailing transrerse course of the fronto-nasal suture (11-15) and the more regular convergence of the lateral margins of the nasals to the fore ends of the naso-premaxillary sutures $(15-22)$. Beyond these the lateral margins of the nasals converge more rapidly to their apices $\left({ }^{2} 5^{\prime}\right)$, which extend freely further forward than in the two preceding species. The breadth of the nasals at the base of their free extremities is greater than in the bare-nosed Wombats, and the upper surface of the entire bones is flatter.

In one of the two skulls before me of Phascolomys latifrons the left frontal breaks the transrerse course of the fronto-nasal suture by a sharp-pointed process or wedge between the two nasals (indicated by the upper line in fig. 4); in the second skull the right frontal sends forward in the same way a more obtuse triangular process; in my type skull (Zool. Trans. vol. iii. pl. xxxvii. fig. 4) both frontals contribute equal

* Jicrie, Proc. Zool. Soc. p. 803 (1567). 
shares to the wedge, which is longer (as shown by the lower dotted lines, $u, a$, in fig. 4). Outside this, in all Latifront Wombats, the fronto-nasal suture runs straight outward to

Fig. 4.

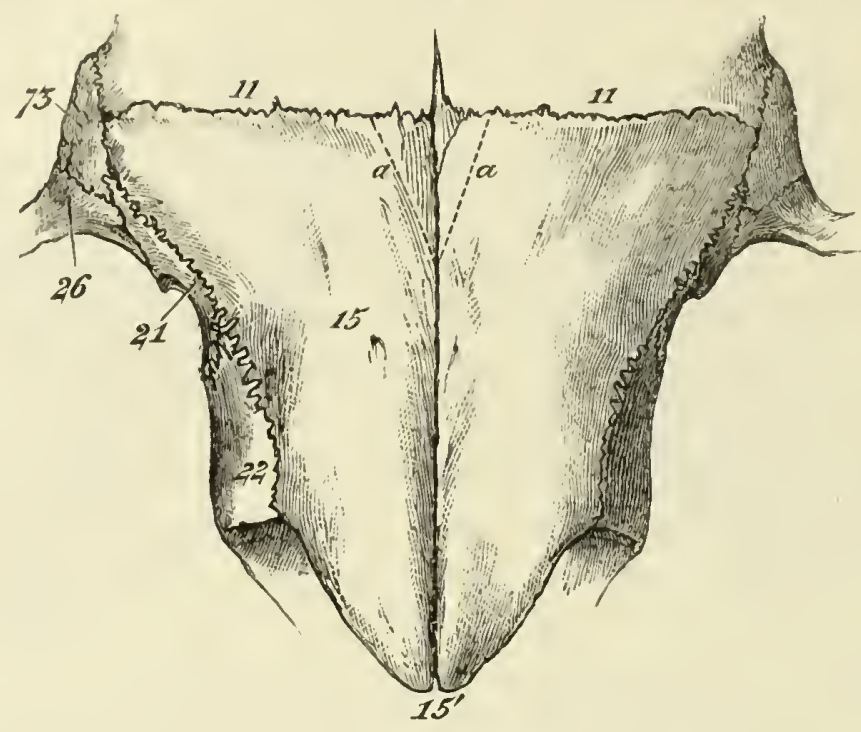

Yasal bones and their connexions, Phascolomys latifrons, Ow.

the lacrymal (73), from which bone it is not separated, as in I'hascolomys platyrhinus and Phasc. combatus, by the maxillary (21). The extent of the naso-maxillary suture (15-21) equals that of the naso-premaxillary suture (15-22).

These differences in the comnexions of the nasals are more significant of specific distinction than the shape of the bones. The naso-maxillo-premaxillary suture $(15-21-22)$ is very slightly concave outwardly in the Latifront Wombat; and the free border of the nasals beyond the suture affects a convex bend toward the apices.

$\$ 5$. Nasal bones in Phascolomys Mitchelli, Ow.-'There would be no doubt in determining Phascolomys latifrons by the naso-maxillo-premaxillary part of the skull, at least as being distinct from the other two known recent species, if even the still more characteristic part of the frontal bones was wanting. 'There might be more difficulty in pronouncing as to whether a fore part of the skull belonged to l'hascolomys platyrlinus or to Plasc. vombatus.

I now proceed to compare such a fragment of a fossil skull of a Wombat on the basis of the characters which comparisons of different individuals of the three well-determined recent species of Phascolomys affords.

The fragment in question (Plate $I$. figs. $1,3,4,5$ ) includes the nasals (15) with parts of the frontals (11), lacrymals (73), malars $(26)$, maxillaries (21), premaxillaries (22), and palatines (20). The nasals (15) are of the type of those in Phascolomys vombatus and Phascolomys plutyrhimus; in the proportion of basal breadth to length and the speedy narrowing as they adrance they resemble the modification shown in Woodcut, fig. 1, p. 316, in Phasc. vombatus. But small as is the extent of the naso-maxillary suture 
$\left({ }_{15-21}\right)$ in Phasc. vombatus (figs. 1 \& 2) and Phasc. platyrhinus (fig. 3), it is still less in the fossil, the apex only of the basal expanse of each nasal (15) touching the maxillary (21) (Plate L. fig. 1) on each side of the skull. The naso-premaxillary suture (ib. ${ }_{15-22,}{ }^{2}{ }^{\prime}$ ) runs along the side borders to within half an inch of the extremities $\left({ }_{15}\right)$, which are obtusely pointed, as in Phascolomys platyrhinus. The suture or lateral border of the nasals describes but two curves, concave at the basal half, convex at the apical one; slight in both, in Phascolomys Mitchelli. The angle formed by the fronto-nasal suture $\left({ }^{11-15}\right)$ is as in Phasc. platyrhinus (fig. 3); and an obtuse process, 3 lines broad, of the frontal is wedged into the beginning of the internasal suture.

Seeing the variations in regard to such frontal wedge, as in the sinuous course of the lateral borders of the nasal, these bones could not differentiate by their form the fossil from the existing continental Wombat (Phasc. platyrhinus). The superiority of size is but small in the fossil; but the difference of connexion, shown in the almost exclusion of the maxillary from junction with the nasal, is a satisfactory distinctive characteristic of this part of the skull of the fossil Wombat under consideration, which I refer to the Phascolomys Mitchelli, Ow.*

The present representative of that species is from the same bone-cave as the type fossils $\uparrow$; it has been flattened or crushed from above vertically downwards. The facial parts of the premaxillaries $\left(22,22^{\prime}\right)$ are on the same horizontal plane as the nasals $(15)$, which they suturally join. The frontals $\left(11,{ }_{11}\right)$ have been pressed away from the nasals along the major part of the suture, and all the bones are more or less fractured. To this condition the skull had been reduced before the drip of the cavern had hardened the red mud about it. The process of clearing away such matrix was long and tedious.

Did the skull show the violence of a carnivorous troglodyte destroyer, or the effect of some cosmical force operating on the breccia-bed of the cave? If the former, the blunted laniaries of our old Thylacoleo are the only animal dynamic in Australia capable of so smashing the Wombat's head that I am as yet cognizant of.

§. 6. Nasal bones in Phascolomys Krefftii, Ow.-This species is founded on a fore part of a skull (Plate L. figs. 2, 6) discovered by Gerard Krefft, Esq.. in the same bone-cave as the last-described fossil. It is as closely allied to the broad-fronted or hairy-nosed Wombat as Phascolomys Mitchelli is to the bare-nosed continental species; and the value of the nasal characters comes well out in the comparisons determining the present fossil.

It includes the major part of the nasals (15), with the connected parts of the premaxillaries (22) and maxillaries (21). The nasals are broad and flat; their lateral margins are suturally joined with a smaller proportion of the premaxillaries than in Phascolomys latifrons (Woodcut, fig. 4, 22).

* First defined in the Appendix to Mrrcuelu's 'Three Expeditions into the Interior of Eastern Australia,' vol. ii. 8vo, 1838, pl. 48. figs. 4-7, p. 368 (2nd ed.).

† Mrtchell's 'Three Expeditions into the Interior of Eastern Australia,' vol. ii. 8vo, 1838, pl. 48. figs. 4- 7. 
The free anterior extremities of the nasals (15') show nearly the same form and proportions as in that Woodcut; their basal breadth, where the naso-premaxillary suture encls anteriorly, is 1 inch 3 lines; the length of the outer margin is 1 inch in a straight line, but is rather more following the curve. The lateral suture, as it extends along the maxillary (21), shows a slight uniform curve, concave outward. A portion of the left frontonasal suture (11-15) indicates an oblique course from within outward and forward in about the same degree as in Phascolomys platyrhimus, fig. 3. I have not seen such course, as a raricty, of that suture in any specimen or figure of the skull of the recent Phascolomys latifrons. Other instances of combination in the smaller fossil Wombats, such as are now under review, of characters which respectively specialize the Platyrhine and Latifront Wombats will be adduced in the present memoir.

'The length of the left nasal, as far as it is indicated by the preserved extent of its suture with the frontal, is 2 inches 10 lines; the extreme basal breadth cannot be given, on account of the side-fractures.

'The internasal suture seems to be partially obliterated ; and there is a narrow elliptical racuity with rounded margins, situated ten lines from the tips of the nasals, six lines in lengtl and two lines in extreme breadth, which seems to be natural, though probably an individual varicty. I shall return again to this fossil in relation to other characters.

\$ 7. Lacrymal, maxillery, and palatal characters of Phascolomys Mitchelli, Ow.-So much of the lacrymal ( 33 ) is fortunately preserved on the right side of the subject of Plate L. firg. $3, t$, as to indicate the affinity of the fossil to certain existing Wombats. This bone, both in Phascolomys vombatus and Phasc. platyrhimus (Woodcut, fig. 5), developes

Fig. 5.

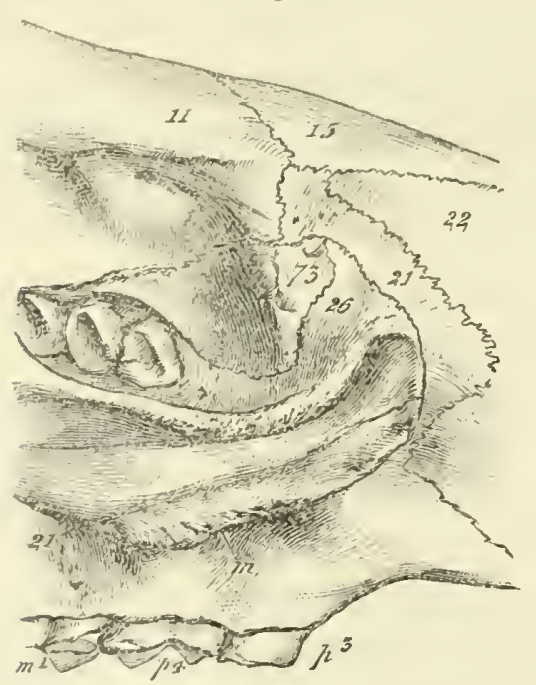

Lacrymal \&c. characters, Phascolomys platyrhinus.
Fig. 6.

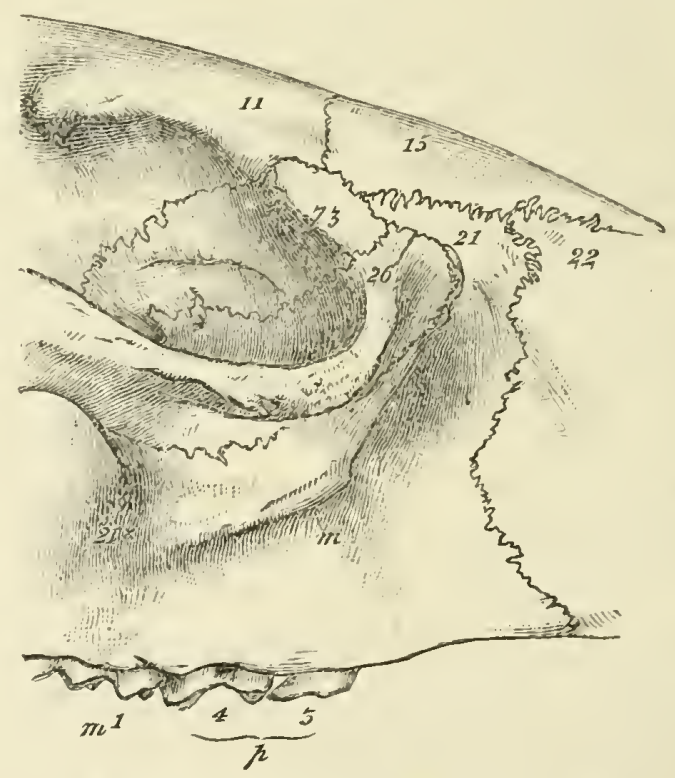

Lacrymal \&c. characters, Phascolomys latifrons.

a prominent tubercle above $;_{3}$ at its upper border, below the fronto-maxillary suture (11-21). In Phascolomys latifrons (fig. 6) a feeble swelling of the lacrymal (73), where it 
joins the frontal (11), answers to the tubercle. The indications of a lacrymal canal are minute in all Wombats. The lacrymal of Phasc. Mitchelli (Plate L. fig. 3, ;3) shows the well-developed tubercle $(t)$ in the same relative position to the fronto-maxillary suture as in Phascolomys vombatus and Phasc. platyrhinus: the bone anterior to the tubercle is flatter, less excavated in Phasc. Mitchelli than in those existing Wombats, and herein more resembles the lacrymal in Phascolomys latifrons.

The alveoli of the five upper molars of each side (Plate L. fig. 5, $p_{3,4}, m_{1,2,3}$ ) with the intervening part of the bony palate (ib. 20,21) are preserved in the present fossil. The form of the latter adheres to the type of that of Phascolomys vombatus and Phasc. platyrhinus (Woodcut, fig. 7); in Phasc. latifrons (Woodcut, fig. 8) the palate $(20,21)$ is less

Fig. 7 .

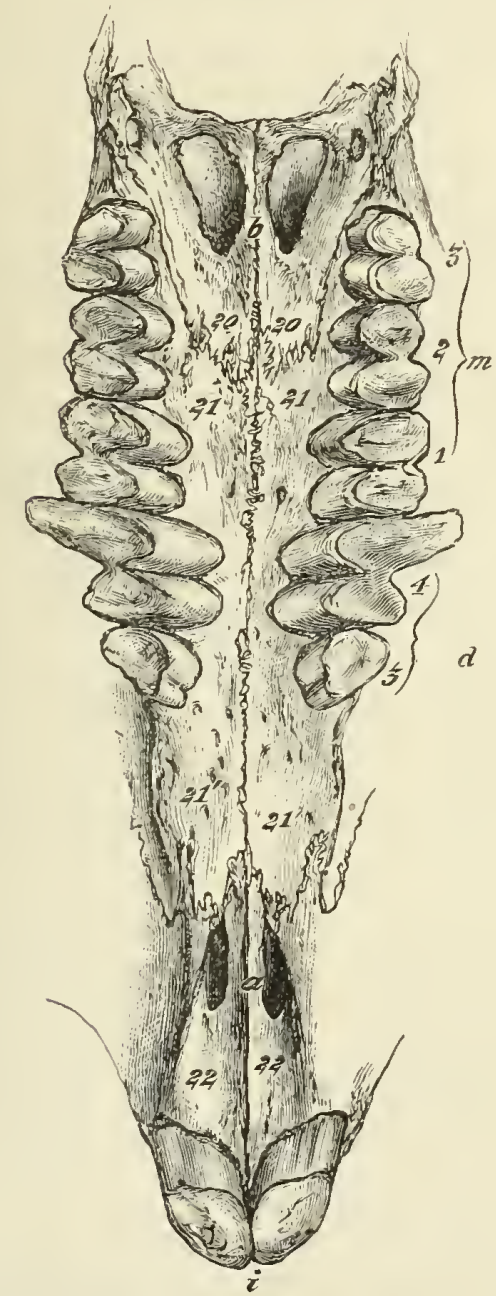

Palatal surface of upper jaw and teeth,

Phascolomys platyrlinus: nat. size.
Fig. 8.

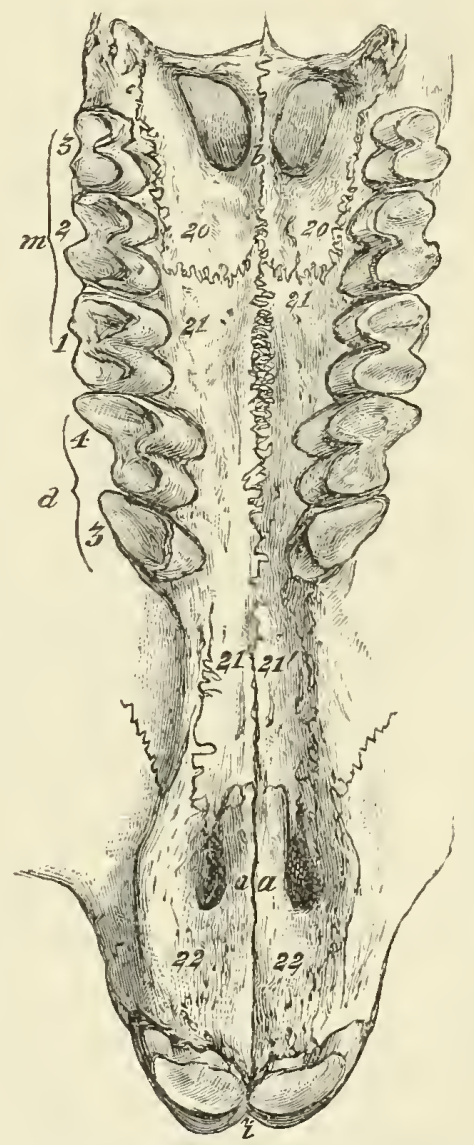

Palatal surface of upper jaw and teeth, Phascolomys latifrons: nat. size.

contracted anteriorly. The fore part of the postpalatal apertures (Plate L. fig. 5, b) does not reach that of the hindmost socket $\left(m_{3}\right)$ in the fossil, which also in this respect 
agrees with Phascolomys rombatus and Phasc. platyrhinus (Woodcut, fig. 7,6); whilst it differs from I'hescolomys latifrons (Woodcut, fig. 8, 6 ), in which the postpalatal apcrtures extend forward beyond, or at least as far as, the interval between the last and penultimate sockets $\uparrow$. In the more advanced portion of the roof of the mouth I noticed (in 1845) a claracter ${ }^{+}$in Phascolomys latifrons by which it differed from Phasc. vombatus, and as I now know it also differs from Phasc. platyrhinus. The portion of bony palate between the molary series and the incisors is more concave transwersely, or deeper, in Phuscolomys latifions (Woodcut, tig. S, 21',21',22, 22), and the cluannel is bounded by welldefined or sharp borders: this character is much better marked in the fossil (Plate $\mathrm{L}$. fig. 5. 21, 21, 22, 22) than in the skulls of Phascolomys vomlatus or Pliasc. platyrhinus.

Another character in which the fossil resembles I'hascolomys latifions more than it (loes the other two recent species is the greater vertical extent of the maxillary (Plate l. figs. $\left.\mathcal{S} \& 4,23^{*}\right)$ beneatl the origin of the malar or zygomatic process $\left(21^{*}\right)$ of that bone (compare with Cuts $5 \& 6,21^{*}$ ). I shall recur to this character in the description of another fossil of the present genus.

§ S. Uprer molurs of Phascolomys Mitchelli, Ow.- The differential characters of these tecth, as compared with their homologues in Phascolomys combatus, have been elsewhere pointed out $\delta$. As to the two larger existing species, in the molar dentition of the upper jaw Phrscolomys Jitchelli more resembles the platyrline than the broad-fronted Wombat. In the latter the right and left upper molar series (Woodent, fig. 8, $d_{3}-m_{3}$ ) run more parallel to each other, are less convergent anteriorly, with absolute greater brearlth of the bony palate there. The first molar $\left(l_{3}\right)$ in Phascolomys latifions is, relatively to the second, larger in both upper and under jaws. I therefore limit the comparison of the upper molars in the present fossil to those of Phascolomys platyrhimus (fig. $7, d_{3}-m_{3}$ ). The extent of the fire alveoli, lengthwise, taken at their outlets, is the same in both; $m$ at least the fossil (Plate I. fig. $5, d_{3}-m_{3}$ ) exceeds only by about a line, giving 2 inches $2 \frac{1}{2}$ lines instead of 2 ,inches 1 line as in I'hascolomys platyrhinus. I have seen no example of Phrseolomys latifions in which the molar series extended beyond 2 inches; it is commonly less, as in Woodcut, fig. 8.

'The alreolus of the first molar $\left(d_{3}\right)$ of the fossil indicates a tooth not larger than in the Platyrhine Wombat. The other four molars, of which the first three are preserved on the left side and the last two on the right side, closely repeat the characters of these teeth in the Platyrhine Wombat $\|$. This gives more weight to the differential characters of greater length and less breadth of the nasals, the greater concavity and sharper defi-

i in the latter variety (fig. \&) the afertures should extend more forward than is represented.

$\mp$ Trans. Zool. Soe. rol. ii. plate lxxi. fig. 1. "The palatal surface of the intermaxillaries is deeper" (ए. 304).

\$ Mrrcield's 'Three Expeditions into the Interior of Eastern Australia,' rol. ii. p. 368, pl. 48. See also

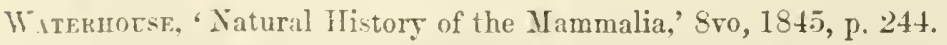

II The second molar is abnormally worn, through slight displacement of the opposing tooth, as happens in other partially enamelled teeth of perpetual growth. 
nition of the diastemal part of the bony palate, and the greater depth of the maxillary below the anterior pier of the zygomatic arch in Phascolomys Mitchelli.

\$ 9. Palatine foramina in Phascolomys. - I next proceed to notice Phascolomydian fossils from the freshwater deposits of Queensland, in the interpretation of which some observations must be premised on the palatal foramina in existing species of Wombat.

In my first paper on the Osteology of the Marsupialia I state that Phascolomys resembles Phascolarctos and Hypsiprymmus in having "the posterior palatal openings large and situated entirely in the palatal bones; and that posterior and external to these are two small perforations"*. In the other two species (Phascolomys latifrons and Phascolomys platyrhimus) determined by cranial characters since the date of that remark (1838), the generic characters of the postpalatal openings are repeated. These additional materials serve to test the statement that in Marsupials "the perforations of the bony palate deserve particular attention; they are generally specific, and of consequence in the determination of recent and fossil species" $\$$.

In the skull of the Wombat from Tasmania (Phasc. vombatus), figured in the same Paper\$ to illustrate the palatal and other characters afforded by a basal view of the cranium, the foramina are oval, the base which is behind being rounded; but the small anterior end of the oval is so nearly pointed as to suggest the term "triangular." In two skulls since compared these foramina present the same shape and proportions; in two smaller and younger skulls of Phasc. vombatus they are relatively smaller, and rather elliptical than oval. In two skulls of Phascolomys platyrhimus in the Collection of the British Museum I note that the postpalatal foramina are longitudinally elliptical or oblong in one, and are triangular in the other; the larger continental bare-nosed species showing the same variety as the smaller Tasmanian Wombat. This, therefore, is an exception to the general rule of the specific value of the postpalatal character. The larger, especially the longer postpalatal rarieties, encroach more forward and come nearer to the transverse parallel of the anterior wall of the hindmost socket. Allowance must be made for this variation.

In two skulls of Phascolomys latifrons the postpalatine foramina are relatively larger, especially longer, than in either the Tasmanian or Platyrhine Wombats, and they are rounded anteriorly, but less broad there than behind.

Dr. Murie $\oint$ notes the larger size of the postpalatine foramina in Phasc. latifrons as compared with Phasc. platyrhimus, and I therefore attach the more value to the cham racter, as probably being more constant in the latifront species. It must, however, be considered in connexion with the more constant cranial characters. The following fragmentary fossil from the "breccia-cave" of Wellington Valley exemplifies the need of keeping this relation in view. The fossil consists of a left maxillary and palatine, with

* "On the Osteology of the Marsupialia," Trans. Zool. Soc. rol. ii. p. 389.

† Ibid. p. 388.

¥ Ibid. plate lxxi, fig. 6 .

\&oc. cit. p. 844. 
the molar alveoli, fractured at both ends (Plate L. figs. 7, 8); the anterior tracture exposes the socket of the first molar, $d_{3}$. By the anterior contraction of the palate and by the size and proportions of the alveoli the fossil resembles I'hascolomys platyrhinus; by the parallelism transverely of the fore part of the postpalatal aperture and the same part of the posterior alveolus, and by the height of the maxillary below the malar process of that bone (fig. 7, ${ }_{21}$ ), it resembles Phascolomys latifions. By the combination of both characters it proves its relationship to Phascolomys Mitchelli; as in that species the prezygomatic ridge is less prominent or definite, and is higher placed than in existing Wombats.

$\S 10$. Palate and upper molars, Phascolomys Mitchelli, from freshwater deposits, Queensland.-In a heary petrified fragment of skull (Plate LI. figs. 1-4)†, including the molary series, upper jaw, and their alveoli, with the bony palate from its hind border or bar $(a)$ to 4 lines in advance of the molars $\left(21,{ }_{21}\right)$, the palate, as compared with that of the last-described fossil (Plate L. fig. 5), is more concave transversely, and its concavity is divided by a sharp ridge, extending from the interpalatine $\left.{ }_{20}{ }_{20}\right)$ along the intermaxillary $\$$ palatal suture, as far forward as the second molar $\left(d_{4}\right)$.

The upper molars have a somewhat zigzag arrangement: the second (Plate LI. fig. $\left.1, d_{4}\right)$ extends more mesiad than the first $\left(d_{3}\right)$ or the third $\left(m_{1}\right)$, the hind lobe of the third more so than the fore lobe of the fourth $\left(m_{2}\right)$, and the hind lobe of the fourth more so than the fore lobe of the last molar $\left(m_{3}\right)$. This arrangement is also shown in the palatal view of the fossil of Phascolomys Mitchelli (Plate L. fig. 5), and by the alveoli in the more fragmentary fossil of the same species (fig. 8) of the same Plate. The same character is seen in a minor degree in the outer contour of the grindingsurfaces. 'The antero-external angle of one tooth projects more outwardly than the postero-extcrnal angle of the tooth in advance. This arrangement, a tendency to which has been noted in Diprotodon and Nototherium, is more marked in the Tasmanian and Platyrhine Wombats, as in Mitciell's fossil, than in Phascolomys latifrons.

The intermolary bony palate in the present fossil (Plate LI. fig. 1), though exceeding in length by the antero-posterior diameter of the last molar tooth that of Phascolomys latifrons (Woodcut, fig. 8), is narrower anteriorly than in that species, without being so broad posteriorly. It further differs from both this, the Platyrhine (Woodcut, fig. 7) and the Tasmanian existing Wombats, in the smaller size of the postpalatal foramina (ib. $b, b$ ); they are absolutely smaller than in Phascolomys vombatus, although the fossil indicates an animal as large as the largest Phascolomys platyrlinus. These foramina are, unfortunately, not preserved in the two previously described fossils; but the anterior boundaries in the subject of fig. 5, Plate L., indicate a size or breadth of the foramina equal to those in either the Latifront or Platyrhine existing species.

The antcro-posterior extent of the molary alveoli, upper jaw, of the present fossil is

+ This fossil was presented to the British Museum, in 1861, by George Bexretr, Esq., F.L.S. It is from a freshwater deposit, Darling Downs.

$\mp$ I use the term to signify the suture between the maxillary bones, in a sense different from that in which it is sometimes applied, viz. to the "premaxillary bone." 
2 inches $2 \frac{1}{2}$ lines, which is exactly that in the cave-fossil (Plate L. fig. 5) and in the largest Platyrhine Wombat. But the palate is narrower in the fossil by 1 line posteriorly, besides being deeper or more concave across, and divided by a mid ridge.

The differential character noticed in the preceding fossils is here repeated, viz. the greater depth of the outer alveolar plate of the maxillary (Plate LI. fig. 2, ${ }_{21}$ ) below the zygomatic process (ib. ${ }^{2}$ ) ; it is $10 \frac{1}{2}$ lines in the present fossil, and the premasseteric ridge or tuberosity (ib. $m$ ), less defined or prominent than in existing Wombats, is correspondingly raised above the alveolar outlets.

The worn surfaces of the molar teeth are rather broader transversely than in Phascolomys platyrhinus, and the inner ends of the two lobes are more sharply, or less obtusely, angular than is usual in that species. The difference both in this character and the breadth of the molars is also notable between the present and the first-described fossil ; but seeing the influence direction and degree of attrition have upon the size and shape of the grinding-surface of the molars, the differences noted may be within the limits of that influence. In the subject of Woodcut, fig. 7, $d_{4}$ had been abnormally abraded.

The characteristic downbending of the hind part of the palatines, which forms a transverse bar (Plate LI. fig. 1, $a$ ) behind the postpalatal apertures (ib. $b, b$ ), perforated at each end from behind forwards by a smaller aperture in the recent Wombats, is repeated in this present instructive fossil (ib. fig. $4, d, d$ ).

This evidence of Phascolomys Mitchelli (Plate LI. figs. 1-4), from freshwater deposits, resembles Phasc. platyrhinus in the depth and position of the antero-internal longitudinal groove of $d_{3}$, which tooth is wanting in the cave fossil, although the socket (ib. fig. $\left.5, d_{3}\right)$ indicates the same position of the groove. In Phascolomys latifions the fore part of $d_{s}$ (Woodcut, fig. 8) is less produced than in Phasc. platyrhinus and Phasc. Mitchelli.

A difference in the grinding-surface of the upper molars and in the intervening bony palate between the subjects of fig. 5, Plate L., and fig. 1, Plate LI. is appreciable; but, as above remarked, the one may be due to a phase of attrition; and, moreover, the outer side of the surface is slightly mutilated in fig. 5, Plate LI.; whilst the variety in regard to a rising along the mid palatal suture in the Platyrhine Wombats warns against founding a specific distinction thereon.

These characters are of the less consequence, since, where they are not preserved in a fossil, there may be others which allow of no such hesitation in regard to the specific distinction of the Wombats; as, e.g., in the case of that to which the fragment of skull about to be described belongs (Plate LI. figs. 5, 6,7). It is a portion of the left maxillary with the bony palate intervening between the left and right molary series, the left series being in place (ib. fig. 7), the right represented by the second molar and the alveoli of the two following teeth: the extent of the left molary series at their issue from the alveoli is 2 inches 2 lines.

The chief value of the present specimen is the character of the malar process of the maxillary (ib. fig. 5, ${ }_{21}$ ), which is preserved with the beginning of the attached part of 
the malar (ib. ib. ${ }_{26}$ ) on the left side, showing the malo-maxillary suture. To this help in the determination of fossils of the marsupial genus under consideration I was led by the following comparisons.

In the largest of three skulls of Phascolomys vombatus available for the purpose, the left upper molary series, taken as in the fossil, does not equal 2 inches; it falls short by nearly a line. In the specimen figured in my "Osteology of the Marsupialia" $\phi$, it is 1 inch 8 lines; in the next in size it is 1 inch 10 lines; in an evidently younger Wombat, with all the molars in place and use, the series is 1 inch 7 lines.

'These five ever-growing teeth gain in fore-and-aft as in transverse diameter, until the full size of the individual is attained; they grow with the growth of the skull, though in a minor ratio; and I lave no evidence of their exceeding in size the teeth requiring the extent of alveoli noted in the largest of the cranial specimens of Phasc. vombatus before ine.

Now in this, as in the second-sized skull, the lower border of the malar process of the maxillary bone is 6 lines above the margin of the outer wall of the alveolar opening of $m_{2}$; in the younger and smaller skull it is 5 lines. In all the specimens the maxillary contributes to the inner and lower part of the beginning, or anterior pier, of the zygoma, speedily narrowing to a point as it passes backward on the outer side of the arch, where it ends about 7 lines from the back part of the origin of the process; the depth or vertical diameter of the outer side of the base of the zygomatic process of the maxillary is about 2 lines.

In the skull of a Phascolomys latifrons with an upper molary series, taken at the alveolar outlets, of 1 inch 10 lines in extent, the malar process of the maxillary rises $7 \frac{1}{2}$ lines above the issue of the second molar, there contributes $3 \frac{1}{2}$ lines in depth to the under and fore part of the beginning of the zygoma, and narrows to a point 7 lines behind its origin. In another skull of Phascolomys latifrons with a molary series of 1 inch 1 line in extent, the maxillary process rises 8 lines above the outlet of the second molar, and contributes a similar small proportion to the under and fore part of the zygoma.

In the skull of a Phascolomys platyrhimus with a molary series 2 inches 1 line in extent, the malar process of the maxillary (Woodcut, fig. 5, ${ }_{21}^{\circ}$ ) rises 6 lines above the outlet of the second molar, and contributes $3 \frac{1}{2}$ lines to the rertical extent of the beginning of the aygoma $(26)$, which here has a total depth of 1 inch 4 lines; the process (21") decreases to a point at 9 lines from its origin.

In the fossil (Plate LI. fig. 5) with a molary series of the same extent as in the last skull, the malar process of the maxillary (21) rises 9 lines above the outlet of the inolar, and contributes 7 lines to the vertical extent of the fore part of the zygoma (26). The different relation of the malo-maxillary suture to the premasseteric ridge $(\mathrm{m})$ is strongly marked between the fossil and any of the recent species of Wombat, the interspace between the front pier of the zygomatic arch and the alveolar outlets being much greater in the fossil.

† Trans. Zool. Soc. vol. ii. (1838) plate lxxi. fig. 6. 
In the extent, especially hinder breadth and feeble concavity, of the bony palate, Phascolomys platyrhinus most resembles the present (ib. fig. 7) as it does the preceding fossil ; but the zygomatic character only stands out the more strongly in connexion with this resemblance and the general size.

In Phascolomys vombatus the form of the palate resembles that in Phascolomys platyrhinus. It is rather more concave in some individuals than in others in both species; and in the Platyrhine Wombat I have noticed a slight mesial ridge along the bony palate.

In Phascolomys latifrons the palate is not only more concave, but is wider anteriorly, less triangular; and at the hind part formed by the proper palatine bones, their median suture rises as a longitudinal ridge dividing the bony palate there into two concavities or longitudinal channels, leading backward to the postpalatal apertures.

$\$ 11$. Mandibular characters of existing Wombats. - In differentiating by cranial characters the species of Wombat called Phascolomys latifrons, I noted, in comparing it with Phascolomys vombatus, that "the curre of the lower border of the lower jaw is much deeper, the inner angle of the condyle is less produced, the coronoid process is higher and narrower, and the postsymphysial depression is almost obsolete in the Latifront Wombat"*. With the exception of the latter particular, which is variable in both species, subsequently acquired skulls hare confirmed the constancy of the above characters. They likewise serve to differentiate the mandible of Phasc. latifrons from that of Phascolomys platyrhinus, except that the coronoid process rises higher in the platyrhine species (Plate LII. fig. 2,c) than in the Tasmanian Wombat (ib. fig. 1,c); but the broader proportion of the process as compared with that in the Hairy-nosed Wombat (ib. fig. 3, $c$ ) is retained. The deeper curre described by the lower contour of the jaw from the neck of the condyle to the incisive alveoli, as shown in fig. 5, Plate xxxvii. of the undercited volume $\phi$, is a constant and well-marked character of Phascolomys latifrons; so, likewise, is the less produced inner angle of the condyle, shown in fig. $\tau, c d$, of the same Plate. In both the Tasmanian and Platyrhine Wombats this angle is more produced and deflected.

The diastemal part (Plates LIII., LIV. \& LV.l, $s^{\prime}$ ) of the long symphysis (ib. $s, s^{\prime}$ ) is subject to some variety in existing Wombats. In two mandibles of Phascolomys platyrhinus, in which the length of the series of molar alveoli is 2 inches 3 lines, that of the interval between the first alreolus and the foremost angle of the symphysis is, in one skull, 1 inch $7 \frac{1}{2}$ lines (Plate LV. fig. 2), in the other 1 inch $6 \frac{1}{2}$ lines; the breadth of the diastema, midway, is the same in both, viz. 10 lines.

In a mandible of Phascolomys latifions with the molar series of alveoli 2 inches in extent (Plate LIV. fig. 1 ), the diastema $\left(l, s^{\prime}\right)$, taken as above to the foremost point at the interspace of the incisors, is 1 inch 6 lines; in a second mandible with the molar alveoli 1 inch $10 \frac{1}{2}$ lines in extent, that of the diastema is also 1 inch 6 lines : the breadth of the diastema, midway, is in the first mandible 8 lines, in the second 7 lines.

* "On the Osteology of the Marsupialia" (Part II.) (1815), in Transactions of the Zoological Society, vol. iii. p. 304, plate xxxvii, figs, 2 \& 5 .

$\dagger$ Trans. Zool. Soc. rol. iii. 
In the two mandibles of the Platyrhine Wombat compared, the diastema is slightly convex both lengthwise and across; it is traversed by a pair of shallow longitudinal groores, and is not sharply defined from the sides of the symphysis. In a third mandible of the same species (Plate LIII. fig. $2, l, l$ ) the defining ridges are better marked, the transverse convexity is less so; and this part of the symphysis is rather longer and narrower than in the other two mandibles. In these respects the third mandible approaches nearer to Phascolomys latifrons; but it differs, as do the other mandibles of the same species as well as those of 1 hasc. vombatus, in the larger, especially broader, incisive alveoli, and in the oblique course of their upper margins from the mid line of the symphysis outward and backward. The fore end of the symphysis of Phasc. latifrons is at once recognizable by the narrower outlets of the incisive alveoli, and the more transverse course of their upper border (Plate LIV. fig. $1, s^{\prime}$ ). The lateral borders of the outlets are also more nearly vertical, and do not slope backward as they descend, like those of the incisive alveolar outlets in Phascolomys platyrhinus and Phasc. vombatus*.

With the narrower alveoli associated with the more compressed form of the incisors of Phasc. latifrons, one may predicate of a generally narrower diastemal part of the symphysis, the upper surface of which, with a mesial canal towards the end and the two parallel longitudinal grooves obsolete or nearly so, is better defined from the sides of this part of the symphysis. In one jaw of Phasc. latifrons the defining ridges are sharp, and the intervening upper surface is concave transversely to near the incisive outlets, where the defining ridges subside. I may note that the anterior outlet $(v)$ of the dental canal in three mandibles of Phascolomys platyrhimus is 1 inch 4 lines, or 1 inch 5 lines behind the foremost point of the symphysis (Plate LII. fig. 2, v): in one mandible of Phasc. latifrons (ib. fig. 3 ) it is 1 inch behind the fore end of the symphysis, in another mandible it is 10 lines from the same part. The foramen is more anteriorly situated in the broad-fronted or hairy-nosed species: it opens nearer to the molar series in Phasc. vombatus (ib. fig. $1, v) \uparrow$. I may further note that in the mandibles of two individuals examined since describing that of the type skull of Phascolomys latifrons, the intercommunicating foramen from the entry of the dental canal to the outer surface of the base of the coronoid is smaller in one, as in the type mandible, than in the Platyrhine and Tasmanian Wombats, while in the other it does not exist. It is interesting to find this variety, because, in the great Diprotodon and Notothere, with some affinities to Phascolomys, the absence of the perforation of the base of the coronoid process is the rule, as in the Marsupialia generally.

The first lower molar $\left(d_{3}\right)$ in Phasc. latifrons (Plate LIV. fig. 1 ) has a subquadrate transverse section; in Phasc. platyrhimus (Plate LIII. fig. 2) and Phasc. vombatus (ib.

* This latter character differentiating Phascolomys vombatus from Phasc. latifrons is shomu in figs. $3 c \& 7 c$ of plate xxxrii. tom. cit.

+ This character is shown in the figures of the mandible of the Tasmanian and Broad-fronted Wombats in plate xxxrii. of my second memoir (tom. cit.); but I could not then, as now, depend upon the constancy of such character. 
fig. 1, $d_{3}$ ) it has an elliptic or ellipsoid transverse section. The outer depression (Plate LII., $f$ ) of the ramus ascendens, or "ectocrotaphyte cavity," is less deep in Phasc. latifrons (ib. fig. 3), and shallows more gradually forward, than in the bare-nosed recent species (ib. figs. $1 \& 2$ ); the inflected angle $(a)$, viewed from below as in Plate LVI., has a broader base in proportion to its length, and is not produced so far or directly backward in Phascolomys latifrons (fig. 3) as in Phasc. platyrhinus (fig. 1).

$\S 12$. Mandibular characters of extinct Wombats similar in size to the recent species. -I now proceed to apply the above characters and comparisons of the mandibles of the known existing kinds of Wombat in the attempt to elucidate the fossil mandibular evidences of similar-sized Wombats, of which I have received or worked out twelve specimens from the breccia-masses transmitted to the British Museum by the Trustees of the Australian Museum, Sydney, New South Wales, in conformity with the desire of the Colonial Legislature, and in connexion with their liberal vote in aid of further explorations of the bone-caves discovered by Sir Thomas Mrtchell, C.B., Wellington Valley. Four other and more complete specimens are from the freshwater deposits of Queensland. The first of the cave specimens which I shall describe consists of the almost entire symphysis (Plate LIV. fig. 2 \& Plate LVI. fig. 4), and it is the only specimen from the breccia which shows this instructive part of the lower jaw. With the bone are included the implanted bases of the incisors $(i)$, the three anterior molars of the right side $\left(d_{3}, d_{4}, m_{1}\right)$, and parts of the first and second molars of the left side. The upper surface of the diastemal part of the symphysis $(l, s)$ is concave transversely, divided by sharp margins from the sides, and has a mesial longitudinal channel at the anterior third, without the pair of such channels. Lengthwise the upper contour of the diastema is slightly concave (Plate LII. fig. $\left.7, l, s^{\prime}\right)$. From the fore part of the anterior molary alveolus to the broken end of the symphysis is 1 inch 6 lines; the breadth of the symphysis midway is 9 lines. Sn far the fossil shows a closer affinity to Phascolomys latifrons (Plate LIV. fig. 1) than to the other two existing species, and more especially to the variety, fig. 3, Plate LII.

This affinity is more decisively shown by the form of the incisors in transverse section (Plate LIV. fig. $2 a, i, i$ ) and of the anterior molars (ib. $d_{3}$ ). The enamel covers and defines the lower broad flattened side of the incisor, bending up a little way upon both outer and inner sides, which converge toward the upper, narrower surface, but unequally; the outer surface descending therefrom, at first more vertically, toward the base, while the inner surface slopes to the mid line of the symphysis as it descends.

Thus there is a greater interval between the upper than the lower sides of the two incisors; the vertical exceeds the transverse diameter of the transverse section of the tooth. In these characters the lower incisors of the fossil agree with those of Phascolomys latifrons.

In the Platyrhine and Tasmanian Wombats the transverse prevails over the vertical diameter of the exposed end of the incisors, and the enamel bends up from the lower along the outer surface nearly to the upper one, describing a uniform convexity, transversely.

The fossil adheres also to the latifront type in the shape of the first molar, $d_{3}$ (fig. "2, 
Plate LIV.), and resembles the Hairy-nosed Wombat in the size of its molars, which is less than in Phascolomys plutyrhimus (Plate LIII. fig. $2, d_{3}, d_{4}, m_{1}$ ). But the following differences present themselves in the comparison of the present fossil with the corresponding part of the mandible of Phascolomys latifions. In that species the upper trausversely concave intermolar part or surfice of the symphysis does not extend backward beyond the alreolus of the second molar; at the third molar the inner wall of the jaw soon changes its concavity for a convexity bending down to the back part of the symphysis. In Phascolomys platyrhimus the concave upper surface of the symphysis extends further back, and this character is exaggerated in the fossil ; for the inner wall of the socket of the third molar (Plate LIV. fig. $2, m_{1}$ ) arches inward as it descends; continuing the diastemal transverse concavity to that part of the molar series where the hinder fracture of the present fossil has occurred, exposing the long curved implanted part of the third molar ( $m_{1}$, fig. 3 ).

Anotler difference is seen at the under part of the symphysis of the fossil (Plate LVI. fig. 4) as compared with that in the latifront species (ib. fig. 3). In this the longitudinal contour is convex, concurrently with the greater general convexity of the curve of the lower border of the mandible (Plate LII. fig. 3); in the fossil (ib. fig. T) the lower surface of the symphysis runs straiglit, or very nearly so, from the hind fracture to the outlets of the incisive alveoli $\left(s^{\prime}\right)$, along a preserved symphysial extent of 2 inches 8 lines. It is interesting to see that liere, again, the fossil resembles the Platyrhine species (Plate LII. fig. 2), the older spelxean form combining to a certain extent characters kept apart in still existing species of Wombat. Nevertheless the more essential resemblances are to the Phascolomys latifrons. The pair of subsymphysial foramina (Plate LVI. fig. $4, r)$ characteristic of the Wombats are wider apart (4 lines) than in the Platyrhine (ib. fig. 1,r) and Tasmanian (ib. fig. 2, r) species, and show rather the latifront character; they have the usual relative position to the fore and hind ends of the symphysis.

The specific distinction between the broad-fronted (Plate LII. fig. 3) and other existing Wombats (ib. figs. $1 \& 2$ ) afforded by the ascending ramus of the mandible induced attention to all the cave fragments of that part of the lower jaw, and led to careful remoral of the matrix from both the outer and inner depressions. This brought to light the modification of the lower part of the ectocrotaphyte depression $(f)$ shown by the subject of fig. 6, Plate LII. In the minor depth of the base or lower part of that depression the fossil mandibular fragment agrees with Phascolomys latifrons (ib. fig. $3, f$ ), and more especially with the variety above noted with the absence of the transverse perforation (Plate LII. fig. 3). The part of the base, or below the base, of the coronoid in the fossil where the canal opens externally in the normal mandibles of Phasc. latifrons* is entire; it is also less depressed there than in the perforate variety. From this and the normal mandible of the latifront species the fossil (Plate LII. fig. 6) differs in the relative position of the anterior beginning of the "ectocrotaphyte ridge" $(h)$ or that bounding below the ectocrotaphyte depression $(f)$. In the three recent species (ib.

* Trans. Zool. Soc. vol. iii. plate xxxrii. fig. 5. 
figs. 1, 2,3) this ridge $(h)$ begins near the lower border of the ramus; in the fossil (ib. fig. $6, h$ ) it begins midway between the lower and upper borders, and on a vertical parallel with the third or antepenultimate molar $\left(m_{1}\right)$-consequently more in advance than in the recent Wombats, in which both the ridge and the base of the coronoid $(q)$ begin below the fore part of the peuultimate molar $\left(m_{2}\right)$. Both penultimate and last molars are in place and are worn in the fossil, so the differences above noted cannot relate to nonage. The beginning of the ectocrotaphyte ridge is $10 \frac{1}{2}$ lines below the outlet of the first division of the alveolus of $m_{2}$ in Phasc. latifrons (ib. fig. $3, h$ ), and is 1 inch below the same part in Phasc. platyrhinus (ib. fig. $2, h$ ); in the fossil it is 6 lines below the hind division of the alveolus of $m_{1}$. The anterior origin of the coronoid appears to be proportionally advanced in the fossil. The outer surface of the ramus below the beginning of the ectocrotaphyte ridge slopes more gradually inward and lower down before passing into the broad under surface of the jaw in the fossil (Plate LII. fig. 6). In the recent Wombats the same surface curves, with a stronger and shorter convexity, into the lower border, yet less abruptly in Phasc. latifrons (ib. fig. $3, k$ ) than in Phasc. platyrhinus (ib. fig. 2, $k$ ).

The ectalveolar groove is longer, deeper, and narrower in the fossil (Plate LIII. fig. 3, $u$ ), owing to the more advanced origin of the coronoid $(q)$ and its greater proximity to the last two alveoli $\left(m_{2}, m_{3}\right)$; this differential character is still more marked as compared with the Platyrhine species (ib. fig. 2, u). From so much of the entocrotaphyte ridge, or anterior beginning of the inflected angle, as is preserved, the degree of inflection appears to have been less in this fossil (Plate LVI. fig. 5, a) than in the recent species (ib. figs. 1, 2, 3, a). The surface broadening as it recedes, between the ecto- and entocrotaphyte ridges, is not only flattened but becomes rather concave in the fossil toward the inner border.

The two hindmost molars in place (Plate LIII. fig. $3, m_{2}, m_{3}$ ) are narrower than those in Phasc. latifrons (Plate LIV. fig. $1, m_{2}, m_{3}$ ), as are the anterior molars in the fossil previously described (ib. fig. $2, d_{3}, d_{4}$ ). To the species represented by the lastcited fossil, I am disposed, from the resemblance of the symphysis to that in the imperforate variety of Phasc. latifrons, to refer the present fossil. 'They might be parts of the same mandible, as well as of the same species; but more complete specimens must confirm or confute this supposition. It is certain that both fossils show the nearest resemblance to the mandibular imperforate variety of Phascolomys latifrons above named, yet with marked differences, in value equalling those interpreted and accepted as specific. The part of the dental canal which courses along the inner side of the molar alveoli and the bottoms of the last two alveoli are exposed by fracture of the thin film of bone originally covering them.

In reference to the characters of the two portions of fossil mandible above defined, as they plainly justify the inference that they belonged to a species of Phascolomys as distinct from the three accepted recent species as these differ from one another, each might be indicated by a specific name; and it may ultimately prove that they do belong 
to distinct species. The same remark applies to both or either in relation to the maxillary fossil from the same cavern (Plate L. figs. $2 \& 6$ ) which I liave referred to a Phascolomys líeffii.

Considering, however, that the two portions of mandibles combine, like that maxillary one, characters of affinity to Phascolomys latifrons with differential ones forbidding a reference to that species, it may be, and may be probable even, that they all belong to the same extinct species. I prefer, therefore, to indicate them as parts of a Phascolomys Krefftii, and leave to those who may be so fortunate as to obtain evidence to the contrary, to impose their own specific denominations on the so demonstrated distinct kind of Tombat.

\$ 13. Mandibular fossils of Phascolomys latifrons.-Of six otler mandibular fragments showing the fore part of the ectocrotaphyte depression, two mutilated right rami (Plate III. figs. 4 \& 5), by the gradual beginning and degree of deepening of that depression $(f)$, agree with the perforate or normal mandible of Phascolomys latifrons. 'The outer orifice of the transverse canal or perforation (ib. $p$ ) holds the same position in these fossils: one of them (ib. fig. 4) includes the four anterior molars and the socket of the fifth; the other (fig. 5) includes the four posterior molars. The fore-and-aft extent of the series of five sockets, in each specimen, is 2 inches, the depth of the mandible at the back part of the symphysis is (in fig. 5) $6 \frac{1}{2}$ lines; in fig. 4 it is 1 inch 5 lines. The ectalveolar groove (Plate LIII. fig. 4, $u$ ) is narrow. The inner wall of the ramus, forming that of the second $\left(d_{3}\right)$ and third $\left(d_{4}\right)$ sockets, descends more vertically than in the first described fragment (Plate LIV. fig. 2), or in the Tasmanian (Plate LIII. fig. 1) and Platyrhine (ib. fig. 2) Wombats. The lind end of the symphysis is on the vertical parallel of the interval between $d_{4}$ and $m_{1}$, or not further back than the middle of $m_{2}$ (Plate LIII. fig. 4, $s^{\prime}$ ). In both these characters the present fossils come nearer to the latifront species (Plate LIV. fig. 1,s) than to the Platyrhine and Tasmanian Wombats. 'The first molar $\left(d_{3}\right)$ repeats the formal characters of that tooth in the Phasc. latifrons.

I conclude, therefore, that the mandibular fossils under description belonged to a "hairy-nosed" Wombat, and one nearer to the existing species than the preceding fossil (Plate LIV. fig. 2), in which the symphysis appears to have extended as far back as it does in Phascolomys platyrlinus (Plate IIII. fig. 2).

\$ 14. Manditular fossils of Phascolomys Mitchelli.-I now come to mandibular fossils which, in the depth of the base of the ectocrotaphyte depression (Plate LV. fig. 5, f), rescmble the Tasmanian and Platyrhine Wombats. Four of these have the entire molar series in place. In one (Plate LIII. fig. 5) the extent of the series is 2 inches 2 lines; the first molar, however $\left(d_{3}\right)$, agrees in shape and size with that in Phasc. latifions (Plate LIV. fig. 1, $d_{3}$ ).

'The transverse concavity of the inner wall, continued from the first and second molar sockets and upon the symphysis half an inch in advance, more resembles that in the imperforate varicty of the Latifront Wombat than in any other mandible of recent species. The symphysis (Plate LV. fig. 6,s) does not extend so far back as in the Tasmanian 
(ib. fig. 1, s) and Platyrhine (ib. fig. 2, s) Wombats. From the fore part of the first molar socket to the back part of the upper division (ib. fig. $6, s^{*}$ ) of the symphysial surface, in the fossil, measures 1 inch; and this part of the symphysis is on the vertical parallel of the hind lobe of the second molar. The lower division $(s)$ terminates, as in fig. 4 , below the interval between $d_{4} \& m_{i}$.

The fore part of the root of the coronoid, in the fossil (ib. fig. 5, $q$ ), stands out from the alveolar wall of the penultimate molar, as in Phasc. latifrons; not from that of the last molar, as is the rule in the Tasmanian (Plate LII. fig. 1, q) and Platyrhine (ib. fig. $2, q$ ) Wombats. The extent of the molar series and the sizes of the individual teeth accord, save in the narrower character of the lower molars, with the teeth of the upper jaw in the subject of figure 5, Plate $\mathrm{L}$. If these fossils are maxillary and mandibular specimens of the same species of Wombat, the lower molars are relatively narrower transversely, compared to the upper ones, than in any of the existing species.

In the mandibular specimen under consideration we see combinations of characters confined severally to distinct species in existing Wombats. I am disposed therefore, and for reasons above assigned, to refer this mandibular fossil, with the maxillary one above cited, to Phascolomys Mitchelli.

A second similar specimen of left ramus, including part of the symphysis and of the ascending ramus, has a molar series 2 inches in extent, and, as in fig. 5, Plate LIII., the teeth have the general characters of those in Phascolomys latifrons; they are transversely narrower than in Phascolomys vombatus or Phasc. platyrhinus. The ectocrotaphyte depression is deeper than in the perforate mandible of that species; the perforation $(p)$ here shows a similar position and size. The depth of this fossil jaw at the backpart of the symphysis is 1 inch 5 lines. The symphysis terminates below the interval, between the second $\left(d_{4}\right)$ and third $\left(m_{1}\right)$ molars. The ectalveolar groore is wider than in the subject of fig. 3, Plate LIII., but is deeper than in the Platyrline and Tasmanian Wombats. The symphysis is not bilobed behind, as in fig. 6, Plate LV.; but this and the before-mentioned differences from that subject probably exemplify the range and seat of variety in the mandibular characters of one and the same species.

The characters noted in the subjects of figs. 4 \& 5, Plate LVI., of fig. 4, Plate LV., and of figs. $2 \& 3$, Plate LIV., are of specific value; but, as in the maxillary fossils (Plate I. figs. 1 \& 2), I do not feel grounds for indicating, after comparison of the mandibular fossils from the Wellington-Talley breccia-caves, more than two species of a size not exceeding the known existing Wombats, and not referable thereto.

$\S 15$. Mandibular characters of Phascolomys Thomsoni, Ow.-From the freshwater deposits of Queensland I have receired mandibular fossils of the genus Phascolomys, which, with decrease of size, show characters not in accordance with those of any of the cave fossils.

The subject of figs. $8 \&$ 9, Plate LI., and fig. 7, Plate LV., is a right mandibular ramus, witl slight mutilation at both ends. In the lower contour of the jaw, the depth of the ectocrotaphyte depression $(f)$, the breadth of the ectalveolar groove $(u)$, the position 
and size of the intercommmicating foramen $(p)$, the shape of the anterior molar $\left(d_{3}\right)$, and the shape and proportions of the incisor (i), so far as these are indicated, the present fossil agrees with Phascolomys platyrhinus, and differs from I'hascolomys latifions and Phase. Mitchelli. It agrees, however, with these, and differs from both the bare-nosed Wombats, in the relative position of the back part of the symphysis (Plate LV. fig. 7, s), which does not extend beyond the rertical line dropped from the front lobe of $m_{1}$.

The grinding-surface of $d_{3}$ (l'late LI. fig. 9) is an ellipse with the long axis nearly parallel with that of the mandible. 'The outer side of the incisor is transversely convex, and curves uninterruptedly to the underside, as in Phasc. platyrhinus and Phasc.vombatus. In size this fossil does not exceed the Tasmanian species. The antero-posterior extent of the working-surfaces of the five molars is the same, viz. 1 inch 11 lines; but the tecth are rather narrower transversely, and the last molar, especially its hinder lobe, shows a greater decrease, as in the Hairy-nosed Wombat.

I indicate the species of Phascolomys, from which the present fossil has been derived, by the name of a former estimable Professor of Geology in the Sydney University, New South Wales, Alex. M. 'Thomsor, D.Sc. The specimen is from a lacustrine deposit at Gowrie, Darling Downs, Queensland, and was presented to the British Museum by Sir William M ${ }^{\mathrm{C}}$ Arthur, Bart.

\$16. Mandibular fossil of Phascolomys platyrhinus, Ow. -The subject of figs. $3 \& 4$, Plate LIV., well exemplifies the differences by which Phascolomys platyrhinus differs from P'hascolomys Thomsoni. The symphysis has the same backward extent and relative position to the molar series as in the recent specimen (Plate LIII. fig. 2); the character of the upper surface of the diastemal tract $(l)$ is repeated; the formal characters of $d$ s and of $i$ in the fossil are precisely those in the recent continental bare-nosed Wombat: in size the fossil equals the largest living specimen of that species. The antero-posterior extent of the molar series is 2 inches $2 \frac{1}{2}$ lines. The shape and proportions of the molars characteristic of Phascolomys platyrhinus are closely preserved in the fossil. It was obtained from the bed of a tributary of the Condamine River, Queensland, by EDWARD S. Hril, Esq., and shows that the characters of the actual Platyrhine species were established at a period coeval with the existence of Diprotodon and Thylacoleo.

$\$ 17$. Mandilular and lower molary characters of Phascolomys parvus, Ow.-With present evidence of the constancy of size of the molar series of teeth in existing and extinct species of Wombat, such series fully in place and well worn, having a longitudinal extent of 1 inch 5 lines, cannot be referred to a species with a longitudinal extent of molars never less than 1 inch 9 lines, and usually more: as, e.g., in the Tasmanian Wombat, which is the smallest of the known existing species. The series of molars in Plate LIII. fig. 6 , contrasted with those in fig. 1 , is implanted in a mandible of similar small size (Plate LIV. figs. $6 \&$ T). In the lower contour, the depth of the ectocrotaphyte fossa $(f)$, the breadth of the ectalveolar groove, the shape and size of the incisor, and the shape of the grinding-surface of the anterior molar $\left(d_{3}\right)$ this fossil agrees with Phascolomys platyrhimus. But the symphysis (Plate LIV. fig. 7, ${ }_{3}$ ) does not extend so far 
back; it ends there below the interspace between the second $\left(d_{4}\right)$ and third $\left(m_{1}\right)$ molars. The hind contour of the symphysis is subbilobed (ib. $\left.s, s^{*}\right)$; it is long, but less deep relatively than in Phascolomys Mitchelli (Plate LV. fig. 6).

The grinding-surface of the anterior molar (Plate LIII. fig. $6, d_{3}$ ) is subelliptic, with the long axis nearly parallel with that of the jaw, 2 lines and 1 line in the two diameters, showing the usual disposition of the incomplete coat of enamel. The succeeding molars have the normal bilobed or biprismatic shape; their grinding-surfaces do not exceed severally $3 \frac{1}{2}$ lines, the fore lobe of the first $\left(d_{4}\right)$ and the hind lobe of the last $\left(m_{3}\right)$ being the smallest. The hinder half of the diastemal tract, above, is bounded by a ridge $(l)$ or each side, and is there transversely concave. The outlet of the dental canal (Plate LIV. fig. $6, v$ ) is more advanced in position than in Phascolomys vombatus (Plate LII. fig. $1, v)$. The outer enamelled surface of the incisor is transversely or vertically convex, curving uninterruptedly to the lower border of the tooth, as in the bare-nosed Wombats, but with less relative breadth of the tooth than in those existing species. Sufficient of the angle of the jaw is preserved to show the partial division of the large cavity formed by its inward extension into the inner $(d)$ and outer $(e)$ angular depressions (Plate LVI. fig. 7). The base of the coronoid process (Plate LIV. figs. $6 \& 7, c$ ) is 6 lines in fore-and-aft extent; in Phascolomys vombatus it is 11 lines.

The well-marked characters of this small extinct species are satisfactorily repeated in a second mandibular specimen, also of the left ramus, but more mutilated behind. It retains, however, the anterior end entire; and the incisor shows its worn surface (Plate LIII. figs $6 \& 7, i$ ). The vertical diameter of the incisor equals the long diameter of the working-surface of the second molar tooth, $d_{4}$.

A third illustration of this diminutive species is likewise afforded by a portion of the left mandibular ramus; it is a small portion, but includes the last two molars and the hind half of the antepenultimate molar. The base of the common plate of the coronoid and condyloid processes is in part preserved, with a broken beginning of the ectocrotaphyte ridge: these, with the postalveolar ridge and ectalveolar groove, repeat the characters of the more complete ramus (Plate LIV. figs. $6 \& 7$ ). The size of both bone and teeth is the same in all. The present fossil, by the well-worn crowns of the molars, appears to be from an old individual. The formal characters are incompatible with a reference of those of size to immaturity.

All the specimens of Phascolomys parvus were in the Boydian Collection of fossils from the Lacustrine deposits of King's Creek, Darling Downs, Queensland, purchased by the British Museum, and are in the same mineralized condition as the remains of Diprotodon in the same collection. 


\section{Explanation of the Plates.}

PLA'TE L.

Fig. 1. Upper view of anterior portion of skull of Phascolomys Mitchelli.

Fig. 2. Upper view of anterior portion of skull of Phascolomys Krefftii.

Fig. 3. Right side view of anterior portion of skull of Phascolomys Mitchelli.

Fig. 4. I.eft side riew of the same skull.

Fig. 5. Under view of the same skull.

Fig. 6. Front view of the portion of skull of Phascolomys Krefftii.

Fig. 7. Portion of left maxillary, Phascolomys Mitchelli.

Fig. 8. Palatal surface and upper molars of Phascolomys Mitchelli.

\section{PIAT'TE LI.}

Fig. 1. Palatal surface and upper molars, Phascolomys Mitchelli.

Fig. 2. Side riew of the same portion of skull.

Fig. 3. Front view of the same portion of skull.

Fig. 4. Back view of the same portion of skull.

Fig. 5. Side view of the left maxillary, I'hascolomys Mitchelli.

Fig. 6. Front view of the same portion of skull.

Fig. 7. Palatal surface and molar tecth of ditto.

Fig. 8. Outside view of right mandibular ramus of Phascolomys Thomsoni.

Fig. 9. Upper view with grinding-surface of lower molars of the same fossil.

\section{PLATE LII.}

Fig. 1. Outer side riew of the right mandibular ramus, Phascolomys vombatus.

Fig. 2. Outer side view of the right mandibular ramus, Phascolomys platyrhimus.

Fig. 3. Outer side vicw of the right mandibular ramus, Phascolomys latifrons.

Fig. 4. Outer side view of part of the right mandibular ramus, Phascolomys latifrons.

Fig. 5. Outer side view of part of the right mandibular ramus, Phascolomys latifrons.

Fig. 6. Outer side view of the hind part of the right mandibular ramus, Phascolomys Krefftii.

Fig. T. Outer side riew of the fore part of the right mandibular ramus, Phascolomys Krefftii.

\section{PI,ATE LIII.}

Fig. 1. Upper view of mandible and mandibular tecth, Phascolomys vombatus.

Fig. 2. Upper view of mandible and mandibular teeth, Phascolomys platyrhinus.

Fig. 3. Upper view of a portion of the left mandibular ramus with the last two molars, Phascolomys Krefftii. 
Fig. 4. Upper view of a portion of the right mandibular ramus, Phascolomys latifrons. Fig. 5. Upper view of a portion of the left mandibular ramus, Phascolomys Mitchelli. Fig. 6. Upper view of a portion of the left mandibular ramus, Phascolomys parvus. Fig. 7. Outer side view of the same fossil.

\section{PLATE LIV.}

Fig. 1. Upper view of mandible and mandibular teeth, Phascolomys latifrons. Fig. 2. Upper view of the fore part of the mandible, Phascolomys Rrefftii: 2 a, transverse section of the incisors.

Fig. 3. Upper view of a portion of the mandible of Phascolomys platyrhinus.

Fig. 4. Under view of the same fossil : $4 a$, transverse section of the incisors.

Fig. 5. Side view of fore part of the same jaw.

Fig. 6. Outer side view of the left mandibular ramus, Phascolomys parvus.

Fig. 7. Inner side view of the same fossil.

Fig. 8. Under surface of angular part of the same fossil.

\section{PLATE LV.}

Fig. 1. Inner side view of the right mandibular ramus, Phascolomys vombatus.

Fig. 2. Inner side view of the right mandibular ramus, Phascolomys platyrhinus.

Fig. 3. Inner side view of the right mandibular ramus, Phascolomys latifrons.

Fig. 4. Inner side view of a portion of the right mandibular ramus, Phascolomys latifrons.

Fig. 5. Outer side view of a portion of a left mandibular ramus, Phascolomys Mitchelli.

Fig. 6. Inner side view of the same fossil: drawn without reversing.

Fig. 7. Inner side view of a portion of the right ramus, Phascolomys Thomsoni.

\section{PLATE LVI.}

Fig. 1. Under view of mandible, Phascolomys platyrhinus.

Fig. 2. Under view of the left ramus and symphysis of mandible, Phascolomys rombatus.

Fig. 3. Under view of the right ramus and symphysis of mandible, Phascolomys latifrons.

Fig. 4. Under view of the symphysis of mandible, Phascolomys Krefftii.

Fig. 5. Under view of the hind part of the left ramus of mandible, Phascolomys Kreffiti.

Fig. 6. Back view of the hind part of the left ramus of mandible, Phascolomys parvus.

Fig. 7. Upper view of the same part of the fossil.

Fig. 8. Transverse section of lower incisors, Phascolomys platyrhinus.

Fig. 9. Transverse section of lower incisors, Phascolomys latifrons. 


\section{l.IST' OF WOODCUTS.}

Fig. 1. Nasal bones and their comnexions, var. 2, Phascolomys rombatus.

Fig. ". Nasal bones and their comexions, var. 3, I'hascolomys rombatus.

Fig. "). Nasal bones and their connexions, Phascolomys platyrhimus.

Fig. 1. Nasal bones and their connexions, l'hascolomys latifions.

Fig. 5. I acrymal and maxillary characters, Phrescolomys platyrhimus.

Fin. 6. Jacrymal and maxillary characters, I'hescolomys lutifrons.

- Fis. 7. Palatal surface of upper jaw and teeth, Phascolomys platyrhinus.

Five. S. Palatal surface of upper jaw and teeth, Phascolomys latifions.

All the figures are of the natural size. 


\section{Genus Phascolomys.}

Species exceeding the existing ones in size.

Is the preceding section I applied the cranial, mandibular, and dental characters of the existing species of Wombat to the determination of the fossil species resembling them in size; in the present are given the results of an easier task, viz. the determination of extinct Wombats of markedly superior size to any now living; and I shall describe the fossils as the species they represent progressively predominate in bulk.

$\S 1$. Phascolomys medius, Ow.-This species is represented by a lower jaw, fractured at both ends, presented by Sir Charles Nicholson, Bart., to the Geological Society of London; also by the fore part of the upper jaw of two individuals and by the right ramus, fractured at both ends, of the lower jaw, obtained by EDWard S. Hill, Esq., from freshwater deposits exposed in the bed of a tributary of the Condamine River, at Eton Vale, Queensland: the latter were submitted to me in 1865, and have been liberally presented, with other Queensland fossils, to the British Museum by Sir Daniel Cooper, Bart. All these fossils are in the usual heary, petrified, rolled, and more or less mutilated condition of such remains from the above formation and locality.

The first to be described (Plate LVII. figs. $2-7$ ) consists of so much of the premaxillary $\left.{ }_{22}\right)$ and maxillary $\left.{ }_{21}\right)$ bones as includes the sockets of the incisors $(i)$ and of the first three molars $\left(d_{3}, d_{4}, m_{1}\right.$, fig. 2$)$, with part of that of the fourth, $m_{2}$. The incisors are broken off at the level of their alveolar outlets (fig. $6, i$ ); the first and second molars, left side, show their natural grinding-surface; part of that of the following tooth is broken; the rest of the molars are more or less mutilated or wanting.

The superiority in size of the present extinct species to the two largest of the existing Wombats will be seen by comparing the above-cited figures, especially fig. 2, Plate LVII., with the corresponding parts of the skull of Phascolomys latifrons (ib. fig. 1) and of Phascolomys platyrhinus (Plate LVIII. fig. 1); it needs not to introduce the smaller Tasmanian Wombat into the comparison.

The following admeasurements give the degree, or value, of the character from the size of teeth and extent of diastema of the species above cited:-

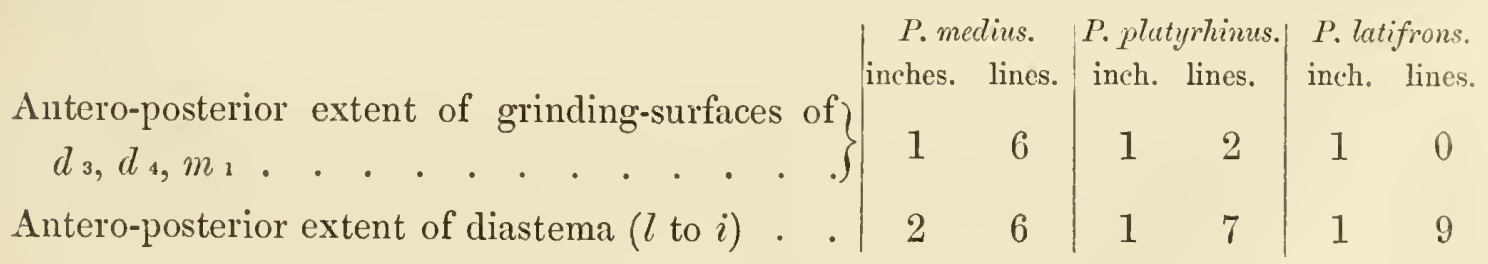

In the relative length of the interval between the socket of the incisor (Plate LVII. fig. $2, i)$ and that of the anterior molar $\left(d_{3}\right)$, the present fossil resembles the latifront 
species (ib. fig. 1, $\left.l, 22^{\prime}, i\right)$. 'The same relationship is shown in the form of the intermolar part of the bony palate, which is less contracted anteriorly in the fossil than in the hare-nosed Wombats (1'hascolomys platyrhinus, Plate IVIII. fig. 1). 'The entire bony palate is more concave transversely in the hairy-nosed Wombat than in the other recent kinds; and this character is more strongly marked in the fossil, especially in the depth of the diastemal palatal tract into which open the "incisive" or premaxillo-maxillary palatal foramina (Plate I,VII. fig. 2,a,a). This deeply arched form of the bony roof of the mouth will be again noted in larger extinct species of Wombat.

'The present appears to have been one half larger than the largest individuals of Phascolomys platyrhimus. In a specimen of this existing species, the length of the diastema equals three fifteenths of that of the entire skull, which is 7 inches 5 lines (Plate I.VIII. fig. 1, 21',22'). If the diastema bore the same proportion in Phascolomys medius, the length of its skull may be set down at 1 foot 6 inches.

The first molar (Plate I.VII. fig. 2, $d_{3}$ ), with the usual curvature, concave outward, and with the exposed part inclined obliquely backward, has a grinding-surface, or transverse section, of an oval form, with the small end forward. The long diameter is 5 lines, and is in the direction of the molar series; the greatest transverse diameter is 4 lines. 'Ihe enamel does not extend from the inner surface so far outward upon either the front or back parts of the tooth as in the recent Wombats; it shows no trace of the antero-internal fold which is feebly marked in Phascolomys latifions, and strongly marked in Phascolomys platyrhinus and Phasc. vombatus. 'The coat of cement covering the outer side of the tooth is continued in a thinner layer over part of the enamel, and where absent has been probably accidentally removed from that partial deposit of the hardest dental tissue.

The second molar (ib. $d_{4}$ ) is divided by the usual deep inner groove and shallow outer one into two lobes, the hinder one being broader both transversely and from before backward. 'The antero-posterior extent of the grinding-surface is $7 \frac{1}{2}$ lines, the transverse extent of the front lobe is 4 lines, of the hind lobe $4 \frac{1}{2}$ lines; the inner end of this lobe is less obtusely rounded than that of the front lobe. From the unequal depth of the outer and inner alveolar walls, only a small part (about a line) of the unenamelled outer part of the tooth projects from the socket, while an extent of four lines of the inner enamelled part of the tooth projects beyond the lower inner alveolar wall (Plate LVII. fig. $\left.7, d_{4}\right)$. The enamel-coat is thinner at the bottom of the inner inflection or groove, and terminates near the rounded external angles of the tooth: portions of the thin cement covering the enamel are preserved.

'The third molar (ib. fig. $2, m_{1}$ ) resembles $d_{4}$ in size and shape; the anterior lobe does not extend so far inward as the contiguous lobe of the antecedent molar. The portion of the anterior lobe preserved of the fourth molar $\left(m_{2}\right)$ shows the same relative position to the hind lobe of $m_{1}$. 'The enamel in all the molars is longitudinally striate, the striæ being feebly marked and subrugose.

Completing the upper molar series according to the analogy of Phascolomys latifrons, 
its antero-posterior extent would be about 2 inches 8 lines; and this is the extent shown in a photograph (Plate LX. fig. 7), nat. size, of a portion of the upper jaw of Phascolomys medius, with the entire molar series of the right side, from the breccia-care of Wellington Valley, New South Wales, in the Australian Museum, Sydney, for which I am indebted to the Trustees of that Museum.

The margin of the diastemal part of the upper jaw (Plate LVII. fig. $2, l$ ) is sharp to near the incisive outlets $(i)$, where it broadens and becomes obtuse. The cross section of the incisor (ib. fig. 6) is a transverse oval, 6 lines in long diameter, $4 \frac{1}{2}$ lines in short diameter; the small end of the oval is obtuse and turned outward. The enamel bends from above a very short way down upon the inner sicle or large end of the oval; it arches dorm over the small end. The enamelled surface of the tooth is more convex than the hind or lorver cement-clad surface; but this is more convex, or less flattened, than in Phascolomys latifrons. 'The long and short diameters of the transverse section of the incisor in the other two living species are in opposite directions to those in the present fossil and the Latifront Wombat.

In Plascolomys medius the malar process of the maxillary (Plate LXII. fig. 3, ${ }_{21 *}$ ) rises thirteen lines above the alveolus of the third molar: the intervening wall of the maxillary is moderately concave vertically; in the smaller living Wombats it is convex; but in the character of height of origin of the process we again have an evidence of affinity to the latifront species. The photograph (Plate LX. fig. 7) shows a close correspondence with the fossil in this character.

The prezygomatic ridge (Plate LVII. fig. $3, m$ ) is low and broad, but in course and length resembles that in Phascolomys latifrons; in Phasc.platyrhinus this ridge is shorter, relatively thicker, and more prominent. Anterior to the ridge and the socket of $d_{3}$ the maxillary part of the skull of Phasc. medius contracts transversely, seemingly more suddenly than in existing Wombats, to form the diastemal part of the upper jaw. The maxillo-premaxillary suture runs vertically, with a sinuous and strongly denticulate course, about 5 lines in adrance of the socket of $d_{3}$. The front walls of the incisive sockets (Plate LVII. figs. 3, 4, \& 5, 22, 22) are relatively higher or deeper than in Phascolomys latifrons, in which they are relatively higher than in the bare-nosed Wombats. The contour of this part of the premaxillary is rather concave in the fossil.

The photograph above referred to (Plate LX. fig. 7) of the cave fossil shows the same depth and shape of the bony palate, and the same somewhat abrupt contraction of the diastemal part of the maxillary, as in the fossil (Plate LVII. fig. 2) from Eton Vale.

These evidences of specific distinction, superadded to the marked superiority of size of Phascolomys medius, are acceptable; although the degree of constancy of size and shape of teeth in the three species of living Wombats would hare justified an inference, from the teeth alone of the present fossil, that a still larger Wombat than the platyrhine continental species had formerly existed in both Queensland and New South Wales.

As so much, however, depends on ascertained constancy of characters in the comparative work preliminary to determination of extinct species, I believe it will be acceptable 
to palixontologists to have a description and figures of a fossil of Phascolomys medius somewhat larger than the subject of Plate LVII. figs. 2-7.

The fore-and-aft extent of the first threc molars in fig. 2, Plate LVIII., is 1 inch 11 lines; in fig. 2, Plate LVII., the saine dimension yields 1 inch 8 lines. The closer agreement, as to size, in all other parts of the two fossils leads me to regard the above clental difference as coming within the limits of age- or sex-variation. The present fossil has been more crushed than the former; the socket of $d_{3}$ may have been pressed forward a little way from that of $d_{4}$, and so have contributed somewhat to the above difference. It is singular how the lethal or posthumous violence has operated so as to detach almost the same parts and proportion of the fore part of the skull from the remainder in both representatives of Phascolomys medius. Some transverscly acting force has nipped in the maxillaries in advance of the sockets of $d_{s}$, breaking the diastemal from the alveolar part of the left maxillary and crushing it inwards; this, in the present fossil, has somewhat approximated the right and left anterior molars $\left(d_{3}, d_{4}\right)$, and has converted the concavity of the palate at the hind part of the diastema into an angular cleft. But the fore part expands and conforms in character with that in the lastdescribed fossil. The length of the diastema and the characters of its borders are the same. 'The differences mentioned are obviously accidental. Rather more of the anterior picr of the zygonatic arch is preserved on the left side of the present fossil (Plate LVIII. fig. 3, $21^{\circ}$ ).

The first molar $\left(d_{3}\right)$ and the incisors have the same shape as in Plate LVII. Nearly the whole of the implanted part of the left incisor $(i)$ is exposed in the subject of fig. 3, Plate LVIII. The incisors slightly converge as they curve downward and forward to the outlets of their long sockets. The enamel shows the same longitudinal rugous striation as in the other fossil. In both the median ridge is shown along so much of the floor of the nasal passages as is exposed (ib. fig. 4, n). In fig. 6 is given an inside view of so much as is preserved of the molars of the left side, upper jaw, corresponding with that from the preceding fossil given at fig. 7, Plate LVII.

With the two foregoing fossils I received from Queensland, through the same liberal and enlightened contributors of materials for the history of Australian marsupial fossils, the portion of mandible, with the entire molar scries, figured in Plate LIX. figs. 1 \& 2.

'I'his fossil, from the size of the teeth and of the jaw supporting them, I refer to the same species as the upper jaw (Plates LVII. \& LVIII.). It includes an extent of 5 inches of the right ramus, wanting both extremities, but with a symphysial portion of the left ranus (Plate LIX. fig. 2, $v, \ddot{i}$ ) adherent by matrix, though slightly displaced, showing that the joint $(s)$ had not been obliterated.

The general curre of the lower contour resembles that of the mandible of Phascolomys latifrons (Plate LII. fig. 3). The anterior part of the origin of the coronoid (Plate LIX. fig. 1,q) bears the same relation to the penultimate molar, and is more advanced than in Phascolomys platyrhinus. The ectalveolar groove (ib. fig. $3, u$ ) between this process and the last two alveoli is relatively narrower than in any of the living species. "The fore 
part of the ectocrotaphyte depression $(f)$, bounded below by the prominent outstanding ridge $\left(h^{\prime}, h\right.$, fig. 1$)$, is less deep than in the bare-nosed Wombats, and is more gradually excavated, as in the hairy-nosed species.

The ramus maintains its depth ( 1 inch 10 lines) to the socket of the first molar (Plate LIX. $d_{3}$, figs. $1 \& 2$ ). The hind part of the symphysis (ib. fig. $3, s$ ) is on the vertical parallel of the hind part of the second molar (fig. $2, d, 4)$, being rather more advanced than in Phascolomys latifrons (Plate LV. fig. 3, s), and much more so than in Phasc.platyrhinus (ib. fig. 2,s) or Phasc. vombatus (ib. fig. 1,s). The upper surface of the symphysis (Plate LIX. fig. 3, $s$ ) repeats the character of the opposed palatal part of the upper jaw (Plate LVII. \& LVIII. 21',22') in its degree of transverse concavity; and this, at the diastemal tract, is bounded by lateral ridges, sharper than those above; they indicate a slightly curved course as they advance, concave outward, so far as they extend in the fossil. These characters of the upper surface of the symphysis are most nearly repeated by Phascolomys Krefftii (Plate LIV. fig. 2, l,s) amongst the smaller Wombats; but in that extinct species the symphysis extends back as far as it does in Phasc. platyrhinus or Phasc. vombatus (Plate LIII. figs. 1 \& 2). In Phasc. latifrons the symphysis is shorter, more concave and more definitely bounded above than in the bare-nosed Wombats, but is not so much so as in Phascolomys Krefftii. The lower contour of the symphysis in Phascolomys medius rises at a less open angle with the axis of the ramus than in Phasc. latifrons, and still less so than in the bare-nosed species. The lower surface shows the pair of vascular outlets, of small size, 15 lines in advance of the hind border. The anterior outlet of the dental canal (Plate LIX. fig. 1,v) is relatively rather nearer the socket of $d_{3}$ than in the smaller fossil and recent Wombats. The vertical convexity of the outer wall of the ramus and comparative flatness of the postsymphysial inner wall are according to the generic type, and relate to the direction of convexity of the long, bent, deeply implanted, ever-growing molars.

The first molar $\left(d_{3}\right.$, ib. figs. $\left.1,2,3\right)$ has the usual generic small size and simple form, representing, as it were, like its homotype above, one half of the succeeding molars. The grinding-surface resembles that of the upper jaw in being suboval, with the long axis lengthwise. In this it differs from Phascolomys latifrons, Phasc. Mitchelli, and Phasc. Krefftii, in which that surface is subquadrate, and it resembles, rather, Phascolomys platyrhinus; but the larger end of the oval is at the fore part of the tooth in Phasc. medius, not at the hind part, as is usually seen in Phasc. platyrhinus. The fore part of $d_{3}$ in Phasc. medius shows a feeble longitudinal groove, as in Phasc. latifrons. The enamel, as usual, coats the outer and fore part of the tooth, but is not extended so far from the fore part upon the inner side as in Phasc. latifrons. There seems to be a slight interruption in the course of the enamel at the middle of the fore part of the tooth, which I have noticed in some of the smaller Wombats. The enamel was coated by cement in the fossil.

The succeeding molars slightly decrease in breadth of grinding-surface from the third (Plate LIX. $m_{1}$ ), the decrease being most marked in the hind lobe of the last molar. This 
character is more marked in Phascolomys latifrons than in Phasc.platyrlinus. The longitudinal extent of the series of five tecth in Phascolomys medius is 2 inches 6 lines, as agrainst '2 inches 1 line in Phasc. platyrhinus, and 1 inch 8 lines in Phasc. latifrons.

The lower incisors of Phascolomys medius resemble in relative size those in Phascolomys latifrons, in which they are smaller than in the bare-nosed Wombats; but the shape of the transwerse section in Phasc. medius is different (Plate LIX. fig. 4, $)$ ); it gives a full cllipse, $4 \frac{1}{2}$ by $3 \frac{1}{2}$ lines, with the long axis almost vertical, but obliquely inclined from above downward and rather inward. The enamel is thin, and limited to the lower half of the long procumbent tooth. They are smaller, especially narrower transversely, than the upper pair, and in this respect resemble the lower incisors of the hairy-nosed, not the bare-nosed, Wombats.

From the proportions which the extent of the molar series bears to the length of the entire mandible in existing Wombats, I cstimate that the lower jaw in the present cxtinct species must have been between 6 and 7 inches in length.

$\S 2$. Phascolomys magnus, Ow.-This species is founded on two portions of the upper jaw, one containing the entire molar series of both sides (Plate LX. figs. 1-4), the other retaining the second, third, and fourth molars of the right side. Both are from the freshwater deposits of Queensland. The less fragmentary specimen includes rather more than an inch of the diastema in adrance of the molars, so much of the outer wall of both maxillaries as includes the malar process, and a small portion of the premaxillaries.

The extent of each molar scries is 3 inches 6 lines; they run almost parallel with a slight curve convex outward: the least interspace between the right and left series, viz. at the forc part of the second molar $\left(d_{4}\right)$, is 1 inch; the greatest, viz. at the hind part of the last molar $\left(m_{3}\right)$, is 1 inch 6 lines; the interspace between the right and left anterior teeth $\left(d_{3}\right)$ is 1 inch $2 \frac{1}{2}$ lines.

Thus, as in Phascolomys medius, the disposition of the upper molars and general form of the intervening palate is after the type of the cxisting hairy-nosed Wombat; but the concarity, transversely, of the palate is even greater than in Phascolomys medius, and becomes still more marked at the diastemal region.

The malar process of the maxillary (Plate LX. fig. $2,{ }_{21}{ }^{*}$ ) rises at the same elevation above the socket of the third molar as in Phascolomys medius, showing a variety amongst the larger extinct Wombats which has been noted in the smaller existing speciest.

The prezygomatic ridge resembles, in its curved course, length, and narrowness, that in Phascolomys latifrons. The maxillary anterior thereto advances and bends in with a convexity lengthwise: in the latifront and other living species the bone is here concare in the direction of the skull's axis. As the maxillary in Phascolomys magnus proceeds to join the premaxillary, the convexity changes to a concavity, in which remains of the maxillo-premaxillary suture may be traced.

The diastemal border (Plate LX. fig. $2,{ }_{21}^{\prime}$ ) rises as it advances from the molar alveoli at a + P. 321 , figs. 5 \& 6. 
less open angle than in Phascolomys medius, in which, as in the recent species, it extends forward nearly on the same parallel with the line of the alveolar outlets.

A shallow channel marks the inner surface of the commencement of the diastemal border (ib. fig. $1,{ }_{21}$ ), its course being from above obliquely forward; there is a feeble rising of the surface anterior thereto. The palate between the ridges is regularly arched, the span being 1 inch 6 lines, the depth or height of the arch 1 inch. The extent preserved just reaches the place of entry of the prepalatal or " incisive" foramina, showing from the nasal cavity the hind wall of those canals and the increased vertical extent of the free inner surface of the premaxillary, making the sudden deepening of this part of the palate when viewed from below in such specimens as have that part entire, such as the subjects of fig. 2, Plate LVII., \& fig. 2, Plate LVIII. a, from the smaller extinct species, Phascolomys medius.

The fractured surface of the premaxillaries (Plate LX. fig. 5) exposes the incisors near the apical end of the long pulp-cavity, about 1 inch 3 lines above the diastemal ridge: the premaxillary increases in thickness as it rises to form the alveolus. The upper fractured surface of the present fossil (Plate LX. fig. 4) exposes part of the floor of the nasal passages, gradually descending as they retrograde toward the place of the postpalatine apertures. Most of the intermolar floor of these passages and roof of the mouth has been broken away.

On each side of the nasal passages appear the hollow implanted ends of the molar teeth. That of $d_{3}$ (fig. 4) projects above the prezygomatic ridge, that of $d_{4}$ between this and the front pier of the zygoma $\left(21^{*}\right)$; and the relative position of the rest conforms with the generic type of these singular elongate, outwardly curved, evergrowing teeth.

The total length of the first and smallest, following the curve, is 2 inches 9 lines. The long diameter of the oval or subtriangular grinding-surface is 6 lines; the breadth near the base, which is backward, is 5 lines. The inner enamelled side extends forward, with a very slight outward bend, from the axial line of the skull to the apex, which is narrow and obtuse, and round this the enamel bends for a short way along the outer side of the tooth; this is the longest side, and curves from behind forward and inward to the apex more strongly than does the inner side. 'The enamel can be traced from the inmer side over the greater part of the hind surface of the tooth. The coat of cement covering the outer side of the tooth can be traced over parts of the enamel, the whole of which it seems originally to have covered.

The grinding-surface of the second molar $\left(d_{4}\right)$ gives 9 lines in fore-and-aft diameter, 6 lines across the hinder lobe; that of the third molar $\left(m_{1}\right)$ has the same longitudinal with rather less transverse extent; and the two succeeding teeth diminish, chiefly in transverse thickness. The grinding-surface of the last molar $\left(m_{3}\right)$ has a fore-and-aft extent of $6 \frac{1}{2}$ lines, with a transverse diameter at the hind lobe of but 3 lines. In shape, implantation, and structure, showing interruption of the enamel coating at the outer side, these upper molars closely adhere to the generic character of Phascolomys. 'The exposed 
implanted ends show the widely open persistent pulp-cavities. The section of the base of the right incisor has a transverse diameter of 6 lines, a vertical one of $5 \frac{1}{2}$ lines. The upper, which would become the front surface, is transversely convex; the under surface is transversely concave, but irregularly so, from the greater production downward of the inmer angle. The upper incisor appears, from the present remnant of it, to differ in shape as well as size from that of Phascolomys medius. 'The inner interspace between the pair at the place of fracture (Plate LX. fig. 5) is 7 lines; they no doubt converged as they descended to come into contact at their exposed and working ends.

The above-described fossil is from a full-grown and seemingly old individual.

I am glad, however, to have another example of the size of teeth which typifies Jhascolomys maynus. It is afforded by a fragment of the right maxillary, with the second, third, and fourth molars in situ, and portions of the sockets of the first and fifth.

'The antero-posterior extent of the grinding-surfaces of the three teeth in place is 2 inches 4 lines, according in all dimensions and in relative size with those in the subject of figs. 1-.4, Plate LX. 'The outer surface of the bone shows the same relative position of the malar process of the maxillary, the same shape and course of the prezygomatic ridge, so far as it is preserved. Part of the malar bone contributing to the fore part of the orbit is also here preserved; but the fragment has been much rolled and worn, and is incrusted with the petrified lacustrine deposit.

In both specimens the enamel has a finely reticulate surface, with a tendency to longitudinal striation. This surface aids the attachment of the cement.

A nongst the detached teeth worked out of the portions of breccia from the WellingtonValley bone-caves transmitted to the British Museum was one entire molar tooth and the halves of two others (Plate LX. fig. 6), of the size of those of Phascolomys maymus. The entire molar corresponds closely with the third, upper jaw, left side, in the specimen last described from Darling Downs (ib. fig. 1, $m_{1}$ ). TVe thus get evidence of the former range of Phascolomys magnus over some hundreds of miles of the Australian continent.

\$3. Phascolomys gigas, Ow.*-Of the lower jaws of Wombats exceeding in size that of Plerscolomys medius (Plate I,IX.), I have seen none with a molar series having the same relative size to the upper one in Phascolomys marnus (Plate LX.) which the teeth of the lower jaw bear to those of the upper one in existing IVombats, and in all the extinct species of wlich I possess means of comparing those teeth.

A series of lower molars with an extent of grinding-surface of 4 inches 3 lines (Plate LXI. fig. 3) cannot have worked, in the same head, upon an upper series of only 3 inches 6 lines (Plate LX. figs. 1 \& 3). The anterior molar of the lower or movable jaw in Phascolomys merlius (Plate LIX. fig. $2, d_{3}$ ) has a somewhat smaller extent of grinding-surface, as in all existing Wombats, than the corresponding tooth of the upper or fixed jaw (Plate LVII. fig. 2, $d_{3}$, and Plate LVIII. fig. 2, $d_{3}$ ). The smallest

$$
\text { * Art. "Palæontology," Encyclopædia Britannica, 1858, rol. xrii. p. 175. fig. } 114 .
$$


example of $d_{s}$ in the remains of large Wombats yet to be described gives 9 lines and $4 \frac{1}{2}$ lines as the two diameters of its almost elliptical grinding-surface (Plates LXI. \& LXII. $\left.d_{3}\right)$. Such a tooth cannot have belonged to the same species as the one which has an upper anterior molar with the dimensions above given as characteristic of Phascolomys magnus (Plate LX. $d_{3}$ ).

Of this species the lower jaw and teeth have not yet come under my observation. All the examples of the large extinct Wombats now before me for description belong to the species Phascolomys gigas, of which the grinding-surface of a lower molar is figured in the "Article" quoted above, and in my 'Palæontology' (p. 431, fig. 172, 2nd ed. 1861); the former existence of which Wombat I noticed, some years before, in my second memoir "On the Osteology of the Marsupialia"*.

Satisfactory evidence of this species has since reached me, of which I propose, first, to describe a considerable proportion of the mandible, obtained by Edward S. Hill, Esq., from a freshwater deposit at Eton Vale, Darling Downs, in 1863, and presented by Sir Daniel Cooper, Bart., to the British Museum.

It consists of the right ramus (Plate LXI. fig. 1) with the fore part broken off near the socket of the first molar $\left(d_{3}\right)$, and with some mutilation of the outstanding parts of the ascending ramus; also of the fore part of the left ramus (ib. fig. 2), with the hind part broken off at the socket of the penultimate molar $\left(m_{2}\right)$. They are both parts of the same mandible, and I have therefore supplied, in the subjects of Plate LXI. fig. 2, Plate LXII. fig. 1, and Plate LXIII. fig. 1, from one ramus what was wanting in the other.

Reference to Plate LII., where the side view is given of the mandible in the three known living species of Phascolomys, will make at once appreciable the character of the present extinct Wombat, in the minor relative antero-posterior extent of the ascending ramus, and its greater relative height before dividing into the condylar $(b)$ and coronoid (c) processes. The intervening notch sinks nearly to the level of the grinding-surface of the molars in the recent and smaller extinct Wombats; whereas in Phascolomys gigas the common plate $(f, g)$ rises much higher before dividing into $b$ and $c$ (Plate LXI. figs. $1 \& 2)$. The fore-and-aft extent of the rising branch at the neck of the condyle equals in extent that of the last four molars in Phascolomys platyrhinus, and rather more in Phascolomys latifrons; in Phascolomys gigas the same dimension equals only the last two molars and half of the antepenultimate one.

The ectocrotaphyte ridge (Plate LXI. fig. $1, h, h$ ) is relatively more prominent and the depression $(f)$ which it circumscribes below is relatively deeper in Phascolomys gigas than in either the Platyrhine or Tasmanian Wombats, and the intercommunicating vacuity is relatively wider in the gigantic Wombat, in which its long diameter is 9 lines.

* Trans. Zool. Soc. vol. iii. p. 306, 1845:-_" I have recently obtained evidence from the postpliocene deposits of the district of Melbourne, through the kindness of my friend Dr. Hosson, of an extinct Wombat, or true Phascolomys, at least four times as large as either of the known existing specics." These were Phascolomys vombatus and Phascolomys latifrons; the somewhat larger continental Wombat (Phascolomys platyrhinus) had not then been determined. 
The neck of the condyle at its origin (b) is but 9 lines across; it expands to a breadth of more than an inch where the condyle has been broken off. The base of the coronoid process $(c)$ has an antero-posterior extent of 1 inch 3 lines; the anterior margin continued into that of the rising ramus subsides upon the outer surface of the jaw $(q)$ below the socket of the penultimate molar $\left(m_{2}\right)$.

The lower contour of the mandible (Plate LXI. figs. $1 \& 2$ ) describes a strong convex minterrupted curve to the fractured diastemal part, herein resembling rather the latifront, or hairy-nosed, than the bare-nosed Wombats.

The inflected angle (Plate LXIII. fig. 1, a) begins, posteriorly, at a lower level than the ectocrotaphyte plate (ib. $h$ ), as in existing Wombats, but it has a minor relative extent; that of its base, as defined anteriorly by the "mylo-hyoid groove" (Plate LXI. fig. 2, w), does not exceed 2 inches; consequently the superangular cavity $(e)$ is relatively small. 'The dental canal (Plate LXII. fig. 4,o) begins as a wide transverse fissure, internal to which is the large racuity above mentioned leading to the ectocrotaphyte fossa. The postalveolar ridge (ib. $t$ ) forms a low angle as it bends to the superangular fossa. 'The ectalveolar groove (ib. $u$ ) is relatively narrow.

The depth of the horizontal ramus augments more rapidly to the back part of the symphysis (Plate LXI. fig. 2,s) than in recent or smaller extinct Wombats; from being 2 inches behind the last alveolus it grows to 3 inches 3 lines below the interval between the penultimate and antepenultimate alveoli. The smooth thick lower border shows prominences indicative of the matrices of the linder molars, the bone being here reduced to extreme thinness. The symphysis begins behind at a vertical line dropped from the interspace between $m_{1}$ and $m_{2}$; it has been partially obliterated, the separation of the rami here being attended with fracture of the confluent portion. This indicates an aged animal. The hinder and upper border of the symphysis is divided into two curves by the encroachment of the smooth inner surface of the ramus a little below the swelling $\left(i^{*}\right)$ indicative of the closed and formative end of the socket of the incisor. The interlocking rough narrow ridges of the joint show the usual tendency to radiate from above downward. There are two anterior outlets of the dental canal (in the subject of Plate LXI. fig. $1, v$ ) on the same vertical line, about half an inch in advance of the alveolus of $d_{3}$ and near the diastemal margin.

The length of the "ascending ramus" before dividing into the condylar and coronoid processes shows a resemblance in the gigantic Wombat to the large herbivorous Notothere and Diprotodon, which is not seen in the smaller species of Phascolomys. The bold curve of the lower contour of the "horizontal ramus" in Phascolomys gigas recalls that feature of the mandible of the Megathere, and it has a like relation to the lodgement of the formative matrices of long, ever-growing molars $\uparrow$.

+ Should any successor deem the differential characters of the giant Wombat of generic or subgeneric valuc, as the minor differences of Phascolomys latifrons have been by Dr. Mrorie (Proc. Zool. Soc. 1867, p. 815), they may, perhaps, accept the name 'Phascolonus, having reference to the size of this species, which equalled that of the Wild Ass. 
The first molar (Plate LXI. figs. $1 \& 3, d_{3}$ ) is subbilobed, through opposite longitudinal shallow groores equally dividing the tooth. The tendency to a gain of grinding-surface in the direction of the jaw's axis seen in the same tooth of Phascolomys medius is in the larger species carried further, so as to substitute for the representative of one half or lobe of the succeeding molars in the anterior one of smaller Wombats a more simplified condition of the normal bilobed phascolomydian type of molar. The enamel of $d_{3}$ in Phascolomys gigas is continued from the outer over the front side, and along nearly the whole of the hind side of the tooth. A coat of cement of similar thickness covers the inner side, and is continued more thinly upon the enamel. The surface of the enamel is longitudinally rugoso-striate.

All the succeeding molars have a partial coat of enamel, extending from the outer side upon the fore part to where this comes into contact with the antecedent tooth, and continued, perhaps, a little further upon the hind surface. The rest of the dentine has the coating of cement. The proportions of the several teeth are shown in the figures above cited.

As before remarked, the smaller size of the last molar indicates the Latifront Wombat to be nearer akin to the extinct giant than are the bare-nosed living species. The same affinity is shown by the small size of the lower incisors in Phascolomys gigas (Plate LXV. figs. 1, $\ddot{i}, 2,3,4$ ). They are smaller, especially narrower, in Phascolomys latifrons than in Phasc. platyrhinus and Phasc. vombatus, and are, relatively, still smaller in Phasc. gigas, with a distinctive shape. But the characters of the lower pair of incisors are better shown in another mandibular specimen of the present large species.

The section or transverse fracture of the hollow base of the right incisor is shown in Plate LXII. fig. 2, $i$; the length and currature of the implanted part of the second molar $\left(d_{4}\right)$ are seen in the same figure, in which $e e$ indicates the anterior terminal line of the outer enamel. The hinder fracture of the left ramus of the same jaw (ib. fig. 3) shows the length and curve of the penultimate molar $\left(m_{2}\right)$, and the posterior terminal line of its partial covering of enamel $(e)$.

Of the above-described instructive specimen of Phascolomys gigas little more than an inch of the diastemal part of the jaw is preserved (Plate LXI. figs. 1 \& 2, l). Fortunately, the first specimen which made known to me the fact of so large a Wombat having formerly existed in Australia included 2 inches 8 lines of the diastemal part of the jaw, which contracts rapidly to the terminal outlets of the incisive alveoli (Plate LXIV. figs. 1 \& 2); whence I conclude that but little had been broken away from that end of the mandible.

The subject of Plate LXIV. figs. 1, 2, 3 was obtained from "a salt-lake, nearly 100 miles west of Melbourne," and was transmitted to me by Dr. Hobson*. It is the symphysial end of the mandible, with $4 \frac{1}{2}$ inches of the joint $\left(s, s^{\prime}\right)$, the obliteration of which indicates the age of the individual; it includes the implanted parts of the incisors $\left(i^{\prime}\right)$, and of the three anterior molars of each ramus (fig. 1). The under part of the symphysis

* Letter from Dr. Hobsor, March 3rd, 1814. 
(fig. 2, Plate LXIV.) shows the pair of subsymphysial foramina $(r)$ in the same relative position as in the existing Wombats (ib. fig. $4, r$ ). The prolongation of the attenuated anterior end of the mandible shows a nearer resemblance in Phascolomys gigas to Phascolomys latifions (Plate LVI. fig. 3) and Phascolomys Krefftii (Plate LIV. fig. 2) than to Phascolomys platyrhinus (Plate LIII. fig. 2) or to Phascolomys vombatus (ib. fig. 1). 'The upper surface of the specimen (Plate LXIV. fig. 1) shows the same concavity between the right and left anterior molars as in the more perfect specimen of Phascolomys gigas (Plate LXII.). The hollow implanted ends of the incisors (Plate LXIV. figs. $1 \& 3, i^{\prime}$ ), exposed by fracture of the fossil, hold the same relative position to the third molars $\left(m_{1}\right)$ as in the more complete mandible. 'The anterior outlets (ib. fig. $1, v, v$ ) of the dental canal are in the same position.

'The subject of fig. 6, Plate LXV., shows a slight inferiority in the size of the molar teeth as compared with that of figs. $1,2, \& 3$, Plate LXI. The present fossil is a portion of the left ramus with the last four molars in place. The longitudinal extent of their grinding-surfaces is 3 inches 5 lines (Plate LXV. fig. 5 ), as against 3 inches 6 lines (Plate LXI. fig. 3); that of the first three molars is the same in both specimens, and the difference is due to a smaller size of the last molar in the present (Plate LXV. fig. $5, m_{3}$ ), the lind lobe of which also shows a longitudinal indent. I am unwilling to regard this as signifying more than a rariety of Phascolomys gigas. The features of the mandible, such as the anterior origin of the ectocrotaphyte ridge (ib. fig. $6, h$ ), and of the ascending ramus (ib. fig. $6, q$ ), as also the ectalveolar groove (ib. fig. 5, $u$ ) and postalveolar ridge (ib. ib. $t$ ), so far as they are preserved, closely resemble those of the more complete specimen of mandible of the present large species.

The fourth example of Phascolomys gigas I know through a cast and photograph of the original, now in the Australian Museum, Sydney, New South Wales. The cast was prepared by direction of the Trustees of that Museum, and was transmitted as a donation to the British Museum. A photograph of the natural size, showing the grinding-surface of the molar teeth, was forwarded to me through the same liberality. The specimen is a portion of the right ramus, including the series of five molars and the entire incisor (Plate LXV. figs. 1-4), of which tooth a separate cast was prepared and transmitted. The molars show a slight superiority of size orer those in the subject of Plate LXI., as may be seen by comparison of figs. $3 \& 4$ in that Plate; but this I take to be within the limits of individual or sexual range of size. The configuration of the ramus, so far as the comparison can be made, closely resembles that of the more complete mandibles of the present species (Plates LXI., LXII., \& LXIV.): the portion of the ectocrotaphyte cavity preserved in the present cast indicates the same depth; the symphysial articular surface (Plate LXV. fig. $1, s, s^{\prime}$ ) has the same shape and extent; the molar teeth (ib. fig. $1, d_{3}, d_{4}, m_{1,2,3}$ ) show the same configurations and proportions of their grinding-surface (Plate LXI. fig. 4)-the extent of the series is 4 inches 7 lines. The length of the incisor (Plate $L X V$. figs. $1, \ddot{z}, \& 2$ ) is 7 inches, its vertical diameter is 8 lines, its transverse diameter 6 lines. The section of the tooth (ib. fig. 4 ) is lozenge- 
shaped, with the four angles rounded. The lateral angles $\left(e, e^{\prime}\right)$ are nearer the upper $(u)$ than the lower $(o)$ angles, and the lower inner facet $(g)$ is broader than the lower outer one $(h)$; the convergence of the two broad lower facets to the obtuse lower angle makes that part of the incisor the narrowest or smallest: if the angles were rounded off, the shape of the transverse section would be an oval with the large end upward. The upper and inner angles are less rounded and more marked than the outer and lower angles. Two low narrow ridges traverse lengthwise the inner and lower facet (ib. fig. 1, $g, g$ ), dividing it into three tracts, the lowest being the narrowest; the outer and lower facet (ib. fig. $2, h, h$ ) is slightly hollowed. A thin layer of enamel coats the lower and lateral parts of the tooth up to the lateral angles $\left(e, e^{\prime}\right)$, where it subsides abruptly after becoming thinner than it was below.

The base of the incisor in the left ramus of the first-described jaw of Phascolomys gigas (Plate LXI. figs. $1 \& 2, \ddot{i}$, and Plate LXII. fig. 2, i) repeats the characters above given from the cast of the entire incisor, the original of which is in the Australian Museum; the outer lateral angle is more sharply marked at the implanted part of the incisor compared.

The contrast in the shape and relative size of the incisor of the giant Wombat with that of the largest known living species (Phascolomys platyrhinus) is great. The section of the incisor in that species has an area double that of the section of the first molar; in Phascolomys gigas these proportions are almost reversed. The long diameter of such section of the incisor is transverse in Phascolomys platyrhinus; it is rertical in Phascolomys gigas. Amongst living. Wombats an approach to the extinct giant is made by the Phascolomys latifrons, in which the vertical diameter prevails in the section of the incisor-only the large end of the oval, or base of the triangle, is below, not above as in Phascolomys gigas; and the area of the section in Phasc.latifrons rather exceeds that of the anterior molar, $d_{3}$. In the extinct Phascolomys medius (Plate LIX. fig. 4, $i$ ) we have a nearer approach to the characters of the lower incisors in Phascolomys gigas.

Another evidence of Phascolomys gigas is the hind part of the right mandibular ramus with a more mutilated "ascending branch" than in the subject of Plate LXI.; it includes the sockets of the last four molars and the base of that of the incisor. The teeth in this specimen must have presented the size of those in the subject of fig. 4 (ib.); the longitudinal extent of the last three sockets is 2 inches 10 lines. The hina fracture is at the intercommunicating canal (Plate LXII. fig. $4, p$ ), exposing the wide beginning of the dental canal (ib. $o$ ), with its larger division continued along the outer side of the bases of the molar alveoli, and the smaller division $\left(o^{\prime}\right)$ extending along the inner side to emerge at the anterior dental outlet $(v)$; the "mylo-hyoid groove" is broader and less deep than in Plate LXI. fig. 2, $w$. The characters of the ectalveolar groove, of the postalveolar ridge, and of the ectocrotaphyte fossa $(f)$ agree with those of the type mandible of Phascolomys gigas.

The present specimen was discovered by M. Satcie St. Jear, at St. Jean Station, Queensland, in the bed of a tributary creek of the Condamine River. 
The last specimen which I have now to notice was obtained by F. Nicriolsox, Esq., from the same freshwater deposits at Clifton Plains, Darling Downs, Queensland. I am indebted to the kindness of Professor Harkness, of Queen's College, Cork, for the opportunity of here describing and figuring it. It either exemplifies the largest observed varicty of Phascolomys gigas, or indicates a still larger species, i.e. one in which modifications of the shape of the jaw may be associated with its superiority of size. Of this the mutilated state of the fragment does not permit me to judge, and I am disposed to refer the specimen to a large old male of Phascolomys gigas.

'The longitudinal extent of the outlets of the last three molars of Mr. Nicholsox's fossil (Plate LXIII. fig. $4, m_{1,2,3}$ ) is 3 inches 1 line; they show the same kind and degree of decrease of size from the first to the third as in the smaller examples of the species. The breadth and apparent depth of the ectalveolar groove (ib. figs. $3 \& 4, \imath$ ) are as in the first-describerl mandible (Plates LXI. \& LXII.). 'The fore part of the base of the coronoirl or ascending ramus (ib. fig. 3, q) and of the ectocrotaphyte ridge (ib. $h$ ) show likewise the same relatire positions. On the inner fractured side of this specimen the large inner division of the dental canal is seen about 9 lines above the closed ends of the last two alveoli.

$\S 4$. Conclusion.-In the case of Phascolomys, as of most Mammalian genera, when due time and pains are applied to the acquisition and study of the fossil evidences, the number of species which have passed away is found to exceed that of the living ones which remain.

Until comparatively lately the Wombat was known to zoologists as a solitary exceptional form of small Tasmanian marsupial, peculiar in its scalpriform dentition combined with burrowing habits*. We now know this generic form under many specific structural modifications, and with gradations of bulk rising from that of a Marmot to that of a Tapir.

The rodent type of incisors, both as to number and kind, are retained in all, certainly in the lower jaw of the gigantic species; but it would not be safe to infer that the subjects of the present Paper burrowed like the smaller living Wombats.

If we knew the Hare (Lepus timidus) only by fossil remains, we should err in attributing to it the habits and mode of life of the smaller species, Lepus curiculus. It is probable that the larger extinct Wombats did not conceal themselves under ground.

What we know is, that of the series of forms specifically varying the generic type of Phascolomys the larger ones have perished. Here, as in the case of the gigantic wingless birds of New Zealand, size and bulk seem to have been a disadvantage in the "contest for existence" $\uparrow$. The small burrowing Kivis\$, like the small Wombats, have s.rvived. Phascolomys gigas and Phascolomys magnus are not likely to have escaped obserration if they still lingered in any of the localities made known by the adventurous

* Hence the synonym, Phascolomys fossor, of W

+ Owes, "On Dinornis," Part IV., Trans. Zool. Soc. vol. iv. (1850) p. 15.

$\ddagger$ Apteryx australis, Shaw Apteryx Owenii, Gould. 
explorers of Australia; but the diminutive Phasc. parvus may yet be found living in some part of that continent.

Another inference, or tributary illustration of a general law, is shadowed forth less plainly, perhaps, than that bearing upon the "battle of life."

The majority of the fossils of common-sized Wombats exemplify, as in the case of Phascolomys Mitchelli, the more generalized structure; osteological characters, now distinguishing respectively the hairy-nosed and bare-nosed Wombats, are combined in the skull of that extinct species. At the same time divergent courses of variation had reached the stages indicated by Phascolomys latifrons and Phascolomys platyrhinus at a period when the larger species, now extinct, appear to have been living in Australia. This is less ambiguously shown, as to time, by the mandible of the continental bare-nosed Wombat from Queensland, than by that of the hairy-nosed species from the breccia of the Wellington-Valley caverns; for, with regard to specimens obtained from cares, there are grounds of uncertainty as to contemporaneity of introduction not affecting, at least in the same degree, the fossils from stratified deposits of known geological age.

The extirpating cause of the larger Wombats, especially if they were unable to take refuge and conceal themselves under ground, was probably the hostility of man. No human remains, however, or weapons have yet been discovered in the substalagmitic breccias of the caves or in the freshwater deposits of Australia. But as the unseen planet is inferred by evidence of its force, so may the destroyer be conjectured and his discovery anticipated by the effects of his power; such, $e . g$., as the disappearance of species which, from their easicr detection, capture, or bringing to bay, and greater profit when slain, would be the first objects of chase to the primitive Aborigines.

Table of Localities of Fossils of Phascolomys, showing:-

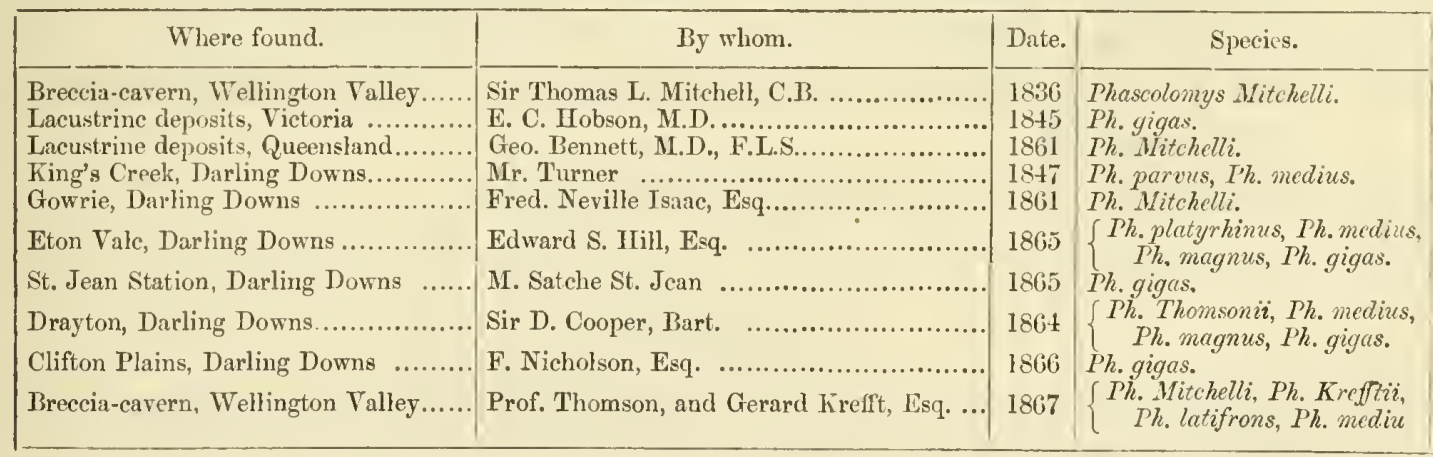

Explanation of the Plates.

\section{PLATE LVII.}

Fig. 1. Base of skull and working-surface of the teeth of the upper jaw, Phascolomys latifions.

Fig. 2. Part of base of skull, with working-surface of some molar teeth, Phascolomys medius. 
Fig. 3. Left side view of the same fossil.

Fig. 4. Right side of fore part of the same fossil.

Fig. 5. Front view of premaxillary part of the same fossil.

Fig. 6. Fractured surface of ditto, showing transverse section of the implanted part of the incisors, $i$.

Fig. 7. Inner side view of the crowns of the three anterior molars and fore lobe of the fourth molar of the same fossil.

\section{PLATE LVIII.}

Fig. 1. Base of skull and working-surface of the teeth of the upper jaw, Fhascolomys platyrhinus.

Fig. 2. Part of base of skull, with fractured and working-surface of some molar teeth, Phascolomys medius.

Fig. 3. Left side view of the same fossil.

Fig. 4. Posterior fractured end of the same fossil.

Fig. 5. Front view of premaxillaries and fractured incisors of the same fossil.

Fig. 6. Inner side view of exposed part of the three anterior molars and fore lobe of the fourth inolar of the same fossil.

\section{PLATE LIX.}

Fig. 1. Outside view of portion of right mandibular ramus, Phascolomys medius.

Fig. 2. Inner side view of the same fossil.

Fig. 3. Upper view and grinding-surface of molar teeth of a mutilated mandible of Phascolomys medius.

Fig. 4. Front fractured end, with section of implanted part of the lower incisors, $i, \ddot{i}$, of the same fossil.

Fig. 5. Hind fractured end of left ramus of the same fossil.

\section{PLATE LX.}

Fig. 1. Under view of part of upper jaw and molar teeth, Phascolomys magnus.

Fig. 2. Left side view of the same fossil.

Fig. 3. Inner side view of the right molars of the same fossil.

Fig. 4. Upper view of the same fossil.

Fig. 5. Anterior fractured surface of the same fossil, with sections of the base of the incisors, $i, i$.

Fig. 6. Third molar and hind half of second molar, Phascolomys magnus: the workingsurface is shown below.

Fig. T. Part of upper jaw, with molar teeth, Phascolomys medius (from a photograph). 


\section{PIATE LXI.}

Fig. 1. Outside view of part of the right mandibular ramus and teeth, Phascolomys (Phascolonus) gigas.

Fig. 2. Inside view of part of left ramus and teeth of the same mandible.

Fig. 3. Working-surface of the right molars of the same mandible.

Fig. 4. Working-surface of the right mandibular ramus of a larger Phascolomys gigas.

\section{PLATE LXII.}

Fig. 1. Upper view of the lower jaw and teeth, Phascolomys (Phascolonus) gigas.

Fig. 2. Anterior fractured surface of right manus of the same jaw.

Fig. 3. Posterior fractured surface of right manus of the same jaw.

Fig. 4. Posterior fractured surface of another mandibular ramus, Phascolomys gigas.

\section{PLATE LXIII.}

Fig. 1. Hind view of mandible, Phascolomys (Phascolonus) gigas.

Fig. 2. Hind view of mandible, Phascolomys latifrons.

Fig. 3. Portion of left mandibular ramus of a large Phascolomys gigas.

Fig. 4. Upper surface of the same fossil.

Fig. 5. Portion of left mandibular ramus, Phascolomys parvus.

Fig. 5. Upper surface of the same fossil.

\section{PLATE LXIV.}

Fig. 1. Upper surface of fore part of mandible, Phascolomys (Phascolonus) gigas).

Fig. 2. Under surface of the same fossil.

Fig. 3. Back view, showing roots of incisors $\left(i^{\prime \prime}\right)$ and interior molars $\left(d_{3}\right)$ of the same fossil.

Fig. 4. Under surface of fore part of mandible, Phascolomys vombatus.

\section{PLATE LXV.}

Fig. 1. Inner side view of the fore part of a right mandibular ramus and teeth, Phascolomys (Phascolonus) gigas.

Fig. 2. Outer side view of incisor of the same fossil.

Fig. 3. Working-surface of the same incisor.

Fig. 4. Transverse section of the same incisor.

Fig. 5. Outer side view of the same fossil (without reversing).

Fig. 6. Upper view of a portion of the left mandibulary ramus and last four molars of a smaller Phascolomys gigas.

All the figures are of the natural size: the symbols and letters of reference are explained in the text. 


\section{Genus Phascolomys.}

\section{Osteology of the existing Species.}

The endeavour to restore the lost species of Wombat presumes a power of recognizing the bones or portions of bones when discovered in a fossil state; and this can only be acquired by a knowledge of the characters of the corresponding bones of the existing species. Contributions thereto, in reference to the skull of Phascolomys, have been made in a preceding section (p. 305); the remainder of the skeleton is the subject of the present one, in which the descriptions and figures are limited to those bones of the trunk and limbs yielding satisfactorily distinctive and determinative characters subservient to the above-defined aim.

\$1. Vertebral Column. - The general characters of the vertebral column in the genus Phascolomys are defined in pp. 297-299. The annular atlas was first recognized, in a specimen of Phascolomys vombatus in the Museum of the Royal College of Surgeons of England, to have the lower part of its ring "completed by dried gristly substance," not, as in some kinds of Kangaroo, by "extension of ossification from centres in the superior laminx"'. The term 'neurapophysis' had not then been proposed for these vertebral elements, nor had I, in 1838, satisfied myself that the 'centrum' of the atlas was the 'odontoid process' of the succeeding vertebra. It is further remarked that "the transverse processes are grooved merely by the vertebral arteries," and that " the atlas presents only the perforation on each side of the superior" [now called 'neural '] "arch".

These general characters of the atlas of the bare-nosed Wombat of Tasmania are repeated in that of a not fully grown specimen of Phascolomys platyrhinus (Pl. XCVIII. figs. $3 \& 4)$; but in the atlas of an older and larger specimen of that species ossification has extended into the sclerous representative of the pleurapophysis, and has converted the vertebrarterial notch into a foramen on both sides (as indicated by the dotted line, $p l$, in fig. 3).

The same bony circumscription obtained on the right side in the atias of a Phascolomys latifrons (PI. XCVIII. figs. $1 \& 2, p l$ ), The first cervical nerve, in both species, perforates obliquely the neurapophysis (at $c 1$, figs. $1 \& 3$ ), the aperture within the neural canal being above the articular concavity $\left(z^{\prime}, z^{\prime}\right)$ for the occipital condyle.

The transverse diameter of the atlas is less in proportion to its vertical one in Phascolomys latifrons (ib. figs. 1 \& 2) than in Phascolomys platyrhinus (ib. figs. $3 \& 4$ ); the cups for the condyles (fig. $1, z^{\prime}, z^{\prime}$ ) are less turned outward, and the diapophyses (ib. $d, d$ ) are more tuberous in Phascolomys latifrons; in Phascolomys platyrhinus (figs. $3 \& 4, d, d$ ) they are flattened below as well as above. The articular surfaces for the odontoid are more oblong and more nearly transverse in Phascolomys latifrons (fig. $2, z^{\prime}, z^{\prime}$ ), and their

\footnotetext{
1 "On the Osteologg of the Marsupialia" (Part I. 1838), Trans. Zool. Soc. vol. ii. p. 394. I hare since seen the atlas of an old male Macropus rufus, incomplete below.

3 Tom, cit. p. 394.
} 
outer border is not so much inclined backward as in Phascolomys platyrhinus (ib. fig. 4, $\left.z^{\prime}, z^{\prime}\right)$. The unossified lower tract of the atlantal ring is greater in the bare-nosed Wombats (ib. figs. $3 \& 4, h$ ); but this character varies with age. Nevertheless in the atlas of the large old Phascolomys platyrhinus the interval is greater than in the atlas of the Phascolomys latifrons (ib. figs. $1 \& 2, h$ ), the skeleton of which shows fewer marks of age.

The neurapophyses of the dentata are thicker and narrower from before backward in Phascolomys latifrons (ib. fig. $5, n$ ) than in Phascolomys platyrhinus. In both species the neural spine (ib. $n s$ ) is strongly developed in both height and anteroposterior breadth. That part in the succeeding cervicals is short and slender; it is longer in the fourth $(n s, 4)$ and seventh (fig. $6, n s, c 7$ ) cervicals in Phascolomys latifrons than in Phascolomys platyrhinus. The pleurapophysis of the sixth cervical extends downward and backward as a thick ridge (ib. fig. $5, p l$ ).

In all existing Wombats the dorsal series begins with a sudden and great increase in the length and strength of the neural spine (Pl. XCVIII. fig. 6, 1). The diapophyses (ib. $d^{\prime}$ ) are thickest in this vertebra and are deeply cupped at the end for the tubercle of the first rib.

In the skeleton of the Phascolomys latifrons, described in the present section, the number of rib-bearing vertebræ is thirteen, leaving six for the lumbar series. In this particular the hairy-nosed species agrees with the majority of the Marsupialia. The greater number of dorsal vertebræ in the bare-nosed Wombats ${ }^{1}$ is exceptional in the order.

The first rib (Pl. XCVIII. fig. 7) is the shortest and broadest; the last (ib. fig. 10) is the most slender and is least curved. The articular surface is retained on the tubercle (ib. figs. $7,8,9, b$ ) in the ten anterior pairs of ribs ; only a trace of tubercle, rough for ligamentous attachment, is seen on the last three pairs.

The costal head (ib. fig. 7, a) is furthest from the tubercle (b), or, in other words, the neck $(c)$ is longest, in the first rib. The head shows, as in the succeeding ribs, two articular facets $\left(a^{\prime}\right)$, which meet at a rather acute angle. Each side of the hind surface of the seventh cervical accordingly shows the facet (ib. fig. $6, p l$ ) fitted to the anterior of those surfaces. 'The tubercle presents an articular surface (ib. fig. $7, b, b^{\prime}$ ) larger and more convex than in any of the other ribs; and this fits the deep cup on the diapophysis of the first dorsal vertebra (ib. fig. $6, d^{\prime}$ ). There is a rough low tuberosity (ib. fig. $7, d)$ on the middle of the outer or anterior surface of the first rib for the attachment of a strong scalenus muscle. In the second rib (ib. fig. 8) besides the head $(a)$, neck $(c)$, and tubercle $(b)$, there is, on the outer border, at the same distance from the tubercle as this is from the head, a second tubercle or process $(e)$, smaller than the normal one (b), and serving exclusively for muscular attachment; it answers to what is called the 'angle of the rib' in anthropotomy. The articular surface on the tubercle

${ }^{1}$ Phascolomys vombatus, e. g., Part I. tom. cit. p. 393. 
is that (b), as in all the succeeding ribs possessing it; anterior to this surface is a tubercle for the attachment of the costal ligament. In the fifth rib (ib. fig. 9), besides the process holding the same relative position to the tubercle as in the second rib, there is another $(f$ ' $)$ at a greater distance, which answers better to the 'angle.'

The neck $(c)$ shortens as the ribs recede in position, and disappears with the loss of the articular tubercle in the last three pairs. The longest ribs are the seventh and eighth pairs in Phascolomys latifrons. 'The hind border of the proximal third of the shaft is slightly produced, indicative of an 'intercostal groove.' 'The shaft is flattened and expanded at its distal end ( $g$ and fig. $9^{\prime}$ ), which is twisted at right angles to the broadest part of the neck of the rib. 'This terminal expansion (fig. $9^{\prime}$ ) is lost in the last three pairs (fig. 10). Six anterior pairs of rib-cartilages(Pl. XCVIII. fig. 11, $h, 1-6$ ) articulate directly with the sternum, which consists of six bones, including the manubrium $(m)$ and xiphisternal $(x)$. The fourth and fifth sternebers coalesce earlier than any of the others; the articulation of the cartilages of the fifth pair of ribs (5) indicates the place of the harmonia and the shortness of the fifth stemeber compared with the rest; its antero-posterior thickness is considerable, and increases as it recedes (as shown in the side view (ib. fig. 11, $a$ 1). The cartilages of the sixth pair of ribs $(h, 6)$ articulate to the lower angles; and the inner or hind border alone affords attachment to the xiphisternal $(x)$. The manubrium (ib. fig. $11, m$ ) is subcarinate, and affords oblong syndesmotic surfaces for the strong clavicles.

Phascolomys, like all the other genera of Marsupialia of which the vertebral formula is known, has twenty-six vertebræ between the skull and sacrum. The nineteen vertebre following the seven cervical vary as to the number of the pleurapophyses developed as movably articulated ribs. In the two examples of Phascolomys platyrhinus of which I have had the opportunity of examining the entire skeleton, fifteen vertebræ sustain such pairs of ribs, leaving four vertebræ as 'lumbar ;' and this was the formula presented by the corresponding part of the vertebral column of the Phascolomys vombatus described in my first memoir on Marsupial osteology ${ }^{2}$. In the only complete skeleton of Phascolomys latifrons which has yet reached me the number of lumbar vertebræ is six. In this formula it deviates less from the rule of 'dorsal' and 'lumbar' vertebral notation in the marsupial order than do the bare-nosed Wombats of Tasmania and Australia.

The number of vertebræ which are confluent in the sacral region of Phascolomys latifrons is four (Pl. XCIX. fig. 1, s 1-s 4), the two foremost of which articulate with the ilia. The syndesmotic surface is formed on each side by an expansion of the hinder half of the diapophysis of the first vertebra (ib. $d_{1}$ ) and of the whole of that of the second $(d 2)$, forming together an oblong subreniform tract (ib. fig. 2) with an indication of its division into two surfaces $\left(d_{1}, d_{2}\right)$. The entire longitudinal extent of this joint is 1 inch 2 lines, with an extreme breadth of 6 lines. The diapophyses are confluent along 
their expanded distal halves of the first and second, and by a less proportion in the third and fourth sacrals, leaving vacuities $(s d 1-s d 3)$ between their proximal portions, into which open the joints between the bodies of the sacral vertebræ. These joints are not anchylosed in the specimen figured. The bodies of the sacral vertebræ (ib. fig. 1, $s 1-s 4$ ) are depressed, losing vertical extent as they recede, but maintaining breadth beyond the first, which is the largest. In the first sacral the prezygapophyses resemble those of the lumbar vertebræ, and develop external to the joint a small tuberous metapophysis. The postzygapophyses are small; and both articular processes of the neural arch decrease in size to the last sacral. Between this and the third sacral the coalescence is limited to the extreme ends of the diapophyses, which in the last $(d 4)$ are produced forward.

In the first caudal (ib. fig. 1, $c$ 1) the broad depressed diapophyses $(d 5)$ are curved backward, as in the succeeding caudals $(d 6, d 7)$.

In a large full-grown Phascolomys platyrhinus there are four sacral vertebræ by terminal coalescence of diapophyses, the two anterior of which articulate with the ilia, the articular surface being extended along the whole terminal expanse of the first sacral diapophyses. The fifth vertebra by the backward direction of its diapophysial expansions indicates its caudal characters; but on the right side the diapophysis is confluent with that of the following vertebra.

In the sacrum of a second, not quite full-grown, example of Phascolomys platyrhinus (Pl. XCIX. fig. 3) the vertebra $\left(\begin{array}{ll}c & 1\end{array}\right)$ succeeding the four anchylosed sacrals has its diapophyses $(d 5)$ similarly directed and expanded, the left touching the one in advance by its extreme angle, with the interposed ligamentous matter not yet ossified. In the sixth vertebra $(c 2)$ the diapophysial expansions extend backward and coalesce at their hinder angles with the diapophyses of the seventh vertebra, forming, as it were, a second small sacrum $(d 6, d \tau)$, according to the character of coalescence.

The articular surface for the ilium (ib. fig. 4) is longitudinally more extended, and the proportions contributed by the first and second sacrals $\left(d 1, d_{2}\right)$ are further apart than in Phascolomys latifrons (fig. 2).

In the example of Phascolomys vombatus, described in the 'Catalogue of the Osteology in the Museum of the Royal College of Surgeons' (4to, 1853, no. 1814, p. 333), anchylosis of the fifth vertebra, having expanded antroverted diapophyses, with those of the fourth sacral has been completed, and a sacrum of five vertebræ by coalescence results. But, in both specimens, as in the skeleton of the Tasmanian Wombat (tom. cit. p. 330, no. 1792), the two anterior vertebræ only are sacral by the character of abutment against and syndesmotic junction with the iliac bones.

In an old individual of Phascolomys vombatus I have seen, and figured', a sacrum of seven vertebræ by anchylosis of the centrums. Of these the first four repeat the characters of the four sacrals in Phascolomys latifrons by coalescence of the terminally

1 Anatomy of Vertebrates, vol. ii. p. 331, fig. 213. 
expanded diapophyses; those of the three succeeding vertebræ are retroverted and anchylosed together. Moreover the articulation with the ilia is extended along the expanded anchylosed end of the four anterior sacrals.

But under all these modifications the homologies of the respective vertebræ (as indicated by the symbols, $s$ 1-c 3) in both bare-nosed (fig. 3) and hairy-nosed (fig. 1) Wombats are unmistakable; and we discern, in the degree in which the caudal characters are assumed by the vertebre succeeding the four anchylosed sacrals in Phascolomys latifrons, that the general character of the sacro-caudal region of the spine in Marsupialia is least departed from in that species.

The tail is short and inconspicuous in all kinds of Wombat. Reckoning the series of vertebræ to begin after the fourth sacral, there are not more than eleven caudals; and the two or three terminal ones are mere tubercular rudiments of the centrum.

Bones of the Fore Limbs. - The clavicle in Phascolomys (Plate XCVIII. figs. 12, 13) is a long, strong, slightly bent and twisted bone, expanded at both ends, but chiefly at the sternal one (ib. $a$ ). This is deeply canaliculate, the groove (ib. $b$ ) opening upon the fore or outer surface of the bone. The sternal end $(a, b)$ is larger, and the groove is less and shorter in Phascolomys latifrons (ib. fig. 12) than in Phascolomys platyrhinus (ib. fig. 13); and the convex articular part forms a larger proportion of that end. The shaft of the bone is triedral in Phascolomys latifrons; it is subcompressed in Phascolomys platyvhinus, in which the bone is flatter on the fore or outer surface, and is more convex on the opposite surface. The longitudinal bend is somewhat greater in Phascolomys platyrhinus (fig. 13); the acromial end is also flatter and rather broader in this species (ib.), and the two surfaces for ligamentous attachment to the acromion are more distinct and further apart than in Phascolomys latifrons.

The scapula of Phascolomys (Plate C.) maintains the form of a pretty regular quadrilateral plate nearly as far forward as the attachment of the spine extends (ib. $e, f$, figs. $1 \& 4$ ), the length of the quadrilateral being one third greater than the breadth in Phascolomys platyrhinus (figs. 4,5), and nearly one half greater in Phascolomys latifrons (figs. 1,2). The hind border $\left(a, a^{\prime}\right)$ is continued on straight, or nearly so, to the glenoid carity; the fore border $\left(b, b^{\prime}\right)$ gives the length of the quadrilateral plate by its parallelism with the hind one, and is then continued on by a deep and large emargination $(c)$ to the base of the coracoid $(h)$; this emargination defines what may be termed the 'neck of the scapula.' The upper border or ' base ' $(d)$ is straight, and at right angles to $a$ and $b$. The spine $(e)$ beginning near the angle $(b)$ of the base $(d)$ rapidly gains in depth or breadth as it approaches the neck $(c)$, where the acromion $\left(f, f^{\prime}\right)$ rises clear of the body of the bone. The spine is thickest at the two ends and along its free border, which gradually gains thickness as it bends downward to form the acromion $\left(f^{\prime}\right)$, where thickness becomes breadth, the plane of the process being nearly at right angles with that of the spine.

The glenoid cavity $(y$, and figs. 7,8$)$ is an irregular oval, with the small end upon the 
base of the coracoid $(h)$. The tubercular ridge ( $i$, figs. 3,6$)$ for the 'triceps longus' muscle is well marked; it begins near the lower usually sharp border of the glenoid cavity; and a roughness may be traced from it along one third of the hind border $(a)$. The acromion $\left(f, f^{\prime}\right)$ extending beyond the glenoid cavity, curves gently toward the coracoid. This element, or process $(h)$, is short, thick, and inclines obliquely inward, or toward the subscapular surface or aspect (figs. 2, 5). This surface is undulate. A longitudinal channel, parallel with the origin of the spine, is bounded by longitudinal convexities, the upper one subsiding to a concavity at the antero-superior angle of the quadrilateral, the lower one to a concavity along the hind border. The short straight 'base' $(d)$ or 'vertebral border' of the scapula is thicker than either of the other borders or ' costæ,' and is thickest at the angles where it joins them, and which are rounded off. The spine takes a more oblique course to the neck in Phascolomys platyrhinus (fig. 4) than in Phascolomys latifrons (fig. 1); the body of the scapula is broader in proportion to its length, and the glenoid cavity is narrower in proportion to its length in Phasc. platyrhinus. In Phasc. latifrons I have noted a variety in which the antero-inferior angle of the quadrilateral was more produced and the cervical emargination shorter and deeper; but usually the form of this part is nearly the same in both species. The hind angle of the base is produced backward in Phasc. latifrons (figs. $1 \& 2, a$ ); not so in Phasc. platyrhinus. The subscapular surface (figs. 2, 5, $k$ ) near the postsuperior angle (b), for the attachment of part of the 'serratus magnus,' is defined by a stronger ridge in Phascolomys latifrons (fig. 2) than in Phascolomys platyrhinus (fig. 5).

I append the following dimensions :-

\begin{tabular}{|c|c|c|c|c|}
\hline & \multicolumn{2}{|c|}{$\begin{array}{l}\text { Ph. latifrons }{ }^{1} \text {. lines. } \\
\text { in. }\end{array}$} & \multicolumn{2}{|c|}{$\begin{array}{l}\text { Ph. platyrhinus } \\
\text { in. lines. }\end{array}$} \\
\hline treme length of the blade-bone & 5 & 0 & 6 & 0 \\
\hline Length of hind border (' external or axillary costa') & 4 & 0 & 4 & 3 \\
\hline rder (' superior costa') & 3 & 1 & 3 & 5 \\
\hline Length of base ('vertebral costa') & 1 & 11 & 2 & 4 \\
\hline From lower (cervical) angle of front border to end of corac & 1 & $11^{3}$ & 2 & 5 \\
\hline Breadth of the middle of the scapula . & 1 & 10 & 2 & 5 \\
\hline
\end{tabular}

The head of the humerus (Pl. CI. figs. 1-4), especially the articular part (a), shows a difference of proportion corresponding with the indication afforded by the glenoid cavity of the scapula; its antero-posterior or short diameter is greater, in comparison with its transverse or long diameter, in Phascolomys latifrons (ib. fig. 2, a), where it extends lower down and is narrower at its termination at the back of the humerus, than in Phasc. platyrhinus (ib. fig. 4,a). The entire bone is stronger, broader in proportion to its length, in Phasc. latifrons (ib. figs. 1 \& 2).

In both species the proximal tuberosities are well developed, but they are relatively

' Pl. C. figs. 1-3.

${ }^{2}$ From a larger indiridual than the subjeet of Pl. C. figs 4-6.

${ }^{3}$ In a second specimen it was 2 inches 2 lines. 
more so in I'hasc. latifrons (figs. $1 \& 2, b, c$ ). In this species the 'ecto-tubcrosity' extends its base orer laalf the diametcr of the forc part of the humerus (ib. fig. 1, b); in Phase. platyrhinus over two fifths (ib. fig. $3, b$ ).

The ento-tuberosity protrudes inward further in Phasc. latifrons (ib. figs. 1 \& 2,c) than in Phasc. platyrhinus (ib. figs. $3 \& 4, c$ ).

'The ridge $(d)$ for the insertion of the conjoincd 'tcres major' and part of the 'triceps' is shorter, thicker, more prominent, and better defined in Phasc. latifrons; it is situated chicfly on the thenal or forc part of the sliaft, near the inner surface; but morc of it is visible in the anconal vicw in Phasc. latifrons (fig. 2, d) than in Phasc. platyrhinus (fig. $4, d$ ).

The linc of inscrtion $\left(e, e^{\prime}\right)$ of the large and complcx 'pectoralis' extends from the lower and fore part of the ecto-tuberosity to that of the deltoid ridge $(f)$, nearly along the mid line of the forc part of the humerus; but it is to the inncr side of that line in Phasc. latifrons (fig. 1, $e, e^{\prime}$ ), and to the outer side in Phasc. platyrhinus (fig. $3, e, e^{\prime}$ ).

The outcr contour of the humerus curves almost parallel with the 'pectoral' ridge to the projecting anglc of the deltoid onc $(f)$ in Phasc. latifrons (fig. 1). This angle is less promincnt in Phasc. platyrhinus (fig. $3, f$ ), and the distance between it and the 'predcltoid ridge' $(g)$ is less.

'The 'supinator ridge' $\left(h, h^{\prime}\right)$ is strongly developed in both species, and terminates above in a frecly projecting, sometimes unciform process $(h)$; below, it rapidly expands into the ectocondylar triangular surfacc $\left(h^{\prime}\right)$, giving attachment to the origin of the 'extensor digitorum' muscle. 'The cntocondylar process $(i)$ is more produced and angular, and is largest in Phasc. latifrons (ib. fig. 1). The bony bridge (k) extending from the fore part of the humeral shaft to that angle (i) is thicker in Phasc. latifrons (fig. 1) than in Phasc. platyrhinus (fig. 3). The foramen which it defines is large and elliptic in both specics.

The radial division of the distal articular surface $(l)$ is homispheroid anteriorly (ib. fig. $1, l)$, the convexity subsiding somewhat as it is produced backward; the ulnar division $(m)$ is almost flat transversely, convex from before backward; the joint in this direction is narrowest at its middlc, where the ulnar passes into the radial division (Pl. CIII. fig. 13). Both divisions arc larger, especially the ulnar one, in Phasc. latifions (fig. 1, $m$ ) than in Phasc. platyrhimus (fig. $3, m$ ). The shaft of the humerus is least thick between the dcltoid and supinator crests; and a deep sulcus is continued from the interval obliquely downward and inward, expanding and bccoming lost upon the fore part of the broad distal end of the bone.

At the back or anconal part (ib. figs. 2,4) the head of the humerus $(a)$ is seen to dcscend lower and in a more angular form in Phasc. latifrons (fig. 2, a) than in Phasc. platyrhinus (fig. $4, a$ ). The short transierse ridge for the humeral head of the triceps is most strongly marked in Phasc. latifrons (fig. $2, n$ ). The margin of the supinator ridge is thicker, and is bent forward in the bare-nosed spccies (fig. $4, h$ ). 
The bone is reduced to transparent thinness between the coronal $(o)$ and anconal $(p)$ depressions; but I have not noticed a vacuity here in either of the continental species, as in one individual of the Tasmanian Wombat'.

The figures 1-4 of Pl. CI. will supply other features of the bone, not noted in the text, which has been purposely restricted to the salient differential characters of the humerus in the two continental species of Phascolomys, most likely to be available in the determination of fossils.

The radius of Phascolomys latifrons (ib. figs. 5-8) is a strong bone, slightly bent, with the convexity forward; the head (fig. 7 ) is subcircular and concave for adaptation to the humeral ball (ib. fig. $1, l$ ). From the outer side of the head a narrow semielliptical convex surface ('lesser sigmoid cavity' of Anthropotomy) (figs. 5 \& 6, a) is adapted to the radial concavity of the ulna (fig. 11,e). A few lines below the neck of the radius projects a large tuberosity (figs. $5 \& 6, b$ ) for the biceps.

The shaft gradually expands as it descends, and assumes a triedral shape; a ridge (fig. $5, c$ ) for the insertional fascia of the 'supinator longus' defines at the lower third of the shaft the fore from the inner surface of that part of the bone. This ridge leads to a small tuberosity $(d)$ above the base of the short thick styloid process $(e)$. The interosseal ridge or angle is well marked, and shows a rough tract at its middle third (fig. $6, f$ ). The broad distal articular surface (fig. 8) is gently convex from before backward, concave from side to side; it is adapted to the large scapho-lunar carpal bone, and to the radial facet of the cuneiform.

The head of the radius is less circular in Phascolomys platyrhinus than in Phase. latifrons, and the bicipital tubercle is rather nearer to it; the entire bone is less thick in proportion to its length; but the differences are not such as to call for a drawing of the bone in this species.

The ulna (ib. figs. 9-11) in both Wombats is remarkable for the length and breadth of the olecranon $\left(a, a^{\prime}\right)$, and for the concavity $(b)$ continued from its ulnar (inner) side (figs. 9, 10) downward below the proximal articulation. This presents three continuous facets-one (fig. 11, $c$ ) for the ulnar division (fig. 1, $m$ ) of the humeral articulation, one (fig. 11, d) for the back part of the radial division of the same (fig. 2, l), and the third (fig. 11,e) for the side of the head of the radius (fig. 5, a).

The thick hind border of the olecranon contracts into the sharper hind border of the shaft of the ulna, which is compressed, rounded, and thicker anteriorly, gradually narrowing from before backward to the distal end, which suddenly contracts to form the base of the short obtuse 'styloid process' $(g)$. The ridge (fig. 11, $f$ ) opposing the interosseal one of the radius, begins below the radial articular cavity, and projects as it descends along the radial side of the anterior border of the ulna, developing a rough facet at its middle third, which is bound by strong ligaments to the corresponding surface (fig. $6, f$ ) on the radius. On the radial side of the extension of the bone supporting 1 "On the Osteology of the Marsupialia," tom. cit. p. 401. 
the surface for the ulnar division of the humeral articulation is the mark of the insertion (fig. $11, h$ ) of the 'brachialis anticus.'

The ulna of Phascolomys latifrons (ib. fig. 9) differs chiefly from that of P'hascolonys platyrhimus (ib. fig. 10) in the quadrate form of the long olecranon $\left(a, a^{\prime}\right)$ which preserves its breadth to the truncate summit, while in Phasc. platyrhinus (fig. 10) it contracts to that summit (fig. 10, a), which is thick, obtuse, and tuberous. The hind border of the olecranon is thicker in P'hascolomys latifrons than in Phascolomys platyrhinus. The surface (fig. 11,c) for the ulnar division of the humeral joint is relatively longer, narrower, and more oblong in P'hase. latifions than in Phasc. platyrhimus.

The carpus of Phlascolomys (Pl. XCIX. fig. 5) consists of a scapholunar (ib. sl), a cuneiform (ib. $c u$ ), a pisiform $(l)$, a trapezinm $(t)$, a trapezoïdes $(z)$, a magnum $(m)$, and an unciform $(u)^{1}$. Of these seven carpals the first and last are the largest.

The scapholunar has the proximal articular surface $(s l)$ traversed lengthwise by the obtuse ridge or angle between the anterior subconvex and posterior subconcave surfaces, both of which are adapted to corresponding surfaces of the radius; it articulates also with the cunciform, trapezium, trapezoïdes, magnum, and unciform. Of the mammals in which a single carpal bone repeats the proportion, position, and connexions of two carpal bones, viz. the 'scaphoid ' and 'lunar,' in man, the most numerous instances are afforded by the Carnivora and Rodentia ${ }^{2}$. In the former the extent to which the unciform joins the lunar part of the scapholunar resembles that in man; in the latter (Castor, e.g.) the extent of such junction is much less. In P'hascolomys the radial surface of the scapholunar is broader in proportion to its length, and less convex than in Macropus; it contracts more suddenly to its outer end above the part extended to offer the convexity to the trapezium. The anconal or dorsal non-articular tract is mainly reduced to a small subtriangular space between the concavity for the trapezoïdes and that for the magnum, the former concavity coming almost into contact with the radial convexity, yet separated by a linear tract continued from the triangular portion to the trapezial process or convexity. The chief extent of non-articular surface is at the under or thenal aspect of the bone.

The cuneiform (ib. fig. 5, cu) presents a concavity for the styliform process of the ulna, to the reception of which the pisiform $(p)$ also contributes; the cuneiform supports the rest of the pisiform, and articulates with the lunar part of the scapholunar and with the unciform.

The pisiform (ib. fig. 5, $p$ ) is a strong, thick, subelongate bone, expanded at both ends; the proximal one offers two articular surfaces for the ulna and cuneiform, the distal end is simply convex and smooth; it might be mistaken for a proximal phalanx, to which it has a general resemblance; but the form of the two facets of the proximal surface distinguishes the pisiform.

1 The same letters are used as those which indicate the homologous bones in the carpus of Phascolomys vombatus in fig. 15, pl. i., 'Nature of Limbs,' 8 vo, 1849. Neither in that species, nor in the two larger continental kinds, have I found a distinct os lunare.

2 Cerrier, 'Leçons d'Inat. Comp.' 8vo, 1835, rol. i. p. 427. 
The trapezium $(t)$ presents a concavity to the scaphoid $(s l)$, a convexity to the metacarpal of the pollex ( $m \mathrm{I}$.$) , and a concavity for the contiguous border of the base of the$ metacarpal of the index ( $m$ II. $)$.

The trapezoïdes $(z)$ supports the metacarpal of the index ( $m$ II:) on the major part of its distal surface, and applies the rest to the radial extension of the magnum $(m)$; it also articulates with the trapezium and the scapholunar.

The magnum $(m)$ pushes its head between the lunar part of the scapholunar $(l)$ and the unciform $(u)$, so as almost to touch the cuneiform, but leaves a small part of both those bones for mutual union, as in the Beaver. The expanded distal end of the magnum offers a very slight concavity to the broad base of the third metacarpal ( $m$ III.); it also contributes a facet to part of that of the index ( $m$ Ir.).

The unciform $(u)$ touches the ulnar margin of the scapholunar $(s l)$, presents a triangular convexity to the cuneiform $(c u)$, mainly supports the metacarpals of the fourth and fifth digits at its distal surface, and touches, there, the outer extension of the base of the mid metacarpal.

The metacarpal of the index ( $m$ II.) has its base extended 'proximad,' to be wedged between the trapezium and pollex, on one side, and between the magnum $(m)$ and medius metacarpal, on the other side, but is mainly applied to the trapezoïdes $(z)$.

The outer or ulnar part of the base of the mid metacarpal ( $m$ III.) is similarly extended and interposed between the base of the fourth metacarpal and the magnum $(m)$, so that the three chief metacarpals overlap, interlock, or wedge each other firmly into their places, adding, of course, to the strength and power of resistance of this main part of the fossorial foot. The comparatively narrow base of the metacarpal of the 'minimus' $(m r)$ is wedged between that of the fourth metacarpal and the unciform $(u)$.

The numerical character of the digital phalanges adheres to the mammalian formula. The proximal ones of the three outer digits are shorter in proportion to their breadth than those of the thumb (I.) and index (II.), as are also the second phalanges (2). The ungual ones (3) are larger than the two preceding phalanges $(2,1)$ in the three outer digits III., IV., v.; they are depressed and subtruncate at the free end on each side the lever of insertion (fig. $7, f$ ) of the flexor perforans tendon; they are subdepressed and subtruncate at the free end, near which the bone shows many small vascular perforations, indicative of the rich supply of material for the quickly worn digging claws.

A pair of strong sesamoids (fig. $6, s, s$ ) increase the force of the flexor tendons as they pass over the proximal joints of the digits. A flexor process ( $f$, figs. $6 \& 7$ ) adds to the leverage of insertion beneath the base of the ungual phalanges (3).

Pelvis.-The os innominatum in Phascolomys (Pl. CII. figs. 1-6) is about one fourth the length of the entire skeleton: the leverage it affords to the limb-muscles by the extension of the ilium $(62, a)$ in advance of the acetabulum $(t)$, and by the extension of the ischium $\left(63, h, h^{\prime}\right)$ behind that centre of motion, is considerable and adds greatly to the power of those muscles. 
The ilium, long, slender, subcompressed, and almost subprismatic, is twisted at right angles to the ischium, the plane of its expanded fore end $(a, b)$ looking vertically, while that of the ischium $\left(h, h^{\prime}\right)$ looks laterally, in the standing pose of the skeleton.

'The dorsum ilii (Pl. CII. figs. 1 \& 2, $62^{\prime}$ ) is directed upward with a slight obliquity backward; it is divided into an upper facet $(62, d 62)$ marked off from the hinder facet $\left(62^{\prime}\right)$, by a longitudinal rising parallel with the upper or sacral border $(b, u)$. The part corresponding to the 'internal iliac fossa' of Anthropotomy is a short triangular tract (fig. 4, 62*) which is continued to the apex (a) of the outer production of the 'labrum.' About 2 inches of this expanded part of the ilium (figs. $1 \& 2, a, b$ ) is in advance of the sacral articulation ( $p, u$, fig. 1 , and $p$, fig. 3 ). The hind end of this part answers to the post-inferior spine (figs. $1 \& 2, u$ ) of the human ilium, and to the beginning of the 'great sacro-sciatic notch' ( $m, l$, figs. $1 \& 2$ ). 'The dividing angle of the dorsal surface is continued to the tuberosity $(d)$ answering to the 'ridge of the reflected tendon of the rectus muscle'? in Anthropotomy, but which here gives attachment to the sole origin of the 'rectus femoris muscle'.

'The anterior border or 'crest' of the ilium $(a, b, c)$ is obtuse, thick, and rough, broadest at the produced angle $(a)$ answering to the 'antero-superior spine' of Anthropotomy. 'The lengtl of the 'crest' is less than half of that the entire ilium.

The mesial or sacral surface of the ilium is smooth and uniform, gently concave across, in a less degree convex lengthwise. The joint for the sacrum is limited to its hinder part, is reniform (ib. fig. 5), and is divided into two flat, oval or oblong facets $(p 1, p 2)$ for the pleurapophyses of the two anterior sacral vertebræ.

Below this surface the ilium contracts to a strong three-sided prism $(z)$ with the angles rounded off, and then expands to form the anterior half of the acetabulum $(t)$, where it coalesces with the pubis (64) and ischium (63). At this junction with the pubis is developed the ilio-pubic process (fig. $3, e$ ).

The pubis is compressed, especially at its symphysial part $(l)$; the oblong ridge $(k)$ for the articulation of the marsupial bone (fig. 7 ) terminates near the angle at which the symphysis begins.

The ischium, contributing the lower half of the acetabulum (i), is strong and triedral below that cavity, and then rapidly expands into a long and large subquadrate plate of bone $\left(63^{\prime}\right)$, the hinder angle of which $(h)$ is thickened and produced upward with a curve bounding there the long sacro-sciatic notch, which is not divided by any 'spine of the ischium.' 'This, however, is indicated by a feeble ridge or production of the hind or upper border of the ischium (at $l$, figs. $3 \& 4$ ).

The bare-nosed Wombat differs from the hairy-nosed species in the greater production of the iliac angle ( $a$, fig. 2 ), and in the narrower less robust body of the ilium $(62, z)$; in the greater length, minor breadth, and less definitc bipartition of the articular surface

1 This tuberosity is not the homologue of the 'anterior inferior spine' of the ilium (see 'Annals and Magazine of Natural History,' 1870, vol. v. p. 168. 
for the sacrum (compare figs. $5 \& 6$ ); in the minor development of the ilio-pubic process (fig. $4, e$ ) and of the 'rectus tuberosity' (fig. 2, $d$ ); in the longer and more slender pubis (fig. 4,64$)$, in the shorter ridge $(k)$ for the marsupial bone; in the larger obturator foramen $(0)$, and the absence of the projection from its ischio-pubic margin (as at $v$, fig. 3); in the narrower ischium, prior to the expansion (63') of the great tuberosity $\left(h, h^{\prime}\right)$; in the minor extent of that expansion, which, in Phascolomys platyrhinus, is rather triangular (fig. 4) than quadrate as in Phascolomys latifrons (fig. 3, 63'). The twist of the innominatum is not carried so far in Phascolomys platyrhinus as in Phascolomys latifrons, whereby in the bare-nosed species part of the sacral plane (fig. 4, 62*) of the ilium is brought into view when that of the ischium (63') isin direct view; whilst the outer or lower border only (fig. $3, t$ ) of the ilium meets the eye in this position of the bone in Phascolomys latifrons; and this border is thicker in Ph. latifrons than in Ph. platyrhinus. There are slight differences in the acetabulum: it is rather deeper in Phascolomys platyrhinus (fig. $4, i, \ddot{i}$ ); and the entering groove $(y)$ is narrower in the bare-nosed than in the hairy-nosed Wombat (fig. 3,y).

Bones of the Hind Limbs.- The femur (Pl. CIII. figs. 1-4) is thicker in proportion to its length in Phascolomys latifrons than in Phascolomys platyrhinus. Both trochanters $(d, g)$ are rather more prominent; but the generic characters of the bone, as $e . g$. depth of the post-trochanterian fossa (fig. $2, e$ ), production of subtrochanterian ridge $(f$ ), longitudinal extent of trochanter minor $\left(g, g^{\prime}\right)$, flattening of the back part of the shaft (ib. h), community of rotular (fig. $1, i$ ) and condylar (fig. $2, k, l$ ) articular surfaces, are closely preserved in all Wombats.

In the genus Phascolomys the two bones of the 'cnemion' or leg, bear a closer resemblance and a nearer relative proportion to their homotypes in the forearm than in any other mammal. They were selected, on that account, to exemplify such homotypal relations in my works on the 'Archetype of the Vertebrate Skeleton,' 8vo, 1846, and on the 'Nature of Limbs' (pl. 1. figs. 15 \& 16).

The head of the tibia (Pl. CIII. fig. 8), like that of the radius, presents a horizontal surface $(a, b)$ for the condylar articulations of the proximal limb-bone (fig. $4, k, l$ ), and a smaller vertical articular surface (fig. $6, e$ ) for the contiguous bone; this surface for the lower division of the proximal articulation of the fibula (fig. 11, $d, e$ ) is the homotype of the surface in the radius (Pl. CI. figs. $5 \& 6, a$ ) for the 'lesser sigmoid cavity' of the ulna (ib. fig. 11,e).

As in the radius, the shaft of the tibia (Pl. CIII. figs. 5-7) is compressed (fig. 7), slightly bent (figs. 5,6), with the concave border rather sharp; and the shaft gains thickness as it approaches the distal end.

The proximal end (fig. 8) retains the usual superior extent of articular surface in this bone of the hind limb as compared with its homotype in the fore limb. The surfaces $(a, b)$ adapted to the femoral condyles are partially divided posteriorly by a shallow groove $(c)$, the sides of which, especially the inner one, rise to give attachment to the 
'crucial ligaments; the chief and larger division $(\alpha)$ for the inner condyle of the femur, is more concave than usual, especially in Phascolomys platyrhinus, recalling the form of the liumeral articular surface of the radius. 'The rotular tuberosity (figs. 5, 8, $d, y$ ), homotypal with the bicipital one of the radius, is lower down and more remote from the proximal articular surface than nsual. 'The fore part of the tibia continued down from this tuberosity soon contracts to a ridge, which near the middle of the shaft projects from the anterior contour and inclines slightly towards the fibula (figs. $5,6, h$ ). 'The inner side of the shaft (fig. 5) is broad, smooth, almost flat. The outer side (fig. 6), which includes what in most tibix is the linder side, is sinuous at its proximal half and angularly convex across at its distal third $(i)$. The concavity between the back parts of the proximal articular surfaces, answering to the 'popliteal notch' of Anthropotomy, expands, as it descends, into a longitudinal concavity, which merges into the inner side of the bone by the ridge-like backward projection of its inner border, and the low development and speedy suppression of its onter one (fig. $6, l, i$ ). This border is continued lower and becomes more ridge-like in Phascolomys platyrhimus than in Phasc. latifrons, marking out more definitely a hinder facet of the tibial shaft, although characteristically narrow, and giving a more concave or canaliculate character to the fore part of the outer surface of the sliaft. A hinder surfacc of the tibial shaft can only be defined in Phascolomys latifrons at the thicker distal half. The general bend, concave backward, of the tibia is greater in Phascolomys latifrons than in Ph. platyrhimus.

The modification of the distal articular surface of the tibia (fig. 9) resembles that of the radius. The facet for the proximal surface of the astragalus $(a)$ is continued upon the inner malleolus (b) at a more marked angle than the homotypal surface is continued upon the 'styloid process' of the radius (Pl. LXXII. fig. 5, e); but the homotypy of the part so called in the radius with the part called 'internal malleolus' in the tibia (Pl. CIII. fig. $7, k$ ) is unmistakable in the Wombat. This process (fig. 9, $b$ ) articulates with the scaphoid or naviculare of the tarsus (Pl. XCIX. fig. 8, s), whilst the horizontal facet (fig. 9, a) articulates with the astragalus as its homotype in the forearm articulates with the 'lunar' part of the scapho-lunar bone.

The fibula in Phascolomys (PI. CIII. figs. 10, 10',11) presents the rare ulnar character of proximal expansion $(a)$ and olecranal leverage $(b)$; only that the terminal summit of the lever retains its individuality and articular union with the basal part of the uprising process.

The proximal articular surface of the fibula has one facet (fig. 11, d) for the outer condyle of the femur, and a rather more concave surface $(e)$ for the contiguous lateral facet or the proximal end of the tibia (fig. $6, a$ ). The articular surface (figs. 10, 11, a) for the 'fabella' (ib. ib. b) is subcircular and almost flat.

The proximal half of the fibula is triedral; the outer facet (fig. $10, f$ ) between the homotype of the olecranon $(a)$ and the antero-external ridge $(g)$ is deeply concave, 
repeating the character of the homotypal facet of the ulna, the concavity in both being transverse. The anterior facet is slightly concave and of less longitudinal extent; the inner facet (fig. 11, $h$ ) is feebly convex transversely, with low longitudinal ridges and impressed marks of muscular attachments.

The distal half of the shaft beomes more cylindrical, though with indications of the three facets; and these are better marked in Phascolomys platyrhinus than in Phascolomys latifrons, although the fibula, like the tibia, is a relatively stronger bone in the hairy-nosed Wombat. The outer malleolus (i), answering to the styloid process of the ulna (Pl. CI. figs. 9-11, g), presents, as in this production at the inner side of its base, a strip of smooth articular surface (Pl. CIII. fig. 11, $k$ ) for the contiguous part of the parallel bone (fig. $6, k$ ). But the 'process' or produced part of the distal end of the fibula is broader than its homotype, and is longitudinally grooved on its outer surface.

The tarsus of Phascolomys (Pl. XCIX. figs. 8, 9, 10) consists of the usual seven bones'naviculare' $(s)$, ' astragalus' $(a)$, 'calcaneum' $(c l, c t)$, 'ento-' $(c i)$, 'meso-' $(c m)$, ' ecto-' $(c e)$ cuneiforms, and 'cuboid' $(b)$, together with the peculiar marsupial accessory ossicle (o) described (in Dasyurus macrurus) as " a small sesamoid bone wedged in between the astragalus, tibia, and fibula".

The naviculare or scaphoid $(s)$ is transversely oblong, interposed between the tibial malleolus and the astragalus above, and the three cuneiforms and cuboid below. The proximal surface is transversely concave for the ball of the astragalus $(a, 4)$; posteriorly it is continuous with a narrow tract articulating with the fore and inner part of the calcaneum, and externally with the small flattened facet for the cuboid $(b)$, which is continuous with the outer of the three facets for the cuneiforms.

The astragalus (Pl. XCIX. fig. 8, a, \& fig. 9) is broad, depressed, and remarkable for the continuity of all its articular surfaces. The upper or proximal mid surface (fig. 8, $a$ 1), gently concave transversely, convex longitudinally, slightly broadening as it advances, is adapted to the horizontal terminal surface of the tibia; the lateral facets (ib. $2 \& d$ ) slope away from this surface, the inner one $(d)$ to be adapted to the oblique one on the inner malleolus, the outer one (2) with a gentler slope to the more nearly horizontal facet at the distal end of the fibula. The anterior convexity (4) fits into the concavity of the scaphoid, touching also part of the cuboid; it is continuous internally by a narrow tract (fig. 9,5) with the tibial malleolar surface (fig. $8, d$ ), and below with the surface articulating anteriorly with the cuboid and continued backward expanding (fig. 9, a) to rest upon and articulate with the calcaneum.

The calcaneum (Pl. XCIX. fig. 8, $c l$, and fig. 10) has three articular surfaces on its expanded tarsal or articular half:-one above, feebly convex, subtriangular in shape (fig. 10, $a$ ), for the astragalus; one anterior, concave $(b)$, for the cuboid; and a narrow slip continued therefrom to the inner side of the bone for articulation with the scaphoid. 'The posterior fulcral or 'sesamoid' part of the bone (ib. $c t$ ) is triedral, broad, and 
convex below, concave on the inner side (fig. 10,c), toward which the lever $(c t)$ is slightly bent, flat and rough on the outside: this part shows an oblong tuberosity $(d)$; and there is a second, smaller, hemispheroid one $(e)$ close to the cuboidal articular surface.

Of the three cunciforms the mid one (fig. $8, \mathrm{~cm}$ ) is the smallest; their relations to the toes are shown in Pl. XCIX. fig. 8. That with the scaphoid is analogous to, or homotypal with, the proximal relations of trapezium, trapezoides and magnum with the scapho-lunar in the carpus (ib. fig. $5, t, z, m$ ). 'The cuboid (fig. $8, b$ ), like the unciform (fig. $5, u$ ), is the largest of the distal series. It presents a convexity behind for the astragalus and calcaneum, a small surface for the outer end of the naviculare, and expands as it advances to support part of the proximal ends of the fourth and fifth metatarsals, the latter sending outward an obtuse process beyond the proximal articulation.

'The 'pyramidale' (ib. fig. 8,o) has a slightly convex non-articular base, which is turned backward; the three sides of the cone are almost flat and articular; the under anterior one plays upon the hinder part of the upper articular surface of the astragalus, the upper one upon the hind end of the horizontal terminal articular surface of the tibia, the outer one upon the hind end of the malleolar surface of the fibula.

'The metatarsals progressively increase in length and breadth from that of the hallux (I) to the fourth (IV); that of the fifth (v) is somewhat shorter, but is twice as thick as the fourth, and sends outward and backward a strong obtuse process from its outer and basal part. The hallux is reduced to one phalanx; the other toes have the usual number of phalanges, progressively increasing in thickness from the second to the outermost, but in a slighter degree in III. than in IV. and V., thus showing a slight tendency towards the condition' ${ }^{1}$ described in the 'Cyclopædia of Anatomy and Physiology,' rol. iii. (1841), Art. Marsupialia, p. 286, fig. 111.

\section{DESCRIPTION OF THE PLATES.}

\section{PLATE XCVIII.}

Fig. 1. Front view of atlas vertebra, Phascolomys latifrons.

Fig. 2. Back view of atlas vertebra, Phascolomys latifrons.

Fig. 3. Front view of atlas vertebra, Phascolomys platyrhinus.

Fig. 4. Back view of atlas vertebra, Phascolomys platyrhinus.

Fig. 5. Side view of second to sixth cervical vertebræ, Phascolomys latifrons.

Fig. 6. Side view of seventh cervical and first three dorsal vertebræ of Phascolomys latifrons.

Fig. 7. Side view of left first rib of Phascolomys latifrons; $7 \alpha^{\prime}$, articular surface of ' head ;' $7 b$, articular surface of ' tubercle,' of ditto, Phascolomys latifrons.

' Flower, 'Osteology of the IIammalia,' 12mo, 1870, p. 321. 
Fig. 8. Side view of left third rib; $8 b^{\prime}$, articular surface of tubercle, Phascolomys latifrons.

- Fig. 9. Side view of right fifth rib; $9^{\prime}$, front view of distal end of ditto, Phascolomys latifrons.

Fig. 10. Side view of left last (free or dorsal) rib, Phascolomys latifrons.

Fig. 11. Front or outer view of sternum, Phascolomys latifrons.

Fig. 11a. Side view of distal end, with parts of attached rib and xiphoid sterneber, Phascolomys latifrons.

Fig. 12. Under view of right clavicle, Phascolomys latifrons.

Fig. 13. Under view of right clavicle, Phascolomys platyrhinus.

\section{PLA'TE XCIX.}

Fig. 1. Under or inner view of sacrum and anterior candal vertebra, Phascolomys latifions.

Fig. 2. Articular surface for ilium on the first two sacral vertebræ, Phascolomys latifrons.

Fig. 3. Under or inner view of sacrum and anterior caudal vertebræ, Phascolomys platyilinus.

Fig. 4. Articular surface for ilium on the first two sacral vertebræ, Phascolomys: platyrhinus.

Fig. 5. Dorsal or anconal view of the bones of the right fore paw, Phascolomys latifrons.

Fig. 6. Thenal view of phalanges and sesamoid of fourth digit, Phascolomys latifrons.

Fig. 7. Side view of ungual phalanx of third digit, Phascolomys latifions.

Fig. 8. Dorsal or upper view of the bones of the right lind foot, Phascolomys latifrons.

Fig. 9. Under view of astragalus, Phascolomys latifrons.

Fig. 10. Upper view of calcaneum, Phas'ulomys latifrons.

\section{PLA'TE C.}

Fig. 1. Dorsal or outer view of left scapula, Phascolomys latifirons.

Fig. 2. Inner or under view of left scapula, Phascolomys iatifrons.

Fig. 3. Side view of left scapula, Phascolomys latifrons.

Fig. 4. Dorsal or outer view of left scapula, Phascolomys platyrhimus.

Fig. 5. Inner or under view of left scapula, Phascolomys platyrhinus.

Fig. 6. Side view of left scapula, Phascolomys platyrhinus.

Fig. 7. Glenoid cavity of left scapula, Phascolomys latifrons.

Fig. 8. Glenoid carity of left scapula, Phascolomys platyrhimus. 


\section{PIAIE ('I.}

Fig. 1. Anconal view of right humerus, Phascolomys latifrons.

Fig. 2. 'Thenal view of right humerus, Phascolomys latifrons.

Fig. 3. Anconal view of right humerus, Phascolomys platyrhinus.

Fig. 4. Thenal view of right liumerus, Phascolomys platyrhinus.

Fig. 5. 'Thenal view of left radius, Phascolomys latifrons.

Fig. 6. Anconal view of left radius, Phascolomys latifrons.

Fig. 7. Proximal articular surface of left radius, Phascolomys latifrons.

Fig. S. Distal articular surface of left radius, Phascolomys latifrons.

Fig. 9. Ulnar or outer side view of right ulna, Plascolomys latifrons.

Fig. 10. Ulnar or outer side view of right ulna, Plicscolomys platyrhinus.

Fig. 11. Radial or inner side view of right ulna, Phascolomys latifrons.

\section{PI,ATE CII.}

Fig. 1. Dorsal view of left 'innominatum,' Phascolomys latifrons.

Fig. 2. Dorsal view of left 'innominatum,' Phascolomys platyrlinus.

Fig. 3. Outer side view of left 'innominatum,' Phascolomys latifrons.

Fig. 4. Outer side view of left 'innominatum,' Phascolomys platyrhinus.

Fig. 5. Iliac articular surface for sacrum, Phascolomys latifrons.

Fig. 6. Iliac articular surface for sacrum, Plisesolomys platyrhinus.

Fig. T. Outer or under surface of left marsupial bone. Phascolomys latifirons.

\section{PIA'TE CIII.}

Fig. 1. Front view of left femur, Phascolomys latifrons.

Fig. 2. Back view of left femur, Pliascolomys latifrons.

Fig. 3. Proximal end of left femur, Phascolomys latifrons.

Fig. 4. Distal end of left femur, Plascolomys latifions.

Fig. 5. 'Tibial or inner side view of left tibia, Phascolomys latifrons.

Fig. 6. Fibular or outer side view of left tibia, Phascolomys latifrous.

Fig. 7. Front view of left tibia, Pliascolomys latifrons.

Fig. 8. Proximal end of left tibia, Phascolomys latifions.

Fig. 9. Distal end of left tibia, Phascolomys latifrons.

Fig. 10. Outer side view of left fibula and fabella, Phascolomys latifrons.

Fig. 10'. Distal end of left fibula, Phascolomys latifrons.

Fig. 11. Tibial or inner side view of left fibula and fabella, Phascolomys latifrons.

Fig. 12. Proximal end of right humerus, Phascolomys latifrons.

Fig. 13. Distal end of right humerus, Phascolomys latifrons.

All the figures are of the natural size. 


\title{
Suborder DIPRO'TODONTIA.
}

\author{
Section SALTIGRADA.
}

\section{Family MACROPODIDÆ.}

\section{Osteology of the existing Species.}

$\$ 1$. Introduction.-The combination of the marsupial economy with herbivorous diet, and of unguiculate fore paws having the requisite extent and variety of movements for the manipulation of the pouch with a power of swift and extensive locomotion for attaining fresh pastures and escaping enemies, results in one of the most singular modifications of the terrestrial mammalian form; and it is not surprising that a passing glimpse of the first Kangaroo by Banks and his fellow voyagers on their landing at Botany Bay left the impression that they had seen hopping away from them some strange, large, new, wingless bird. In fact, the work of ordinary locomotion on land, in the poephagous Marsupials, is transferred to and concentrated upon the hinder end and members, the fore limbs being reserved, as in birds, for other functions. This involves modifications of the whole frame, and especially of the proportions and structure of the caudal vertebræ and pelvic limbs.

Pander and D'Alton, in their elegant work on the skeletons of the Mammalia '. have given in the Part devoted to the Marsupialia ${ }^{2}$ reduced views of the skeletons of Macropus major, Shaw, and M. (Halmaturus) elegans, F. Cuvier, with full-sized figures of those of Iypsiprymnus murinus, Illig., and of some species of Didelphys. In the same Part the skull and atlas of Macropus major are figured of the natural size, and a somewhat reduced view is given of the carpus and tarsus in that Kangaroo. A front view of the pelvis of a young Kangaroo, in relation to its osteogeny, is given in my article "Marsupialia" ; and the bony palate, with the dentition and part of the base of the skull of Macropus bennettii, is figured, of the natural size, in the first of the series of papers on the Osteology of that order ${ }^{4}$.

For the purpose of palæontological comparison, however, there is the same need of illustrations of the osteology of one or more of the existing species of Macropodidæ as of those of the Phascolomyidæ.

In oblong folio, 1821-31.

? 'Die Skelete der Beutelthiere,' Bonn, 1828.

'Cyclopxdia of Anatomy, vol. iii. (1847) p. 284, fig. 110.

- Trans. Zool. Soc. vol. ii. (1838) p. 406, pl. 71. fig. 5. 
In the present 'Section' I have selected those of the great Rufous Wallaroo (Macropus rufus, Desm.', M. laniger, Gaimard ${ }^{2}$ and Gould ${ }^{3}$ ).

\$2. The Skull.-The skull in Kangaroos (Macropodidx, Ow. ") is characterized by the great length of the diastema between the molars and incisors in both jaws. A minute rudiment of a canine, or a minute depression where such rudiments may have been lodged, is present in some small kinds of Kangaroo, but is inconstant in them. 'The skull (Plate LXVI.) is long, through the extension of the facial or maxillary part in front of the orbits (fig. 1,o); and these cavities, interposed between the facial and cerebral part, are large; they widely communicate, as in the rest of the order, with the temporal fossa (ib. $t$ ). The paroccipital (ib. figs. $1 \& 4,4$ ) and masseteric (ib. 21 x) processes are produced downwards-the former to an extreme degree, to which Phascolarctos, perhaps, affords the nearest approach in the marsupial order. A sagittal crest may be indicated in old males of some of the larger Kangaroos, but is never elevated. The zygomatic arch is deep, with the malar (26) element, suspended between the maxillary (21) and squamosal ( $2 \tau)$ piers. 'The malar contributes a small but definite share (ib. fig. $3,26 x$ ) to the outer part of the joint for the mandible, the entire articular surface $(27 x)$ being subquadrate, feebly convex transversely, partially concave lengthwise, through the descent of a postglenoid process (ib. figs. 1, 3, pg), internal to which is a perforation.

The alisphenoid (ib. fig. $3, t r$ ) sends down a process (ib. fig. 1, $6^{\prime}$ ) abutting against the paroccipital (4). 'The three compartments of the cranial cavity-epencephalic, prosencephalic, and rhinencephalic-succeed each other lengthwise; and the olfactory cavity extends backward both above and beneath the rhinencephalic fossa. The "sella turcica" is indicated by the entocarotid foramina, not by clinoid processes. The basioccipital (ib. fig. 3, 1) is hexagonal, the hind border emarginate, forming the lower fourth of that of the foramen magnum (ib. fig. 4,o) and contributing a very small part to each condyle $(g)$. The exoccipital (ib. fig. 4,2) develops the rest of that jointsurface $(g)$, which is oblong-convex, with an upper or back portion bent at a right angle to the rest of the convexity. In young Macropodidæ the superoccipital (ib. fig. 4, 3) contributes a small share to the upper border of the foramen, which extends thereto by a fissure-like prolongation upward, between the then separate occipitals. These,

1 ' Mammalogie,' Supplément, p. 541 (1822).

2 Bulletin des Scienees par la Société Philomathique (1823), p. 138.

' Jammals of Australia,' fol. part $\mathbf{}$.

'Not the Macropidæ of J. E. Gray, nor the Maeropodidæ of Waterhouse. The former term, like the Didelphidæ of De Blainrille, is equivalent to the ordinal term "Marsupialia," see "Catalogue of the Bones of Mammalia in the eollection of the British Museum,' $8 \mathrm{vo}, 1862$, pp. 119-140. The latter term includes the Potoroos (Hspsiprymnidx) with the Kangaroos. The species, however, which have the dental formula $i \cdot \frac{3-3}{1-1}, c \cdot \frac{00}{00}$, $p \cdot \frac{1-1}{1-1}, m \cdot \frac{4-4}{4-1}$, manifest, in the series of extinct with recent forms, so many generie modifications, that a name for the canineless family of Poëphaga is requisite. 
however, by subsequent growth contract the fissure, and in adults of some large species obliterate it and complete the foramen by the exclusion of the superoccipital. There are two or more precondyloid foramina (ib. fig. $3, p$ ), anterior to which is the vagal foramen $(v)$, and next the larger single jugular notch, through which may be seen the hind end of the petrosal (16); this notch is usually completed, as a foramen, by the paroccipital process of the alisphenoid $6^{\prime}$, anterior to which the fore part of the petrosal is visible; but in some the union with the exocctpital (ib. fig. 2) does not take place, and the whole extent of the basal part of the petrosal is seen; the junction of the alisphenoid (ib. fig. 1, 6') with the paroccipital (4) is constant and extensive. A smooth channel curves round the upper part of the condyle (ib. fig. $4, g$ ) between it and the base of the paroccipital (4). The superoccipital (ib. fig. 4,3) is octagonal, the upper and lower borders being the shortest; the lateral ones next these above and below are the longest; the two outer sides are of intermediate extent. There are two rough oblong depressions (ib. $3, x$ ) near the upper lateral borders, for tendinous attachments. Superiorly the superoccipital joins the interparietal (ib. fig. 2,3), varying in shape and composition; laterally it joins the parietal ( 7 ) and mastoid (8), and in some species also a small intervening bit of the squamosal (Pl. LXVI. fig. 4, 27); inferiorly it unites by its longest borders with the exoccipitals (ib. 2, 2') by straight sutures, slightly descending as they converge to the foramen magnum (ib. o), to which the shortest and lowest border originally contributes. The exoccipitals and their paroccipital productions unite laterally with the mastoids (ib. 8), below which the paroccipitals receive the alisphenoid abutments (ib. fig. 1, 6'). The basioccipital unites by its postlateral border's with the exoccipitals, by its prelateral borders with the petrosal and alisphenoids, with more or less interruption through the intervening postlacerate fissures (ib. fig. $3, q$ ), and by its fore border with the basisphenoid. The contiguous or conjoined borders of these elements usually swell out so as to produce same convexity at this part of the base of the skull.

The basisphenoid (ib. fig. 3,5 ) loses breadth as it extends from the basioccipital forward; its sides are pierced or deeply grooved obliquely by the entocarotids, which have impressed the contiguous part of the basioccipital; the entocarotid canal, commencing at the fore part of the postlacerate fissure, is completed by the base of the alisphenoid. 'The pair of canals converge upward and forward, and terminate within the cranium at the hind part of the "sella," separated there by a bony tract not exceeding the diameter of the arterial canal. The basisphenoid is longer than the basioccipital; it unites with the third cranial centrum (9) beneath the vacuity common to the prelacerate and optic foramina. The alisphenoid (6) forms a large outward swelling for the lodgment of the natiform protuberance of the cerebrum, the pressure of which reduces the neurapophysial plate to almost transparent thinness. Below the convexity as large a concavity is formed, with an irregular surface, for the attachment of the pterygoid muscles, the cavity being completed by the proper pterygoid bone (ib. fig. 3, 24). 
The base of the alisphenoid articulates with the side of the basisphenoid, leaving a small hind part of that element clear for the entry of the entocarotid, and as small a fore part for the exit of the optic nerve. From this attachment it extends backward and forward, attaining an antero-posterior extent equalling that of the parietal. The alisphenoid is pierced by the "foramen ovale" (tr) opposite the fore end of the petrosal, and by the "foramen rotundum" near the fore part of its attachment to the basisphenoid. The alisphenoid gains thickness and loses breadth as it extends backwards outside the cranial walls to articulate with the squamosal (2i), tympanic (28), mastoid ( 8 ), and paroccipitals (4), and contributes to form the tympanic cavity. The thinner cranial plate ascends anterior to the squamosal to join the parietal, frontal, and orbito-sphenoid.

'The sagittal suture (ib. fig. $2, r^{\prime}$ ) persists until maturity, its obliteration beginning behind. Here the parietals $(7)$ join the interparietal $(3 x)$ and superoccipital ( $\left.3^{\prime}\right)$, an intervening "fontanelle" long remaining, reduced to a fissure which is continued between the mastoid and parietal; it is usually obliterated in aged Kangaroos.

The mastoid shows externally a narrow roughish vertical tract (Pl. LXVI. fig. 1, 8) between the exoccipital ( 2 ) and post-tympanic base of the squamosal ( $\left.2 \tau^{\prime \prime}\right)$, which forms the lateral border of the occipital plane (ib. fig. 4,27), but not so broad a one as in Phasrolomys (Pl. XIJVI. figs. 2, 3, 4, 6, 7, 27). The upper end of the mastoid has a persistent round renous aperture behind the masto-parietal fissure (Pl. LXVI. fig. 1,7f). In front of that fissure is the suprazygomatic venous foramen (ib. fig. 1, $m$ ).

Each parietal (ib. fig. 2, $\tau$ ) extends forward in a pointed form into a corresponding notch of the frontal, the apex ending at the usual place of a postorbital process (ib. fig. 2, 12), which is rarely developed in the Kangaroos, and is never large. The presphenoid (ib. fig. 3,9) extends forward to coalesce with the "septum narium;" its hind portion contributes to the optico-prelacerate foramen; its fore part supports the small orbito-sphenoid which completes that foramen, overarching it to join the alisphenoid, 6.

The interfrontal suture (ib. fig. 2,11) is persistent; even very old males of Macropus major show a trace of it. Each frontal begins behind, narrow or pointed, expands as it advances, and bends down more or less abruptly to form the inner wall of the orbit, where it unites with the orbito-sphenoid (10), palatine (ib. fig. 1, 20x), maxillary (21xx), and lacrymal (73); anteriorly the broad end or base of the frontal joins that of the nasal (15), and is wedged between the nasal (fig. 1, 15) and facial plate (21) of the maxillary. The frontals contribute a small share to the anterior walls of the cranial cavity; their chief expansion is subservient to the development of the large and complex sinuses in comnexion with the olfactory cavity. This expansion is such in Macropus antilopinus, $\mathrm{Gd}$., as to have suggested for it the subgeneric term Osphranter ${ }^{1}$; it is somewhat less developed in the present nearly allied species.

\footnotetext{
' Gr. ¿øфpurripeus, sharp-smelling.
} 
The vomer forms the basis of the "septum narium," and speedily coalesces with the plates which the prefrontals (14) contribute thereto.

The nasals (ib. figs. $1 \& 2,15$ ) are long and narrow; their bases, less expanded than in most other Marsupials, are subangular or rounded, and enter an emargination of the frontals between the fronto-maxillary sutures; the sides of the nasals articulate in two thirds of their length with the maxillaries (21), in the remainder with the premaxillaries (22), anterior to which the ends of the nasals are bevelled off to points, freely overhanging the external bony nostril, but not extending so far forward as the dentary part of the premaxillary. The external nostril (ib. fig. 5) is vertically oval, narrower than deep; the aspect of the aperture is forward and slightly upward.

The upper turbinal sense-capsules (ib. fig. 5, 18) coalescing with the compressed centrum called "vomer," and with the neurapophyses called "prefrontals', compose the bone which anthropotomy terms "ethmoid."

The palatines, descending from the pre- and orbito-sphenoids, the ethmoid, and frontal (at 20x, fig. 1), internal to the hind part and entorbital plate of the maxillaries $\left(21 x^{\prime}\right)$, bend inwards at right angles to unite together at the bony palate (ib. fig. 3, 20), of which they form the hind portion from the penultimate molars backwards. From the sockets of these and of the last molars the palatal plates of the palatines are separated by a narrow strip of the maxillaries (ib. $21^{\prime \prime}$ ), behind which the palatines ( $20^{\prime \prime}$ ) extend and expand to join the pterygoids (24).

The hind border of the bony palate is feebly concave. The postpalatal apertures pierce the outer angles of the palato-maxillary sutures; they are small oval foramina in some (usually the larger) species of Kangaroo (as at b, fig. 3), but extend into both bones to form wide vacuities in other species ${ }^{1}$, the bony palate being one of the seats of variety in the present family. The proper palatine plates may show one or more foramina behind the normal postpalatal or maxillo-palatine vacuities.

The orbital plate (ib. fig. 1, 20x ) of the palatine is pierced by the orbito-palatal foramen, and is notched to contribute, behind, to the spheno-palatal foramen, and, in front, to the palato-maxillary foramen.

The maxillary is a large and complex bone. Articulating with the fore and onter parts of the palatine, it develops the alveolar tract for the grinders, also the part of the bony palate between the palatines and premaxillaries, and the main part of the floor of the orbits where it is pierced by the entorbital canal $(e)$ and notched by the palatomaxillary foramen $(f)$. Then extending from the orbit forward, beneath or internal to the lacrymal and malar bones, the maxillary forms the side wall of the face (fig. 1, 21) as far as the premaxillary (ib. 22). This facial wall is sinuous, convex vertically at its upper part, concave at its lower part, the concavity being deeper in the larger kinds of Kangaroo: it articulates behind witl the frontal (11), lacrymal (73), and malar (26), above with the nasal (15), in front with the premaxillary (22). At the lower part of the maxillo-

${ }^{1}$ Pl. LXXXXIV. fig. 3 (Halmaturus valabatus): Pl. XC. fig. 1 (H. brachyurus). 
premaxillary suture the maxillary usually sends forward a sharp narrow process to be wedged into the premaxillary, receiving into a notch below a similar process from that bone. The suborbital canal divides into a dental and an antorbital canal. 'The anterior outlet (ib. fig. 1, 21') of the antorbital canal, usually vertically oval in shape, varies in its relative position to the orbit in different species of Kangaroo. A ridge near the maxillo-malar suture leads to the zygomatic process, of which it forms the outer border. 'This process $(21 \times)$ is the seat of variety, as to shape and size, in different species of Macropodida.

The premaxillaries unite by a rhomboid facial plate (ib. fig. 1, 22) with, usually, the terminal third of the nasals (15) and with the maxillaries (21). They develop sockets for three pairs of incisors $(i 1,2,3)$, and form the anterior end of the bony palate, which is pierced by the "incisive foramina" (ib. fig. 3, 22') in the form of oblong slits, closed behind by the pointed ends of the palatal plates of the maxillaries. External to these foramina the premaxillaries usually show a smaller foramen (ib. $a^{\prime}$ ).

'The malar contributes the outer half of the floor of the orbit, articulating there with the lacrymal and maxillary; the zygomatic part of the malar (ib. fig. 1, 26) is decp or vertically extended; it articulates by an oblique suture with the maxillary pier of the $\operatorname{arch}(21 x)$, and diverges to receive, by a large and deep notch, the pointed fore part of the squamosal zygoma (27). The malar is excavated, as it were, below the orbital rim, from which a ridge extends backward nearly parallel with the horizontal part of the malo-squamosal suture; the hind end of the malar expands horizontally or is produced inward to form the fore part of the glenoid cavity (ib. fig. 3, 26x) or mandibular articulation. The zygomatic part of the squamosal $\left(2 \sigma^{\prime}\right)$ rather exceeds in depth that of the malar, rising abruptly bchind from its attachment to the cranial part (27'). Close to this attachment is the squamosal venous foramen $(m)$; below this is a larger vacuity (tympano-zygomatic cell, $n$ ) between the squamosal and tympanic; and behind this is the shallower "tympano-squamosal" cell. The cranial plate of the squamosal (27) unites with the parietal and alisphenoid, with the superoccipital and mastoid, and with the tympanic.

'The tympanic (Pl. LXVI. fig. 1, 28) is a cylinder, expanding toward the brain-case in to an irregular triedral bone. The upper and fore side receives the postglenoid process; the under and outer part (ib. fig. 1,28) articulates with the alisphenoid (6), the inner part with the petrosal (ib. fig. 3, 16), the hinder part with the mastoid (8). The tympanic long retains its individuality. The auditory canal is directed outward and a little upward and backward; its outlet is circular; but the canal loses vertical and gains transverse extent as it passes inward.

The pterygoid (ib. fig. 3, 24) has an antero-posteriorly extended base, which articulates with the basi- and alisphenoids, completing the large concavity of the pterygoid process of the alisphenoid and extending the hinder aperture of the nasal passage. The lower end of the pterygoid articulates with the inner side of the pterygoid process of 
the palatine (20"), and develops a short compressed "hamular" process ( $\left.24^{\prime}\right)$ slightly bent outward.

The petrosal (ib. fig. 3, 10) has two free surfaces-the "cranial" and "basilar." The former is the most extensive, is bifurcate anteriorly and impressed near its hind part by a deep cerebellar pit, below and a little in advance of which is the "meatus auditorius internus;" a sharp ridge overhangs the cerebellar or appendicular pit. The exposed basilar surface is small and narrow, pointed anteriorly, grooved externally for a venous canal, and, in most Kangaroos, crossed by a slender bar of the exoccipital uniting with the paroccipital process of the alisphenoid. The lacrymal has a small "facial" (ib. fig. 1,73') and a large "orbital" plate (73); the angle between the two shows two foramina with an intervening tubercle; and in some species of Kangaroo there is a second tubercle above the upper foramen. These lacrymal foramina (ib. fig. $2, l, l^{\prime}$ ) are rather ectorbital than entorbital; both lead to a canal descending and bending forward to terminate in the nasal meatus.

The angle of the lower jaw (ib. fig. 1,a) is tumid, strongly inflected and upbent into a ridge bounding a wide and deep concavity, indicated by as strong a convexity $(k)$ externally. The fore part of the cavity communicates with the external crotaphyte fossa $(f)$ by a perforation, in front of which is the entry of the dental canal. The symphysis is long, narrow, and usually rather loose, permitting movements of the rami on each other ${ }^{1}$. There are no subsymphysial foramina as in Phascolomys. The vertical extent of the ramus increases from behind the last molar $(m 3)$ to the antepenultimate one $(m 1)$; it suddenly decreases in front of the molar series, and is continued forward along an extensive diasteme $(l, l)$, chiefly devoted to the support of the long procumbent incisor $\left(i^{\prime}\right)$. The external orifice of the dental canal $(v)$ is a little in advance of the molar series.

The skull which forms the subject of Pl. LXVI. is from a male Rufous Walleroo, which measured 8 feet 2 inches from the nose to the extremity of the tail. This animal had the last molar in place and use, and still retained, though much worn down and probably soon to be shed, the tooth answering to the last of the deciduous series in Diphyodont Mammals (ib. fig. $6, d 4$ ); the phase of dentition answers to that marked $\mathbf{F}$ in my article "Odontology," in the 'Encylopædia Britannica' (vol. xvi. p. 484) - the teeth, according to the symbols there adopted and explained, being $d 4, m 1, m 2, m 3$; consequently three of the molar series, viz. $p 3, d 3$, and $d 2$, had been shed.

1 "The Mus maritimus, or African Rat, has the singular property of separating at pleasure to a considerable distance the two front teeth of the lower jaw, which are not less than an inch and a quarter long. That elegant and extraordinary creature, the Kangaroo, which, from the incrcase that has lately taken place in his Majesty's Gardens at Kew, we may soon hope to see naturalized in our own country, is possessed of a similar faculty."-Mason Good, The Book of Nature, 8vo, 1826, vol. i. p. 285. This power of divaricating the lower incisors, or rather their sockets, through laxity of the ligamentous symphysial joint, has since been noticed by Waterhouse (Nat. Hist. of the Mammalia, 8vo, 1845, vol. i. p. 52), and by inyself and others. 
The four retained molars on the left side of the upper jaw present the two chief transverse ridges as in the lower jaw ; but they are broader in proportion to their length than in that jaw, and the curve of the ridges (as shown in $m 3$, fig. 3) where they are least worn is slightly concave backward, instead of forward as in the lower jaw (fig. $6:$ in this figure the grinding-surface of $d 4$, pushed out of line in the lower jaw, is added in front of the figure of the tooth so displaced).

'The first, perhaps chief, difference between Macropus rufus, Dsm., and M. major, Shaw (Pl. LXXX. fig. 17), is the smaller relative extent of the crown of the upper and outer incisor, $i 3$, which shows only one shallow vertical impression along the middle of the outer surface (Pl. LXVI. fig. 1). On this mainly would rest its clain to a subgeneric distinction, such as Gould has indicated by the term Osphranter; but the incisol-character is not repeated in other species of Osphranter (M. robustus, M. antilopinus, e. g.). 'The above dental distinction of M. rufus, however, is associated with several cranial ones. In the skull of a full-sized male, with teeth more worn than in that of a M. major compared with it, the temporal ridges have not met along the sagittal suture, but are separated by a tract lialf an inch in breadth, along the middle of which the sagittal suture persists. 'The anterior angles of the parietals give better indications of postorbital tubercles. These, however, are not more shown in M. rufus than in $M$. major. In a skull of the $M$. (Osphranter) robustus compared, which retains the premolar $(y 3)$ with four fully developed molars behind, the sagittal crest is better marked than in M. major and M. vufns, in which that premolar is shed.

The Great Red Kangaroo is one of the largest of the tribe; yet the skull indicates a less powerful animal. The paroccipitals are more slender. The zygomatic arches have less span and depth; the masseteric process is much shorter; the ridge above the fore part of its base is due to the malar more than to the maxillary. 'The mandible is more slender; the coronoid process is shorter and narrower from before backward; the depth of the ramus behind the molar series is notably less in M. rufus; yet the last molar, with the same fore-and-aft extent as in $M$. major, is broader.

The basioccipital ridge in $M$. rufus is sharper. 'The upper border of the foramen magnum is notched. The condyles are narrower, and the ectocondylar grooves deeper and wider. The superoccipital is less elevated and more truncate atop; the base of the occiput is narrower. 'The facial plate of the lacrymal is broader, and the lower and larger foramen is more external. The antorbital foramen is further from the orbit. The premolar part of the skull is shorter and deeper; the maxillary outswelling is less definite. The facial plate of the premaxillary is broader anteroposteriorly. The incisive foramina are longer and further from the third incisors. The postpalatal apertures are larger, especially the right one; but this may be a variety: the bony palate behind them shows more and larger irregular perforations, the hamular process of the pterygoid is less defined, than in Macropus major.

Such are the chief differences observable in the skulls of $M$. rufus and $\boldsymbol{M}$. major; 
and they are here noted as guides in the comparison of fossil cranial parts of Macropodidæ.

§ 3. Vertebro.-The atlas (Pl. LXVII. figs. 1-4) is remarkable for the low, broad. flat roof of the neural arch (ib. fig. $4, n, n$,), which extends almost transversely across from the upper ends of the articular cups (fig. $2, z, z$ ) for the condyles of the occiput. A small tubercle (ib. fig. 2,ns) at the fore margin of the arch (the origin of the "rectus capitis posticus minor") is the sole indication of a neural spine. The ossification of the neurapophyses $(n, n)$ below the condylar cups $(z, z)$ does not extend, as in Halmaturus thetis, so as to complete the arch. An interspace of a line and a half intervenes, in $M$. rufus as in M. major, between the obtuse ends of those elements, above which the centrum of the atlas projects (as an "odontoid process," ib. figs. 5, 6, c,a) with an articular lower surface, which rested on the ligament (indicated by dotted lines in fig. $2, h$ ) and rotated upon corresponding facets at the ends of the neurapophyses (ib. $n p, n p$ ). The diapophyses $(d, d)$ are continued outwards from the upper and hind part of the neurapophyses, and expand to their free end, which is produced forward and backward, most so and more pointedly forward. The neurapophysis is perforate above the fore part of the base of the diapophysis, at $f$, fig. 1, by the first spinal nerve; posteriorly it is deeply grooved above the postzygapophysis (fig. $3, z^{\prime}$ ) by the vertebral artery. The atlas in Macropus lias a less vertical diameter in proportion to its breadth, and a lower and antero-posteriorly broader arch above the diapophyses $\left(2^{\prime}, 2^{\prime}\right)$ than in Phascolomys (Pl. XCVIII. figs. 1-4).

The centrum of the axis (Pl. LXVII. fig. $5, c, x$ ) is subcarinate below and shows a pair of venous foramina (fig. $6, c, x$ ) near its posterior third. The pleurapophysis (ib. $p l$ ) is half an inch long, slender and obtuse; a vertebrarterial foramen (fig. 8, $v$ ) is completed by the confluence of the riblet (fig. $5, p l)$ with the par- $(p)$ and di- $(d)$ apophyses. The neural spine (ib. fig. $5, n . s$ ) is coextensive with the arch, and is produced anteriorly so as to overhang the base of the odontoid (ib. fig. $5, c, a$ ); its hind border is vertical; a pair of tubercles project at the sides of the angle formed between the hinder and the upper almost straight border. The prezygapophyses (figs. $5 \& 6, z$ ) cover the fore part of the centrum on each side of its confluence with that of the atlas $(c a)$ : the postzygapophyses (fig. 5, z) extend a little beyond the hind border of the neural spine.

The transverse processes of the other five cervical vertebræ are perforated. The spine of the third is compressed, laminate, truncate, coextensive with the neural arch; in the fourth (ib. fig. 7, ns) it contracts antero-posteriorly, loses height, but gains in breadth at its summit; this character of the spine increases in the fifth; the spine lengthens and becomes obtusely pointed in the sixth, is still longer and more merits the name of spine in the seventh cervical (ib. fig. 9, $c, n s$ ). The parapophysis projects as an angular plate in the fourth (ib. fig. $7, p$ ) and fifth, and more so with increased thuckening in the sixth (ib. fig. $8, p$ ); it is reduced to a mere tubercle in the seventh cervical, in which the pleurapophysis is longest and strongest. The neural arch is 
perforated vertically on one or both sides by epineural canals (fig. $7, e n, c n$ ) in the third to the seventh vertebra; each neurapophysis is also perforated lengthwise near the inner surface by " entoneural canals" (fig. $8, i n$ ), the orifices being within the neural irch; they are largest in the sixth and seventh cervicals, but coexist here with the vertebro-arterial canals (ib. figs. $8 \& 9, c, v$ ) in their usual position external to the arch. The anterior surface of the centrum is transversely concave (figs. $7,8, c$ ), the posterior one convex in all the cervicals following the axis.

The entoneural canals are repeated in the first dorsal, which shows a sudden increase in the length of the neural spine (Pl. LXVII. fig. 9, D 1,ns). 'The transverse concavity of the fore part of the centrum, as in the cervicals, is retained in the first dorsal rertebra. There is one large cup for the head of the first thoracic rib on each side of the anterior half of the centrum and contiguous part of the neurapophysis. This element (ib. $n$ ) articulates and has coalesced with the corresponding part of the centrum, leaving the hinder half free. 'The half-cup for the second rib impresses the angle between the hinder concave articular surface and the free lateral surface of the centrum. 'The strong diapophysis is impressed below its outer end by the large and deep cup (ib. $d$ ) for the tubercle of the first rib. 'The right side of the neural arch has an epineural canal. 'The second dorsal (ib. fig. 9, D 2) has a longer and more slender spine (ns). The neural arch shows the vertical perforation on the left side. The intraneural canals are reduced to two minute posterior perforations. The anterior articular surface of the centrum is convex. In the third dorsal (ib. fig. 9, D 3) the centrum lengthens and the sides are defined by an angle from the under surface. There are neither ento-nor epineural foramina. The anterior costal pit in this and succeeding dorsals seems to be a mere folding-back of the outer ends (fig. 9, D 3) of the anterior convex articular surface of the centrum. In like manner the half-surface for the head of the next rib seems to form the outer end of the posterior transverse surface of the centrum. The diapophyses (ib. d) increase in antero-posterior extent and become more depressed. After the third dorsal the neural spines gradually become shorter and gain in fore-and-aft brearlth to the eleventh dorsal (fig. 10, D 11, ns). . In this rertebra a short broad metapophysis $(m)$ rises above the base of the præzygapophysis, and clasps the end of the postzygapophysis of the tenth dorsal. The neural spine ( $n s)$ becomes vertical in the eleventh dorsal, indicating the centre of motion of this part of the rertebral column. In the twelfth dorsal (ib. D 12), the metapophysis ( $m$ ) suddenly gains in size; it is compressed, truncate, and exceeds the diapophysis $(d)$ in length. The præzygapophyses are represented by nearly vertical articular surfaces on the inner and fore part of the base of the metapophysis. An anapophysial ridge $(a)$ is developed from the upper and back part of the diapophysis $(d)$. In the thirteenth dorsal the anapophysis (ib. fig. 10, D 13, a) projects backwards from the hind part of the neurapophysis as a distinct process, five lines in length: it clamps externally the base of the metapophysis of the first lumbar. The convexity of the fore part and concavity of the hind part of the centrum is retained 
in the second to the last of the dorsal series; and in the large hinder vertebræ of the present subject the articular surface is still supported by an epiphysis, although the individual was fully mature, with completed and worn dentition (Pl. LXVI.). The intraneural and epineural canals are present on one or both sides in the hinder dorsals. In the last dorsal the diapophysial pits (Pl. LXVII. fig. 10, D 13, $d$ ) are the sole articulations retained for the last pair of ribs.

Of the thirteen costal pairs, the first rib (Pl. LXVIII. fig. 1) is the shortest and thickest, and has the longest neck $(c)$ in proportion to the body $(d)$. The head $(a)$ is divided into two surfaces meeting at an acute angle; the tuberosity $(b)$ is large and convex. From that prominence to the distal end the outer border describes almost a straight line; the inner border curves from the head to the distal expansion; the body is slightly twisted. The second rib (ib. fig. 2) is the most bent; its outer border near the tuberosity $(b)$ inclines backward and makes the inner side of that part of the body concave. The remaining pairs are long and slender, especially so and with a strong curve proximally in the middle pairs (ib. fig. 4), shorter and less curved in the hinder pairs (ib. fig. 5). The "head" and "tubercle" are developed in all. In the third rib (ib. fig. 3) there is a depression on the upper part of the neck $(c)$, not shown in the rest. The seven anterior pairs of ribs articulate by cartilaginous hæmapophyses with the sternum, which consists of six bones (sternebers, or hæmal spines). The manubrium (ib. fig. 6) is subcarinate on the outer surface, broadest where it gives attachment to the cartilages of the first pair of ribs, narrowing thence forward to a point, and developing a pair of rough convexities $(b, b)$ over the converging borders for the clavicles; it slightly expands at the narrower end (fig. 7 ), which has two half-surfaces $(b b)$ for the cartilages of the second pair of ribs, and a middle square surface $(a)$ for the second sterneber. A long and expanded "xiphoid cartilage" succeeds the sixth sterneber.

The first lumbar vertebra (PI. LXVII. fig. 11) is marked by the reduction of the diapophysis $(d)$ to a small rudiment. The metapophyses $(m)$ have usurped the place of the prozygapophyses in all the lumbars. The anapophyses $(a)$ become shorter, broader, and compressed; they diminish in the fourth and fifth (fig. 13,a), and disappear in the sixth lumbar. The diapophysis increases to the fifth, with a forward production in the second and third (fig. 12, d), together with a hinder production in the fourth and fifth (fig. 13, $\left.d, d^{\prime}\right)$, the whole plate being depressed; in the last lumbar it is shortened, but thickened.

The centrums increase from a length of 1 inch 3 lines in the first lumbar (ib. fig. 11) to that of 1 inch 9 lines in the fifth lumbar (fig. 13). The sixth again becomes shorter, but broader. The neural spine (ns) becomes narrower antero-posteriorly and longer in the third lumbar, then again shortens in the fifth and sixth. The vertical "epineural" perforations are present on both sides of the neural arch in all the lumbars. The intraneural canals communicate with the epineural ones, and in the last lumbar are their direct continuations downward and forward. One or two outlets of veins excavate the lower surface of the centrum in each lumbar vertebra. 
The sacrum (Pl. I.XVIII. figs. $8 \& 9)$ consists of two coalesced vertebra. 'The first, with a broad subconves articular surface (ib. fig. $8, c$ ) for the last lumbar vertebra, contracts to two thirds that breadth where it joins the second sacral; the body of this again slightly expands to form the surface for the first caudal. 'The pair of venous canals opening on the upper surface of the centrum, within the neural canal, unite into one, which perforates the under surface. 'I'he pair of vertical epineural canals (ib. fig. 9, en, en) open near the fore part of the neural arch as " intrancural canals" (ib. fig. 8, $i n$, in). 'The metapophyses (ib. ib. $m, m$ ) lave oblique shallow facets (ib. fig. $9, z, z$ ) at the lower part of their inner surfaces for junction with the postzygapophyses of the last lumbar vertebra. 'The pleurapophysial part (fig. $8, p l$ ) of the transverse process expands as it recedes from the centrum and neural arch to form the large reniform articular surface (fig. $9, p^{\prime}$ ) for the iliac bone, to which the second sacral contributes only the hinder angle (ib. $\left.p l^{\prime \prime}\right)$. 'I'his articular surface equals half the length of the entire sacrum. Above or behind the flat syndesmotic surface $\left(p l^{\prime}\right)$ is a smooth depression. 'The hiemal surface of both centrums is concave lengthwise, convex transversely. A wide circular intervertebral canal (fig. $9, j$ ) perforates the sacrum vertically on each side of the confluence of the centrums; the dorsal or neural opening is partially overhung by a rudiment of the postzygapophysis (ib. $z^{\prime}$ ) of the first sacral. 'The postzygapophyses $\left(z^{\prime \prime} z^{\prime \prime}\right)$ of the second sacral are normally developed, and diverge fiom the upper and hinder part of the neural arch; their articular surface is flat and looks downward and outward. 'The neural spines of the two sacrals are confluent as a thin compressed crest of bone (ib. fig. $9, n s$ ) one inch and a half in extent, and half an inch in height. 'The transverse process of the second sacral is continued from the hind angle of the articular pleurapophysis (ib. ib. $p l^{\prime \prime}$ ) as a thin depressed plate to the hind end of the base of the neurapophysis, beyond which the centrum (fig. 9, c) extends about three lines.

The chief vertebral characteristic of the Macropodida is the strength and length of the caudal region, and the number of vertebre composing it. In Macropus rufus there are twenty-two caudals, fourteen of which, after the second, have the hæmal arch. The metapophyses (Pl. LXVIII. fig. $10, m, m$ ) resume a considerable size in the first caudal, in the form of quadrate plates an inch in length by eight lines across the truncate ends; the lower half of the fore border is slightly produced as a zygapophysis ( $z$ ), the surface of which is continued back upon the base of the metapophysis. The neural spine is represented as a pair of low ridges ( $n s)$ diverging to the postzygapophyses $\left(z^{\prime}, z^{\prime}\right)$. 'These, in the first caudal, resemble those of the second sacral. The diapophyses are depressed plates, extending horizontally outward and backward, where they end in obtuse rather thickened points (ib. fig. 10, $d, d$ ). The second caudal chiefly differs from the first in the smaller postzygapophyses. 'The hæmal arch (fig. 11) is small, with a longish slender spine $(h s)$. The third and following caudals have no zygapophysial junctions, but coarticulate by their centrums only. The diapophyses are much diminished in the fourth caudal, and are reduced to tuberosities terminating the sharp lateral longitudinal 
ridges of the centrum in the fifth caudal. In this vertebra the prædiapophyses (ib. fig. $12, p d$ ), are developed; they are thence continued along a great part of the caudal region. The hæmal arch is strengthened; its spine shortened, but extended lengthwise (fig. 13, $h s$ ). A pair of hypapophysial ridges, beginning in the third caudal, form the sides of a canal at the fore part of the fifth and following caudals (fig. 12, hy).

The hæmapophyses articulate with the tubercular expansions of the hypapophyses by almost flat subcircular surfaces (figs. 14-16, h, $h$ ), which coalesce in the fifth and succeeding vertebræ, circumscribing the hæmal arch or canal exclusively of the centrum. These hæmal arches derelop ectapophyses (ib. figs. 15, 16,e,e), which are vertical homotypes of the diapophyses of the neural arch. The fore-and-aft extension of the hæmal spine is greatest in the seventh caudal (fig. 13, $h s, h s^{\prime}$ ). Beyond this the hæmal spines gradually decrease (ib. figs. $15 \& 16$ ), and the arch is finally reduced to simple lozenge-shaped plates overlying the joint between two caudals. I find the last of these at the antepenultimate of such caudal joints in Macropus rufus.

$\$$ 4. Bones of the Fore Limbs. - The scapula (Pl. LXX. fig. 1) is broad in proportion to its length; the supraspinal plate (i) extends so as to describe a bold convexity $\left(g^{\prime}\right)$ along the major part of the upper border or "costa;" and the infraspinal plate $(j)$ expands to the rounded postinferior angle of the bone $(h)$; both tracts are almost flat, and the supra- and infraspinal fossæ are comparatively shallow. The glenoid carity (ib. fig. $2, d$ ) has the usual ovate form, with the small end next the coracoid $(c)$. The outer border, or that next the acromion (e), is sharp and rather produced. The coracoid (fig. $1, c$ ) is represented by a mere tuberosity. The spine (ib. $f$ ) begins by an elevation $\left(f^{\prime}\right)$ of the dorsal surface near the upper rounded angle of the base $(b)$, and contracts as it rises to form a thin plate, slightly bent toward the infraspinal surface $(j)$; then, inclining to the supraspinal surface, it is continued at the neck of the scapula into an acromial process $(e)$. This slender acromion is associated with a diminutive clavicle.

There is a low tuberosity $(a)$ below the glenoid cavity, but no trace of that singular production of the fore part of the inferior costa which distinguishes the scapula of Diprotodon (Pl. XXX. a).

The clavicle (Pl. LXX. fig. 3) has a syndesmotic articular surface (fig. 4, a) at the sternal end, which is expanded accordingly; the shaft contracts, becomes compressed, then slightly broadens at the acromial end, where a narrow ridge on the under surface of the hind border gives attachment to the short ligaments tying it to that part of the scapula. The non-articular surface (fig. $4, b$ ) of the sternal end is excavated. The bone is bent, with the convexity forward.

The humerus (Pl. LXIX.) of the Rufous, as of other Kangaroos, is slightly bent, with the concavity ulnad; the tuberosities and ridges are strongly developed, and the entepicondyle $(i)$ is perforated.

The articular head is large and subhemispheric (ib. fig. 4); it is produced anconad, so as to overhang that side of the shaft. The thenal third of the proximal end of the 
bone is occupied by the two tuberosities and their intervening (bicipital) groove, $p$. The ectotuberosity (ib. $c$ ) is a long thick ridge; the entotuberosity (ib. $b$ ) is shorter and thicker; both rise above the level of the head (ib. fig. 2). 'The proximal third of the shaft is four-sided; the two broader sides (ib. fig. $2, l, r$ ) are on the anconal aspect, and meet at the round or obtuse ridge (ib. $h$ ) continued from below the overhanging head one third down the bone. The facet on the ulnar side (l) of the ridge is bounded at its lower half by the ridge $(e)$ for the insertion of the "pectoralis." The two facets on the thenal side of the proximal part of the shaft are of unequal breadth; the broader one (ib. fig. $1, g$ ) is flat, and is bounded below by the ridge $e$ and the stronger deltoid ridge (ib. $d$ ), which is continued below the middle of the shaft. The fourth facet (ib. $f$ ) is the narrowest; it is bounded on the outer (radial) side by the deltoid ridge, which is continued from the ectotuberosity downwards; a thicker ridge from the entotuberosity (ib.t) subsides upon a roughish surface (ib. fig. $3, v$ ) about one third down the bone. The shaft contracts below the deltoid region, assumes the cylindrical form for a short extent, and sends off the supinator ridge (ib. figs. $1 \& 2, k^{\prime}$ ).

A strong bony column (ib. figs. $1 \& 3, s$ ) rises more gradually, at a lower part of the shaft, from the fore and inner part of the distal expansion, then springs from the surface and extends freely downward and inward for about half an inch, and again unites with the bone, subsiding above the entepicondyle (ib. fig. 1, $i$ ). The column $(s)$ bridges over a canal, 5 lines in long diameter, for the passage of the median nerve and an artery. The supinator ridge (ib. $k, k^{\prime}$ ) commences abruptly at the outer side of the distal third of the shaft: its rough thin border is slightly bent forward, and thickens a little before it is lost in the ectepicondyle (k). The distal end (ib. fig. 5 ) is subcompressed antero-posteriorly; the transversely extended articular surface is divided into two parts by a broad groove, shallow anteriorly, deeper behind, and is slightly produced forward or "thenad," and more so at its outer or radial end. This articular surface presents a convexity broadest in front (fig. 1,n), contracting to a point or ridge behind (fig. $2, n$ ); it is the "radial" condyle, and articulates with the shallow circular cavity (Pl. LXX. fig. 7) at the proximal end of the radius. The inner or ulnar surface is slightly convex transversely at its fore part (Pl. LXIX. fig. 1,o), but is mostly concave transversely, and convex from before backward, forming a trochlear surface with two parallel borders, the inner of which is the most prominent (ib. fig. 2,o). The fore part of the articular surface (fig. $1, n, 0$ ) is undulated transversely, a feeble convexity intervening between those of the ulnar $(0)$ and radial $(n)$ divisions. There is no coronoid depression, and only a shallow olecranal one (ib. fig. $2, m$ ).

In the Kangaroo, as in all Mammals charged with the manipulation of a nursingpouch, the elbow-joint is fashioned to facilitate the movements of pronation and supination of the fore paw ${ }^{1}$, as well as those of flexion and extension of the forearm. The

1 These movements are least free in Choropus, in which the functional digits of the fore paw are reduced to two (II. \& nI.). 
proximal articular surface of the radius (Pl. LXX. fig. 7) is circular, very shallow, at right angles to the shaft or length of the bone. The articular smoothness continued upon the periphery of the head is a little broader (ib. fig. $5, b$ ) where it rotates upon the lesser sigmoid cavity (ib. fig. $8, b$ ) of the ulna, but is narrow where it plays upon the "orbicular ligament." The so-called neck (ib. fig. 5,c) is long, and equals the shaft in thickness. The tuberosity (ib. $d$ ) rises an inch below the head and is obliquely elongate; a ridge divides the raised rough surface next the ulna, for the insertion of the biceps tendon, from the smoother tract occupied by the "bursa," intervening between the tendon and the bone. The shaft is slender in proportion to its length, subtriedral at the proximal third, subquadrate at the distal one (ib. fig. 6). The interosseous line is scarcely developed into a border: it is traceable from behind the tuberosity, along the ulnar side of the shaft, to the distal end, which expands to a little beyond the breadth of the upper part of the shaft at the tuberosity (fig. $5, d$ ). The distal articulation (fig. $6, e$ ) forms the broadest part of the bone.

The ulna (ib.figs. $8 \& 9$ ) presents atits proximal end the two continuous articular surfaces known in anthropotomy as the "greater" $(a)$ and "lesser" $(b)$ sigmoid cavities. The greater is oblong and concave vertically, transversely convex, slightly emarginate on each side. The lesser cavity is semioval, bent down at right angles with the greater; it is moderately concave; it receives the head of the radius, as the greater cavity does the trochlear part of the distal joint of the humerus. The angle between the articular surfaces, $a$ and $b$, represents the "coronoid" process $(c)$. Below this is an oblique ridge and roughness $\left(d^{\prime}\right)$ for the insertion of the "brachialis anticus." 'The olecranon $(e)$ extends about an inch above the joint; it is subcompressed and tuberous terminally. The shaft is more compressed and develops a sharp "interosseous ridge" (ib. fig. 9,f) from its middle third. The length of the ulna is 1 foot 3 lines; its greatest breadth is 1 inch 2 lines; its distal end, like that of the radius, was in the epiphysial state (ib. fig. 10, 55); it terminates by a "styloid process" which works in a pit of the "os cuneiforme" (ib. $c$ ).

The fore paw is pentadactyle, with divergent and freely movable unguiculate digits.

The carpus (ib. fig. 10) consists of a scapho-lunar $(s l)$, cuneiform $(c)$, and pisiform $(p)$ in the proximal row, and of the usual four bones in the distal row, of which the unciform $(u)$ is the largest, is interposed between the lunar part of the scaphoid and the cuneiform, and supports part of the middle as well as the fourth and fifth digits. The scapho-lunar (ib. fig. $10, s l$ ) presents to the radius (ib. 54 ) a convexity transversely elongate, broadest ulnad, the breadth there being one third the length; narrowing radiad almost to a point $(s)$ : the curve of the convexity is bold in both directions, but greatest across or in the short diameter of the surface. The major part plainly answers to the convex radial articular surface of the lunar bone in Man and the Orang ${ }^{1}$. A non-articular surface, with irregular elevations and depressions on the anconal (dorsal) surface of the bone, of a subtriangular form, exceeding in brealth that

'See 'Anat. of Tertebrates,' rol. ii. p. 541, fig. 361, b. 
of the radial convexity, intervenes between this and the two distal concave articular surfaces for the trapezoides (ib. $z$ ) and magnum (ib. $m$ ) respectively; whence the nonarticular tract is continued upon the radial extension of the bone, which terminates in the convexity for the trapezium (ib. $t$ ), such articular surface being very small and forming the apex of the scaphoid. 'This part of the scapho-lunar is similar to the scaphoid in the Orang ${ }^{1}$. Between the radial convexity and the magnal concavity there is a narrow smooth tract adapted to the hinder and upper border of the unciform $(u)$. Behind and below the uluar end of the radial convexity is a slightly convex surface for the cuneiform: in the front or anconal view of the carpus this articulation is not seen.

The cuneiform (ib. ib. $c$ ) is a comparatively small bone, with a concavity on its proximal surface for the "styloid process" of the ulna (ib. 55), and a smaller and less deep articular surface for the "head" of the pisiform (ib. $p$ ). 'The distal surface of the cuneiform presents a large undulate articular surface for the unciform; and its backward extension just reaches the scapho-lunar. The pisiform (ib. ib. $p$ ) is clavate, articulated by a sort of condyle to the outer proximal cup of the cuneiform; it then loses thickness and gains breadth, and expands to a broad subtruncate end. The bone projects backward and is twisted out of place to show its form in figure 10. The trapezium (ib. $t$ ) is small, just touches the tips of the scapho-lunar, and offers a small surface for part of the base of the broad metacarpal of the pollex (I.). 'The trapezoid (ib. $z$ ) is still smaller, is wedged between the scaphoid $(s)$ and magnum $(m)$, and offers a surface to the outcr (radial) part of the proximal articular surface of the second metacarpal (II.) 'The magnum (ib. $m$ ) is the next carpal of the distal row in point of size: it is wedged between the scapho-lunar and unciform, and articulates with the ulnar half of the proximal surface of the second metacarpal (II.), and with a larger portion of that of the third metacarpal (III.). The unciform, equalling in size the scapho-lunar, here occupies the position in the wrist held by the unciform and intermedium ${ }^{2}$ in the Orang. It accordingly articulates by its proximal surface with the scapho-lunar and cunciform, and by its distal surface with the magnum and the fourth and fifth metacarpals. But in the Kangaroo it also offers a surface to the ulnar angle of the base of the third inetacarpal.

$\$ 5$. Bones of the Hind Limbs. - The pelvis in Kangaroos is remarkable for its size, especially its lengtl, and for the strength of the long prismatic columnar ilia. 'The length from the "crista ilii" (Pl. LXXI. fig. 1,c) to the distal end of the ischio-pubic symphysis (ib. $h^{\prime}$ ), in Macropus rufus, is 1 foot; from the crista $(c)$ to the fore part of the acctabulum $\left(t^{\prime}\right)$ is 5 inches 4 lines: this gives the length of the ectiliac surface (ib. 62) $)^{3}$, which has an oblique hæmal and outer aspect, and is concave both lengthwise and transversely, but it does not exceed an inch in breadth. The neural surface

'Sce 'Anat. of Vertebrates,' rol. ii. p. 541, fig. 361, $a$.

? $g$ \& $h$ in fig. 361, op cit.

"Answering to the "internal iliac fossa" of anthropotomy. 
(Pl. LXXII. fig. 1, 6.' $)^{1}$, also concave, both lengthwise and across, especially in the latter direction, has its breadth increased by the hinder extension, $u$, of the sacro-iliac syndesmosis to 1 inch 5 lines. The inner ("median" or "sacral") surface (Pl. LXXII. fig. $3,62 x)$ is slightly convex lengthwise, almost flat across; and at 3 inches from the tuberous "crista" $(c)$ begins the reniform surface $\left(p_{1}, p^{2}\right)$ adapted to the sacrum. The "crista ilii" $(c)$ is reduced to a subtriangular, roughish, convex tuberosity (Pl. LXXI. fig. 2), 1 inch 3 lines in length, by 9 lines in greatest breadth. The base forms the homologue of the "antero-superior spine" of the ilium $(a)$; the apex $(b)$ answers to the "postero-superior spine" of anthropotomy. The ridge between the free facets (62 and $\left.62^{\prime}\right)$ terminates in a rough raised oval surface (Pl. LXXII. fig. $2, d$ ) called "precotylar tuberosity," representing the "antero-inferior spine" of anthropotomy. At the beginning of the ilio-pubic ridge is a strong rough subquadrate "ilio-pubic" process (ib. $e$, to which the pubis contributes (Pl. LXXI. fig. 3, s). The hinder and neural production (Pl. LXXII. fig. 2, $u$ ) of the ilio-sacral articulation answers to the "posteroinferior spine," and marks the fore part of the feeble concavity $(m)$ representing, or indicative of, the "great sacro-ischiadic notch."

The ischium, like the ilium, is a long, straight, triedral column; its inner or median side (Pls. LXXI. \& LXXII. fig. 1, 63') is broadest; the outer and upper side (Pl. LXXII. fig. 1, 63*) has less breadth; the outer and under side (ib. 63) is the narrowest: this is continued upward, and sinks, near the acetabulum, to form the deep cotylar notch $(y)$. Here the bone seems to bifurcate, the anterior pillar swelling to join the pubis at the pubic cotylar tuberosity (6t'), the hinder one expanding to form the ischio-cotylar tuberosity $\left(63^{*}\right)$. A low and long slightly roughened convexity of the hind or neural border of the ischium $(l)$ represents its "spine." The thick tuberosity $\left(h, h^{\prime}\right)$ is of great extent, and runs almost straight and at right angles with the body of the ischium from the hind prominence $(h)$ to that which, bending forward, at $h$, terminates the long ischio-pubic symphysis $\left(k 61^{* *} 63^{* *}\right)$. The hinder end of this symphysis is formed by a triangular epiphysis, which coalesces ultimately with both ischia. Each ischium rapidly expands as it advances forward, or "hæmad," to form the hinder half of the ischio-pubic symphysis and of the foramen ovale $(o)$.

The pubis (64) contributes one half to the ilio-pubic process $(e)$ by a projectiou answering to the pectineal process of the pubis in Monotremes and many Reptiles; and the lower and outer part of that expanded end of the bone forms the pubo-cotylar tuberosity $\left(64^{*}\right)$ and a small contiguous part of the acetabulum. Contracting to a narrow plate of bone, the pubis inclines downward and forward, slightly expanding, to join its fellow at the fore half $\left(64^{* *}\right)$ of the ischio-pubic symphysis, where it extends backward and contributes to the same proportion, and to the anterior part of the circumference, of the "foramen ovale" $(0)$.

The acetabulum (Pl. LXXI. $t, t$ '; Pl. LXXII. fig. $2, x$ ) has a subtriangular brim, the angles rounded off and swollen to form the ilio-cotylar $\left(t^{\prime}\right)$, the pubo-cotylar ( $\left.64^{*}\right)$, and

1 Answering to the "dorsum ilii" of anthropotomy. 
the ischio-cotylar ( $\left.63^{*}\right)$ tuberosities. 'The margin subsides between the two last-named prominences, and becomes thinner between the two first. The cotylar pit $(x)$ and notch (y) are deep.

In the development of the Macropodal pelvis (Pl. LXXI. fig. 3) three epiphyses appear. One of these (ib. $6 t^{\prime}$ ) belongs to the acetabular end of the pubis, and becomes the pubo-cotylar tuberosity (ib. fig. 1, 64*); a second belongs to the symphysial ends of the pubis, and forms the hæmal projection at the fore part of the ischio-pubic symphysis; a third epiphysis (ib. fig. $3, h^{\prime}$ ) belongs to the symphysial ends of the ischia, and forms the hamal prominence at that end of the symphysis.

'The epiphysis $(k)$ gives attachment to the entobasilar articular end (ib. fig. $1, r, r$ ) of its marsupial bone from this part and the ectobasilar process $(s)$; the bone decreases in breadth to the free $(t)$ extremity. An oblique low ridge runs along the outer surface of the pelvic end of the bone; the rest is a thin plate with a sharp edge at the outer or lateral border.

'The characteristics of the femur in the Kangaroos are:-1, the height of the great trochanter, which seems due to a superimposed additional and ankylosed tuberosity (Pl. LXXIII. figs. 1, 2, 3, $f$ ), divided by an antero-internal constriction from the part below; 2 , the length and strength of the small trochanter (ib. $n$ ); 3 , a rough, welldefined tract $(p)$ from the middle of the hind surface (fig. 2) of the shaft, outstanding, in large species, like a "third trochanter;" 4, the rough depression (ib. figs. 2, 3,y) above the outer condyle (ib. $v$ ); 5 , the great transverse extent of the articular surface of that condyle by the production of its outer part, changing there the convexity into a concavity transversely (fig. $2, v$ ). With these may be noted the length and depth of the post-trochanterian fossa (fig. $2, l$ ).

In $M$. rufus there is a small tuberosity (fig. 3. g) a few lines below the pointed termination of the ectotrochanterian ridge (ib. $h$ ). The medullarterial hole is at the inner side of the hind tuberosity $(p)$ : the canal leads downward and inward. A "linea aspera" is continued from the small trochanter $(e)$ two thirds of the way down the inner side of the shaft. The convex fore part of the outer condyle (fig. 1,s) is prominent; the rotular $(r)$ and condylar $(s, t)$ surfaces are continuous.

In $M$. rufus, as in $M$. major, the tibia is nearly twice the length of the femur. Its head (Pl. LXXIV. fig. 4) is peculiax for the excess of antero-posterior over transverse diameter; the outer facet of the triedral shaft (ib. fig. 1, k) is more remarkable for its deep excavation, and the sharpness and production of the ridges dividing it from the inner and hinder facets: but these characters are limited to the proximal half of the bone; at the distal half the surfaces are more or less flattened and the dividing angles rounded; the anterior one, a continuation of the proximal procnemial ridge $(h)$, is least so; and the hind facet of the distal half (ib. fig. 6) is feebly concave across.

In fig. $4, a$ is the outer articular surface, $b$ is the inner articular surface, and $c$ is the "spine." This rises 3 lines in advance of the intercondylar notch $(y)$, to a height of 5 lines; the fore and-aft extent of its base is 11 lines. The fore part of the head of 
the tibia gradually contracts to a tuberosity $(g)$, the non-articular surface behind which is less rough, is moderately convex and undulated by a transverse rising and shallow groove (ib. $d$ ): there is a slight depression in front of each articular surface.

The procnemial ridge (ib. fig. $1, h$ ) extends from the tuberosity $(g)$ downward, retaining a sharpish margin, slightly bent outward, for an extent of 3 inches, then becomes thicker, smoothly rounded, and subsides; it seems to be resumed as a low angle between the outer and inner surfaces of the lower half of the shaft (ib. fig. 5, $h$ ). The ectocnemial ridge (ib. figs. 2 and $3, i$ ) is sharper and less produced superiorly than the preceding $(h)$; but it becomes rather more prominent as it descends, and begins to thicken and subside near the lower half of the shaft. At 5 inches distance from it its origin it is grooved behind by the tibial medullary artery, which enters the bone an inch lower down: the canal runs distad. The proximal third of the inner surface (ib. fig. 2, $r$ ) of the shaft is smooth and flat, below which it gradually becomes convex, and is again rather flattened at the distal third. The hind facet (ib. fig. $3, l$ ) is the narrowest: it is slightly concave across at its outer half, and convex at its inner half: the concavity deepens as the surface is extended by the outgrowth of the ectocnemial ridge, where the medullary artery enters the bone. The hind part of the articular surface $(a)$ is produced to give depth to the transrerse fibular groove (ib. figs. $1 \& 3, e$ ), which becomes continuous by the hind facet (fig. $3, f$ ) with that surface.

The distal end of the tibia (ib. fig. $\bar{\tau}$ ) is more expanded transversely than from before backward. The inner malleolus $(m)$ has greater fore-and-aft breadth than vertical extent: its outer surface is bituberculate; the opposite or articular surface (ib. fig. $6, n$ ) is convex transversely, but extended vertically to join the horizontal terminal articular surface; this is feebly trochlear and bounded externally by the outer malleolus, due to the distal epiphysis of the fibula.

The distal articular surface of the tibia, also, is supported on an epiphysis; and this sends upward at its fore part a process (ib. fig. $\tilde{j}, p$ ) wedged, as in the Bird, into a groove of the corresponding part of the diaphysis: the epiphysis is later in its confluence than in the Bird. The inner articular part of the distal trochlea in the Bird, shows its homology with that of the inner malleolus in the Marsupial by its greater production. The length of the tibia in the male Wallaron affording the bone here described is 1 foot 8 inches; that of the fibula is lalf an inch shorter.

The fibula (Pl. LXXIV. figs. 8-11) has its proximal end expanded antero-posteriorly, with a corresponding elongate angular articular tract (ib. fig. 10, a) fitting the angular groove (ib. fig. 1,e) of the outer tibial condyle; a tuberous production (ib. figs. 8, 10, $b$ ) of the hinder part, which does not rise above the level of the tibial condyle, and to which is ligamentously attached the "fabella" in the tendon of the "gastrocnemius externus," plays upon the hinder facet of continuity (ib. fig. $3, f$ ) between the femoral and fibular articular surfaces of the tibial condyle $(\alpha)$. The fibula rapidly contracts below its proximal and articular epiphysial end, joins the ectocnemial ridge (ib. figs. 2 $\& 3, i$ ) about one fourth of the way down the shaft, becomes concare as that ridge 
subsides into the rounded angle between the adjoining tibial facets, and is closely applied thereto to near the distal end of the tibia. In this course the fibula is reduced to a mere chammelled plate', as shown in the transverse section (11 a). The distal end of the fibula again slightly expands, and contributes by its epiphysis an outer malleolar buttress (ib. figs. 9, 11, b) to the mammalian ossifications in the tarsal segment of the foot.

'The ossified tarsal segment is singularly modified in Macropodidx (Pl. IXXV.), in relation to the concentration of the powers of the hind feet, as saltatory locomotive instruments, upon the outermost pair of toes, and mainly upon one of these, answering to the fourth in the pentadactyle foot.

The narrowness of the hind foot as compared with the fore foot, which leads to the displacement of the tarsal homotype of the carpal scaphoid to a more distal position in its segment, is extreme in the Kangaroos-and being associated with atrophy of the inner or tibial side of the metatarsus, renders still more obscure the true character of the "naviculare" (P'l. I.XXV. fig. 1, N). 'The homotype of the carpal "lunare" almost monopolizes the distal articulation of the leg-bones. In the tarsus it is the "astragalus" (ib. figs. 3, 4, 5), and, in the Kangaroos, is subdepressed, triangular, with the base turned forward (figs. $3 \& 4$ ): viewed from the inner or tibial side (ib. fig. 5) it is arched, with the convexity towards the leg. 'The upper surface (fig. 3) is chiefly formed by the trochlear articulation (1) for the tibia, convex from behind forward, concave transversely, passing into a convex outer or fibular border (2), but more definitely bounded by a ridge (3) on the inner side, over which the articular surface passes, at almost a right angle, to form the flattened one (ib. $d$, \& fig. $5, d$ A) adapted to the inner malleolus. Beyond this surface a depressed non-articular part of tlic bone (fig. 3,e) extends a short way inward and forward, where it is terminated by the narrow anterior oblong convexity (fig. $5, f$ ) for the naviculare. The inmer non-articular part of the astragalus terminates in a tuberosity (ib. g). 'The posterior non-articular part, forming the apex of the triangle (ib. $h$ ), applies itself to the hind part of the inner articular expansion of the calcancum, to which it is ligamentously attached. On the under surface of the astragalus (fig. 4 ) is the antero-posteriorly concare surface (i), articulating with the convex one on the outer half of the upper expanded articular part of the calcancum (fig. $6, i$ ). Internal to this, at the middle of the under surface of the astragalus, is the oblong flattened articulation (fig. $4, k$ ) for the flattened surface on the inner division of the upper articular part of the calcaneum (fig. $6, k$ ). Anterior and internal to this is a smaller facet (fig. $4, l$ ), continuous with the navicular one $(f)$, but articulating with the inner side of the anterior calcaneal surface for the cuboid. No part of the surface $(f, l)$ is extended to the tibio-malleolar articulation as in Phascolomys. The astragalar characters are well marked, and could not fail to be recognized in a fossil bone of the Macropodal family.

The calcaneum of a Kangaroo is equally well characterized (Pl. LXXV. figs. 1 \& 2, $c, b$, figs. $6 \& 7$ ). The fulcral portion $(a b, a c)$ is long and triedral, the narrowest, 
roughest, flattened side, or "sole," being below (fig. $7 \mathrm{c}$ ); the two broader, smoother concave sides converge to the superior or anterior rounded angle (fig. $6, b$ ): the free end is due to a tuberous epiphysis $(a)$ with an upper smooth bursal surface on the terminal facet. The upper angle (fig. $6, b$ ) expands to the anterior articular or tarsal portion of the bone, which is more abruptly enlarged, and especially to the outer side: this supports the subconvex articular surface $(d)$ for the external malleolus formed by the distal epiphysis of the fibula (Pl. LXXIV. fig. 8,b). The upper surface of the expansion supports the convex surface $(i)$ for the articulation $(i)$ of the astragalus (fig. 4). The upper and inner rising is divided into a small anterior smooth articular surface (fig. 6, $k$ ) for that marked $k$ in the astragalus (fig. 4), and a posterior, chiefly roughened, surface $(h)$ for syndesmosis with the apical part of the astragalus (fig. $4, h$ ). In advance of the astragalar expansion the calcaneum, somewhat contracted, extends, and terminates in the large subtriangular vertical surface for the " $\mathrm{cu}$. boildes." The outer half of this surface (fig. $8, e$ ) is more produced than the inner one (ib. $f$ ), and is continued into the lower or apical part (ib. $g$ ) of the cuboidal facet. The astragalar expansion (figs. $6,7, d, n, e$ ) overhangs the lateral concave surface on both sides of the bone, but most so on the outer one (fig. 2), which develops two tuberosities (fig. $7, n, n^{\prime}$ ).

The inner production has more vertical extent, and is impressed by a longitudinal channel : it supports the surface (fig. $6, l$ ) for that so marked on the navicular part of the astragalus (fig. 4). The ridges, so formed (figs. 1 \& 2 , $\left.m, n^{\prime}\right)$, afford fulcral resistance to the strong tendons gliding along the concave channels (ib. $b, b^{\prime}$ ) from the leg to the foot beneath them. A well-marked groove (fig. 7,o) divides the fore part of the "sole" of the calcaneum from the apical part of the cuboidal articular facet $(e, f)$.

The navicular (fig. $1, \mathrm{~N}$ ) is a small, oblong, subquadrate, compressed bone, presenting a narrow concavity to the facet $(f)$ of the astragalus (figs. 4,5 ), and an oblong undulate surface divided between the proximal ones of the ento- $(c i)$ and the ecto- $(c e)$ cuneiform bones.

The entocuneiform (cut, Fig. 1, $c i$ ) is an oblong flattened bone notched at its hind margin. It is pushed

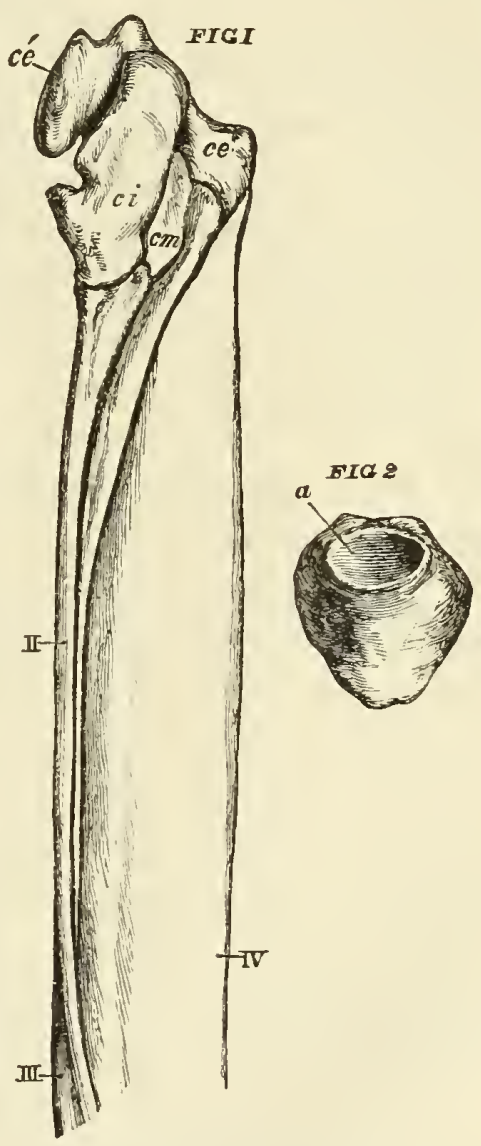

Parts of tarsus and metatarsus, Macropus major. inward and backward, articulates by its upper (proximal) end or surface with the nariculare, by the inner surface of its proximal part with the ectocuneiform $(c e)$ which it overlaps, by its anterior border and contiguous inner surface of its distal half with the mesocuneiform $(\mathrm{cm})$, and by its distal end with the major part of the proximal articular end of the metatarsal (II). 
The mesocuneiform $(\mathrm{cm})$ is also a compressed ossicle, of smaller size, wedged between the entocuneiform, the proximal ends of the two small metatarsals (II, III) and the ectocuneiform $(c e)$. 'The back part of the proximal ends of III for an extent of five lines is ligamentously and closely commected with the mesocuneiform; but the proximal articular surface of $n$ joins the fore part of the distal surface of the ectocuneiform (ce). This $(c e)$ extends backward beyond the overlapping entocuneiform, and swells out into an expanded quasi-calcaneal process $\left(c e^{\prime}\right)$, which is closely united to a similar process of the cuboid. A large plantar sesamoid (cut, Fig. 2), has a smooth surface (ib. a) adapted to the surface $h$ (fig. 1, Pl. CXX.), below the grooved process $(g)$, upon the back of the fourth metatarsal. The above description is from a dissection of a fullgrown inale $M$. major.

The cuboïdes (Pl. LXXV. figs. $1, s b, \& 2, \mathrm{c} b$, and figs. 10, 11, 12) equals the astragalus in the longest diameter, and exceeds it in thickness and massiveness. It is moderately smooth and flat from behind forward, on its upper (rotular) part, but is convex across. At the hind proximal part the surface (fig. 11, $f$ ), concave in both directions but chiefly vertically, is more produced proximally than is the less-concave surface (ib. $e$ ); these positions correspond to the different levels of the distal calcaneal surfaces (ib. figs. $6,7,8, e, f$ ) to which they are adapted. 'The surface $e$ (fig. 11) is produced downward and inward (at $g$ ) coextensively with the surface $g$ of the calcaneum (fig. 8). On the inner tibial side of the bone a narrow strip (fig. $11, h$ ) is extended from the surface $f$ to articulate with the naviculare. The lower (plantar) part of the cuboid (fig. 12) is developed into three prominences: the inner one $(i)$, in the form of an oval tuberosity, articulates with the neck of the similar tuberosity $(t)$ of the ectocuneiform (fig. 9); the middle tuberosity (fig. $12, k$ ) is coextensive with the length of the cuboid, but is decply grooved at the outer and under part of its origin; the outer prominence $(l)$ supports the flat articular surface for the fifth metatarsal. The main part of the anterior surface of the cuboid is articulated, but immovably, with the base of the great (fourth) metatarsal ( $N$ ). The outer side of the cuboid (fig. 2, $c b$ ) extends downward and backward beyond the metatarsal $\mathrm{I}$, so far as was required to offer an articular surface (fig. $12, l$ ) to the proximal end of the fifth metatarsal (fig. 14).

Of the metatarsal series of foot-bones the first (or that of the hallux, 1) is suppressed; the second (fig. 1, II) and third (ib. III) are filamentary, but almost as long as the fourth (ri), which constitutes the chief part of this segment of the foot.

The fourth metatarsal (ib. figs. $1 \& 2, \mathrm{w}$ ) has the upper or anterior surface (PI. CXVI. fig. 4) convex across, and most so at the proximal half of the shaft, rising to a low ridge near the joint with the tarsus. The lower or under surface is slightly concave transversely at the distal two thirds (ib. fig. 5), prominent and rugged at the proximal third, where toward the inner or tibial side it is developed into a low, thick, rough ridge about an inch in length (ib. fig. 6,o). It presents a shallow channel with some rough surfaces for the attachment of the proximal third of the fifth metatarsal on the outer side. Above this attachment the fourth metatarsal sends backward a process (ib. fig. 6,e) 
presenting an articular surface $(h)$ for the tarsal sesamoid, above which is a grooved impress of a peroneal tendon. The distal joint (Pl. LXXV. fig. 13) at its upper half is simply convex vertically, almost flat across; but at the lower half there is a median rising, or ridge $(\alpha)$, causing two lateral surfaces concave across, and affording a firm trochlear joint to the proximal phalanx of the fourth toe (ib. figs. 16, 17).

The fifth metatarsal (ib. fig. 2, v, fig. 14) is compressed to near its distal end, having a sigmoid flexure vertically. The proximal articulation (ib. fig. 14) is an oblique flat triangular surface for that marked $l$ on the cuboildes (ib. fig. 12). The distal articulation (ib. fig. 15) is simply convex, and chiefly so vertically.

The digits correspond in size with their supporting metatarsals. The two diminutive inner ones terminate each in an unguiculate phalanx, and are enveloped as far as this joint in a common sheath of tegument, from which the two small claws protrude; they are applied to dressing the hairy integument of the Kangaroo.

Of the first phalanx of the fourth toe an upper (ib. fig. 16), an under (fig. 17), and a proximal-end view (fig. 18) are given. An upper view of the second phalanx is given at fig. 19. The last phalanx of the chief toe (iv) is elongate and conforms to the long, sharp-pointed, straight, three-sided, bayonet-like claw, which forms the chief weapon of the Kangaroo. 'The broad underside of this claw rests, like a hoof, on the ground; the smaller sheath of the ungual phalanx of the fifth toe has a similar quasi-ungulate character.

\section{DESCRIPTION OF THE PLATES.}

\section{PLA'TE LXVI.}

Figs. 1-5. Skull of Macropus rufus. Fig. 6. Lower molars, left side, grinding-surface.

\section{PIATE LXVII.}

Figs. 1-4. Atlas vertebra. Figs. 5, 6. Axis vertebra.

Fig. 7. Fourth cervical, upper view.

Fig. 8. Sixth cervical, front view.

Fig. 9. Seventh cervical and first three dorsal vertebræ. Fig. 10. Last three dorsal vertebræ (D 11, 12, 13).

Fig. 11. First lumbar vertebra. Fig. 12. Third lumbar vertebra. Fig. 13. Fifth lumbar vertebra.

\section{PLATE LXVIII.}

Fig. 1. First rib. Fig. 2. Second rib. Fig. 3. Third rib. Fig. 4. Fifth rib. Fig. 5. Tenth rib.

Fig. 6. Manubrium sterni, outer or under surface. Fig. 7. Idem, distal end.

Fig. 8. First sacral vertebra, front articular view.

Fig. 9. First and second sacral vertebræ, neural surface.

Fig. 10. Second caudal vertebra. Fig. 11. Id., hæmal arch. 
Fig. 12. Fiftl caudal vertebra, hæmal surface. Fig. 13. Id., hæmal arch, side view.

Fig. 14. Hæmal arch of sixth caudal vertebra. Fig. 15. Id. of tenth caudal vertebra.

Fig. 16. Id. of thirteenth caudal vertebra.

\section{PLATE LAXIX.}

Figs. 1-j. Right humerus.

\section{PIATE LXX.}

Fig. 1. Left scapula, outer surface. Fig. 2. Idem, glenoid cavity.

Fig. 3. Left clavicle. Fig. 4. Id., sternal articular end.

Figs. $5-7$. Right radius.

Figs. 8, 9. Right ulna.

Fig. 10. Right carpus, anconal surface.

\section{PIA'TE LXXI.}

Fig. 1. Pelvis, under or lımal view.

Fig. 2. Crista ilii.

Fig. 3. Pelvis of young Kangaroo, side view.

\section{PLATE LXXII.}

Fig. 1. Left os innominatum and marsupial bone, neural side. Fig. 2. Id., outer-side view.

Fig. 3. Left ilium, inner-side view.

\section{PLATE LXXIII.}

Figs. 1-5. Right femur.

Figs. 1-7. Left tibia.

\section{PIATE LAXXIV.}

Figs. 8-11. Left fibula.

\section{PIA'TE IXXXV.}

Fig. 1. Right tarsus and metatarsus, tibial-side view. Fig. 2. Id., outer- or fibular-side view.

Figs. 3-5. Astragalus.

Figs. 6-8. Calcaneum.

Fig. 9. Ectocuneiform, inner- or tibial-side view.

Figs. 10-12. Cuboid.

Fig. 13. Distal articular end of fourth metatarsal (figs. $1 \& 2$, IV).

Fig. 14. Fifth metatarsal, upper view. Fig. 15. Id., distal end.

Fig. 16. First phalanx of fourth toe, upper surface. Fig. 17. Id., under surface.

Fig. 18. First phalanx of fourth toe, proximal end.

Fig. 19. Second plalanx of fourth toe, upper surface.

All the figures are of the natural size. 


\section{Family MACROPODIDÆ.}

\section{Extinct Genera and Species.}

$\S 1$. Introduction.-As the extinct Marsupials which I now proceed to define (their restoration awaiting further materials) have chiefly been made known to me by their fossil jaws and teeth, some remarks on the latter organs will be briefly premised.

The dentition of the Kangaroos (bilophodont Macropodida* ${ }^{*}$ ) is summarily described and figured in my 'Odontography' $\uparrow$ : in later works \$ its phases of development and mutation are exemplified in detail in Macropus major $\S$. The last phase delineated (Anat. of Vert. vol. iii. fig. 296, F) is that which is shown in the subject of figs. 15 \& 16, Plate LXXX., in the mandible of Macropus major, in which the anterior of the four retained molars $\left(d_{4}\right)$ is "nodding to its fall." I have seen a specimen of an older Kangaroo of this species in which the series of grinders was reduced to two, viz. $m_{2}$ and $m_{3}$. Fig. 15, Plate LXXX., is also introduced to exemplify the largest size of mandible to be derived from any known existing kind of Kangaroo. The other figures in that Plate show modifications in the size, form, structure, and order of succession and shedding of teeth requisite for the description and comprehension of characters of fossil jaws and teeth of the present family of Marsupials.

Thus, in Macropus (Osphranter) robustus, Gd. (Plate LXXX. figs. 13 \& 14), the premolar $\left(p_{3}\right)$, which is not larger than that in Macropus major $\|$, is later retained; and the following molar $\left(d_{4}\right)$ in my subject had undergone a much greater degree of wear than in Macropus major before $p_{3}$ had risen into place. This is plainly shown by the lower level of the much-worn $d_{4}$ in fig. 13. It would also seem to have been originally a relatively smaller tooth than its homologue in the "greater Kangaroo." The last molar is in place, and shows the same slight degree of masticatory wear in both species; but with this the molar series is reduced to four teeth in one, and shows five teeth, or four and a half, in the other.

In Macropus (Halmaturus) ualabatus, Less. \& Gd. (ib. fig. 11), the premolar ( $\left.p^{3}\right)$,

* This is a section distinct from the Kangaroo-rats, Bettongs, \&e., with quadritubcrculate molars, included in the subfamily Hypsiprymnidce.

+ 4to, 1840-45, pp. 389-393, pls. 100, 101, 102.

$\ddagger$ Art. TeEtr, in 'Cyclopædia of Anatomy,' vol. iv.; also 'Anatomy of Vertebrates,' 8vo, vol. iii. p. 380, fig. 296.

§ I have always referred to this large and first-discovered species of Kangaroo under Sнaw's later name (General Zoology, vol. i. pp. 505, 800). Mr. Waterhouse alludes to it sometimes (as in p. 52 of his execllent 'Natural History of Mammalia') as Macropus major, sometimes as Macropus giganteus (ib. p. 55), the synonym of Zimmerman's Jerboia gigantea (1777) and of Senreber's Lidelphis gigantea (1778).

II Anat. of Vertebrates, vol. iii. fig. 296, E, $p 3$. 
which is relatively larger than in the two preceding Kangaroos, has risen into place before the crown of the following molar $\left(d_{4}\right)$ was worn down to its base. The hinder thickened end of $p_{3}$ is not worn level with the more complex grinding-surface of $d_{\mathrm{s}}$, which, morcover, indicates, by the extent of exposed dentine, that that tooth had been in use when the deciduous predecessors $\left(d_{2}\right.$ and $\left.d_{3}\right)$ of the premolar $\left(p_{3}\right)$ were in place. 'The last molar is here fully developed; its front lobe is abraded, and the scries of five tecth are in a condition to continue together the work of mastication for a great part, at least, of the lifetime of this smaller lind of Kangaroo.

In the Red-necked Kangaroo (Macropus (Ilalmaturus) ruficollis, Dm., Gd.) (ib. figs. 9 $\& 10)$ the penultimate molar $\left(m_{2}\right)$ is in place and use before the first two deciduous molars $\left(d_{2}, d_{3}\right)$ are shed, and when the premolar $\left(p_{3}\right)$ is concealed, with the two roots as yet unformed, in its cell of development. The crown of the last molar $\left(m_{3}\right)$ is also formed, and was about to pierce the gum. The permanent dentition of Halmaturus ruficollis, Gd. (Kangurus ruficollis, I)m., 1817), is that of H. ualabatus.

In Macropus (IIalmaturus) erubescens, Scl.*, the premolar (ib. figs. 1-8, $p_{3}$ ) has, in the upper jaw (fig. 1), nearly risen into place, the crown being extricated from the formative socket before the penultimate molar has appeared through the gum. The skull here figured gives an interesting phase of dental development. The premolar has displaced the second deciduous molar $\left(d_{3}\right)$ on both sides of the upper jaw, $d_{2}$ continuing on the left side, and its socket being unobliterated on the right side. In the lower jaw (fig. 4) the premolar $\left(p_{3}\right)$ has pushed laalf its crown abore the socket on the left side, from which both $d_{2}$ and $d_{3}$ are displaced, whilst $d_{3}$ remains on the right side, the premolar not having come into view; a trace of the socket of the shed $d 2$ remains. In a younger individual of Macropus erubescens, the skull of which, marked " "Uroo, far north," was kindly sent to me from Adelaide, South Australia, by G. F. Wateriouse, Esq., the three deciduous molars are in place and use (Plate LXXX. figs. $\left.6 \& 7, d_{2}, d_{3}, d_{4}\right) ; m_{1}$ has nearly risen into place in the upper jaw (fig. 6), but is not so far advanced in the lower jaw (fig. 7). The germ of the premolar $\left(p_{3}\right)$ is exposed by removal of bone in the upper jaw.

In the skull of a nearly full-grown Kangaroo (Macropus (Boriogale) magnus, Ow.), also from the "far north" of the province of South Australia, the premolar is represented by the foremost deciduous tooth. On the left side of the upper jaw it is in contact with $d_{4}$, and $m_{3}$ is nearly risen into place; on the right side (ib. fig. 12) a vacuity corresponding with the hind half of $d_{3}$ remains, and shows the socket of the hind root of that deciduous tooth. Its homotype in the lower jaw (fig. $12 a$ ) is shed in both rami, and the very small bilobed crown of $d_{2}$, or $p_{3}$, is in close contact with $d_{4}$. If $d_{2}$ had a

- Sclater, 'Proccedings of the Zoological Society,' Mareh 7th, 1871, p. 240 (Cut, figs. 5 \& 6). 'This eminent moologist remarks :- " The muffle of 1 . erubescens is quite naked; and the species therefore belongs strietly to the scetion Halmalurus of Mr. Waterhoose's arrangement." But the bony palate is entire, as in most large

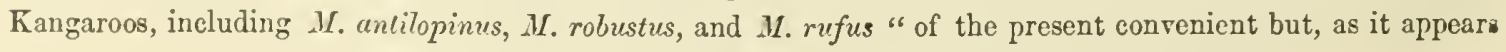
to me, arbitrary division" (WATERHOdSE, op. cil. p. 95). 
predecessor, it must then be the tooth $\left(p_{3}\right)$ which I suppose it to represent. In either case the modification is rare, and, so far as I know, unique in the bilophodont section of Macropodide: assuming the foremost tooth to be $d_{2}$, it repeats the condition and formula of the molar series in Diprotodon and Nototherium.

I shall not here carry further the account of the dental changes in living species of Kangaroos; but there are modifications of the grinding-surface and crown of the molar teeth which are useful in tracing out the affinities of extinct species.

The premolar, like the foremost deciduous molar, has an antero-posteriorly extended crown, with a more or less trenchant margin, supported by two roots. The margin may be slightly thickened and obtuse posteriorly, with a still more feeble swelling anteriorly, and the crown may not show any other modification; such is the very small lower premolar of Macropus (Osphranter) robustus, Gd. (ib. fig. 13, $p_{3}$ ). In the upper jaw of this species the premolar (fig. 14', $a, b$ ), with an increase in antero-posterior and transverse extent, shows none in the vertical direction; but the thickened fore part of the crown is divided by a notch from the rest of the trenchant border, and this by a smaller notch from the hind swellings; moreover the base of the crown is produced inward, and this ridge swells out posteriorly. The fore-and-aft dimension of the upper premolar does not, however, exceed that of the adjoining molar, $d_{4}$.

In Macropus (Boriogale) magnus (fig. 12) the upper premolar, or its representative, is not so long from before backward as the adjoining two-ridged molar. 'The anterior thickening is not marked off by a notch; it is connected by a basal rising with the hinder. thickening, and the intermediate rather depressed outer surface shows two faint rertical ridges. An inner basal ridge swells into a small tubercle posteriorly.

In the lower jaw (fig. $12 a$ ) the still smaller homotype has the crown transversely cleft to its base, and the hinder, somewhat larger lobe is thickest behind, with a feeble internal tubercle.

The upper premolar of Macropus erubescens (ib. figs. 1 \& $2, p_{3}$ ) is similarly cleft, though not quite to the base; it has an inner basal ridge swelling behind into a tubercle, which abuts upon the hinder and larger division of the cleft crown. The lower premolar, of smaller size (Plate LXXX. figs. $4 \& 5, p_{3}$ ), is cleft in a minor degree.

In Macropus ualabatus the premolar exceeds the adjoining molar $\left(d_{4}\right)$ in anteroposterior extent. In the upper jaw the trenchant border is slightly notched by a few vertical grooves traversing the outer side of the crown; and the immer basal ridge is similarly but more deeply notched; the entire crown is also broader than in the premolars of the previously cited species.

The modifications of the crown in the transversely two-ridged or "bilophodont " molars add characters in the discrimination of fossils, and it is convenient to define and name the parts affording them. The main "lobes" (ib. figs. 29, 30, \& Plate LXXXI. fig. 13, $\left.m_{3}\right)$ are "front" $(a)$ and "back" $(b)$; a ridge along the fore part of the base of the crown is "prebasal " $(f)$; if, as is usual, there be one at the back part of the crown it is "postbasal" ( $g$, fig. 29, Plate LXXX. \& Plate LXXXI. figs. 12 \& 15, m s). Com- 
monly these several transverse clevations are comnected together by ridges which affect a longitudinal course: that which ties the prebasal ridge to the front lobe is the "fore link" (Plate LXXX. fig. 29, \& Plate LXXXI. fig. 13, $\mathrm{m}_{3}, \mathrm{~s}$ ), that which ties together the main lobes is the "mid link" $(r)$, that which descends to the "postbasal" ridge is the "hind link" $(t)$, of which ridge it frequently seems to be the sole representative (Plate IXXX1. fig. 18, $t$ ).

'The upper molars are broader than the lower ones, and the prebasal ridge is narrower (antero-posteriorly); but the ridge descending from the hinder and inner angle of the back lobe to the base of the hind surface of that lobe ("hind link" and "postbasal ridge") is nsually better marked or more commonly present in the upper than in the lower molars.

'The coronal modifications of these teeth are represented in certain existing species in figs. 23 to 28, Plate LXXX.; to these are added figures of a lower molar in two of the extinct species of Kangaroo (ib. figs. 29, 30), which I next proceed to define.

$\S 2$. Macropus Titan, $\mathrm{Ow}$.-This species was founded on a portion of the right ramus of a lower jaw from the Breccia-cave in Wellington Valley, New South Wales; in which jaw, notwithstanding the superiority of size of the molar and of the portion of molar in place to any of those in Macropus major, I was led from certain indications of immaturity to ask permission from the possessor and discoverer of the then (1836) unique fossil to excavate the substance of the bone; this being granted, led to the detection of the nearly complete premolar or successional tooth in its formative alveolus, such as is figured in vol. ii. pl. 29. fig. 3 of Sir 'Tuomas Mitchell's work*.

The discovery of the premolar was a satisfactory addition to the less conspicuous differences in the molars of the present as compared with those in the fossil jaw of a similarly sized extinct Kangaroo, also in Sir 'Tiomas Mitcirell's collection, on account of the remarkably large and complex character of the premolar in that fossil, now the type of Sthenurus (Macropus) Atlas (comp. fig. 18, $p_{3}$ with fig. $4, p_{3}$, Plate LXXXII.). But I had not at that time the further satisfaction of determining the characters of the maxillary dentition of Macropus Titan by fossils of that species, either at the corresponding immature stage of the animal affording the mandibular fragment or of fullsrown individuals. I have subsequently received both desiderata, some of which reached me in time to notice in the under-cited work $\phi$, and of which figures are now for the first time given. The maxillary specimen (Plate LXXXI. figs. 6-9), in its phase of dentition, relates as closely to the mandibular one (Plate LXXXII. figs. 17, 18) as does the upper jaw of Sthenurus Atlas (Plate LXXXIV. figs. $4 \&$ 5) to the portion of lower jaw (Plate LXXXII. figs. 3 \& 4).

The fossil in question (Plate LXXXI. figs. 6-9) is not from the Breccia-cave of Wellington Valley, but from a freshwater bed at Gowrie, Queensland, where it was obtained and

* Three Expeditions into the Interior of Eastern Australia, \&c. 8ro. 1838, vol. ii. p. 360 (2nd edit. 1839, p. 366, pl. xlrii.).

† Catalogue of the Fossil Mammalia and Birds in the Museum of the Royal College of Surgeons, 4to, 1845, p. 324, Nos. 1500 and 1510. 
transmitted to me by my friend George Bexnetr, M.D., F.L.S. This is interesting as evidence of the range of the large and now extinct species: the bone shows the usual state of petrifaction of fossils from that formation and locality. It is a portion of the left maxillary bone, with a series of five molars in situ. The first (Plate LXXXI. figs. $6,7,8, d_{2}$ ), slightly mutilated externally, has a simple subcompressed unilobate (or subbilobate?) crown, broadest behind, of much smaller size than that of the following two-ridged grinder $\left(d_{3}\right)$; its working-surface had been worn so as to expose a broad field of dentine. The next tooth $\left(d_{3}\right)$ shows a minor degree of abrasion, the third molar $\left(d_{4}\right)$ still less. In the fourth $\left(m_{1}\right)$ the summits of the two transverse ridges have just been touched; those of the hindmost molar $\left(m_{2}\right)$ in place had not come into use, although they attained nearly the level of the ridges of the antecedent tooth. Moreover, behind the fifth molar was the fore part of a smooth subspherical cavity (ib. fig. 9), plainly the formative alveolus of another molar $\left(m_{3}\right)$ still to come into place.

Accordingly the five molar teeth in this maxillary fossil I interpreted as homotypal in the upper jaw with the five molars in the lower jaw of a similarly immature Macro pus major. Adopting the symbols in fig. 296, D, vol. iii. of my 'Anatomy of Verte. brates,' those of the fire teeth in the present fossil would be :- $d_{2}, d_{3}, d_{4}, m_{1}, \& m_{2}$. To test this conclusion I proceeded to remove the outer table of the jaw-bone above $d$, and detected the germ of $p_{3}$ (ib. fig. 6), in a stage of development like that of $p_{3}$ in the lower jaw of the type specimen (Plate LXXXII. fig. 18), and corresponding with the state of the dentition in the upper jaw of Macropus erubescens (Plate LXXX. fig. 6). The back tooth, when formed in the hindmost closed alveolus, would be $m_{3}$, completing the total of seven teeth developed in the molar series of the Macropodida.

In the upper premolar of Macropus Titan the crown consists of two simple, conical, subcompressed lobes, the hindmost being thickest posteriorly; it is supported on 's'u roots, the formation of which had commenced in the specimen described: its movement into place, or into the masticatory series, would have involved the shedding of $d_{2}$ and $d_{3}$; its crown would then contrast with that of $d_{4}$ by its freshness or freedom from wear. The convexity of the outer surface of the two lobes, and the depth of the dividing indent, accord with the characters of the lower premolar of the type specimen of Macropus Titan expressed in fig. 18, Plate LXXXII.

The bilophodont* upper molars of Macropus Titan (Plate LXXXI. fig. 8) show a welldeveloped "prebasal ridge" connected by a "link" of enamel with the fore part of the front lobe, near the middle and inclining rather toward the inner angle. In Sthenurus Atlas (Plate LXXXIV. fig. 6) this link is feebly if at all developed.

The mid link comnecting the two main lobes in Macropus Titan (Plate LXXXII. fig. 11) is rather sinuous and tumid; it is better developed in this species than in Sthenurus Atlas (Plate LXXXIV. fig. 6). The oblique posterior ridge (Plate LXXXII. fig. 11, $m, g$, and Plate LXXXI. fig. 18, $t$ ) is strongly marked, and defines a depression at that

* This term signifies not only that the crown is composed of tro principal ridges or lobes, but that these are transverse in position. 
side of the upper molars. 'The main lobes have broad convex bases in the side vicw of the molars (l'late IXXXII. fig. 10), and the entire crown is longer in proportion to its transverse breadth than in Sthenurus Atlas.

'The front pier of the zyomatic arch (Plate I.XXXI. fig. 6, 21') is in advance of the hindmost molar in place $\left(m_{2}\right)$ in this young specimen. 'The anterior outlet of the suborbital canal (ib. fig. 6, 21) is 9 lines in adrance of the orbit. Behind the outlet $(21)$ is the small orifice ( $\iota$ ) of a (vascular ?) canal, descending into the substance of the maxilla. I have not observed this orifice in the large existing Kangaroos. So much of the bony palate as is preserved (ib. fig. S) is entire aud imperforate, as in Macropus major. 'This character, associated with the small size and simple structure of the premolar, and, as will be seen in subsequently described fossils, its comparatively early loss, support a reference of the present large Kangaroo to the genus Macropus, as restricted by most zoologists of the present day.

In the specimen from the Breccia-cave, Wellington Valley, of the left upper maxilla and molar series (ib. fig. 10) the premolar had risen into place; the last molar ( $\mathrm{m}_{3}$ ) was protruding from the formative cell, but had not come "into line;" the first two deciduous molars had been shed.

'The crown of the foremost tooth was broken off, but the fangs remained (ib. $p_{3}$ ). 'They were two in number (the hindmost the largest), corresponding in relative size, degree of divarication, and extent of jaw occupied by their insertion with those developed in the unprotruded premolar of the younger specimen (ib. fig. $6, p_{3}$ ). The choice of the tooth belonging to the fangs in front of the series in the subject of fig. 10 lies between $p 3$ and $d_{3}$; but the latter tooth has, in conformity with its broader bilophodont crown, four roots, each pair diverging from a transversely extended base. The evidence of the roots remaining in the socket of the broken molar is therefore decisive of its homology; the loss of the crown of $p_{3}$ is nevertheless regrettable. Its working-surface would have contrasted with that of the tooth $d_{4}$, which, having been longer in place and use, shows each transverse lobe worn to near its base, exposing corresponding broad tracts of dentine united by a linear strip along the base of the mid link. In $m_{1}$ the dentine exposed on the transverse lobes is a linear tract, rather broader on the front lobe; the front $(s)$ and mid $(r)$ links show abrasion, but not carried to the exposure of the dentine. In $m_{2}$ the enamelled summits of the ridges are slightly abraded; $m$, as before stated, had not risen into place.

The molar characteristics of the species (Macropus Titan) are well exemplified in this care-specimen. Sufficient of the palate is preserved to show, as in the preceding one, that it had no large vacuities. The relative position of the zygomatic pier (21) seems to have retrograded as compared with fig. 8, Plate LXXXI.; but it still strengthens the jaw where the hindmost molar here $\left(m_{2}\right)$ was in use; when $m_{3}$ comes into place and takes its share, the jaw, as we shall see again, becomes concomitantly modified.

The specimen described and figured formed part of the collection of duplicate fossils obtained, under the farourable circumstances detailed in pp. 135 \& 239, by Professor 
Thomson and Mr. Kreffe from the Breccia-cavern discovered by Sir Thomas L. Mitchell, C.B.

In a collection of marsupial fossils at Worcester I recognized a portion of the right upper jaw, with the molar series, of a Macropus Titan exemplifying the stage of dentition when the last molar as well as the premolar had come into place, but the former so recently that the zygomatic pier had not much receded in position. The first and second deciduous molars $\left(d_{2}\right.$ and $\left.d_{3}\right)$ had been shed. The part of the series $d_{4}$ to $m_{2}$ inclusive occupied a space rather short of that containing the homologous teeth in the younger specimen (fig. 10, ib.); but the structure of the last two teeth and the proportions of the premolar were those of Macropus Titan. Unfortunately the crowns of the first three teeth had suffered fracture. A portion of the hinder fold of enamel remained on the broken base of the crown of the premolar, showing that the hind lobe of that tooth, besides being thicker than the fore one, was divided into an outer and inner lobule. Its longitudinal extent agreed with the crown of the germ of $p_{3}$ exposed in the subject of fig. 6, Plate LXXXI.

The same phase of dentition is exemplified in a similar portion of the right maxillary of another and somewhat larger individual of Macropus Titan (ib. fig. 11), in which the crown of the premolar is entire, and shows by its unworn condition that it had but recently risen into place. This tooth instructively contrasts with the next grinder, which is worn down so as to expose a continuous field of dentine, encroached upon by two opposite folds of enamel from the inner and outer sides of the crown meeting at the middle. In the next tooth the dentine is exposed upon each of the tralisverse lobes and upon part of the anterior "link." In the penultimate molar a thin line of dentine appears on the front lobe, but the enamel is not worn down so far in the hind lobe. The enamel ridge of the front lobe of the last molar is touched by abrasion. The crown of the premolar shows it to have been the last of the series of five teeth now come into place. It is trilobed: externally it shows only the bilobed structure (as in fig. 6); but there is a smaller third tubercle on the inner side of the hind lobe, increasing the breadth of that part of the tooth, as was indicated by the last-described specimen (Plate LXXXI. fig. 10, $p^{3}$ ). The length of the entire series of five teeth is 2 inches 9 lines; that of the premolar (fore-and-aft diameter of crown) is 5 lines, that of the next tooth $\left(d_{4}\right)$ being the same; that of the penultimate molar is 8 lines. The whole series is bounded on the inner side by an almost straight, very feebly concave, line; the outer contour is rather more convex.

The two specimens above described are in the Museum of the Natural-History Society of Worcester, to the Council of which I am indebted for the opportunity of describing and figuring them. They were obtained by the donor, Henry Hughes, Esq., in the freshwater deposits of Darling Downs.

The subject of tigs. $15,16, \& 17$, Plate LXXXI., is also from the fresh water deposits of Queensland. It includes a considerable proportion of the right maxillary, with the last four grinders in situ, the dentine being exposed along a very narrow strip of the front 
lobe of the hindmost tooth $\left(m_{3}\right)$. In the foremost $\left(d_{4}\right)$ the channel of dentine along the mid link is not quite exposed, the enamel at the base of the link still remaining. The two anterior deciduous molars and the premolar have been shed and the alveoli nbliterated. 'This, therefore, is from a fully mature individual. The three teeth $\left(d_{4}, m_{1}\right.$, $m_{2}$ ) lomologous with the last three molars of the young specimen (ib. figs. 6-8) occupy the same longitudinal extent, viz. 1 inch $8 \frac{1}{2}$ lines: with the fully developed succeeding teeth they exemplify the later stage of the upper molar dentition in the present extinct species. The last molar (ib. figs. $15 \& 16, m_{3}$ ) shows well the characteristic modifications of its working-surface in Macropus Titan as compared with that in Sthenumes Atlas (Plate LXXXIV. fig. 6, $m_{3}$ ): the prebasal ridge $\left(f^{\prime}\right)$ is broader; its margin rises (the tooth being viewed prone) from the outer end to near the middle of its transverse course, then sinks inore rapidly to its inner end, which bends up upon the front lobe. From the low or open angle thus described by the sharp margin of the prebasal ridge, the linking process $(s)$ extends to near the middle of the fore part of the front lobe. In Sthenurus Atlas there is no front link ; the margin of the narrower and lower prebasal ridge forms no angle as it sinks to terminate at the fore and inner end of the front lobe.

The mid link (Plate LXXXI. fig. 15, $m_{3}, r$ ) comes off from the front lobe nearer to its inner end in Macropus Titan, but not from that end as in Sthenurus Atlas (Plate LXXXIV. fig. $6, m_{3}, \cdots$. It is more developed in Macropus Titan, and its course is more longitudinal as it recedes to abut against the middle of the hind lobe; the postbasal ridge $(g)$ extends from the postinternal angle of the hind lobe downward and outward to the postexternal part of the base of that lobe, leaving a well-marked oblique dent or cavity on the posterior surface of that lobe. In Sthenurus Atlas a general slight concavity of the hind surface of the hind lobe of $m_{3}$, upper jaw, is bounded below by a feeble postbasal ridge. With an equality of breadth, the fore-and-aft extent of the last molar in Macropus Titan exceeds that of Sthenurus Atlas by 1 line.

'The hind border of the front or maxillary pier of the zygomatic arch is on the vertical parallel of the interval between the fore and hind lobes of $m_{3}$ (Plate LXXXI. fig. 15). The retrogression of this buttress of bone is concomitant with the grinding-function now assumed by the last of the molar series (compare with figs. 10 \& 8).

The anterior outlet of the suborbital canal (ib. fig. 16, 21) is 1 inch in advance of the anterior border of the orbit. Three lines behind the antorbital foramen is the smaller oblique aperture $(a)$ leading down to the interior of the maxillary bone. The outer plate of the maxillary, in advance of and below the antorbital foramen, shows a depression; while the maxillary wall of the nasal cavity swells outward in existing Kangaroos. The proportion of the bony palate preserved shows the small narrow fissure where the maxillo-palatine suture bends inward opposite the fore part of $m_{3}$; elsewhere the palate is entire, as in Macropus proper, in Boriogale, and Osphranter. The fore part of the palate near $d_{4}$ shows a longitudinal channel (ib. fig. 15, $b$ ), 4 lines broad, bounded anteriorly by a ridge, or hind part of the diastema, extending forward and inward from the fore part of the socket of $d_{4}$, where the sockets (here obliterated) of $p_{3}$ and $d_{3}$ had 
been. This prepalatal groove is not shown in Macropus major, Macropus rufus, or Ospleranter robustus.

The maxillary bone extends for 10 lines behind the last molar, on the level of the alveolar openings, and is there impressed by the shallow groove leading to the foramen and canal between the back part of the maxillary and the pterygoid process of the alisphenoid. The figures (ib. figs. 15-18) being of the natural size preclude the need of verbally noting admeasurements.

The side view of a corresponding part of the upper jaw of a large male Macropus rufus, at the same stage of dentition as in the present fossil, is given in Plate LXXXIII. fig. 1; it is from one killed by Mr. Gould, and was the largest Kangaroo which he saw in Australia.

In reference to the constancy in size and other characters of Macropus Titan, I was fortunate in finding a second specimen from an adult of this fine extinct Kangaroo in the Geological Museum of the University of Oxford, which Professor Phillips liberally transmitted to me for comparison and delineation. It was accompanied by an almost entire lower jaw of the same species, at the same phase of dentition, and apparently of the same individual. Both had been obtained by Dr. Nicholson, of Sydney, New South Wales (now Sir Charles Nicholsox, Bart.), from the freshwater deposits of Queensland.

The subject of figs. 10, 11, \& 12, Plate LXXXII., is part of the left upper jaw with the last four molars $\left(d_{4}-m_{3}\right)$ in place; $d_{3}$ and $p_{3}$ have been shed and their sockets obliterated. 'The crowns of the remaining teeth show different degrees of abrasion: the summits of the last molar being slightly worn, not so as to expose the dentine. This specimen, therefore, bespeaks a fully mature but not aged animal.

The bone includes the base of the anterior pier of the zygomatic arch (from which the dependent process has been broken away), part of the floor of the orbit with the orbital aperture of the antorbital canal, and a considerable extent of the bony palate (showing the same imperforate structure as in the preceding specimens of Macropus Titan).

The pier of the zygoma extends obliquely from the under and fore part of the orbit down ward and backward, the hind border being on the vertical parallel of the middle of the last molar. The ridge from the outer side of the masseteric process subsides, as it rises toward the orbit, sooner than in Macropus major or Macropus laniger. As in the last described specimen, the anterior outlet of the suborbital canal is relatively further in advance of the orbit than in Macropus major, being an inch from that part and on a vertical parallel with the diastema in advance of the front molar $\left(d_{4}\right)$; in Macropus mrijor it is above the interval between $d_{4}$ and $m 1$, and opens only $4 \frac{1}{2}$ lines in advance of the orbit. In Osphranter robustus, Gd., the antorbital foramen is 10 lines in advance of the nearest part of the orbital margin, and is on the vertical parallel of $d_{4}$. It thus more nearly resembles Macropus Titan than does Macropus major; but the larger extinct Kangaroo differs from both the large existing species in the following structure, which I now have ground for regarding as constant. There is, as observed in former fossils of Macropus Titan, a foramen (a) 3 lines behind the antorbital one (21), fig. 10; it 
is not another outlet of the suborbital canal, but leads obliquely downward into the entrance or substance of the maxillary bone. Of this foramen $(\alpha)$ I have not seen a trace in any existing Kangaroo, save Hacropus erubescens (Plate IXXX. fig. 1, a). 'The degree of attrition of the upper molars in fig. 11, Plate LXXXII., agrees with that of the lowel molars in fig. 14, ib. The exposed tract of dentine in $d_{4}$ is continuous, the mid link being worn down to its base; the fore part of the crown is broken off. In $m$ i the front lobe is worn down to the level of the prebasal ridge, which is well marked, overlies the back part of $d$, and shows a rudiment of a link or mid rising to the front lobe of its own tooth. 'The line of alsrasion of this lobe is from without inward and a little backward. not transverse to the skull's axis: a mid link is continued from it to the midlle of the front surface of the hind lobe; this is worn, but not so as to obliterate the oblique outer clett dividing it from the postbasal ridge which rises to be lost in the inner end of the lind lobe.

In $m_{2}$ the characteristic configuration of the crown of the upper molar of Macropus Titan is well shown. 'The two chief lobes are more nearly transverse in the direction of their summits than in Macropus major; the prebasal ridge with its linking process and the nid link are as well marked as in that species, and the oblique postbasal ridge is longer. In the last upper molar of Nacropus Titan this ridge $(g)$, which is almost obsolete in Macropus major, is as well marked as in the preceding molar, $m$. The mid link of the last molar is more curved than that of $m_{2}$; the concavity of the curve is turned inward.

Compared with the molars of Sthenurus Atlas (Plate LXXXIV. fig. 6) the prebasal ridge is rather more developed, the mid link is thicker, the outer and inner sides of the transverse ridges are thicker and more prominent, and the fore-and-aft extent of the crown is relatively greater.

The crowns of the upper molars are, as usual, broader than those of the lower jaw, and, as in Macropus major and Nototherium, the last lower molar has a greater longitudinal extent of grinding-surface than the tooth above.

In another specimen of a smaller portion of the left maxillary of Nacropus Titan in the University Museum of Geology, Oxford, the dentition is shown at the same phase of development as in the preceding fossil, with a rather greater degree of abrasion. A thin line of dentine is exposed upon the sumnit of the anterior lobe of $m_{3}$; the mid link is worn to its base, exposing a linear tract of dentine uniting the broader field upon the anterior and posterior lobes. 'The size and other characters of the upper molars in figs. 10-14 (Plate LXXXII.) are satisfactorily repeated in the present evidence of Iracropus Titan.

Both specimens are from the freshwater beds or drifts of Queensland, and were presented to the Oxford Museum by Sir Charles Nicholsox, Bart., M.D., and formerly Speaker of the Legislative Assembly at Sydney, New South Wales.

'The portion of right upper maxillary (Plate I.XXXIII. figs. " \& $\&$ ) in which the adult series of five grinders had been acquired, but with posthumous mutilation of the crowns 
of the two anterior ones, shows a modification of those of the three following $\left(m_{1}, m_{2}\right.$, $m_{3}$ ) which I now know to be a variety, although not such as to induce me to refer the fossil to another species. The mid link (fig. $3, r$ ) as it passes forward from the hind to the front lobe expands and divides; the more direct or nornal continuation, after reaching the front lobe, bends to terminate or be continued into the inner border of that lobe; the other lower and shorter division turns outward to be lost upon the lower part of the outer half of the hind surface of the front lobe.

This character I briefly expressed as "a more complex form of the longitudinal rirge connecting the two principal transverse eminences" than in Macropus major or Macropus laniger, in my "Catalogue of the Fossil Mammals* in the Museum of the Royal College of Surgeons'; at the date of which work this specimen was the sole evidence of the upper jaw and teeth which appeared to me to be referrible to Macropus Titan.

Besides the structure of the grinding-surface of the molars above defined, those in fig. 3 , Plate LXXXIII., are arranged with a curve rather more narked than in the subject of fig. 11, Plate LXXXII.; but as the teeth here are less straight than those in the subject of tig. 8, Plate LXXXI., this seems to be but a ground of variety. The relative position of the zygomatic pier in figs. $2 \& 3$, Plate LXXXIII., may relate to the recent movement of $m_{3}$ into its working position: the untouched lobes of this tooth are longer and sharper than usual; yet the general concordance with the molar characteristics of Macropus Titan lead me still to refer the specimen No. 1510 to that species.

The modification of the mid link seems a small matter, but is not so in the actual phase of zoology. Evolutionally speaking, this variety may be viewed as either a rem. nant or a dawn of a complex condition of the part which will be described in subjects of a subsequert section.

Of the mandibular dentition of Macropus Titan an early stage is exemplified in the fragment of lower jaw from the Breccia-cave of Wellington Valley on which the species was founded $\uparrow$.

I have given an improved figure of the outer side of this specimen, with the premolar exposed in the primitive alveolus, in Plate LXXXII. fig. 18, and have added a view of the grinding-surface of the two mutilated molars in situ (ib. fig. 17). This portion of (right) mandible of Macropus Titan includes the hind part of the first molar $\left(d_{4}\right)$ and a larger proportion of the succeeding molar $\left(m_{1}\right)$. The anterior lobe of this tooth is entire; the hind part of the posterior lobe is broken away.

The anterior talon or "prebasal ridge" of $m$, has almost the character of a lobe; it is united to the anterior normal transverse lobe by a well-developed fore link, commencing

* 4to, 1845, p. 324, No. 1510 .

† Three Expeditions, 8ro, 1838, by Sir Thомаs L. Mitchell, C.B., vol. ii. p. 359, pl. xxix. fig. 3. This specimen, with other fossils from the Wellington Valley cavern, submitted by its discorerer to me, were presented to the Geological Society of London, to the President and Council of which I am indebted for the opportunity of reexamining and figuring this collection, which initiated our knowledge of the fossil Mammals of Australia. 
near the outer angle of the fore lobe, and describing a slight bend in its forward course to expand upon the hind part of the "prebasal ridge" nearer its outer than its inner end. The projecting angle of the "link" is directed inward. The valley between the anterior lobe and the prebasal ridge is thus divided into two hollows, the inner one being the largest. 'The inner border of the prebasal ridge is sharp, and abuts against nearly the middle of the back part of the antecedent tooth $\left(d_{4}\right)$. 'The outer border of the prebasal ridge is thicker than the inner one, less inclined inward, and projects freely a little external to the level of the hind lobe of $d_{4}$. The back part of this lobe is entire; it shows a submedian posterior vertical indent; there is no perceptible trace of basal ridge.

The mid link (fig. 17, Plate LXXXII.) repeats the characters of the fore link, save that it sinks lower to comnect itself with the anterior lobe, leaving more of the summit of that lobe free thian is left to the prebasal ridge. The summit of the anterior ridge of $m_{1}$ inclines a little forward as it crosses the tooth from without inward, and is slightly bent with the convexity backward. The mark of wear, which in the young animal owning this tooth had not exposed the dentine, affects the hinder slope of the summit of the transverse ridge.

The characters of the crown in the two lower grinding-teeth of the type specimen of Hacropus Titan above described are, in the main, those of the largest existing representatives of the true or subgenerically restricted Macropus.

In the lower jaw of Macropus major (Plate LXXX. fig. 15) the prebasal rillge (fig. 16, $f$ ) of $m_{1}$ and $m_{2}$ has a like size and shape, and is connected with the anterior lobe by a similar link; but this is less bent inwardly in its forward course. In Macropus rufus the prebasal ridge is less developed (Plate LXXXI. fig. 4); there is no postbasal ridge or talon. A feeble vertical notch is shown by the back part of $m_{1}$ and $m_{2}$; this does not appear in $m_{3}$. The proportion of length to breadth of the grinding-surface of the true molars is the same in the recent as in the extinct species compared; the difference is mainly in size.

In a portion of the right mandibular ramus of Macropus Titan, with the three posterior molars in situ, these, like the single entire molar in Plate LXXXII. fig. 17, $m_{1}$, show a proportionally greater antero-posterior extent of the prebasal ridge than in Macropus major or Macropus (Osphranter) rufus. Of the latter existing species* Mr. Gould, F.R.S., was so good as to place in my hands, for the purpose of these comparisons, the jaws and teeth of a male which he killed between the rivers Murray and Adelaide, Australia; it measured 8 feet 2 inches from the nose to the end of the tail, and was the largest Kangaroo which that eminent naturalist saw in the continent of which he has so admirably illustrated the rich ornithology as well as its singular mammalogy.

These specimens I presented, in Mr. GovLD's name, to the Royal College of Surgeonst, after their application to the requisite comparisons with the fossils from the Wellington

* Then known as the Hacropus luniger.

† See 'Catalogue of the Fossil Mlammals and Birds' \&c., 4to, 1845, pp. 324, 325, Nos. 1510, 1511. 
Valley caves and freshwater beds of Australia. Figs. 1 \& 14 in Plate LXXXIII. give a side view, and figs. $2 \& 4$, Plate LXXXI. the grinding-surface, of the right series of upper and lower molars of this animal, of the natural size.

So much of the mandibular ramus of a Macropus Titan (Plate LXXXII. figs. 13-16) as remains in the specimen in the Oxford Museum closely agrees, save in size, with that of Macropus major (Plate LXXX. fig. 15). As in that recent specimen, the individual affording the present fossilized relic had shed both the premolar and the two anterior milk-teeth; $d_{4}$ also shows a wear of crown and exposure of roots indicative of speedy expulsion. The long diastemal border (between $d_{4}$ and $i$ ) is trenchant to near the outlet of the incisive alveolus. It descends, more rapidly than in the living Kangaroo, from the anterior molar socket, with a concave curve, reducing the vertical extent of the symphysial part of the ramus at the outlet of the dental canal (ib. fig. 13, $v$ ) to two thirds of that at the outlet of the anterior molar socket, $d_{4}$. In advance of the dental canal the symphysial part of the jaw is reduced to a mere case of the root of the long prucumbent incisor, $i$.

The descent is less sudden, and the concavity of the diastemal border somewhat less, in another specimen of the mandible of Macropus Titan, which more closely resembles in this respect the recent Kangaroo.

The symphysial surface in Macropus Titan (Plate LXXXII. fig. 15) begins behind, in advance of the vertical parallel of the fore part of the first molar socket; it expands so as to cover the lower half of the inner surface of the ramus at the part opposite the outlet $(v)$, and then contracts to terminate before attaining the outlet of the incisive alveolus, at least as regards its grooving and other rough markings for ligamentous union. The contrast between this structure of the symphysial joint and that in fig. $6, s$ (Sthenurus Atlas), is considerable, and supports the inference that the junction between the right and left rami was not more close in the large Macropus Titan than in Macropus major. The direction of the elongated socket of the incisor and the procumbent position of that tooth in the fossil are as in the existing species of Macropus. The crown of the incisor, so far as it is preserved, agrees in shape, relative size, disposition of enamel, position and obliquity of the back part of the abraded working-surface, with that of Macropus major. The configuration of both outer and inner surfaces of the horizontal ramus, especially the ridge indicating the lower limit of insertion of the crotaphyte muscle and extending a little : elow the margin of the ectocrotaphyte cavity, as shown in Macropus major (Plate LXXX. fig. 15), are repeated in Macropus Titan (Plate LXXXII. fig. 13,e). The last molar stands out more freely, or entirely, in adrance of the fore margin (ib. fig. 13, q) of the coronoid process in Macropus Titan than in Macropus major (Plate LXXX. fig. 15); and it advances further as the animal grows older and the molar series is further reduced.

The inflection of the inner and lower border of the ascending ramus begins anteriorly nearly in the same relative position. The anterior border of the intercommunicating vacuities (Plate LXXXII. fig. 15,e,d) between the outer and inner cavities of the 
ascending ramus appears to be the same in the present fossil as in the largest existing species of Kangaroo. The inner postalveolar border is smoothly rounded, and forms no angle indicative of a postatveolar process.

'The molars in the fossil under description are more worn than in the Macropus major compared, with a similarly reduced series of teeth. In $d$ (Plate IXXXII. fig. 14) the exposed tract of dentine is continuous, the mid link crossing the valley being worn though. 'The prebasal ridge is indicated only by the internal notch ; the basal remunt of the crown is supported by fangs, which are partially exposed by absorption of the alveolus, and the crown overhangs the beginning of the diastema, indicative of the impending fall of the tooth (ib. fig. $13, d_{4}$ ); whence I infer that the molar dentition of Marropus Titan would be reduced in advanced age, like that in Macropus major, by the loss of $d_{4}$, and perhaps ultimately of $m_{1} *$.

'The pattern of the working-surface of the succeeding molars closely accords with that in Macropus proper. The prebasal ridge is considerable, both longitudinally and transversely: the fore link is well marked; it joins the front lobe external to the mid line, leaving a fossa on each side. The contrast with the rudiment of this link in Sthenurus Atlas (ib. figs. $8 \& 9$ ) is considerable, as is that also in the development of the mid link and the breadth of the anterior margin of the prebasal ridge.

'The antero-posterior brealth of the transverse ridges is greater in Nacropus Titan than in Sthemurus Atlas, especially at their outer sides (comp. figs 13 \& 5); the longitudinal cxtent of the crown is relatively greater as compared with the transverse diameter in Macropus Titan.

In the next illustration of the mandibular characters of Macropus Titan, so much as is preserved of the two rami shows the angle at which they meet to unite at the symphysis (Plate LXXXVI. fig. 9). It also shows that the comparatively loose union of the symphysis had permitted the right ramus to glide a little forward from the left one before they were fixed in position by the petrified nuatrix; but this correspondence with the large living Kangaroos is more decidedly shown in the subject of fig. 11, Plate LXXXVI. The right ramus of fig. 9 includes the last four molars, $d_{4}, m_{1}, m_{2}, m_{3}$, and a part of the premolar, $p_{3}$ (this tooth, like the crown of $m_{1}$, has suffered more from fracture than from masticatory action). 'The left ramus inclurles the last three molars and the hind half of the crown of $d_{4}$. The present fossil was obtained by Hexry Hughes, Esq., in the freshwater deposits of Queensland, and is now in the Museum of the NaturalHistory Society of Worcester.

In a fossil with three molar teeth $\left(d_{4}, m_{1}\right.$, and $\left.m_{2}\right)$, and the formative cavity of $m_{3}$, these teeth are somewhat inferior in size to their homologues in fig. 13, Plate LXXXII., and probably indicate that they come from the female of Macropus Titan. 'The subject of figs. 12 \& 13, Plate LXXXIII., is the original specimen in the Museum of the Royal College of Surgeons, No. 1512t, which first afforded the characters of the

- Since this passage was penned I have received from my friend Dr. Bexsmat, F.L.S., evidence of the fact.

+ Catalogue, ut suprì, p. 3:5. 
penultimate and last molars of Macropus Titan: this I now believe to have come from a female of that species.

The mandible of Macropus Titan (Plate LXXXVI. figs. 11 \& 12), after solution of the soft parts in its original burial-place, shows the effect of the disturbance of the grave by the dislocation of the rami, which had been somewhat loosely attached during life by the partial syndesmosis of the symphysis. So separated and shifted, the right ramus being pushed about 2 inches in advance of the left, the parts have rested without further disturbance long enough to permit the dislocated rami to become connected together by the petrified matrix. The bone, which during the same period had undergone some degree of petrifaction, appears again to have been subject to movements of the matrix, resulting in the amount of fracture of the most prominent parts which is common in the fossils from the freshwater beds of the Australian localities yielding the subjects of the present paper. But the later disturbances have not affected the artificial union of the previously separated and dislocated rami.

The jaw-bone in this specimen exceeds in depth and a little in length that of the Macropus Titan in the Oxford Museum (Plate LXXXII. figs. 13, 15), but the longitudinal extent of the four molars is the same. The present fossil is from an older individual: $d_{4}$ is worn down to its base, and the ridges of $m_{3}$ (both of the lobes and links) show more abrasion. The vertically oblong pit toward the inner side of the back part of the last molar (ib. fig. 15) is well marked. The symphysial articular surface (ib. fig. 12) is neatly defined behind; its rougher part subsides anteriorly, and ceases about an inch from the outlet of the incisive socket. The rertical diameter of this socket is 8 lines; that of the base of the incisor, where the tooth has been broken off, is 7 lines.

The portion of a left mandibular ramus of a fine old male of Macropus Titan (Plate LXXXVI. fig. 13) shows the largest size of the lower jaw which I have as yet seen in fossils of this species. But though the depth of the mandible at the interval between $d_{4}$ and $m_{1}$ is nearly half an inch greater than in the subject of fig. 11, or in the Oxford specimen (Plate LXXXII. figs. 13,15), the teeth are not much larger. A figure of the workingsurface of the last molar in this large Macropus Titan is given in fig. 14, and one of the hind surface of the same tooth in fig. 15, to exemplify the characteristic pit there in the fossil.

In the hind part of a man:libular ramus of a fine old Macropus Titan, with the last molar well worn, and now much in advance of the coronoid process, the depth of the jaw behind this tooth is 1 inch 6 lines, and the same at the interval between $m_{2}$ and the débris of the socket of $m_{1}$ *

\$3. Macropus affinis, Ow.-In a small collection of Marsupial fussils made by: Sir Thomas Mitciell, C.B., in a surrey undertaken after his return to Australia in 1839, and which he was so good as to transmit to the Royal College of Surgeons, there were confirmatory evidences of the two large species represented by the fossils of his first

* This is the specimen alluded to as having been received, since the present paper was prepared, in the last collertion of fossils from the freshwater deposits of Queensland, transmitted by George Bexnett, M.D., F.L.s. 
collection in Wellington Valley, described and figured in his work published in 1838 * and also indications of a third species of large Kangaroo, which I described in my Catalogue of the Fossil Mammalia of the Musenm of the College, and referred to a Macropus affinis $\uparrow$. This second collection was obtained, according to the notes accompanying it, "from the alluvial or newer tertiary deposits in the bed of the Condamine river, west of Moreton Bay."

The best evidence it contained of the Macropus affinis was a portion of the left mandibular ramus, now for the first time figured (Plate IXXXIII. figs. $10 \& 11$ ), including the antepenultimate and penultimate molars, and the sockets and fangs of the premolar $\left(p_{3}\right)$ and of the first $\left(d_{4}\right)$ and last $\left(m_{3}\right)$ two-ridged molars. The two molars $\left(m_{1}\right.$ and $\left.m_{2}\right)$ retaining their crowns showed the specimen to have come from an aged individual. The pattern of that of $m_{1}$ had been worn away, with mere indications of the two chief divisions and the prebasal ridge. The crown of the penultimate molar agreed in its general proportions more with that of Macropus Atlas than with that of Macropus Titan, but was nmower in proportion to its antero-posterior diameter than in Macropus Atlas, and the mid link was more developed. From its homologue in Macropus Titan the tooth differed in liaving no trace of a postbasal ridge (compare with fig. 13, Plate ISXXXIII.). 'The depth of the jaw containing the teeth was greater than in Macropus rufus (of which a corresponding part of the mandible of a large individual is given in fig. 14, ib.). 'The teeth, lowever, indicate a species of less size than either of the two extinct ones above cited. I therefore continue to regard this fossil as evidence of an extinct Kangaroo of intermediate proportions between the largest known living species and those defined in my original memoir, and of which additional illustrations are given in the present.

$\oint$ 4. Osphranter Cooperi, Ow.-The subject of figs. 17 \& 18, Plate LXXXIV., is the fore part of the left mandibular ramus of an aged individual of a Wallaroo, of the size of Osphianter robustus. It retains the first three molars $\left(p_{3}, d_{4}, m_{1}\right)$, the second of which, as having been longest in place, has the crown worn down to its base, from within obliquely outwards, and in a rather greater degree than in the corresponding tooth of the recent species compared, the mandible of which is the subject of fig. 13, Plate LXXX. 'I'he premolar $\left(p_{3}\right)$ shows three small tubercles on its working-surface, arranged from before backward; the crown is subcompressed, and very slightly thickened behind; the inner surface of the fore part of the crown is gibbous, as in Ospliranter, and its proportions are as in Osphranter robustus. The degree of wear of the next tooth is such as would be incompatible with the retention of the foremost if it were the deciduous tooth, $d_{2}$; but, for decisive eridence, I remored the inner wall of the ramus where the germ of $p_{3}$ would have been, and there was no trace of such successional tooth. The present fossil, therefore, has come from a fully mature individual. A species of true Macropus would not have retained the premolar or the following tooth at this age, or have kept d with a crown so far worn down. Thus the fossil accords with Osphranter in the 
proportions of $p_{3}$ and $d_{4}$ and their long continuance in line with the following molars. The third tooth $\left(m_{1}\right)$ in the fossil is relatively broader than in Osphranter robustus. The outer side of the diastemal and symphysial part of the mandible is less convex vertically than in Osphranter robustus. The symphysis begins behind in the same relative position to the premolar. I indicate the present fossil Kangaroo by the name of the donor, Sir Daniel Cooper, Bart.; it was discovered in the freshwater beds of Darling Downs, Queensland.

§5. Osphranter Gouldii, Ow.-The subject of figs. $15 \& 16$, Plate LXXXIII., is a corresponding part of the lower jaw of a young specimen of the same subgenus, but of smaller size. 'The fossil shows a remnant of the socket of $d_{2}$, and the much-worn crown of $d_{3}$; that of $d_{4}$ is also much worn, but not reduced to the degree shown in fig. 18 , Plate LXXXIV. To this smaller kind of fossil Wallaroo (Osphranter Gouldii) I have attached the name of the discoverer and founder of the genus.

$\S 6$. Phascolagus altus, OW.-Of this species a portion of the upper jaw and teeth was figured in the Palæontological Appendix to Mitchell's 'Three Expeditions into the Interior of Eastern Australia,' \&c., vol. ii. plate xxix. (plate xlvii. of 2nd edition) figs. $4 \& 5$, with the following remark:- "This specimen I believe to belong to Macropus Titan. The permanent false molar, which is concealed in the upper jaw, is larger than that of the lower jaw of Macropus Titan; but I have observed a similar discrepancy of size in the same teeth of an existing species of Macropus" (ib. p. 360). Subsequent and closer comparisons have, however, shown that the pattern of the grinding-surface of the upper molars is more like that in Halmaturus and Osphranter than in Macropus major or Macropus Titan; and the discovery of the upper jaw of the latter species at a corresponding phase of dentition (Plate LXXXI. fig. 6) has shown that, in size and simplicity of form, the upper premolar much more closely accords with the lower one in the type mandible of Macropus Titan (Plate LXXXII. fig. 18) than does the premolar exposed in the specimen under examination (ib. fig. 1).

These phases of dentition, illustrative of the characters and affinities of the fossil under review, are shown in the specimens Nos. 1741, 1742, and 1743, in the Osteological Series of the Mnseum of the Royal College of Surgeons of England*, and are illustrated in Plate LXXX. figs. 1-12 of the present Paper. In the recent species (Mucropus (Phascolagus) erubescens) the upper premolar (ib. fig. 6, $p_{3}$ ), in its form and proportions, still more closely resembles that (Plate IXXXII. fig. 1, $p_{3}$ ) of the larger extinct Kangaroo (Phascolagus altus) of the Wellington Valley Bone-cave.

This species combines with the proportion of the premolar, affording one of the characters of the subgenus IIalmaturus, the entire or imperforate bony palate, which is found in all the species of Macropus in its restricted or subgeneric sense (ib. fig. 2). In this combination of characters the fossil agrees with the existing Phascolagus erubescens.

The degree of developinent of the concealed premolar, the crown being completed with the basal portions of both roots, coincides, as in Phascolagus erubescens, with the

* Osteological Catalogue, 4to, 1853, p. 324. 
incompleted cruption of the molar $\left(m_{1}\right)$ and the still hidden and undeveloped state of $m_{2}$ and $m_{3}$; whence may be inferred a like precocious appearance of the premolar in the working series, with the concomitant shedding of the two anterior deciduous teeth $\left(d_{2}, d_{3}\right)$, the premolar preceling the penultimate molar in entering upon the work of mastication. 'The differences observable between the fossil and the recent Kangaroos combining the above characteristics of the proposed subgenus are, at least, specific.

The premolar, divided in both by a vertical cleft into a smaller anterior and a larger posterior lobe, shows in the fossil a more definite basal ridge along the outer side of the latter lobe than in Phascolagus crubescens; there is also a more definite outswelling of the hind part of the hind lobe in Phascolagus altus; two feeble grooves divide the outer surface of the fore part of the anterior lobe into three rertical prominences, but these are faintly marked in the present fossil.

In the bilophorlont molars the prebasal ridge is narrow and the indication of the fore link is minute. 'The mid link is narrow, neatly defined, and sinks rapidly from the inner and posterior apex of the front lobe to the lower part of the interlobal valley. The postbasal ridge is represented by a similar outbending and descent of a sharp ridge from the inner angle of the hind lobe; which ridge, curving to subside upon the outer part of the base of the hind lobe, circumscribes, below, the depression or transverse concavity on the hind surface of that lobe.

The position and extent of the origin of the anterior pier of the zygoma is the same in the fossil and the recent species compared. 'The configuration of the hind margin of the bony palate is the same. But our extinct Kangaroo shows these characters of its subgenus on a larger scale than the largest known existing species of Phascolagus. The tooth $d 4$ (Plate LXXXII. fig. 2) is as large as its homologue in Macropus major; the antero-posterior extent of $m_{1}$ is a trifle more in the fossil. We may infer from the superior size, both absolute and relative, of the premolar in Phascolagus altus that the permanent molar dentition would be represented for a longer period of life by the five teeth, $p_{3}, d_{4}, m_{1}, m_{2}$, and $m_{3}$, than in the existing Great Kangaroo (Macropus major).

'The specimen above described, with the rest of Sir 'Thomas L. Mitculele's first collection of care-fossils from Wellington Valley, is in the Museum of the Geological Society of London. I am indebted to the President and Council for the opportunity of giring new and better figures of the type of Phascolagus altus than the original ones in the 'Appendix' of the above-cited work.

In the collection of fossils from the freshwater deposits of Queensland, Iately received from Dr. George Bexiett, F.L.S., of Sydney, New South Wales, there are instructive evidences of Phascolagus altus adding to our knowledge of its cranial and dental characters. The specimen No. 35752, Register of Fossils, British Museum, is part of a riglit maxillary of a young animal with the dentition in nearly the same state as he subject of figs. $1 \& 2$, Plate LXXXII. 'The germ of the premolar seems rather less than in that type specimen; but the hind angle was broken off in the work of exposure, 
which the state of petrifaction of the lacustrine fossils made more difficult than in the Cave specimen. The fore link is a little more marked in $m_{2}$ than in the type specimen, but the agreement in other characters is sufficiently close to determine the species and subgenus as above defined.

The next Bennettian specimen is from a somewhat older individual of Phascolagus altus; it is a portion of the right maxilla with $d_{4}, m_{1}$, and $m_{2}$ in place; these three molars occupy the same extent as that in the skull of Boriogale magnus, the upper molars of which are figured in Plate LXXX. fig. 12-anl extent about 1 line short of that in Macropus rufus (Plate LXXXIII. fig. 1), and about 1 line more than that in Osphranter robustus (fig. 3, Plate LXXXI.). We have here, therefore, plainly demonstrated, the representative of a Kangaroo about the size of the largest now living in Australia. Independently of the premolar character shown in the previous specimens, the present fossil could not be referred to Macropus major. The antorbital foramen is too remote from the orbit and from the ridged beginning of the masseteric process, which also is more directly continued from the fore border of the orbit than it is in Macropus major. The foramen in question is 7 lines in advance of the nearest part of the masseteric ridge in the fossil; it is $3 \frac{1}{2}$ lines in advance of that ridge in Macropus major.

In the position of the antorbital foramen the fossil more resembles Osphranter robustus, in which, however, the foramen is about a line further in advance of the masseteric ridge; this, in its prominence, sharpness, and the depression anterior to it, resembles more than does Macropus major the fossil fragment compared. Boriogale more closely repeats the above-defined cranial character in the fossil. But Phascolagus has the palate entire, where Boriogale shows the large vacuity (Plate LXXX. fig. 12) common to it with the type species of Halmaturus, F. Cuv. In the molars of Phascolagus the prebasal ridge is larger than in Boriogale; the breadth of the outer sides of the two main lobes is greater; the postbasal ridge better defines the hinder depression below.

Both the cranial and dental characters of Phascolagus forbid its reference to a Boriogale. In the upper molars of Osphranter, with a prebasal ridge developed in the same degree as in Phascolagus, the fore link is also present, though feeble; yet in a more conspicuous degree than in Phascolagus, where it can hardly be said to exist: the fore link is better developed in the upper molars of Macropus major, and the valley is wider between the two lobes.

The remains of the alveolar cavities for the two roots of the premolar show that it had come into place in the fossil under review; and the fore-and-aft extent which the two cavities occupy with the width of the intervening tract of bone indicate a premolar about the size, in that dimension, of that of the type specimen (Plate LXXXII. fig. 1, $p_{3}$ ), and rather longer than the following tooth $\left(d_{1}\right)$, but far short of the proportions which characterize $p_{3}$ in the genera Sthenurus and Protemnodon, next to be defined. The state of the socket of $m_{3}$ in the Bennettian specimen, and the rising of its base between the insertions of the fore and hind fangs, clearly bespeak that this tooth had likewise come into place, and that the fossil under comparison is from a nearly mature indi- 
vidual of its kind. Sufficient of the bony palate remains to show (as in the younger type specimen) that it was entire, as in Macropus proper and Osphranter.

'l'he interorbital aperture of the suborbital canal in Phascolagus is single, subcircular, and well defined; its fore and upper border rises upon a ridge or plate of bone, which 'xtends forward and outward to near where the masseteric ridge subsides into, or rises from, the fore border of the orbit. 'This structure I liave not observed in the skull of any existing species of Macropus, Osphranter, or Halmaturus; the nearest approach to it is seen in the skull of Boriogale maynus.

A second and larger proportion of the upper jaw of Phascolagus altus in the Bennettian series shows, on the left side, the base part of the crown of the premolar in place, and the sharp summits of the lobes of the last molar emerging from their nursery. 'The antecedent molars show more wear than in the preceding specimen. 'The mid-link in $d_{\mathrm{s}}$, in the present, is worn down to the dentine; yet the second lobe of $m_{2}$ is less abraded, and the fore link is rather more conspicuous.

On the right side the hind molar and its socket have been broken away. More of the premolar is preserved, but the bilobate outer part of the crown is wanting; it had, plainly, the antero-posterior dimensions of the"entire crown exposed in the type specimen (lare IXXXII, fig. 1). 'The tract of the suborbital canal is exposed in both halves of this upper jaw; and we see that its anterior outlet must be far in advance of the orbit, and about half an inch above the fore end of the premolar.

'The molar series in this fossil equal in extent and in the size of the teeth those of Macropus rufus and Macropus major; they rather exceed in size those in the younger, perhaps female, individuals represented by the first-described fossil from the freshwater beds of Queensland and by the type specimen of Phascolagus altus.

§. Sthemurus Atlas.-Similar considerations to those which influenced judgment and action in regard to the type fossil of Macropus Titan, added to plainer indications of the incomplete development of the rear teeth of the molar series in the fragment under scrutiny, led me, in 1837, to perform the same operation on the subject of fig. 4 , Plate LXXXII.*; and great was my surprise at the result.

'l'he hidden germ ( $\left.p_{3}\right)$ equalled in antero-posterior diameter both the deciduous molars which it would have displaced, and surpassed in that diameter the largest of the molars to the extent of one half that length of their crown. For the great extinct species of Kangaroo so indicated I proposed the name of Macropus Atlast.

'The tooth so discovered recalled a dental characteristic of the Potoroos, or Kangaroorats (IIypsymymmus, \&c); but the molars in the fossil were strictly bilophodont, more so. inleed, than in Macropus Titan or the existing Macropus major. There was less indication, for example, in the "links" of any subdivision or reduction of the two transverse ridges to a quadrituberculate grinding-surface; they stood out more definitely and more freely. Moreover, the large premolar of the fossil was primarily divided externally into a fore lobe and hind lobe by a vertical fissure continued as a groove almost
‘ Plate xxix. fig. 1, Mrtchell's 'Three Expeditions,' \&c., vol. ii. 1838.
† Ibid. p. 359. 
to the base of the crown, whilst the oblique extension of that fissure inward and backward gave a transversely subbilobed character to the unworn surface of the hinder part of the tooth. As, however, I have since obtained a portion of the upper jaw with the right series of molars of the same species, I will proceed with its description before entering upon further and requisite details of the mandibular evidences originally indicating the present extinct subgenus of Kangaroo.

The instructive illustration of the maxillary dentition of Sthenurus Atlas (Plate LXXXIV. figs. 4, 5, 6) formed part of a collection of fossils sent to me by F. G. WaTERHouse, Esq., Cor.M.Z.S., Curator of the Museum of Natural History in Adelaide, South Australia, in the freshwater deposits of which province this fossil was obtained.

The portion of maxilla includes the masseteric process (ib. fig. 4, $21^{\prime}$ ), the hind border of the maxillary pier from which it is continued being parallel to the interval between the penultimate $\left(m_{2}\right)$ and last $\left(m_{3}\right)$ molars. The process extends down a little below the alveolar border of $m_{2}$, and appears to be entire with an obtuse end. It is not so long relatively, does not reach so low, as in Macropus major or Macropus (Osphranter) robustus, but is more produced than in Macropus (Halmaturus) ualabatus: its proportions are most nearly those of Macropus (Phascolagus) erubescens. The outer surface of the base of the process is less deeply excavated than in any of the above-named recent species.

The convex tract behind the masseteric process and maxillary pier of the zygoma leads into the orbit, and there, about 8 lines in advance of the hind border of the pier, is the orbital aperture of the suborbital canal. It is single, subcircular, well defined, without any appearance of the oblong depression we there see in Macropus, Osphranter, and Halmaturus, where a second large foramen also conmunicates with the orbit.

The floor of the orbit presents an oblong depression (the "entorbital fossa"), with a snarp anterior and superior margin. From the fore part of this depression proceeds the suborbital canal, commencing by a large circular hole ("entorbital foramen "); a little way behind this is a smaller ("spheno-palatine") foramen.

The inner wall of the orbit, formed by the maxillary and palatine, curves outward and upward from the upper border of the depression to unite with that in advance contributed by the lacrymal, leaving the outer circumference of the entorbital foramen free from any direct rise of the interorbital plate. Anterior to the entorbital canal there is a more shallow and imperforate depression affecting the lower part of the lacrymal, at a little distance from the anterior border of the orbit. This structure of the orbital surface agrees with that in Macropus and Osphranter, with minor differences.

In Macropus major the entorbital fossa is deeper, the sharp upper border being extended backward beyond the spheno-palatine foramen; there is a third smaller "pterygo-palatine" foramen at the end of that border; but the fractured state of the fossil prevents the determination of its agreement or otherwise in regard to that third foramen.

In Osphranter rolustus the second foramen is as large as the first, and is situated to 
its inner side and very little posterior to it, the intervening bony plate with a sharp concave edge forming the inner border of the entorbital foramen and the anteroexternal border of the more oblique spheno-palatine foramen.

In Sthemerus Atlas the upper border of the entorbital fossa, in its shortness and degree of sharpness, is more like that in Macropus Titan. The inner wall of the orbit ascends rather more directly therefrom than in Macropus major. The pterygo-palatine foramen in the palatine part of the inner orbital wall is more minute in Osphranter than in Macropus. In Phascolagus erubescens the proximity of the first and second foramina is closer than in Osphranter.

In the unique skull of Boriogale magnus it appears that part of the inner wall of the orbit completing, above, the circumference of the second foramen is unossified; and such part of the skull in a petrified state would show only one large circular orifice, answering to the first or entorbital one in Macropus major and Macropus Titan. In the comparison of the orbital part of the skull, Macropus Titan, in the relative size and position of the two anterior foramina (entorbital and spheno-palatine), agrees with Macropus major more closely than with the above-cited representatives of other subgenera of living Kangaroos.

From the upper and anterior margin of the entorbital foramen (Plate LXXXIV. fig. 5, o) rises a plate of bone ( $n$, figs. $4 \& 5)$, quickly narrowing to form part of the inner wall of the orbit, or partition-wall between that cavity and the nasal one. This structure implies a less relative depth, or diameter, of the orbit from without inward or transversely than in the existing genera above cited*. But a nearer approach to the above-defined orbital character in Phascolagus and Sthenurus appears in Boriogale, where the nerves and vessels, passing by the floor of the orbit to the maxilla, leave only one mark of perforation of that floor by a subcircular entry to the canal, the other elements forming the second and contiguous foramen in Macropus, \&c., here traversing the above-surmised membranous or unossified state of the inner and under wall of the orbit. 'The reduced ossified part continued from above the bony canal rises somewhat like the lamellate process shown at $n$, figs. $4 \& 5$, in Sthenurus. Boriogale also shows the longitudinal depression above and exterior to the cntorbital foramen, terminating anteriorly in a blind end, as is seen in Sthenurus and in a feebler degree in Halmaturus.

The outlet of the suborbital canal in Sthemurus Atlas is relatively further from the orbit than in Macropus major, in which respect the present fossil resembles Osphranter and Halmaturus: the distance in the present example of Sthenurus Atlas is 1 inch 1 line. The lower part only of the outlet and canal is preserved in the present specimen; and below the outlet is a second small foramen, the canal from which passes backward, not downward as in Macropus Titan.

There is not sufficient of the bony palate preserved to determine whether it was as entire as in the larger living Kangaroos (Macropus major, Osphranter robustus, Phasco-

- Whence may be inferred a smaller cycball, associated perhaps with more diurnal habits, than in the still living Kangaroos. 
lagus erubescens), or with vacuities, as in most species of Halmaturus; but part of the border opposite the interval between $d_{4}$ and $m_{1}$ (Plate LXXXIV. fig. 6 ) is so smoothly rounded off as to suggest that it is a natural, not a broken, tract.

The premolar has the middle two fourths of its outer surface slightly depressed and feebly concare lengthwise (ib. figs. $4 \& 6, a$ ), with two chief vertical ridges and others faintly indicated. The fore and hind ends of the outer surface are smooth and convex, or bulging; the free margin is subtrenchant, with the ends of the terninal bulges obtuse. The inner surface or division of the crown (ib. fig. $5, b$ ) is much lower than the outer one, yet having more of the character of a part of the crown than of a developed "cingulum;" it increases in height as it recedes, the hind part swelling into an inner lobe, continued at the back part of the crown into the postexternal tubercle and abutting against the inner side of that part by a second transverse ridge. The lower and less dereloped fore part of the inner division of the crown is similarly connected with the antexternal tubercle, viz. by a low ridge forming the fore part of the crown, and by a buttress-like production against the inner surface of that tubercle. The intermediate part of the inner division is connected with the outer division by three transverse ridges (ib. fig. $6, p_{3}$ ). A premolar of the size shown in the figures, and with the structure above described, would be held, according to its proportions to the molars behind, as indicative of a subgeneric section of Macropodida, for which I propose the term Sthenurus, suggested by the form and proportions of a vertebra of the very powerful tail of this great extinct Kangaroo*. I shall presently be able to show that the modifications of the mandible and mandibular incisor support this distinction.

The bilophodont upper molars of Sthenurus are characterized by a narrow prebasal ridge (ib. fig. $6, f^{\prime}$ ) without a fore-link; by a still narrower and shorter postbasal ridge, represented by that, $g$ (fig. $4 \mathrm{a}$ ), which curves from the outer part of the base to the inner angle of the hind lobe, along the back part of the crown, that surface sinking a little above the part of the ridge nearest the base of the tooth. 'The mid-link (Plate LXXXIV. fig. $\left.6, m_{3}, r\right)$ is thin, low, or rudimental, yet still traceable from the back part of the inner angle of the anterior lobe to the middle of the base of the fore part of the hind lobe. The contour of the working-surface of the molars is more subquadrate than in Macropus Titan, the fore-and-aft diameter being not so much greater than the transverse. The series describes a feeble curve convex outward, but changes anteriorly to a slight concavity through the modification of the premolar at $a$, as above described. The abraded state of $d_{4}$ contrasts with the almost untouched crown of $p_{3}$, showing the earlier development of the hinder tooth. 'The dentine is just exposed on the inner halves of the lobes of $m_{1}$. The enamel only shows abrasion at the summits of the lobes of $m_{2}$; the edges of those of $m_{3}$ are slightly polished by wear anteriorly. This fossil has come from an individual that perished in the prime of life.

In existing Kangaroos the upper premolar of Macropus ualabatus, Lesson (Plate LXXXIV. figs. 1-3, $p_{3}$ ), bears the nearest resemblance to that of Sthenurus Atlas, and is

* Gr. oféros, strength; oipir, tail. 
associated with the same general pattern of working-surface of the molars $d_{\imath}, m_{1-i,}$ except that the fore-link and mid-link, though feebly developed, are more neatly defined and readily recognizable in the small existing Kangaroo. The figures of both these recent and fossil Kangaroos, or "Wallabies," being of the natural size, preclude the need of stating dimensions.

A portion of the right and a portion of the left maxilla of two individuals of Sthenurus Atlas (Plate LXXXVIII. figs. 1-4), each containing the premolar and contiguous 2-ridged molar, confirm the characters of the singularly modified premolar of the smaller species on which the genus was founded. 'The outer surface between the fore and hind convexities is traversed by three vertical ridges and four grooves in both specimens, the hindmost ridge being the smallest and shortest. The oblique cavity between the outer and inner wall is also crossed by three low short ridges, the inter. spaces of which form small pits.

In one specimen the size of the two teeth correspond with that of the maxillary type (Plate LXXXIV. figs. 4-6); in the other the teeth are rather smaller, probably having come from a female specimen.

Sthenurus Atlas was first indicated by a fragment of the under jaw from the Brecciacave in Wellington Valley. In this (mandibular) type specimen (Plate LXXXII. figs. $3 \& 4)$ three molars $\left(d_{3}, d_{4}\right.$, and $\left.m_{1}\right)$ are in place; the penultimate molar $\left(m_{2}\right)$ is lost; the crown of the last molar $\left(m_{3}\right)$ is just rising from the formative alveolus.

'The first true molar ( $\left.m_{1}\right)$ affords an instructive comparison and contrast with that in the type specimen of Macropus Titan (ib. figs. 17, 18, $m_{1}$ ). The grinding-surface of $m_{1}$ in Sthenurus Atlas is broader in proportion to its length, especially behind. 'The prebasal ridge is narrower and lower; a simple link descending from the fore and outer angle of the front lobe slopes straight to the middle of the summit of the prebasal ridge.

The outer convex borders of the two lobes (ib. fig. $4, m_{1}$ ) are narrower than in Macropus Titan (ib. fig. 18, $m_{1}$ ), and maintain their breadth, like columns, more uni. formly to their summits. The inner borders are rather broader below, but are narrower than in Macropus Titan. In Sthenurus Atlas the valley between the lobes is both wider transversely and deeper, the link being lower; it slopes from a point rather external to the middle of the front surface of the hind lobe, and runs almost straight down to the middle of the base of the hind surface of the front lobe. 'The mid link becomes almost obsolete in the last molar (ib. fig. $3, m_{3}$ ). The summits of the lobes bend slightly backward vertically, and from the thickening of the outer and inner angles are feebly concave across anteriorly. There is a slight swelling of the base of the hind surface of the hind lobe, but not any distinct postbasal ridge.

I have given a new figure of the side view of part of this fossil (Plate LXXXII. fig. 4)* and an upper view of the entire fragment (ib. fig 3), showing the characters of the working-surface of the molars.

"It is shown entire from this view in "Mitcheld," op. cit. 1st ed. vol. ii. pl. xxix. fig. 1. 
In a risit this year to the Geological Museum, Oxford, I was much gratified and interested in finding, in the series of fossils from the freshwater deposits of Darling Downs presented by Sir Charles Niciolsox, Bart., M.D., evidence of which I had been long in quest, of the fully, or nearly fully, developed dentition of the lower jaw of Sthenurus Atlas. Through Professor Phillips's kind permission, this unique fossil forms the subject of figs. 5-8, Plate LXXXII. It is a left mandibular ramus, wanting the ascending branch, of a nearly mature indiridual of Sthenurus Atlas.

The last molar $\left(\mathrm{m}_{3}\right)$ has risen into place, and the summits of its transverse lobes have been just touched by masticatory abrasion, acting from above obliquely backward, without exposing the dentine: but the large and characteristic premolar $\left(p_{3}\right)$ has not risen beyond the level of the basal third of the crown of the adjoining molar $\left(d_{4}\right)$, and its summit is quite unworn.

This specimen, moreover, gives the mandibular characters of the genus Sthenurus as distinguished from those of Macropus (ib. figs. 13, 15) -as, e.g., the shorter symphysis (fig. $6, s$ ), the larger extent thereon of the articular surface (which reaches to the outlet of the incisor socket), the angle which its lower border makes with that of the horizontal ramus, and the continuation of the upper or diastemal border to the incisor outlet in a direction more nearly parallel with that of the molar alveolar border, not descending so much or so abruptly from that border as it advances forward. The outlet (ib. fig. $5, v$ ) of the dental canal is nearer the molar series, and the part of the jaw anterior to the outlet is shorter than in Macropus Titan. The depth of the ramus behind the last molar $\left(m_{3}\right)$ is relatively greater. The inner surface of the hori zontal ramus (ib. fig. 6) is less convex vertically than in Macropus Titan.

The symphysial surface, though free or unanchylosed in the not quite mature individual yielding the specimen, must, from its greater vertical extent and uniform flatness, fit closer to its fellow, and permit less divaricating movements of the two rami than in Macropus. Besides the anterior outlet (ib. fig. 5,v) there is a vascular foramen below $m_{1}$, midway between the alveolar and inferior borders of the ramus; but this may be an individual character.

The broken border of the ascending ramus shows the fore half of the margin of the wide intercommunicating foramen (ib. fig. $6, e$ ), and the fore part of the large cavity from the inner half of which the dental canal is continued forward.

The postalveolar platform has a sharper inner border, and forms a more marked angle at that border, than in Macropus, indicating the place of the postalveolar process in Nototherium, to which, in the form and proportions of the symphysis, its closer and firmer junction of the rami, as well as in the characters of $p_{3}$, the present genus offers a nearer approach than does Hacropus proper. Moreover, as the socket of the incisor follows the direction of the symphysis, the tooth projects less horizontally than in Macropus, and rises at a similar angle with the horizontal lower border of the ramus. In all the characters of the symphysial end of the mandible Halmaturus 
valabatus (Plate LXXXIV. figs. 10, 12) agrees with Macropus and differs from sthenurus.

'The lower border of the crown of the incisor, with the free end of that tooth, is broken away in the Oxford specimen, but enough of the crown remains to show that it is shorter but vertically broader than in Macropus proper. 'The enamel is confined to the under and outer sides; the radical cement encroaches on the outer enamel in an angular form (Plate IXXXII. fig. 5, i). 'The upper border of the base of the crown is trenchrant; the tooth gradually gains in thickness to the lower border, but even liere it is less than half the vertical breadth of the crown; the inner surface, behind the working one, is vertically more concave than in Macropus Titan. 'The hind part of the narrow surface of attrition upon the upper edge of the crown begins half an inch from the hind border of the enamel.

The premolar with a fore-and-aft extent of crown of 8 lines (17 millims.), a vertical extent of 6 lines (12 millims.), and a greatest breadth, near the hind border, of 3 lines ( $6 \frac{1}{2}$ inillims.), is, externally (ib. fig. $5, p_{3}$ ), divided into two subequal lobes; but the vertical fissure runs obliquely backward and inward, so that the lobe forming the anterior half of the outer surface of the crown forms the whole of the imner surface.

This lobe has a slight prebasal prominence, and is divided above by two vertical transverse fissures, the foremost of which is in view on the outer surface, extending nearly halfway down the crown; this fissure widens to the upper border, where the two divisions of the lobe which it separates are linked by a slender longitudinal bar of enamel. The second transverse fissure is not so widened above, but the rudiment of an enamel link appears behind the second transverse division of this lobe; the third division is less definitely cleft or marked off from the rest of the antero-internal lobe, which is continued with a trenchant border to the back part of the crown to which it descends; vertical depressions, hardly to be called fissures, are indicated on the inner surface of this hinder portion of the lobe (Plate LXXXII. fig. $6, p_{3}$ ). The posteroexternal lobe (ib. fig. $5, p_{3}$ ) has a simple trenchant edge, describing a slight convexity lengthwise; it is connected with the postinternal lobe by two transverse enamel links, the foremost being the largest (ib. fig. $8, p:$ ).

The outer surface of this complex tooth $\left(p_{3}\right)$ is shown in fig. 5 , the inner surface in fig. 6, and the upper surface in fig. 8. The homologous tooth in Malmaturus ualabatus (Plate LXXXIV. figs. $10,11,12, p$ ) shows nothing of the complexity answerable to that which renders the upper premolar of that Wallaby so similar to the upper premolar of Sthemurus; it lias an undivided trenchant crown, slightly thickened behind, with some very feeble indications of vertical grooving on both inner and outer sides. Two teeth $\left(d_{2}, d_{3}\right)$ have been displaced by the rise of $p_{3}$ in the Oxford specimen of Sthenurus Atlus (Plate LXXXII. figs. 5-8): one of these, viz. $d_{3}$, is retained in the type specimen (ib. figs. $\left.3 \& 4, d_{3}\right)$.

The molar following $p_{3}$ in Plate LXXXII. figs. $5,6,8$, answers to $d_{4}$ in the placental 
diphyodont dentition*; its crown differs from that of the younger (type) Sthenurus Atlas only in a slight superiority of size. The prebasal ridge is linked to near the middle of the front transverse lobe, a little nearer the outer side, making the worn surface there somewhat thicker; the mid link rising from the middle of the base of the hind part of the front lobe rises to join the hind lobe at a similar position, and with a similar result to the grinding-surface. The more produced prebasal ridge of the next molar presses upon the back part of the hind transverse lobe of $d_{4}$, above the feeble outswelling of the base of that tooth. The fore-and-aft extent of the prebasal ridge, with its linking bar inclining obliquely outward to abut upon the front transverse lobe, characterizes the three true molars, $m_{1}, 2,3$. 'The transverse breadth of the hind lobe of $m_{3}$ is rather less than that of the front lobe.

The molar series of the present mandible describes a feeble convexity outward. The figures in Plate LXXXII. being of the natural size precludes the need of recording admeasurements.

The subject of figs. $7 \&$ 8, Plate LXXXIV., and of fig. 9, Plate LXXXII., is a portion of the left mandibular ramus (drawn in the Plate without reversing) of Sthenums Atlas, from an older individual than that which afforded the more entire ramus, but retaining the four first molars and part of the socket of the fifth.

The outer and posterior lobe of the premolar (Plate LXXXII. fig. $9, p_{3}, b$ ) has been worn down below the level of the posterior part of the antero-internal lobe (Plate LXXXIV. figs. $7 \& 8, c$ ), which stands up as an angular trenchant ridge; on the broader outer lobe a flat field of dentine is exposed, showing that the back part of this premolar, as in Nototherium, took some share in mastication, not merely in division of the food as in Halmaturus ualabatus; so much of the grooves, ridges, and other accentuations of the crown of $p_{3}$ as remain in the present specimen repeat those characters in the unworn homologue of the two preceding specimens.

The crown of $d_{4}$ (Plate LXXXII. fig. 9) shows a field of dentine enclosed by a border of enamel encroaching by a curved indent in opposite sides, and with a feeble fold at the outer part of what was the prebasal ridge. The dentine of this ridge is worn in $m_{1}$ into continuity with that of the front lobe, and a small portion of the same tissue is exposed on the back lobe. In $m_{2}$ the enamelled summits of the transverse lobes are worn obliquely backward, the enamel showing there a finely polished tract. The basal swelling at the back part of this molar is better defined than in the type specimen; in neither is the hind surface of the molars impressed as in Macropus Titan. 'The present specimen agrees in size with the comparable or homotypal parts of the upper jaw (Plate LXXXIV. figs. 4, 5,6). The slight difference of size as compared with the mandible of the younger individual (Plate LXXXII. figs. $5,6,8$ ) is well within the limits of individual and sexual range of variety.

The outer surface of the portion of mandible of Sthenu'us Atlas (Plate IXXXIV. fig. 7) shows a longitudinal sinuous shallow channel, extending from below the fore part of $p_{3}$ 
to $m$, at a distance varying from 2 lines to 5 lines below the alveolar border. Below the chamel the ramus swells to greater thickness than in the largest of the mandibular fossils of Macropus Titan. The lower border has been broken away; and in the longitudinal extent of mandible here preserved, the fractured surface shows a pretty uniform brealth or thickness of 9 lines.

The increase of the fossil (Plate LXXXIV. fig. 7) over the younger Sthenurus (Plate LAXXII. fig. 5) is shown by the bone more than by the teeth. But even in the smaller specimen (ib. figs. 5, 6) the mandible is relatively stronger and deeper than in Mracropus Titan (ib. figs. 13,15$)$. In this species the last four molars $\left(d_{4}\right.$ and $\left.m_{3}\right)$ occupy a longitudinal extent of 2 inches 4 lines, but in Sthenurus Atlas of 2 inches. These differential mandibular and dental characters come well out in comparing figs. 5 \& 13 , and figs. 8 \& 14, in Plate IAXXII.

\$ 8. Sthenurus Brehus, Ow.-This species is represented by two fossils from the Breccia-cave of Wellington Valley, presented to the British Museum by the 'Trustees of the Natural-History Museum of Sydney, New South Wales, and forming part of the results of the exploration by Prof. Thomson and Gerard Krefet, Esq., carried out with the aid of the legislative grant*.

The specinens formed part of a series of duplicates, thickly encrusted, like those of Thylacoleo and Phascolomys $\downarrow$, with the reddish stalagmite of the cave.

The most acceptable and instructive results of the clearance of the fossils from their matrix were the subjects of figs. 5-9 of Plate LXXXVII. The largest specimen (figs. $5 \& 6$ ) consists of a portion of cranium including a great part of both maxillaries, with the intervening palatal plates and both palatine bones; the zygomatic masseteric process came out entire on both sides of the skull. The molar series of the left maxillary $\left(p_{3}\right.$ to $\left.m_{3}\right)$ had undergone fracture of the crowns of the two anterior teeth; the portion of the right maxillary included the two posterior molars.

The pattern of the molar crowns closely accords with that of Sthenurus Atlas, and the narrow but well-defined prebasal ridge (ib. fig. $6, m_{2}, f^{\prime}$ ) was without the link; the mid-link (ib. ib. $r$ ) was represented by a rudiment at the bottom of the ralley between the two transverse lobes, $a, b$; the postbasal ridge $(g)$ was represented by the crescentic border of a depression on the hind surface of the hind lobe; the main ridges were rather narrow antero-posteriorly in proportion to their breadth and vertical extent.

The superiority of size of Sthenurus Brehus over Sthenurus Atlas may be estimated by comparing figs. 5-9, Plate LXXXVII, with figs. 4-6, Plate LXXXIV. The base of the broken premolar (Plate LXXXVII. fig. 6, $p_{3}$ ) shows similar proportions of that tooth, although, as the crown swells out beyond the part retained, this does not yield the whole fore-and-aft extent. Fortunately another cranial fragment of the species(Plate LXXXVII. figs. $7,8,9$ ) included the premolar and adjoining molar entire, and yielded the required subgeneric character of the anterior tooth. The crown is 10 lines in fore-and-aft length, $5 \frac{1}{2}$ lines in vertical extent, $4 \frac{1}{2}$ lines across the thickest part of the base, which is near 
the hind end of the tooth. The fore end (Plate LXXXVII. figs. $7 \& 9, d$ ) is subtrenchant, with a prebasal triangular prominence, one angle subsiding halfway along the trenchant fore border. The middle two thirds of the outer surface (fig. $7, a$ ) show the usual concavity lengthwise between the smooth and prominent fore $(d)$ and hind $(e)$ ends of the crown, and on this depressed surface are three vertical obtuse ridges, dividing four shallow linear grooves. The cutting-edge $(a)$ similarly sinks below the angular summits of the terminal prominences $(d, e)$. On the inner side of the crown may first be noticed a low narrow ridge (fig. $8, f$ ), extending a few lines backward from the inner basal angle of the prebasal prominence. Above the ridge $(f)$ begins the broader rising, which soon stands out as a low inner basal division of the crown; it bends up posteriorly to abut against the inner side of the hind expansion (e), leaving a small triangular depression between the buttress and the hind margin of the tooth. The interval between the inner basal lobe or ridge $(b)$ and the outer or main part of the tooth is less depressed than in Sthenurus Atlas, and does not show the small transverse connecting bars in the hollow. Masticatory attrition has polished the inner side of the blade or outer main part of the crown of this premolar and the inner basal prominence, indicative of a corresponding transverse extension of the crown of the lower premolar. A speck of dentine has been exposed on the buttress. As compared with the upper premolar of Sthenurus Atlas, the generic pattern is closely retained, but with the specific modifications above defined.

The crown of the adjoining molar $\left(d_{4}\right.$, fig. 9$)$ is worn obliquely from without nearer to the base of the inner side of the tooth. The very narrow prebasal ridge is shown. The dentine exposed on each lobe is broadest at the inner half of the grinding-surface, and it extends in both lobes into an angular form behind, that of the fore lobe indicating the rudimental link, that on the hind lobe the rudimental postbasal ridge.

The third tooth (ib. figs. $5 \& 6, m_{1}$ ) shows, as in Sthenurus Atlas (Plate LXXXIV. figs. 4-6, $m_{1}$ ), a marked increase of size over $d_{\star}$. The prebasal ridge is more developed; the exposed dentinal tracts resemble those in Plate LXXXVII. fig. $9, d_{4}$, bnt are rather less extensive. The characters of the slightly worn penultimate and last grinders have already been defined, and are sufficiently given in figs. $5 \& 6, m_{2}, m_{3}$.

'The hind border of the bony palate is so entire in the present evidence of Sthenurus Brehus as to show that it described a moderate unbroken concave curve, as in Osphranter robustus. So much of the palate itself as is preserved suffices to exemplify its correspondence with that and other larger existing Kangaroos (Macropus major, Macropus rufus, Phascolagus erubescens) in the degree of its integrity.

The masseteric process descends opposite the hind lobe of the penultimate molar, and the hind margin of the anterior zygomatic pier is opposite the fore part of the fore lobe of the last molar (ib. fig. $6, m_{3}$ ).

The extent of the alveolar part of the maxillary in adrance of the masseteric process is relatively greater than in Macropus major, and more resembles that in the Kangaroos which longer retain the premolar and which have that tooth of larger relative dimensions than in the type of Macropus proper. The amount of fracture and variety of 
distortion which this cave cranial fragment has undergone indicates a persevering exercise and diverse direction of force, such as only accords with the operations of the powerful jaws of a litrge camivore.

A third example of Sthemurus Brehus (Plate IXXXVIII. figs. 5, 6, 7) has reached me, through the persevering and successful cooperation of Dr. BexsetT, F.I.S., which more closely or directly shows the distinction of this species from Sthenurus Atlas ('late LXXXIV. figs. 4, 5, 6; Plate LXXXVIII. figs. 1-4), as it consists of an almost identical portion of the upper jaw and grinding series of teeth with that which yielded those instructive characters of the smaller giant Wallabec.

'The longitudinal extent of the dental scries in the present maxillary fossil is 3 inches 5 lines; in Sthenurus Atlas it is 2 inches 10 lines. The dimensions of the premolar are precisely those of the cave-specimens (Plate IXXXVII. figs. 7, 8, 9). 'The characters which mark the species are closely repeated. The fore part of the inner lower wall $(b)$ is more distinctly marked off from the oblique ridge $(f)$ in a small notched prominence $\left(f^{\prime}\right)$. The hollow between the walls $a$ and $\zeta$ is rather decper, and there is one low transverse ridge at the bottom of the hollow. The hind triangular (lepression (c) and other generic characters of the premolar of Sthenurus are instructively repeated. 'The same may be said of the succeeding bilophodont molars; the degree of wear of which is identical with that of the type maxillary specimen of Sthenurus Atlas (Plate LXXXIV. fig. 6). The inner end of the prebasal ridge (Plate LXXXVIII. fig. $5, f$ ) extends further forward from the front lobe, $a$.

The masseteric process (ib. fig. 5, $21^{\prime}$ ) seems to have been relatively longer, and more compressed from before backward than in Sthenurus Atlas (Plate LXXXIV. fig. 4, 21'); it holds the same relative position to the last two molars. The outlet of the suborbital cunal is 1 inch 6 lines in advance of the orbit, and 9 lines above the base of the premolar, on a rertical parallel with the hinder third of that tooth.

'The depression at the back of $m_{3}$ (Plate IXXXVIII. fig. 9) is bounded by two ridges which converge from the outer and inner apices of the hind lobe as they approach the base of the crown. The inner ridge (ib. fig. 10, g) is the strongest and longest; it curves toward the base of the outer part of the hind lobe, but subsides before attaining either the base or the outer border; its termination is marked off by a short notch. The outer posterior ridge subsides before reaching the basal end of the inner one. Both ridges are due to an excavation of the hind surface of the lind lobe, repeating more strongly the depressions on the same surface of the front lobe; and the inner hind ridge of the hind lobe is the scrial repetition of the ridge which runs from the corresponding apex of the front lobe to the low mid-link. 'The hindmost molar has been lost, but the alveolus remains (ib. fig. 6, $\mathrm{ms}_{3}$ ), showing that the transverse pair of anterior roots had been developed, and the longitudinally impressed, but incompletely divided, hind root, had been formed; the crown had evidently been in place, though from the slight abrasion of the apical ridges of the lobes of $m_{2}$, in $m_{3}$ they may not have been worn.

A second specimen of a smaller portion of the right maxilla, with the three hinder 
molars in situ, of an older Sthenurus Brehus gives the molar $\left(m_{3}\right)$ with the apical ridges obliquely worn at their fore surface, but not through the enamel. It permits a comparison with the homologous tooth in the type specimen (Plate LXXXVII. figs. 5 \& 6 , $m_{3}$ ), has been added to the figures 5, 7 (Plate LXXXVIII.), and completes the confirmation of the dental characters of the species.

§ 9. Genus Protemnodon*, Ow.-The genus Protemnodon is allied to Sthenurus, but distinguished therefrom chiefly by the more simple trenchant shape of the crown of the premolar.

Having ascertained the characters of that tooth in the upper jaw of Sthenurus Atlas, in the specimen from the lacustrine deposits of South Australia (Plate LXXXIV. figs. 4, $5,6)$, I subjected to a reexamination the fossil upper jaw brought to me in 1842 by Count StRzelecki from the Breccia-cave of Wellington Valley, and the specimen transmitted in the following year from the bed of the Condamine by Col. Sir Thomas L. Mitchell, C.B., both of which specimens, from the size of the germ of the premolar (Plate LXXXIII. figs. 6 \& 9), had been referred, in my 'Catalogue of the Fossil Mammalia in the Royal College of Surgeons,' to Macropus Atlas $\uparrow$.

I had fortunately begun the quest of this tooth from the inner side of the formative alveolus, and was now able to recognize, in the absence of the inner ridge or lobe characteristic of the upper premolar of Sthenurus, and giving the crown of that tooth a breadth corresponding with the lower premolar, that the fossils Nos. 1513, 1519 must belong to another species, and, according to the estimate of the value of premolar modifications, to another subgenus of Macropodide.

The subsequent acquisition of mandibular fossils, with the premolar simple and trenchant, and with equivalent modifications of the form of the bone, have afforded the requisite ground for proposing the genus, and for referring these maxillary specimens to the species Macropus Anak, originally founded on characters of the lower jaw and teeth.

The upper molars of Protemnodon are more like those of Sthenurus Atlas than of Macropus Titan; they have a narrow prebasal ridge without the link. The oblique ridge extending downward and backward from the inner and hinder angle of each chief lobe is more definitely marked, and the two lobes are more alike than in Sthenurus Atlas. The breadth of the crown in $m_{1}$ and $m_{2}$ of Protemnodon Anak (Plate LXXXIII. figs. 5 \& 8) is greater in proportion to the fore-and-aft length than in Sthenurus; and the inner border of the two lobes (ib. figs. $6 \&$ 9) is narrower and more sharply pointed than the outer border (ib. figs. $4 \& 7$ ), in a more marked degree even than in Sthenurus.

Proceeding to the characters afforded by the mandible and teeth (Plates LXXXV.\& LXXXVI.), I have first to remark that the premolar ( $p_{3}$ in all the figures), in its relative antero-posterior extent to the molars which follow, rather exceeds that tooth in Sthenurus Atlas. The proportion of $p_{\text {: }}$ in Protemnodon is much the same as in the Bettongs⿱中; it is not equal to that in Dendrolagus dorcocephalus $\oint$. As in this Tree-Kangaroo, the

* $\pi \rho \dot{o}$ (before), $\tau \dot{\tau} \dot{\mu} \mu \omega$ (to cut), jòoús (tooth) -in reference to the sectorial form of the anterior molar or premolar.

$\dagger 4$ to, 1845, pp. 325, 327, Nos. 1513, 1519. 。 $\quad \ddagger$ Ante, p. 170, fig. 18.

$\S$ Ibid. fig. 16. 
lower molars, like the upper ones, retain the Macropodal bilophodont character. But the lower premolar of P'rotemnorlon shows no indication of the three-lobed division which is marked on the outer surface of the crown of that premolar of I)endrolagus. It is rather more like that in the Potoroos, though the indications of vertical grooves and ridges on the compressed part of the crown between the slight fore and hind thickened ends are feebler.

The greatest height of the crown of the premolar, which is at the fore part (Plate $\mathrm{L} \times \mathrm{XXV}$. figs. $3,5,7, \& 8, p 3)$, is but half the antero-posterior diameter; the utmost thickness (at the back part of the crown) (ib. fig. 2) is less than the height. The free or trenchant margin is straight, and runs nearly parallel with the base of the crown. The fore border is subtrenchant, the hind one flattened, and closely adpressed against the contignous molar. 'The fore part is defined behind by the subsidence of the narrower following part of the crown on the outer side (ib. fig. $3, p^{3}$ ), and, less definitely, by the foremost of the shallow vertical grooves on the inner side (ib. fig. 8). The base of the fore part of the crown bulges forward beyond the anterior root. The hind part of the crown slightly expands, but is not defined, like the front expansion, from the rest of the crown. A feeble indication of a "cingulum " runs along the outer side of the base of the crown, and is more dubiously represented by a slight smooth outswelling along the base of the inner surface. The tooth is implanted by two anteroposterior, slightly divergent, fangs.

\$10. Protemnodon Anak, Ow.-The subject of Plate LXXXV. figs. 1 \& 2, the type specimen on which the species Macropus (Protemnodon) Anak was founded*, is a portion of a left mandibular ramus, including the molar series. All the tecth of the permanent dentition are in place, and from the degrees of wear of their crowns it may be inferred that the foremost $\left(p_{3}\right)$ was the last to come " into line."

Only the hinder angle of the enamelled trenchant border of the crown of this tooth is touched, whilst the dentine is exposed on the ridges of the last molar (ib. fig. 2, $m_{3}$ ). The crown of $d_{4}$ has been worn down nearly to the bases of the two lobes, and the dentine of the mid-link connects the trro exposed wide tracts of that tissue, forming the bases of the worn-out ridges. The next molar (ib. ib. $m_{1}$ ) shows a greater degree of wear; the dentinal part of the mid-link is broader, and the lobes, as seen in the side view (ib. fig. $1, m_{1}$ ), are worn down lower or nearer to their base than in $d_{4}$. The front lobe of $m_{2}$ has been abraded to the level of the link, which, being low in this species of Protemnodon, is hardly touched. A broad tract of dentine is also exposed on the hind lobe. A narrower bilobed tract appears on the front lobe of $m_{3}$; the enamelled summit of the hind lobe is smoothly worn downward and backward. The prebasal ridge $(f)$ is broadest in this tooth, and shows a low link $(s)$ continued from the fore part of the outer swelling of the front lobe. The inner alveolar border (ib. fig. 8) runs from the postalveolar ridge $(t)$ with a feeble concavity to $m_{1}$, and then takes as feeble a convex course to the diastema $(l)$.

* Proceedings of the Geological Society of London, vol. xv. p. 185 (June 23, 1858). 
The subject of figs. $1 \& 2$, Plate LXXXV., was obtained by Henry Hughes, Esq., from the freshwater deposits exposed in the beds of creeks in Darling Downs. It is now in the Museum of the Natural-History Society of Worcester, to the Council of which Society I was indebted in 1858 for the permission to take the above description and figures of this instructive and, at that time, unique fossil.

'To Sir Daniel Coopen, Bart., I have since been indebted for the opportunity of describing and figuring a larger proportion of the left mandibular ramus of the same species of Protemnodon, with the molar series at nearly the same stage of attrition. It was discovered by ED. S. Hill, Esq., in the freshwater deposits of Eton Vale, Queensland. Of this fossil I give an external view (ib. fig. 3), in which it will be observed that, as in the foregoing example, the crown of $m_{1}$ is more worn (has borne more of the work of mastication) than that of the antecedent molar $\left(d_{4}\right)$. I have noted the same circumstance in a Macropus major of similar age. This may not relate to an earlier period of $m_{1}$ coming into the line of work than the molar which precedes it, but more probably is due to the greater degree of pressure upon a tooth nearer the centre of motion of the mandible. The last molar (ib. figs. $3 \& 4, m_{3}$ ) shows the narrower hind lobe $(b)$ : the seemingly broader prebasal ridge $(f)$ than in $m_{2}$ may relate to the less amount of attrition in $m_{3}$. The links are low and ill-defined in this, as in the type specimen. There is a slight bulge behind, but no indent marking a postbasal ridge in the hindmost molar. The inner vertical plate of the horizontal ramus is continued further back than in existing Kangarnos and Wallabies, forming an inner wall (ib. fig. 8, $t$ ), with a definite and sharp margin, beneath the base of the coronoid process; and fiom the point where this hind margin of the inner mandibular plate is continued upward into the coronoid, a low ridge extends on the side of the plate next the large cavity of the ascending ramus forward and downward to the entry of the dental canal. This ridge (ib. fig. $14, g$ ) divides the cavity into an upper $(f)$ and lower $(\alpha)$ compartment. The structure is repeated, as will be seen, in the specimen next to be described.

'The curve and direction of so much of the diastemal ridge (ib. fig. $3, l$ ) as is here preserved resemble rather that of Macropus and Halmaturus than of Sthenurus; but the less mutilated specimen (ib. figs. $7 \& 8$ ) shows the toothless tract $\left(l, s^{\prime}\right)$ to be relatively shorter as compared with the molar series than in either of those genera of existing Kangaroos.

This specimen likewise forms part of the series of fossils from the river-beds at Eton Vale, Darling Downs, presented by Sir Daniel Cooper, Bart., to the British Museum.

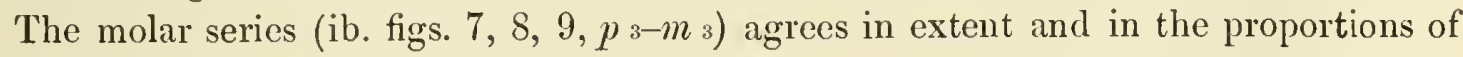
the five teeth with the type specimen, but the fossil is from a less aged individual. The hind angle of the sectorial crown of $p_{3}$ (fig. 9) is made obtuse and polished by wear. The dentine exposed on both lobes of $m_{2}$ is transversely linear, with a slight forward production in both links $(r$ and $s)$. In $m_{3}$ a speck of dentine appears on the inner angle of the front lobe $(a)$ : the enamelled ridges of this and the hind lobe show the oblique polished tract at their hinder surface. 'The characteristic proportions of both 
fore and mid links are well shown in $m_{3}$, and contrast with the better developed ones in the somewhat larger Protemnodon represented by the subject of figs. 11, 12, \& 13 , Plate L.XXXV.

'The last molar in Protemnodon Anak rises, in the outer side view of the mandible, clear of the front root of the coronoid process (ib. fig. 7, q). 'The fore part of the outer crotaphyte excavation (fig. $7, f^{*}$ ) sinks as abruptly from the prominent anterior border as in Macropus and Ilalmaturus; but the cavity appears to be divided in Protemnodon by a curver ridge into an upper $\left(f^{\prime}\right)$ and lower $(a)$ chamnel, the latter being that which leads to the large hinder orifice of the dental canal. A similar fracture of the ascending ramus of the naudible in existing Kangaroos would not produce this appearance, but it may be due to the minor development and closer approximation to the coronoid plate of the base of the inflected mandibular angle in Protemnodon.

In the deptl or vertical breadth of the ramus beneath the last molar and the minor degree of vertical convexity of that part, Protemodon contrasts with the narrower and more bulging character of the same part of the jaw in Macropus. It is rather less convex, though narrower, in Halmaturus. 'There is a trace at $a$, fig. 8 , of the beginning of the excavation, or lower chamel, leading to the intercommunicating aperture and to the entry of the dental canal; but the extent of the inner plate of the mandible, from $t$ to $\alpha$, is not matched by any existing Kangaroo the lower jaw of which I have compared with the fossil.

In the extent of the edentulous and symphysial part of the mandible (ib. fig. $8, l, s^{\prime}$ ) Protemnodon agrees with Halmaturus rather than with Macropus; but the syndesmotic surface extends nearer to the alveolar outlet of the incisor $(i)$, although it does not indicate so firm a union as in Sthenurus (Plate LXXXII. fig. 6). It extends more in the axis of the ramus than in Sthenurus.

'The breadth of the incisor and that of the surface (Plate LXXXV. fig. 10, i) which was opposed to the upper incisors point significantly to a Nototherian tendency.

'The configuration of the crown of the unworn molars (ib. figs. 11-13, $m_{2}, m_{3}$ ) in a portion of a mandibular ramus of a large Protemnodon Anck supplements the illustrations of the mandibular dentition of the species. 'The fossil was part of an individual, probably male, in which the hindmost molar had recently risen "into place." The links (fig. 13, $r, s$ ) are more neatly defined in this unworn tooth, which also had not moved forward so clear of the coronoid process (fig. 11) as in the older example (fig. 7 ).

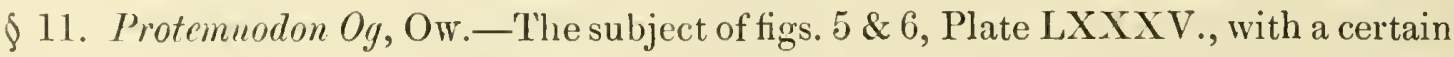
increase of size of both mandible and molar teeth, repeats the form and size of the premolar $\left(p_{3}\right)$ in Protemnodon Anak, but shows a distinct linear indication of the postbasal ridge $g$, and a more definite development of the links $r$ and $s$ in the last molar, $m_{3}$. 'These characters may be subsequently found in other individuals, and sufficiently evince an established variety; but they are so strongly marked in the still larger mandibular fossils next to be noticed as to justify their ascription to another (zoological) species, and the imposition of the name which heads the present section. 
\$12. Protemnodon Himas, Ow.-In this species a greater depth and thickness of mandible and a concomitant larger size of molars are associated with a relatively smaller size of the trenchant premolar, which does not exceed that in Protemnodon Anak. Such character of the variable tooth might be expected, having regard to those which it exhibits in different species of existing Wallabies (Halmaturus, Cur.).

In the present large extinct species of Protemnodon a marked modification of the molar teeth accompanies their relative proportions to the premolar, and confirms the taxonomic deductions as to specific status, but does not give ground for assigning thereto subgeneric value.

The postbasal ridge (Plate LXXXVI. fig $3, g$ ) though narrow is definite; the prebasal ridge (ib. $f$ ) is proportionately as well developed as in Protemnodon Anak; its "link" (ib. $s$ ) also, and that (ib. $r$ ) of the two chief lobes, are more distinct than in the type of that species.

The smaller mandible and teeth (Plate LXXXV. figs. $7 \& 8$ ) cannot hare come from a younger specimen of the present species; both molars and premolars are more worn, and prove that fossil to have been derived from an older Kangaroo than the animal which owned the subject of the present description.

The premolar of Protemnodon Mimas (Plate LXXXVI. fig. 1, $p_{3}$ ) shows on the outer side of the intermediate part of its crown five rertical grooves and four ridges, more strongly developed than in Protemnodon Anak; these are, in part, worn smooth on that side of the tooth of the subject of fig. 7, Plate LXXXV. For the rest, the characters of the premolar of the larger species are those of Protemnodon Anak.

'The crown of $d_{4}$, figs. 1-3, has suffered more from fracture than abrasion. A linear tract of dentine is exposed in each transterse lobe of $m_{1}$, slightly expanding at the origin of the "link" from near the outer end of their anterior surface. Only the enamel shows abrasion in $m_{2}$. The crown of $m_{3}$ is entire, has but recently risen into place, and, contrasted with that tooth in the subjects of fig. 6 \& fig. 13, Plate LXXXV.. exemplifies the coronal character of the molars of the present well-marked species. It is partially concealed in a direct outer side view by the coronoid process, $q$, fig. 1 , Plate LXXXVI.

For this fine evidence of Protemnodon IFimas I am indebted to my friend Dr. GEoRGE Bexretr, F.L.S., of Sydney, New South Wales, who obtained it from the freshwater deposits forming the bed of "Gowrie Creek," Darling Downs.

From the same fertile district, but in another locality (Eton Vale), Sir Daxifu Cooper. Bart., received and presented to the British Museum the portions of mandible (Plate LXXXIV. figs. 13 \& 14, and Plate LXXXVI. figs. 4 \& 5), little, if at all, exceeding in size the corresponding part of that of Macropus major or Macropus rufus. 'The best-preserved molar in each of these fossils indicated, howerer, a larger species. This molar, moreover, presented good differential characters in the presence of the well-defined, though small, postbasal ridge (ib. fig. $7, g$ ), the large prebasal ridge (ib. $f$ ), and the welldeveloped and almost equal-sized fore-link $(s)$ and mid-link $(r)$; the proportions of the 
two principal transverse lobes in the minor breadth of their outer and inner convex borders as compared with their height were rather those of Sthemurus than of Macropus. But Sthenurus Atlas shows no postbasal ridge (comp. Plate LXXXIV. fig. 15, $m_{3}$, Protemnodon Mimas, with the same view, Plate LXXXII. fig. 8, of the homologous tooth in Sthenurus).

On the hypothesis that the specimens (Plate LXXXIV. figs. 13-16 and Plate LXXXVI. figs. $4 \& 5$ ) belonged to the same species as the specimen (Plate LXXXVI. figs. $1 \& 2$ ), the last, largest and best-preserved unworn molar in the smaller jaws would be homologous with the anteperultimate and worn molar in the larger jaw. 'The testscrutiny was accordingly applied, and the germ of the large premolar characteristic of the genus Protemnodon was brought to light in both the smaller fossils (Plate LXXXIV. fig. 14, p 3, Plate LXXXVI. fig. 5, $p$ s). The Kangaroos leaving these remains had each perished at the same phase of dentition as that shown in the type specinen of Sthenurus Atlas (Plate LXXXII. figs. 3 \& 4); the subgeneric characters afforded by the premolar are well exemplified thereby. The comparatively flat undivided outer surface, with the continuous straight trenchant margin of the crown of $p_{3}$ in Protemnodon, contrasts with the two convex lobes defined by the median fissure notching the trenchant margin and deeply grooving the outer surface of the crown of $p_{3}$ in Sthenurus; and the differences are better marked in the originals than in the figures above cited, although these give the details with sufficient accuracy.

'The mandibular fossils of the young Protemnodon supply acceptable additional evidence of the dental characters of the species. Thus the crown of $d_{4}$, which is mutilated in the type mandible (Plate LXXXVI. figs. 1-3), is entire in figs. 4-6, save as regards the degree of masticatory abrasion to which it has been subject, exposing a linear tract of dentine on each main lobe expanding where the link joins such lobe. 'The postbasal ridge (Plate LXXXIV. fig. 13, $d_{4}$ ) is as conspicuous in this as in the succeeding tooth, $m_{1}$; the prebasal ridge shows also a proportionate development, with the tore-link distinct (Plate LXXXVI. fig. 6, $d_{4}, s$ ). The first and second deciduous molars (ib, $d_{2}, d_{3}$ ) occupied an alveolar extent of 9 lines; they were displaced, as usual, by the rise of the premolar with a crown of corresponding antero-posterior extent. 'The subject of figs. 13-15, Plate LXXXIV., was from a younger animal than that of figs. 4-6, Plate LXXXVI. ; in the former the molar $\left(m_{1}\right)$ had very recently risen into place; in Plate LXXXVI. figs. 4-6, the enamelled summits of the transverse ridges of $m_{1}$ are a little worn, as usual, fiom above downward and backward.

'The socket of the incisol in the subject of fig. 4 is broken across about an inch from its closed end: the fracture (ib. fig. 8, i) gives, therefore, the breadth and thickness of the front tooth at that part, which would be, at least, the same as that of the exserted crown of the large procumbent incisor in Protemnodon Mimas.

Of the upper jaw and teeth of this species (Protemnodon Mimas) my present evidence consists of photographs of the natural size of a specimen obtained by Professor 
Thomson and Mr. KrefFT in the Breccia-cave of Wellington Valley, and deposited in the Museum of the Natural-History Society of Sydney, New South Wales.

The photographs, liberally transmitted to me by the Trustees of that Museum, and prepared under the superintendence of their able Curator, Mr. KREFFT; give an outer side view (Plate LXXXVII. fig. 1), an inner side view of part of the left premaxillary and teeth (ib. fig. 2), an inner side view of the premolar (ib. fig. 3), and a view of the grinding-surface of the two best-preserved molars $\left(d_{4}, m_{1}\right.$, left side, ib. fig. 4$)$. These teeth, the premolar of the left side, and perhaps the front and second incisor are tolerably perfect; the remaining teeth have suffered more or less fracture; but the remains of the molar series in situ on the left side enable the requisite admeasurements and comparisons as to size to be made with the mandibular teeth of the kinds of Protemnodon previously described. From their close accordance in this character with the mandibular teeth of Protemnodon Mimas (Plate LXXXVI. figs. 1-3) I refer the subject of the photographs to that species.

The upper incisors, as in existing Macropodida, are three in number in each premaxillary. The foremost (Plate LXXXVII. fig. $1, i_{1}$ ) is curved lengthwise, with the convexity forward, and has a thick enamelled crown, with the fore part convex transversely ; its convex cutting-edge projects slightly beyond that of the second incisor. The crown of this tooth $\left(i_{2}\right)$ is smaller, less convex, and less prominent than that of the foremost one. The indications of the socket of the third incisor support the inference that, as in the large existing Kangaroos (Macropus major, Macropus (Osphranter) robustus, Macropus (Osphranter) rufus), the antero-posterior dimension of the crown of that tooth exceeded that of the second and first incisors; but of the precise proportions of these teeth exemplifying specimens are still desiderata.

The antero-posterior extent of the incisive alveoli of the left premaxillary is 1 inch 5 lines, that of the toothless interral between the third incisor and the premolar is 1 inch 9 lines; the extent of the molar series is 3 inches 2 lines. The diastema is relatively shorter than in the above-cited existing Kangaroos, and indicates a corresponding condition of the lower jaw, whereby, as regards length. Protemnodon resembles Sthenurus.

The premolar $\left(p^{3}\right)$, however, retains in the upper jaw the more simple trenchant form which afforded the subgeneric distinction in the homotypal tooth below. There is a slight expansion of the fore and hind parts of the crown, the intermediate part of the blade having an entire and nearly straight trenchant edge, with the indication of a low ridge or cingulum along the base. The corresponding part on the inner side of the crown (ib. fig. 3), though much less developed than in the upper premolar of Sthenurus, adds another character differentiating Protemnodon Mimas from Protemnodon Anak.

The bilophodont molars have both pre- and post-basal ridges; the former, as usual in upper molars, less produced than in the lower molars. The indication of the fore link is recognizable, and that between the main lobes is more plainly shown (ib. fig. 4); the mid link is worn down to the base, exposing a broader tract of dentine in the 
foremost $\left(d_{4}\right)$ and a linear tract in the next tooth $\left(m_{1}\right)$. A broad field of dentine had been brought to the grinding-surface of both lobes in both molars. Mr. KrEFrt has noted on one of the photographs of a fossil upper jaw, which I refer to Protemnodon Mimas, "Molars worn down, premolar in good condition"-an appearance which is the consequence of the later development of the front tooth of the series. The crowns of the other molar teeth seem to have suffered mutilation from fracture in the original of the plotograph. 'The maxillo-premaxillary suture (between 21 and 22 in Plate LXXXVII. fig. 1) is unmistakable in the plotograph; anterior to it, in a line with the hind part of the last incisive socket, the premaxillary has suffered fracture. 'The extent of the diastema contributed by the maxillary (21) is 1 inch 1 line. 'The course of the suture resembles that in Halmaturus; it does not describe an angle or curve forward before ascending obliquely backward to the nasal, as in Macropus major.

If photographs alone, such as those in ib. figs. 1-4, of which I have given the foregoing interpretation, should be thought insufficient evidence of an extinct species, I may remark that the characters of Protemnodon Mimas, and the determination of that species of extinct Kangaroo, are independent of them, and are sufficiently exemplified in the fossil remains, before described, of the mandible and mandibular teeth of this gigantic Wallaby.

§ 13. Protemnodon Røechus, Ow.-The subject of figs. 10-13, Plate LXXXVII., from King's Creek, Clifton Station, presented by the proprietor, GEongE Kivg, Esq., is a part of a left mandibular ramus, with the permanent dentition, save the last molar, in place and use; and, from the degree of attrition of the crown of $m_{2}$, it is plain that $m_{3}$ had risen into place, and been lost with the supporting part of the jaw by mutilation of the fossil. The retained molars have characters of those of Protemnodon Anak, in wanting the postbasal ridge (fig. 13), and having the links less sharply defined (fig. 12) than in Protemnodon Mimas. But the increase of size is more than can be granted to difference of sex. The protemnodont pattern of premolar is closely adhered to ; the hind swelling of the crown (ib. fig. 10,b) is relatively somewhat greater than in Protemnodon Anak, and a smooth triturating surface has been worn upon its summit; the trenchant border is abraded, as usual, upon its outer side. The anterior lesser expansion is defined externally by an oblique, not vertical groove. The lower border as well as both ends of the mandible have been broken or worn away.

The series of preserved teeth describes a slight curve, convex inward-a character (if it be specific) which is not shown by any of the other and smaller kinds of extinct Kangaroos forming the subject of the present communication. In this I have continued the practice, began in my Appendix to Mitciell's work (1838), of attaching the names of giants, familiar to the students of biblical and mediæval histories, to the several extinct species which towered of old above the tallest of the living Kangaroos. 
\$14. Macropus Titan (skull). - The first evidence of this extinct species yielded by any considerable part of the skeleton in addition to the maxillary and mandibular ones is the chief subject of Plates LXXVI.-LXXLX.

It is a great part of the skull of a Kangaroo, wanting the lower jaw, but including the cranium proper, the interorbital and the hinder part of the facial division of the skull; also great part of the left zygomatic arch with the included orbit and temporal fossa, the bony palate, and the molar dentition, of which the two hindmost teeth are sufficiently entire to afford the means of specific determination.

Other projecting parts and processes have suffered fracture, and the region of the large frontal sinuses has been obliquely crushed.

The specimen is in the usual heavy petrified condition of fossils from the freshwater drift; it shows the effects of transport and attrition during the movements of this matrix, at the locality now forming the bed of "King's Creek," near Clifton, Darling Downs, Queensland*; it was picked up by Mr. W. F. Тоотн, Jun., at a part of the creek indicated by Dr. BexnetT as likely to yield fossils when the bed was exposed at the dry season succeeding a flood. As much of the matrix has been cleared away as could be safely meddled with, since it came into my hands, and the present state of the fossil is figured, of the natural size, in Plates LXXVI.-LXXIX.

According to the Cuvierian precept the molars received the first attention; and the characters of these in several of the large extinct Macropodidoe having been determined and characterized in the foregoing pages, I had helpful subjects of comparison with those in the present skull, which were in an instructive state of preservation.

The upper molars of Macropus Titan differ from those of Macropus major not only in size, but in pattern. Not, indeed, so much in the general one affecting the transverse lobes, links, and prebasal ridge, as in the sculpturing of the hind surface of the tooth, which is the seat of instructive modifications characteristic of genus and species in other members of the family Macropodida.

In Macropus major that surface (Plate LXXIX. fig. 3) is moderately hollowed lengthwise, and thickly coated with cement, which partly fills the triangular transverse concavity, the apex of which shallows to the ordinary level of the hind surface before reaching the base of the crown; when the cement is removed, the inner enamel boundary $(g)$ is sharper and more produced than the outer one $(h)$.

In Macropus Titan the enamel, after coating the inner border of the hinder lobe, extends backward, downward, and outward, projecting as a sharp-edged ridge (ib. fig. $2, g$, and Plate LXXXI. fig. 18, $t$ ), defining a deeper depression on the hinder surface of the tooth. There is also a shallow vertical groove $(h)$ continued from the hind part of the apex of the inner border of the hind lobe downward toward the base of the crown, which groove seems to define the inner limit of the oblique posterior ridge. One sees that this groove repeats the deeper cleft that defines the mid link, internally, from the

"See "A Trip to Queensland in search of Fossils," by Dr. Georar Bensetr, F.L.S., in Annals \& Magazine of Natural History, April 1872. 
inner cnd or border of the anterior lobe. The oblique hind ridge (Plate LXXXI. fig. $15, g)$ is, indeed, a serial repetition of the mid $(r)$ and fore $(s)$ links, but subsides with a more oblique course downward toward the base of the outer border of the hind lobe, having no other division of the molar to connect with such lobe. From the fore part of the base of the inner end of the hind lobe a low ridge defines the anterior surface of that lobe to the inner side between it and the mid link; this defining ridge is not present in the upper molars of Macropus major, but there is a small tubercle at the inner entry of the valley between the two main lobes of the upper molars in Macropus major, which is not present in Macropus Titan.

'The fossil skull, with the molars agreeing in the above characters, and in size, with those of more fragmentary examples of Macropus Titan (Plate LXXXI. figs. 8, 10, 15, 16 and Plate LXXXII. figs. 10-12), is of a mature and somewhat aged individual. 'The summits of both lobes of the hindmost grinder (Plate LXX1X. fig. 1) are worn so as to expose a linear tract of enamel, widest of course on the anterior lobe. In the penultimate grinder a broad field of dentine is exposed on this lobe extending backward by a linear tract along the base of the mid link $(r)$, but not so far as the transverse tract of dentine exposed on the hind lobe. In the antepultimate grinder both lobes are so worn that the lozenge-shaped fields of exposed dentine touch and communicate at the base of the worn-down link. The foremost grinder $\left(d_{4}\right.$, Plate LXXVII.) is retained on the right side, worn down to its base; but this tooth has been shed on the left side, and the grinding series reduced to the three true molars, as in old individuals.of Macropus major.

The skull of this large existing species which I lave to compare with the present fossil retains the last deciduous molar $\left(d_{4}\right)$ on both sides of the upper jaw, without any trace of the socket of the premolar which had worked in advance of the four retained grinders $\left(d_{4}, m_{1,2}, 3\right)$.

In the maxillary fossil of Macropus Titan, figured in Plate LXXXI. fig. 10, the two roots of $p_{3}$ are retained, the crown having been accidentally broken away. That of the last molar $\left(m_{3}\right)$ had not come into place, although the front lobe had pushed its way out of the formative cell. The two lobes of $m_{2}$, in the same fossil, show attrition of the enamel-ridge, but not so as to reacl the dentine.

In the younger subject of figs. $6,7,8$, Plate LXXXI., the four teeth in place are $d_{3}, d_{4}, m_{1}$, and $m_{2}$; above the first of these is exposed the crown of $p_{3}$, in its formative cell ; and part of that of $m_{3}$ is shown behind $m_{2}$.

The series of changes of the upper molar dentition of the extinct Macropus Titan are thus as instructively and almost as completely displayed in petrified specimens as in the existing species (Macropus major) of which I have obtained specimens in number and periods of age sufficient to exemplify these phases*. I have lately received a mandibular specimen of Macropus Titan with the molar dentition reduced to $m_{2}$ and $m_{3}$ (Plate IXXXIX. fig. 1) as in the latest observed phase in Macropus major. 
The cranial specimen exemplifying the reduction of molars to three on the left and four on the right side lacks, unfortunately, the part of the upper jaw which supported the incisor teeth. Nearly 2 inches of the diastemal tract is, however, preserved in advance of $d_{1}$ on the right side. A fossil mandible of another individual of Macropus Titan, with a similar stage of dentition as the right side in Plate LXXIX., fortunately gives the extent of the diastema between the molars and incisors (Plate LXXXVI. .fig. 11), and, guided by the proportion which this part bears to the upper diastema in Macropus major, I have restored, in outline, in Plates LXXVI., LXXVII. \& LXXIX., what is wanting in the present fossil, together with an outline of the mandible and mandibular teeth.

The length of the mandibular diastema in Macropus major is 1 inch 9 lines, that of the maxillo-premaxillary one is 2 inches 6 lines. The length of the mandibular diastema in Macropus Titan being 2 inches 6 lines, that of the maxillo-premaxillary diastema, according to the pattern of the recent species, should be 3 inches 6 lines. There are indications, however, that the muzzle was relatively rather shorter in the larger extinct Kangaroo, and I have restored it, with an interval of 3 inches 3 lines between the foremost molar and hindmost incisor.

Of this characteristic tooth fossil specimens reveal different patterns of the outer surface of the crown, of which I give two in examples indicative of species as large as Macropus Titan and Sthenurus Atlas.

In one type (Plate LXXVI. fig. 4, Plate LXXVII. fig. 2) the anterior half of the crown is divided into three unequal convex tracts by two oblique grooves, of which the hinder one extends nearest to the base or root of the tooth; in the other type (Plate LXXVI. fig. 3, Plate LXXVII. fig. 5) a deeper oblique fissure subequally bisects the crown; it marks off a more prominent fore part of the outer surface from a lower and vertically shorter, but rather more longitudinally extended, hind tract. As the first of these patterns is repeated in the third upper incisor of Kangaroos with a small premolar (Macropus major, Plate LXXVII. fig. 3), and the second pattern is found in Kangaroos with a large trenchant premolar (Halmaturus ualabatus, Plate LXXX. fig. 20, Halm. ruficollis, ib. fig. 21), I refer the fossils of the second pattern to Sthenurus Atlas, and those of the first pattern to Macropus Titan.

Macropus Titan has the triangular form of occiput (Plate LXXVIII. fig. 2) as in Macropus major (ib. fig. 3), the apex of which at the summit of the superoccipital ridge (3) is somewhat rounded off.

In like manner a second inner ridge from the base of the paroccipital (4) converges towards its fellow as it rises, parallel with the outer ridge from the mastoid, but subsides at 2 , before attaining the summit of the exterior ridge, 3 .

The crown of the superoccipital arch projects rather more backward in the fossil than in Macropus major; it is not on a vertical plane with, or sloping forward from, the occipital foramen. The surface below the arch is traversed by a less prominent medial vertical ridge in Macropus Titan than in Macropus major. 
The upper border of the occipital foramen $(o)$ is mutilated in the fossil, but seems to have been more arched, less angular, and the foramen to have been less transversely widened than in Macropus major (fig. 3,o).

The upper and larger ends of the condyles (ib. fig. $2^{\prime}$ ) subside more gradually into the occipital surface, are not defined by a depression there, as in Macropus major (ib. fig. 3). The channel or concavity between the condyle and paroccipital (4) is relatively wider in Macropus Titan. In this species the foramen magnum seems as if it had been notched at its upper border, where the exoccipitals may not have met, and where the foramen may have been bounded by an intercalated portion of the superoccipital.

The basioccipital (Plate LXXIX. tig. 1) is carinate below, as in Macropus major and Macropus rufus (Plate LXVI. fig. 3,1 ); but there is more tumefaction at its suture with the basisphenoid in Macropus Titan. A low crest runs along the sagittal suture (Plate LXXVIII. fig. 1) which bifurcates, the divisions diverging to the postorbital prominences, which, as usual, are feeble. In Macropus rufus (Plate LXVI. fig. 2) at a similar phase of dentition the sagittal suture persists, and the low ridges $\left({ }^{\prime}\right)$ have not met at the mid line.

The fore part of the glenoid surface is contributed by the malar, in Macropus Titan, as in other Kangaroos. The outer surface of the zygoma seems not to be so deeply impressed or concave as in Macropus major or Macropus rufus (Plate LXVI. fig. 1, 26). The facial part of the skull anterior to the orbits seems to have been relatively broader in Macropus Titan than in Macropus major; but there is an oblique crush at the upper part, here, in the fossil, with loss of the outer table of the cranium. The antorbital foramen is relatively further from the orbit in Macropus Titan than in Macropus major; in this character Macropus rufus more resembles the fossil. The front pier of the zygoma springs more posteriorly than in either of the large existing Kangaroos.

The bony palate (Plate IXXIX.) is extended further backward, and the production of the alveolar border of the maxillary behind the last molar $\left(m_{3}\right)$ is more convex transversely than in Macropus major or Macropus rufus (Plate LXVI. fig. 3, 21").

The bony palate is entire in the fossil, and is relatively wider than in Macropus major. 'The interspace between the right and left ultimate molars in Macropus Titan is two and two thirds of the fore-and-aft diameter of that tooth; in Macropus major that interspace is two diameters and one fifth of the same tooth.

The lower area or outlet of the zygomatic arch is relatively larger in Macropus Titan than in Macropus major; it exceeds the length of the molar series of four teeth $\left(d_{4}, m_{1}\right.$, $\left.m_{2}, m_{3}\right)$ by the length of $m_{3}$, in Macropus Titan; while in Macropus major this outlet does not equal the length of the same series by half the anterior molar $\left(d_{4}\right)$.

The diastemal border is less obtusely rounded in Macropus Titan than in Macropus major; it resembles more that border in Macropus rufus (Plate LXVI. fig. 3), and in some of the smaller Kangaroos, such as Phascolagus erubescens.

Of the extent of the diastemal interval in the upper jaw the fractured fore end of the present fossil of Macropus Titan precludes any certain estimate, but I have ascertained 
it approximately on the grounds previously defined. If, however, a narrow vacuity with a rounded concave hind border in the bony palate be structural, it would represent, in the fossil, the right incisive foramen, and would indicate a shorter diastema and intervening bony palate than I have estimated; I incline, however, to view such vacuity as accidental, and to place the incisive foramina as in the outline to Plate LXXIX. Further acquisitions of the cranial parts of Macropus Titan may be hoped for to determine this part in the restoration of that fine extinct species.

Subjoined are admeasurements of the fossil skull above described, with corresponding ones of the skull of a mature male Macropus major.

$\begin{array}{cc}\text { Macropus } & \text { Macropus } \\ \text { major. } & \text { Titan. } \\ \text { in. lines. } & \text { in. lines, }\end{array}$

Length of skull from superoccipital ridge to fore part of $d_{4}$. $\quad \begin{array}{lllll}4 & 9 & 6 & 6\end{array}$

Breadth of skull at widest span of zygomata . . . . $4 \begin{array}{llll}4 & 3 & 5 & 9\end{array}$

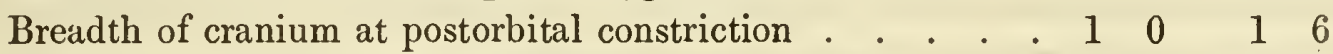

Breadth of cranium at the mastoids . . . . . . . . 21138

Breadth of foramen magnum . . . . . . . . . $010 \quad 011$

Length of cranium from superoccipital ridge to postorbital constriction . . . . . . . . . . . . . . $27 \begin{array}{lll} & 7 & 3\end{array}$

Length of cranium from superoccipital ridge to fore border of orbit . . . . . . . . . . . . . . . . $4 \begin{array}{llll} & 4 & 5 & 8\end{array}$

Length of orbito-temporal vacuity, lower opening . . . . . $\begin{array}{lllll} & 1 & 9 & 2 & 6\end{array}$

Breadth of orbito-temporal vacuity, lower opening $\quad$. . . . $\begin{array}{lllll} & 1 & 4 & 1 & 8\end{array}$

From hind border of palate to fore border of $d_{4}$. . . . . 2430

Breadth of palate between the right and left molars $\left(m_{2}\right) \quad: \quad \begin{array}{lllll}1 & 4 & 1 & 10\end{array}$

From alveolus of $m_{3}$ to hind border of palate . . . . . . $\begin{array}{lllll}0 & 6 & 1 & 1\end{array}$

From lower border of orbit to alveolar border at $m_{1}$. $\quad$. $\quad \begin{array}{lllll} & 1 & 0 & 1 & 6\end{array}$

Length of series of four molars $\left(d_{4}\right.$ to $\left.m_{3}\right)$. . . . . . 11022

Length of $m_{2}$ and $m_{3}$. . . . . . . . . . . . . . . . 1113

Breadth of fore lobe of $m_{3}$. . . . . . . . . . . . $0 \begin{array}{lllll} & 4 & 4 & 0 & 0\end{array}$

$\$ 15$. Sthenurus Atlas (fore part of skull, with incisors and milk-molar dentition).Confirmation of the ascription of the second type of upper third incisor to an extinct species of Kangaroo with a large premolar tooth, has been had by the reception of a specimen of that part of the skull and dental system which, as a rule, is wanting in cranial fossils of these extinct Marsupialia.

This specimen consists of the facial part of the skull, including the anterior halves of the orbits to the ends of the premaxillaries, with their incisor teeth (Plate LXXVI. fig. 2). The molar dentition is represented by an anterior tooth of trenchant character, followed by three double-ridged molars on the left (ib. ib. $d_{3}, d_{4}, m_{1}$ ) and two on the right side (Plate LXXVII. fig. $4, d_{s}, d_{s}$ ). The third on the left is emerging from its socket with the ridged summits of the lobes narrow ; a portion of a formative cavity of 
a larger molar is preserved behind that tooth. This evidence of immaturity is supported by the incomplete exclusion of the crown of the third incisor (ib. ib. $i_{3}$ ); and the correspondence of the stage of dentition with the second (B) of the series in Macropus major, figured in my 'Anatomy of Vertebrates' *, was demonstrated by the usual test, viz. the exposure of the crown of the replacing tooth $\left(p_{3}\right)$ in its formative alveolus, above the deciduous teeth $\left(d_{2}, d_{3}\right)$ in place and use (Plate IXXVII. fig. 4$)$. The third bilophodont tooth $\left(m_{1}\right)$ on the left side is not so far advanced as its homologue in the jaw showing the third stage (op. cit. ib. C) of the dentition of the Macropus major. The germ of the premolar and the deciduous teeth in place accord with the characters shown in more fragmentary specimens of Sthenurus Atlas. Consequently can be added, by means of the present fossil, the characters of the first and third upper incisors to the previous knowledge of the dentition of that large extinct species.

The present portion of a young individual of Sthenurus Atlas presents a condition which significantly points to the nature of its violent death, and to the operation of the powerful jaws and teeth of its carnivorous destroyer.

The upper jaw, anterior to the orbits, has been nipped in by a cross-bite; another grip in a vertical or obliquely vertical direction in the orbital region has crushed the right half in the course of the interfrontal and internasal sutures, to a lower level than the left half, with a similar degree of forward dislocation. 'The skull has been subject to this violence in its fresh state, and the matrix has subsequently become petrified about it, and has preserved the dislocations. If they had been due to movements of the matrix after fossilization, the petrified bed would show fracture corresponding to the bone; but no such evidence of posthumous crushing of matrix and fossil being present, I presume that the skull, if it had been imbedded, uninjured, would have retained its form when petrified, and conclude that the actual state of the fossil was that in which it was interred before petrifaction began.

'The anterior incisor (Plate LXXVI. fig. 2, $i_{1}$, Plate LXXVII. fig. $4, i_{1}$ ) is curved, as in most existing Kangaroos; but besides its superiority of size to that in the largest kind as shown by the breadth of the crown (Macropus major, e. g. Plate LXXX. fig. 17, Macropus rufus, Plate LXVI.), the exserted and enamelled portion is both absolutely and relatively longer, and thus makes a nearer approach to the character of the first upper incisor in Diprotodon (Plate XIX. $i_{1}$ ).

The convex or fore surface of the crown of $i_{1}$ in Sthenurus Atlas is traversed longitudinally by a shallow and rather wide groove behind the mid line of that surface, which groove deepens near the cutting edge, and thus marks it with a feeble notch. The enamel also shows some fine longitudinal striations. 'The enamel is uninterrupted, but becomes much thinner at the back part of the tooth. A transverse section of the crown would give a long narrow oval, rather broader at the outer and hinder end.

The breadth of the tooth, or length of the oval, is 10 millims. or $4 \frac{3}{4}$ lines; the thickness or antero-posterior extent is 4 millims. or $2 \frac{1}{2}$ lines. The hind margin of the tooth, 
near the cutting edge, shows the shallow indent caused by the crown of the second incisor; but this tooth, in both premaxillaries, has been displaced by the lateral crushing of these bones in the recent state, and was probably lost prior to the imbedding of the skull. The second incisor is the smallest and least deeply implanted in most Kangaroos.

The third incisor (ib. ib. $i_{3}$ ) had not been fully developed; its crown has only partially emerged from the socket, whence its preservation. It is in the form of a scalene triangle; the shortest side is turned forward, the longest forms the cutting edge, which is notched anteriorly by an oblique groove extending from near the middle of the outside of the crown down to the cutting edge, then inward and forward along that edge to near the antero-inferior angle of the crown. The grooved part of the edge in its present unworn condition thus presents two trenchant borders. The fore side or border of the crown shows an anterior low convex ridge through the subsidence of the enamel between this and the mid groove; the enamel behind this groove is again at a lower level; thus the antero-posterior lay of the outer enamel is undulated. The fore-and-aft extent of the exposed crown is 6 lines; the front border or side of the triangle measures 5 lines.

The indent caused by the second incisor is present on both right and left anterior incisors; the interspace between the first and third incisors from which the second has been pushed is greater on the left than on the right premaxillary. A detached fully developed third incisor of a full-grown Sthenurus Atlas is figured in Plate LXXVII. fig. 5 .

In the lower jaw of this species (Plate LXXXII. fig. 5) the interval between the molars and procumbent incisor is less than in Macropus Titan (ib. fig. 13). The present specimen shows that a similar character marks the upper jaw. 'The extent of the maxillo-premaxillary diastema is, here, 10 lines, but would be, of course, greater in the full-grown Kangaroo.

The anterior molar (Plate LXXVI. fig. $2, d_{2}$ ) with a crown 6 lines in antero-posterior extent, shows a depressed middle tract of the outer surface traversed by two vertical ridges. The inner surface, which forms postcricrly a prominent conrex lobe, sinks rapidly to a basal ridge as it extends forward to a low angle on the inner side of the anterior division of the tooth. The second molar $\left(d_{3}\right)$ has a prebasal ridge without the fore link; the mid link is small and low placed, in chief continuation with the inner angle of the fore lobe. 'The hind surface of the hind lobe has a triangular excavation.

'These characters are repeated in $d 4$ and $m_{1}$; the crown of the latter is protruding from the formative cell, and is unworn. The crown of the premolar, exposed in its formative cavity, is incomplete with the concomitant wide and deep excavation at the basal part for the unexhausted pulp. The longitudinal grooves and ridges of the trenchant apical border, part of which are visible in the worn premolar of the subject of fig. 4, Plate LXXXIV., are well shown in the germ of the premolar in that of fig. 4, Plate LXXVII.; its fore-and-aft extent agrees with that of the fully developed homologue, viz. 9 lines $=18$ millims.

The bony palate, so far as it is preserved, appears to have been entire. 
The valve of an Australian freshwater shell (Melania nana) adheres to the front pier of the right zygomatic arch, just above the masseteric process, which descends outside the socket of the last molar $\left(m_{1}\right)$ coming into place. The movements attending the growth of the maxilla, whereby the relative position of this process to the hindmost molars, subsequently developed, is changed, have been already noted.

For fuller illustration of the dental characters of Sthenurus Atlas, figures of portions of the right and left maxillary, each with the two anterior teeth $\left(p_{3}, d_{4}\right)$ of the mature dentition, are given in Plate LXXXVIII. figs. 1-4. They show the low transverse ridges crossing the bottom of the valley between the high outer and low inner wall of the crown, and repeat other characters exemplified in the jaws of the mature animal (Plate LXXXIV. figs. 4-6) by which the genus Sthenurus is distinguished from the genus Protemnodon and from the genus IIalmaturus.

For further exemplification of the two specific representatives of Sthenurus, figures of portions of jaws of a mature Sthenurus Brehus are given in Plate LXXXVIII. figs. $5,6,7$, corresponding with the subjects of Sthenurus Atlas in Plate LXXXIV. Further exemplifications of the larger species are the subjects of the following section.

$\S 16$. Sthenurus Brehus (restoration of dentition and skull).-This species was founded on a maxillary portion of cranium with the left molar series, in part mutilated, and with the last two molars of the right side (Plate LXXXVII. figs. $5 \& 6$ ); also on a fragment of the left maxillary with the premolar and contiguous molar entire (ib. figs. 7, 8, 9) from a younger individual. Both fossils were from Mitciell's Breccia-cave in Wellington Valley, New South Wales, and formed the first cvidence of this extinct species which came to my hands.

Since the text and plate illustrative of these fossils were printed off $I$ have been favoured, through the persevering and successful quest of GEorge F. Bennetr, Esq., in Queensland, son of my old and esteemed friend Dr. George Bennett, F.L.S., of Sydney, New South Wales, with portions of the skull and lower jaw of older and younger individuals of the same species, from the freshwater drift at Clifton Downs, Queensland. One of these specimens exhibits the entire molar series, left side upper jaw, with that of the right side, less the last molar; another fossil includes the premaxillaries and upper incisors; and a third consists of the fore part of the mandible with the lower incisors and with the first three molars of the right side. All three specimens are parts of the same skull.

A fourth lot consisted of four portions of the upper jaw of a mature but younger individual than the subject of Plate LXXXVII.; they included the incisors and premolars of both sides, and the entire molar series of the right side.

A fifth specimen consisted of the fore part of the upper jaw of an aged individual with much of the crowns of the incisors worn away, and the smaller ridges on the inner side of the premolar rubbed smoothly down.

These specimens instructively exemplify the constancy of the maxillary molar characters of the genus and species, as shown in the type specimens, and add those of the mandible, and the characters of both upper and lower incisors. 
From these materials I have attempted to restore the skull, as in Plate CVIII.

Of the incisors the first, or foremost (ib. figs. $1,2,3, i_{1}$ ), has a greater relative superiority of size over the second and third than in any existing species of Kangaroo that has come under my observation; in this character Sthenurus approaches the Koalas and Potoroos among existing, and the colossal Diprotodonts among extinct Marsupials.

The transverse diameter of the crown of $i_{1}$ is 8 lines ( 17 millims.); it nearly equals that of the two following incisors, of which the third is broadest, viz. 5 lines (10 millims.) along the oblique trenchant or working border; the thicker, triturant surface of the second incisor is 4 lines ( 8 millims.) in longest diameter. The crowns of the six incisors describe a semicircle (ib. fig. 3); those of the anterior pair, separated by a line's breadth in the fossil, evidently touched each other in the living animal at their median angles, which show the effects of mutual pressure.

Each incisor is curved lengthwise with a strong outward or forward convexity; the exposed enamelled crown of the first measures in a straight line 1 inch 1 line ( 27 millims.); that of the second incisor $7 \frac{1}{2}$ lines $(15$ millims. $)$; that of the third incisor the same: this, as usual, expands to the working-surface; its outer enamel is bisected by a feeble linear longitudinal groove. The transverse interval between the two incisors of the third pair is 1 inch and a half. The outer half of the fore surface of the crown of the second incisor is prominent, and is pressed into a corresponding channel of the hind surface of the first incisor (ib. fig. 3); the channeled part of the contiguous surface of the second incisor reciprocally receives the prominent part of the opposed first incisor. The crown of the third incisor presses closely against that of the second; thus firmly interlocked, they worked as one tooth. The enamel of the second and third incisors is continued from the outer or fore part of the crown upon part of the hind or inner surface; but the enamel of the large anterior incisors is limited to the fore part. Thus, in both proportion and structure, the large incisor more resembles, than the other two, the still larger proportional tooth in Nototherium and Diprotodon; but it still is an incisor of limited growth, and its implanted fang tapers to the end.

From the back of the medial border of the front incisor (Plate CIX. fig. 10, $i_{1}$ ) to the fore border of the 'foramen incisivum' (ib. $a$ ) is $1 \mathrm{inch}$; from this border a groove (b) is continued forward, shallowing, to within an inch of the tooth. The breadth across the outsides of the last pair of incisors is 1 inch 11 lines; the breadth of the palatal part of the premaxillaries at the fore part of the prepalatal or incisive foramina is 1 inch $9 \frac{1}{2}$ lines. From the third incisor to the premolar is 2 inches 1 line; in other words, this is the extent of the diastema or toothless space (Plate ('VIII. fig. 1, $d, d^{\prime}$ ) between the incisors and molars. The breadth of the bony palate anterior to the premolars is 2 inches 1 line. The length of the molar series (Plate CVIII. fig. 1, $p_{3}{ }_{3} m_{3}$ ) is 3 inches 6 lines; in Sthenurus Atlas it is 2 inches 9 lines. The premolar $\left(p_{3}\right)$ exceeds the rest in fore-and-aft diameter, which is, as in the cave-specimen (Plate IXXXVII. fig. 7, $p_{3}$ ), $9 \frac{1}{2}$ lines (20 millims.); the three low transverse ridges which connect the inner with the outer wall are well marked in the present comparatively young though full-grown 
individual. 'These ridges become less salient in the course of the oblique wear of the crown of the premolar from the outer to the inner ridge, as in fig. 6, Plate LXXXVIII.; and in old individuals they are 'polished off,' as in fig. 10, Plate CIX. But all the generic and specific characters of the premolar of Sthemurus Brehus from Mitcuell's Breccia-cave in New South Wales are repeated in the present specimens from the fluviatile beds of Queensland. The same may be said of all the succeeding molars which in the type-specimen are sufficiently complete for comparison. The last molar in the present example (Plate CIX. fig. $3, m_{3}$ ) has not quite come to the grinding level, and its ridges are untouched. The enamel-fold from the inner angle of the lind ridge, which defines by its oblique tract along the lind surface the angular depression there, seems as if it were folded on itself or notched at its basal termination.

'The zygomatic process (Plate CVIII. fig. 1, ${ }_{21}$ ') is more perfectly preserved than in any other fossil, transmitted, of the genus Sthemurus; it descends below the level of the grinding-surface of $m_{2}$; in older examples it would show the same relation to $m_{3}$, as the grinders move (or seem to move) forward.

I next proceed to notice the portions of skull of a more aged individual of Sthenurus. Brehus, from Clifton, Queensland. 'The laterally crushed maxillary part of the skull (Plate CIX. fig. 4) includes the entire molar series of the left side, and major part of that of the right side. The premolar $\left(p_{3}\right)$ with a fore-and-aft length of 10 lines $(20$ millims.) in the type-specimen (Plate IXXXVII. fig. $7, p_{3}$ ) is but half a millimetre less in the present fluviatile fossil, and this seems due to the wear of the anterior prominence; but all the formal characters are closely repeated.

I have had no evidence from the spelæan haunt of the Thylacoleons, of a Sthen. Brehus which had attained the experienced age of the yielder of the present Queensland fossil. The molar contiguous to $p_{3}$ contrasts, as usual, its great degree of wear with the fresher crown and higher level of the antecedent subsectorial tooth; the fore-and-aft diameter, 6 lines (12 millims.), is the same in both fossils; the minor transverse breadth in the Queensland specimen is due to the wearing down of the outer angles of the transterse lobes or ridges, which are prominent in the cave-fossil. The superiority of size, slight as it is, in $m_{1}$ of the type-subject of Plate LXXXVII. figs. $5 \& 6$, is chiefly due to the minor wear of the crown of that tooth in the cave-fossil. The last two molars occupy a longitudinal extent of 1 inch 6 lines ( 37 millims.) in both specimens. The linkless prebasal ridge $(f)$ is transverse, not curving at either end to be continuous with the corresponding angles of the fore lobe; the low short mid link $(r)$ is less distinctly continued to the inner angle of the fore lobe than in Sthenurus Atlas; the depression on the hind surface due chiefly to the ridge $(t)$ curving from the inner and hinder angle of the hind lobe toward the outer side of the base of the crown, with the lower and shorter ridge $(g)$ from the outer angle, are all characters of Sthenurus lirelus, repeated in the present as in the preceding Queensland sedimentary fossil.

'The left molar series in this instructive specimen (Plate CIX. fig. 4) occupies a longitudinal extent of 3 inches 3 lines. 
The dentine is exposed on the fore lobe of the last molar, and the fore part of the enamel-ridge of the hind lobe is nearly worn through; the prebasal ridge $(f)$ also shows abrasion. A hollow transverse field of dentine is exposed on both lobes of the penultimate molar. With these indications of greater age, the maxillary pier (21') has retrograded, and projects on the transverse parallel chiefly of the last, instead of the penultimate, molar, as in the younger specimens (Plates LXXXVII. \& CVIII.). In all the bony palate is entire.

The fore part of the present skull has been broken away in front of the premolars, and shows a diastema 2 inches in extent. From the back of the socket of the third incisor to the fore part of the crown of the first is 1 inch 3 lines. Of the third incisor (the seat of variety in existing Kangaroos), the left is lost, and of the right one only the fang remains. The crown of the second right incisor is worn nearly to its base. 'The first or front incisor (Plate CIX. fig. 6) is present in both premaxillaries, with its fang exposed in the left one. The crown is worn to the level of the palate (ib. fig. 4, $i_{1}$ ); the smooth and polished surface presents an oval figure, the great and outward; the long dameter is $7 \frac{1}{2}$ lines (15 millims.); the short diameter, near the outer side of the worn surface, is $5 \frac{1}{2}$ lines ( 11 millims.). The enamel, nearly 2 millims. in thickness, is limited to the anterior surface, bending slightly back at the outer and inner margins; not more than 9 lines length of the enamelled crown remains. The whole incisor, as usual, is curved lengthwise, with the greater convexity anterior; the root contracts to its implanted end ; the length of the incisor, in a straight line, as here worn, is 1 inch 8 lines. The portion of cranium preserved, from the fore part of the front incisor to the back of the last molar, measures 6 inches 8 lines. According to the proportions of some existing Wallabies, which retain the premolar with the last molar in use, 5 inches may be added for the extent of skull behind the last molar, and the total length of the skull in Sthenurus Brehus may be moderately estimated at 12 inches (as in the restoration, Plate CVIII.).

About 2 inches of the facial part of the premaxillaries are preserved, bounding by a curved and obtuse border, thinning as it rises, the anterior nostril (Plate CVIII. fig. 1, 22).

The skull, so far as it is shown in the present specimen, has been crushed sideways, not partially, as in the cave-fossil, but by a pressure operating through a more extensive plane, and which I deem to be due to movement of the matrix, rather than to the jaws of a destroyer or devourer.

The lower jaw, which appears to have been imbedded originally in connexion with the upper one, has suffered similar lateral compression. Only the fore part of the mandible has been obtained or transmitted; it includes the pair of lower incisors, with the premolar and two following molars of the right side (Plate CIX. figs. $7 \& 8$ ); these are much worn. The length of the diastema is 2 inches; in Sthenurus Atlas (Plate LXXXII. fig. 5) it is 1 inch 3 lines. In the course of the pressure to which this mandible of Sthenurus Brehus has been subject, the attachment of the broad symphysis has been overcome, and the right ramus has been moved a little in advance of the left (ib.fig. 7). 
'I'he thin alveolar sheath does not extend to, or has been lost from, the end of the cement-clad root next the enamelled crown. 'This expands as it extends forward, and terminates in a polished worn surface 10 lines in long diameter (obliquely transverse), 5 lines in fore-and-aft diameter. 'The leugth of the enamelled (under or outer) part of the crown is 8 lines; that of the entire tooth is $2 \frac{1}{2}$ inches. 'Ihe fang, as usual, tapers, as it recedes in its socket (I'late CVIII. fig. 4). The narrow symphysial border sinks from the premolar alveolus (ib. fig. $8, l$ ) with a sharp curve before extending forward to expand upon the terminal part of the socket of the incisor (ib. $l^{\prime}$ ). 'The outlet of the dental canal $(v)$ is nearer the molars, and the diastema, with the symphysial part of the ramus, is longer, relatively, than in Sthenurus Atlas.

A third example of the premaxillary part of the skull with the fore part of the right maxillary, of a still older individual of Sthenurus Brehus, from Queensland deposits, shows the six incisors in situ much worn, and the form and transverse extent of the palate between those teeth and the molars (Plate CIX. fig. 10). The length of the diastema is 2 inches 1 line; the breadth of the palate at the prepalatal foramina is 1 inch 9 lines. The foramina (ib. $a, a$ ) are elongate, from 2 to 3 lines broad, about 6 lines long, and continued forward by a groove (ib. $b$ ) which shallows out when parallel with the third incisors. 'These are much worn; the working-surface of the third is 7 millims. by 6 millims. The enamel which is continued from the outer upon the hinder surface is impressed, as in the less worn tooth of the younger Brehus, by a longitudinal groove almost equally bisecting the outer surface. The second or mid incisor is worn almost to the stump. The front pair of incisors, being more worn than in the subject of fig. 4 , show a working-surface of similar shape but rather smaller dimensions; the anterior coat of enamel (ib. fig. 1) is reduced to a length of 4 lines (10 millims.).

In the collection of Marsupial fossils from Queensland, at Worcester, I noted the left lower incisor of a Kangaroo, of which I made drawings of the under or outer side (Plate CVIII. fig. 4). This tooth best agrees with the corresponding incisor of Sthenurus Brehus. It had preserved an extent of enamelled crown of 8 lines, the breadth being that of the more worn incisor of fig. 8. In the great Kangaroo (Macropus major, Plate LXXX. fig. 15) the breadth of the crown of the lower incisor is $4 \frac{1}{2}$ lines; in Osphranter rufus (Plate LXVI. fig. 1) it is barely 4 lines.

The portion of skull of a Sthenurus Atlas (Plate LXXVI. fig. 2, Plate LXXVII. fig. 4) permits comparison to be made of the first and third incisors with those teeth in Sthenurus Brehus. The first incisor is but half the size of that in the larger species, while the third incisor presents a crown of equal size. 'The generic character of equal division of the crown by the longitudinal groove is retained, but the anterior border of the groove is produced at the lower part of the crown. Such characters, however, may have existed in the part of the crown worn away in the subject of Plate CVIII. fig. $1, i_{3}$. But the difference of proportion in the upper incisors is, at least, specific. In Macropus Titan (Plate LXXVI. fig. 4 \& Plate LXXVII. fig. 2) the modification of the pattern of the third incisor is associated with generic distinction in other parts of the dental 
system and in the skull. If the unworn crown of $i_{1}$, in Sthenurns Brehus, should show other proportions to the two following incisors than in Sthenurus Atlas, it might tempt a labourer in the 'gattungs-macherei' to impose a new generic term upon the larger Wallaby.

$\S 17$. Protemnodon Mimas (mandibular dentition, continued).-Of this genus and species a portion of a right mandibular ramus, recently received, shows the molar series entire, and from an older animal than that yielding the type-specimen (Plate LXXXVI. figs. 1, 2, 3). The last molar $\left(m_{3}\right)$ is in place with the hinder slope of the ridge of each lobe worn, but not so as to expose the dentine. The narrow postbasal ridge is present as in the type; $m_{2}$ is worn to about the same degree as $m_{1}$ in that specimen (ib. fig. 3); $m_{1}$ in the present jaw shows a broad field of dentine on each lobe, on a level with the low link. In $d_{4}$ the fields are connected by a linear strip of dentine traversing the mid link. A small spot of dentine is exposed on the inner part of the hind swelling of the premolar.

The dimensions of this molar series, as of the individual teeth, are almost precisely those of the type. The anterior part of the alveolar border of the four anterior teeth swells into a narrow ridge or bead below their bases. A corresponding longitudinal narrow groove is below the ridge, and a little lower down is a second shorter but wider groove.

This specimen affords satisfactory confirmation of the mandibular dental cliaracters of the species Protemnodon Mimas.

Another example of the species is afforded by a larger portion of a left mandibular ramus with the base or root of the incisor and the molar series, save the fore end of the premolar. This is from an old, and by the size I believe, male indiridual, with the dentine exposed on both lobes of the last molar $\left(m_{3}\right)$. The next molar $\left(m_{2}\right)$ has the dentinal lozenges of both lobes united by a linear sirip across the low link; a broader bit of dentine is exposed upon the fore link. In $m_{1}$, as in $d_{4}$, a uniform field of dentine is bounded by a peripheral line of enamel, and no lobes or other characters of the crown are left, the crown being worn down to the stumps. A narrow triangular strip of dentine is exposed on the hinder two thirds of the premolar. The oblique wear of the enamel of the back part of the last molar has destroyed the inner half of the postbasal ridge, but the outer half remains. The bead and groove along the outer alveolar plate are feebly shown; the lower wider subparallel longitudinal groove is also there. 'The upper and lower borders of the horizontal ramus are nearly parallel; the depth of the jaw beneath the last molar and beneath the premolar is the same, viz. 1 inch 8 lines. The lower contour of the ramus is straighter, less undulate than in Macropus Titan or Macropus major; more resembles that in Sthenurus. The upper sharp border of the diastema descends with a less abrupt curve than in Protemnodon $\mathrm{Og}$. The outlet of the dental canal is nearer the vertical line from the fore part of the premolar in the present specimen of Protemnodon Mima:. The symphysis begins, behind, in the same relative position as in Protemnodon Anak; but it occupies only the lower half of the inner 
surface of this part of the mandible; is not so deep, relatively, as in Protemnodon Anak. The root of the incisor exposed by fiacture of the symphysial part of the jaw is solid, but shows no coat of enamel. 'The vertical diameter of the tooth is $6 \frac{1}{2}$ lines; the transverse diameter is 4 lines; but these, with the shape and relative position to the symphysis, are shown in Plate LXXXVI. fig. 4.

The last molar is well in advance of the coronoid plate in the present old jaw. It must have belonged to a fine animal, but the superiority of size of Protemnodon Roechus (Plate LXXXVII. figs. 10-13) is well marked; the first four teeth there figured almost equal in extent the entire molar series in Protemnodon Mimas.

\& 18. Protemnodon Antaus, Ow.-A large portion of a left mandibular ramus with the molar dentition (Plate CX. figs. 1-4) of a Protemnodon agrees with Protemnodon Anak in the absence of the postbasal ridge (ib. fig. 4), but differs in size, the molar series extending along 3 inches 1 line ( 80 millims.) as against 2 inches 8 lines (68 millims.) (Plate LXXXV. figs. 7, 8, 9). The extent of the molar series in the present specimen is the same as in Protemnodon Mimas (Plate LXXXVI. figs. 1, 2, 3); but the proportions of the teeth differ. The bilophodont molars in Protemnodon Mimas have a greater longitudinal (fore-and-aft) extent, but the superiority in this dimension of the premolar in Protemnodon Antaus makes up for the deficiency. Add to this character the absence, in Protemnodon Antæus, of the postbasal ridge, which, though narrow, is clearly shown in the last three molars of Protemnodon Mimas (ib. fig. $3, m_{1}, m_{2}, m_{3}, g$ ).

'The superiority of size of Protemnodon Rochus is such as at once to forbid a reference to that species of the present specimen, which shows by its dentition that it was from an animal as advanced in age as that which afforded the type-specimen (Plate LXXXVII. figs. 10-1 $)$ of the hugest of this genus of extinct Wallabies which has yet reached me.

I have no alternative, therefore, than to symbolize the observed distinctive characters in the mandibular fossil under review by the binomial term which heads the present subsection.

The outer side of the crown of the premolar (Plate CX. fig. 1, $p_{3}$ ) is obliquely and smoothly worn along its upper and hinder part, in advance of which the triangular fore lobe stands out; on the inner side (ib. fig. $2, p_{3}$ ) a few feeble longitudinal indents mark the hollow between the fore and hind prominences; on the summit of the latter a speck of dentine is exposed (ib. fig. 3). The ridged summit of the fore lobe of $m_{3}$ shows masticatory wear; the hind lobe of this tooth stands up clear of the coronoid plate (ib. ib. q). 'The outer alveolar 'bead' is indicated by a linear groove, and below this the wider longitudinal channel extends from beneath the premolar to the penultimate molar. The diastemal ridge (ib. ib. $l$ ) curves gently forward, without the abrupt descent as in Protemnodon Anak (Plate LXXXV. fig. $8, l$ ); in this feature the present species more resembles Protemnodon Mimas (Plate LXXXVI. fig. 1). The outlet of the dental canal (Plate CX. fig. 1,v) is nearer the premolar than in Protemnodon Og (Plate LXXXV. fig. 5). The elliptical section of the socket of the incisor (ib. fig. 5) gives 6 lines by 4 lines in its two diameters, but the fang has begun to contract at this part. The direction of the incisor was more that in Macropus than in Sthenurus. 
A second illustration of Protemnodon Antceus is afforded by a part of a right mandibular ramus with the four two-lobed molars and the socket of the premolar. It is from an older individual than the type-specimen; $d_{4}$ and $m_{1}$ are more worn; $m_{2}$ shows a speck of dentine on each lobe where the fore and mid links rise to terminate on the transverse ridges; $m_{3}$ shows the hinder slope of wear on the summits of both lobes; it is devoid of postbasal ridge. The extent of the series preserved is 2 inches 3 lines. The socket of $p_{3}$ indicates the same size of that tooth as in the type jaw. The characters of the bone are closely repeated. But for the difference of degree of wear of the grinders, and a slight superiority in the older specimen of vertical extent of the ramus, they seemed at first glance to form parts of the same mandible.

As far as dental characters are shown I am led to refer both the subject of Plate CX. figs. 6 \& 9, and that of Piate IXXXVIII. fig. 18, to Protemnodon Antaus. The degree of superiority of size of the mandible, with, perhaps, that of the procumbent incisor, in the latter, may be within the limits of sexual distinction.

The latter specimen is a portion of a right mandibular ramus with the entire symphysis and socket of the incisor. Like the type-specimen it shows, it compared with Protemnodon Mimas, relatively smaller molars and a relatively larger premolar. The depth of the ramus at $m^{\prime}$ is 1 inch $T$ lines, as in the specimen regarded as of an old male of Protemnodon Mimas (Plate LXXXVI. figs. 1-3); but the fore-and-aft length of $d_{4}$ in Proteminodon Antceus is 5 lines instead of 6 lines; and that of $m_{1}$ is 6 lines instead of $\tau$ lines; the breadth of the molars is also less, in the present jaw, than in Protemnodon Mimas. There is thus 2 lines difference in the fore-and-aft extent of the two anterior bilophodont teeth in Protemnodon Anteus and in Protemnodon Mimas, together with the absence of the postbasal ridge (compare, e.g., Plate CX. figs. 4, 6, $\tau$, with Plate LXXXVI. figs. 1-5).

Protemnodon Anak, on the other hand (Plate LXXXV. figs. 7-9), is in a greater degree too small, and more especially so in relation to the size of the jaw-bone.

In Protemnodon Antaeus the extent of the three molars $\left(d_{4}, m_{1}, m_{2}\right)$ is 1 inch 8 lines ( 43 millims.); from the back of the socket of $m_{2}$ to the front of that of $p_{3}$ is 2 inches 7 lines (58 millims.). The prebasal ridge $\left(f^{*}\right)$, with the fore link, seems to have been rather less developed than in Protemnodon Nimas; the premolar had a greater relative length of crown.

$\S 19$. Pachysiagon* Ferragus, Ow.-The characters of certain fossils from the freshwater beds of the Queensland province, showing the hindmost mandibular molars of the general type of those of the Macropus Titan, but with modifications indicative of specific difference, will be better understood if I premise figures and descriptions of the corresponding molars at a similar stage of wear and age, which are plainly referable to Macropus Titan.

In the subjects of figs. $12 \& 13$, Plate LXXXIII., the last mandibular molar had but recently come into use; the edges of the two main lobes showed the backwardly

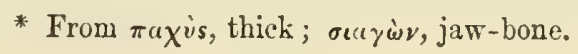


oblique abrasion of the enamel, but not carried so far as to expose the dentine; the links were entire from their origin at the fore and outer angles of the two lobes; the hind surface of the second lobe showed the whole of the angular fossa on its inner half, and the small faint vertical notch external thereto.

In the subjects of Plate I.XXXIX. figs. 1-4, the direction of wear against the upper molar from above downward and backward has extended the abrasion from the second lobe to its hind basal surface, where the bottom of the hind fossa $(g)$ alone remains: with the edges of the wedge-shaped lobes the origins of the link $(r)$ are gone, and only the lower antero-posterior ends remain, dividing the valley into a smaller outer and a larger inner depression. The prebasal ridge $(f)$ is correspondingly reduced in foreand-aft extent.

That these changes or modifications of working-surface of $m_{2}$ and $m_{3}$ are due to age and wear will be clear to any one comparing these teeth in Plate LXXXIX. figs. 2 \& 4, with those before quoted of large full-grown individuals of Macropus Titan, described (p. 408) and figured, Plates LXXXII.\& LXXXVI. The size and form of the portions of mandible preserved closely agree with those of the corresponding parts of the more entire mandibles of Macropus Titan, figured there. I here subjoin a view from above (Plate IXXXIX. fig. 1), not before given, to illustrate the correspondence in the breadth and direction of the "ectalveolar groove" $(u)$ and in the thickness of the mandible, including the fore part of the base of the coronoid, with corresponding parts of the bone from the more aged animals that have afforded the subjects of figures $2 \& 4$, Plate I.XXXIX.

The only difference of note is in the more advanced position of the last molar; and this is due to the well-known general forward movement of the serviceable teeth when those anterior to them have been worn down and shed-a movement which reaches its maximum in the Elephants.

A portion of a right mandibular ramus with the last two molars in place and worn (Plate XCVI. fig. 4, and Plate XCVII. figs. 3 \& 4) indicates, both by the size of the teeth and that of the jaw itself, a Kangaroo too much exceeding in size the largest individuals of Macropus Titan to belong to that species. A comparison of the above-cited figures with figures 13,15 in Plate LXXXII. will demonstrate this fact.

The jaw-bone of Pachysiagon Ferragus is relatively thicker in proportion to the teeth, and the last molar (Plate XCVII. fig. $3, m_{3}$ ) rises more in advance of the origin of the coronoid process; but this may relate to the greater age of the individual as shown by the exposure of the dentine in both lobes (ib. fig. 4) of that tooth, though they are not worn to quite the same degree as in fig. 2, Plate LXXXIX. The base of the notch (Plate XCVII. fig. $4, g$ ) remains on the hind part of $m_{3}$, and internal thereto are indications of two vertical ridges (Plate CV. fig. 3) which I have not found in any fossil of the genus Macropus.

$\oint 20$. Leptosiagon* gracilis, Ow.-On similar grounds the present genus and species

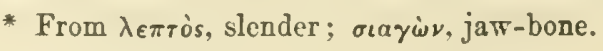


of extinct Kangaroo are based upon a portion of a right mandibular ramus with $m_{1}$ and $m_{2}$ in place, part of the socket of $m_{3}$, and the whole of that of $d_{4}$, from which the tooth appears to have been naturally shed or worn away (Plate LXXXIX. figs. 11-15). The transverse fracture of the mandible anterior to $d_{4}$ (ib. fig. 15) shows the bone to be unusually thin in proportion to its depth; the partial thickening on the inner side is almost ridge-like; the outer thickening, beginning opposite the inner one, is continued with a convex curve to the lower border of the ramus.

The distinctive dental character of the present subgenus is in the sculpturing of the hind surface of the molars (ib. fig. 14); two slender well-defined pyramids of enamel, in high relief, rise from the base of that surface at its inner half, and terminate in points, the inner one within a line of the unworn summit of the hind lobe, the outer one within two lines of the same. A deep reversed, narrow, angular or pyramidal notch divides the inner pyramid from the inner side of the hind lobe, a deeper notch of corresponding form divides the inner from the outer pyramid, and a fainter, narrow, short, linear groove separates the outer pyramid from the rest of the outer part of the hind surface, which is continued by a bold convexity into the outer side of the molar.

The outer end of both transverse lobes incline more forward than in Macropus Titan; but, as in that species, the outer bases of the two lobes meet to define an acute-angled pointed lower termination of the interval or valley there (ib. fig. $11, m_{1}, m_{2}$ ). In Sthenurus and Protemnodon the lower termination of the same interspace is rounded, not pointed, the outer bases of the lobes not being in the same degree extended anteroposteriorly.

There is no accessory ridge from the inner side of the mid link; but in the smaller outer part of the hollow between the front lobe and the prebasal ridge, defined by the fore link, there is in $m_{2}$ a vertical enamel ridge: it is not present in $m_{1}$ (Plate LXXXIX. fig. 13). I have seen none such in the corresponding part of any molar of Macropus Titan; and it may be a variety in the individual specimen exemplifying or indicating the present subgenus.

But the character of the back part of the molar is decisive, so far as my present observation of existing and extinct Kangaroos has extended, of the taxonomic distinction which I have assigned to Leptosiagon gracilis.

$\$ 21$. Genus Procoptodon*, Ow.-The indications of this genus, at first fragmentary, have been raised, by evidences successively received since the year 1845 , to demonstration, under, at least, three specific modifications.

The first of these is exemplified, mainly, by maxillary fossils. The most instructive are portions of the right and left maxillary bones, each with three molars $\left(d_{4}, m_{1}, m_{2}\right)$ and part of a fourth, $d_{3}$ (Plate XC. figs. 2-6), of the same skull.

In antero-posterior extent and in breadth the two molars $\left(m_{1}, m_{2}\right)$ do not exceed their homologues in the upper jaw of Sthenurus Brehus $\uparrow$; but the configuration of the

* From $\pi \rho \grave{o}$, before; кó $\pi \tau \omega$, to pound; ócoùs, tooth.

$\dagger$ Plate LXXXVII. fig. 6, $m_{1}, m_{2}$. 
grinding-surface is different and much more complex, of itself indicating a distinct genus if not subfamily of Macropodida.

'The prebasal ridge $(f)$ is narrower than in Sthenumus; it descends (the tooth being viewed prone) from the fore part of the outer angle of the front lobe $(a)$ and then passes inward with a slighter descent to the fore part of the base of the inner half of the front lobe, subsiding before attaining the inner side of that lobe. 'The fore link $(s)$ is feebly represented by a vertical ridge on the fore part of the front lobe, nearer its outer than inner end, the rest of that fore surface being marked by more minute vertical ridges and groores. 'The hind surface of the front lobe is bounded by sharp subvertical ridges, respectively descending, with a slight degree of convergence, from the hind part of the outer and inner angles of the front lobe. In the transverse concavity of the hind surface of that lobe, so bounded, two stronger sharp vertical ridges of enamel descend toward the intervening valley, the outer ridge being continued backward across the valley as the ' mid link' $(r)$, with a slightly sinuous course, convexly outward. The hind surface of the hind lobe (ib. fig. $5, m_{2}$ ) almost repeats the characters of that of the front lobe; the inner $(g)$ of the two submedian vertical ridges in the concavity of such surface expands at its base into the convexity of that part of the molar; the outer submedian ridge is minute. From the outer lateral or boundary-ridge a sharp vertical plate of enamel $(h)$ is directed inward, and there are some minor sculpturings of this part of the hind surface. Its basal part is somewhat bulging and smooth, as are the outer and inner swollen ends of the two main transverse ridges or lobes (ib. fig. $6, a, b$ ).

The second molar $\left(m_{2}\right)$ is rather larger than the first; both are feebly abraded along the fore part of the transverse summits of the wedge-shaped lobes, but not so far as to expose the dentine; both teeth are behind the back surface of the masseteric process $\left({ }^{\prime \prime}\right)$. These signs of immaturity were associated with and confirmed by the presence of the undeveloped and unextricated premolar (Plate XC. figs. $2,3,4, p_{3}$ ); it was so far advanced as to have pushed its crown to near the level of the base of $d_{3}$, at the interval between the diverging pairs of the fore and hind fangs of that deciduous tooth (ib. fig. $6, d_{3}$ ). The major part of $d 4$ had been broken away on the right side, but the crown remained in the left maxillary. The mid link and the accessory ridge are here present, and the hind surface of the second lobe shows the complex accentuation, which is further carried out in the succeeding teeth. On the summits of both lobes of $d_{3}$ and $d_{4}$ the dentine had been exposed by masticatory abrasion.

The thin smooth partition-wall between the sockets of $m_{2}$ (the hindmost tooth in place) and of $m_{3}$ was manifest at the back part of each maxillary (fig. $5, m_{3}$ ), confirming, with the more decisive evidences at the fore part, the homologies of the more or less complete teeth, and demonstrating the immaturity of the individual from which the fossils had been derived; the usual process for exposing the premolar had the usual result.

The crown of the premolar (ib. figs. $2,3,4, p_{3}$, and fig. $7, p_{3}$ ), in its antero-posterior extent, resembles that of Macropus proper, not being quite equal to that of the crown of the next tooth $\left(d_{\triangleleft}\right)$; but it is thicker transversely than in Macropus or Sthenurus, with a 
ransversely ridged complexity of the broad working-surface between the outer $(a)$ and inner (b) longitudinal ridges or walls (fig. 7 ), which shows it to have acted as a pounder rather than a divider of the vegetable food, a character which suggested the name proposed for the genus (Note *, p. 451).

The vertical extent of the enamelled crown of the premolar does not exceed the breadth of the hind part of the tooth. The outer surface shows three conical elevations, in low relief, of the enamel, one behind another (fig. $2, p_{3}$ ). The apex of the foremost constitutes the anterior prominence of the outer longitudinal ridge; that of the second slightly projects from the middle of that ridge $(a, p s$, fig. 7$)$; that of the hindmost one subsides before it gains the ridge, which is continued, sharply, upon the outer and back part of the crown of the premolar. The foremost of the three conical low reliefs of the enamel forms the outer part of the fore swollen end of the crown (fig. $4, p_{3}$ ), which is divided by a depression from the lower and narrower, basally swollen beginning of the inner longitudinal ridge $(b)$. This slightly diverges as it recedes from the outer ridge, obeying the hinder enlargement of the crown, and it is united near that end by a transverse ridge with the outer longitudinal one. The transverse ridge is a miniature or rudiment of a hind lobe, and its hind surface is excarated and ridged in a feeble or rudimental way like that part of the normal hind lobe of the bilophodont molars. The horizontal triturating surface of the premolar between the outer and inner longitudinal ridges is sculptured by transverse sharp enamel-ridges and deep depressions.

There is a character in the upper jaw of Procoptodon which is not present in the large existing Kangaroos of the subgenera Macropus and Osphranter. It is present, under some modifications, in Boriogale and in the smaller Kangaroos or Wallabies of the subgenera Halmaturus and Petrogale. I find, indeed, in Petrogale xanthopus, Gd., and Halmaturus brachyurus, Wth. (Plate XC. fig. 1, $b$ b), the nearest approach to the structure in question. It is a large unossified tract of the palate, shown in both maxillaries of the fossil (ib. fig. $6, b b$ ) by the passage of the palatine (fig. 3, ${ }_{21}$ ) into the nasal $(n)$ plate at a distance of from $2 \frac{1}{2}$ lines to 3 lines from the inner wall of the alveoli of $d_{4}, m_{1}$, and $m_{2}$. This upward bend of the palatal plate (ib. tig. $3, n$ ) is at nearly a right angle with the narrow horizontal palatal strip, and in both maxillæ the continuation of the nasal plate of the maxillary into the orbital one by the large sphenopalatine foramen (fig. $3, s$ ) is shown.

Arrested ossification of the palate is, however, a marsupial rather than a macropodal character, and is exemplified, in my "Osteology of the Marsupialia" *, in the Thylacine, the Sarcophile, the Dasyure, the Bandiconts, the Peragale, and the Potoroo, as well as in a small species of Kangaroo (Halmaturus Bennettii). In this species the palatal vacuities are four in number, in two lateral pairs $\downarrow$. In Halmaturus brachyurus (Plate XC. fig. $1, b b$ ) the intervening strip of bone between the fore and hind vacuity is wanting, and each pair is blended into one large lateral unossified tract, which either falls into its fellow, or is separated from it by a mere filament of bone. Such was the structure in

* Zoological Transactions, 4to, vol. ii. part 1, 1838, p. 388, plates $70 \& 71 . \quad+$ Op. cit. pl. 71. fig. 5. 
the great procoptodont Kangaroos, the vacuity, moreover, extending more forward than in Ilalmaturus or Petrogale.

I need scarcely say that the dentition of the small existing species of these genera is of the ordinary halmatural type; the premolar is trenchant, the inner ridge being low or 'basal.'

'The front pier of the zygoma (Plate XC. figs. 2-5, 21', 21"), extending from the fore part of the orbit obliquely downward and backward, terminates below, in the present immature specimen of Procoptodon, above the interval between $d_{4}$ and $m_{1}$; it might recede in relative position to the molar series when this was fully in place; but so much of the pier as is preserved is more compressed, and stands out relatively further than in any existing Kangaroo. I shall subsequently be able to show that the more advanced position of the descending masseteric process is constant at all ages in Procoptodon, and may be added to the palatal and dental characters of the genus.

$\$ 22$. Procoptodon Pusio.-These characters, as above defined, added to size, exemplify the present species.

The antero-posterior extent of the three molars $d_{4}, m_{1}, m_{2}$, in the subject of figures 2, 3, 6, Plate XC., is 1 inch 10 lines; the four teeth, the premolar being in place, would reach along 2 inches 4 lines: taking the fore-and-aft diameter of the last molar, $m_{3}$, to equal that of the penultimate one, $m_{1}$, here in place, the permanent upper molar series of Procoptodon Pusio (ib. fig. 7) would be 3 inches 2 lines in longitudinal extent. All things being equal this Kangaroo was one third larger than Osphranter rolustus, Gd.*

The subject of figs. 7-10, Plate LXXXIX. is a portion of the right ramus with the three hindmost molars, corresponding in fore-and-aft extent with those of Macropus Titan, but with the following well-marked distinctions. 'The prebasal ridge does not extend so far forward, and the hind surface has two vertical narrow grooves to which a third shorter and feebler one is added in $m_{3}$ (ib. fig. 10,g). These grooves do not extend lower than the valley indicating the base line of the transverse lobes, below which level the common base of those lobes rises smoothly and convexly for a line and a half clear of the socket; the innermost notch is very little deeper or wider than the next, contrasting with that on the inner half of the hind surface of the molars in Macropus Titan, which descends nearer to the origin of the hind fang of the tooth. Again, the mid link (ib. fig. 9, $r$ ) sends off from the inner side near its termination in the hind lobe a short and low ridge of enamel descending to be lost in the inner division of the transterse valley. There is likewise a small vertical ridge from the fore part of the hind lobe internal to the link and its accessory process, which ridge descends straight to the bottom of the valley. 'These productions of enamel cause corresponding complexities of the grinding-surface, which are correlatively associated with a more massive character of bone wielding the grinding instruments. Comparison of fig. 9 with figs. 1, 3 of Plate LXXXIX. will exemplify the character of greater thickness, as that of

* Compare figure 7 , Plate XC. with figure 3, Plate LXXXI. 
fig. 7 with 4 will do of greater depth, relatively to the size of the teeth, in the species in which those teeth have a more complex grinding-surface. The characters of this complexity, especially in connexion with the mid link, and the conformity of anteroposterior extent of the mandibular molars $\left(m_{1}, m_{2}\right.$, fig. 9) with the homotypal maxillary teeth of Procoptodon Pusio (Plate XC. fig. 6), led me to suspect that they might be parts of the same species-a suspicion which the subsequent reception of the greater proportion of the lower jaw and teeth, figured in Plate XCI., has confirmed.

For this evidence of the mandible and its dentition of Procoptodon Pusio I am indebted to George B. King, Esq., of Gowrie Station, Queensland. It was discovered in the bed of a tributary of the Condamine River, called "King's Creek." It consists of the right ramus, part of the left, with the uniting symphysis, fractured anteriorly, where the implanted roots of the two incisors are shown (fig. $4, i, i$ ). In the right ramus are preserved the last molar $\left(m_{3}\right)$, part of the second $\left(m_{2}\right)$, and the bases and roots of the three antecedent grinders $\left(m_{1}, d_{4}, p_{3}\right)$. The detached portion of the left ramus (figs. $2 \& 3$ ) and part of a right ramus of another mandible (fig. 5) afford the illustrations of the dentition, figured, as restored, in fig. 1.

As compared with the typical Kangaroos the diastema is short; the symphysis, in like manner, is short and thick, and its anterior surface ( $s$, fig. 2$)$ is directed upward and forward at an obtuse angle with the axis of the ramus, not extended, as in Macropus proper, in a direction with that axis. The incisors accordingly are much less procumbent, but yet slope forward from the perpendicular. 'Their direction I estimate from that of the roots remaining in the symphysial part of the rami.

'The section of the incisor made by the fracture (fig. $4, i$ ) is elliptic, the long axis inclined a little outward from the rertical line, 6 lines by 4 lines. The interspace of bony structure at the place of fracture would not be that of the exposed crowns; the incisors converge as they advance. The middle of the outer surface of the symphysis is slightly produced, giving a convex curve to that part of the slope; above which the contour becomes rather concave through a production of the floor of the incisor's socket (fig. 2,s). The breadth of the symphysis external to the broken part of the sockets is 1 inch; at the fore part of those of the premolar it is 2 inches; the breadth of the mandible at the hind end of the symphysis is 2 inches 10 lines; the length of the preserved part of the symphysis is 2 inches 6 lines, and I estimate as much, at least, to have been broken away. On the inner or posterior surface of the symphysis is a large and deep depression (fig. $\mathbf{1}, s$ ), just opposite the prominence on the outer or anterior surface. The vertical extent of the ramus at the hind end of the symphysis is 1 inch 10 lines; it slightly decreases as the ramus recedes. A shallow channel below both the outer and inner alveolar border gives this the appearance of a low ridge; below the outer channel the surface swells out into a bold convexity; the inner vertical surface deviates from flatness by being feebly convex. Longitudinally it is rather more convex. Behind the last molar the inner surface begins to be divided into two shallow concavities (fig. $3, b, c$ ) by the inward production of the part of the jaw which would have been continued into 
the strongly and broadly inflected angle (ib.a). The lower concavity is bounded below by a feebler inflection of the obtuse lower border of the ramus (ib. $d$ ) which soon subsides. This inflected border answers to the more forwardly placed part of that border in Nototherium (Plate XL. fig. 4, $d^{\prime}$, Not. Mitchelli, Plate XLI. fig. 2, $d^{\prime}$, Not. Victorice). The correspondence of Procoptodon with Nototherium in this particular, as in the masive proportions of the inandible, is suggestive *.

'The outer surface of the horizontal ramus rapidly gains in vertical convexity as it recedes from the symphysis, but rather loses in vertical extent. The fore border of the coronoid (Plate XCI. fig. 2, q) is thick and obtuse, and rises abruptly and vertically, as in Nototherium (Plate XLI. fig. 1), in advance of the hind end of the molar series; in the present aged Procoptodon its fore border is on the transverse line of the middle of the last molar (fig. $3, q, m_{3}$ ). The channel (fig. $1, u$ ) between the coronoid process $(q)$ and the last molar and postalveolar production is wide and deep. The hind surface of $m_{3}$ (fig. 6) is divided into three parts by a pair of feeble vertical indents, the intervening part being impressed by shorter and finer grooves; there is no postbasal ridge. 'The mid link receives two small buttress-like ridges on its inner side; the fore link shows a small swelling or accessory ridge on the same side. The prebasal ridge is as in the subject of fig. 9, Plate LXXXIX. The dentine is exposed on both lobes of the hindmost molar ( $m_{3}$, Plate XCI.); in greater proportion on those of $m_{2}$. In the second mandibular fossil (fig. 5 ) is shown the more worn $d_{4}$, and the less worn, later developed, $p_{3}$. In the larger specimen (fig. 1) the two fangs only of $p_{3}$ are preserved. They indicate a similar fore-ancl-aft diameter of this tooth, viz. 5 lines. The extent of the series of five teeth is 2 inches 11 lines, corresponding, as is the case with each individual tooth, in their dimension with their homotypes in the upper jaw (Plate XC. fig. 7). The lower molars differ from the upper ones, as usual, in their minor breadth; in the hinder surface being impressed at its upper half by numerous fine vertical ridges or wrinkles, and not being excavated; in the inner part of the fore side of the hind lobe being the seat of longitudinal accessory ridges, instead of the outer half; in the accessory parts of the mid link being produced from the inner, not the outer, side; in the absence of the backwardly produced borders of the upper half of the hind surface of the front lobe, which, as in the hind lobe of the upper molar, bound or make the excavation on that surface; whereas, in the lower molar, the mid link passes from near the outer end of the flat hind surface of the fore lobe backward. 'The prebasal ridge with its fore link is more produced in the lower than in the upper molars; the link in the former is supported or thickened by an enamel buttress on its inner side, and the surface of the fore part of the front lobe on the inner side of the link is produced into a pair of low narrow vertical ridges.

The hind surface of the premolar, at the base of the crown, slopes backward to a medial vertical ridge; the sides of the crown are compressed and slightly excavated in

* Of such facile eonjectures, e.g., as that one had been developed into or degenerated from the other. 
advance of the hind end. The fore-and-aft extent of the crown of this tooth, as in that of the upper jaw, is less than that of the next tooth $(d$, .

In all these modifications the analogies of the before-described genera and species of extinct Macropodida, support the conclusion that we have in the subjects of Plate XCI. the requisite completion of our knowledge of the dental characters of the chief subjects of Plate XC., viz. of the new and interesting genus and species Procoptodon Pusio.

I have next to submit, as in the case of Sthenurus, evidences of a larger species of the genus.

\$23. Procoptodon Rapha, Ow.-The size of the premolar (Plate XC. fig. $8, p_{3}$ ) in the fragment of lower jaw of the immature Procoptodon there figured, indicates it to have come from another and larger species than Procoptodon Pusio, yet of inferior size to Procopt. Goliah (Plate XCV. fig. 7, $p_{3}$ ); the shape of the incisor indicates likewise a difference of species.

The size of the remains of the two anterior fully developed molars (Plate XC. fig. $8, d_{2}, d_{3}$ ), in proportion to the jaw supporting them, suggested immaturity, and the excavation of the bone beneath them exposed the crown and beginning of the fangs of a large and thick premolar, of the crushing type of the present genus.

The outer part of the crown (ib. fig. $8, p_{3}$ ) is divided into two subequal lobes by a marginal notch, from the apex of which a linear groove is continued down the outer side of the crown. The height of this is 6 lines, the fore-and-aft extent is 7 lines ; the breadth behind is 5 lines. The crown bulges out above the roots, the hinder one of which bifurcates 6 lines below the crown. The enamel is smooth, white, and the exposed parts show more or less convexity.

The base of the broken crown of the first deciduous molar (ib. fig. 11, $d_{2}$ ) is triangular, with the angles rounded off and the base turned backward; the length of the triangle is 4 lines, the basal breadth 3 lines. The base of the next bilophodont tooth $\left(d_{3}\right)$ is subquadrate, $5 \frac{1}{2}$ lines in length, 5 lines in breadth.

The diastemal tract (figs. $8,9, \& 11, l, s^{\prime}$ ) has a characteristic shortness; it is continued with, at first, a feeble concavity almost straight on to the outlet of the incisive alveolus, to which it slightly bends down. The outlet of the dental canal (fig. 8, v), about 2 lines below the diastemal border, would be about 7 lines from the alveolar outlet were this entire. The lower or symphysial border (figs. 8, 9, $s, s^{\prime \prime}$ ) rises to the alveolar outlet at a less open angle with the lower border of the horizontal ramus than in Sthenurus*. The syndesmotic articular surface is flat, rough, and is continued, well defined, to the outlet; it indicates the generic firmer union of the rami than in the type Kangaroos, and a greater development of the uniting or binding structure than in Sthenurust.

The thickness of the ramus at the formative cell of the premolar, in Procoptodon Rapha, is $10 \frac{1}{2}$ lines (Plate XC. fig. 10). The base of the incisor (ib. figs. 8 \& 9,i) indicates a tooth of less relative thickness than in Procoptodon Goliah. The fractured 
end gives an ovoid section $5 \frac{1}{2}$ lines in vertical, 3 lines in transverse diameter; the outer side is moderately convex, the inner side less so: both upper and lower borders are thick and obtuse; a thin coat of enamel extends from the lower upon the outer sides of the tooth. 'I'he shape of the working crown cannot be inferred from the basal part here preserved; but this shows faint longitndinal broad impressions on the outer side, and also that the incisor must have risen obliquely npward at a low angle $\left(140^{\circ}\right)$ with the lorizontal line of the molar series.

'Thus the present, like the following evidence of the genus Procoptodon, indicates, with the shortness and depth of the symphysial part of the jaw, the thickness of the crown of the lower premolar especially behind, and the thickness and apparent depth of the ramus, a nearer approach to the characters of Nototherium than is shown in any of the foregoing extinct genera of the Macropodal group of Marsupialia.

What is wanting in the above-described fragment of jaw with the small proportion of dentition, by which is indicated a second species of Procoptodon, has been supplier by a plaster cast and photographs of an almost entire right ramus, with the molar series. 'The complex characters of the hindmost and least worn teeth (Plate XCIII. fig. 3, $\left.m_{3}, m_{3}\right)$ unmistakably repeat the generic type of those of the upper molars of Procoptodon Pusio (Plate XC. fig. 7); but the difference of dimension is, to my experience, specific; and since it is in degree that shown by the premolar germ in the fragment of immature jaw (Plate XC. fig. S), I regard the specimen in the Sydney Museum, from which the cast and photograplis were taken, as part of a mandible of a mature individual of Procoptodon Rapha. 'Ihe longitudinal extent of the upper molars $\left(d_{4}-m_{3}\right)$ in Proc. Pusio is 2 inches 6 lines; that of their homotypes in the mandible of Proc. Rapha is 3 inches. The breadth of these lower molars similarly exceeds that of the upper ones in the subjects of Plate XC. figs. 6, 7 , which is fatal to the hypothesis of those of Plate XCIII. belonging to the same species.

'The mandibular ramus of Procoptodon Rapha is short, straight, deep, and thick; in the latter dimension (fig. 3) increasing from the symphysis to the ascending branch more gradually but to a greater extent than in preceding genera of Kangaroos. The lower border is convex across, thickest behind the symphysis, and suddenly becomes thinner at its hinder third (ib. fig. $2, d, d^{\prime}$ ), where a longitudinal channel (ib. $b^{\prime}$ ) along its inner side gives it the appearance of being slightly inflected that way; but the channel $\left(b^{\prime}\right)$ is interrupted by a more sudden or direct inflection of the proper "angle of the jaw" (ib. a), which here, as in the other macropodal fossils, has been broken away.

'The fore border of the symphysial end of the ramus bends up at about an angle of $135^{\circ}$ with the axis of the mandible. On the outer side (ib. fig. 1) the alveolar tract is impressed by an irregular longitudinal moderately deep channel, below which the bone swells out and the vertical convexity to the lower border augments from below the first molar $\left(p_{3}\right)$ to the origin of the coronoid process $(q)$. A little way behind the anterior border of this process it is feebly impressed, or the surface subsides; but the low 
rough ridge (fig. $1, h$ ), indicative of the lower boundary of the ectocrotaphyte fossa, is at a higher level.

'The ramus gains slightly in depth or vertical extent from the groove $\left(b^{\prime}\right.$, fig. 2$)$ to the symphysis $\left(s, s^{\prime}\right)$. The articular syndesmotic surface is broad, strongly roughened and sculptured, and extends from the lower border of the ramus $(s)$ to the outlet of the incisor (i); the hind border of the symphysial surface is feebly impressed, as in Phascolomys (Plate LXIII. fig. 2).

The union of the two rami must have been firm, not admitting of any reciprocal movement; indeed the fore part of the joint had become obliterated by anchylosis, and part of the left ramus is here adherent in the fossil. The inner surface of the ramus is almost flat to where it bends to the under border; the narrow continuation forward of that surface between the symphysial joint and the diastemal tract (fig. $2, l, s^{\prime}$ ) is traversed by a ridge, between which and the joint is a narrow groove. The hind part of the ectalveolar groove (fig. $3, u$ ) is deep and moderately wide; the postalveolar angle (ib. $t$ ) is better marked than in the type Kangaroos.

The crown of the premolar has been worn or broken off in the original of Plate XCIII.; the length and breadth of its base are the same as in the undeveloped lower premolar (Plate XC. fig. 6, $p$ s). The strong fore and hind roots are longitudinally striate.

The crown of $d_{4}$ is worn down to the base; each lobe shows a broad tract of dentine united by a linear tract along the remains of the mid link. The third tooth $\left(m_{1}\right)$ shows a broad prebasal ridge; the fore link has been worn down to its base, and the dentine there is continuous with that exposed on the anterior lobe. The tract continued along the mid link to the hind lobe is much narrower, being finely linear. A ridge from the inner side of the link is indicated, and a second ridge from the fore part of the hind lobe internal to the confluence therewith of the link. Indications of the procoptodont sculpturing of the back of the hind lobe are unmistakable, but the pattern is better shown in the succeeding molars; the outer and inner smooth convex enamelled ends or sides of the hind lobe are continued a short way upon the back of that lobe and terminate there in well-defined borders, between which the surface sinks. This broad, shallow fossa is divided in two by a pyramidal process of enamel in low relief, the basis below being coextensive with the breadth of the fossa, the apex reaching to the working ridge, in its present degree of wear, of the hind lobe of the last molar.

In the penultimate tooth $\left(m_{2}\right)$ the greater degree of wear gives a strong undulatory course to the enamel-ridge bounding behind the working-surface of the complex molar.

From what may be discerned, in the cast, of the implanted base and outlet of the socket of the incisor, that tooth was relatively small, as in the subject of Plate $\mathrm{XC}$. fig. 8, and was directed obliquely upward and forward at nearly the same angle as that of the posterior border of the symphysis; but the cast does not supply safe data for further particulars.

We have thus in the foregoing evidences of the singular phytophagous Marsupial 
genus, with the dentition, as to the formula and fundamental pattern of the molars, of the bilophodont Macropodida, the extremest deviation from the characters of the existing subgenera which the fossil remains of the family have yet exhibited.

I infer from the proportions and shape of the mandible that the rest of the skeleton may have presented a more robust character, with thicker and shorter extremities and with less inequality between the fore and hind pairs of limbs than in the living Kangaroos. Of these, as before remarked, Procoptodon Pusio must have exceeded in bulk the largest known. 'This excess is greater in Procoptodon Rapha. But the following fossils show that their generic modifications have been exemplified on a more gigantic scale.

\$24. Procoptodon Goliah, Ow.-The present extinct species of Macropodide was first indicated by a fragment of a maxillary bone with three molars, transmitted to me by Sir 'Thomas I. Mirchell, C.B., in 1844.

As the tivo smallest of these measured rather more than one inch and a half in the antero-posterior direction, and the least transverse diameter was $7 \frac{1}{2}$ lines, I provisionally assigned to the species the name "Macropus Goliah," and communicated my brief notes on the fossil to George R. Waterhouse, Esq., at that time engaged in his excellent work, 'The Natural History of the Mammalia'*. The type-specimen is figured in Plate XCIV. fig. 1.

My hopes of further elucidating the singular extinct gigantic Kangaroo so indicated have been, througl the kindness of friends and correspondents in Australia, abundantly fulfilled. The grounds of the formation of a distinct genus of Macropodides, of which the "Goliah" is the type, are given in the subsection $(\$ 21)$ descriptive of the smaller species, Procoptodon P'usio. As in that species, the two lobes of the molar (Plate XCIV. fig. 1, $\left.m_{1,2}, 3\right)$ have a more regular elliptic basal section than in the foregoing genera ; their outer and inner ends are more convex or bulging; they are not separated by so deep a valley, and this lodges a greater proportion of hard enamel in the form of irregular subundulate ridges, affecting mostly the longitudinal direction, the chief of which may, however, be homologized with the mid link of more normal Macropods. The fore surface of the front lobe and the hind surface of the back lobe are similarly sculptured by irregular ridges, of which two are more conspicuous than the rest at the back of the molar, within a depressed area defined by the abrupt sharp margins, inflected upon that surface of the outer and inner convex ends of the hind lobe. The unworn summits of both lobes are less regularly or extensively transserse than in ordinary Kangaroos, the inner angle curved backward. There is a low and short prebasal ridge, but no such definite production from the back part of the hind lobe.

The fore pier of the zygoma, at least so much of the hind part thereof as was preserved in the present fragment, stands out opposite the antepenultimate tooth $\left(m_{1}\right)$, and its hind curve subsides before reaching the last molar. The narrow plate extending from the palatal wall of the alveoli terminates in a smooth and seemingly natural border. But

\footnotetext{
* Part 2, Macropodidee, 8vo, 1845, "Macropus Goliah, Ow.," p. 59.
} 
this and other characters of the species are more fully and plainly illustrated by the specimens next to be described, of which I commence with the portion of a left maxillary, forming the subject of figures 2, 3, 4 of Plate XCIV.

This portion of jaw retains the five permanent molars $\left(p_{3}\right.$ to $\left.m_{3}\right)$, but with some mutilation as well as wear of their crowns. The fore pier of the zygoma (ib. fig. 2, 21"') springs out above the interval between the second $\left(d_{4}\right)$ and third $\left(m_{1}\right)$ molars; and as the last $\left(m_{3}\right)$ is in place and shows wear, it may be concluded that this anterior portion of that pier is characteristic of Procoptodon.

On the palatal surface of the bone (ib. figs. $3 \&$ \&) the evidence of the same large vacrity as is indicated in the smaller species (Procoptodon Pusio, Plate XC. fig. 6) is unmistakable. The anterior ridge begins to curve to join its fellow opposite the second molar $\left(d_{4}\right)$, the junction taking place at the mid interval between the right and left premolars $\left(p_{3}\right)$; the posterior ridge similarly bridges the palate between the alveoli, right and left, of $m_{2} \& m_{3}$, fig. 4, Plate XCIV.

On the working-surface of the crown of $p_{3}$ the transverse ridges of enamel along the tract occupying the fore and inner part of that surface appear. This tooth is broadest behind; it is supported by three stout fangs; the foremost diverges from the hind pair as it ascends into the substance of the jaw, where two thirds of an inch of it is exposed ; it is thick, and the cemental coat is longitudinally and irregularly striate.

At the back part of $m$, two of the deep vertical notches (ib. fig. $9, h$ ) and the intervening strong ridge of enamel (ib. $g$ ) are conspicuous. The fore link (s) and the accessory link to its inner side, also the mid link and the accessory ridges on the surfaces of the lobes internal to it, are shown. The prebasal ridge $(f)$, with the fore link $(s)$ of the last molar ( $m_{3}$, fig. 4 ), has been broken off and slightly displaced from the rest of that tooth, in which the indents and ridges on the hind surface are well displayed. At every part of the worn and fractured surface of this molar series the stalactitic-like complexity of the thick and hard enamel is exemplified. The figures being of the natural size preclude the need of giving dimensions of the several teeth.

In the smaller portion of maxilla and molar series (Plate XCIV. figs. 5, 6, 7) the coronal modifications of $m_{1}$ and $m_{2}$ are instructively displayed. Viewing the workingsurface from above, the postbasal ridge seems to be represented by a short bar of enamel (figs. $7 \& 9, g$ ) supporting the bases of the narrow but'strongly developed pyramidal ridges (ib. $h$ ), sending their apices to the working-surface of the hind lobe; but the basal bar does not project like a true basal ridge from the hinder convex surface of the crown (fig. 9).

'The correspondence of the complex pattern of the crown of the lower with the upper molars, combined with the usual modifications of greater length of the prebasal ridge, is patent in the subject of figs. $1 \& 2$, Plate $\mathrm{XCV}$. In this fossil the last molar $\left(m_{3}\right)$ had but recently risen into place, and the antecedent one $\left(m_{2}\right)$ showed slight traces of abrasion. In $d_{4}$ the front lobe $(a)$ is narrower than the hind one $(b)$; these proportions are reversed, but in a minor degree, in the last molar $\left(m_{3}\right)$. The fore $(s)$ and mid $(r)$ 
links are well defined. Deep clefts on the back of the hind lobe mark out the rertical ridges of enamel, of which one is shown at $g$, fig. 2 . 'The base of the coronoid process (fig. 1, q) advances forward a little beyond $m_{3}$.

The characters of the lower molars of Procoptodon Goliah are further exemplified in a smaller fragment of a large, apparently male, animal, with the last two molars showing a greater degree of wear. This specimen (Plate XCV. figs. 3 \& 4, Plate XCIV. fig. 8), now in the Museum of Natural History of Sydney, New Soutl Wales, has been made known to me by a good plaster cast. The penultimate molar $\left(m_{2}\right)$ is slightly worn, the last ( $\mathrm{m} \mathrm{s}$ ) in a less degree; but both had been in use and indicate a full-grown though not old individual.

The prebasal ridge (ib. ib. fig. $8, f$ ), commencing externally at the outer and fore part of the base of the front lobe, rapidly rises as it curves inward, and extends as a thick ridge three lines in advance of the front lobe, rising nearly to its level, and assuming more of the character of an accessory lobe than a mere basal ridge or developed portion of the "cingulum." Its lobular appearance is strengthened by the welldeveloped link $(s)$ which connects its outer angle with the fore part of the front lobe (a) near its swollen end. The accessory ridge $(n)$, internal to the link, is well marked, but subsides before reaching the prebasal ridge. This sinks more gradually and with less loss of thickness to the inner and fore part of the base of the front lobe than at its outer end or beginning. 'The anterior surface of this lobe is broken by minor and less regular ridges and grooves of enamel. The mid link $(r)$ has the same relative position to the transverse eminences it connects as has the fore link; the inner accessory ridge $(o)$ subsides in the valley; smaller subsidiary ridges and grooves accentuate and multiply the hard enamel-constituent of the grinding-surface of the lower molars, as in those of the upper jaw.

The last molar $\left(m_{3}\right)$, with a very slight decrease of breadth of the hind lobe, repeats the characters of the preceding tooth ; in both, the hind surface (Plate XCIV. fig. 10) is impressed with a pair of narrow conical excavations, with apices not reaching to the basal beginning of the crown; these impressions define or leave three ridges $(h)$, not extending back beyond the smooth basal part of the tooth, but which, when worn down to near that part, give a strongly undulating course to the enamelled summit of the hind lobe of the molar.

The most complete example of a lower jaw of Procoptodon is that which was presented to the Museum of the Royal College of Surgeons of England in the year 1853, by Dr. FALDER, with a note of its discovery in the freshwater or drift beds of Darling Downs, Queensland, "at a depth of 40 feet from the surface of the soil."

Each ramus of the jaw is preserved as far as the base of the ascending branch; a small portion of the alveoli of the two incisors, with the corresponding part of the diastemal ridges, has been broken away; the lower border of the right ramus has likewise suffered. But the most instructive element in the jaw, viz. the molar series, is almost entire in both rami (Plate XCII. fig. 1). 
This series includes six teeth. The last molar (ib. ib. $m_{3}$ ) is represented by a partially developed crown in its formative cell; the next in advance $\left(m_{2}\right)$ is not fully risen into place, and the summits of its two lobes are unworn. The antepenultimate molar $\left(m_{1}\right)$, with these ridges just touched, shows on each a polished linear tract of enamel; the three anterior teeth, with progressively increasing degrees of wear and decrease of size as they precede in position, are therefore deciduous molars $\left(d_{4}, d_{3}, d_{2}\right)$. Of this phase of dentition, as seen from the outer side view of the right ramus, a figure is given in Plate XCV. fig. 6.

The foremost tooth $\left(d_{2}\right)$ shows a working-surface of a triangular form, the base turned backward, the apex forward and obtuse. The outer border has a submedian notch corresponding to a groove terminating there, which divides the outer surface into a fore and hind lobe, both of which are convex transversely, and in a minor degree vertically. The inner side of the tooth is flatter, and is impressed at its middle third by three shallow parallel grooves descending rather obliquely backward. The coronal ends of these grooves give a crenate character to that part of the enamel. A field of dentine is exposed on the broader hind lobe.

The crown of the second molar (Plates XCII. fig. $1 \&$ XCV. figs. $6 \& 7, d_{s}$ ) has the two transverse lobes and a prebasal production; a continuous tract of dentine is exposed on these parts and along the mid link connecting the two lobes. Certain longitudinal impressions on the outer surface of the crown give a wavy character to parts of the peripheral coat of enamel on the working-surface of the tooth.

The third molar $\left(d_{4}\right)$ is mutilated by fracture in both rami, but least so in the right. The prebasal ridge is narrow transversely in proportion to its length; its enamel coat is indented; the fore limb is feebly indicated. The hind surface of the hind lohe shows three vertical enamel-ridges, two of which attain the grinding-surface. The mid link is strengthened by a vertical ridge on its inner side.

In the fourth molar $\left(m_{1}\right)$ the prebasal ridge has a distinct link passing from its outer angle toward the middle of the fore part of the front lobe, ending nearer the outer side. Short ridges project from this surface on the inner side, marked off by the fore link. The mid link passes from near the outer side of the fore lobe to near the middle of the hind lobe. The link is complicated by a vertical ridge or fold of enamel on its inner surface. Similar ridges mark the inner half of the fore surface of the hind lobe. On the hind surface of this lobe, internal to the ridge by which the outer convex end there terminates, is a narrow pyramidal tract of enamel in low relief, the apex of which reaches the working-ridge of that lobe; internal to this pyramid is a second, less strongly defined by two sharp linear grooves. The inner side or end of each transverse lobe is narrower.

The fresh and unworn crown of the penultimate molar $\left(m_{2}\right)$ shows well the accessory ridges which complicate the enamel cap of its crown. In this tooth, as in $m_{1}$, the prebasal ridge beginning near the base of the inuer end of the fore lobe curves forward and outward, rising rapidly to a narrow summit, which seems to represent a third short transverse lobe; this, as soon as it has received or sent off the fore link, subsides suddenly upon the base of the fore lobe before attaining its outer end. 
The position of the germ of the last molar is such that the transverse lobes turn their working-edges obliquely inward, rather forward, and, with but a very slight inclination, upward, indicating the semirotating movement by which, in the course of the growth of both tooth and jaw, the crown is brought into the latter direction, and in a working line with the antecedent grinders. The superadded complexities noted in these teeth are multiplied in the last molar; at least so much of the hind surface of the hind lobe as is formed shows, in the left ramus, not fewer than six accessory ridges in the Hattened and rather depressed tract included between the hinder terminal ridges or angles of the outer and inner convex ends of the hind lobe. Of these six vertical ridges two are larger than the rest, and of the narrow pyramidal shape before mentioned (they answer to those marked $h$ in fig. 10, Plate XCIV.).

In the unworn molar of this young jaw (Plate XCV. fig. $6, m_{1}$ ) the mid link does not come to the grinding-surface as in the worn molars from the mandible of the adult Procoptodon (ib. fig. 4); they show a sharp concave border slightly notched midway. Notwithstanding some minor differences to be expected in the modifications of the enamel which complicate the crown of the molars in the present genus, the dimensions of $d_{4}, m_{1}, m_{2}$, and $m_{3}$ led me to vicw this mandible as having been derived from a young of Procoptodon Goliah.

The germ of the premolar was accordingly sought for, and the right ramus (Plate $\mathrm{XCV}$. fig. 7) was fortunately so far preserved as to include its formative cell * . The crown of the tooth therein lodged (ib. fig. 3) has a fore-and-aft extent one third greater than the larger of the two teeth $\left(d_{3}\right)$ which it displaces; the outer side of the crown is divided, as in Procoptodon Rapha, by a vertical groove, but more equally; a short second vertical groove or notch indents the hinder division, near the main groove. The convexity of the exposed part of the crown testifies to the procoptodont character of this premolar.

The incisors (Plate XCII. fig. 5, $i$ ), both broken away near their issue from the alveoli, show a full elliptic section, 6 lines in the vertical, 5 lines in the transverse direction; they come almost into contact medially; the transverse extent of the pair is 10 lines; their direction is obliquely forward and upward, as in Nototherium, not procumbent as in the typical Macropodida.

The symphysis is continued, broadly, to the incisive outlets; it has insured, apparently, an attachment to each other of the rami of this instructive mandible, too intimate to be disturbed by posthumous movements, although anchylosis had not been completed, if it had commenced. From the anterior molar to the incisor measures but 10 lines, though it might be 1 inch or a little more if the incisive alveoli were entirc. The outlet of the dental canal (ib. fig. $6, v$ ) is small ; it is 3 lines below the diastemal border, and 5 lines from the fore part of the socket of $d_{2}$.

Each ramus is thick vertically, convex externally, in a degree increasing to the origin of the coronoid plate. 'The thick lower border, where it curves from the horizontal to

* Permission to remore the requisite portion of bone was accorded by the Museum Committec of the Royal College of Surgeons. 
the ascending parts of the ramus, is slightly inflected; a rather wide shallow groove extends above it. The inner surface of the ramus in advance of the inflection is feebly convex vertically. The base of the coronoid process describes a curve convex inward as it extends from before backward.

The lower border of the left ramus is entire from below $\left(m_{1}\right)$ backward to the hind fracture; it is obtuse. The thickness or transverse diameter of the ramus, below the middle of $m_{3}$, is rather more than four fifths the vertical diameter at that part. Thus the characters of the mandible of the smaller species of Procoptodon are closely repeated in that of the immature specimen of the larger species.

If the present mandible of Procoptodon Goliah be compared with that of Nototherium Mitchelli in a like state of preservation, which is the subject of Plate XXXVIII., or if a reference be made to that Plate and Plate XLII. (Nototherium inerme), the interesting and instructive modification of the present extinct Marsupial, as transitional between Macropus and Nototherium, will be obvious. But the true macropodal character comes strongly out in the different result of the quest in the substance of the jaw carried out in the subject of fig. 7 , Plate XCV. of the present memoir, and in fig. 5, Plate XL. of a Nototherium at a similar stage of immaturity.

I have been favoured with a photograph of a portion of a left mandibular ramus of a young Procoptodon Goliah at a corresponding stage of dentition (Plate XCV. fig. 5 ). This was obtained from the Breccia-cave of Wellington Valley; the original is in the Museum of Natural History of Sydney, New South Wales.

$\S 25$. Genus Palorchestes*, Ow.-The finest fossil evidence which has yet reached me of an extinct Kangaroo is the portion of skull figured, of the natural size, in Plates XCVI., XCVII., CV., CVI., CVII.

It was discovered in the year 1851 by Dr. Ludwig BECKER, " in a bed of yellowish sand and clay mixed with very small shells," in the Province of Victoria, Australia. The matrix had been cleared off before the fossil reached me.

I am indebted for the opportunity of now describing and figuring this specimen to the kindness and liberality of my esteemed friend and fellow labourer in palæontology, the late estimable Dr. KaUp, of Darmstadt, to whom the fossil was in the first instance transmitted.

It is much petrified, heary, massive, like most of the fossils from the freshwater formations of Australia; but it partakes of the colour of its matrix, which is lighter than that of the fossils from the drift-beds of Queensland. It includes the facial or fore part of the skull with the bony palate and both right and left series of molars. The sockets of the three incisors are preserved in the right premaxillary (Plates XCVI. \& XCVII. fig. $1, i_{1,2,3}$; the left has suffered fracture in that part, but the teeth are restored in outline in Plate CVII.

Comparing the least-worn molar in this skull (Plate XCVII. fig. 1, $m_{2}$, and fig. 2, restored) with the corresponding tooth in the upper jaw of Procoptodon (Plate XCIV.

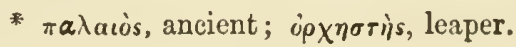


tig. $1, m_{2}$ ), the coronal enamel is disposed on a simpler pattern, more in accordance with that of the normal Kangaroos*. Moreover, as in the larger living and extinct species of Macropus, the bony palate is entire (Plate XCVII. fig. 1).

The usual permanent or adult series of five molars have remained in place and use in our present fossil, whereas at the degree of wear shown by the last grinder, the first, if not also the second, would have been shed in Macropus propert.

In the maintenance of the adult series of five grinders the fossil resembles Osphranter, Halmaturus, and Sthenurus, but the premolar (ib. ib. $p{ }_{3}$ ) differs in shape and proportion. Its antero-posterior extent is but three fourths that of the next tooth (ib. $d_{4}$ ); in Osphranter and Petrogale (Plate XC. fig. 1) the premolar equals, in Halmaturus and Sthenurus it exceeds, $d_{4}$ in that dimension. But in the fossil the transverse diameter of the premolar in proportion to the length of the crown is greater than in any known existing Kangaroo, and in this respect is equalled only by the extinct Procoptodons. As in these, also, the front pier of the zygoma (ib. ${ }^{21}$ ) has a more advanced position in relation to the molar series than in Macropus, Osphranter, or IIalmaturus. But the chief distinctive character of the present fossil is the great proportional length of the premaxillaries (Plates XCVI., XCVII., CV. ${ }_{22}, 2^{\prime}$ ) and the concomitant backward position of the incisive or premaxillary palatine foramina (ib. a), which are closer together, and were separated by narrower processes of these bones, if so separated at all; for the foramina in the fossil seem to have been confluent, and were certainly short and parallel; whereas in Macropus, Osphranter, Halmaturus, and P'etrogale (Plate XC. fig. 1, a a) they are relatively longer, are wider apart, and usually with their narrow or pointed hind ends convergent.

The dental formula, $i_{3-3}, c 0, m_{5-5}$, and pattern of the grinding-surface of the molars (Plate XCVII. fig. 2) being macropodal, the differential characters from known recent and fossil Kangaroos are of subgeneric value, and call for the usual taxonomic indication which heads the present section.

$\S 26$. Palorchestes Azael, $\mathrm{O}_{\mathrm{w} .}$ - The fore end of the premaxillaries is not quite entire, but sufficient of the sockets of the three incisors of the right side remain to show that not more than half an inch of the bone can there be wanting; the teeth have dropped out prior to fossilization. From the fore end of the skull to the premolar $\left(p_{3}\right)$ is 5 inches; the length of the molar series is 4 inches 6 lines. These two admeasurements are relatively almost the same in Osphranter robustus, the length of its series of five molars being 2 inches 2 lines, and that of the skull in advance of the premolar being 2 inches 3 lines; the part of the skull belind the last molar in the fossil is 2 inches 9 lines in length. On this basis the entire skull of Palorchestes Azael may be reckoned at about 16 inches in length.

The extent of the diastema in the upper jaw supports an inference of a like extent in the lower, and would show a nearer resemblance, in the latter respect, of Palorchestes to Macropus, Osphranter, and other genera of normal Kangaroos, than to the extinct

* Plate LxXXI. fig. 10, m 2 (Macropus Titan).

+ Ib. ib. fig. 15 (Macropus Titan). 
Sthenuri, Protemnodons, and Procoptodons, which, in their shorter and deeper diastemal and symphysial part of the mandible, exemplify the transition to Nototherium.

The extent of the premaxillaries (22) from the alveolar outlets to the anterior bony nostril $(n)$ is relatively greater than in any skull of a living Kangaroo I have yet seen (compare fig. 2 with fig. 3, Plate XCVI.). 'The tract in question slopes backward as it rises and curves, more vertically near the nostril, where it swells into a pair of low tuberosities (ib. fig. $1, n$ ). So far the union of the two premaxillaries is close, seemingly anchylosed, though the mid line of their symphysis is traceable. In this character Palcrchestes offers a resemblance to the Koala and Wombat*. A little behind the ruberosities each premaxillary sends upward its plate to form the outer walls of the nostril. The fore or free edge of this plate is thick, rounded, and slopes backward as it rises in a greater degree than the subnasal coalesced plate.

Of the right side-plate but an inch and a half is preserved; the left one (ib. ib. ${ }_{22}$ ) is continued to its junction with the maxillary $\left(21^{\prime}\right)$; and this extends backward to near the orbit, $7 \frac{1}{2}$ inches from the incisive alveoli. The upper border of this plate is, at first, thinner than the anterior or ascending border, but gains in thickness as it approaches the orbit (Plate CV. fig. 1, ${ }_{21}^{\prime}$ ); it may have been broken and the fractured margin worn smooth and obtuse; as it is, it shows no trace of the junction with the nasal bone. As much of the plate as remains is nearly vertical, neither swelling outward, as in Macropus major and Osphranter, nor bending inward at its upper part to join the nasal, as in all recent Kangaroos. The external nostril must have been relatively narrower, and seems to have been longer and more upward in aspect than in other known Macropodidee.

The floor of the nostril is continued backward by the coalesced premaxillaries 2 inches behind the lower border of the aperture (Plate CV. fig. $1, n$ ); it is here half an inch in breadth, concave and pitted along the line of the interpremaxillary suture. Then, seemingly, it has been broken off, the thinner vertical plates rising from the partition of the confluent prepalatine openings (ib. a), which are seen at a lower lerel. Behind these the bony base of the "septum narium" rises for about half an incl before its fracture; and it can be traced back three inches (as at $n$ ) before it suddenly sinks down to the lower level of the upper surface of the bony palate (ib. $b b$ ). This subsidence is more abrupt than in living Kangaroos (ib. fig. 2, $b$ b), and each lateral division of the superpalatal part of the floor of the nasal chamber forms, anteriorly, in Palorchestes a blind fossa (ib. fig. $1, b b$ ) below the level of the floor of the antorbital part (ib. $n^{\prime}$ ) of that chamber.

Some traces are discernible of the suture between the premaxillary and maxillary upon the palate (Plate XCVII. fig. 1, ${ }_{21}$ ) and upon the side of the facial part of the skull. Behind the third incisive alveolus, on the right side, a narrow oblique cavity like an alveolus (Plate XCVI. fig. $1, c$ ) is exposed by fracture or attrition of the outer palate of the premaxillary, into the base of which cavity opens a small vascular or nervovascular canal; this may have contained the germ or aborted rudiment of a canine. 
The bony palate (Plate XCVII. fig. 1) loses a little breadth behind the incisive foramen $(a)$, then expands with an outward curve to the sockets of the premolirs $\left(p_{3}\right)$. A mid tract of the breadth of the incisive foramen is continued backward as a very shallow chrmmel to opposite the third grinder $\left(m_{1}\right)$, where the uniform level of the bony palate is gained. A similar but rather deeper channel is continued forward from the fore part of the incisive foramen, and slightly expands to its termination at the outlets of the nid incisors $\left(i_{1}\right)$. The intermolar tract of the bony palate is less concave longitudinally than in Macropus and Ospleranter, and less so transversely than in Macropus major. Osphranter more resembles Palorchestes in this direction.

There is no trace in Palorchestes of the pair of small oblong holes where the palatomaxillary suture (ib. ib. ${ }_{20}$ ) begins to bend backward near the socket of the last molar. In Palorchestes this suture describes a less angular, more semicircular course than in existing Kangaroos. The hind border of the bony palate appears to have been more concave than in Macropus major or Osphranter robustus, in which respect it resembles nore some of the Halmaturi. A pair of small vascular foramina, 1 inch 3 lines apart, occur at the interval between the right and left premolar $\left(p_{3}\right)$.

'The anterior pier of the zygoma (Plates XCVI., XCVII., CV., CVII., 21") is subtrihedral, the hind surface or side being the broadest, nearly flat vertically, concave transversely. The fore part is subequally divided into an upper and lower facet by a forwardly directed rounded angle. A narrow semicircular notch (Plate XCVI. fig. 1,o) at the upper part of the base of this pier indicates a part of an orbit relatively smalier than in the Kangaroos. Above and in advance of this notch is the ectorbital aperture of the lacrymal canal characteristic of the Marsupialia. There does not appear to be, in either side of the skull, a trace of an antorbital foramen; but I incline to believe in some accidental obliteration of that issue, rather than that it never existed.

Each molar series describes a slight curve convex outward. 'The base of the broken crown of the premolar is subelliptic (Plate XCVII, fig. $1, p_{3}$ ), $7 \frac{1}{2}$ lines in long diameter, 6 lines in transverse diameter, which is at its middle; it is not broadest behind as in most other Kangaroos; the inner. side is more convex than the outer one. The second molar (ib. ib. $d_{4}$ ) is bilophodont, with a prebasal ridge; a fold of enamel (ib. $f$ ) indicative of the ridge remains on the inner side; the rest of the ridge is lost in the continuous hollow tract of dentine occupying the base of the worn-down anterior lobe $(a)$. Opposite folds of enamel, the inner one the longer, indicate the interlobal valley; the dentine at the base of the link $(r)$ leads across from the anterior to the posterior field of attrition. The third molar (ib. ib. $m_{1}$ ) has been worn down to the same degree. In both these molars the inner side of the basal part of the front lobe $(a)$ encroaches further than that of the hind lobe $(b)$ upon the bony palate, forming the origin of a very strong antero-internal root. In the fourth molar $\left(m_{2}\right)$ and in the last $\left(m_{3}\right)$, the corresponding root makes a projection beyond the inner side of the hind lobe of the tooth in advance. 'The base of the mid link $(r)$ remains in $m_{2}$; in $m_{3}$ that link shows a median notch. More of the narrow prebasal ridge $(f)$ is apparent in the last two teeth. The 
hind surface of the penultimate and last molars seems to have been slightly depressed at $g$, fig. 2, but much less so than in Macropus major and Osphranter robustus; the hind lobe of $m_{3}$ is narrower than that of $m_{2}$. 'The greatest breadth of the crown of the third molar $\left(m_{1}\right)$ is 10 lines. The surface of the enamel in all the grinders appears to be finely rugous.

Thus, so much of the dental characters as can be defined in the present unique fossil concurs with the cranial ones in showing Palorchestes Azael to have deviated less from the type of the existing bilophodont Macropodidee than have the species of Procoptodon, some of which (Proc. Goliah, for example) were its rivals in bulk.

'This conclusion is sustained by the evidence of the mandible and mandibular teeth which has subsequently reached me. It is afforded by portions of a lower jaw from fluviatile deposits of a tributary of the Condamine, for the examination of which I am indebted to Sir Daviel Cooper, Bart. The chief fragment is a portion of the right mandibular ramus with $d_{4}, m_{1}, m_{2}$, and part of $m_{3}$ (Plate CVI. figs. 1-3); there was also a smaller part of the left ramus of the same jaw with $m_{1}$ and the sockets of $d_{4}$ and $p_{3}$ (ib. fig. 5).

The depth of the ramus at the interval between $p_{3}$ and $d_{4}$ is 3 inches 3 lines; at the socket of the last molar $\left(m_{3}\right)$ it is 2 inches 8 lines. Such gain of depth as the mandibular ramus extends from the back to the front of the molar series is a character of the lower jaw of Macropus (Plate LXXX. fig. 15, Plate LXXXII. fig. 13), which contrasts with that in Sthenurus and Protemnodon.

The socket of the premolar (Plate CVI. fig. $5, p_{3}$ ) shows the two roots of that tooth to have been simple; the hinder one, in section circular, with a diameter of 3 lines, was larger than the fore one, which was compressed and elliptic in section. The fore-and-aft length of the crown of this tooth is indicated to have been between 8 and 9 lines. The fore root of $d_{*}$ (ib. fig. $5, d_{4}$ ) is transversely elliptic, 5 lines in long diameter, with a mid groove along its hind surface (it is an inch in length). The hind root, with a larger and deeper longitudinal groove on its fore surface, is also transversely elliptical, with a long diameter of $6 \frac{1}{2}$ lines. The crown of this tooth, preserved in the right ramus (ib. figs. $1 \& 2, d_{4}$ ), shows a low short prebasal ridge (fig. $2, f$ ), upon which the exposed dentine is continuous with that of the much-worn surface of the fore lobe $(a)$ indicative of a short linked connexion therewith. A linear tract of dentine extends along the short mid link. The postbasal ridge (fig. $1, d, g$ ) is indicated by a narrow fold of enamel which extends from the dentinal tract at the back of the grinding-surface of the hind lobe, downward and outward to near the base of the crown. The fore-and-aft diameter of $d_{4}$ is $10 \frac{1}{2}$ lines $\left(23\right.$ millims.), the transverse diameter of the hind lobe is $7 \frac{1}{2}$ lines (15 millims.).

In $m$, the wear of the crown exposes a continuous tract of dentine from the fore lobe along the nid link to the postbasal ridge $(g)$. The prebasal ridge is seen on the inner half of the fore surface of the fore lobe, to which part it seems to be limited. Above it the fore surface shows a vertical indent. The postbasal ridge (ib. fig. $7, g$ ) is more 
developed on the inner side of the hind link (ib. $s$ ), where it is divided from the hind lobe by a fossa; on the outer side of the link the ridge $\left(g^{\prime}\right)$ rapidly sinks and subsides near the base of the crown; the mid part of the postbasal ridge is half an inch above the base-line of the enamel in $m$, (fig. 8 ). 'The main valley expands as it descends from each side of the mid link $(r)$, and is closed by a low bar on both the outer (ib. fig. $6, v$ ) and inmer (ib. fig. 5, $v^{\prime}$ ) sides of the tootl. The fore-and-aft extent of $m$, is 1 inch; the transverse diameter of the hind lobe is 8 lines.

The less worn crown of $m_{2}$ shows better the pattern of the grinding-surface in the lower molars of the present species. The vertical indent (ib. fig. 1, $m_{2}$ ) on the inner and fore part of the crown, leading to the better developed inner part of the prebasal ridge (ib. $f^{\prime}$ ), is deeper than in $m_{1}$, and causes a concave contour of the anterior enamelborder of the fore lobe. The mid link projects from the middle of the hind enamelborder of that lobe, touches, but is not continuous with, the hind part of the link $(r)$ sent off from the outer side of the fore part of the hind lobe $(b)$. The vertical prominence from the corresponding part of the crown of the lower molars in Nototherium (Plate XLIV. figs. $2 \& 3, r$ ) is the homologue of this part of the mid link in Palorchestes.

The inner concave part of the fore surface of the hind lobe shows two fine vertical fissures in $m_{2}$ (fig. 2). From the low link at the back of the hind lobe the postbasal ridge sinks toward the base, thicker and shorter on the inner (fig. $2, m_{2}, g$ ) than on the outer side. 'The fore-and-aft extent of $m_{2}$ is 1 inch $1 \frac{1}{2}$ line (29 millims.); the transverse breadth of the lind lobe is $8 \frac{1}{2}$ lines (18 millims.).

'That of the fore lobe of $m_{3}$ is 9 lines; the length of the crown, if entire, would be 1 inch 2 lines (fig. 4). The fracture at which the hind lobe of that tooth has been broken away shows the continuous part of the mid link to be 3 lines in vertical extent; the whole heiglit of the link being 5 lines where it rises from the valley (ib. fig. $3, m_{3}$ ). The exposed hind root of this molar curves outward as it descends, and is bifurcate at the extremity. Beneath it the fracture shows the dental canal. The inner bar is hardly marked at the inner entry of the valley in $m_{2}$ and $m_{3}$ (fig. 4). 'The enamel near the base of the crown and at parts of the outer surface shows the fine rugæ and punctations like those in the molars of Nototherium and Diprotodon. One cannot help sceing in the generic pattern of the molars of Palorchestes a transitional condition between the small existing Kangaroos and those extinct gigantic Marsupials.

A restoration of the skull of Palorchestes Azael is added, in outline, to a view of the left side of the subject of Plates XCVI. \& XCVII. in Plate CVII. 
Description of the Plates.

(Illustrative of the Skull and Teeth of Extinct Macropodidae. All the figures are of the natural size.)

\section{PLATE LXXVI.}

Fig. 1. Left side view of cranium, with skull restored in outline, of Macropus Titan. Fig. 2. Left side view of fore part of cranium, of a young Sthenurus Atlas.

Fig. 3. Outside view of left upper third incisor, Sthenurus Atlas.

Fig. 4. Outside view of crown of left upper third incisor, Macropus Titan.

\section{PLATE LXXVII.}

Fig. 1. Right side view of cranium, with skull restored in outline, of Macropus Titan.

Fig. 2. Outside view of right upper third incisor, Macropus Titan.

Fig. 3. Outside view of right premaxillary and incisors, Macropus major.

Fig. 4. Outside view of fore part of right upper jaw and teeth of a young Sthenurus Atlas.

Fig. 5. Outside view of right upper third incisor, Sthenurus Atlas.

Fig. 6. Outside view of right premaxillary and incisors, Halmaturus ruficollis.

Fig. 7. Outside view of right premaxillary of Sthenurus Brehus (?).

\section{PLATE LXXVIII.}

Fig. 1. Upper view of cranium, with skull restored in outline, of Macropus Titan.

Fig. 2. Part of occiput of ditto.

Fig. 3. Occiput of Macropus major.

\section{PLATE LXXIX.}

Fig. 1. Under or base view of cranium, with skull restored in outline, of Macropus Titan.

Fig. 2. Hind surface of last upper molar ( $\left.m_{3}\right)$ of ditto.

Fig. 3. Hind surface of last upper molar $\left(m_{3}\right)$ of Macropus major.

Fig. 4. Under view of fore part of right upper jaw and teeth of a young Sthenurus Atlas. 


\section{PLATE LXXX.}

Fig. 1. Side view of the cranium and teeth of a nearly full-grown Uroo (Macropus (Phascolagus) embescens).

Fig. 2. Working-surface of the molars, left side, upper jaw, of a nearly full-grown Uroo.

Fig. 3. Inner surface of the molars, left side, upper jaw, of a nearly full-grown Uroo.

Fig. 4. Outer side view of mandible and teeth of the same skull.

Fig. 5. Working-surface of the lower deciduous molars of the same skull.

Fig. 6. Side view of molar series, left side, upper jaw, of a younger Phascolagus erubescens.

Fig. 7. Working-surface of the molars in place of a younger Phascolagus erubescens.

Fig. 8. Side view of portion of mandible, with the molar series, of the same skull; the germ of the premolar is exposed in its formative cell.

Fig. 9. Side view of molar series, left side, upper jaw, of a young Red-necked Kangaroo, Macropus (Halmaturus) ruficollis.

Fig. 10. Side view of molar series, left side, lower jaw, of the same skull.

Fig. 11. Side view of the left mandibular ramus and teeth of the yellow-foot Kangaroo, Macropus (Petrogale) xanthopus.

Fig. 12. Working-surface of upper molars, right side, of Macropus (Boriogale) magnus. Fig. $12 a$. Side view of three anterior lower molars of Boriogale magnus.

Fig. 13. Side view of the left mandibular ramus and teeth of Macropus (Osphranter) robustus.

Fig. 14. Working-surface of the molar series of ditto. 14'. $a$, side view of upper premolar; $b$, working-surface of ditto.

Fig. 15. Side view of the left mandibular ramus and teeth of the Giant Kangaroo, Macropus major.

Fig. 16. Working-surface of the molar series of the Great Kangaroo.

Fig. 17. Side view of the left upper incisors, Macropus major.

Fig. 18. Idem, Osphranter robustus.

Fig. 19. Idem, Boriogale magnus.

Fig. 20. Idem, Halmaturus ualabatus.

Fig. 21. Idem, Halmaturus ruficollis.

Fig. 22. Idem, Petrogale xanthopus.

Fig. 23. Working-surface of left upper molar $\left(m_{2}\right)$, Macropus major.

Fig. 24. Idem, Macropus rufus.

Fig. 25. Idem, Ospleranter antilopinus.

Fig. 26. Working-surface of left lower molar $\left(m_{2}\right)$, Boriogale magnus.

Fig. 27. Working-surface of left upper molar $\left(m_{2}\right)$, Halmaturus ualabatus.

Fig. 28. Idem, Petrogale xanthopus.

Fig. 29. Working-surface of left lower molar, Macropus Titan.

Fig. 30. Idem, Sthenurus Atlas. 


\section{PLATE LXXXI.}

Fig. 1. Working-surface of right upper molars, Macropus major.

Fig. 2. Idem, Macropus rufus.

Fig. 3. Idem, Osphranter robustus.

Fig. 4. Working-surface of right lower molars, Macropus rufus.

Fig. 5. Idem, Boriogale magnus.

Fig. 6. Outer side view of left maxillary bone and molar series of a young Macropus Titan.

Fig. 7. Inner side view of left maxillary bone and molar series of a young Macropus Titan.

Fig. 8. Working-surface of molars of left maxillary bone of a young Macropus Titan.

Fig. 9. Back view of the same fossil, showing formative cell of the last molar, $m_{3}$.

Fig. 10. Palatal or under view of a left maxillary, with working-surface of the molar teeth of an older Macropus Titan.

Fig. 11. Working-surface of right upper molar series of a mature Macropus Titan.

Fig. 12. Working-surface of the last two lower molars, right side, Macropus Titan.

Fig. 13. Outer side view of the same teeth, with outline of part of mandible.

Fig. 14. Inner side view of the same teeth, with outline of part of mandible.

Fig. 15. Under or palatal view of right maxillary bone and teeth of an old Macropus Titan.

Fig. 16. Outer side view of right maxillary bone and teeth of an old Macropus Titan. Fig. 17. Inner side view of teeth of right maxillary bone of an old Macropus Titan.

Fig. 18. Hind surface of last upper molar $\left(m_{3}\right)$ of Macropus Titan.

\section{PLATE LXXXII.}

Fig. 1. Outer side view of part of right maxillary and teeth of a young Phascolagus altus; the premolar $\left(p_{3}\right)$ and penultimate molar $\left(m_{2}\right)$ are exposed in their formative alveoli.

Fig. 2. Under view of the same specimen.

Fig. 3. Upper view of portion of right mandibular ramus, showing the working-surface of the molars in place, and of the crown of the last molar $\left(m_{3}\right)$ in its formative alveolus, of a young Sthenurus Atlas.

Fig. 4. Outer side view of part of the same specimen, with the crown of the premolar exposed in its formative alveolus. (These figures are from the type-specimen of Macropus Atlas, Ow., figured in Mitchell's 'Three Expeditions,' \&c., Svo. vol. ii. 1838, p. 359 , pl. xxix. fig. 1.)

Fig. 5. Outside view of a larger portion of the left mandibular ramus of an older individual of Sthenurus Atlas; the premolar ( $\left.p_{3}\right)$ has not quite risen into place. 
Fig. 6. Inside view of the same specimen.

Fig. 7. Upper view of symphysis and incisor of the same specimen.

Fig. 8. Working-surface of the molars of the same specimen.

Fig. 9. Working-surface of the lower molars of a full-grown or mature individual of a large male of Sthenurus Atlas (or of a larger species of Sthenurus).

Fig. 10. Outside view of part of left maxilla and teeth of a mature individual of Macropus Titan.

Fig. 11. Under view, with working-surface of molars, of the same specimen.

Fig. 12. Inner side view of the same specimen.

Fig. 13. Outside view of major part of the left mandibular ramus and teeth of a mature individual of Macropus Titan.

Fig. 14. Working-surface of the molars of the same specimen.

Fig. 15. Inside view of the same specimen.

Fig. 16: Upper riew of part of the symphysis and incisor of the same specimen.

Fig. 17. Upper view of a small portion of the right mandibular ramus of a young Macropus Titan.

Fig. 18. Outer side view of the same specimen, with the germ of the premolar $\left(p_{3}\right)$ exposed in its formative alveolus. ('This is the type-specimen of Macropus Titan figured in MitcilelL's 'Three Expeditions,' \&c., p. 359, pl. xxix. fig. 3.)

\section{PLATE IAXXXII.}

Fig. 1. Outer side riew of right maxillary, with the molar teeth and their roots exposed, of a large old male Macropus rufus.

Fig. 2. Outer side view of right maxillary and teeth of Macropus Titan. (From the specimen No. 1519, 'Fossil Mammalia,' in the Museum of the Royal College of Surgeons: Catalogue of Fossils, 4to, 1845, p. 324.)

Fig. 3. Under view, with working-surface of the teeth, of the same specimen.

Fig. 4. Outer side view of portion of right maxillary and teeth of a young Protemnorlon Anak.

Fig. 5. Working-surface of the teeth of the same specimen.

Fig. 6. Inner side view of the same specinien, with the premolar $\left(p_{3}\right)$ exposed in its formative cavity. (From the specimen No. 1519, 'Fossil Mammalia,' in the Museum of the Royal College of Surgeons; wrongly ascribed to Macropus Atlas in my 'Catalogue,' 4to, 1845, p. 327.)

Fig. 7. Outer side view of portion of the left maxillary of a young Protemnodon Anak.

Fig. 8. Working-surface of the teeth of the same specimen.

Fig. 9. Inner side view of the same specimen, with the premolar $\left(p_{3}\right)$ exposed in its formative cavity. (From the specimen No. 1513, 'Fossil Mammalia,' in the Museum of the Royal College of Surgeons; wrongly ascribed to Macropus Atlas in my 'Catalogue,' 4to, 1845, p. 325.) 
Fig. 10. Inner side view of part of the left mandibular ramus and teeth of Macropus affinis, Ow.

Fig. 11. Working-surface of the best-preserved molars $\left(m_{1}, m_{2}\right)$ of the same fossil. (This is the type-specimen of the species, No. 1524, 'Fossil Mammalia,' in the Museum of the Royal College of Surgeons: 'Catalogue,' 4to, 1845, p. 328.)

Fig. 12. Outside riew of portion of right mandible, with last three molars, of an old (female ?) Macropus Titan.

Fig. 13. Working-surface of the teeth of the same specimen.

Fig. 14. Corresponding portion of lower jaw of Macropus rufus. (From the largest existing Kangaroo, obtained by JoHx Gould, Esq., F.R.S., during his sojourn in Australia.)

Fig. 15. Outside view of portion of left mandibular ramus and four molars of an immature Osphranter Gouldii, Ow.

Fig. 16. Working-surface of the teeth of the same specimen.

\section{PLATE LXXXIV.}

Fig. 1. Outer side view of skull and upper teeth of a nearly mature Halmaturus ualabatus.

Fig. 2. Inner side view of molar series of ditto.

Fig. 3. Working-surface of molar series, and portion of bony palate, of ditto.

Fig. 4. Outer side view of right maxillary bone and teeth of a full-grown Sthenurus Atlas.

Fig. $4 a$. Hind view of penultimate molar $\left(m_{2}\right)$ of ditto.

Fig. 5. Inner side view of the same fossil.

Fig. 6. Under view of ditto, with working-surface of teeth.

Fig. 7. Outer side view of portion of mandibular ramus and teeth of a mature Sthenurus Atlas.

Fig. 8. Inner side view of the same fossil.

Fig. 9. Hinder surface of the crown of penultimate molar $\left(m_{2}\right)$ of ditto.

Fig. 10. Outer side view of mandibular ramus and teeth of a nearly mature Halmaturus ualabatus.

Fig. 11. Working-surface of molar series of ditto.

Fig. 12. Inner side view of the same mandibular ramus and teeth.

Fig. 13. Outer side view of a portion of the right mandibular ramus and tooth of a young Protemnodon Mimas.

Fig. 14. Inner side view of the same fossil, with the premolar $\left(p_{3}\right)$ exposed in its formative cavity.

Fig. 15. Working-surface of the molar $\left(m_{1}\right)$ of the same fossil. 
Fig. 16. Back view of the molar $\left(m_{1}\right)$, with part of the formative cavity of $m_{2}$, of the same fossil.

Fig. 17. Inner side view of fore part of the mandibular ramus of an Osphranter Cooperi.

Fig. 18. Outer side view of the three molars, $p_{3}, d_{4}, m_{1}$, of ditto.

\section{PLATE LXXXV.}

Fig. 1. Outside view of portion of the right mandibular ramus, with the molar series, of a full-grown Protemnodon Anak.

Fig. 2. Working-surface of the teeth of the same fossil.

Fig. 3. Outside view of a larger portion of the left mandibular ramus, with the molar series, of Protemnodon Anak.

Fig. 4. Working-surface of the two hindmost molars of the same fossil.

Fig. 5. Outside view of a portion of the left mandibular ramus and molar series of a Protemnodon $\mathrm{Og}$.

Fig. 6. Working-surface of the teeth of the same fossil.

Fig. 7. Outside view of a left mandibular ramus, nearly entire, with incisor and molar teeth, of Protemnodon Anak.

Fig. 8. Inside view of a left mandibular ramus, nearly entire, with incisor and molar teeth, of Protemnodon Anak.

Fig. 9. Working-surface of the molar series of the same fossil.

Fig. 10. Upper view of symphysial part, with the incisor, of the same fossil.

Fig. 11. Outside view of a portion of mandible, with last two molars, of Protemnodon Og.

Fig. 12. Inside view of a portion of mandible, with last two molars, of Protemnodon $\mathrm{Og}$. Fig. 13. Working-surface of the two molars, $m_{2}, m_{3}$.

Fig. 14. Hinder fractured surface of the mandibular ramus of Protemnodon Anak (fig. 3).

\section{PLATE LXXXVI.}

Fig. 1. Outside view of part of left mandibular ramus, with the molar series, of a mature Protemnodon Mimas.

Fig. 2. Inside view of part of left mandibular ramus, with the molar series, of a mature Protemnodon Mimas.

Fig. 3. Working-surface of the teeth of the same fossil.

Fig. 4. Inside view of part of the left mandibular ramus of a young Protemnodon Mimas.

Fig. 5. Outside view of the same fossil, with the premolar $\left(p_{\text {a }}\right)$ exposed in its formative cavity.

Fig. 6. Working-surface of the molars preserved in the same fossil. 
Fig. 7. Working-surface of the first lower molar $\left(m_{1}\right)$ of the specimen, fig. 14, Plate LXXXIV., of a young Protemnodon Mimas.

Fig. 8. Fractured anterior end of specimen, fig. 4, with section of alveolus of incisor (i).

Fig. 9. Upper view of a large portion of the mandible and molar series of a full-grown Macropus Titan.

Fig. 10. Working-surface of the lower molars $\left(m_{2}, m_{3}\right)$, with remains of $m_{1}$ and $d_{4}$, of an older (female?) Macropus Titan.

Fig. 11. Outer side view of a nearly entire right mandibular ramus, with the fore part of the left ramus of the same jaw attached by matrix, of a (male?) Macropus Titan.

Fig. 12. Inner side view of symphysial part of right ramus of the same fossil.

Fig. 13. Inner side view of part of right mandibular ramus of a larger individual, or variety, of Macropus Titan.

Fig. 14. Working-surface of last molar $\left(m_{3}\right)$ of the same fossil.

Fig. 15. Hinder surface of the same molar.

\section{PI،ATE LXXXVII.}

Fig. 1. Left side view of fore part of cranium and teeth of Protemnodon Mimas.

Fig. 2. Right side view of part of premaxillary and broken incisors of the same fossil.

Fig. 3. Inner side view of left premolar of the same fossil.

Fig. 4. Working-surface of the right upper molars $\left(d_{4}, m_{2}\right)$ of the same fossil. (The above four figures are from photographs of the specimens, now in the Museum of Natural History, Sydney, New South Wales.)

Fig. 5. Left side view of part of cranium and teeth of Sthenurus Brehus.

Fig. 6. Under or palatal view of the same fossil.

Fig. 7. Outer side view of left upper premolar $\left(p_{3}\right)$ and following molar $\left(d_{4}\right)$ of Sthenurus Brehus; with fore end view of $p_{3}$.

Fig. 8. Inner side view of the same teeth.

Fig. 9. Working-surface of the same teeth.

Fig. 10. Outer side view of part of left mandibular ramus and teeth of a mature Protemnodon Rochus.

Fig. 11. Inner side view of the same fossil.

Fig. 12. Working-surface of the teeth of the same fossil.

Fig. 13. Hind surface of the molar $\left(\mathrm{m}_{2}\right)$ of the same fossil.

Fig. 14. Portion of palate and of right molar series of Protemnodon Mimas. (From a photograph of the specimen in the Museum of Natural History, Sydney, New South Wales.) 


\section{PLA'TE LXXXVIII.}

Fig 1. Outer side view of part of left maxillary and two anterior teetl of Sthenurus Atlas.

Fig. 2. Outer side view of part of right maxillary and two anterior teeth of sthenurus Atlas.

Fig. 3. Working-surface of the two anterior molars, left side, of Sthenuras Atlas.

Fig. 4. Working-surface of the two anterior molars, right side, of Sthenurus Atlas.

Fig. 5. Outer side view of right maxillary and molar series of Sthenurus Brehus.

Fig. 6. Under view of right maxillary and molar series of Sthenurus Brehus.

Fig. 7. Inner side view of right maxillary and molar series of Sthenurus Brehus.

Fig. S. Working-surface of last molar, removed from its socket, shown in fig. 6, of Sthenurus Brehas.

Fig. 9. Hind surface of crown of penultimate molar of Sthenurus Brehus.

Fig. 10. Hind surface of crown and fang of last molar of Sthenurus Brehus.

Fig. 11. Outer side view of first and second upper molars, left side, of Nototherium Mitchelli, Ow.

Fig. 12. Working-surface of Nototherium Mitchelli, Ow.

Fig. 13. Inner side view of first molar of Nototherium Mitchelli, Ow.

Fig. 14. Hinder surface of first molar of Nototherium Mitchelli, Ow.

Fig. 15. Outer side view of first and second molars, left side, of Nototherium inerme, Ow.

Fig. 16. Inner side view of first molar of Nototherium inerme, Ow.

Fig. 17. Hinder surface of first molar of Nototherium inerme, Ow.

Fig. 18. Inner side view of part of right ramus (the mandible restored in outline), with teeth, of Protemnodon Antceus.

\section{PLA'TE LXXXIX.}

Fig. 1. Upper view of portion of right mandibular ramus, with the hindmost nolars, of Macropus Titan.

Fig. 2. Upper view of portion of right mandibular ramus, with the hindmost molars, of an aged individual of Macropus Titan.

Fig. 3. Upper view of portion of left mandibular ramus, with the hindmost molar and débris of antecedent ones, of an aged Macropus Titan.

Fig. 4. Outside view of figure 2.

Fig. 5. Inner side view of figure 3.

Fig. 6. Outer side view of the teeth in ditto; $6 a$, hind surface of much-worn last molar of Macropus Titan.

Fig. T. Outside view of portion of right mandibular ramus, with three hindmost molars, of Procoptodon Pusio.

Fig. 8. Inside view of the same fossil. 
Fig. 9. Upper view of the same fossil.

Fig. 10. Hind view of the same fossil.

Fig. 11. Outside view of part of right mandibular ramus, with the penultimate and antepenultimate molars, of Leptosiagon gracilis, Ow.

Fig. 12. Inner view of the same fossil.

Fig. 13. Upper view of the same fossil.

Fig. 14. Hind view of the same fossil.

Fig. 15. Section of middle of mandibular ramus of the same fossil.

\section{PLATE XC.}

Fig. 1. Under view of cranium of Halmaturus brachyurus, Wth.

Fig. 2. Outside view of part of the left upper jaw and teeth of Procoptodon Pusio, Ow.

Fig. 3. Inside view of the same fossil.

Fig. 4. Front view of the same fossil.

Fig. 5. Back view of the same fossil.

Fig. 6. Under view of right and left maxillæ and teeth of the same young Procoptodon Pusio.

Fig. 7. Left upper molar series of adult Procoptodon Pusio.

Fig. 8. Outer side view of fore part of left mandibular ramus, with the premolar exposed, of Procuptodon Rapha, Ow.

Fig. 9. Inner side view of the same fossil.

Fig. 10. Back view of the same fossil, showing relation of the premolar $\left(p_{3}\right)$ to the milkmolar, $d_{3}$.

Fig. 11. Upper view of the same fossil: $a$, section of incisor.

Fig. 12. Under view of the same fossil.

\section{PLATE XCI.}

Fig. 1. Rami and teeth of lower jaw of Procoptodon Pusio.

Fig. 2. Outer side view of left ramus and teeth of Procoptodon Pusio.

Fig. 3. Inner side view of left ramus and teeth of Procoptodon Pusio.

Fig. 4. Front view of symphysis mandibulæ and stumps of incisors of Prucoptodon Pusio.

Fig. 5. Working-surface of molars of right mandibular ramus of Procoptodon Pusio.

\section{PLA'TE XCII.}

Fig. 1. Rami and teeth of lower jaw of a young Procoptodon Goliah, Ow.

Fig. 2. Outer side view of left ramus and teeth of Procoptodon Goliah, Ow. 
Fig. 3. Outer side view of teeth in right ramus of Procoptodon Goliah, Ow.

Fig. 4. Inner side view of tecth of right ramus of Procoptodon Goliah, Ow.

Fig. 5. Front view of symphysis mandibulx and stumps of incisors of Procoptodon Goliah, Ow.

Fig. 6. Fragment of right maxillary and two hindmost molars of Sthenurus Brehus.

Fig. 7. Working-surface of the same teeth.

\section{PLATE XCIII.}

Fig. 1. Outside view of right mandibular ramus of adult Procoptodon Rapha.

Fig. 2. Inside view of the same fossil.

Fig. 3. Upper view of the same fossil.

\section{PLATE XCIV.}

Fig. 1. Portion of upper jaw and hinder molars of Procoptodon Goliah.

Fig. 2. Outer side view of left maxillary and teeth of an old Procoptodon Goliah.

Fig. 3. Inner side view of the same fossil.

Fig. 4. Under view of the same fossil.

Fig. 5. Onter side riew of a portion of left maxillary and teeth of a less aged Procoptodon Goliah.

Fig. 6. Inner side view of the same fossil.

Fig. 7. Working-surface of the grinders of the same fossil.

Fig. 8. Upper view of hind part of left mandibular ramus, with two hind molars ( $\left.m_{2}, m_{3}\right)$, of Procoptodon Goliah.

Fig. 9. Hind riew of last upper molar of Procoptodon Goliah.

Fig. 10. Hind view of last lower molar of Procoptodon Goliah.

Fig. 11. Outer side view of adult series of grinders, right side, lower jaw, of Procoptodon Goliah.

\section{PLATE XCV.}

Fig. 1. Inside vicw of part of right mandibular ramus of a mature Procoptodon Goliah.

Fig. 2. Grinding-surface of the teeth in the same fossil.

Fig. 3. Outside view of a fragment of the left mandibular ramus, with the penultimate molar, of a mature Procoptodon Goliah.

Fig. 4. Inside view of the same fragment, showing the last two grinders.

Fig. 5. Inside view of part of the right mandibular ramus of an immature Procoptodon Goliah (from a photograph).

Fig. 6. Outer side view of right mandibular ramus of an immature Procoptodon Goliah.

Fig. 7. Portion of the same ramus, with the premolar $\left(p_{3}\right)$ exposed in its formative cell.

Fig. S. Grinding-surface of worn penultimate lower molar of Procoptodon Goliah. 


\section{PI.ATE XCVI.}

Fig. 1. Right side view of fore part of the skull of Palorchestes Azael, Ow.

Fig. 2. Fore end of the same fossil.

Fig. 3. Fore end of the skull of Osphranter robustus, Gd.

Fig. 4. Inner side view of a fragment of the right mandibular ramus of Pachysiagon Ferragus, Ow.

\section{PLATE XCVII.}

Fig. 1. Under view of the fore part of the cranium of Palorchestes Azael, Ow.

Fig. 2. Pattern of working-surface of penultimate upper molar of ditto.

Fig. 3. Outer side view of portion of right mandibular ramus and last two molars of Pachysiagon Ferragus, Ow.

Fig. 4. Upper view of the same fossil.

(PLATES XCVIII.-CIV. are described at pp. 356-372.)

\section{PLATE CV.}

Fig. 1. Upper view of the fore part of the cranium of Palorchestes Azael.

Fig. 2. Upper view of corresponding part of the skull of Macropus ruficollis, Gd.

Fig. 3. Back view of mandibular fragment, with last grinder, of Pachysiagon Ferragus.

\section{PLATE CVI.}

Fig. 1. Portion of right mandibular ramus and teeth of Palorchestes Azael.

Fig. 2. Working-surface of the same tooth of Palorchestes Azael.

Fig. 3. Hind fractured surface of the same fossil.

Fig. 4. Inner side view of last lower molar of Palorchestes Azael.

Fig. 5. Upper view of part of left mandibular ramus, with teeth and stumps, of Palorchestes Azael.

Fig. 6. Outside view of the molar $\left(m_{1}\right)$ of left mandibular ramus of Palorchestes Azuel.

Fig. 7. Inside view of the molar $\left(m_{1}\right)$ of left mandibular ramus of Palorchestes Azael.

Fig. 8. Back view of the molar $\left(m_{1}\right)$ of left mandibular ramus of Palorchestes Azael.

\section{PLATE CVII.}

Left side view of fore part of the skull and teeth of Palorchestes Azael: the entire skull and dentition restored in outline. 


\section{PI,ATE CVIII.}

Fig. 1. Outside view of parts of right upper and lower jaws, with skull restored in outline, of Sthenurus Brehus, Ow.

Fig. 2. Upper view of premaxillaries and incisors of Sthenurus Brehus, Ow.

Fig. 3. Under view of the same fossil.

Fig. 4. Under view of right lower incisor of Sthenurus Brehus, Ow.

Fig. 5. Upper surface of worn end of right lower incisor of Sthenurus Brehus, Ow.

\section{PLA'TE CIX.}

Fig. 1. Front view of premaxillaries and incisors, Sthenurus Brehus.

Fig. 2. Portion of upper jaw showing the palatal surface and first two molars $\left(p_{3}, d_{4}\right)$ of Sthenurus Brehus.

Fig. 3. Portion of upper jaw showing working-surface of last three molars of Sthenumes Brehus.

Figs. 4 \& 5. Palatal surface and teeth of upper jaw of Sthenurus Brehus.

Fig. 6. Side view of first incisor of Sthenurus Brehus.

Fig. 7. Upper view of part of mandible, with incisors and first three molars, right side, of Sthenurus Brehus.

Fig. 8. Right side view of the same fossil.

Fig. 9. Right side view of part of upper jaw of Sthenurus Brehus.

Fig. 10. Palatal surface of premaxillaries and teeth of an old Sthenurus Brehus.

\section{PLATE CX.}

Fig. 1. Outer side view of part of left mandibular ramus and molar series of teeth of Protemnodon Antceus, Ow.

Fig. 2. Inner side view of the same fossil.

Fig. 3. Working-surface of the teeth of Protemnodon Antous, Ow.

Fig. 4. Hind surface of crown of last lower molar of Protemnodon Antaus, Ow.

Fig. 5. Fractured fore part of the same fossil with socket of incisor.

Fig. 6. Outside view of part of right mandibular ramus of an older and larger Protemnodon Antaus.

Fig. 7. Upper view of the same fossil.

Fig. S. Fore part, with socket of incisor, of the same fossil.

Fig. 9. Back part of the same fossil. 
$\S 26$. Procoptodon Rapha (Characters of Mandible and lower Incisor).-The detection of the crown of the premolar in the formative cavity of a fragment of the mandible (Plate XC. figs. S-12) of an immature Macropod, with the indication which the proportions of that fragment yielded of its Procoptodont character, led to a reference of such fragment to the genus and species represented by the plaster cast of a mutilated mandibular ramus with the molar series of teeth figured in Plate XCIII., the original of which is in the Museum of Natural History, Sydney, New South Wales.

This ramus was of a mature and somewhat aged individual; the molar series shows wear even to the hindmost grinder; the premolar is ground down to the stump, but it enabled a comparison to be made with that in the young specimen (p. 457); and the conformable relation of size of the succeeding molars with that exemplified between the premolar and molars of Procoptodon Pusio and Procoptodon Goliah seemed to support a conclusion as to a species of intermediate bulk, for which the name Procoptodon Rapha was proposed.

Since pages 454-465 and Plates XC.-XCV. have been printed off, I have been favoured by my friend Dr. George Bennett, F.L.S., with the mandible and teeth forming the subject of Plate CXXVIII., which specimen was discovered by his son, George Bennett, Esq., in the drift deposits of one of the creeks in Darling Downs.

Sufficient of the worn premolar (Plate CXXVIII. $p_{3}$ ) in this mandible remains to show its identity, in antero-posterior and transverse dimensions of the crown, with that in the type-subject of figs. $\delta \& 10$ of Plate XC. The agreement in size of the succeeding molars with those of the cast figured in Plate XCIII. is also specific. The additional characters, therefore, yielded by the specimen under view are those of Procoptodon Rapha.

I may first note the deep depression (Plate CXXVIII. figs. $3 \& 4, a$ ) behind the roughly sculptured symphysial surface $(s)$ in each ramus. This depression is just below the middle of the long diameter of that surface; its aperture is elliptical, with the long axis (of 8 lines) in the same direction; it extends forward half an inch into the substance of the jaw, ending in a point. The depth of this postsymphysial depression was obscured in the cast described at p. 459. Phascolomys has also the pair of depressions, as seen in the entire mandible at the back of the symphysis, but of smaller relative size and rounder shape: Macropus has not this character.

Above the symphysial surface in Procoptodon Rapha a low longitudinal ridge bounds above a shallow longitudinal channel (fig. $4, b$ ).

'The alveolus (ib. $c$ ) of the incisor is $1 \frac{1}{2}$ inch in depth, 6 lines in antero-posterior diameter, 4 lines in transverse diameter near the outlet; the socket decreases slightly in both diameters to the bottom. The direction of the socket inclines more forward than does the long axis of the symphysis. The size and position of the outlet of the dental canal (figs. $1 \& 3, v$ ) is the same as in the cast (Plate XCIII. fig. 1, v).

The enamelled crown of the lower incisor (figs. $1 \& 3, i$ ) is less, especially in fore-andaft diameter, than the root; it is also relatively much shorter and thicker than in 
Macropus. The surface, worn by attrition of the upper incisors, is a broad angular notch, whence I infer that it has been made chiefly, if not exclusively, by the vertically directed crown of a disproportionately developed anterior upper incisor.

A snall portion ( $d^{\prime}$, fig. 2) of the lower inflected border of the mandible is preserved; but the longitudinal channel $(b)$ which it bounded is traceable above the line of fracture. The thinness of this part of the lower border of the ramus makes it liable to be broken away in the fossil.

The extent of the true or " marsupially" inflected angle $(a)$ is well defined, although it also has suffered fracture. The longitudinal extent of the angular fracture is 1 inch; but it is continued along the ridge or plate extending upward to form the hinder inflected border of the ascending ramus, which border is also broken away. 'The smooth channel, between $a$ and $d^{\prime}$, fig. 2, dividing the inflected part of the lower border of the horizontal ramus from the inflected angle, repeats that in Nototherium, shown in Plate XLI. fig. 2, between $d^{\prime}$ and $a e$; but it is relatively less or narrower in Procoptodon. It is not present in Macropus or Phascolomys.

The inner (mesial) surface of the ascending ramus (fig. 2) is divided into two depressions by a ridge continued from the postalveolar angle (fig. $2, t$ ) upward and backward to the subcondylar protuberance, answering to that in Tototherium, marked $n$ in Plate XLI. fig. 2. The ridge ( $r$, fig. 2, Plate CXXVIII.) is not present in Nototherium and is faint in Phascolomys (comp. Plate LV. fig. $3, t$ ). It is very short where it is recognizable in Macropus (Plate LXXXIV. fig. 12); and in Procoptodon it subsides ere it reaches the subcondylar protuberance $(n)$. The depression anterior to the ridge ( $r$, fig. 2 ) is divided into the "ectalveolar groove" $(u)$ and the ecto-crotaphyte surface $(0)$. The deeper depression $\left(e, e^{\prime}\right)$ posterior to the ridge $(r)$ is perforated by the "fenestral foramen " $(f)$. This foramen is above the level of the grinders in Procoptodon, but is below that level in Macropus. It is not present in Nototherium, and is very small and low-placed when it exists in Phascolomys. In Procoptodon Rapha it is of a full oval form, 6 lines in long diameter; it opens into the upper part of the large and deep "fenestral vacuity" (fig. 3, c), at the bottom of which begins the dental canal.

In the chief characters in which Procoptodon deviates from the type Macropodidee (Macropus, e.g.), it approaches Phascolomys, but more closely Nototherium.

The halves of the lower jaw have lost all reciprocal movement at the symphysis; and where bony confluence has not begun, the greater superficial extent and deep sutural interlocking surface of the apposed parts of the rami bind them firmly together. The inflected border $\left(d^{\prime}\right)$ anterior to the true "angle" $(a)$ in Procoptodon is a significant mark of affinity to Nototherium, and concurs with the type of the grinders in demonstrating this relation.

On making first acquaintance with Procoptodon Rapha, a misgiving question suggested itself, viz. whether its inferiority of size to Proc. Goliah might not indicate a sexual character belonging to the female of that species. But such inferiority, which is manifested in the females of most existing Kangaroos, is shown in general size and 
concomitant parts of the skeleton, not in the molar teeth, or in a very inferior degree to that shown in the comparison of Proc. Rapha and Proc. Goliah.

In like manner the question might be raised whether Procoptodon Rapha might not be the male of Proc. Pusio; but the degree of difference in the size of the dental series (as shown in Plates XCI. \& XCIII.) negatives the supposition, and, of course, equally excludes the hypothesis that the species Proc. Pusio has been founded on a female of Proc. Rapha.

I may finally add that every additional specimen, or comparable fragment, of the three extinct species of the present seemingly extinct genus of osculant Macropod has concurred in demonstrating the constancy of the characters assigned to them.

Description of the Plate.

\section{PLATE CXXVIII.}

Procoptodon Rapha.

Fig. 1. Outer side view of right mandibular ramus and teeth.

Fig. 2. Inner side view of molar series and contiguous parts of the same ramus

Fig. 3. Upper view of the same ramus and teeth, with fore part of the left ramus.

Fig. 4. Symphysial articular surface and socket of incisor.

All the figures are of the natural. size. 


\title{
Family MACROPODIDE.
}

\author{
Extinct Gexera and Species.
}

Bones of the Trunk and Extremities.

$\S 1$. Palorchestes? (Sacrum).-In the series of fossil bones which have been transmitted to me from the drift-deposits of Darling Downs have been vertebre and portions of the vertebral column, from which I select for the subject of the present Section the sacrum of a Macropod of a size and proportion corresponding with those of the skull of Palorchestes Azael.

The sacrum (Plate CXXIX. fig. 1) consists of two vertebræ with the characters of those of Macropus rufus (Plate LXVIII. figs. 8, 9, Plate LXXI. fig. 1), but with a difference of size shown in the following admeasurements:-

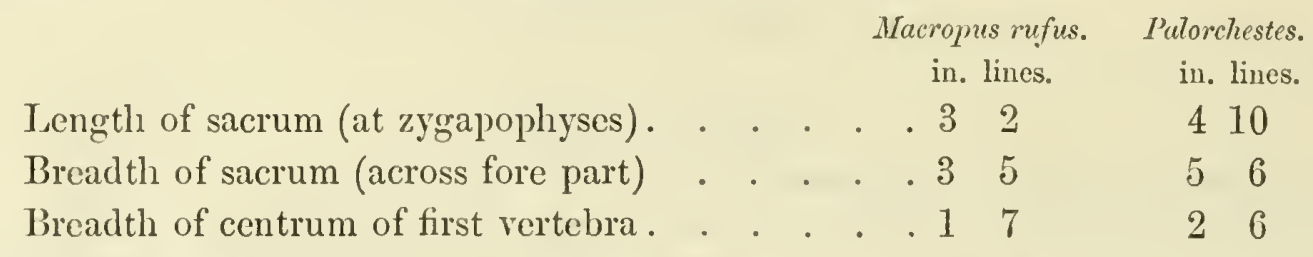

The Kangaroo yielding the recent bone compared was the largest example seen by Mr. Gochd in his travels in Australia, and no specimen of Macropus major has yet been recorded of superior size.

The comparatively gigantic leaper yielding the fossil seems to have been an aged individual, for so much anchylosis has taken place between the second sacral (Plate CXXIX. fig. 1, $c_{2}$ ) and first caudal (ib. $c d_{1}$ ) as to have kept those rertebræ in natural connexion during the period of petrifaction.

The transverse processes of the second sacral take a greater relative share in the formation of the sacro-iliac symphysis in.Palorchestes than in the above-named recent species, and the shape is rather more subquadrate than triangular. 'The joint between the first and second sacral is not obliterated. The intervertebral foramina (ib. $i, i$ ) are rather smaller, relatively, than Macropus rufus, and suggest that the hind limb may not have predominated over the fore limb in so great a degree in the larger and heavier Kangaroo. 'The pair of ridges on the hæmal surface of the centrum of the second sacral $(\mathrm{ib} . k, k)$ are better marked in the fossil. In this the neural arch of the first sacral has been broken away.

The first caudal vertebra of Palorchestes (ib. figs. 2,3) is 2 inches 11 lines in length, 1 inch 6 lines across the hinder articular end of the centrum. The base of the lamelliform depressed transverse process (ib. $d, d$ ) is 1 inch 8 lines in extent, reaching within 2 lines of each articular end of the centrum. The longitudinal extent of the base of the neural spine is 1 inch. The characters of the corresponding vertebra in Macropus 
rufus are closely repeated, with the difference of size and slight increase of breadth over length, as in the sacrum; and these permit an inference that the tail in Palorchestes corresponded in strength, if not quite in relative length, to that in Macropus.

§2. Palorchestes? (Os innominatum).-The pelvis of the Kangaroo is characterized by a long prismatic ilium, an oblong tuberosity above or anterior to the acetabulum, a "pectineal" or "ileo-pubic" process, the articular surfaces for the marsupial bones, the broad, compressed, subprismatic form of the ischium, the slenderness of the pubis, and the great length of both those elements of the pelvic arch.

The length of the pelvis due to the great extension of the os innominatum both in front and behind the acetabulum is a well-marked feature of resemblance to the same part of the skeleton in the Bird, and similarly relates to the faculty of station and progression on the hind pair of limbs-the movement being, in the Kangaroo, as in some tribes of birds, by a series of hops, the fore limbs, however, in the mammal taking also an occasional share in progression on land, which is not permitted to the volant class.

'The portion of pelvis (Plate CXXX.) corresponding in size with the sacrum (Plate CXXIX.), although reduced to the parts immediately surrounding the acetabulum, includes the base of the ilium, showing its three-sided prismatic form, the precotylar tuberosity, and, above all, the "pectineal process" (ib.e), in size, shape, and position closely corresponding with that in Macropus rufus (Plate LXXI. fig. 1,e,e).

The anterior or hæmal facet of the ilium (Plate CXXX. fig. 1, 62) is more deeply excavated than in the recent Kangaroo; the rounded angle $(a)$ dividing that facet from the inner or median facet (ib. fig. $2,{ }_{62}$ ) is relatively thicker. The precotylar tuberosity $(d)$ is more prominent, is relatively nearer the acetabulum; and a ridge is continued from the fore part of the tuberosity to the brim of that cavity, which more definitely or abruptly there defines the hæmal from the neural facets of the ilium than in recent Kangaroos.

The contour of the acetabulum is more ovate, the smaller end, at the fore part of the brim, being narrower in the larger fossil. The notch $(y)$ at the hind part of the brim is narrower, and is nearly bridged over by the extension of the ischial $\left(6^{*}\right)$ toward the pubic $\left(6^{*}\right)$ border of the notch; the depression $(x)$ into which the notch expands at the bottom of the cup is relatively narrower in Palorchestes than in Macropus.

These characters would have indicated specific distinction if the present fossil hacl not exceeded in size the corresponding part in the largest living Kangaroos; the degree to which Palorchestes surpassed them is exemplified in the pelvis as in the skull.

Admeasurements of Pelvis.

Palorchestes. Macropus infus.

Breadth of hæmal surface of ilium above the precotylar in. lines. in. lines. tuberosity . . . . . . . . . . . . . . . 3000

Breadth of neural surface of ilium above the precotylar tuberosity 


\begin{tabular}{|c|c|c|c|c|c|c|c|}
\hline \multirow{2}{*}{ 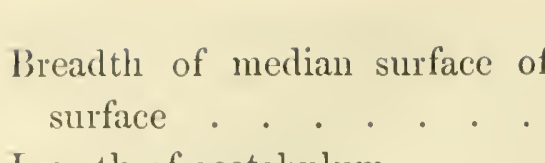 } & \multirow[b]{2}{*}{ of ilium } & \multicolumn{4}{|c|}{ Palorchestes. } & \multicolumn{2}{|c|}{ Macropus rufus } \\
\hline & & & & & & & $\begin{array}{c}\text { lines. } \\
0\end{array}$ \\
\hline ength of acetabilum . & . & . & • & 2 & 8 & 1 & 7 \\
\hline cadit & • & • & - & 2 & 6 & 1 & 4 \\
\hline earlth of ischium behind the & e lower & part of & acetabu & 2 & 2 & 1 & 3 \\
\hline
\end{tabular}

§3. Macropus? (Scapula).-In a series of fragmentary fossils from drift-deposits of Darling Downs the articular end of a left scapula with the glenoid cavity and the acromial end of the spine shows a greater relative height of that part than in Macropus mufies (Plate LXX. fig. 2). The brealth of the neck of the scapula in that large living species is twice the lieight of the fore part of the spine; in the fossil it is only one third more. 'The fore part of the spine in the fossil springs from the dorsal surface of the bladebone relatively nearer to the concare border of the upper costa than in Macropus rufus. In other respects the correspondence is close, save in size. In the lattcr character the present fossil might well belong to a Macropus Titan.

$\$ 4$. Sthemurus? (Scapula).- The corresponding part of a right scapula belongs to a distinct species. The glenoid cavity is broader and deeper in proportion to its length. There is an oblong depression at the cervical part of the lower costa, not present in the preceding fossil, nor in the scapula of Macropus rufus. The degree of difference may indicate this fossil to have belonged to a Sthenurus Atlas.

§5. Phascolagus? (Humerus).-This bone in existing Kangaroos (Plate LXIX., Macropus rufus) has long been noted by the Comparative Osteologist as an exception to the supposed rule that the perforation of the entepicondyle (ib. $s, i$ ) was a characteristic of that bone in certain members of the placental Carnivora *. 'The perforation relates, howerer, though not absolutely, as is now well known, to the degree of transverse expansion of the distal end of the humerus needed for adequate surface of attachment of muscles concerned in the application of the fore paw in rotatory movements. But such movements may effect, and be required by, other purposes than the catching, lolding, and killing a prey. In the Kangaroos they relate mainly to the manipulations of the pouch, but give a power to the fore limb in other vegetablefeeding Marsupials in acts of burrowing (Phascolomys) and climbing (Phascolarctos).

The generic characteristics of the humerus in Macropodidae are given at pp. 387, 388, and are illustrated by figures of that bone in one of the largest of the existing species, Macropus (Osplicunter) rufus (Plate LXIX.).

I commence the descriptions of the modifications of this bone in extinct Kangaroos by the subject of Plate CXI. It was obtained from the bed of King's Creek, Darling Downs, and was presented by Frederic Nerille Isaac, Esq., to the British Museum.

* Certer, 'Ossemens Fossiles,' tto, vol. iv. p. $28+$ (1825). In the posthumous 8 ro edition the editor adds to the earnirorous genera there eited, "ainsi que dans les Didelphes et tous les animaux à bourse" (vol. vii. p. 276). But there are exceptions in the Marsupial order, as, e. g., in Dasyurus Mangei, Phalangista Cookei, Peturus sciureus. See my 'Anatomy of Tertebrates,' rol. ii. p. 352 (1866). 
The chief peculiarity of this bone is its great thickness in proportion to its length. The latter dimension is one fifth less than in the humerus of Macropus major or of Osphranter rufus; but it is thicker than either at the proximal half of the shaft and its articular extremity; the distal end is of equal thickness, but the supinator ridge (Plate CXI. $k, k^{\prime}$ ), which is shorter in $M$. major than in $O$. rufus, is still shorter in the extinct Kangaroo which I provisionally ascribe to the genus Phascolagus. In this fossil the anconal end of the articular head is rather more produced and angular, and the upper surface is less convex than in the cited recent species.

The channel dividing the "head" ( $a$ ) from the extended ectotuberosity ( $c$, figs. $2 \& 5$ ) is less deep; the bicipital groove $(p)$ is wider; the ridge $\left(d, d^{\prime}\right)$ passing straight down from the fore or palmar end of the ectotuberosity $(c)$ to join the shorter oblique pectoral ridge $(e)$ is sharper, more produced in Phascolagus, and is more patently continued, as a ridge, from that prominent confluence (fig. 1, $d^{\prime}$ ) to the bridge $(s)$ spanning the entepicondylar canal. The pectoral ridge $(e)$ is thicker, less sharp, than in the recent species; such also is the character of the shorter supinator ridge $\left(k, k^{\prime}\right)$ in Phascolagus. The anconal surface of the proximal half of the shaft is more convex across, less distinctly divided into facets (marked $l, r$ in fig. 2, Plates LXIX. \& CXI.) than in the large cited existing species of Kangaroo. At the distal articular end the radial $(n)$ and ulnar $(o)$ convexities are rather better marked, and the thenal boundary line (fig. 1, $t$ ) dips in between them in Phascolagus, is not straight as in Macropus major. or nearly so, as in Osphranter rufus (Plate LXIX. fig. 1). But the chief characteristic of the present fossil is that first noted, viz. its shortness as compared with its thickness or strength. It indicates a Kangaroo as large as, perhaps even larger in the trunk, tail, and hind limbs than the largest living kind, but with proportions of the fore limbs reminding us, in their relative shortness, of those of such small Wallabies as the species of Lagorchestes.

§. Macropus Titan (Humerus). - A second example of an entire fossil humerus of a Macropode, also from the bed of King's Creek, I owe to my friend Dr. George BenNeTt, F.L.S.

It exceeds in length that bone in the largest examples of Macropus major as much as the last-described fossil falls short. But its strength, or thickness, in proportion to the length, is greater than in Phascolagus.

Two views, front and side, natural size, of this humerus are given in Plate CXII., and other views of the articular extremities form the subjects of figures $1,2, \& 3$, Plate CXIII. I propose to refer, provisionally, this fossil to Macropus Titan. A greater proportion of the shaft is occupied by the deltoid ridge (Plate CXII. $d, d^{\prime}$ ). and a smaller proportion by the supinator ridge (ib. fig. $1, k, k^{\prime}$ ), than in the recent species; in this respect the present resembles the smaller fossil humerus (Plate CXI.). 'The "head" (Plate CXII. fig. 2) is less produced backward than in that species, and is more convex above (Plate CXIII. fig. 3), in both which characters the large fossil more nearly resembles the part in Macropus major and $M$. rufus. 
'The tuberosities, and especially the outer one (Plate CXIII. figs. $1 \& 2, c$ ), are less produced beyond the head $(a)$ than in Osphranter rufus; and in this respect the fossil comes nearer to Macr. major.

'The deltoid ridge, continued down from the outer tuberosity, is much more produced from the shaft, throwing the surface $(y)$ more to the outer aspect than in the recent species. 'The roumded angle of the shaft leading to the ridge (c) in Osphranter rufus and Mucropus major is less marked in the fossil.

'The long persistence of the epiphysial suture $(t)$ at the proximal end of the humerus in Macropodida, as exemplified in the full-grown and dentally mature Macropus major and Osphrenter rufus (Plate LXIX.), is also shown in both the preceding and the present humeri of the extinct species, of which the subjects of Plates CXI. and CXII. doubtless give the full size of the liumerus in those species.

To limit the predication of maturity to the obliteration of such epiphysial suture would be, in my opinion, incorrect in the Macropodida; the epiphysial state of the proximal end of the humerus is retained far on into the "procreative" stage or period of existence of such Marsupials.

§. Macropodidae (Humerus). - Amongst the more fragmentary evidences of Macropodal humeri may be noted a shaft which shows less robust proportions than the lastdescribed fossil, but it must have been at least of equal if not greater length. From the end of the deltoid process, for example, to the entepicondylar canal is 3 inches 1 line, the same admeasurement in the subject of Plate CXII. giving 2 inches 6 lines: the breadth of the fragmentary shaft below the deltoid process in 1 inch 2 lines; in the entire humerus it is 1 inch 3 lines; in Macropus major it is 8 lines, as in Osphranter rufus.

'The transverse extent of the distal articular surface (Plate CXIII. figs. 4, 5, 6) is greater than in the subject of Plate CXII.

'The broken fossils show the usual proportion of the medullary cavity in the shaft of the humerus.

In a general way the humeri may be ranged into a thicker-and a thinner-shafted series, the length and size of the bone varying in both.

In one of the slender-shafted large humeri the deltoid ridge is more prominent, and the surface leading to the pectoral ridge slopes more backward. In another of this series the pectoral ridge is continued upward or proximad, dividing a tract of the sliaft into two well-marked facets; in a third fossil the corresponding tract or surface of the humeral shaft is undivided.

There are minor characters indicative of almost as many large species of Macropodidae as have been defined by the jaws and teeth. Unfortunately the haphazard way in which those fossils have been drifted along the present river-beds precludes the possibility of associating unequivocally the limb-bones with the maxillary and dental fossils.

It may, most probably will, be the work of succeeding palæontologists to complete the restoration of the skeletons of the extinct Macropodida; but I refrain from multiplying 
plates with figures of fragments of bone which cannot with certainty be referred to their species.

It appears to me to be probable, however, that the relatively shorter bones would belong to animals which had more of the general form of the existing Kangaroos; while the relatively larger humeri, associated with correspondingly proportioned fore limbs, and with a nearer approach to equality with the hind limbs, might have belonged to extinct species which, like the Procoptodonts, made a nearer approach to the equipedal giants of the Diprotodont family.

The way and degree in which this indication may be pursued will be exemplified in the bones of the hind limb.

\$ 8. Macropus (Femur).-I have received many fossils of thigh-bones, for the most part fragmentary, and here proceed to notice those showing characters of the Macropodal type of femur. These characters have been defined and illustrated (Plate LXXIII.) in that bone of a large male Osphranter rufus.

Several of the fossils exhibit the large rough depression (ib. $y$ ) at the back of the shaft, a little way above the outer condyle (Plate CXIV. figs. $2 \& 4, y$, Plate CXV. fig. 2,y); but some with a shallower pit here (Plate CXV. fig. 3, $z$ ) have a smaller depression, and this is in great part filled up, as it were, by a rough thickening of an ascending process of the distal epiphysis, of which a rudiment exists in the first defined series, and is shown in Plate LXXIII. fig. 3, $z$.

I commence the special description of the more instructive and better preserved of these femoral fossils by specimens which, retaining the character above referred to in Osphranter rufus, may be inferred to have departed least from the type of such existing large Kangaroos.

Of these femora an almost entire one, in the same petrified condition as the skull described at p. 436, is from the same freshwater drift in King's Creek. It is of the right side, in length 11 inches 6 lines; but would equal, if not exceed, a foot in length were the summit of the great trochanter entire. The bone is figured, of the natural size, in Plate CXIV., $2 \frac{1}{2}$ inches of the middle of the shaft being omitted in figs. 1 and 2 to bring them into the quarto form. The macropodal characters of this fine fossil femur, and the deviations, besides size, from the femur of the largest existing Kangaroos, will be readily appreciated if the above Plate be compared with Plate LXXIII. of the femur of Macropus (Osphranter) rufus.

A trace of the antero-internal groove, defining in that recent species the supertrochanterian tuberosity, is plain in the fossil at $e$, figs. 1 \& 2, Plate CXIV., where that tuberosity has been broken away. Compared with the femur of Macropus rufus that of the present fossil shows a relatively wider and shallower concavity (ib. fig. 1, d) between the fore part of the great trochanter and the head $(a)$ of the bone. The "cervix femoris" (b) is relatively thicker. The transverse diameter below the head is relatively greater, mainly through the greater extent of the bone internal to the 
"small trochanter" (ib. fig. 2, n), whereby that outstanding ridge-like process does not nppear in a direct front view (ib. fig. 1). The same relative position of $n$ in the femur of L'alorchestes Azacl (l'lite CXV. fig. 1) is also due to the inward extension of the support of the neck and head of the bone.

The femoral shaft in the present fossil is relatively thicker, especially from before backward, than in Macropus major and Macr. rufus. The rough depression (Plate CXIV. fig. $4, y$ ) above the outer condyle is relatively larger, deeper, more sliarply defined. The inner condyle (ib. figs. 1 \& $2, t$ ) has its inner (tibial) border better defined and produced so as to give a slight concavity, transversely, to that half of the back part of the condyle. This character is more marked in Pulorchestes (Plate CXV. fig. 2, $t$ ); but there is no trace of it in the inner femoral condyle of the large existing Kangaroos. 'The intercondylar notch ( $u$, fig. 2, Plate CXIV.) is narrower and deeper than in Macropus rufus, again repeating a femoral character of P'alorchestes, but not in so marked a degree. 'ihe ectocondylar pit (ib. fig. $4, v$ ) is equally well marked.

'The broad shallow vertical groove at the back part of the outer condyle, which in Macropodidce offers so interesting an approach to the characteristic structure of that part of the thigh-bone in Birds, is well shown in the femur of the fossil Hacropus (ib. fig. 2,w) as it is in that of Palorchestes (Plate CXV. fig. 2, w).

The epipliyses are confluent with the shaft at both ends of the femur, but the line of separation is traceable in the fossil as in the figured femur of Macropus rufus above referred to.

I may here refer to portions of fossil femora which depart from the type of the two already described by deviating further from the characters of the femur in the existing species of Macropus. The chief difference is in the smaller and shallower depression (Plate CXV. fig. 2, y) abore the outer condyle, such depression being filled up, as it were, in fig. $3, z$, by a rough and thick ascending process of the distal epiphysis, of which a rudiment only exists in the femur of the fossil Macropus (Plate CXIV. fig. 4, z) and of Palorchestes Azacl (Plate CXV. fig. 2,z). The femora with the larger and longer "clamping process" are thicker in proportion to their length than in the above-cited fossils, and still more so than in the recent Kangaroos. This stronger type is manifested by full-sized or mature femora of three dimensions, of which the distal end of the largest is figured in Plate CXV. fig. 3. I shall at the conclusion of the present Cliapter adduce eridence which leads me to deem these fossils to belong to the genus Procoptodon; and I, provisionally, refer the portion of femur figured and the shorter type of calcaneum in the same Plate (fig. 4) to Procoptodon Goliah.

\$9. Palorchestes? (Femur). - The fossil thigh-bone of which the two extremities are figured in Plate CXV. figs. 1 \& 2, shows an articular head $(a)$ fitting the acetabulum of the pelvic fossil ( $(2$, Plate CXXX.). The height of the trochanter major $(f)$, the length and backward position of the narrow trochanter minor $(n)$, the depth of the carity $(l)$ undermining the hind extension of the great trochanter, and the ridge $(p)$ at the back part of the upper half of the shaft, bespeak the macropodal characters of the 
present fossil in the upper portion of the bone, as the partial division of the outer condyle (fig. $2, v$ ) by the channel $(w)$, and the deep rough oblong fossa $(y)$ above that condyle, do in the lower portion.

Guided by the proportions of the femur in Macropus major and Macropus mufus, I estimate the subject of fig. 1, Plate CXV., to include the proximal third of that bone in Palorchestes Azael, or in a species akin to a Macropus of that size; and I suspect, as the upper portion of the great trochanter is still epiphysial, or but partially united to the shaft, that this thigh-bone may have come from a not fully mature individual.

Since in Macropus rufus the extreme breadth of the proximal end of the femur exceeds that of the distal end by 3 lines, I estimate the difference in those admeasurements of the ends of the fossil femur, figs. 1 \& 2, in Plate CXV. to be within the limits of individual character in Palorchestes; the breadth of the shaft, where broken across, in both upper and lower portions is the same and the circumference in both is 5 inches. The somewhat larger proportional proximal end, due to the development of the great trochanter, may be taken as one of the differential characters of the present huge femur as compared with that bone in the largest living Kangaroos.

The great trochanter is continued as a strong ridge (ib. fig. $1, g$ ) $5 \frac{1}{2}$ inches along the outer border of the bone; but the trochanter itself $(f)$ is, relatively, less raised above the head (a) than in Macropus major. The articular surface of the head is less convex than in Macropus rufus, and the anterior concavity between it and the trochanter is less marked. 'The demarcation of the summit of the trochanter by the antero-internal channel is more feebly given in Palorchestes. The upper surface of the neck of the femur $(c)$ is relatively broader in Palorchestes than in Macropus.

The lesser trochanterian ridge $(n)$ is more posterior in position than in Macropus rufus, in which its free margin just comes into view when the femur is seen from the front; this is not the case in Palorchestes, in which the ridge descends to the parallel of the beginning of the posterior ridge, which resembles at its most prominent part $(p)$ a third trochanter. The trochanterian fossa (fig. 1, l) has the extreme generic or family depth in Palorchestes; it forms a long narrow cavity, undermining the hinder basal part of the great trochanter.

From the summit of this trochanter $(f)$ to the third trochanter $(p)$ being $6 \frac{1}{2}$ inches, the total length of the femur of Palorchestes may be reckoned, from the analogy of Macropus rufus, to have been not less than 18 inches; in that recent species it is $10 \frac{1}{2}$ inches. The epiphysial line of the great trochanter is distinct, but confluence of the central part has liept the process in place in the present fossil.

The upper end of the linea aspera is preserved, expanding to form the process $p$.

At the distal end of the femur (ib. fig. 2) the chief distinction of Palorchestes from Macropus is in the relatively narrower postintercondylar fissure $(u)$ and its minor expansion, where it is closed anteriorly. The depression $(y)$ is strongly marked in Palorchestes. The epiphysial line is traceable in the fossil ; a medge-shaped process at 
both the outer $(z)$ and the imner $\left(z^{\prime}\right)$ borders rises as if to clamp more securely the epiphysis to the shaft.

The following admeasurements exemplify the difference of size between Palorchestes Azael and Macropus rufus, the measured femur of the latter being of a full-grown male :-

\begin{tabular}{|c|c|}
\hline ulorchestes Azcel. & Macropus ref \\
\hline in. lines. & in. lines. \\
\hline . 49 & 29 \\
\hline . 18 & 10 \\
\hline . 39 & 25 \\
\hline
\end{tabular}

\$10. Sthenurus Brehus? (Femur).-To this species I incline to refer a distal end of the left femur, which shows, besides the well-marked cavity $(y)$ on the anterior and posterior part of the distal end of the diapophysis, a similar but shallower large depression on the inner posterior side. Into the lower border of both these depressions the wedge-like processes of the epiphysis project. The relative breadth of the intercondylar fossa agrees with that in P'clorchestes, and shows as little expanse of the anterior closed end. The fore-and-aft extent of the outer condyle is 3 inches 3 lines; and the breadth of both condyles, if the inner one was entire, would be at least as much. 'The weight and petrified state of this fossil are remarkable.

\$11. Procoptodon? (Femur).-Of the series of femoral fossils with the depression $(y)$ less marked, and seemingly blocked or filled up by the epiphysial "clamping" process $(z)$, a specimen is selected to exemplify this character in figure 3 of Plate CXV.

The postintercondylar fissure $(u)$ is more expanded anteriorly, and there takes a winding course about a flat part or process $\left(t^{\prime}\right)$ of the inner condyle, which process extends outward into the expanded part of the intercondylar cavity. The small pit on the outer side of the posteriorly projecting part of the outer condyle is here represented by a notch.

I refer, provisionally, this type of femur to the genus Procoptodon; the present fragment might belong to a Procopt. Rapha. True, the fore-and-aft diameter of the outer condyle is but 2 inches $3 \frac{1}{2}$ lines, not exceeding that in the recent Osphranter rufus (Plate LXXVII. fig. 3); but the breadth of the distal end of the femur in Procoptodon Rapha is 3 inches 1 line, whilst in Osphranter rufus it is but 2 inches 3 lines, the two diameters being subequal in the recent Kangaroo compared. The excess of transverse diameter in Procoptodon Rapha depends on the greater development of the inner condyle, which equals that of the outer one. The small depression for the lateral ligament on the inner non-articular surface of the inner condyle is deeper and better defined than in Macropus or Osphranter.

A second example of the distal end of a femur (left) with the "procoptodont" character of the depression $(y)$ exceeds in size that of Procoptodon Rapha as much as the mandible and teeth of that species surpass those parts in Procoptodon Rapha. I refer, therefore, the present fossil to Procoptodon Goliah. The line of epiphysial 
suture is better marked than in the femoral specimen of the smaller species, and the present fossil has belonged to a less aged individual.

The characters of the intercondylar groove are repeated, except that the process from the inner condyle encroaching on the expanded end of the groove is less defined.

The breadth of the distal end of this femur, if the inner condyle were entire, would be 3 inches 6 lines; the antero-posterior extent of the outer condyle is 2 inches 9 lines.

\$12. Protemnodon? (Femur).- In the fossil here referred to that genus the small trochanter projects so as to come well into view, looking upon the front of the shaft. Between the lower ends of the two trochanters at the middle of the back part of the shaft begins a sharp, well-defined ridge, which extends down to the outside of the "third trochanter." This character is not presented in the fossil femora referred to Macropus, Sthenurus, Procoptodon, or Palorchestes. The head is less convex above than in Palorchestes. The distinct epiphysial cap of bone which overlies what seems to be the diapophysial part or basis of the articular head is well marked in this fossil. The length from the top of the head to the commencing expansion of the distal end of the shaft is 10 inches; the circumference of the middle of the shaft is 5 inches.

\$13. Palorchestes? (Tibia). - The locality of the discovery of the fine portion of tibia figured in Plate CXXXI., with its characters and proportions, leads me to refer it to the same genus and species as the mandibular fossil figured in Plate CVI.

If the subject of Plate CXXXI. be compared with the corresponding views of the entire tibia of the large male Red Kangaroo (Plate LXXIV.), the association of the peculiar characteristics of the macropodal tibia with the grand proportions of that bone in Palorchestes will be readily appreciated.

The length of the present fossil remuant from the proximal end of the bone to the subsidence on the shaft of the procnemial plate is $7 \frac{1}{2}$ inches. 'The fore-and-aft diameter of the tibia, at the upper part of the plate, is 3 inches 5 lines; the span of the excavation between the procnemial and ectocnemial plates or ridges is 2 inches 4 lines; the antero-posterior diameter of the head of the tibia is 3 inches 10 lines; the breadth of the back part of the tibia, at 5 inches below the articular head, is 1 inch 6 lines. The head of the tibia is in a state of epiphysis; its undulatory course along the inner side of the bone is shown in fig. 4, but partial confluence, as in the case of the epiphysis of the femur of probably the same individual Palorchestes, has tended to retain the epiphysis in place, notwithstanding the movements and shocks of alluvial transport through which, seemingly, the fractures of the fossil are due.

The inner articular facet (ib. fig. 5), the only one preserved on the head, is relatively more extensive and more concave transversely than in Macropus rufis. The hind surface of the shaft (ib. fig. 3), continued down from that articular surface, is thicker and more convex across; it contracts in the large recent Kangaroo to an angular ridge, sharply dividing the hinder from the antero-internal surface of the shaft of the bone.

The following are a few comparative dimensions of the fossil tibia :- 
Palorchestes Azal. Ospheranter rufus.

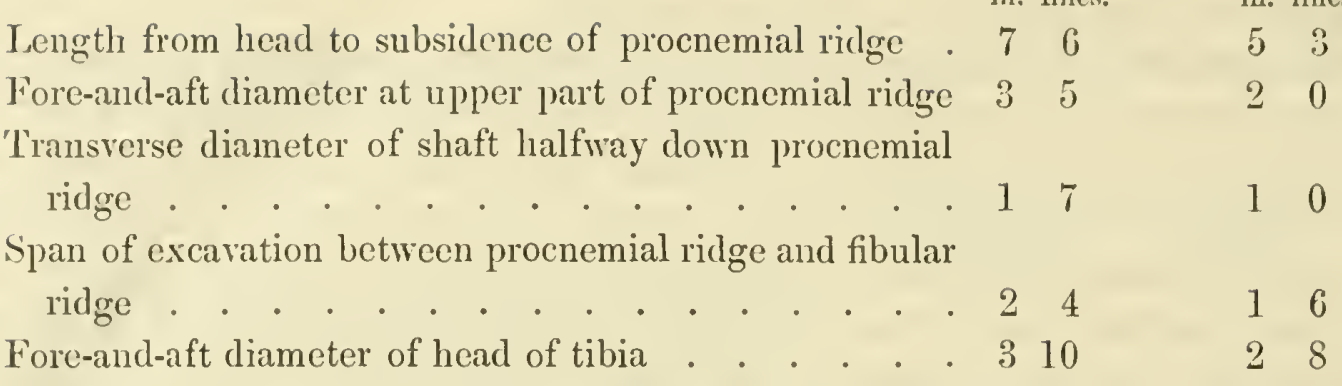

$\$ 14$. Palorchestes (Calcancum).-In Macropus (Osphranter) rufus the length of the calcaneum exceeds the transverse breadth of the distal end of the femur by two sevenths; the extreme breadth of the calcaneum is one third greater than that of the middle of the shaft of the femur. By these proportions I am guided in the clioice of the two fossil calcanea (figs. 4 \& 5, Plate CXV.), and refer the longer bone to Palorchestes.

'The length of the subject of fig. 5, Plate CXV., exceeds the transverse breadth of the distal end of the femur (ib. fig. 2) by two sevenths. The length of the calcaneum (ib. fig. 4) exceeds the transverse breadth of the distal end of the femur (ib. fig. 3) by one fourth. 'The breadth of the calcaneal process of fig. 4 is equal to that of the longer calcaneum, fig. 5 .

On the grounds subsequently to be adduced for concluding the leg and foot of Procoptodon to have been shorter in proportion to its length than in Macropus, I therefore assign the shorter and thicker calcancum to that genus, together with the portion of femur (fig. 3), which shows more generalized characters, or those less strictly macropodal, than the femora assigned to Palorchestes, Macropus, and Sthenurus.

'The figures of both the calcaneal fossils may be compared with those of the existing Mrcropus rufus (Plate LXXV. fig. 6), and with the characters described, p. 390.

$\S 15$. Macropodidce (Metatarsals). - The hind foot in Kangaroos exhibits an extreme modification of the osseous structure (ante, pp. 390-393, Plate LXXV.). The inner toe ( $I$ of the typical pentadactyle foot) is suppressed; the metatarsals of the toes $I I \& I I I$ are long and filamentary, supporting a pair of small pendent fur-cleansing claw-toes; that of the toe $I V$ is both long and large, with characteristic modifications of its proximal end; that of $r$ is much less in size, with the shaft compressed, but supporting, like the metatarsal of $I V$, a toe with a quasi hoof for station and progression.

In Plate CXVI. fig. 4, is given a view of the fourth $(\mathrm{Ir})$ and fifth $(r)$ metatarsals, natural size, of the right hind foot of Macropus rufus; two other views of the same bones are given in Plate LXXV. I may here add to the previous description, as a guide for distinguishing the right from the left fourth metatarsal, the following characters:-Below the proximal articular surface the inner (tibial) side of the shaft shows a bilobed articular surface (Plate CXX. fig. 3, $m, n$ ), the subtriangular expanded portions being united by a narrow tract, varying in breadth, and linear in some species; beneath this articular surface there is a large rough triangular depression 
(ib. ib. $k$ ), from which a narrower rough tract is continued downward (distad) far backward (plantad), assuming more or less the character of a groove to, or near to, midway down the shaft.

The depression $(k)$ is bounded behind (plantad) by the peroneal process, the groove of which $(g)$ and the sesamoid surface $(h)$ beneath the groove slope upward and outward (fibulad).

On the outer (fibular) surface of the proximal end there is a transversely elongate concave articular surface (ib. fig. 1, $v$, and Plate CXVIII. fig. 2, v), less narrow vertically, at the middle, than is the opposite (bilobed) surface (ib. $m, n$, fig. 1). Below the articular surface is a transversely subelongate rough depression from the hinder (plantar) end, of which the shallow rough tract (ib. fig. 2, $u$ ) for ligamentous attachment of the fifth metatarsal is continued about two thirds down the shaft. These characters distinguish the inner tibial from the outer fibular side of the shaft of this metatarsal, and determine the foot, right or left, to which it belongs. In the description of the Plates the bone is called right or left as it there appears, but most of the figures were drawn without reversing from bones of the opposite foot.

A considerable number of metatarsal bones of Kangaroos (Macropodida), chiefly of the toe $(\mathrm{IV})$, has now accumulated on my hands from kind contributors of fossils in Australia. Not any of the specimens, however, have been discovered so associated with other remains of an individual of a species the characters of which are known, or were so recognizable as to justify more than probable or provisional ascription to such species.

It would seem that the conditions of association are scarcely to be expected in the beds of the creeks and rivers of Queensland which have yielded the majority of these metatarsal specimens. Their matrix seems to be made of materials transported from those drift-like deposits through which the well-sinkers bore for a hundred feet deep or more in quest of spring-water, and in the course of which borings the least fractured and abraded mammalian fossils, and seemingly the least disturbed after imbedment, have hitherto been obtained.

It will be understood, therefore, that the results of my attempts to associate any of the metatarsal bones with species or genera previously defined by dental and cranial characters are tentative, resting on analogical grounds and inferences stated, and must be received subject to confirmation or otherwise by the more fortunate finders of a sufficient proportion of an entire skeleton to demonstrate a foot to have been part of the same animal as the associated jaws and teeth.

I have divided, in the first place, the metatarsals best agreeing in proportions with those of the large existing Kangaroos from those that deviate in a marked degree from such proportions, and which indicate a less extremely modified form and length of the hind foot.

Commencing with the first group, I begin the comparisons with the metatarsals which are nearest in size to those of existing Kangaroos, such as Macropus major and Osphranter rufus. 
\$ 16. Nacropus affinis (Metatarsal $\mathrm{IV}$ ). - Of this extinct Kangaroo I select for description and figuring a fossil referable to the upper two thirds of a left fourth metatarsal (Plate CXVI. fig. 6, and Plate CXVII. figs. $7 \&$ 9) with a proximal articular surface (fig. 9) of the same breadth as in Macropus rufus and Macropus major, but with a markedly thicker shaft, being broader from side to side in proportion to the depth from before backward. 'The smooth tendinal groove answering to that marked $n$ in fignre 4, Plate CXVI., on the fore part of the shaft in Macropus rufus, is bounded in the fossil by stronger ridge-like risings, and the groove does not reach so far down the fibular half of the anterior surface of the bone. On the tibial side of the tibial ridge of this groove the fore part of the shaft shows a slight concavity in Macropus affinis, whereas in both cited species of the large existing Kangaroos the answering part of the metatarsal is transversely convex. At the back part of the proximal third of the shaft the rough surface or ridge for muscular attachment (Plate CXVI. fig. 6, o) is more prominent, better defined, yet less extended longitudinally, in the fossil. 'This specimen is from King's Creek, Darling Downs, Queensland.

\& 17. Phascolagus altus (Metatarsal $\mathrm{N}$ ). - A right fourth metatarsal (Plate CXVII. figs. 1-5), from the same formation and locality, has come from a larger kind of Kangaroo than Macropus affinis. It is an inch longer than the subject of figure 4, Plate CXVII. (Macropus rufus), is relatively thicker, and, like the previous fossil, differs in presenting a stronger ridge (Plate CXVII. fig. 1,r) bounding the fibular side of the anterior surface of the shaft. 'This part of the bone is also more prominent, giving a convexity to the outline of a side view (ib. fig. $3, r$ ) not present in the fourth metatarsal of Macropus major or Osphranter rufus. The present fossil likewise shows a relatively broader distal end (ib. fig. 6), which is barely 1 line less in transverse diameter than is the proximal end (ib. fig. 5). On this surface, as in Macr. rufus and Macr. affinis, the hinder prominence shows the oblique tendinal groove (ib. fig. $4, g$ ) and the flat inferior facet $(h)$ for the articulation of the large tarsal sesamoid (Cut, fig. 3, p. 391). The fibular or outer side of the proximal end, in both fossils, shows, as in the recent Kangaroos, the antero-posteriorly prolonged, bilobed, articular surface (ib. fig. 2, $m, n$ ) for the side of the head of the fifth metatarsal. Below this surface is the depressed rough tract (ib. $k$ ), continued down nearly three fourths of the back third of the fibular side of the shaft, for the ligamentous attachment of the smaller compressed shaft of the fifth metatarsal. The posterior ridge in the present metatarsal, which I refer to a Phascolagus altus, answering to that marked $o^{\prime}$ in Plate CXVI. fig. 6 (Macropus affinis), is continued lower down, nearly to the end of the shaft. 'The hinder half of the distal articular surface (Plate CXVII. fig. 6) is fashioned by a mid rising into a double trochlea, as in existing Kangaroos.

\$18. Protemnodon Anak (Metatarsal $w$ ). - The metatarsal referred to this species (Plate CXX.) combines equality of length with that of Macropus (Osphranter) rufus (Plate CXVI. figs. $4 \& 5$ ), and a greater antero-posterior thickness of shaft with greater breadth of the distal portion of the bone (compare Plate CXX. fig. 1, with Plate CXVI. 
fig. 5). The lateral portions of the distal trochlea are likewise divided by a sharper ridge-like rising than in Osphranter rufus, Macropus major, or Phascolagus altus. The longitudinal channel on the fore part of the shaft, answering to that marked $n$ in fig. 4 , Plate CXVI., and bounded by the ridges $q$ and $o$ in fig. 4 , Plate CXX., is both wider and deeper in Protemnodon. The transverse diameter of the proximal half of the shaft is relatively less than in IIacropus affinis or in Phascolagus altus.

$\S$ 19. Macropus Titan (Metatarsal ${ }_{I V}$ ).-The specimen of "fourth metatarsal," next in size (Plate CXVIII. figs. 1-5), bears the same proportion to a femur assigned to Macropus Titan as does the fourth metatarsal to the femur in Macropus major. The proximal articular surface (ib. fig. 3) is smaller in proportion to the shaft in Macropus Titan than in Phascolagus altus (Plate CXVII. fig. 5); the groove $(g)$ is broader. The shaft is relatively thicker, the ridge $(r)$ is less produced, and the contour less convex than in Plate CXVII. fig. 3. The anterior surface shows a wide and shallow longitudinal channel along its proximal half, not present in Phascolagus; the distal articulation (Plate CXVIII. fig. 5) is relatively larger antero-posteriorly.

$\S 20$. Palorchestes (Metatarsals ${ }_{I V} \& V$ ). - The breadth of the middle of the shaft of the fourth metatarsal of Macropus rufus is two thirds that of the same part of the femur. The breadth of both fourth and fifth metatarsals, naturally united one third down, is nearly equal to three fourths of the breadth of that part of the femur.

The breadth of the middle of the shaft of the fourth metatarsal, the subject of Plate CXVI. fig. 1, is two thirds that of the same part of the femur, as shown at the broken ends in figs. 1 \& 2 of Plate CXV. The breadth of the naturally united fourth and fifth metatarsals (Plate CXVI. figs. $1 \& 2$ ), one third from their proximal ends, equals four fifths of the same part of the femur of Palorchestes Azael.

To this species, therefore, I provisionally refer the fossil subjects of figs. 1, 2, and 3 of Plate CXVI. The length of the fourth metatarsal in those figures is restored in outline from an entire homologous bone of the same extinct species which had become detached from the contiguous metatarsals, and which I have not thought necessary to figure.

In the fossil under description, to the great fourth metatarsal lacking the distal end there remained attached the fifth metatarsal (ib. figs. $1 \& 2, v$ ), wanting only a portion of the plantar or posterior wall of the proximal end; and, similarly attached, the proximal half of the third metatarsal (ib. ib. ${ }_{I I I}$ ), exhibiting the characteristic macropodal slenderness. It is interesting to note, however, that the fifth metatarsal in the huge extinct Kangaroo shows more nearly the normal proportions of the bone than in the existing species, even the largest, as, e. g., Macropus rufus (Plate CXVI. fig. 4, r); and the more slender third metatarsal bone of Palorchestes (III, fig. 2, Plate CXVI.) is relatively less atrophied than in existing Kangaroos. Its proximal end (ib. fig. 3, III) presents an oblong, subquadrate, almost flat surface for the ectocuneiform, and a triangular surface on the inner side (ib. fig. 2, $b$ ) of the proximal end for part of the head of the second metatarsal, which bone is wanting in the fossil. It articulates with the tibial 
side of the proximal end of the fourth inetatarsal by a surface which is extended by the backwardly directed process (ib. fig. 2,c). Below the articular head (ib. $a-c$ ) the shaft narrows and becones compressed in its upper third, below which it assumes a subtrihedral figure, with a trenchant margin both before and behind along its upper fourth.

The shaft does not exceed 2 lines in breadth at the point of fracture $(d)$. 'The bone closely adheres, either by anchylosis or matrix, to the shaft of the great fourth metatarsal, inclining from the imner (tibial) side to the plantar aspect of the shaft, as does the corresponding metatarsal in Macropus mufus (Plate LXXV. fig. 1, III). The proximal articular surface of the fourth metatarsal (Plate CXVI. fig. 3, ${ } \mathrm{V}$ ) presents an undulating tract adapted to the distal surface of the cuboid; its broadest rotular (anterior) half is gently convex transversely at the fibular half, concave at the tibial half; the narrower plantar or posterior subquadrate tract is feebly concave rotuloplantad, almost level transversely; this tract extends plantad, or backward, so as to overhang the shaft; it is grooved at $e$, fig. 3 , by the "peroneus" tendon, which runs across the back or under (plantar) aspect of the tarsus to be inserted into the entocuneiform bone; also, as in existing Kangaroos and in Macropus affinis, it has a flat articular surface at the underside of the overhanging part for the large tarsal sesamoid. The inner or tibial side of the proximal end of the fourth metatarsal shows the two small vertical facets for the ectocuneiform, and a well-marked rough depression for the proximal ends of the third and second slender metatarsals.

The shaft of the great metatarsal of Palorchestes is subtrihedral; the rotular surface (ib. fig. 1, ${ }^{\mathrm{V}}$ ) is slightly concave transversely along its middle third as in Macropus Titan, not prominent as in Macropus rufus (ib. fig. 4). The plantar side (ib. fig. 2) is produced into a ridge, broad along the upper third (o), becoming sharper $(h, h)$ as it descends, and subsiding about one half of the length of the bone $\left(o^{\prime}\right)$ from the distal end. The corresponding portion of the metatarsal of Macropus rufus (ib: fig. 6) is widely channelled where in the fossil it is angularly convex. The greatest rotuloplantar thickness of the shaft in Palorchestes is 1 inch 4 lines, the greatest transverse thickness is 1 inch; that of the proximal end is 1 inch 6 lines, its rotulo-plantar thickness is 1 inch 5 lines.

The fifth metatarsal of Palorchestes Azael (Plate CXVI. figs. 1, 2, 3, v) is relatively much stronger than in Macropus major or Macr. rufus (ib. fig. 4,v). The plantar part of the proximal end, broken away in the fossil figured, is entire in a later acquired homologous bone of Palorchestes. This presents a small, oval, flat, vertical surface for the fourth metatarsal, a broader subtriangular one for the backwardly extended process of the cuboid (Plate LXXV. fig. 11, k), and a larger horizontal facet for the surface, marked $l$, of the same tarsal bone. The proximal articular surface of the fifth metatarsal is very small in proportion to the bone in Palorchestes. External (fibulad) to that surface the bone rises above the proximal end of the fourth metatarsal in the form of an antero-posteriorly extended thick round edge.

The shaft of the fifth metatarsal is subcompressed along the proximal three fourths; 
it measures 13 lines in rotulo-plantar thickness, one third down; and here, near the plantar side, its thickness (or tibio-fibular breadth) is 6 lines. The opposite (rotular) border is not sharp, as in Macropus major and Macr. rufus; but though thin, in comparison with the plantar surface, the border is rounded off. The shaft loses rotuloplantar thickness and gains transverse breadth as it approaches the trochlear articular surface ( $v$ ); this is 1 inch transversely, 10 lines where thickest from before backward. The surface is not simply convex, as in Macropus rufus (Plate CXVI. figs. 4 \& 5, r.), but is made trochlear by a plantar median ridge, on each side of which the surface, transversely, is feebly concave. The outer (fibular) side of the shaft has a feeble median longitudinal channel along the middle of the proximal two thirds. The upper half of the shaft shows in fractured portions of homologous fossils a small medullary cavity.

Thus we learn that in the large extinct Kangaroos of the genus Palorchestes the fourth and fifth digits were less unequal in strength, and the fifth took more share in station and locomotion than in the largest existing kinds. The metacarpal segment and the rest of the foot were proportionally broader; but the length of the fourth metatarsal in Palorchestes indicates, nevertheless, that it was a powerful leaper.

$\S 21$. Procoptodon (Metatarsals $I V \&$ ). - In deprecation of the foregoing details, more wearisome perhaps to the reader than the inditer, I may plead the great proportion of fragmentary evidences of the hind feet of large extinct Kangaroos as compared with entire or nearly entire bones. The grateful aid which such rare specimens have yielded has impressed me with the duty of defining and recording all characters which may help future collectors, especially in Australia, in determining such fossil fragments which are likely to accumulate in the public and private museums of that great colony.

I have alluded to the primary step in the survey of the vast series of metatarsal fossils which led to setting apart those indicative of a hind foot shorter in proportion to its breadth, and yet retaining unmistakable macropodal characters.

In the specimen, for example, of the naturally united fourth and fifth metacarpals figured in Plate CIX. figs. 1-5, the fourth (IV) is thicker than, but is little more than two thirds the length of, the homologous bone in Macropus rufus (Plate CXVI. fig. 4). The fifth metatarsal (Plate CXXI. figs. 1, 2, 3, v) shows a greater degree of thickness, in proportion to its length, than in Palorchestes Azael (Plate CXVI. figs. $1 \& 2, v$ ).

The proximal end of the fourth metatarsal (Plate CXXI. fig. 4, ${ }^{\mathrm{r}}$ ), though somewhat mutilated, exhibits the characteristic modifications of the articular surface in the normal Kangaroos; and these characters are shown more plainly in the homologous bone of a larger kind of Procoptodon (ib. fig. $8,{ }_{r V}$ ), viz. the non-articular peninsula $(f)$, the backward or plantar production ( $e$, "peroneal process"), with the terminal groove $\left(g^{\prime}\right)$ for the tendon before mentioned; but this groove is less deep than in the type Kangaroos: the flat surface beneath (fig. $6, h$ ) indicates a larger proportional sesamoid than in the species of Macropus.

The fore surface of the shaft of the fourth metatarsal (ib. fig. 2) is more even or flattened than in Macropus affinis, Macr. Titan, and the great recent kinds of Kan- 
garoo. The distal end is more expanded, surpassing the proximal end in breadth. The ridge on the back part of the shaft (ib. fig. 1, o) is broader, less produced, and less exteuded downward than in Macromus, Protemnodon, or P'alorchestes.

The well-preserved proximal end of the fifth metatarsal shows its apophysial production (ib. figs. $1 \& 2, z$ ) proximad of the articular surface of the fourth metatarsal. 'This process is absolutely as well as relatively longer than in P'alorchestes Azacl. As in that species three articular facets are present at this end of the bone, two for the cuboid and one for the contiguous (fourth) metatarsal, the cuboidal surfaces being relatively larger than in Palorchestes, and the tubercle projecting tibiad beyond the metatarsal surface is more developed in Procoptodon.

At the distal articular surface the chief difference is seen in the greater production of the tibial convexity of the trochlea. By reason of this prominence its preservation is rare in the rolled fossils of the present form of metatarsal from the creek-beds of Queensland.

Of the metatarsals of this shorter type three modifications are shown by the fossils that have reached me, which are indicative of three species of Procoptodon. The metatarsal (Plate CXIX. figs. 10-12), of equal length with that (ib. figs. 1, 2) of Procoptodon P'usio, but more slender, I take to be from a female Kangaroo of that species.

Deeming it probable that the form (family or genus) of Macropodal Marsupials which, by dental and mandibular characters, offered the nearest approach to the large isopodal or gradatorial family (Diprotodontid $c$ ) would present a corresponding approach thereto in the form and proportions of the hind foot, I refer the present type of metatarsal bones to the genus Procoptodon.

In this genus the above-described representative of the smallest known species would answer, as to size, to the evidences which have been given of the maxillary, mandibular, and dental characters of Procoptodon Pusio (p. 454, Plate XC. figs. 2, 7).

The specimens next in size (Plate CXIX. figs. 6-9) I refer, on similar grounds, to Procoptodon Rapha (p. 457, Plate XC. figs. 8-12).

Parts of a hind foot of a still larger species similarly relate to Procoptodon Goliah (p. 460, Plate XCIV.).

The fourth metatarsal (Plate CXXI.) is 6 inches 3 lines in length, with a proximal breadth of 1 inch 8 lines, the opposite dimension being 1 inch 5 lines. The fore part of the cuboidal surface is relatively broader from before backward than in Procoptodon Pusio. There is no indication of the proximo-tibial ridge, in which character the present bone resembles its homologue in Procoptodon Pusio (Plate CXIX. fig. 2, IV).

The posterior angle at the proximal half of the shaft is less marked and less produced than in Procoptodon Pusio. The posterior depressions above the distal trochlea are deeper and better defined than in Procoptodon Rapha or Procop. Pusio.

The fifth metatarsal of Procoptodon Goliah (Plate CXVIII. figs. 8-11) is 5 inches in length; the greatest diameter of the shaft is 1 inch, equalling that of the homologous bone in Palorchestes Azacl, which is more than one fourth longer. The tibial convexity 
of the distal trochlea is less produced than in Procoptodon Rapha, and the whole hind surface of the joint is less obliquely disposed than in that species or in Procoptodon Pusio.

Thus the resolution of these shorter and stouter metatarsals into three categories, characterized by modifications of shape as well as by size, concurs with the previously adduced evidences of jaws and teeth in showing that the procoptodont modification of Macropodidce was of old manifested by Australian Kangaroos under three specific forms.

But these, which my present materials have enabled me to define, may prove not to have been the only links connecting the saltigrade with the gravigrade groups of phytiphagous Marsupials.

\section{Description of the Plates.}

\section{PLATE CXI.}

Phascolagus altus.

Fig. 1. Front view of right humerus.

Fig. 2. Back view of the same.

Fig. 3. Inner side view of the same.

Fig. 4. Outer side view of the proximal end of the same.

Fig. 5. Proximal articular end of the same.

Fig. 6. Distal articular end of the same.

\section{PLATE CXII. \\ Macropus Titan.}

Fig. 1. Front view of the right humerus.

Fig. 2. Side view of the right humerus.

\section{PLATE CXIII.}

Macropus Titan.

Fig. 1. Oblique view of the proximal end of the right humerus.

Fig. 2. Proximal articular end of the same.

Fig. 3. Back view of the proximal end of the same.

\section{Undetermined Species.}

Fig. 4. Front view of the distal end of the right humerus.

Fig. 5. Back view of the same.

Fig. 6. Distal articular end of the same. 


\section{PLATE CXIV.}

Macropus, sp. ind.

Fig. 1. Front view of right femur (omitting 2 inches of shaft).

Fig. 2. Back view of right femur (omitting 2 inches of shaft) of the same.

Fig. 3. Inner view of proximal end of right femur of the same.

Fig. 4. Outer view of distal end of right femur of the same

\section{PLA'TE CXV.}

Fig. 1. Back view of proximal portion of right femur of Palorchestes Azael.

Fig. 2. Back view of distal portion of the left femur of the same.

Fig. 3. Back view of distal portion of right femur of Procoptodon Goliah.

Fig. 4. Upper view of right calcaneum of the same.

Fig. 5. Upper view of left calcaneum of Palorchestes Azael.

\section{PLATE CXVI.}

Fig. 1. Front view of metatarsals $I V$ and $v$ and part of $I I I$ of Palorchestes Azael.

Fig. 2. Back view of the same.

Fig. 3. Proximal (upper) articular end of the same.

Fig. 4. Front view of metatarsals $I V$ and $v$, with part of cuboid, of Macropus rufus.

Fig. 5. Back riew of distal portion of the same.

Fig. 6. Back view of upper two thirds of fourth metatarsal of Macropus affinis, Ow.

\section{PLATE CXVII.}

Phascolagus altus.

Fig. 1. Front view of the right fourth metatarsal.

Fig. 2. Outer side view of the same.

Fig. 3. Inner side view of the same.

Fig. 4. Back view of the same.

Fig. 5. Proximal articular surface of the same.

Fig. 6. Distal articular surface of the same.

\section{Macropus affinis.}

Fig. 7. Outer side view of portion of the right fourth metatarsal,

Fig. 8. Back view of part of the same.

Fig. 9. Proximal articular surface of the same.

\section{Undetermined Species.}

Fig. 10. Front view of proximal phalanx of fourth toe of an extinct Kangaroo, of the size of Phascolagus altus. 


\section{PLATE CXVIII.}

\section{Macropus Titan.}

Fig. 1. Inner (tibial) view of right fourth metatarsal.

Fig. 2. Outer (fibular) view of the same.

Fig. 3. Proximal articular surface of the same.

Fig. 4. Hinder view of proximal end ( $q$, peroneal groove of peroneal process).

Fig. 5. Distal articular surface.

Fig. 6. Inner side view of left fifth metatarsal.

Fig. 7. Distal articular end of the same.

\section{Procoptodon Goliah.}

Fig. 8. Outer side view of right fifth metatarsal.

Fig. 9. Inner side view of the same.

Fig. 10. Front view of proximal end of the same.

\section{PLATE CXIX.}

Fig. 1. Back view of metatarsals $2 v$ and $v$ of Procoptodon Pusio, OW.

Fig. 2. Front view of the same.

Fig. 3. Outer side view of the same.

Fig. 4. Proximal (upper) articular end of the same.

Fig. 5. Distal (lower) articular end of metatarsal ${ }_{I V}$ of the same fossil.

Fig. 6. Back view of metatarsals $I^{V}$ and $r$ of Procoptodon Rapha, Ow.

Fig. 7. Outer side view of metatarsal $r$ of the same.

Fig. 8. Proximal (upper) articular ends of metatarsals $I r$ and $v$ of the same.

Fig. 9. Distal (lower) articular end of metatarsal $\mathrm{l}$ of the same.

Fig. 10. Front view of metatarsal $I V$ of Procoptodon Pusio, fœem.

Fig. 11. Proximal articular end of the same.

Fig. 12. Back view of distal half of the same.

\section{PLA'TE CXX.}

\section{Protemnodon Anak.}

Fig. 1. Back vicw of the fourth metatarsal.

Fig. 2. Outer (fibular) side view of the same.

Fig. 3. Inner (tibial) side view of the same.

Fig. 4. Front view of the same.

Fig. 5. Proximal articular end of the same.

Fig. 6. Distal articular end of the same.

Fig. 7. Front view of distal portion of the fourth metatarsal of a Protemnodon.

Fig. 8. Back view of the same. 


\section{PLATE CXXI.}

\section{Procoptodon Goliah.}

Fig. 1. Front view of right fourth metatarsal of a female.

Fig. 2. Inner (tibial) side view of the same.

Fig. 3. Proximal articular surface, somewhat mutilated, of the same.

Fig. 4. Outer side view of the proximal end of the same.

Fig. 5. Distal articular surface of the same.

Fig. 6. Front view of left fourth metatarsal of a male.

Fig. 7. Back view of the same.

Fig. 8. Proximal articular surface of the same.

Fig. 9. Outer (fibular) side riew of the same surface.

Fig. 10. Proximal articular surface of first phalanx of the fourth toe.

Fig. 11. Distal articular surface of fourth metatarsal of a male.

Fig. 12. Distal articular surface of fourth metatarsal of a female.

\section{PIATE CXXIX.}

Fig. 1. Hæmal (under or front) view of the sacrum and first caudal vertebra of Palorchestes Azael.

Fig. 2. Right side view of first caudal vertebra of the same.

Fig. 3. Neural (upper or back) view of the same.

\section{PLATE CXXX.}

Fig. 1. Outer side riew of part of right "os innominatum" of Palorchestes Azael.

Fig. 2. Inner side riew of the same.

Fig. 3. Transverse section of ischium at 63 , fig. 1 .

Fig. 4. Transverse section of pubis at 64 , fig. 2.

Fig. 5. Acetabulum of Procoptodon Goliah(?).

\section{PLATE CXXXI.}

\section{Palorchestes Azael.}

Fig. 1. Fibular (outer) side view of proximal portion of left tibia.

Fig. 2. Rotular (front) view of the same.

Fig. 3. Popliteal (back) view of the same.

Fig. 4. Tibial (inner) side riew of proximal end with epiphysis of the same.

Fig. 5. Tibial (inner) proximal articular surface of the same.

All the figures are of the natural size. 


\title{
Family GRAVIGRADA.
}

\author{
Genus Diprotodon.
}

\section{Sp. Diprotodon australis.}

$\S 1$. Scaphohenar bone.-A series of marsupial fossils collected by George BennetT, jun., Esq., at King's Creek, Clifton Station, Queensland, and transmitted to me since the Chapter on Diprotodontia, pp. 189-248, and its illustrative Plates XIX.-XXXV. were printed off, included the subjects of Plates CXXII., CXXIII.

These bones presented proportions and anatomical characteristics new to my experience, and, in ultimate analysis, I was led to refer them to a fore foot of a Diprotodon. An unusually well-preserved mandible of Dipr. australis and some other evidences, or homologues, of parts of the skeleton which had been previously described and figured were in the same series and from the same locality.

The result of the comparisons of the subject of figures 1-3, Plate CXXII., was its determination as the left scapholunar bone.

In the skeleton of a full-grown and large Wombat (Phascolomys latifrons) the answerable carpal bone measures $10 \frac{1}{2}$ lines in length; in that of the Macropus rufus (Plate LXX. fig. 10, l,s) it measures 1 inch 3 lines in length; the scapholunar. of Plate CXXII. figs. 1-3 is 4 inches 5 lines in length; with it are given corresponding views of a left scapholunar of a large male Macropus major (ib. figs. 4-6).

In contrasting the mandible of Phascolomys latifrons with that of Phascolonus gigas, and the mandible of Macropus rufus with that of Palorchestes Azael, the difference of size is so much less than that shown between figures 1 and 4, Plate CXXII., that the larger scapholunar cannot be referred to the largest known extinct Kangaroo or Wombat; and after corresponding comparisons of the mandible of Nototherium with that bone in known Macropodes and Phascolomyds, I am led to refer the fossil in question to the still larger extinct form Diprotodon australis. Its proportions to the distal extremity of the radius in that species, moreover, correspond with those between the radius and scapholunar bone in existing Kangaroos and Wombats.

The radial convex surface (Plate CXXII. fig. 1, $a$ ) is ovate in form; it is broader in proportion to its length than in Phascolomys (Plate XCIX. fig. 5), and in this character our large scapholunar resembles more its homologue in Macropus (Plate CXXII. fig. 4, a). It shows, however, more resemblance to the scapholunar of Phascolomys than to that of Macropus in the limited extent of the dorsal non-articular tract (fig. 1, $b$ ), which has its triangular shape better defined, with the apex projecting between the trapezoidal $(e)$ and the marginal $(c)$ surfaces. That for the trapezoides is relatively smaller than in either Phascolomys or Macropus; and that for the magnum 
is less concave than in Phascolomys, and is much less so than in Macropus. The ulnar half, indeed, of the marginal surface is slightly convex.

The triangular facet has its outer angle continued as a narrow groove, also as in Phascolomys, dividing the radial $(a)$ from the trapezoidal $(e)$ surfaces. The outer ball (d) for the trapezium is rather larger relatively and more prominent, more hemispheric, than in Phascolomys, and $\grave{a}$ fortiori differs from that in Macropus.

Thus the scapholunar carpal bone in Diprotodon exhibits, as in some other parts of the skeleton, combined phascolomydian and macropodal characters. It may be said to exhibit a more generalized type. But I am led to remark, considering that the huge quadruped, with a dentition essentially macropodal, required a development of its fore limbs to enable them to take such a share in habitual support and progression as do the fore limbs of the Wombat, the predominance of similarity in certain carpal bones to those in Phascolomys may not indicate affinity, or derivative relation, to that genus, but may be simply an adaptive character, such as a Kangaroo so huge as to be obliged to walk on all fours, and to part with the porver of leaping, may be expected to slow.

$\S 2$. Metacarpal.-In the bones of the fore foot of the Kangaroo one of the metacarpals, the fifth (Plate LXX. fig. 10,v), has a process extending outward from its base just beyond the proximal articular surface. Not any of the metacarpals in the Wombat (Plate XCIX. fig. 5) shows an answerable prominence, but it appears in the fifth metatarsal (ib. fig. 8). In neither genus does any phalanx of fore or hind foot exhibit such lateral prominence or process. But this is a marked feature in both bones of the fore foot of Diprotodon, one of which (Plate CXXII. figs. 7, 8, 9, \& 10) I suspect may prove to be a metacarpal of an aborted fifth toe; the other (Plate CXXIII.) is an ungual phalanx of one of the normally developed toes, probably the second, $i$ i.

The proximal articular surface (Plate CXXII. fig. 10, $a$ ) of the metacarpal is slightly concave transversely, almost flat from before backwards, and was adapted to the outer metacarpal facet of the "os unciforme." That the present metacarpal was a terminal or marginal one of the series is indicated by the absence of any surface for a contiguous metacarpal at the smaller end of the carpal surface. At the greater end there is the narrow fore-and-aft extended surface for articulation with the base of the contiguous "fourth" metacarpal.

The fifth (?) metacarpal is rather broader than it is long, it is flattened and even on the dorsal (anconal) surface (fig. 8), is irregular on the palmar surface (fig. 7), and is there deeply grooved between the outer process $(c)$ and the outer condyle $(d)$. The distal articulation is reduced to two distinct and somewhat remote convexities or condyles $(b, d$, figs. $7 \& 9)$, which I conjecture to have supported a clawless phalanx, the sole rudiment of a fifth digit.

\$3. Ungual phalanx.-The proximal surface $(a)$ of the subject of Plate CXXIII. shows a simple uniform concavity, indicative of its articulation with the distal convexity of an antecedent metacarpal ; yet the distal surface (fig. $1, d$, and fig. 5 ) proves the phalanx 
to have been a terminal one. If it has been articulated with a proximal or middle phalanx, the proximal surface differs from that of any of the distal phalanges in Wombats or Kangaroos by the absence of the trochlear character of such surface in those phalanges. On the plantar surface of this Diprotodon's phalanx, close to the smaller end of the proximal concavity, is an almost flat articular surface (fig. $3, b$ ), probably for a sesamoid bone. Along the inner border of the larger end of the proximal concavity (fig. $3, a$ ) there projects a thick rough tuberosity. Between the plantar end of this tuberosity and the sesamoid (?) surface is a pit big enough to receive the end of a man's finger. In advance of this pit the plantar surface of the phalanx (fig. 2) is crossed by a rough subbilobed ridge for the insertion of a broad and strong flexor tendon; the flattened surface leading to the distal end of the bone shows a few tubercles. The anconal surface (fig. 1) is less sculptured and is undulate. The transverse marginal process $(c)$ projects midway between the proximal and distal ends of the phalanx. The shape of the bone, viewed in profile from the margin sending off the process $(c)$, is shown in fig. 4 . This view exhibits the transverse groove $(e)$ which traverses the transversely convex terminal border (fig. 5) of the present singular bone. From the rugged, irregular, tubercular character of the two divisions of this border, with their vascular foramina, it may be concluded that the epidermal case or sheath of the phalanx was more like a hoof than a claw.

\section{PLATE CXXII.}

\section{Diprotodon australis.}

Fig. 1. Proximal surface of left scapholunar bone.

Fig. 2. Distal surface of the same.

Fig. 3. Radial lateral surface of the same.

\section{Macropus major.}

Fig. 4. Proximal surface of scapholunar bone.

Fig. 5. Distal surface of the same.

Fig. 6. Radial lateral surface of the same.

\section{Diprotodon australis.}

Fig. 7. Plantar surface of left fifth metacarpal bone (?).

Fig. 8. Anconal surface of the same.

Fig. 9. Distal end of the same.

Fig. 10. Proximal end of the same. 


\section{PLA'TE CXXIII.}

\section{Diprotodon australis.}

Fig. 1. Anconal surface of a distal phalanx of the left fore foot.

Fig. 2. 'Thenal surface of the same.

Fig. 3. Proximal end of the same.

Fig. 4. Side view of the same.

Fig. 5. Distal end of the same.

All the figures are of the natural size.

\$4. Mandible and Teeth-My friend Dr. Bexwett, F.L.S., received from W. Gipps, Esq., a considerable proportion of the right mandibular ramus of a Diprotodon which was discovered by Mr. Gipps a.t "a place called Mandoona, near Wallarawang, New South Wales," who kindly desired that it might be forwarded to me.

The specimen arrived at the British Museum, with the instructive collection of Australian fossils referred to at p. 507, which included the almost entire mandible of a Iliprotodon australis. Both specimens are of mature animals, with the teeth symbolized as $d_{4}, m_{1}, m_{2}, m_{3}$ in Plate XXIV.; and judging from the degree of wear of these teeth in Dr. BexNerT's specimen, and of the penultimate molar, the only tooth sufficiently entire for comparison in Mr. Gipes's specimen, both are from aged individuals, but with some difference in that respect.

The above molar series ranges along an extent of $7 \frac{1}{2}$ inches in both specimens; and as far as the mutilated condition of $m_{2}$, which is fractured and has lost much of its enamel. will permit, the teeth are alike in size, shape, and proportions.

It remains to be determined whether the following differences in the shape and proportions of the jaw relate to age, or are sexual or specific.

Assuming the latter, with a name for convenience of comparison, the horizontal ramus in Diprotodon Bennettii is more slender in proportion to its length, and maintains a more equable depth to the symphysial boss. The depth or vertical diameter at the middle of the last molar is 4 inches 6 lines, in Diprotodon australis it is the same; the depth at the fore part of the socket of $d_{4}$ (first of the four molars in place) in Dipr. Bennettii is 4 inches 6 lines, in Dipr. australis it is 5 inches 10 lines. From this greater vertical extension of the fore part of the ramus the lower contour from the symphysial boss to the antangular inflection is more concave in Dipr. australis. The outer symphysial surface is continued from the boss more directly inward, more transversely in Dipr. australis than in Itipr. Bennettii, in which it slopes more forward to the median line of the fore part of the jaw. The outer alveolar wall of the molars, especially of the first $\left(d_{4}\right)$, is rertical and thin in Dipr. Bennettii, not swollen or protuberant as in Dipr. australis. The "foramen mentale" has the same relative position to the boss in both species, but is midway between the upper and lower borders of the 
ramus in Dipr. Bennettii by reason of the minor height above the boss; in this it is 2 inches, in Dipr. australis it is 2 inches 9 lines.

In Dipr. Bennettii the ascending ramus begins gradually to rise from the antangular inflection, and the lower border is continued by a regular and gentle convex curve to the neck of the condyle, where it becomes gently concave. The sub- or post-crotaphyte ridge gradually extends outward, but the thicker and most outstanding upper 3 inches has suffered fracture. The coronoid process has been broken away. The thinnest part of the lower border of the ramus is between the antangular inflection and the angular one for an extent, viz., of 3 inches. The antangular inflection I reckon to be, in the entire jaw, midway between the condyle and the outlet of the incisor socket.

The neck of the condyle in the more slender jaw of Dipr. Bennettii is thicker than that in Dipr. australis; the difference is as 1 inch 6 lines to 1 inch 1 line (measured across the back part); it is also shorter in Dipr. Bennettii. The hinder third of the base of the coronoid process is also thicker in Dipr. Bennettii than in Dipr. australis, but the subcrotaphyte ridge is thicker in Dipr. australis.

'Ihese latter differences incline me to the hypothesis that we have here an established variety or species of Diprotodon; and it is the first evidence that has come under my observation which seems to warrant such conclusion.

The Diprotodon minor of HuxleY* is founded on the teeth $\left(d_{3}, d_{4}\right)$ of species of Nototherium (compare figs. 1-5, plate xxi. of the undercited Paper "On the Premolar Teeth of Diprotodon, and on a new Species of that Genus" with Plate XLIII. figs. 3-5, $d_{3}, d_{4}$, and Plate LXXXVIII. figs. 11-16 of the present work).

\$5. Mandible and Teeth of a young animal.-In 1845 I described and figured a series of teeth, discovered in sinking a well near Mount Macedon, Port Philipp, Province of Victoria, referred them to a left ramus of the lower jaw of a young Diprotodon australis, and described them as the four hinder molars $\left(d_{4}, m_{1}, m_{2}, m_{3}\right)$ of such jaw $\uparrow$. To the figures of this series was added (in Plate XXVI.) an anterior molar $\left(d_{3}\right)$, in outline, to complete the view I then entertained of the entire molar series on one side of both upper and lower jaws in that extinct species. I had no evidence in 1845 of the molars then figured having belonged to one and the same individual, and their determination was based on the nature of each individual tooth with consequent deduction as to the place it held in the molar series.

I have lately received from my esteemed correspondent and indefatigable contributor of materials for the present work, Dr. BExxETT, F.L.S., an almost entire mandibular ramus (Plate CXXIV.) of an immature Diprotodon australis, which exemplifies the degree of abrasion of the molars answering to those above described, and fortunately retains the small anterior molar $\left(d_{3}\right)$ confirmatory of the restoration in Plate XXVI. and of the sketch (ante, p. 204, fig. 2) transmitted to me by my friend Dr. Hobson.

* Quarterly Journal of the Geological Society, vol. xviii. (1862) p. 422, pl. xxi.

+ Descriptive and Mlustrated Catalogne of the Fossil Mammals and Birds in the Museum of the Royal College of Surgeons of England, 4to, 1845, p. 309. nos. 1493-1496. 
The degree of abrasion of the three anterior molars in place $\left(d_{3}, d_{4}, m_{1}\right)$, when the penultimate molar $\left(m_{2}\right)$ has partially emerged and the last molar $\left(m_{3}\right)$ has pushed the summit of its crown through the bony cell (the walls of which were in part broken away in the fossil), confirms the ascription of the molars (Plate XXIV. figs. 1, 2, 5, 6, 9,12 , copied from the original Plate of 1845) to one and the same young individual Iliprotodon.

When folio 13 of the present work was struck off I lad not received any specimen of $d_{3}$ (p. 203), and based my description of the tooth on the indications of its socket and the sketch of the tooth in situ sent to me in 1848. The confirmation of those grounds of restoration, afforded by the subject of Plate CXXIV. $d_{3}$, was most acceptable, inasmuch as it placed beyond question the generic distinction between Diprotodon and Nototherium afforded by the foremost molar tooth $\left(d_{3}\right)$. The two transverse ridges (fig. $3, d_{3}, a, b$ ) have been abraded by attrition against corresponding transverse ridges of the opposing molar $\left(d_{3}\right)$ of the upper jaw. The homologous molar $\left(d_{3}\right.$, Plate XLIII. and figs. $11 \& 12$, Plate LXXXVIII.) of Nototherium required the same degree of modification of the mandibular milk-molar $\left(d_{3}\right)$ figured in Plate XL. Under present evidence fragments of either upper or lower jaw with the entire anterior molar $\left(d_{3}\right)$ of a Diprotodon or a Nototherium would at once reveal their generic character to the palæontologist conversant with the dentition of these huge extinct Marsupials.

'The descriptions of the lower molars of Diprotodon in pp. 204-208 precludes the necessity of further dwelling on the acceptable subject of the subjoined Plate.

\section{PLATE CXXIV.}

Diprotodon australis.

Fig. 1. Outside view of part of mandible and mandibular teeth of a young individual. Fig. 2. Inside view of the same.

Fig. 3. Grinding-surfaces of the first three molars and of the coronal portions of the undeveloped last two molars of the same.

\section{Genus Nototherium.}

5. 1. Specific Characters of deciduous Molars, $d_{3}, d_{4}$.- - Since the printing off of folio 23 and Plate XLIII., descriptive and illustrative of the dentition of the upper jaw of Nototherium Mitchelli, I have been favoured with the opportunity of studying certain teeth $\left(d_{3}, d_{4}\right.$, e. g.) which previously I knew only through photographs or plaster casts. Thus I have now the certitude that the trilobed character of the outer half of the upper milk-tooth $\left(d_{3}\right)$ is natural; but the cast from which were taken figs. 3 \& 4 of Plate XLIII. shows it rudely, and minor characters of the tooth are obscured through imperfect moulding. I therefore give figures, taken from the tooth itself, in Plate LXXXVIII. figs. 11-14, $d s$. The trilobed outer surface is an 
exaggeration of that of the same part in the premolar of Procoptodon (Plate XC. figs. $\left.2,7, p_{3}\right)$, of the predecessor of which $\left(d_{3}\right)$ the present tooth in Nototherium is the homologue; but this tooth $\left(d_{3}\right)$ does not push out any deciduous predecessor in the larger herbivorous bilophodont Marsupials (Nototherium, Diprotodon).

The anterior lobe (Plate LXXXVIII. figs. $11 \& 12, d_{3}, \alpha$ ) is the smallest and shortest; the enamel of its obtuse summit is polished by wear, but no dentine is exposed. A fold of enamel $(f)$ detaches itself from the fore part of its base and curves backward and inward to rise again and subside near the summit of the inner lobe $(d)$ of the tooth. This fold of enamel, which may be termed a "prebasal" one, is sinuous in its course. The mid lobe $(b)$, rather broader than the fore one, has its summit worn down, and a flat field of dentine, with a border of enamel, is exposed (fig. 12), the contracted inner part of which border is continuous with the apex of a similarly worn surface of the inner lobe $(d)$. The hinder $(c)$ of the three outer lobes is the largest, chiefly through the expansion and backward extension of the base. The exposed dentine on its worn summit is continued inward with its enamel border to that of the inner lobe, which thus seems to be a production of the third lobe. The cleft between the middle and hinder of the outer lobes expands as it passes inward, and the inner lobe $(d)$ bends round the expansion to be continued into both middle and hinder lobes. The hind surface of this milk-molar (ib. fig. 14) is less broad than either the inner or outer sides of the tooth; it is flat, slopes from below forward, and is bounded by a thick, but narrow postbasal ridge $(g)$, which gradually subsides as its extremities pass vertically to the outer and inner summits of the posterior lobe.

The enamel of the flat sloping surface shows fine vertical grooves and punctations where it is not worn. The crown of the tootl, in the present worn state, is broader from before backward than it is high. The transverse basal breadth and the exterior height of the unworn crown are the same. It is supported by two roots, the hindmost being the largest. The length of the crown is 1 inch $1 \frac{1}{2}$ line (29 millims.); the greatest breadth is 10 lines (21 millims.).

In Nototherium Vicioria (Plate LXXXVIII. figs. 15-17) the three outer lobes of the milk-molar are represented by as many vertical angular ridges (ib. fig. 15, $\left.d_{3}, a, b, c\right)$ witl wide transversely concave or angular intervals, bounded below by curved lines, the hinder one formed by a bulging ridge (fig. 15,e). The anterior lobe $(a)$ seems to be rather an angular ridge forming the fore part of the crown; its hind border (fig. 16, $f$ ) extends inward and backward, rising at an acute angle and thickening to terminate on the hinder apex $(d)$ of the back surface of the crown. The mid external lobe (fig. 15,, ) has a flat field of dentine exposed, shaped as in Nototherium Mitchelli, and is continuous by its apical part with the inner lobe. The outer and hinder lobe $(c)$ is chiefly represented by the enamel covering its outer surface. The hinder surface (ib. fig. 17), bounded below by the postbasal ridge $(g)$, slopes to terminate in the ridge of enamel continued from the apex of the postexternal lobe $(c)$ across the summit of the crown to $d$. The length of the crown is 1 inch, the breadth is $9 \frac{1}{2}$ lines (20 millims.). 
Nototherium inerme, as exemplified in Plate XLIII. fig. $5, d_{3}$, has a still more simplified and relatively smaller anterior milk-molar.

Only the hinder of the two outer channels in Nototherium Victorice is here present, anterior to which the convex enamel-wall is continued to the fore angle of the crown.

The differences between the $d_{3}, d_{4}$ of Diprotodon (ante, p. 204) and of Nototherium are well marked and constant.

\$2. Mandible of young individual.-The dental characters of the species (N. inerme) have been yielded chiefly by those of the maxilla*. The teeth of the type specimens of mandible were too mutilated to yield them satisfactorily $\dagger$. Since its description I have had the pleasure to receive a right mandibular ramus of a young individual with the teeth at the same phase of development as in that of Nototherium Mitchelli (Plate XL.), and similar views of the mandible of Nototherium inerme are therefore given in Plate CXXV. The specimen was discovered by George F. Bennett, Esq., at Gowric, Darling Downs, Queensland, and was transmitted to me by his father, Dr. Gigorge Bexietr, F.L.S., in 1874.

The crown of $d_{3}$ is mutilated, but sufficient remains to show that it accords with the generic type of Nototherium (Plate XL. $d_{3}$ ), and is not bilophodont as in Diprotodon; sufficient also to give its antero-posterior extent, which agrees with that in its homotype of the upper jaw (Plate XLIII. fig. $\left.5, d_{3}\right)$. The next tooth $\left(d_{4}\right)$, first of the bilophodont series, shows the same fore-and-aft extent as $d_{4}$ above, but, as usual, is narrower transversely (Plate CXXV. fig. 3). The ridge of enamel which in Nototherium Mitchelli descends obliquely inward from the fore part of the outer angle of the hind ridge or lobe to terminate near the middle of the valley is not present in $d_{4}$ of Nototherium inerme. In $m_{1}$ the ridges which define the concavity of the front surface of the fore lobe in Nototherium Mitchelli are not so developed in Nototherium inerme; but at the back of the fore lobe there is a mid vertical prominence not shown in N. Mitchelli; the front surface of the hind lobe of $d_{4}$ in Not. inerme lacks the ridge of enamel from the outer angle which gives, or adds to, the transverse concavity of that surface in Not. Mirchelli.

The molar $\left(m_{1}\right)$, like the two preceding tecth, shows the same agreement in fore-andaft extent with its homotype in the upper jaw (Plate XLIII. fig. 5), viz. 1 inch 3 lines. The summits of the two lobes of $m_{1}$ show wear in a greater degree than those in the young jaw of Not. Nitchelli (fig. 3, Plate XL.). The unworn summits of $m_{2}$ in Not. inerme (Plate CXX. figs. $3 \& 4$ ) have risen to the top of its alveolus and have begun to protrude therefrom. But the increased size of the jaw and the proportion of the depth to the length of the ramus are greater than the slight advance of age would account for, and must be put to the specific distinction of Nototherium inerme. Whether there may be arrest of the vertical growth in the course of acquisition of the mature length of the mandible is questionable; but if the proportions of this young

$$
\begin{aligned}
& \text { * Ante, pp. 275, } 277 \text { ("minor relatire size of } d 3 \text { "), Plate XLIII. fig. } 5 . \\
& \text { + Ante, p. } 271 \text {. Plate XLII. }
\end{aligned}
$$


jaw are maintained to full growth, the remark on the minor depth of the horizontal ramus (p. 271) may not be applicable to a specimen less "mutilated and abraded" than is the type of the species (Plate XLII.).

The nototherian modifications of the lower border of the hinder half of the ramus, exemplified by the anterior $(d)$ and posterior $(a)$ inflections in fig. 4 , are well shown in the subject of the present description.

\section{PLA'TE CXXV.}

Nototherium inerme.

Fig. 1. Outer side view of a mutilated right mandibular ramus and teeth.

Fig. 2. Under surface of the same.

Fig. 3. Upper surface of the same.

Fig. 4. Inner side view of the same.

All the figures are of the natural size.

Q3. Atlas Vertebra.-In the description of the fragment of an atlas of a large mammal with marsupial characters of that bone, I expressed (ante, p. 209) a doubt whether the ring of the vertebra "had been completed below by bone;" but by reason of other demonstrable modifications traceable in the fragment, I was led to refer it to a Diprotodon custralis, and to figure it in Plate XXVIII. fig. 2.

I have since received an almost entire atlas confirming that determination, and one, also nearly entire, of a Nototherium (Plate CXXVI.), both of which demonstrate the fact that, as in some species of Macropus (Plate LXVII. figs. 1-3), of Phascolomys (Plate XCVIII. figs. 3 \& 4), and in certain other Marsupials*, that vertebra was not completed below by bone.

The atlas in the two cited genera of large extinct Marsupials presents so close a similarity that a description, with references to the figures of the smaller one (in Plate CXXVI.), will suffice to indicate their leading characters.

Each neurapophysis, after developing the large articular surfaces $(z, z$, fig. 1$)$ for the occipital condyle in front, and the prezygapophysis $\left(z^{\prime}, z^{\prime}\right.$, fig. 2) for the axis vertebra behind, terminates below these surfaces in a short, thick, rough tuberosity (ib. fig. $1, m p$ ). The pair leave an interspace of 1 inch $7 \frac{1}{2}$ lines, which received the permanently detached centrum, here, as usual in Hematotherms, confluent, as an "odontoid process," with the succeeding centrum (Plate XXVIII. fig. 1, ca).

I know not at present any mammal showing this non-completion by bone of the ring of the atlas save in the limits of the Marsupial order.

The unossified interval (fig. $2, h$ ) is relatively greater in Nototherium than in Dipro-

* Art. Marsepialis, Cỵclopædia of Anatomy, rol. iii. 8ro, 18t1, p. 277, fig. 98 (Perameles), fig. 99 (Phascolarctos). I did not then foresee the applicability of the character, here first defined, to a determination of the marsupial nature of a mammal little less than an elephant. 
todon. A similar difference is shown by the two species of Wombat of which the atlas is figured in Plate XCVIII.

'The bony arch overroofing the neural canal above the articular cups $(z, z$, Plate (XXVI. fig. 1) is lower and flatter than in Phascolomys, and more resembles that part of the atlas in Macropus. But the upper surface of the arch, instead of being flattened as in Macropus, rises into a large median tuberosity (fig. 1), and more resembles the shape of that part in Phascolomys. In the minor extent of the neurapophyses below the articular cups both Diprotodon and Nototherium more resemble Phascolomys platyrhimes (Plate XCVIII. figs. $3 \& 4$ ) than they do Phasc. latifrons or Macropus rufus (Plate LXVII. figs. $2 \& 3, n p$ ).

'The inward extension of the neurapophysis from the lower half of the articular cup, indicative of the level of the floor of the neural canal (ib. $n$ ), gives a square form to the racuity, the lower half of which was mainly filled by the centrum of the atlas ("odontoid process"). 'The antero-inferior angles of the neurapophyses are produced into low conical processes (ib. $\mathrm{mp}$ ). The lower opening of this vacuity was doubtless closed by ligamentous matter at $h$.

The inner aperture of the canal, answering to $c_{1}$, figs. $1 \& 3$, Plate XCVIII., in Phascolomys, is present at the side of the neural canal, near the upper part of the articular $\operatorname{cup}(z)$. Its course is transversely outward, the length of the canal being 1 inch 3 lines; its diameter is $4 \frac{1}{2}$ lines in Diprotodon. It is continued by an open groove, gradually widening, to the interspace between the prezygapophysis (ib. $z$ ) and the diapophysis (ib. $d$ ). The diapophyses, at their origin, have greater antero-posterior than vertical thickness, but swell out soon after their origin into rough irregular subspherical tuberosities.

The under part of the neck of the process is grooved by the vertebral artery. A process from the lower and outer side of the neurapophysis tends to circumscribe the gronve below, but terminates in a point, leading to an open channel, as in Macropus (Plate IXVII. figs. $2 \& 3, v$ ) and in Phascolomys platyrhinus (Plate XCVIII. figs. $3 \&$ $4, v)$. The postzygapophyses (Plate CXXVI. fig. 2, $z$ ) are subtriangular, feebly coneave, with the margin sharp and prominent, save along the median part, which subsides upon the vertical wall bounding the vacuity for the centrum.

Subjoined are admeasurements of the atlas in the two species:-

\begin{tabular}{|c|c|c|}
\hline & $\begin{array}{l}\text { Diprotodon. } \\
\text { in. lines. }\end{array}$ & $\begin{array}{l}\text { Nototherium. } \\
\text { in. lines. }\end{array}$ \\
\hline Extreme length or antero-posterior diameter & 50 & 30 \\
\hline Extreme breadth or transverse diameter & .120 & $9 \quad 0$ \\
\hline Extreme height or vertical diameter. . . & $5 \quad 9$ & 46 \\
\hline $\begin{array}{l}\text { Extreme length of neural canal between fore and hind } \\
\text { articular surfaces . . . . . . . . . . . }\end{array}$ & 16 & 10 \\
\hline $\begin{array}{l}\text { Extreme breadth of neural canal above hind articular } \\
\text { surfaces . . . . . . . . . . . . . . . . . }\end{array}$ & $\begin{array}{ll}3 & 2\end{array}$ & 210 \\
\hline
\end{tabular}


$\begin{array}{rr}\text { Diprotodon. } & \text { Nototherium. } \\ \text { Extreme height of neural canal to upper border of hind in. lines. }\end{array}$ articular surfaces . . . . . . . . . . . 2 2006

Least diameter of postneurapophysial groove . . . . 0496

Least diameter of preneurapophysial canal . . . . . $\begin{array}{lllll}0 & 4 \frac{1}{2} & 0 & 3\end{array}$

Vertical diameter of interspace for centrum . . . . 2842

Transverse diameter of interspace for centrum . . . 111110

From upper border of occipital cup to that of surface for axis . . . . . . . . . . . . . . . 43616

Vertical diameter of cup for occipital condyle . . . . 344211

Transverse diameter of cup for occipital condyle . . . $26 \quad 6 \quad 1 \quad 7 \frac{1}{2}$

Least vertical diameter of diapophysis . . . . . $25017 \frac{1}{2}$

Least fore-and-aft diameter of diapophysis . . . . . 11010

Vertical diameter of surface for axis . . . . . . . 2624

Transverse diameter of surface for axis . . . . . . 300

For extremes of variation in the structure of the mammalian atlas, Plate CXXVI. may be compared with the figures of the atlas of Mylodon robustus given in plate vii. of my work on that species*. A like degree of difference pervades the entire osteology and dentition of the gravigrade Sloths as compared with the gravigrade Marsupials.

\section{PIATE CXXVI.}

\section{Nototherium.}

Fig. 1. Front view of atlas vertebra, nat. size.

Fig. 2. Back view of the same.

$\oint 4$. Humerus.-This bone in Nototherizm (Plate CXXVII.) resembles that of Phascolomys (ib. fig. 7, and Plate CI.) more than that of Macropus (Plate LXIX.). The entotuberosity (Plate CXXVII. c) does not attain, as in Macropus, the level of the articular head (ib. $a$ ) of the bone; but it does not extend ulnad so far beyond the head $(a)$ as in Phascolomys (ib. fig. 7, \& Plate CI. figs. 1-4,c). The head is convex, most so in the ancono-thenal direction, and, as in Phascolomys latifrons (ib. fig. 1, $a$ ), is bent down in a subangular form upon the anconal aspect of the shaft. The ectotuberosity (Plate CXXVII. b) rises above the head, but in a relatively minor degree than in Phascolomys; it is continued down the thenal aspect of the shaft into a pectoral process (ib. fig. $1, e$ ) considerably more developed than in any kind of Wombat; its thick rugous lower and most prominent part gives a quite peculiar feature to the Nototherian lumerus (ib. fig. $3, e^{\prime}$ ). The uninterrupted continuation of the ridge $(e)$ from the ectotuberosity $(b)$ to the pectoral process $\left(e^{\prime}\right)$, dividing the thenal surface of the proximal half of the humerus into the facets $f \& g$, is a character which is more closely repeated in

* Description of the Skcleton of an Extinct Gigantic Sloth (Mylodon robustus), 4to, 1842. 
the humerus of the Kangaroo (Plate LXIX. fig. $1, f, g$ ) than in that of the Wombat. From the lower and outer part of the ectotuberosity extends the process $f$, called "deltoid" in the description of the Wombat's arm-bone (ante, p. 362); and in the prominence and angular form of this process Nototherium resembles Phascolotherium latifions more than it does Phasc. platyrhinus.

'The low, rough process ( $d$, Plate CXXVII.), answering to that which in the Wombats gives attachment to the common tendon of the teres major and short triceps muscles, is as prominent as in Phascolomys latifrons, but is relatively less and better defined. The smooth thenal surface of the shaft continued down between $e^{\prime} \& d$ is uninterrupted by any oblique ridge or rising, continued, as in Phascolomys, from the process $e^{\prime}$ to the bridge $k$, completing the entepicondylar canal. 'The bridge is relatively broader than in I'hascolomys latifions (Plate CI. fig. 1, k), in which species it is broader than in Phasc. platyrhinus (ib. fig. 3, $k$ ). The entepicondyle (Plate CXXVII. $i$ ) is more produced and better defined than in Phascolomys. The same may be said of the supinator ridge $\left(h, h^{\prime}\right)$. There is no definite coronal depression answering to $p$ in Plate CI. figs. $1 \& 3$; in its absence Nototherium resembles Macropus. There is as little definite evidence of an anconal depression, and the bone is thick where it is either diaphanous or perforated in Phascolomys. The anconal surface of the proximal half of the shaft is not traversed or divided by any longitudinal rising; but a sharp and well-defined ridge (l'late CXXVII. fig. 2,n), probably giving origin to a portion of the triceps muscle, differentiates, if it be constant, the Nototherian humerus from that of either the Wombats or Kangaroos. Near this ridge is the orifice (ib. ib. $r$ ) of the medullarterial canal. There is a depressed and tuberous tract (ib. fig. $2, s$ ) on the anconal surface, above the entepicondyle, which is not present in the recent pliytiphagous Marsupials. The ridge bounding the ulnar side of the ulnar articular surface $(m)$ is better defined, and extends further upon the anconal surface than in Phascolomys; there is a closer approach in Nototherium to Macropus in this particular. The radial convexity $(l)$ is relatively smaller and the ulnar surface $(m)$ is less convex than in either Phascolomys or Macropus.

The humerus of Nototherium, at first glance, recalled by its robust proportions and strongly developed muscular ridges and processes that of Mylodon robustus. But on comparison the marsupial type of the former was as clearly indicated as the edentate type of the latter. In Mylodon robustus the articular head of the bone is flanked by nearly equal ento- and ecto-tuberosities, neither of which rise above it. 'The deltoidal tract is low, broad, and long, extending over the proximal two thirds of the shaft, and having its distal, radial border chiefly prominent, and defining there the wide and deep " musculo-spiral " groove. In Nototherium it would seem as if the homologue of this deltoidal ridge bifurcated as it descended, to terminate in the two distinct processes e \& $f$ (Plate CXXVII. fig. 1), the latter of which had the relation to the "musculospiral" channel which the undivided deltoidal tract holds in Mylodon. 'There is no entepicondylar canal in Mylodon; but it may be remembered that this is present in the 
humerus of the allied extinct Megatherioid called Megalonyx. The entepicondyle projects at a part further from the condyle itself in Mylodon than in Nototherium; the ectepicondyle projects, radiad, further than in Nototherium, and it terminates a shorter supinator plate, the upper end of which is not produced proximad in Mylodon as in Nototherium and Phascolomys.

\section{PLATE CXXVII.}

Nototherium.

Fig. 1. Front (thenal) view of left humerus.

Fig. 2. Back (anconal) view of the same.

Fig. 3. Inner (ulnar) side view of the same.

Fig. 4. Outer (radial) side view of the same.

Fig. 5. Proximal articular surface of the same.

Fig. 6. Distal articular surface of the same.

These figures are of half the natural size.

Phascolomys latifrons.

Fig. 7. Inner (ulnar) side view of left humerus, nat. size.

THE END.

ERRATA.

P. 396, 16 lines from top, for "Left" read "Right;" 17 lines from top, for "Left" real "Right ;" 9 lines from bottom, for "Right" read" Left." (The parts were drawn on stone without reversing.) 



\section{FRONTISPIECE.}

Diprotodon australis, left side view of skull, from the specimen in the British Museum (p. 191), nat. size; with outline of a similar view of the skull of Macropus laniger (syn. M. rufus, p. 376).

\section{SUBJECTS OF W00DCUTS.}

Tabular view of the Fossiliferous Strata of the Earth . . . . . . . . . . 4

Section of Oolitic Strata . . . . . . . . . . . . . . . . 11

Dromatherium sylvestre (mandible and teeth) . . . . . . . . . . . . . 20

Section of Purbeck Strata . . . . . . . . . . . . . . . . . . . 22

Thylacinus Ilarrisii (hind part of mandible and teeth) . . . . . . . . . . 74

Plagiaulax minor (mandible and teeth). . . . . . . . . . . . . . . 77

Plagiaulax medius (mandible and teeth) . . . . . . . . . . . . . . 86

Plagiaulax Becklesii (mandible and teeth) . . . . . . . . . . . . . 86

Phalangista Cookii (mandible and teeth) . . . . . . . . . . . . . 89

Dendrolagus dorcocephalus (mandible and teeth, with fore part of maxilla) . . . 90

Phascolarctus fuscus (mandible and teeth) . . . . . . . . . . . . . 90

Plagiaulax medius, magnified (mandible and teeth). . . . . . . . . . . . 90

Bettongia penicillata (mandible and teeth, with magnified view of premolar) . . 92

Hypsiprymus minor (mandible and teeth) . . . . . . . . . . . . . . 92

Thylacoleo carnifex (mandible and tecth) . . . . . . . . . . . . . . 93

Potamogale velox (upper and lower laniariform incisors) . . . . . . . . . 98

Urotrichus talpoides (upper and lower laniariform incisors) . . . . . . . . 99

Thylacoleo carnifex (lower laniariform incisors) . . . . . . . . . . . . 99

Cheiromys madagascariensis (mandible and teeth, incisor exposed) . . . . . . 100

Dasyurus ursinus (mandible and teeth) . . . . . . . . . . . . . . . 103

Potamogale velox (laniary incisors) . . . . . . . . . . . . . . . . 149

Urotrichus talpoides (laniary incisors) . . . . . . . . . . . . . . . 150

Potamogale velox (mandible and teeth, with upper incisor) . . . . . . . . 150

Thylacoleo carnifex (mandible and teeth, front view) . . . . . . . . . . 151

Phascolarctos fuscus (mandible and teeth, front view) . . . . . . . . . . 152

Phascolarctos fuscus (mandible and teeth, side view) . . . . . . . . . . 153

Thylacoleo carnifex (skull restored, after FLower) . . . . . . . . . . . 153

Thylacoleo carnifex (skull restored, after nature) . . . . . . . . . . . 153 
Pago

Cheiromys madagascariensis (mandible and teeth) . . . . . . . . . . . 154

Plagiaulux Becklesii (mandible and teeth, magnified) . . . . . . . . . . 154

Thylarinus cynocephalus (articular end of mandible and last two molars) . . . . 155

Sarcophilus ursimus (mandible and teeth) . . . . . . . . . . . . . 158

Thylacoleo carnifex (skull restored according to the herbivorous hypothesis) • . 165

Thylacoleo carnifex (side view of maxillary and mandibular teeth) . . . . . . 168

Plaginulax medius (side view of mandible and teeth, magnified) . . . . . . 168

Ihendrolayus dorcocephahus (mandible and teeth). . . . . . . . . . . . 170

Hypsiprymms minor (mandible and tecth) . . . . . . . . . . . . . 170

Bettongia penicillata (mandible and teeth) . . . . . . . . . . . . . 170

Phalangista Cookii (mandible and teetlı) . . . . . . . . . . . . . . 174

Plagiaular minor (mandible and teeth) . . . . . . . . . . . . . . 178

Urotrichus talpoides (mandible and teeth). . . . . . . . . . . . . . 178

Dildelphys murina (mandible and teeth). . . . . . . . . . . . . . . 178

Mustela vulgaris (mandible and tecth) . . . . . . . . . . . . . . . 178

Plagianlax Falconeri (mandible and teeth) . . . . . . . . . . . . . . 178

Diprotodon australis (fragment of inandible and tooth, the type specimen) . . . 189

Diprotodon australis (fragment of mandible with foremost milk-molar) . . . . 204

Sus scrofa (deciduous and permanent mandibular dentition) . . . . . . . . 209

Macropus major (deciduous and permanent mandibular dentition, showing homo-

logies of marsupial molars) . . . . . . . . . . . . . . . . . 209

Diprotodon australis (cervical vertebræ 2-5) . . . . . . . . . . . . . 212

Diprotodon australis (scapula) . . . . . . . . . . . . . . . . . . 219

Mount Macedon (outline of volcanic hills and plain) . . . . . . . . . . 241

Nototherium Mitchelli (hind half of mandible and teeth) . . . . . . . . . 250

Nototherium Mitchelli (symphysis mandibulæ, and base of incisor) . . . . . . 269

Phascolomys vombatus (nasal bones) . . . . . . . . . . . . . . . . 316

Phascolomys vombatus, var. (nasal bones) . . . . . . . . . . . . . 316

Phascolomys platyrhinus (nasal bones) . . . . . . . . . . . . . . . 316

Phascolomys latifrons (nasal bones) . . . . . . . . . . . . . . . . 318

Phascolomys platyrhinus (lacrymal bone and environment) . . . . . . . . 320

Phascolomys latifrons (lacrymal bone and environment) . . . . . . . . . 320

Phascolomys platyrhinus (palatal surface of maxilla and teeth) . . . . . . . 321

Phascolomys latifrons (palatal surface of maxilla and teeth) . . . . . . . . 321

Macropus major (parts of tarsus and metatarsus) . . . . . . . . . . . 391 





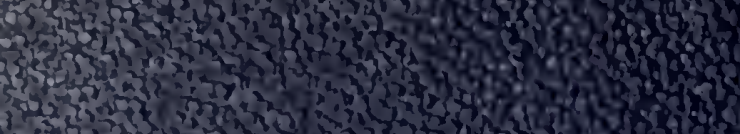

m.

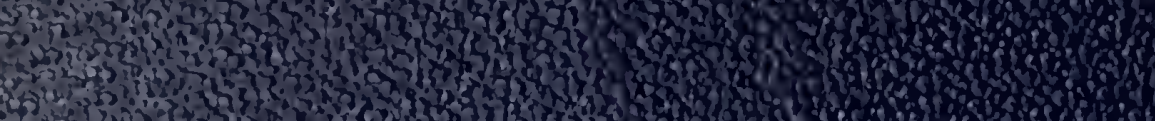

H.

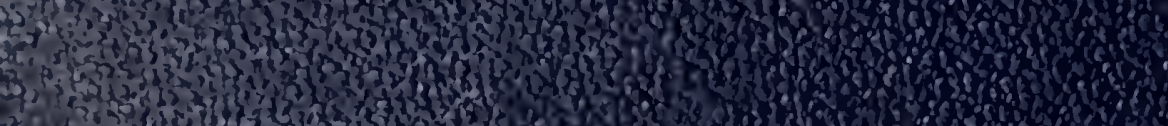

2.

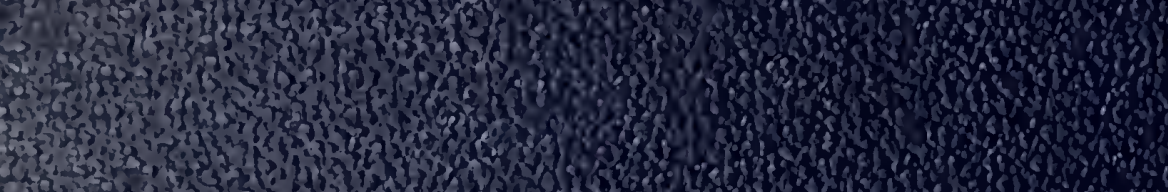

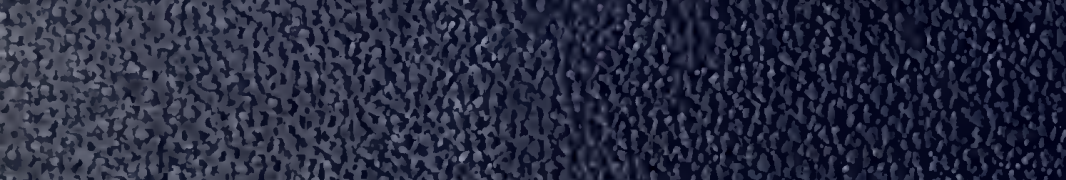
8. 